


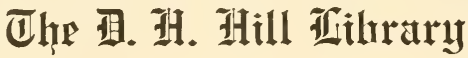

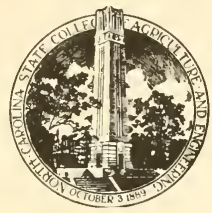

Nurth Caralina State $\mathbb{C}$ allene

SB605

W4N68 
This book is due on the date indicated below and is subject to an overdue fine as posted at the Circulation Desk.

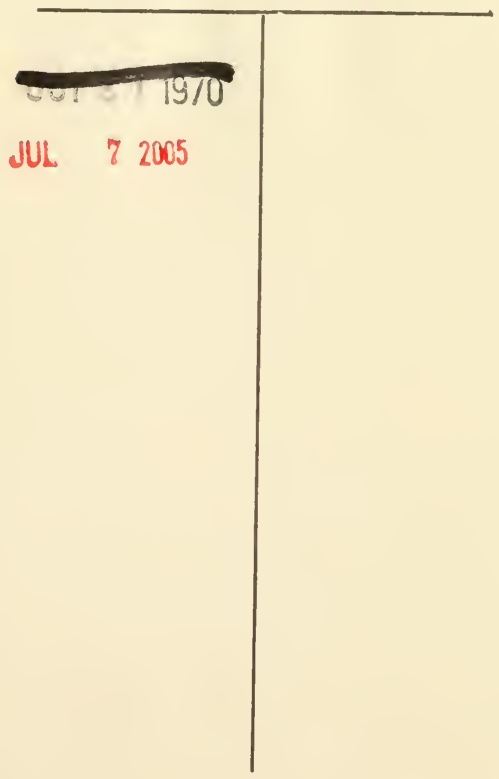








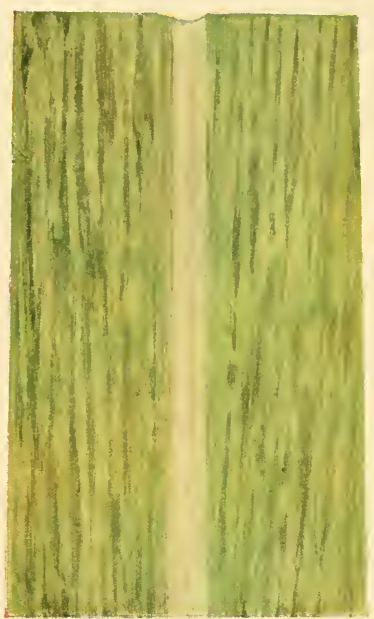

1

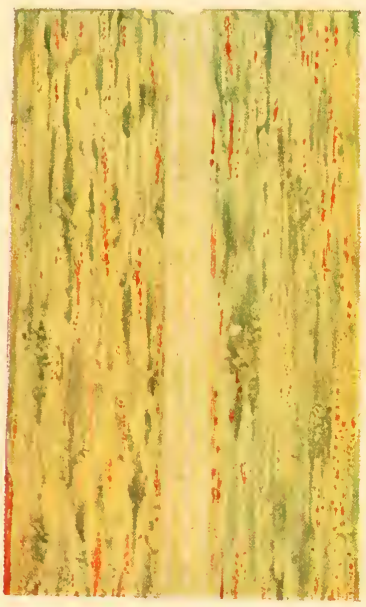

3

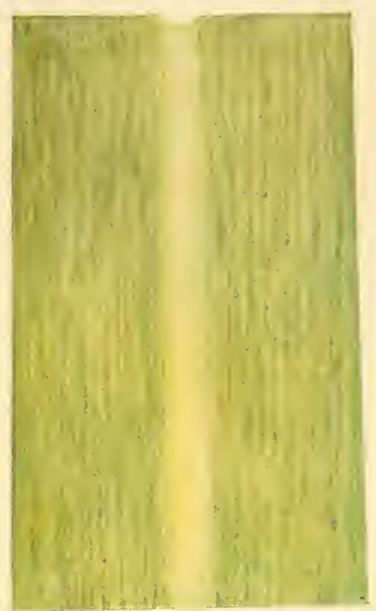

2

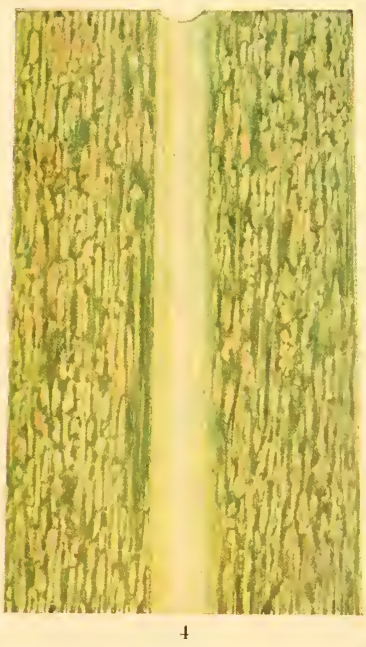

MOSAIC DISEASE OF SUGAR CANE

1. Typical mosaic on dark-green leaf. 2. Typical mosaic on light-green leaf. 3. Effect developed on certain varieties.

4. Type of spotting often mistaken for mosaic. 


\section{DISEASES OF CROP-PLANTS IN THE}

\section{LESSER ANTILLES}

BY

\section{WILLIAM NOWELL, D.I.C.}

Assistant Director of Agriculture, Trinidad and Tobago; late Mycologist on the Staff of the Imperial Department of

Agriculture for the West Indies

WITH A FOREWORD BY

PROFESSOR J. BRETLAND FARMER, F.R.S.

PUBLISHED ON BEHALF OF THE IMPERIAL DEPARTMENT OF AGRICULTURE

BY

THE WEST INDIA COMMITTEE I4 TRINITY SQUARE, LONDON 



\section{FOREWORD}

It is with no ordinary feeling of pleasure that I have fallen in with my friend Mr. Nowell's suggestion that I should write a foreword to his book, although his own established reputation, based on brilliant elucidations of various difficult problems in plant pathology makes the attempt perhaps less easy and certainly more superfluous than it might otherwise have been. Readers will find in this book much more than is often regarded as sufficient to fill a volume purporting to deal with plant diseases. It might, indeed, perhaps be more correctly designated as a treatise on the principles of plant pathology with special reference to the diseases occurring in the West Indies. These islands, with their wide range of soil, with their varied climatal and other environmental conditions, are peculiarly well fitted to provide that broad outlook over the larger matters of pathology which is too apt to escape those who are treating plant diseases from a more purely practical and local standpoint. Mr. Nowell has embraced the opportunity which lay to his hand, and has produced a work which in my judgment constitutes a real landmark of progress in the science of the plant considered in relation to health and disease. As might have been expected from one who has successfully grappled with the interesting and important ætiology of Red Ring in Coconut, with the real nature of the damage wrought by the Cotton Stainer (Dysdercus) and its remarkable parallelism to malarial infection in the human subject, to say nothing of his work on Rosellinia and other pests, the book will be found of great value to the practical agriculturist as well as to the scientific investigator, who looks, or should look, farther afield. But it is in the philosophical treatment of his subject as a whole, as well as in the cautious way in which the principles themselves are put forward, that the wider interest of the author's work as a whole is to be attributed. As is well said in the text, "In every case of parasitism there are two organisms to be considered, the host and the parasite. . . ." In a number of instances it is shown how the incidence of a particular disease depends on external conditions, and the way is thus paved for a rational treatment of an infestation which depends upon a knowledge of what might be called the agricultural physiology of the plant itself. If I may be permitted to recall something of what I have myself observed, while in the West Indies, I might cite the froghopper attack on sugar-cane as an instance of the 
point here referred to. There are, in Trinidad, cane areas where variations in agricultural practice have resulted in practical immunity from " Froghopper Blight," yet, in one instance at least, the immune area was contiguous with plantations, otherwise similar, in which the pest had assumed serious dimensions. Further illustrations are supplied, in the body of the work, by the class of " debility diseases," where a sound knowledge of agricultural physiology has been able to indicate satisfactory methods of coping with the onset of the pests.

Of course the matter is not always so easily brought into line with agricultural practice, and the careful reader will observe the judicious attitude maintained by the author in respect of other diseases in which the factors are not so simple or so susceptible of control. But it is safe to say that no one can peruse the work, more especially if he happens to possess a first-hand acquaintance with the problems under discussion, without feeling that in this book at any rate a successful attempt has been made to grapple with the scientific principles of some of the larger issues that form the background of plant pathology. It is only in this way, i.e. by an intelligent appreciation and application of principles that the ravages caused by the many and various diseases to which cultivated plants, especially in the tropics, are continually liable can ever be satisfactorily controlled.

J. BRETLAND FARMER.

Imperial College of Science and Technology, London. 


\section{AUTHOR'S PREFACE}

This work was prepared as a handbook to the diseases affecting crop plants in the Lesser Antilles at the request of the Imperial Commissioner of Agriculture for the West Indies, Sir Francis Watts, K.C.M.G., during the writer's tenure of the post of Mycologist on the staff of the Imperial Department (I9I3-I920). Full use has been made of the work of previous occupants of this position, namely: Messrs. A. Howard (IgOI-I902), L. Lewton-Brain (I902-I905), F. A. Stockdale (rg05-I909), and F. W. South (Igog-I9I3). The large obligations due to the published papers of plant pathologists in other parts of the West Indies and the Tropics generally are indicated in the text.

The immediate aim has been to provide for the agricultural officer and the planter a means of reference to the present state of knowledge respecting specific diseases, and further to enable him to compare his experience with the general body of knowledge concerning plant pathology and its relation to agricultural practice. The need for a local textbook of the subject in the new West Indian Agricultural College has also been kept in mind.

Certain diseases have been included which have not occurred in these islands, but are of interest in view of the possibility of their appearance or recognition in the future.

As the result of personal experience of which the whole tendency has been to compel a mycologist to become an agriculturist, the writer is convinced of the need for a broad treatment of his subject. The mycologist is most concerned with the fungus, the pathologist with the disease, and the agriculturist with the crop, but a combined view of the interests of all three is necessary for the production of an economic plant pathology.

The writer is conscious that the present work is more successful in revealing the want of knowledge on very many subjects than in imparting it, but has the hope that even this function may be found useful as establishing a datum line for future investigations.

The thanks of the writer are due for critical perusal of the manuscript to Mr. C. B. Williams, late Sugar-Cane Entomologist in the Trinidad Department of Agriculture (the whole text), Dr. S. C. Harland, late Assistant for Cotton Research in the West Indies (Part I and the chapter on diseases of cotton), and Mr. S. F. Ashby, late Microbiologist to the Jamaica Department of 
Agriculture (Part II) : to Sir Francis Watts for valuable help in preparing the chapter on fungicides; to Miss E. M. Wakefield, of the Royal Gardens, Kew, for kindly assisting in proof reading, and Mr. S. F. Ashby, for assistance with the bibliography and illustrations ; to Dr. J. B. Farmer, F.R.S., Professor of Botany at the Imperial College of Science and Technology, not only for the immediate contribution of an introduction, but in a special sense as the director of a course of biological training in which information is held subordinate to essential principles. The writer must further gratefully acknowledge that without the constant assistance of his wife the labour of writing could never have been faced in the time available from other duties. 
(n)

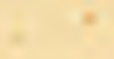




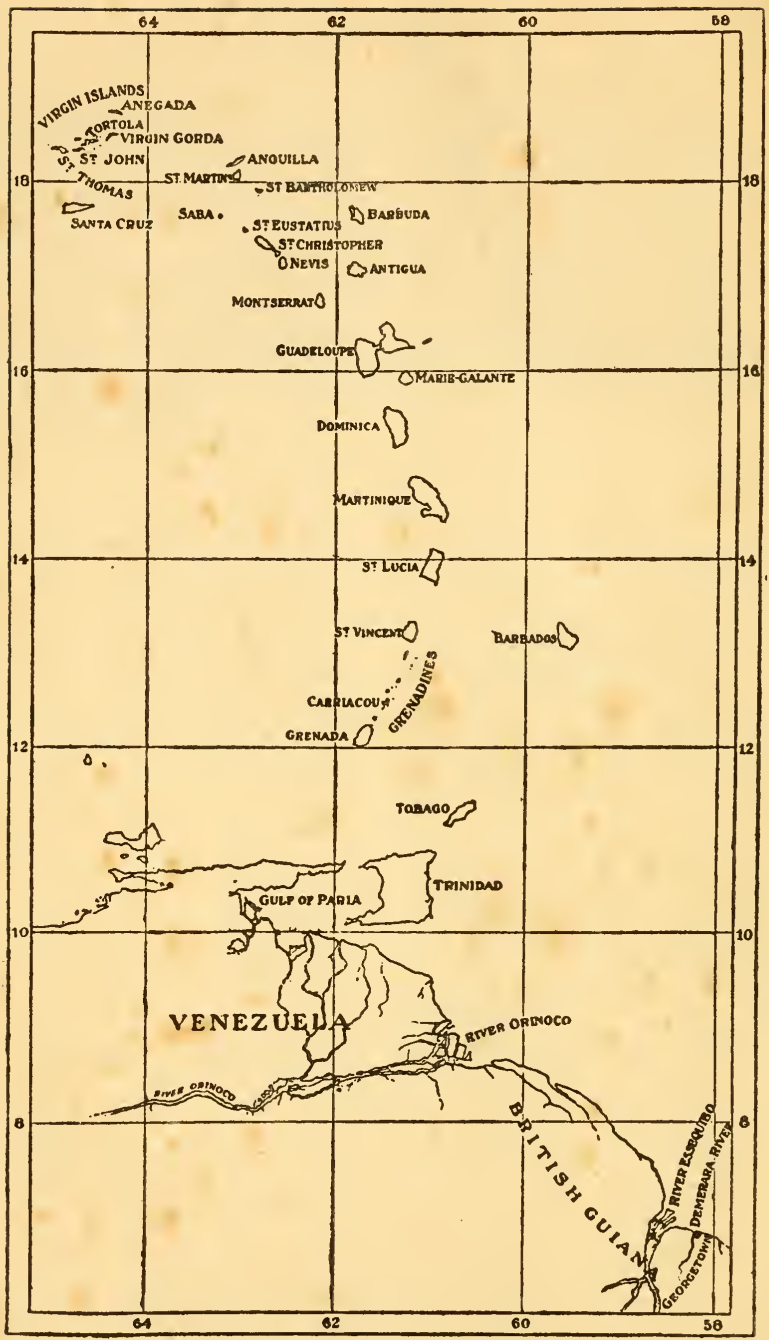

MAP OF THE LESSER ANTILLES. 


\title{
CONTENTS
}

\author{
PART I
}

INTRODUCTION :

THE NATURE AND CLASSIFICATION OF PLANT DISEASES

\section{SECTION I.-CAUSATION}

CHAPTER I: DISEASES CAUSED BY FUNGI.

The Nature of Fungi.

The Mycelium. The Place of Fungi in Nature- - $~ 3$

The Nature of Fungus Parasitism - - - - -5

REPRODUCTION AND INFECTION - - - - -

The Host: Resistance and Susceptibility.

Effect of Agricultural Conditions on Resistance. Immunity by Evasion. Resistant Species or Varieties. Susceptibility to Exotic Diseases. Local Factors affecting Prevalence -

The Principal Types of Fungus Diseases.

Leaf Diseases. Flower and Fruit Diseases. Stem Diseases. Root Diseases - _ _ _ _ _ -

Notable Groups concerned in Fungus Diseases.

The Rusts (Uredinales). The Smuts (Ustilaginales). The Powdery Mildews (Erysiphaceæ). The Downy Mildews (Phytophthora). The Anthracnoses. The Fusariums. The Diplodias. The Rhizoctonias. The genus Marasmius. The Fungi infecting Bug Punctures (Stigmatomycosis). The Sooty Moulds (Capnodiæ) - _ _ _ -

The Classification of Fungi - - $\quad$ - $\quad-34$

CHAPTER II : DISEASES CAUSED BY BACTERIA - - 45

CHAPTER III : DISEASES CAUSED BY INFECTIVE VIRUSES 48

CHAPTER IV: PHANEROGAMIC PARASITES.

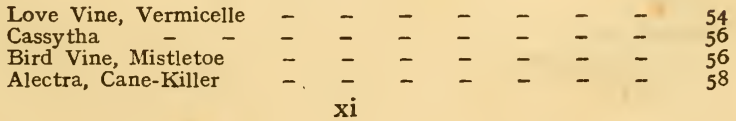


CHAPTER V: DISEASES DUE TO NEMATODES (EELWORMS).

Heterodera radicicola, Greef. Tylenchus devastatrix, Kühn.

Tylenchus tritici. Tylenchus angustus, Butler. Tylenchus ribes, Taylor. Aphelenchus cocophila, Cobb. Tylenchus similis, Cobb and T. musicola, Cobb - _ -

CHAPTER VI: THE RELATION OF INSECTS TO PLANT DISEASES.

Insects as the Cause of Injuries and Diseases. Stigmonoses. Insect Injuries as Openings for Infection. Insects as Carriers of Infection. Susceptibility and Resistance to Insect Infestations

CHAPTER VII: NON-PARASITIC DISEASES - - -

CHAPTER VIII: ENTOMOGENOUS FUNGI - - -

\section{SECTION II -PREVENTION AND CONTROL}

CHAPTER IX: GENERAL CONSIDERATIONS.

Arable Crops and Parasitic Diseases. Sources of Infection. Means of avoiding Damage. Resistance. Disease Evasion. Elimination Methods. Spraying. Permanent Crops - -

CHAPTER X: FUNGICIDES AND THEIR APPLICATION.

The Copper Compounds.

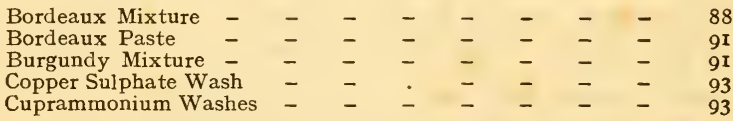

Sulphur Fungicides.

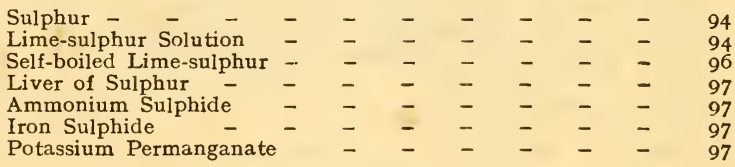

SPRAYING.

Spray Injury - $\quad$ - $\quad$ - $\quad$ - $\quad$ - 98

Dusting - $\quad$ - $\quad$ - $\quad$ - $-\quad$ - 98

Disinfectants.

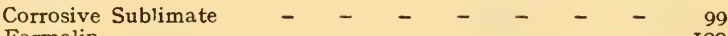

Formalin - - - - - - - - I00 
Page

Sulphuric Acid - $-\quad-\quad-\quad-\quad-\quad-\quad-\quad$ IOI

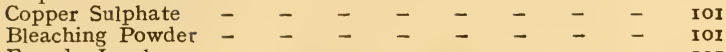

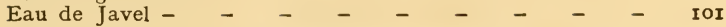

CHAPTER XI : WOOD-ROTS; THE TREATMENT OF TREES.

Structure. Wood-rots. The Healing of Wounds. The Treatment of Wounds. Antiseptics. Protective Paints - - 102

CHAPTER XII : THE CONTROL OF DAMPING-OFF - 107

CHAPTER XIII : PREVENTION OF FRUIT ROTS - - IIO

CHAPTER XIV: PLANT DISEASE LEGISLATION.

Plant Importation, Internal Regulation - _ - - II2 


\title{
PART II
}

\author{
INTRODUCTION : \\ AGRICULTURAL CONDITIONS IN THE LESSER ANTILLES
}

\section{SECTION I.-GENERAL DISEASES}

CHAPTER XV: ROOT DISEASES.

Rosellinia Root Diseases. Sclerotium Rots. Fomes Root Rot

CHAPTER XVI : STEM AND LEAF DISEASES.

Pink Disease. Thread Blights. Horsehair Blight. Algal Disease

\section{SECTION II.-DISEASES OF PERMANENT CROPS}

\section{CHAPTER XVII: DISEASES OF CACAO.}

Dieback. Diplodia Pod Rot. Phytophthora Pod Rot and

Canker. The Surinam Witch-broom Disease. Monilia Pod

Rot. Sphæronema Black Spot and Bark Rot. Anthracnose.

"Male" Cacao. Woody Excrescences. (Root Diseases. Algal Disease. Thread Blight. Horsehair Blight-See

General Diseases) -

CHAPTER XVIII : DISEASES OF COCONUT.

The Red Ring Disease. Bud-rot in general. Bacterial Bud-rot. Bud-rot caused by Phytophthora palmivora. Leaf-stalk Rot caused by Phytophthora parasitica. Stem Bleeding Diseases. Leaf-dwindling or Little-leaf Disease. Bitten-leaf Disease.

Dieback. Leaf Blight - _ _ _ - -

CHAPTER XIX: DISEASES OF LIME AND OTHER CITRUS TREES.

Introduction - - - - - - - -

Limes.

Diplodia Dieback. Deficiency Dieback. (Rosellinia Root Disease-see General Diseases). Red Root Disease. Collar xiv 
Canker. Branch Galls. Anthracnose of Lime. Grey Blight.

Leaf Spots. (Seedling Diseases-see Damping off)

Page

I96

Citrus Trees in General.

Citrus Anthracnose. Gummosis. Foot-rot or Mal-di-goma.

Scaly Bark. Scab. Black Melanose. Citrus Canker. Diseases,

Injuries and Rots of Citrus Fruit - _ _ _ -

CHAPTER XX: DISEASES OF COFFEE.

Viruela, American Leaf Disease. Brown Eye-spot. Zonal Leaf Spot. Bark Disease. Nematode Diseases. Sclerotium Disease of Liberian Coffee. (Rosellinia Root Disease. Thread

Blights. Algal Disease-see General Diseases) - _ -

CHAPTER XXI : DISEASES OF HEVEA.

The South American Leaf Disease - _ _ _ _ -

CHAPTER XXII: DISEASES OF MINOR FRUIT TREES.

Avocado.

Anthracnose - $\quad$ - $\quad-\quad$ - $\quad$ -

DATE PALM.

Leaf Disease. Fomes Stem-rot - $\quad$ - -

GRAPE-VINE.

Anthracnose. Powdery Mildew. Rust - MANGo.

Anthracnose. $\quad$ - $\quad$ - $\quad$ -

NuTMEg.

Canker. Perforated Leaves. (Red Rust. Rosellinia Root

Disease. Thread Blight-see General Diseases) - _ _

\section{SECTION III.-DISEASES OF ARABLE CROPS}

\section{CHAPTER XXIII: DISEASES OF BANANA.}

Banana Wilt, Panama Disease. Marasmius Root Disease and Stem Rot. The Moko Disease. Eelworm Black-rot. Black Spot of Leaves. Bonnygate Disease. Blackhead Disease. Heart-leaf Disease - $\quad$ - $\quad$ -

CHAPTER XXIV: DISEASES OF CORN AND SORGHUMS. CORN.

Brown Rust. Red Rust. Smut. Head Smut. Leaf Scorch.

Dry Rot. Root Disease. Minor Diseases - _ SORGHUMS.

Rust. Kernel Smut. Head Smut. - _ - 26r

CHAPTER XXV: DISEASES OF COTTON.

Internal Boll Disease. Angular Spot. Black Arm. Bacterial Boll Disease. Soft Rot of Bolls. Diplodia Boll Rot. Anthracnose. Curly Leaf, Chibble Leaf. Loggerhead. Rust. Red Leaf Blight. Yellow Leaf Blight. Macrosporium Leafspot. Alternaria Leaf-spot. Leaf Mildew. Crinkled Dwarf, Man Cotton, Mottled Hybrids - 
CHAPTER XXVI: DISEASES OF SUGAR CANE.

Root Disease (General type). Root Disease (Acute type). The Epidemic on the Bourbon Cane. Red Rot. Rind Fungus.

Pineapple Disease of Cuttings. Diplodia Rot. Wilt Disease. Top Rot (Bud-rot). Gumming Disease (Cobb's Disease). Smut. Schizophyllum Rot. The Iliau Disease. Cytospora Rot. Leaf-sheath Rot. Red Spot of the Leaf-sheath. Ring Spot. Eye Spot. Red Leaf-spot. Yellow Leaf-spot. Brown Leaf-spot. Sereh. Mosaic Disease (Mottling Disease, Yellow Stripe Disease). Chlorosis (Gall Patches, Moonshine). Fiji Disease. Sclerospora Disease - _ _ _ _

CHAPTER XXVII : DISEASES OF ROOT CROPS.

Cultivated Aroids.

Dry Rot or Saltpetre. Pythium Rot - _ _ - 33I

ARROWROOT.

Burning Disease (Rosellinia). Cigar Disease - _ _ 332

Cassava.

Wither-tip. Leaf Spots - $\quad$ - - - -335 ONION.

Bacterial Soft-rot - _ _ _ _ _ 335

Sweet Potato.

White Rust - $\quad$ - $\quad$ - $\quad$ -

YAM.

Wilt. Tuber Rot. Leaf Blotch - $\quad$ -

CHAPTER XXVIII : DISEASES OF LEGUMINOUS PLANTS. Ground Nut.

Leaf Rust. Leaf Spot. Root Disease - - - -

KIDNEY BEANS.

Anthracnose. Bacterial Blight. Stem Rot - _ _ 340

Pigeon PeA.

Root and Stem Diseases. Rust -

CHAPTER XXIX: DISEASES OF MINOR FRUIT PLANTS.

Pineapple.

Tangle Root. Root Disease, Wilt or Blight. Base Rot. White Leaf-spot. Leaf-base Rot. Fruitlet Spot, Black Eye, Black Spot. Thielaviopsis Soft Rot. Diplodia Core Rot.

Prevention of Fruit Rots _ _ _ _ _ PAPAW.

Black Leaf-spot. Stem and Fruit Rot - -

TOMATO.

Blossom-end Rot. Leaf Mould. Septoria Leaf-spot. Bacterial

Wilt, Bubbly Fruit-rot _ _ _ _

CHAPTER XXX: DISEASES OF PLANTS NOT CLASSIFIED. Agave.

Anthracnose - - - - - - -

Rose.

Black Spot, Mildew. Other Diseases - _ _ - 36r 


\section{LIST OF ILLUSTRATIONS}

Mosaic Disease of Sugar-cane, coloured plate

- Frontispiece

Map of the Lesser Antilles

- to face xi

Fig. No.

I Fungus Hyphæ in Cells

2 Phytophthora Faberi

3 Hyphæ (Rhizoctonia) Basidia and Spores of Corticium Vagum

Ascomycetes. Stigmatomycosis. Species $\dot{A}$

Basidiomycetes

L

Love Vine on Solanum Sp. enlarged.

Nematode Root Galls (Heterodera radicicola) :

Coconnt root with Nematodes $\quad \cdot \quad \cdot \quad \cdot$

Coconut Parenchyma with Nematodes:

Egg of Aphelenchus cocophilus : :

Entomogenous Fungi

Cephalosporium Lecanii on Saissetia nigra

Cephalosporium Lecanii on Coccus Mangiferæ

Froghoppers (Tomaspis saccharina) killed by Metarrhizium

Metarrhzium Anisopliœ Sorok

Dusting with spores of Froghopper Fungus (Trinidad) :

Equipment for mixing Bordeaux by gravity .

Mixing Bordeaux by hand

Spraying Mango with Spray-motor Pump mounted on 20-gallon oil drum

\section{Charging Compressed Air Sprayer :}

Compressed Air Sprayer in action

Healing of pruning wounds (Mandarin Orange)

Effects of bad pruning (Cacao)

Rosellinia Pepo. Conidial Fructifications $\times 4 \frac{j}{2}$

Perithecia $\times 3 \frac{1}{2}$

" $\quad$ "
"
" bunodes,
" $\quad$ ",
",

Smoky Mycelium on surface of bark $x$ Mycelium under bark, nat. size Conidial Fructifications $\times 4 \frac{1}{2}$ Perithecia $\times 4$ Mycelial Strands in Lime bark, $\times 1 \frac{j}{2}$

$$
\begin{aligned}
& \text { to face } 67 \\
& 6 \mathrm{I} \\
& 6 \text { I } \\
& 64 \\
& 64 \\
& 64 \\
& \text { to face } 75 \\
& \text { " } 76 \\
& \begin{array}{l}
\text { ". } 76 \\
\text {, } 76
\end{array} \\
& \text {,. } 79 \\
& \text {, } 80 \\
& \text {," } 80 \\
& \text {., } 88 \\
& \text {, } 88 \\
& \text { " } 90 \\
& \text {, } 96 \\
& \text { I03 } \\
& \text { I0 } 3
\end{aligned}
$$

Mycelial Strands in Limewood,

". . " $\quad$ Longitudinal Section, $\times 2$ " 2134

Rosell" (paraguayensis Starb ?) Perithecia $\times 3$. " 136

Root Disease of Cacao (R. Pepo). ${ }^{\cdot} \quad \cdot$ to face I39

Pink Disease of Cacao $\quad: \quad: \quad: \quad$ " $\quad$ : 148

Thread Blight of Cacao (Corticium Stevensii) : : " " 150

Algæ Disease of Cacao, Active stage . . . " " I 52 
Fig. No.

48 Diplodia Rot of Cacao Pod

49 Cacao Canker produced by inoculation.

50 Cacao Pod Rot: Tip infection

5I Cacao Pod Rot, produced by inoculating stem

52 Phytophthora Faberi

Surinam Witch Broom Disease

A Typical Witch Broom

Surinam Witch Broom Disease

56

Monilia Disease of Cacao (Ecuador)

Sphæronema Black Spot (Ecuador)

Colletotrichum Cradwickii, Flower Proliferation (Male Cacao) Trinidad

6I Red Ring Disease: Fully infested tree.

62 Sections of Stem of tree in Fig. oo at $\mathrm{Ift}$. 9in. and $3 \mathrm{ft}$. $6 \mathrm{in}$.

Red Ring Disease, Medium Section of Infested Tree

\section{Longitudinal Section of Segment of Stem \\ Transverse Section of Segment of Stem Ring}

66

\section{Gumming of Coconut Stem}

Infestation of a young leaf .

Effect of a Bud Rot epidemic, Trinidad

Coconut Bud Rot, outer leaves removed to show collapse of heart leaves.

Bud Rot, preceded by drooping of leaves (Tobago) : Phytophthora Bud Rot (Jamaica), central leaves alone dead and broken advanced stage, central column

Little Leaf Disease of Coconut

Red Root Disease of Lime (Dominica) :

Anthracnose of Lime

Scab on Lemon Shoot

Foot Rot on old seedling Örange Tree $(a)$ Margin of

80

(b) Treatment in progress plant through the neck

\section{Macroconidia" of Fusarium Vasiniectum :}

Canker on Young Twig

American Leaf Disease of Coffee

Brown Eye-spot of Coffee .

Anthracnose of Avocado

\section{Panama Disease, Early symptoms}

\section{Advanced stage}

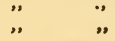

Longitudinal Section of a bulb and base of the stem.

Young Sucker infested from parent 
Fig. No.

99 Corn Smut

roo Incidence of internal Boll Disease

to face $25^{8}$

Internal injuries to Cotton Bolls (St. Vincent, etc.)

IO2 Angular Leaf-spot of Cotton

I03 Bacterial Boll Disease of Cotton.

104 Anthracnose of Cotton Bolls

I05 Curly-leaf Cotton, top view.

I06

Loggerhead C̈otton, young plants:

rog West Indian Leaf Mildew of Cotton

I IO Marasmius Mycelium on Sugar Cane

II I Fructifications of Marasmius associated with acute Root Disease of Sugar-cane (Trinidad)

II 2 Acute type of Root Disease : Infestation of young plant cane with Marasmius (Barbados B 6032)

I 3

Acute type of Root Disease: Buds of young plant cane infested with Marasmius

II4 Fructification of Odontia Sp. on Sugar-cane :

II 5 Odontia sacchari cystidium and basidium with single spore

Ir6 Himantia Stellifera, Mycelium on Sugar-cane :

II7 Himantia Stellifera; Hypha, with stellate crystal and swollen bodies.

I 8

II9

Red Rot of Sugar-cane

Colletotrichum falcatum : $\quad: \quad$ : $\quad$ :

I 2 I

Rind Fungus of Sugar-cane

Melanconium Sacchari, vertical section of Stroma.

Thielaviopsis paradoxa, Sporophores of Micro- and Macroconidia

to face 270

I29 Cytospora Sacchari, surface and sectional views of Pycnidia, spore and sporophore

I 40 Burning Disease of Arrowroot

I4 I Bacterial Rot of Onion

142 Anthracnose of Bean

I 43 Stem Rot of Papaw.

144 Base Rot of Pineapple cuttings

I 45 Cross Section of Pineapple Fruit, showing two infections of Black-eye

I46 Thielaviopsis: Soft Rot of Pineapple

I47 Blossom-end rot of Tomato

I 48 Septoria Leaf-spot of Tomato

I 49 Black Spot of Rose .

150 Rose Mildew. 



\section{PART I}

\section{INTRODUCTION}

\section{THE NATURE AND CLASSIFICATION OF PLANT DISEASES}

HEALTH is a state in which each organ performs its own function and acts in harmony with every other, and disease in the broadest sense of the word consists of any departure from this state. A condition of disease proceeds from a derangement of the function of any organ, and in plants this most frequently follows upon derangement in structure.

Two classes of diseases are generally recognised as coming within the scope of the mycologist or plant pathologist : parasitic diseases caused by fungi or bacteria, and non-parasitic diseases, in the sense of affections characterized by specific symptoms and believed to result from some disturbance of function caused otherwise than by a parasitic organism.

This limitation is one of convenience, not of logic. Insect injuries to the living tissues react on the health or well-being of the plant, and often produce serious derangements of function resulting in general symptoms which in some cases have no obvious relation to the wounds inflicted. These are as definitely diseases as the affections produced by fungi, but are in practice mostly left to the entomologist. It is a defect of this system that the botanical aspects of insect injury often remain unstudied.

The term mycologist, it may be noted here, as applied to a student of plant diseases, dates from the time when the idea of their causation was limited to fungus parasitism. It properly applies to the student of fungi; the general practitioner in plant pathology is more largely concerned with the host, and the range of his vision must extend at least to bacterial diseases, virus diseases and those of non-parasitic origin.

A convenient approximation to a classification of plant diseases, in the broader sense, which is not complete, but includes the chief groups of diseases having more or less obvious specific characters, may be made as follows :-

(a) Parasitic Diseases.-Caused by :-

I. Fungi.

2. Bacteria.

3. Infectious viruses. (Ultra-microscopic organisms?) 
4. Parasitic flowering plants.

5. Nematode worms.

6. Mites.

7. Insects.

(b) Non-parasitic Diseases.

Non-transferable, with specific symptoms and frequently with characteristic lesions.

As no strict definition can be given of disease there is no fixed limit to such a list as this. Injuries, mostly direct, may be produced by grazing animals, by hail, or by lightning, while deficiencies in soil, unfavourable weather, an unsuitable climate, and last, but not least, the unskilful or negligent cultivator, may all be set down as disease-producing agencies, and as such will be referred to upon occasion in subsequent discussions.

Naturally there exist at any given time recognised diseases of which the cause is unknown or disputed. The safest rule in such cases is to regard them tentatively as being of parasitic origin if their mode of occurrence suggests that they are transferable.

The use of the term physiological disease is by common consent undesirable, though there must be few pathologists who have not found it convenient on occasion. It has represented a sort of Cave of Adullam to which diseases not known to be of parasitic origin could be relegated, but is objectionable in form since all diseases properly considered involve disturbances of physiological processes.

In relation to agricultural practice the most important distinction among plant diseases is to be made between those which are able to develop upon plants in normal condition and those which occur to a serious extent only upon plants reduced in vigour by unfavourable circumstances, as of soil, climate, insect infestation, or methods of cultivation. For those which have this character in a marked degree the term debility diseases is used in the following pages. 


\section{Section I-Causation}

\section{CHAPTER I}

\section{DISEASES CAUSED BY FUNGI}

\section{The Nature of Fungi.}

Fungi are vegetable growths, that is, they are plants, but of a relatively simple kind. They range in form from single rounded cells or small cell-groups as in the yeasts, through filamentous forms such as are familiar in the moulds common on bread, cheese, or fruit, to elaborately shaped structures, with tissues built up of filaments, more or less closely amalgamated, of which mushrooms, toadstools, and the bracket-like outgrowths which appear on dead trees are examples.

The nearest relationship of fungi is with another large group of simple plants, the Algæ, which similarly range from singlecelled or filamentous forms such as produce the green colour or the green slimy growth in any body of exposed water to the large and variously fashioned forms known as seaweeds.

There is an essential difference between Algæ and Fungi in the nature of the materials from which they derive their nutrition. The Algæ possess, in common with most forms of vegetation, the green colouring matter chlorophyll, which enables them to build up from inorganic materials-mineral salts, carbon dioxide, and water-the organic compounds required for construction and maintenance. Fungi, on the other hand, have no chlorophyll and therefore no such ability, and can live and grow only at the expense of material which has been previously elaborated by some other plant or animal. It is the mode of life arising from this necessity which gives to fungi their great importance in human economy.

Transitional forms are, however, known between Algæ and Fungi in respect of the chlorophyll content of the former, and some Algæ may assume a parasitic habit.

There are fungi ready to take advantage of all classes of vegetable or animal material if the conditions are favourable; they precede, accompany, or follow the even simpler organisms known as bacteria, most of which are nourished in a similar way. With them they are responsible for the degeneration of dead vegetable or animal matter, which is called in general terms decay, while the parasitic species have become adapted to feed at the expense of living plants or animals. 


\section{The Mycelium.}

The way of life characteristic of the great majority of fungi is for the invaded substance to be covered or interpenetrated with an abundant development of slender filaments, which absorb from it the food materials required. This structure is the vegetative part of the fungus; it is known collectively as the mycelium, and its individual filaments as hyphæ. In mass the mycelium is frequently visible to the naked eye as a cobweblike, threadlike, fluffy or papery investment. Sometimes the hyphæ are combined into threads, as in the black and shining strands of "horse-hair blight" and the whitish threads or strings of thread blight. In certain species cord-like strands of mycelium ramify through soil or vegetable mould, and such structures in general have been named rhizomorphs, from their resemblance

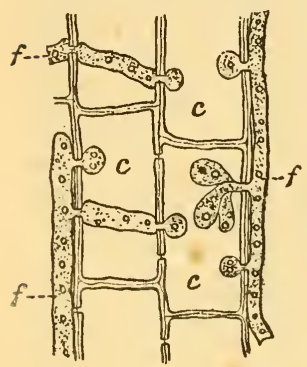

Fig. 1 in these cases to roots. In certain fungi the mycelium collects into hard masses of various shape and size, sclerotia, which by their resistant nature serve to carry the fungus through adverse conditions or aid in its distribution.

If the abstraction of food materials by the mycelium takes place from living tissues or non-living but functioning parts of a plant or animal the mode of life constitutes parasitism ; if from material no longer forming part of a living structure, it is known as saprophytism.

\section{The Place of Fungi in Nature.}

Fungi have a place in the economy Fungus Hyphae in Cells of Nature far wider than that arising from their part in the causation of plant disease. Chiefly by their operation the great mass of vegetable material formed each year in the shape of leaf and stem, flower and fruit, is broken down and returned to the soil. Their activity in this direction has a harmful side, from the point of view of man, when it concerns such commodities as timber or stored foods.

The rapid destruction of humus-forming materials in the tropics as compared with temperate countries-resulting in the absence of notable deposits of leaf-mould even from the forestsappears to be connected with the suitability of tropical conditions for the continuous activity of soil fungi. The only lasting natural accumulations of vegetable material in the West Indies known to the writer are in swampy situations, where the water, by excluding air, prevents their operation. In the biological processes of soils under forest growth or in orchard cultivation it is believed that fungi replace to a considerable extent the bacteria of arable land. 
The Nature of Fungus Parasitism.

There are numerous gradations between the strictly saprophytic and the strictly parasitic habit in fungi. Many species which subsist typically on the dead or dying organs of plants can advance some way towards the invasion of living tissue if its resistance is weakened by age, poor nutrition, or insect or mechanical injury. The debility diseases already referred to are caused by the more advanced examples of this class, of which the Diplodias afford the best illustration in the West Indies. Certain fungi of this genus are abundant on recently dead herbaceous stems, woody branches, and fallen fruits. Further, they readily attack sugar-cane, cotton bolls, cacao pods, or citrus fruits when these are over-ripe; while in the same class of material even a trifling injury at an earlier stage may afford a foothold and permit of infestation. In the case of cotton it would seem that under favourable circumstances the rot can commence unaided. On lime and cacao branches, to mention instances typical of many other trees, the Diplodias get a foothold on a broken branch or dead twig and are only checked when they reach a part situated in a line of normally vigorous growth. Where conditions are adverse to the maintenance of vigour in the tree they can do considerable damage.

From this class of weak parasites advance is made by insensible steps to fungi which can establish themselves on plants in normal or even supernormal vigour. It is somewhat vain to attempt to classify the numerous grades of parasites ; they vary in so many ways that each case must be taken on its merits; the variations will be best appreciated from the descriptions of individual diseases given later. The most notable division is that which marks off the extreme class of parasites. On the one side are those fungi which, though capable of parasitism and frequently typically parasitic, can also live on a greater or lesser range of dead material, often of their own killing: on the other side are the strict or obligate parasites, of which the most advanced forms enter into a close relationship with the living cells of the host and are dependent on the continuance of its life processes for support. Of this nature are the rusts (Uredineæ), the smuts (Ustilagineæ) and the powdery mildews (Erysiphacex). Unlike nearly all fungi in the previous class, the obligate parasites naturally cannot be grown in culture apart from their host.

Another distinction made, with more or less of value, is that which marks off as wound parasites those fungi which cannot attack living organs direct, being unable to penetrate the cuticle of leaves or the cork of stems as the case may be, and only gaining access when the protective layer is in some way broken.

Very important differences exist in regard to adaptation to special hosts. There are at one end of the scale general parasites like the Rosellinias later discussed, which under suitable conditions can infest almost any plant which comes in their way. 
Others only attack plants of one order, genus, or species, and this tendency reaches its extreme in parasites which are so restricted in their range that invisible characters associated with a particular strain of the host species may partially or completely prevent their development.

\section{Reproduction and Infection.}

The active feeding part of a fungus, its vegetative body, is the mycelium already described, typically made up of an aggregate of hyphæ. A portion of mycelium may be detached, with or without fragments of the material on which it is growing, and serve to reproduce the fungus in new situations, as happens with the root fungi of sugar-cane transported on cane cuttings or trash, and in Rosellinia root diseases when fragments of infested wood are washed by floods to lower levels. The common Sclerotium diseases of legumes, sugar-cane, etc., are caused by fungi in which no method of reproduction is known save the characteristic hard, shot-like grains, formed of thick-walled hyphæ.

With very few exceptions, however, reproduction is further provided for by the formation and release of spores-individual cells or less frequently aggregates of 2,3 , or more cells-which can remain, like seeds, dormant for a longer or shorter period and then, under appropriate conditions, germinate and give rise to a new mycelium. In a few of the more primitive fungi there are sexual processes more or less preserved which resemble those of algæ, but in most members of the larger groups there is little more than a reminiscence of sexual fusion, and in very many no certain trace or no trace at all.

Classification, as in the flowering plants, depends mainly on the form of the reproductive structures, and some detail as to this will be given later : only the more general aspects of reproduction are at present in question.

The visible forms of the larger fungi, the mushroom-like, bracket-like, and other shapes in multitudinous variety, are structures erected by the usually obscure mycelium for the production and discharge of spores. The provision of gills, spines, tubes, pores, folds, convolutions, recesses, or chambers, greatly increases the surface available for this purpose. A similar end is served in the simpler forms by the outgrowth and branching of the surface hyphæ.

Broadly speaking, spores may be divided into $(a)$ those produced within a parent cell (an ascus or a sporangium), to which the term spore is sometimes technically restricted (endogenous formation), and $(b)$ those which are budded off from more or less free hyphæ and are known as conidia or conidiospores, or from hyphal terminations of special form (basidia) and distinguished as basidiospores (exogenous formation). In some very simple forms the whole mycelium divides up into conidia or gemmæ. 
Many fungi produce either ascospores or basidiospores in their more elaborate fructifications, and also conidia in some more direct and simple manner. In a vast number of species the latter method is the only one yet recognised, in which case the fungus is classed in a heterogeneous group known as the Fungi Imperfecti, on the assumption that a more definite form of fructification exists or has existed.

The longevity of spores is extremely variable in different species. Many have been shown to be viable after months or years of desiccation, others quickly die. Stahel has found, for example, that the basidiospores of Marasmius perniciosus, the witchbroom fungus of cacao, will not germinate after desiccation, exposed in a thin layer, for an hour. In many species, of which Colletotrichum falcatum, the cause of red-rot in sugar-cane, is an example, special thick-walled resistant spores (chlamydospores) are formed directly on the mycelium.

The dispersal of spores is effected most commonly by wind or minor air-currents. They are frequently set free in vast numbers visible like puffs of smoke, and their lightness makes it conceivable that they may be borne considerable distances through the air. They are carried by birds and insects, washed from one plant to another by rains or transported by streams, and distributed by man, adhering to clothing, implements or articles of merchandise. The chance of any individual spore finding an appropriate resting place is very small, but this is offset by the immensity of their numbers.

For germination to take place the appropriate conditions in respect of moisture, heat and light must prevail, and these vary with different parasites Humid conditions provided by dull wet weather, by soil moisture, or by the transpiration of the host itself, may suffice, or a definite drop or film of water may be required. Heat is presumably never deficient in the tropics, indeed there is reason to believe that the prevalent temperatures are above the optimum for many species, a limiting factor which may be held to account for the relative infrequency of members of some of the parasitic orders largely developed in temperate countries.

Infection of plants by a fungus parasite may take place by the entry of mycelium nourished on some adjoining material, such as the soil, the roots of another plant, or dead adhering leaves or branches, or may be effected through the germination of spores directly on the appropriate living organs. It implies first the penetration of the outer defences of the plant : the cuticle and cell-wall or the corky integument, as the case may be. Advantage may be taken of wounds of various kinds for this purpose, including as such the pathways to living tissue provided by the attachment of dead twigs or branches. Entry may be made through the stomata, or the fungus may be equipped to force or to dissolve a passage, or to provide one by poisoning the 
surface tissue. Habits or powers of this nature in parasites are usually specific. The germinating spore typically produces a preliminary hypha, the germ-tube, by or from which the entry is made.

Penetration being accomplished and the parasite brought into relation with the living cells, the second line of defence, the resistance of the protoplasm, is met with. Very little is understood of the nature of this. The more or less mechanical process of penetration may take place on a variety of plants, but only when the host comes within the range of adaptation of the fungus, which is often very restricted, can parasitism be established. The subject is discussed further in the section relating to the host.

When the resistance of the protoplasm is overcome the fungus proceeds to occupy the tissues. The mycelium may grow into and through the cells of the infected tissue (intracellular mycelium), or ramify between and about them (intercellular mycelium). In the latter event the cells are either killed and their walls thus rendered permeable, or absorbing organs (haustoria) are introduced. Certain fungi, e.g., the Fusariums causing wilt disease, develop principally in the vessels (vascular parasites). In a few cases, as in the powdery mildews (Erysiphaceæ), the mycelium remains external, sending only haustoria into the superficial cells. The black blight or sooty mould fungi (Capnodiæ) develop similarly on the surface of leaves or other organs, but they have no powers of parasitism and do not live at th expense of the plant but of insect or flower secretions of tl nature of "honey dew."

\section{The Host: Resistance and Susceptibility.}

In every case of parasitism there are two organisms to be considered, the host and the parasite, and the reactions of the plant attacked are at least as important as the nature of the attack delivered. The growing recognition of this truth is reflected in the increasing fund of information regarding susceptibility, resistance, and immunity.

\section{Effect of Agricultural Conditions on Resistance.}

Some general power of resistance is conferred by the healthy condition induced in a plant by growth in a congenial situation. Each of the important crop plants of the West Indies is subject to one or more fungoid affections which occur or are serious only when temporary or permanent disabilities such as drought, poverty of soil, and exposure have reduced the resistance normal to the healthy plant. By avoiding unsuitable locations and by the practice of good agriculture it is possible to maintain this resistance at a high level, and by this means not only to escape debility diseases but frequently largely to reduce the prevalence of more definite parasites. To this effect is to be added the greater ability of a well-grown plant to endure, to outstrip, or to recover from the injuries inflicted. 
There are many other parasites, however, against which this type of resistance fails. To them a better-developed plant may mean merely an increase in available food material, while the effect of manuring and good weather may be to develop a softer type of growth which is the easier to infest. In the case of Rosellinia disease of limes, the conditions which best suit the tree best suit the fungus also, with the result that the finest trees are most liable to attack and are most frequently killed. Cacao canker and pod-rot are most prevalent in the well-enclosed humid situations which favour vegetative growth, and in dealing with diseases of this type a point has to be sought to which the humidity can be reduced so as to check the fungus without unduly hindering the development of the trees. In the growing of cotton a similar situation in respect of boll diseases is met by planting so as to take advantage of the wetter months for growth and of the dry season for crop production.

\section{Immunity by Evasion.}

The case of cotton just referred to is an example of the way in which diseases may be "resisted" by evasion. It has frequently been found with short-term crops that the best available protection against a disease or pest lies in growing early maturing varieties, or in planting to escape a season when a particular disease is prevalent. The seasonal distribution of diseases as experienced on early and late plantings of the same crop is frequently quite marked. It may be determined according to the particular case by the effects of climate on either the host or the parasite.

The highly important effect on disease of the practice of crop rotation may be put under this heading, since it mainly depends on the temporary freedom from infestation to be secured by planting disease-free material in uninfected soil.

\section{Resistant Species or Varieties.}

Resistance in the stricter sense of the word, and its complete development immunity, depend on inherent properties of the plants concerned, and may be transmitted to their descendants. Such resistance may or may not be independent of variation in the conditions under which the plants are grown; sometimes a degree of resistance which has proved constant under one set of conditions is not developed when the circumstances are changed.

The characters on which resistance depends are almost always obscure. Attempts to connect its existence with special morphological features are seldom successful, though it may exist in correlation with some difference of form. It appears to be in most cases a property of the protoplasm. In the case of certain obligate parasites resistance has been shown to arise from 
increased local susceptibility, which results in the death of the cells at the point of infection and prevents the mycelium from establishing the necessary connection with living tissues.

The production of resistant strains of cultivated plants has usually been accomplished by the propagation of chance-found individuals showing the required powers. A frequent defect of such varieties is that resistance may not happen to be associated with a high standard in other desirable qualities. Some more or less successful attempts have been made to secure the desired combinations by crossing, a seductive but uncertain line of work which has possibly had more advertisement than the stability of the results yet warrants.

The most striking example of the use of resistant varieties in West Indian agriculture is the replacement of the Bourbon cane by seedlings resistant to red rot and less susceptible to root disease, a measure which has preserved the sugar industry of these islands.

\section{Susceptibility to Exotic Diseases.}

It seems most probable in the light of the available evidence that the failure of the Bourbon cane in the West Indies arose from the introduction of a fungus to which it had not previously been exposed. In this manner have originated many of the great epidemics of plant disease. Where host and parasite are both native or have been long associated there is a natural selection of resistant species or strains and the parasite is frequently inconspicuous in amount and in its effects. Introduced into a new country the parasite may find appropriate hosts quite unable to withstand it. The chestnut bark disease, introduced a few years ago into the United States on resistant species from China, has made a clean sweep of the extensive forests of the American chestnut in the Eastern States, and shows no real abatement in its progress. Similar occurrences have been the introduction of the mildews of the grape-vine and the gooseberry from America to Europe, of the white pine blister rust in the reverse direction, of citrus canker from Japan to Florida and South Africa, and, according to the most probable theory, of the introduction from Africa of the coffee leaf disease which nearly exterminated the main industry of Ceylon.

A similar result may come from bringing exotic plants within the range of native parasites, especially those occurring on related species. The leaf blister mite of cotton in the West Indies, which appears to be indigenous and is known to attack native Malvaceous plants, caused first an epidemic and would now result in an annual infestation of the Sea Island crop if a close season were not enforced. The witch-broom disease of cacao in Surinam comes from a wild Theobroma in the forests of that country. The fungus causing pink disease of various cultivated trees and shrubs, one of the serious troubles of the Malayan rubber planter, 
is native on jungle plants in both the Eastern and the Western tropics.

\section{Local Factors affecting Prevalence.}

An established disease may assume serious or epidemic proportions under the influence of changes in local conditions. The most general of these is the collection of plants previously scattered as individuals or small groups into large blocks of cultivation, which happens when a new agricultural industry arises, as in the case of rubber, or an old one is greatly developed, as has been the case in recent times with cacao, limes, cotton and coconuts in various parts of the West Indies. When a plant is grown by the acre or the square mile in pure culture its parasites are secure of their food in due season and the agencies of dispersal have free play. The absence of serious diseases from scattered plants is thus, as experience has regularly proved, no sort of guarantee that wider cultivations will not suffer. A contributory cause to the increase of diseases with the development of an agricultural industry is the greater activity which arises in the introduction of planting material from more or less distant sources.

$\therefore$ A well-marked class of root diseases, due to fungus parasites similar in the nature of their attack though of ten widely different in taxonomic position, accompanies the establishment of crops on newly cleared forest land. The decaying stumps and logs, and the accumulations of humus to which they give rise, support large numbers of fungi, mostly pure saprophytes but usually including one or more species which are able to extend to the roots and collar of the crop plant introduced. In arable cultivation, with few exceptions (see arrowroot), the cause and the effect quickly disappear. With tree crops the original cause is more slowly removed and the effect may later be continued for a time by its victims, while in cacao orchards where conditions approaching those of forest are maintained by the use of shade trees, one such disease has shown itself in the West Indies to be capable of permanent existence in favourable situations. The tendency of such diseases in general is to decrease with time; sooner if appropriate measures are applied, later and after heavy losses if they are not.

The reverse situation to this is seen in the increase of debility diseases as soils decline in fertility. A period in which they are prevalent comes in the history of new industries and of the exploitation of virgin soils before a tradition of manuring and perhaps rotation is reluctantly acquired. The situation recurs if agricultural practice declines for any reason. In the West Indian sugar industry there has been evidence for many years of a more or less general decline, slow but continuous, in fertility, as shown by the shortening of ratooning periods and increasing prevalence of root disease. This appears to be connected with 
less intensive cultivation resulting from the increase in size of estates under the factory system, the reduction of humidity by clearing away trees, the diminished supply and increasing cost of the labour required for hand cultivation, and perhaps above all to the treacherous facility with which the benefits of organic manures can apparently be obtained by the use of chemical substitutes.

The passing of estates into the hands of mercantile rather than agricultural proprietors (a frequent consequence of agricultural depression) with the break in traditions involved, has often led to a visible decline in agricultural conditions and thus to a corresponding increase in disease.

There is a further cause of debility disease very frequently encountered: the planting of a crop in a situation which from soil or climate is somewhat unsuited to it. If a district or an island is successful with a given crop, attempts are always made to extend it to marginal or supposedly similar locations. Under the less suitable conditions production is smaller, and it too frequently happens that the need for greater attention to agricultural practice in order to offset the defective conditions cannot or will not be understood or the expense cannot be afforded. In such a case the soundest advice that can be given with reference to the diseases which invariably occur is to plant a crop more suited to the situation. It is advice which is frequently required, seldom given, and never heeded until necessity dictates it.

Returning to more definitely parasitic diseases, there are various natural causes producing broad effects in the prevalence of disease. The disastrous potato blight epidemic in Ireland in 1845, the social consequences of which have had a marked effect on British and American history, was brought on by a period of dull and humid weather. Nearer at hand a week or two of heavy rain in St. Vincent has more than once brought about the destruction of the visible cotton crop by boll-rotting fungi. An instance of the complexity of the factors sometimes involved is afforded by the history of internal boll disease in the same island, where the eradication of casual trees of two species, by interfering with the breeding of an insect, has saved the later pickings of cotton from a fungus disease which regularly destroyed them.

\section{The Principal Types of Fungus Diseases.}

Every part of a plant is liable to attack by fungi, but each individual parasite affects only certain parts or stages in a certain way, and usually produces a disease of a constant and recognisable type.

Leaf Diseases.

Fungus infections on leaves commonly give rise to localised 
lesions in the form of spots, streaks or patches. The cause of complete discoloration, wilting or shedding of leaves is more frequently to be found in an infestation of twigs, branches, stems, or roots, according to the distribution of the symptoms.

Leaves are most susceptible in the early and late stages of their development. The tenderness of young leaves, including the absence of cuticle, exposes them to infection by fungi which are unable to attack mature leaves; the anthracnose of limes is an example of this. The fungus may later disappear, but the effects of its presence remain in the shape of spots or distortions which are difficult to account for if the early stages are not seen. Senescent leaves show waning powers of resistance and are frequently infested by parasites too weak to have much if any effect until this condition is reached. Very many leaf spots are of this nature. Influences which depress the vigour of the plant may bring on the susceptible condition prematurely; thus when a coconut palm is infested with nematodes Diplodia attacks the leaves at an earlier stage. Many secondary infestations are brought about in a similar way.

Leaves are affected differently by parasites which establish a relationship with the living cells, like the rusts and mildews, as compared with those which live at the direct expense of the tissues. In the former case the leaf though more or less discoloured remains alive, it may be for its full period or even longer ; in the latter case dead spots are quickly produced. A common type of leaf spot consists of a dead central circle or streak, surrounded by a discoloured margin of cells recently invaded or affected by the secretions of the mycelium. Such an area may become isolated from the surrounding tissue through the production by the host of a ring of corky cells which prevents further extension, and if the dead tissue later drops out the type of injury known as shot-holes is produced, in which the leaf is more or less heavily perforated with roundish holes. In other types of spotting the lines of the veins are followed, or the spot is bounded by veins (angular spot) or quite irregular perforations may be produced (Hevea leaf spot).

It is often difficult to distinguish between leaf spots caused by fungi and those of insect origin, especially as the latter are soon invaded by saprophytic fungi.

The infestation of leaves with fungi reduces their efficiency to a proportionate degree and may lead to partial or entire defoliation. This causes a severe check to growth, and, if repeated frequently, brings about the death of shoots or twigs and sometimes of the whole plant.

\section{Flower and Fruit Diseases.}

The infestation of flowers is not common, but examples of it are found in the blossom blights, due to Gloesporium spp., of mango and of lime, in which buds, open flowers, and newly set 
fruits are rapidly infested and destroyed. The parasitism of the smut fungi, which also destroy flowers, is of a special type in which infection proceeds from within, and is described in another section.

Fruits while yet unripe may be very quickly destroyed by the Phytophthoras (soft-rot of cotton bolls, cacao pod-rot), may be spotted or cankered by the anthracnose fungi and similar parasites, may be scabbed or russeted by surface infections, may develop cracks in consequence of the inability of infested spots to keep pace in growth, and may be internally infected through bug punctures while preserving an uninjured appearance.

As fruits ripen they lose, like senescent leaves, much of the resistance which accompanies the condition of living activity. A ripe fruit is a fruit that is finished with so far as the plant is concerned, and if not protected soon becomes the natural prey of various saprophytic fungi (see Chap. XIII). Some of the ripe rots may commence prematurely before the fruit is picked; usually this happens in consequence of a wound or bruise.

Further examples of fruit affections will be found described under diseases of Citrus spp.

The shedding of young fruits, of which cotton affords the pre-eminent type, may be due to infection or insect injury, but is frequently a result of the disturbance of physiological balance by some change in external circumstances. It may also be an adjustment of numbers to the amount of fruit which can be brought to maturity, as seems to some extent to be the case with coconuts. A similar adjustment in cacao occurs not by shedding, but by the drying up of young fruits, and as these invariably become infested with fungi the loss is often attributed to fungus disease. That the inherent bearing capacities of individual coconut and cacao trees vary widely does not affect the fact of the adjustment, which is demonstrated by the proportionate increase in the amount of fruit which matures when cultivation and manuring are improved.

Stem Diseases.

Tip-wither, the dying of young green shoots, is commonly due to fungi which also attack the young leaves, and may arise from terminal infections or from the ringing of the young stem by infections in the cortex. It may, of course, also be produced by insect injuries or physical causes.

Dieback of twigs often follows on successive defoliations by fungi or insects. It is frequently associated with infestation by weak parasites such as Diplodia spp. or Colletotrichum glcosporioides on trees rendered susceptible by exposure, drought, or poor nutrition. These conditions are themselves capable of originating dieback, and it is usually very difficult to form an opinion as to how far the failure is due to or is aggravated by the presence of the fungus. 
The death of branches may be the result of direct infestation with a parasite such as that of pink disease (see Chapter XVI) or of an infection near the base by a fungus which has attacked the bark or gained access from a broken branch or other wound. The progressive dying of the topmost branches, like the dieback of twigs, is less often due to local infections than to the ebbing of the vitality of the tree as a result of drought, poor nutrition, root disease, or old age.

With regard to the last-mentioned cause it should be always remembered that the age and size to which a tree attains before showing the signs of waning vigour are widely variable according to situation. Trees grown in thin or poor soils, or in a situation drier or more exposed than suits the particular species, reach their natural limits in these respects in a period which is much shorter than the normal one, while highly favourable conditions have the opposite effect.

Bark rots are often of fungus origin, but may be bacterial, or, as it appears in some cases, non-parasitic. Their effects are frequently much increased by insects, as in the case of Citrus trees which become infested with a beetle larva (Leptostylus). Bark rot in the region of the collar is rather frequent, and is often due to soil-inhabiting fungi or to others enabled to exist in this situation by the moisture of the soil or the shelter of weeds. The peculiar liability of Citrus trees to collar rot is discussed elsewhere.

Cankers are usually local infestations of the bark in which the persistence of the fungus and the reactions of the cambium give rise to raised margins or irregular lumpy growth about the wound produced. The application of the term is not clearly distinguished from that of bark rot, but the above would seem its most appropriate use.

Gummosis is a symptom of very variable origin, consisting in the production of gum by the degeneration of cell walls, usually in the neighbourhood of the cambium layer, i.e. just under the bark as that term is commonly used. The gum may saturate the overlying bark and solidify in a crust or in drops on its surface, as in Diplodia disease of limes and collar rot of oranges. New layers of wood or bark may enclose a site of gum formation in the cambial zone, giving rise to gum pockets. Gummosis can occur as a result of fungus infection, wounds, or chemical stimulation.

Wood-rots, which are separately discussed in Chapter XI, are as a rule the result of bark injuries of various kinds, the breaking of branches, or unskilful pruning or trimming, which expose the wood to infestation by fungi otherwise unable to gain access. Their effect is ultimately to destroy the mechanical support of the part affected.

Galls are abnormal outgrowths from leaves or from green or woody stems, and their tissues are soft or woody according to 
their position. They are the result of some irritation of growing tissue, the reaction often appearing very disproportionate to the cause. The larger number of galls are due to insects, but there are many which are of fungoid or bacterial origin. A woody gall, once formed, has its own cambium layer, and consequently continues to grow so long as this maintains connection with the tree. Examples of fungus galls are afforded by the smut disease of Indian corn, and Sphæropsis disease of Citrus, while the deformity produced in the so-called witch-broom disease of cacao is more of the nature of a gall than of the structures after which it was named. The crown gall disease, found on a wide range of hosts, results from the presence in the tissues of Bacterium tumefaciens.

Witches-brooms are structures similar in their origin to galls, in which an abnormal number of crowded shoots is formed at some point on a branch and appears as a tuft or mass of interlacing twigs.

The affections of herbaceous stems may be surface spots akin to leaf spots, invasions of the cortex alone, the vascular tissues alone, or both together. Cortical invasion causes local rot or canker, with yellowness of foliage or other sickly appearances as general symptoms; interference with the vascular bundles produces progressive or sudden wilting.

The type of disease known as bud-rot is peculiar to monocotyledons in which the terminal bud from which growth proceeds is deeply enclosed in the bases of the older leaves. Being thus supported it remains longer in a soft and plastic condition and offers a large mass of highly susceptible material to any parasitic organism which gains access to it. Bud-rots occur in coconut and sugar-cane, but conclusions as to their primary nature should be made with caution, as experience has shown that in both plants the failure of some other part may deprive the bud of the required nutrition and bring about its decay. The closeness of its covering, by excluding air, probably accounts for the predominant part which putrefactive bacteria take in the process.

Root Diseases.

Diseases of the roots are in general the least satisfactory of any to investigate and to combat. Experiment is difficult, and observation cannot always be depended on to distinguish cause from effect. The consequence is that knowledge regarding root diseases is not usually definite, except where very pronounced parasites are concerned.

The soil, with its accumulations of dead matter and its relatively constant moisture, harbours many fungi, and among them are found species possessing powers of parasitism in various degrees.

Sclerotium Rolfsii destroys herbaceous plants hy attacking the stem and crown roots near the surface of the soil. The forest 
root fungi (Rosellinia, Sphærostilbe, and others) infest dead wood or other vegetable material and either spread along the roots of living trees or infest them at the collar from the soil. The parasitic Fusariums obtain access by the roots to the vascular system of the stem. These are all largely or entirely independent of the vigour of the host, and their prevalence depends closely on physical conditions.

The root fungi of sugar-cane (Marasmius, Odontia) live normally on the withered leaves and other dead material of this and other grasses, but by invading the roots contribute, to an extent which is very variable and in any given case difficult to define, to the results of adverse conditions in general. Under certain special conditions Marasmius seems able to become a more active parasite and completely infest the bases of the shoots.

\section{Notable Groups concerned in Fungus Diseases.}

\section{The Rusts (Uredinales).}

The family Uredinales is made up of some two thousand known species of obligate parasites on trees, shrubs, and herbaceous plants (including ferns). Wherever vegetation of these types exists, from the polar regions to the equator, some representatives of the family are found. Conditions in the West Indies are not so favourable to the development of rust-fungi as are those of temperate regions. While recent research has disproved the idea that the species are extremely few, it remains true that with few exceptions they are scanty in their distribution and inconspicuous in their development. A few species occur on minor crop plants, but the damage done is usually quite insignificant and affords a great contrast to the immense losses frequently caused in temperate crops, especially in continental areas. As regards tropical countries generally, there is an outstanding exception to this position in the coffee leaf rust (Hemileia), which is regarded as responsible for the ruin of the coffee industry in Ceylon. That fungus is not known to occur in the Western Hemisphere.

The rust fungi are strictly confined to growth on living tissue, and the species are limited to individual or to related species of host plants-the general tendency being to narrow limitation in this respect-except that in many species the character of heterœcism is exhibited In these cases the fungus occurs in certain stages on one host, and is then capable of transfer by spores to a second and sometimes a third host-commonly of widely different botanical affinities-and there goes through other stages in an entirely different form. Only by infection trials can the relationship of the forms on separate hosts be determined.

Five distinct kinds of spores occur in the Uredinales, described 
below in relation to the manner in which they are produced. The Roman numerals are commonly used for reference. The older terminology is given in brackets.

I. Acia (æcidia), which typically are cup-shaped structures sunk in the substance of a leaf. The æciospores (æcidiospores) are usually globular, or angular by compression, developed in chains. They are capable of immediate germination and the infection of a suitable host.

O. Pycnia (pycnidia), very small flask-shaped structures usually, when present, associated with æcia, sometimes with other forms, but never alone. The pycniospores are minute unicellular bodies the function of which is either lost or has escaped detection.

II. Uredinia (uredo-sori), circular or elongated pustules from which arise stalked roundish unicellular urediniospores (uredospores), often rough or spiny. These are usually produced quickly and in abundance, and, as they germinate at once under suitable conditions, serve for the rapid spread of the fungus. Thick-walled resting forms of urediniospores which occur in some species are distinguished as amphispores.

III. Telia (teleuto-sori). Mingled in the same sorus with the urediniospores, succeeding them, or in separate sori, may occur teliospores (teleutospores) which typically are stalked, one to several-celled, thick-walled resting spores, but may diverge widely from this form, even to the point of resembling æciospores. The real criterion of their nature is the manner of germination, in which each cell produces a germ tube the tip of which divides into a linear row of cells, typically four, each of these giving rise to a short stalk on which one rounded thin-walled spore is borne. This structure is regarded as a basidium, bearing basidiospores, and the Uredinales are accordingly classed as Basidiomycetes. The spores so produced germinate on suitable hosts and produce a mycelium which develops spores of one of the types described.

One species may possess in its full life-cycle all the forms enumerated; or any or all of them, except the telial stage, may be omitted. It is not, however, necessary that the stages be passed through in sequence; an indefinite number of generations, for example, may arise from the successive production of urediniospores. In the heterœcious species the æcia and pycnia are found on one host, and the uredinia and telia, or telia alone, on another.

The mycelium of the rust fungi is freely branched and septate, usually intercellular, with haustoria penetrating the cells.

The commoner rusts on cultivated plants in these islands are the following: Puccinia purpurea, Cke. sorghum rust, very common and generally distributed on guinea corn, imphee, and Sudan grass; Puccinia Sorghi, Schw. (Maydis, Bereng.), brown rust of Indian corn, rather common in some places, but not as a 
rule doing appreciable damage ; Puccinia Cannce (Wint.) Henn., common on garden cannas; Uredo Arachidis Lag., common on ground-nut and sometimes destructive ; Cerotelium (Kuehneola) Gossypii (Lag.) Arth., common and sometimes severe on some perennial cottons, but not very often seen on Sea Island types. The bright yellow Uredo form of Phakopsora vitis Syd. is generally common on grape vines, and a brown Uredo on Dolichos; the pigeon pea is frequently seen in Trinidad with leaves rusted by Uromyces Dolicholi, Arth.

Rust infestations may be kept down by spraying with Bordeaux mixture (see ground-nuts) and resistant varieties have been found in several important cases.

\section{The Smuts: Ustilaginales.}

The smut fungi are somewhat nearly related to the rusts, though very different in their general habit. Like the rusts, they are strictly parasitic, depending for nourishment on living plants. They attack plants of widely different orders, perennials as well as annuals; their economic effects being most serious on the cereal crops. They are few in number and of very small importance in the West Indies.

Typically the host is infected in the seedling stage (the corn and sugar-cane smuts are exceptions to this) and the mycelium keeps pace with the developing plant, growing sparingly, and without producing any notable symptoms of disease, through the softer tissues. The hyphæ are hyaline, branched, sparingly septate, mostly intercellular, with haustoria which enter the cells. When the period of flowering is reached the fungus develops rapidly in the anthers and ovaries and there produces masses of spores (often black and powdery) which replace the pollen and the seeds. In some cases swellings in which spores are produced in a similar way are caused on stems or leaves.

The spores so formed (chlamydospores) are usually thickwalled and very resistant, in some cases retaining their vitality for many years. They germinate in water, producing a short filament (pro-mycelium) on which elongated thin-walled basidiospores (distinguished in this family as sporidia) are formed. These are capable of immediately infecting host-plants which are in the susceptible stage. In nutritive solutions, as soil water or moist manure, the sporidia give rise to a yeastlike form of growth which may continue the life of the fungus until a suitable host is encountered.

Two common types of infection occur in this family, the distinction of which is important in regard to control measures. In certain species the chlamydospores, distributed, after they are set free, in various possible ways but mostly by the wind, adhere to healthy seeds and are planted with them, or are already present in the soil in which planting takes place. They germinate in the soil moisture, producing sporidia, and these proceed to 
infect the host seedlings as they appear. Seedlings beyond a certain size are no longer susceptible.

In other species the infection is through the flower. In this type the chlamydospores are distributed at the time of flowering, and arriving in healthy flowers germinate there and infect the developing seed. The mycelium remains dormant through the ripening process and until the seed in due course germinates, when it grows up with the developing seedling as previously described.

The corn smut (see Chapter XXIV) is different from either of these types, being able to infect its host on any tender part and at any age.

With smuts of the first type, control is easily obtained, where uninfected ground is available for planting, by some form of seed disinfection. Those of the second type cannot be dealt with in this way, and seed from a clean source has to be sought.

With both types rotation of crops should be practised to reduce infection from the soil, and the inclusion of diseased plants in litter or manure should be carefully avoided. Nor is it safe to feed smutted grain to animals, since a proportion of the spores may pass uninjured through the alimentary canal and be distributed with the manure.

\section{The Powdery Mildews (Erysiphacea).}

The Erysiphaceæ is a well-known family of Ascomycetes whose members are strictly parasitic, growing as white webs on the surface of leaves and tender stems, and deriving nourishment from the underlying tissues by haustoria (in a few species by short hyphæ) which penetrate the cells.

The family has a wide range of hosts in temperate countries, and species occurring on cereals, grape, hop, etc. give rise to widespread and destructive epidemics. In the Tropics the family is thinly represented and of small account.

The conidial fructifications, the only stage which appears to be developed in these islands, consist in the great majority of species of short upright hyphal branches bearing a chain of hyaline oblong or rounded conidia. Forms of this type are referred to the genus Oidium, in the absence of the perithecial fructifications on which more definite classification is based. The latter are subspherical bodies formed in the mycelium, usually in autumn, bearing projecting bristle-like or elaborately branched appendages, and containing one or more roundish asci with 2 to 8 spores in each.

The Oidiums of the grape and rose are common in the West Indies, and there are doubtless other species to which attention has not yet been paid. The leaf mildew of cotton belongs to the closely related genus Ovulariopsis.

The standard remedy for this class of disease is dusting with powdered sulphur or spraying with a sulphur compound. Narrow 
biologic specialisation in regard to host plants is sometimes exhibited in this family, and resistant varieties are therefore possible.

\section{The Downy Mildews (Phytophthora).}

Members of the genus Phytophthora are the most rapidly destructive of plant parasites. One of them, $P$. infestans, caused the potato famine of $\mathrm{I} 845$ in Ireland. $P$. faberi is the cause of cacao canker and pod-rot. P. palmivora is the cause of a destructive bud-rot of palms in India, and has been recognised on coconut in Jamaica. Another, or possibly more than one species causes in the West Indies a boll rot of cotton which is very destructive in wet weather.

The mycelium of Phytophthora is hyaline, non - septate when young, much branched, and has a characteristically coarse and vigorous appearance under the microscope. Living tissue is infested and rapidly killed. The common form of reproduction is by large lemon-shaped conidia, developed one by one at the apices of conidiophores produced on

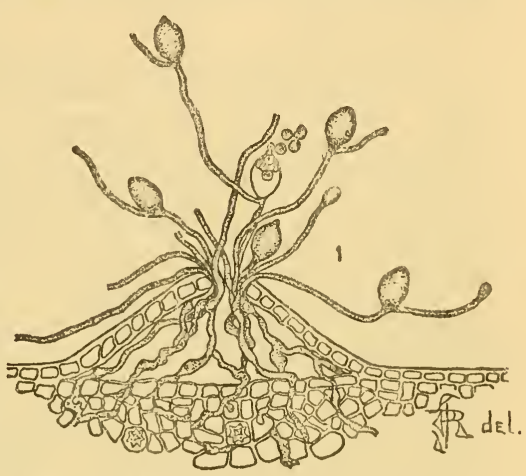

From a drawing? by]

Fig. 2 Phytophthora FABeri the surface of the medium. The massed conidia on the surface of a cacao pod or cotton boll have a granular glistening appearance ; the mycelium, in very moist conditions, may grow out and form a white downy covering. The conidia typically germinate by liberating a number of zoospores, which swim actively in a surface film of water before settling down and producing a germ tube. While in the mobile condition they are splashed about by rain, blown about in drops of water by the wind, and may conceivably be distributed by birds or insects. In the absence of free water the conidia sometimes produce germ-tubes direct.

In addition to the conidia, resistant chlamydospores and oospores may be produced on the mycelium buried in the infested tissues.

The occurrence and prevalence of Phytophthora diseases is dependent on a high degree of humidity in the air about the plants. Close planting, shade and shelter, the inducing of the 
growth of heavy foliage by nitrogenous manuring, all favour their development. The cotton boll rot is frequently confined to the branches close to the moist soil.

The potato blight is perhaps the most amenable of all important diseases to Bordeaux or Burgundy sprays, and cacao podrot has proved to be similarly controllable. These fungi have no importance as saprophytes, as, although they can be artificially grown in pure culture on vegetable media, in nature their existence on dead material is quickly inhibited by the growth of other organisms. The removal of dead material is desirable however on account of the resting spores it may contain.

\section{The Anthracnoses.}

The term anthracnose is not strictly specific, but is usually and conveniently applied to diseases caused by fungi of the genera Colletotrichum and Glœosporium. These are conidial forms, not strictly separable from each other, since the presence or absence of dark-coloured setæ (bristles), on which the division is based, is not a constant character. Certain of the species have been shown to be the conidial forms of Ascomycetes of the genera Glomerella and Gnomonia, but the perithecia are rarely met with in the active stages of disease.

Many species of Colletotrichum and Glœosporium are pure saprophytes, others have weak powers of parasitism which enable them to attack senescent leaves or over-ripe fruit, and many are virulent parasites capable of attacking perfectly healthy tissue. All are able to exist as saprophytes on dead material.

The hyaline septate mycelium permeates the infested part causing the death of the cells. The conidia are borne in acervuli or pustules, for the production of which a matted or compacted layer of hyphæ (the stroma) forms near the surface of the medium. From this bed arise crowded short conidiophores, which bear apical non-septate conidia, twice to several times as long as broad. These are hyaline, but may appear coloured in mass. The rupture of the overlying tissue exposes the acervulus or fruiting layer, which continues to produce conidia. These accumulate in little heaps, adhering in a gelatinous medium until they are washed away by rain. The disease produced may be one of leaves, flowers or fruit or any combination of these, or it may extend to herbaceous stems or even woody twigs.

Characteristic anthracnoses in the West Indies are those of mango (Gl. mangiferce) and of lime (Gl. limetticolum). Both cause small canker spots or tip-wither on the young shoots, dead patches on the leaves, blight of the buds and open flowers, shedding of newly set fruit, and spots or cankers on the fruit that remains. Other local examples are the anthracnoses of Agaves, beans (Phaseolus), cotton, papaw, and cassava. An example of a ripe-rot Glœosporium is everywhere familiar in the fungus which causes spotting on ripe bananas (Gl. musarum). Col. 
falcatum produces the red rot of the sugar-cane stem and a red stripe affection on the leaves and leaf-sheaths; nearly allied species occur on sorghum and other grasses. The citrus anthracnose (Col. glocosporioides), which under some conditions is reported to produce on Citrus species in general effects similar to those of the special anthracnose of the lime, is not known to be of much account in the Lesser Antilles. The cotton anthracnose Glomerella (Coll.) gossypii appears also to be responsible for much less damage than is reported from it in the United States.

For the control of anthracnoses it is desirable, in the first place, to secure clean seed. Adhering spores can be dealt with by the methods elsewhere described, but in some cases the cotyledons are infected while the seed is still on the parent plant. Hot water treatment has been suggested in the case of infected cotton-seed, but with what ultimate results is not known.

For tree crops such as limes and mangoes the only remedy is spraying, and this is the measure adopted for anthracnose in general where the value of the crop warrants the outlay. The control of the destructive epidemic of red rot on sugar-cane in the West Indies was secured by the use of seedling varieties, some of which have proved to be highly resistant, and others apparently immune. Varieties of beans (Phaseolus) resistant to the bean anthracnose fungus have been found, and the character has been transferred to other types by crossing. Various strains of this parasite have been shown to possess differential powers of infesting particular varieties of the host.

On the other hand, many of the reputed species of Glœosporium and Colletotrichum have been shown by infections from pure cultures to have a very wide range of possible hosts.

\section{The Fusariums.}

The genus Fusarium includes many purely saprophytic species and a considerable number of ve.y destructive plant parasites. The latter are typically confined to one host plant, frequently even to the narrower limits of particular varieties or strains, but are capable of living indefinitely as saprophytes, very often in the soil.

The species are very similar in morphological characters, and for that reason, and because of the abundance of saprophytic species likely to be confused with the parasites, have been exceedingly difficult to identify. Of recent years the use of standard culture media and of biometric methods in the comparison of species has removed much uncertainty and laid the foundations of an exact knowledge which is much to be desired with other genera.

The most important section of the genus is the group of species, similar in biological and morphological characters, which function as vascular parasites, and by blocking or destroy- 
ing the vessels produce wilt disease usually destructive of the whole plant. The most notorious of these is the Panama disease of bananas. Others attack cotton, okra, tomato, cow pea, pigeon pea, etc., etc.

Other species of Fusarium cause rots of the lower stem (foot-rot) of seedlings or young plants, as in cow pea, beans (Phaseolus), and cotton in these islands.

Others again cause tuber rots (potato), fruit rots (tomato, water melon, cacao), or stem cankers, while numerous miscellaneous diseases have been described with which Fusarium species have been associated.

The mycelium of Fusarium species is made up of septate, variously branched, hyaline or light-coloured hyphæ. It ramifies through the vascular system (in the wilt diseases) or the tissues in general (in the rots) and in some species develops at the surface into a more or less compact layer forming the basis for the production of conidia. The conidia are typically of two forms : the microconidia, often called the Cephalosporium stage, which are rounded in shape, produced one by one from the tip of a short hyphal branch, and often adhering in roundish heads; and the macroconidia (Fusarium stage), which are elongated, fusoid, usually more or less curved, and when mature generally several-septate. The latter are produced on simple or branched conidiophores, and accumulate in loose and or sometimes slimy masses on the surface of the medium, when they may appear either white or light-coloured, frequently with some shade of pink. The microconidia are sometimes produced within the infested tissues, and in Panama disease, according to Drost, follow the course of the sap and form new centres of infection in the vessels.

Chlamydospores, single or double, and occasionally in chains, are capable of being formed by the mycelium of most of the species. They are thick-walled and resistant.

Attempts to control the Fusarium wilts by treatment are of no avail ; entry is commonly made from the soil, and the injury is deep-seated. With annual crops relief from serious infestation may be obtained by rotation, but, these fungi being usually indefinitely persistent in the soil, a long period is sometimes necessary to reduce the fungus sufficiently for the susceptible crop to be repeated. In the Panama disease of bananas infection is also conveyed in the suckers used for planting, so that an uninfected source of planting material is required as well as clean land. It does not appear that vigour in the host, as affected by cultivation, manuring, soil and climate has much influence in regard to wilt resistance.

The line on which the most notable successes in wilt control have been developed is that of breeding resistant varieties or strains, which is rendered possible by the narrow specialisation of the fungi concerned. There are wilt-resistant cottons, cow peas, 
cabbages, and melons, and some varieties of bananas are not subject to attack by Panama disease.

\section{The Diplodias.}

Nomenclature in the genus Diplodia is particularly confused as the result of attempts to divide up its species amongst smaller genera : Lasiodiplodia, Botryodiplodia, Chætodiplodia, etc., based on characters that have proved to be unstable. The present tendency is to revert to the use of Diplodia pure and simple, and with this policy, in the present unsatisfactory condition of knowledge concerning the delimitation of the species, the writer heartily agrees.

There are many saprophytic Diplodias described, but the species concerned in plant diseases are essentially weak parasites, which (as E. J. Butler has pointed out in relation to $D$. Theobroma), though capable of living as saprophytes, are more often found on dying or recently dead plants than on old dead plant tissue. It would appear that the advantage they secure from their ability to infest weakly but still living tissue is necessary for their success in competition with the pure saprophytes. The limitations of the parasitic powers of a typical Diplodia are well illustrated on lime trees. In young and vigorous trees the infestation of the stub of a broken branch stops short at its base ; in older weaker trees the fungus infests a proportional amount of the wood and bark connected with the stub, giving rise to a sharply defined dead segment, eventually running out to a point, on the older branch or stem. In very weakly trees the extension of this sort of damage gradually kills back the whole tree.

Diplodias of the semi-parasitic type have a general and abundant distribution in the West Indies, but how many species are involved is not known. They have a range of feeding habit wide enough to include fruit pulp and close-grained wood. The diseases with which they are typically associated may be grouped as follows :

(a) Diebacks of twigs and branches when these are in a weakened condition, entry being made from dead tips, broken branches, or other wounds productive of dead material on which the fungus can get a footing. This type has attracted most attention in the tropics on cacao, Citrus, and Hevea, but is common on other trees of lesser importance.

(b) Root diseases of similar nature, occurring on plants debilitated by age, poor or badly drained soil, or other causes. These are met with occasionally on cacao, more frequently on limes in the West Indies; and on tea in the Eastern tropics.

(c) Rots of fruits, which very frequently start from wounds, but do not always seem to be dependent on them, especially if the fruit has been checked in its development. Examples are the Diplodia rots of cacao pods, cotton bolls, citrus fruits and melons. 
(d) Rots of 'non-woody vegetative parts, as injured or weakened stems of sugar-cane and the basal part of failing coconut leaves.

(e) Rots of stored vegetables, such as sweet potato and dasheen.

The mycelium of the common species of Diplodia is freely septate, light to dark brown when mature, and imparts a slaty or smoky colour to infested wood. The spores (pycnospores) develop in small flask-shaped bodies (pycnidia) formed singly or in groups, usually thickly set, below the surface of bark or rind and later breaking through. The spores are oval, hyaline and non-septate when young, dark and one-septate when mature. They may be extruded and germinate in either condition, and mistakes in identification are liable to arise from this habit.

The best form of control of the dieback diseases is cultural, i.e., the maintenance of the trees in high vigour, and, with cacao and limes, avoidance of undue exposure. Careful pruning of failing branches, and prompt treatment of wounds have great value in preserving oldish trees. In relation to fruit diseases the fact mentioned above, that these fungi are only common on dying or recently dead material, gives some force to the usual recommendation regarding the destruction of diseased wood and of such infestable material as cacao pods.

\section{The Rhizoctonias.}

The Rhizoctonias are soil-inhabiting fungi, distinguished by the possession of mycelium and sclerotia of characteristic types. One or more species are very abundant in temperate countries, and several are reported to be prevalent in India. In the tropics they have been very little noticed, but from occasional observations made it seems certain that at least one species is widely distributed in the West Indies.

Rhizoctonia Crocorum (Pers.) DC. (violacea Tul.) is a fungus occurring on numerous hosts but particularly on alfalfa. The disease occurs in the fields in patches, in which the plants appear yellow or chlorotic and eventually wilt rather suddenly. The mycelium completely invests the root system with a weft of hyphæ which at first is pale buff to violaceous, later red-violet and finally violet-brown. The sclerotia are flattened or rounded bodies varying in diameter from a few millimetres to several centimetres, deep violet-brown when mature and thickly clothed with a persistent velvety felt.

No spore-producing stage of this fungus is known. It has rarely been grown apart from the host and appears to be strictly parasitic. It attacks developed plants and is not associated with damping-off. It has not been recorded from the West Indies.

Rhizoctonia Solani Kuhn, is now known to be the mycelial stage of Corticium vagum, B. et C. (Hypochnus Solani P. et D.). It is a fungus of very general distribution in arable soils and 
gives rise to root disease and to damping-off of cuttings and seedlings of very many species of plants. According to G. L. Peltier, epidemics are apparently due to a combination of factors, such as the presence of a virulent strain of the fungus, a sus-

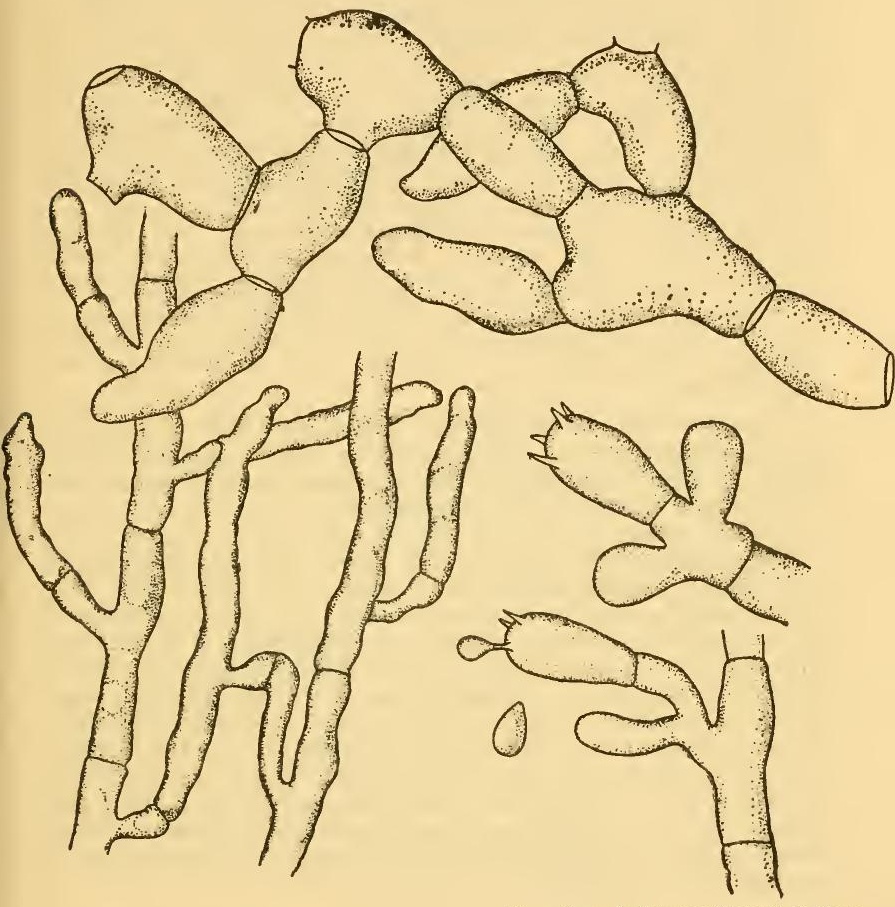

[From Duggar's Fungous Diseases of Plants

Fig. 3 Hyphae (Rhizoctonia) Basidia and Spores of Corticium Vagum

ceptible variety of plant, and optimum conditions of temperature and moisture for infection and development. Under ordinary conditions most of the strains appear to be weak parasites.

The hyphæ freely penetrate soft tissues, and there is usually more or less external mycelium, though never a copious investment as in the previous species. The description given by B. M. Duggar is as follows : 
“The external hyphæ are somewhat coloured, usually yellowish brown, and they are generally of two types. One type may be designated as purely vegetative and another as constituting the external tufts or masses when these occur. All hyphæ are practically colourless when young, vacuolate, more or less irregular, septate with the septa at intervals of $100-200$ microns. The diameter of vegetative hyphæ is $8-12$ microns. Branches arise, and when young these are inclined in the direction of growth and are invariably somewhat constricted at the point of union with the main hyphæ. As the hyphæ mature and become more deeply coloured they are more uniform and rigid, the distances between cross walls are greater, the constrictions where branches arise less marked, and the branches are approximately at right angles to the main hyphæ. On certain affected plants a short tufted or mealy growth occurs and this is made up of hyphæ of very different characteristics. In the young condition threads are profusely branched and lobed, sometimes botryoid, and they a re ultimately divided into short ovate cells, arranged in short chains, or elbowed, and producing branches in a more or less dichotomous fashion. In culture the denser masses give rise to sclerotia. With maturity these hyphæ become light brown in colour; they break up into short hyphal lengths or single cells, the individuals of which bear some resemblance to conidia.

"The sclerotia vary in size from those so minute as to be scarcely visible to others which may be a centimetre or two in diameter. They are generally more or less flattened, irregular, deep chestnut brown, and generally smooth on the surface."

The Corticium fructification is formed as a collar around the base of living stems, or on objects lying on the soil, and consists of a thin web or membrane, pale olive-buff to cream colour, on which the scattered basidia are borne.

In the examples of damping-off which have come to the writer's notice in these islands a mycelium with the characters of Rhizoctonia has frequently been found, and it is probable that this fungus is much more common than the classic parasite of this affection in Europe, Pythium de Baryanum, if indeed the latter occurs at all. A Rhizoctonia collar-rot of bean plants (Phaseolus vulgaris) is not uncommon and the fungus has been found on the roots of diseased sugar-cane seedlings. Whether the collar or crown rot which is reported to prevent the cultivation of alfalfa is also due to Rhizoctonia cannot be said with certainty, but specimens received from Montserrat suggest the possibility. Other occasional root diseases of herbaceous plants occur in which a sterile mycelium is concerned, and require to be examined from this point of view.

\section{The genus Marasmius.}

The genus Marasmius contains several hundred known species, most of which are woodland saprophytes on dead vegetable matter. The fructification is of the toadstool form, and is distinguished by the papery, not fleshy, consistency of its substance, which when shrivelled by drying is capable of restoration to something like its original form on being re-moistened. Several species occur in the West Indies about the bases of the shoots of grasses, including sugar-cane, and are well-known in connection with root disease of that plant. Others occur on the 
leaf-sheaths of banana, where they have also a connection with disease, and the same or similar species are found on the "strainer" of the coconut palm. These are at most rather weakly parasitic.

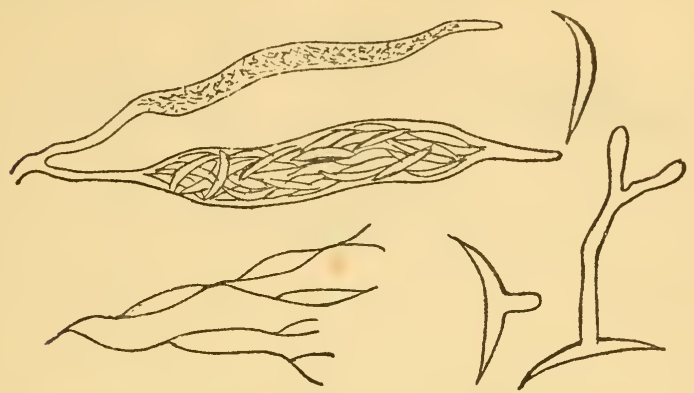

Fig. 4 Stigmatomycosis. Species A

A much more definite parasite is Marasmius perniciosus, Stahel, the cause of the witch-broom disease of cacao in Surinam. The black threads of the so-called horse-hair blight are the mycelial
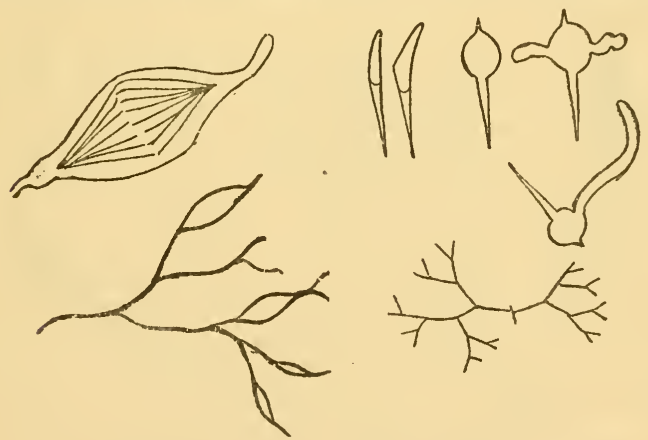

Fig. 5 Stigmatomycosis. Species B (Eremothecium)

strands of a Marasmius, which is no longer regarded as more than saprophytic in habit.

The Fungi infecting Bug Punctures (Stigmatomycosis).

A type of disease not previously recognised has in recent 
years been found to be wide-spread in the West Indies, in which fruits and seeds are infected with fungi of what appears to be a highly specialised group by way of the punctures of plantfeeding bugs (Heteroptera). The experiments which have been
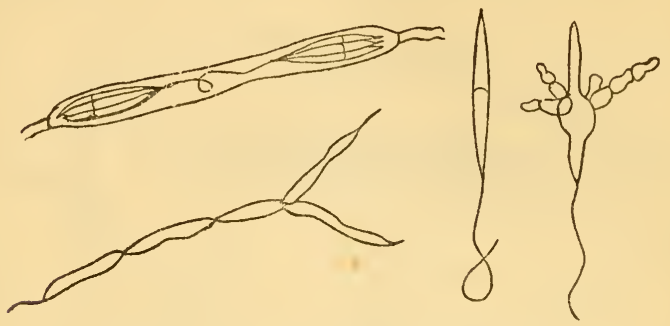

- Fig. 6 Stigmatomycosis. Species C

made indicate that the infection is actually conveyed by the bug from plant to plant.

For disease of this kind the term stigmatomycosis is proposed, a typical example being the internal boll disease of cotton described in Chap. XXV. Two of the fungi concerned, or species

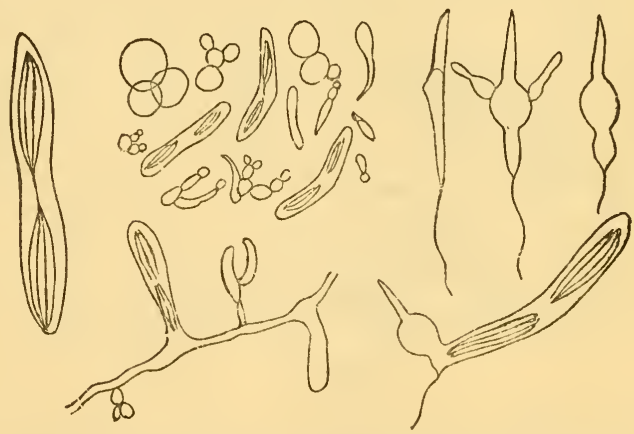

Fig. 7 Stigmatomycosis. Species D (Nematospora)

closely resembling them, had been previously met with; one of them, Eremothecium cymbalaria Borzi, corresponding with the writer's Species B, was found in Italy in I888 in capsules of Linaria cymbalaria and rediscovered in France in I906-I2 in fruits of Cachrys lavigata: the other, Nematospora Coryli 
Peglion, resembling Species D of the writer, was obtained from a diseased hazel nut in Italy in Igor, and appears to have been seen in France in association with the previous species. Nematospora Lycopersici Schneider, described in I9I7 from fruits of tomato supposed to have come from Cuba or Mexico appears to differ only in the recorded measurements.

Four species have been met with in the West Indies, two of which remain as yet unnamed. In species $A, B$, and $C$, the mycelium is byaline, fine to coarse, non-septate except in connection with reproduction, and branching almost entirely by regular dichotomy. In cultures small bud-like projections may occur along the course of the hyphæ. In Species D (Nematospora) the thallus as developed in fruits and vigorous cultures is typically yeast-like, and consists of a mixture of two forms: (I) toruloid cells and cell-groups, the units of which are very variable in form but generally elliptical or ovate, (2) much larger spherical cells, single or attached in small groups. In old cultures or when growing in tap-water, a mycelium is produced which is made up of long, sparingly branched and very sparingly septate hyphæ (Fig. 7).

The spores develop in sporangia which in the three typically hyphal species are expansions of a terminal or intercalary section of a hypha. In the fourth species they are formed from a single cell which separates from the yeast-like thallus, by the lateral expansion of a hypha in the hyphal form, or by direct outgrowth from a germinating spore. The spores are set free in all the species by solution of the sporangium wall.

The spores of Species A are unicellular, falcate, measuring I8-2 I microns: on the convex side they are provided with a thickened rib which extends from about the middle to one end, where it projects in a fine point. They are formed in large numbers in the sporangium, without any appearance of regular arrangement (Fig. 4). The spores of Species B are acicular, rather blunt at one end, sharp at the other, and measure 13.5 microns. They are formed in two equal opposed conical bundles, their broad ends interiocking (Fig. 5).

In Species $C$ and $D$ the spores are alike in form and occurrence. They are spindle-shaped, produced at one end into a long thread-like appendage, and have a slight projection on one side near the middle. They are formed in two equal opposed bundles in each sporangium, joined by a thread formed of their combined appendages. The number on each side varies from one to ten or more. The two bundles are usually rather widely separated, but have been seen to overlap and in extreme cases lie side by side. Occasionally a single bundle is formed occupying the whole of a small sporangium. The measurements obtained of the spore body, without the appendages, have been $27-35 \times 2$ in $C, 30-40 \times 2-3$ in $D$.

Germination in Species A is by an ordinary germ-tube generally developed about the middle; in $\mathrm{B}, \mathrm{C}$, and $\mathrm{D}$ it is preceded by the formation of a spherical swelling, from which are produced one or two germ-tubes, or in C and D several short beaded rows of cells which may set up yeastlike budding. In the last three species the contents of the spore show, from a division near the middle, a difference in refraction and in taking up stains, but the existence of a septum cannot be detected.

These fungi have been found in no other situation than in fruits and seeds, and in the writer's experience infections have always been associated with bug punctures. A list of the plants on which infections have been found is given below, and there is no doubt that the number could readily be largely increased.

The effect on seeds is the production of brown or white 
sunken patches in the cotyledons, and may be trifling or severe. In the tomato the pulp of immature fruit is blackened in spots and the taste of ripe fruit spoilt ; in the case of the orange attention was drawn to the infection by the peculiarity of the flavour.

Species.

LEGUMINOSE.

Vigna catjang, $V$. unguiculata (Cow pea, Rounceval, Black-eye).

Dolichos Lablab (Bonavist).

Phaseolus lunatus, P. vulgaris (Lima, French bean)

Canavalia gladiata (Sword bean).

Crotalaria juncea (Sunn hemp).

Crotalaria retusa.

Tephrosia spp.

Indigofera spp.

Cassia spp. (herbaceous).

A. B. C. D.

MALVACEA.

Gossypium spp. (Annual and perennial cotton) ++++

EUPHORBIACE正.

Ricinus communis (Castor oil).

Jatropha urens.

Jatropha urens.

SOLANACEX.

Lycopersicum esculentum (Tomato).

Datura metel

\section{CUCURBITACE E.}

Momordica Charantia (Coolie pepper).

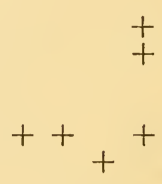

ASCLEPIADACEE.

Asclepias curassavica.

RUTACEA.

Citrus sinensis (Sweet orange).

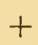

The Sooty Moulds (Capnodice) causing Black Blight.

The Perisporiacex, which include the sooty moulds, are Ascomycetes with superficial mycelium, occurring mostly on leaves or fruits. The family is nearly related to the Erysiphaceæ, which it resembles in habit, but its members are at once distinguishable by their dark brown or black colour. They occur as webs or closely investing films on a great variety of plants, and the sooty moulds give rise to the condition usually called "black blight" in these islands.

The further classification of these fungi is in a very confused condition, and their nomenclature remains a matter of doubt 
among the best authorities. Sooty moulds are not uncommon in temperate countries and have there been usually placed in the genus Capnodium, while those of the tropics were regarded as species of Meliola until they were excluded by Gaillard in I892 as non-typical of that genus. With this exclusion F. L. Stevens, who has recently studied in detail the true Meliolas of Porto Rico, entirely agrees, but he leaves open the question of their correct position, save for the conclusion that in the main they belong to the Capnodiæ of Saccardo. Possibly the genus Fumago, an older name than Capnodium, should be revived to contain them.

The Meliolas proper appear as black blotches on leaves, made up of a network of hyphæ closely set with short branch-like appendages, and bearing various reproductive bodies. They appear to exhibit specialisation on particular plants or related groups much in the same way as the Erysiphaceæ and are probably parasitic, though producing as a rule very little visible effect on their hosts.

The sooty moulds, on the other hand, show no specialisation and no sign of parasitism. They occur most frequently in association with infestations of scale insects, aphides, white flies, and the more sedentary species or stages of leaf-hoppers (Fulgoridæ, Membracidæ, Jassidæ), developing wherever the sweet secretions of these insects (honey-dew) are sprayed by the insect or spread by dew or rain, whether the situation be the leaves and bark of the infested plant and its neighbours, or even soil or stones. They will similarly appear and spread in the nectariferous spray or washings from some profusely flowering trees, and it is said that spraying a tree with a sugary solution will produce a heavy infestation.

The injury to the plant due to prevalence of sooty moulds arises from the film which covers the leaves, reducing the access of light and obstructing the exchange of air and water vapour. There is also some commercial loss from the disfigurement of fruit. The degree of these effects naturally depends on the amount and duration of the fungus, and this again on the continued prevalence of the insect which supplies its nourishment. The effects of the insect, which is frequently obscure, are usually mistaken for those of the fungus, which is prominent, and the latter are consequently greatly exaggerated. Black blight, in fact, is the great bugbear of the West Indian planter and gardener, and it is to be regretted that some of the attention it receives is not transferred to the many matters more deserving of his solicitude.

It is not denied that long-continued infestation may have a debilitating effect on a tree, and reduce its production of fruit, but attention should be directed, not to the fungus, but to the primary pest. The belief which exists that black blight is contagious is true only in the very limited sense that plants 
closely adjacent to an infested tree often receive a share of the secretions which give rise to it. Apprehensions of the general spread of the affection from such a source-of the infestation of cacao from a blackened mango tree, for instance-are baseless as regards the fungus, and, where the plants are of unrelated species, are usually so in regard to the insect as well.

Spraying with fungicides for the removal of black blight, where, as is most commonly the case, this is due to scale insect infestations, makes matters worse in the end by checking the beneficial fungi which in favourable weather reduce the prevalence of the insect. The remedy for black blight must be sought from the entomologist.

\section{The Classification of Fungi.}

The current system of classification of fungi is in a very imperfect condition in many of its sections. In its general lines it is as nearly natural as the state of knowledge permits, but in many of its subdivisions becomes frankly artificial. Judged as a natural system it not infrequently brings together species that are obviously not nearly related, and separates many that are obviously akin. As an artificial system its weakness is demonstrated by the facility with which half a dozen different authorities can place the same fungus in as many or even a larger number of genera.

The confusion which is so frequently apparent arises from the lack of stable morphological features on which distinctions can be based, on the difficulties of preservation in recognisable condition, and not least on the irresponsible way in which new species have been so often founded with a minimum of enquiry on imperfect material imperfectly described.

Among the flowerless plants three groups occur of which the members are wholly destitute of chlorophyll and depend (with a few exceptions among the bacteria) on parasitism or saprophytism for a living. Each group contains parasites which cause plant diseases.

\section{Myxomycetes, SLime-Fungi.}

In the vegetative condition, during which they grow and feed, these consist of naked protoplasm, either in small units or in masses (plasmodia). In their final stage they come to rest and produce spores, often in elaborate sporangia, from which the vegetative form is again derived. The order Plasmodiophorales contains the only parasites of plants, the best known being of the genus Plasmodiophora. The amœba-like plasmodia occupy soft tissues in the roots of certain plants, and give rise to galls or distortions, as in the club-root disease of turnip, cabbage, and other Cruciferæ in temperate countries. Very many saprophytic myxomycetes occur in the West Indies on rotting wood and decaying vegetable matter generally. 
SCHIZOMYCETES, BACTERIA.

Bacteria are exceedingly minute cells, enclosed in a cell wall and frequently furnished externally with protoplasmic threads which serve for locomotion. Some species form an internal resistant body (endospore), which enables them to withstand desiccation and in some cases exposure for a considerable period to the temperature of boiling water. Reproduction is by division of the parent cell into halves, a method quite distinct from the budding of the yeasts, which are true fungi.

Bacteria are classified into genera by form, and into species mainly by their behaviour in cultures on various media. Their part in the causation of plant disease is discussed in Chapter II. Examples of bacterial diseases will be found under cotton, tomato, and citrus.

Eumycetes, Fungi.

The characteristics of fungi have already been described in general terms. The vegetative body (thallus) of a fungus typically consists of branching filaments (hyphæ), growing at the tip, free or combined into more or less definite structures, but may consist of rounded cells free or in groups, multiplied by budding, as is the rule in the yeasts, and is the case in certain stages or conditions of normally filamentous fungi.

Classification is based on the nature and form of the reproductive organs and spore-bearing structures. Where as is often the case the same fungus has more than one method of spore formation, the direct production of conidia from hyphæ, free or enclosed, is regarded as subsidiary to spore production by way of asci or basidia, and any generic name based on the former is superseded by the one appropriate to the latter. Thus Colletotrichum gossypii became Glomerella gossypii when the fungus was found to possess an ascogenous fructification, though in this as in many instances it is convenient to retain in common use the name appropriate to the condition of the fungus as it is ordinarily found.

\section{Class I: Phycomycetes.}

These are fungi which retain considerable resemblance to certain groups of algæ, from which they are thought to have been derived, including a distinct provision of structures for sexual reproduction. The latter have in some cases lost their function and are often largely superseded by the formation of asexual spores. The mycelium, which is commonly well-developed and freely-branched, is without septa except in old hyphæ or in connection with reproductive structures. There are two subclasses :

\section{Oomycetes.}

Most of the species form oospores as a result of a perfectly or imperfectly retained process of the fertilisation of an egg-cell 
by sperms produced in an antheridium. Asexual reproduction is by sporangia, which release either a swarm of motile zoospores, or conidia which germinate by the production of a germ-tube.

The genus Pythium contains the well-known fungus which causes damping-off of seedlings in temperate countries, but has not been found conspicuous in the process in the West Indies. Pythiacystis is a parasite of citrus trees. Albugo is a genus of parasites producing the white rusts, as that of sweet potato, in which conidia are formed in sori under the epidermis of the host, and oospor es occur embedded in the tissues. The family Peronosporaceæ is of great significance in plant pathology ; its most important genus, Phytophthora, is separately discussed on pp. $2 \mathrm{I}-2$.

\section{7ygomycetes.}

Sexual reproduction in this group is by zygospores, formed by the coniugation of two equal hyphal parts. Asexual reproduction, which predominates, is by sporangia, producing numerous spores, or less commonly by conidia. Most of the species are saprophytic, like the Mucors, which make a fluffy growth on foods, some are weakly parasitic, as Rhizopus nigricans, which causes soft rots of vegetables. Choanephora infundibulifera grows on the flowers of cotton and hibiscus in the East and West Indies. The Entomophthoraceaæ are of importance as parasites of insects, and include species of Empusa occurring on the green scale and the sugar-cane froghopper.

\section{Class II. Ascomycetes.}

In the typical Ascomycetes the mycelium is freely septate from the beginning of its development, there is little trace of a sexual process, and the distinctive method of reproduction is the formation of eight spores in a closed tube or sac-the ascus. The asci are commonly produced side by side in a regular layer, the hymenium, which may lie open on the fruiting body or on the substratum, or be enclosed in various ways.

In addition to the ascospores conidia are usually formed by the mycelium at some stage of its existence, and in many species reproduction is generally effected in this way, the production of ascospores taking place only under special and often rare conditions.

There are a few groups of fungi of somewhat uncertain affinities, of which the fructifications show more or less of an approach to or analogy with ascus formation, which are placed in the sub-classes Hemiascomycetes and Protoascomycetes. The latter includes the yeasts, Saccharomycetaceæ, which typically have no hyphæ, but consist of rounded cells reproduced vegetatively by budding and in some circumstances forming one to eight internal spores. Nematospora, found in cotton bolls, etc., is at present placed in this family. The ascomycetes 
proper (Euascomycetes) contain an enormous number of species, a fair number of which are plant parasites.

The Erysiphaceæ or powdery mildews (see p 20) and the
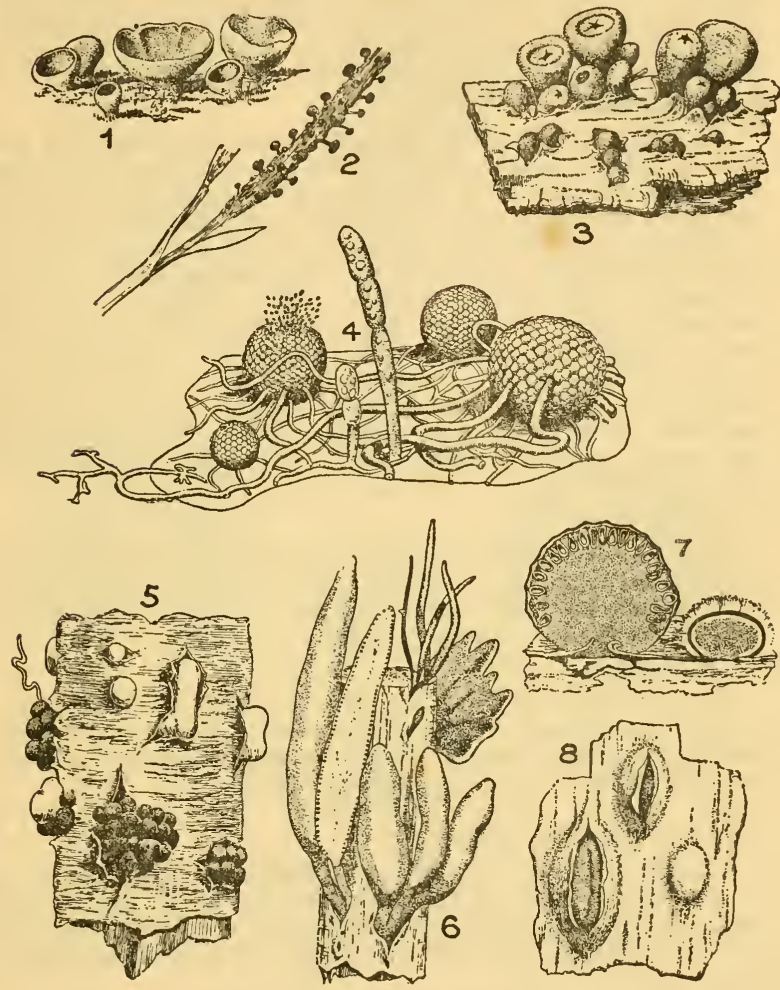

Fig. 8 ASCOMYCETES

1. Peziza, 2. Balansia trinitensis, 3. Scleroderris.

4. Perithecia and Conidia of an Erysiphe. 5. Nectria.

6. XYLARIA.

7. HyPOXYLON.

From Engler \& Prantl. Nat. Pflanz.

Perisporiaceæ (which include the fungi of "black blight") have mycelium which is superficial on the host plant, commonly on leaves, and have the asci enclosed in more or less spherical 
fruiting bodies without special openings, the spores escaping by the rupture or decay of the wall.

The largest number of important parasitic Ascomycetes are included in the group known as the Pyrenomycetes, in which the hymenium is enclosed in a spherical or flask-shaped fruiting body, the perithecium, provided with an aperture through which the spores escape. There are three orders of Pyrenomycetes.

I. Hypocreales.

The members of this order are broadly distinguished by the light or bright colours of the perithecia, as distinguished from those which are brown or black, and their softer consistency as compared with the hard and often carbonaceous condition common in the following orders. The Nectriæ contain the genus Nectria, species of which are very common as saprophytes on dead bark in the West Indies and were at one time held responsible for cacao canker. Some species are wound parasites, but none with this character is known locally. Neocosmospora occurs on the roots of leguminous herbs but is not usually regarded as a parasite. Ophionectria coccicola and Spharostilbe coccophila are of great importance as parasites of scale insects, and species of Sphærostilbe cause serious root diseases under certain conditions (see Limes and Banana).

\section{Dothideales.}

This relatively small order is characterised by the aggregation of the mycelium into a black stroma in which the perithecia occur as cavities. It is represented among the local parasites by Phyllachora spp. on grasses and sedges.

\section{Spheriales.}

This is an enormous order with perithecia mostly carbonaceous in consistency and black in colour. Rosellinia, Melanopsammopsis, Leptosphæria, Gnomonia and Glomerella are examples to which reference is made in Part 2.

\section{Class III. Basidiomycetes.}

The typical Basidiomycetes are distinguished by the presence in a hymenial layer of crowded sporophores of special type (basidia) each terminating a hyphal branch, usually club-shaped, and bearing on short stalks two or four unicellular spores (basidiospores).

Parallel with the classification of the ascomycetes, there are recognised in addition to the basidiomycetes proper (Eubasidii) two somewhat anomalous sub-classes, the Hemibasidii and the Protobasidii. The Hemibasidii contain two families only, made up entirely of obligate plant parasites, the Ustilaginaceæ (see p I9) and the Tilletiaceæ, both giving rise to smut diseases. The mycelium produces the sooty masses of chlamydospores direct, and these on germination produce a short filament on 
which develop a small number of conidia (sporidia), regarded as equivalent to basidiospores. In the Tilletiaceæ the sporidia

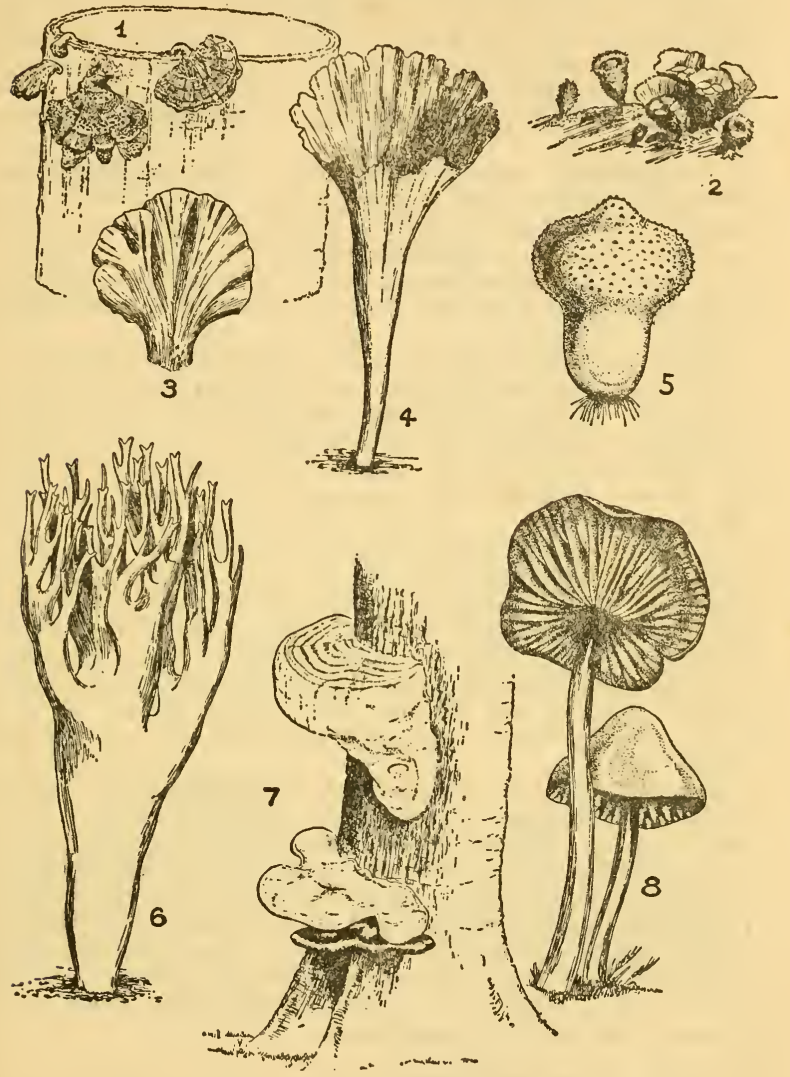

Fig. 9 BASIDIOMYCETES

1. Schizophyllum Commune. 2. Cyathus Microsporus. 3. Thelephora. 4. Craterellus. 5. Lycoperdon.
6. LACHNOCLADIUM.
7. FOMES.
8. Marasmius.

4, 5, 6, 8 after Nat. Pflanz

are elongated and frequently join by a small cross filament to make pairs. 
The Protobasidii include the most important single order of plant parasites, the Uredinales or rust fungi (see p. I7). The relation to Basidiomycetes is shown in the germination of the teliospores, formed direct from the mycelium, which in similar fashion to the chlamydospores of the smuts typically produce in germination a filament divided towards its free end into four cells, each of which produces a sporidium, regarded as a basidiospore.

The Eubasidii contain, among other types, the mushrooms, toadstools, bracket-fungi and other large forms which are the most conspicuous and familiar of fungi. The number of plant parasites among them is relatively small.

Some of the Hypochnaceæ form a thin webby covering on living leaves, and have been held to be associated with thread blights.

The Thelephoraceæ form a thin, leathery, membranous, or web-like covering on the substratum, often in extensive sheets or patches. The genus Corticium contains the fungi of the West Indian thread blights and of pink disease; Odontia spp. are associated with root disease of sugar-cane; the Septobasidiums are believed to live at the expense of scale insects (see Grey Blight of Limes).

The Polyporaceæ, many of which have bracket-like fructifications, take a large part in the destruction of dead wood, and in some cases extend this mode of life to the wood of living trees if they can obtain access through wounds, dead branches, or debilitated parts. They are distinguished by the arrangement of the hymenium as a lining to a system of pores, which may be shallow, or deep and tubular. The fruiting bodies are often large, and may be soft and fugitive or leathery to woody and persistent.

The Agaricaceæ are the gill-fungi, so called from the extension of the hymenium over a series of thin flat plates of tissue, as in the mushroom. Usually the fructifications consist of a roundish cap (pileus), bearing the gills on its under side and supported by a stalk (stipe), or attached by a part of its margin. Very few of the Agaricaceæ are parasites, but Marasmius contains injurious species, one of which is the cause of a serious disease of cacao, while others are associated with root diseases of sugar-cane and banana. Schizophyllum is a common saprophyte which sometimes appears on failing sugar-cane.

\section{Class IV. Fungi Imperfecti.}

The exceedingly numerous groups and species of fungi collected for the sake of reference in this class are not imperfect in their powers of maintaining themselves, but have not been found to possess any character which enables them to be fitted into the classes already described. A very large number of important plant parasites are found among them. 


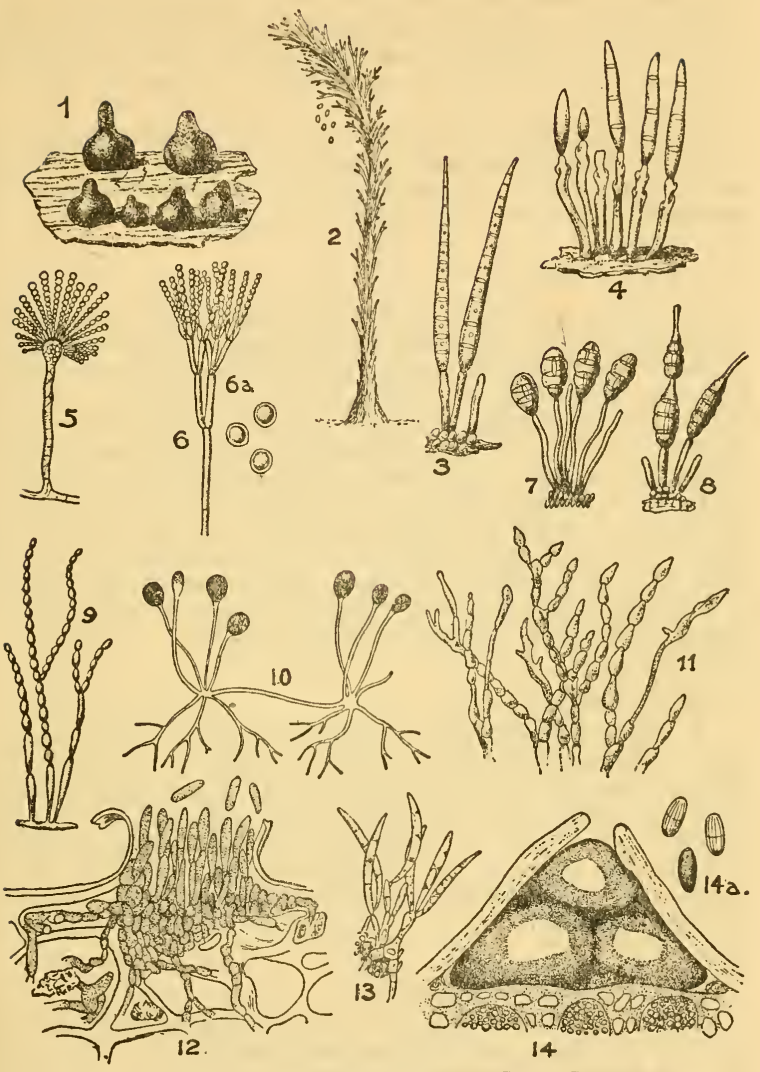

Fig. 10 TYPES OF CONIDIAL FRUCTIFICATIONS

1. Sphaeropsis. 2. Graphium (conid, stage of Rosellinia).
3. 4. Cercospora.
5. Aspergillus.
6. Penicillium.

7. Macrosporium. 8. Alternaria tenuis. 9. Oospora. 10. Mucor (Zygomycetes). 11. Monilia.

12. Gloeosporium lindemuthianum. 13. Fusarium. 14. Diplodia. 
Without doubt many or most of the Fungi Imperfecti have affinities with ascomycetes or basidiomycetes, but it is probable that in a large number of cases the " higher " form of fructification has fallen into disuse, and in others is produced only exceptionally.

Three orders are used in the current system of classification. These are divided into families, and within the families a mainly artificial method of grouping according to coloration and the number of divisions in the spores is adopted.

\section{Spharopsidales.}

This order consists of forms in which the conidia are produced typically on short, closely-set conidiophores in enclosed spherical or flask-shaped fruiting bodies (pycnidia) opening by a pore or slit and resembling the perithecia of ascomycetes. In the family Sphærioidaceæ, which contains those with black or dark brown, often leathery or carbonaceous pycnidia, are a great many kinds which occur on dead or failing leaves, fruits. and twigs, and some which are definitely parasitic on similar material. To this family belong Phyllosticta and Phoma, of which a very large number of species have been described as occurring in leaf-spots or in the cortical tissues of stems. Here also belong Diplodia, which is elsewhere discussed, Phomopsis, Cytospora, Sphæropsis, and the large genus of leaf-spot fungi Septoria.

\section{Melanconiales.}

In this order of only one family, Melanconiaceæ, the layer of short conidiophores is not enclosed in a regular pycnidium, but occurs in groups or patches (acervuli) which are usually irregularly enclosed at first, often only by the epidermis, and become exposed sooner or later. It includes Glœosporium and Colletotrichum, the fungi of the anthracnoses (see page 22), Melanconium (see sugar-cane), Septoglœum (ground nut), and Pestalozzia (coconut).

\section{Moniliales (or Hyphomycetes).}

This is an order of great diversity distinguished as a whole only by the free-standing dissociated conidiophores or conidiaforming hyphæ. The forms of these range from hyphæ which divide up without much differentiation into conidia to special conidiophores of peculiar structure or with elaborate branchsystems. There are four families. The Moniliaceæ (or Mucedinaceæ) and the Dematiaceæ contain the forms in which the hyphæ associated with reproduction are not more than loosely aggregated ; the former contains the hyaline or brightly coloured kinds, the latter those with either hyphæ or conidia, or both, dark coloured, mostly smoky brown or black. In the Moniliaceæ 
are included, to give a few examples, Oidium, Cephalosporium, Aspergillus, Penicillium, Botrytis, Sporotrichum, Verticillium ; in the Dematiaceæ: Thielaviopsis, Cladosporium, Helminthosporium, Alternaria, and Cercospora

The third family, Stilbaceæ, consists of forms in which several or many of the fertile hyphæ are collected into a compact bundle to form the conidiophore, the conidia being borne in a head or tuft at the top or sometimes along the sides. Stilbella (or Stilbum) which includes the conidial forms of Sphærostilbe, Graphium, which similarly includes the conidial form of Rosellinia, Isaria, which has many species parasitic on insects, and Gibellula, parasitic on spiders, are examples.

In the fourth family, Tuberculariaceæ, the fertile hyphæ, together with an admixture of sterile hyphæ, are gathered into a rather compact body known as the sporodochium, which may be globose, discoid, or form a somewhat irregular crust. Often the hyphæ are more or less radially arranged. The consistency of the mass is often waxy or gelatinous, may be horny, or may be merely made up of threads more or less embedded in mucilage. The family is in many respects a vaguely defined one. Its most important parasitic genus is Fusarium. Egerita, the white-fly fungus, is another example.

A further section of the Fungi Imperfecti, the Sterile Mycelia, consists of those fungi for which not even a conidial form of reproduction is known. The important sclerotium-forning parasites Rhizoctonia and Sclerotium remain here. Himantia stellifera, a mycelium on the roots of sugar-cane, will probably be shown to belong to Odontia, a basidiomycete.

The genus Graphiola, parasitic on palms, of which $G$. phrenicis occurs on probably every date-palm in the West Indies, remains unclassified, though it produces spores. It is so individual in form that no relationship to other fungi can be established.

Systematists differ somewhat in regard to the classification of fungi; the following arrangement, which aims at simplicity, is based on the system of Engler and Prantl. The positions both of the groups of parasites mentioned in this chapter and of common saprophytes are indicated. It will be noticed that in this scheme the Perisporiales are included in the group Pyrenomycetes, which is characterised by having the asci enclosed in a perithecium. In most recent classifications the Perisporiales are treated separately, as has been done on p. 37.

MyXomycetes (slime-moulds).

SCHizomycetes (bacteria).

EumYCETES (all other fungi).

Class I. Phycomycetes.

(a) Oomycetes (downy mildews).

(b) Zygomycetes (moulds like Mucor). 
Class II. Ascomycetes.

(a) Hemi- and Protoasci (yeasts, Exoascus, etc.)

(b) Plectasci (common blue, green and yellow moulds).

(c) Discomycetes (Sclerotinia and other cup fungi).

(d) Helvellineæ.

(e) Pyrenomycetes.

I. Perisporiales (powdery mildews and sooty moulds).

2. Hypocreales (Nectria, etc.)

3. Dothideales. bodies).

4. Sphæriales (most forms with black perfect fruiting

Class III. Basidiomycetes.

(a) Hemi- and Protobasidii.

I. Ustilaginales (smuts).

2. Uredinales (rusts).

(b) Hymenomycetes (Marasmius, Corticium, gill and pore fungi.

(c) Gasteromycetes (puff-balls, etc.)

Class IV. Fungi Imperfecti.

I. Sphæropsidales (Diplodia, Phoma, etc.)

2. Melanconiales (anthracnose fungi, etc.)

3. Moniliales or Hyphomycetes (Fusarium, etc.) 


\section{CHAPTER II}

\section{DISEASES CAUSED BY BACTERIA}

BACTERIA are minute organisms, typically unicellular, but in some species and under some conditions adhering in filaments or massed in a colony in a gelatinous matrix. Some are so small as to be close to the limit of visibility with the highest powers of the microscope, and others probably exist which are beyond it. The cells are enclosed by a thin membrane. Bacteria possess no chlorophyll, and for the most part are either saprophytic or parasitic, though there are some which are able to derive their energy from inorganic compounds. In their mode of life they consequently resemble fungi, but differ in their method of reproduction, which is by equal subdivision of the parent cell. They are accordingly classed as Schizomycetes (fission fungi), though there is no sound reason for regarding them as especially related to fungi at all. Their possession of a cell wall is usually held to justify their classification as plants. They are frequently motile by means of protoplasmic threads (flagella). Some species produce thick-walled resistant spores, but this is seldom the case among the known parasites of plants.

The earliest definite discoveries of bacterial disease of plants were made in the years round about I 880 by several independent investigators. The destructive pear-blight of the United States, worked out by T. J. Burrill, was the first to be clearly established as bacterial in origin. For many years the attitude of academic botanists, based on preconceived opinions as to the ability of bacteria to enter or to lead a parasitic existence in plant tissues, was hostile or sceptical, and, although overt opposition to the idea was silenced by the proofs brought forward in Igor by Erwin F. Smith, it is only within the last few years that the reluctance to accept it may be said to have died down in Europe.

To the working pathologist it is now clearly evident that bacterial diseases, though fewer in number and somewhat restricted in range, stand in respect of specific parasitism and capacity for injury on an equal footing with diseases of fungus origin. There is indeed so close an analogy between the two groups of causative organisms in the various degrees of parasitism, in the nature of the attack and of infestation, and in the reactions of the host plant towards them, that it is unnecessary to repeat at any length or much to qualify in respect of bacterial 
diseases the information on these subjects already given for fungus diseases.

The bacteria which give rise to plant diseases form but a minute fraction of the species known to exist, and with the exception of those involved in the rotting of ripe fruit, of storage organs like the potato tuber, or of masses of soft tissue such as the heart of coconut palms, they are parasites specific to the particular plant or disease with which they are associated. A single species may, however, as in the case of a fungus, give rise to several forms of affection on the same plant (as in angular spot, black arm, and boll disease of cotton) or produce the same type of disease on a variety of plants (as in crown gall).

Apart from the parasites there is evidence of the existence of specific epiphytic bacteria on the surface of leaves or other organs. A good instance is afforded by the organism which appears to be always present, in the West Indies as in the United States, on the cotton plant, and takes some part in the infestation of the contents of the boll when bug punctures permit its access.

One of the main objections to the possibility of bacterial diseases was the supposed absence of any means of penetration, and this was so far justified that the ability to penetrate cuticle possessed by some fungi does not seem so far to have been demonstrated in bacterial parasites. The latter can, however, find their way through apparently uninjured cell-walls, for they are often very evident inside, but it is not clearly known how they do it. Some species invariably enter the plant by way of wounds, so that insect injuries are frequently of great importance in the incidence of bacterial diseases, others are capable of entry by way of the stomata (angular leaf spot), the water pores of leaves (black rot of cruciferæ), the nectaries of flowers (blossom blight of pears), and possibly the pistil (bacterial boll-disease).

The tissue of the living plant most liable to attack is the parenchyma of storage organs or of young developing shoots, and two types of infestation may be recognised. The tissue may be destroyed by the action of secretions which dissolve the middle lamella (the material which cements together the walls of the separate cells) or the bacteria may enter into relations with the cells which induce abnormal growth and proliferation, resulting in the formation of galls or swellings. The latter type may be compared with the most advanced form of fungus parasitism, in which the parasite derives its food from cells which continue their existence.

The most generally destructive type of bacterial disease is caused by the vascular parasites, of which Bacterium solanacearum on the tomato is an example met with in the West Indies. In this type, although there is some amount of invasion of the parenchyma, the principal seat of infestation is the vascular bundles, the conducting elements of which are affected and often blocked by the parasite. 
With regard to the phenomena of resistance and susceptibility, and to the measures available for prevention and control, no general distinctions need be made between bacterial and fungus diseases. The methods of distribution are to a large extent the same, except that transport of the dried organisms by the wind is not apparent. Insects undoubtedly have very considerable importance in this respect. 


\section{CHAPTER III}

\section{DISEASES CAUSED BY INFECTIVE VIRUSES}

THE diseases to be discussed in this chapter, which include several of great economic importance, have been usually relegated to the undefined category of " physiological " affections. Though knowledge regarding them is very uneven, it would now seem both possible and desirable to bring them together as a class, distinguished by the possession of an infective principle which can be transferred to a healthy plant and reproduce the disease, but which within the range of our present technique gives no evidence of association with an invading organism. It would further appear that a sub-division of this class may be made by distinguishing between affections in which the juice of the diseased plant is generally and directly infective, as in the true mosaic diseases, and those in which this property is absent and infection is restricted to special means. In some of the latter class transmission depends on contiguity in a manner which is still obscure, in others it is regularly effected by insects. Usually it may be effected artificially by budding or grafting where these are possible, provided that organic union of stock and scion takes place.

The word virus used in connection with these diseases must not be taken as more than a convenient expression of the idea of an infective principle of unknown nature, recognised only by the effects it produces. The validity of such a conception may be more readily conceded if it is remembered that our knowledge of enzymes, useful as it has proved, is of the same nature.

The virus diseases are typically systemic, affecting all parts of the plant. They have apparent analogues in animal and human pathology, some highly infectious, others restricted in their transmission.

In their external symptoms these diseases are liable to be closely simulated, on the same or on other plants, by appearances produced in some cases by the action of external factors, as in the dwarfing of shoots and mottling and crumpling of leaves induced in cotton and ground-nuts by out-of-season planting, in other cases by genetic factors, as in certain hybrids and lossmutations of cotton in which similar characters appear, in still others by insects, as in froghopper blight of sugar-cane, which closely reproduces many of the symptoms of sereh. 
The investigation of virus diseases has in consequence been greatly confused by dependence on symptoms as evidence of identity. This has resulted in wide disparities between the conclusions of investigators dealing with externally similar but separate diseases. There is the further difficulty that wide differences in resistance and response on the part of the affected plants exist in relation to these as to bacterial and fungus diseases.

\section{The Mosaic Diseases.}

The name mosaic disease, which has reference to irregularities of distribution of the green colour of the leaves, has come to be especially associated with a well-marked class of diseases which have in common, in addition to this symptom, an infectious virus, contained in the expressed juice of most or all parts of the plant, capable by inoculation or (except in sugar-cane mosaic) by contact with a wounded surface of setting up the disease in a healthy plant of the same species. The name has been applied to other types of disease, as, for example, the mosaic disease of cotton, which is a deficiency disease, but will probably be restricted in future to the class under discussion.

The best-known mosaic diseases are those affecting tobacco, tomato, potato, and some other Solanaceous plants; there are also similar diseases of bean, cucumber, lettuce and spinach. Recently the mosaic disease of sugar-cane has assumed great importance in the West Indies. It is not a typical member of this class, not having been found to be transmissible by contact or ordinary wounding, and only with great difficulty by artificial inoculation.

There is close correspondence in the general characteristics of these diseases as developed on their appropriate hosts, indicating a generic relationship between them. Such differences as occur are of a minor and specific nature.

The following summary of symptoms given by Allard for tobacco mosaic includes the characters of the whole class.

I. Partial or complete chlorosis (reduction of chlorophyll).

2. Curling of the leaves.

3. Dwarfing or distortion of the leaves.

4. Blistered or " savoyed " appearance of the leaves.

5. Mottling of the leaves with different shades of green.

6. Dwarfing of the entire plant.

7. Dwarfing and distortion of the blossoms.

8. Blotched and bleached corollas.

9. Mosaic sucker growths.

Io. Death of tissues.

These symptoms may be present in part only or on part of the plant only, and may be lightly or severely developed. Infection appears to be in all cases quite general, so that removal of the distorted parts of partially affected plants is no remedy. 
Apparent recovery may take place only in plants not fully susceptible. It is not usual for death to result directly from this type of disease, though more or less necrosis of tissue frequently occurs. In spinach blight this feature is unusually marked, and, contrary to the general rule, its development continues until the plant is killed.

The conditions governing infection by contact and the question of the distribution and characters of the virus have been closely investigated by Allard, working on tobacco mosaic. The virus permeates all parts of the plant, including the corollas of the flowers, the hairs on the leaves, and the roots. It is still contained in juice expressed through a Chamberland or Berkefeld filter. Plant material dried and ground retained its virulence $I \frac{1}{2}$ years. The virus preserved in ether, toluene, and glycerine, was infective 4 months later, as was juice which had been allowed to undergo natural fermentation. It is highly resistant to the action of powerful chemicals, withstanding nitric and hydrochloric acid added to the virus solution until the concentration reaches I per cent., and phosphoric, citric and acetic acids up to 2 to 5 per cent. Carbolic acid had no effect in a 2 per cent. solution and the much more powerful germicides cresol, creolin and phenoco showed no apparent increase over carbolic acid in their effect on the virus. Chloral hydrate (Io per cent.) and naphthalene, camphor and thymol in excess had no appreciable effects. Mercuric chloride I in Ioo affected the virus but little, and quinine bisulphate $I$ in 25 had no appreciable effect after I9 days' treatment. Alcohol destroyed the virus in concentrations above 50-55 per cent., copper sulphate showed itself rather toxic, while 4 per cent. formaldehyde had a rapid action and was found suitable for sterilisation purposes. The virus is destroyed by temperatures above $80^{\circ} \mathrm{C}$.

A dilution of the virus to one part in 1000 in water was as effective in producing infection as the original virus; at one in I0,000 some attenuation was shown, and one case occurred even from a dilution of one in $1,000,000$. The inoculations for these tests were made with only so much of the diluted virus as could be introduced by the prick of a needle.

The incubation period of the mosaic diseases is variable. In tobacco the shortest time observed has been 6-7 days, and usually I2-I5 days are required. The length of the period depends on the kind and age of the plant, and on such external factors as accelerate or retard growth.

Infection can be artificially effected by inoculation as above, and by the touching or handling of healthy plants after diseased ones. Spraying the virus on to sound leaves does not readily give rise to infections, but injury to the leaf hairs such as arises from handling is sufficient to open the way for infection to take place.

It is characteristic of this type of disease that the infective 
principle does not reside in the soil. Even buried diseased material does not as a rule produce many infections, and such cases as do occur are believed to depend on root injuries which give access to the virus. Steam sterilisation is effective in removing any risk of infection from diseased material retained in the soil.

The transmission of mosaic diseases in the field or greenhouse has been repeatedly shown to be effected by aphides (" plant lice" or "green fly.") Most of the experiments have only gone so far as the transfer of the insects from diseased to healthy plants, with others from healthy plants as controls, but in spinach blight McClintock and Smith have demonstrated that the offspring of virus-bearing aphides, as far as the fourth generation, may transmit the disease without themselves having had access to infected plants.

The distribution of mosaic diseases suggests the probability of the occurrence, at least occasionally, of transmission by seed. In several cases, as in tobacco and spinach, the results of attempts to demonstrate this have been uniformly negative; in others, as in the mosaic diseases of bean (Phaseolus) and cucumber, the occurrence of seed transmission has been established.

The viruses of mosaic diseases exhibit specific limitations similar to those of organic parasites. The infectivity of a virus may be confined to one host or it may produce disease, of varying severity, in related species. The disparities in the results obtained by different groups of investigators even suggest the occurrence of different "strains" of virus in the same host species; in fact, it may be said that in respect of susceptibility, resistance and immunity the mosaic diseases exhibit the same phenomena as do those originating from fungoid or bacterial parasites.

\section{Virus Diseases with Restricted TRANSmission.}

Under this heading it is proposed to include for comparison the following diseases: curly-top of beet, leaf-roll of potato, sereh disease of sugar-cane, peach yellows, and peach rosette. These have all shown themselves to be capable of transmission to healthy plants, while affording no evidence of causation by any visible parasite. This leads to the assumption, as in the first group, that an infectious virus is concerned in their production, but in distinction from these it has not been found possible to produce infection by artificial means, if budding and grafting, which involve organic union, be excluded from this category.

The affections mentioned have great economic importance, and include some of the most widely discussed plant diseases, but further experimental information, especially regarding sereh disease, is required before a really definite comparison can be made. 
These affections resemble the typical mosaic diseases in that they are systemic, affecting the whole plant, that recovery is unknown, and that they find expression in general effects on the foliage and in the eventual dwarfing of the shoots. Their symptoms, however, are not nearly so uniform.

In curly-top, leaf-roll, and sereh a degeneration (necrosis) of the phloem strands in the vascular bundles has been claimed to be characteristic, and has been variously regarded as the cause or the consequence of the visible changes in the organs of the affected plant.

In the curly-top of beet the veins of the leaves are distorted, and the leaf blade is either curled inwards, or retracted and puffed out between the veins. The foliage is dull-coloured and brittle, eventually turning yellow from below and dying. Dense masses of rootlets are thrown out. None of the symptoms is in itself specific, but the effect on the veins is regarded as the most definitely characteristic. Where the stage of stem production is reached the development is feeble and results in dwarfed and stunted shoots which may or may not survive to the point of producing seed. Plants may be infected and killed in the seedling stage.

In potato leaf-roll growth is slow, the shoots are dwarfed by the reduction of the internodes, the leaves are discoloured yellow and are rigid and brittle, the edges of the leaflets are rolled inwards. In a later phase the leaf tissue dies locally, producing black or brown spots. The symptoms may appear from the outset of growth, or develop only at the top of the shoots.

In sereh disease of sugar-cane there is great variation in the development of symptoms. Typically there is a shortening of the internodes, which in the leafy top of the shoot results in a characteristic fan-like arrangement of the leaves; the leafblades are short and narrow and may die in an irregular manner; the stems are crowded with aerial roots; the buds develop prematurely, until in the later stages the stool is reduced to a dense mass of grass-like shoots. Two or three years are occupied in reaching the extreme condition. The vascular bundles of diseased canes, especially in the rootstock and at the nodes, are reddened by the deposit of gum in their elements.

The most characteristic symptoms of peach yellows are prematurely ripe, red-spotted fruits, and premature unfolding of the leaf buds into slender pale shoots, or into branched,broomlike growths. In successive seasons the trees become gradually stunted and enfeebled, dying in 3 to 5 years.

Peach rosette is a rapidly developed affection in which all the leaf buds grow into compact tufts or rosettes, containing, though seldom more than two or three incles long, usually several hundred small leaves. A tree thus attacked dies during the following autumn or winter.

As already stated, symptoms of the types described above may 
be produced by the operation of external factors, and diseases of similar type exist which appear to differ only in the absence of known transmissibility. This being the case, most importance must be attached to the facts regarding transmission. In the diseases under discussion the occurrence of epidemics and the infection of plants derived from material originating outside their range afford sufficient evidence of the general fact, but except in the case of curly-top little is known of the manner in which transmission takes place.

It is now well established with regard to curly-top of beet that it is readily and regularly transmitted from diseased to healthy plants by the small Jassid leaf-hopper Eutettix tenella, and recent experiments have indicated that for this to take place a period of at least 24 hours' "incubation " of the virus in the body of the insect is necessary. Leaf-hoppers from healthy beets or from other plants do not produce infection. All attempts at transmission by inoculation or contact have failed. The disease is continued by cuttings, but not, so far as experience has gone, by seed; it can be transferred by grafting.

The remaining diseases are transferred from infested to neighbouring healthy plants by some means as yet unknown. All have shown themselves capable of rapid extension from a small initially infected area. Potato leaf-roll and the peach diseases are transferable by grafting. Leaf-roll and sereh are continued by cuttings. Peach yellows is definitely stated not to be contracted from soil in which diseased plants are grown, and no statement has been seen that this can occur in curly-top. The infection of leaf-roll has been regarded as persisting in the soil for two or more years, but confirmatory evidence of this is lacking and survival may admittedly have been due to deeply buried tubers. Good evidence is produced, however, that transmission takes place through the soil from one growing plant to another. Whether soil infection occurs in sereh does not appear to be known, and the manner of its occurrence would appear to be equally capable of explanation by a theory of insect transmission. 


\section{CHAPTER IV}

\section{PHANEROGAMIC PARASITES}

IN point of species the mistletoes form the only numerous group of parasitic flowering plants in these islands, but in abundance the first place is easily held by the love-vine, which occurs in great masses in some stretches of uncultivated country, and is frequently highly conspicuous on roadside trees and shrubs. In neither case does the prevalence of these plants make more than a narrow contact with plant industries.

\section{Love Vine: Vermicelle.}

The plant commonly known by these names is Cuscuta Americana $L$. of the order Convolvulaceæ, which is common in all the principal islands save Barbados, where it is distributed rather scantily. It is found as a rule on waste land, on wayside shrubs and trees, and on hedges or scattered bushes among gardens or small holdings. The writer has never seen it attacking arable cultivations of any description. It causes annoyance from its infestation and disfigurement of hedges, especially of hibiscus ; and occasionally gets into cultivated trees and bushes.

The plant is without leaves, and forms when well developed large confused masses of slender flexible stems, bright golden yellow in colour. It is completely parasitic. Where it comes in contact with twigs in a suitable condition it twines around them and becomes firmly attached by sucker-like haustoria which make connection with the tissues and put the parasite into communication with the food supplies of the host. Flowers in small clusters are freely produced and give rise to numerous seeds. The plant is an annual one, and sooner or later turns brown and dries up. The seeds, which are tenacious of life, germinate in the soil and produce a filament, the free end of which circles round in search of a suitable stem, and, when this is found, coils round it and loses its connection with the ground. The plant is also freely reproduced from fragments of its stems when these find themselves in an appropriate situation, and transference of this kind is sometimes due to malicious persons or to children.

In several islands the destruction of love-vine is enjoined by ordinance on owners or occupiers of land, but eradication is troublesome to achieve, and the regulations in consequence are difficult to enforce. The common method is to cut down or 
prune back the affected plants, burying the material removed or burning it when it is dry. Small pieces left on living twigs will produce a fresh growth, and if seeds have been allowed to ripen and fall they may give rise to new infestations after a long or

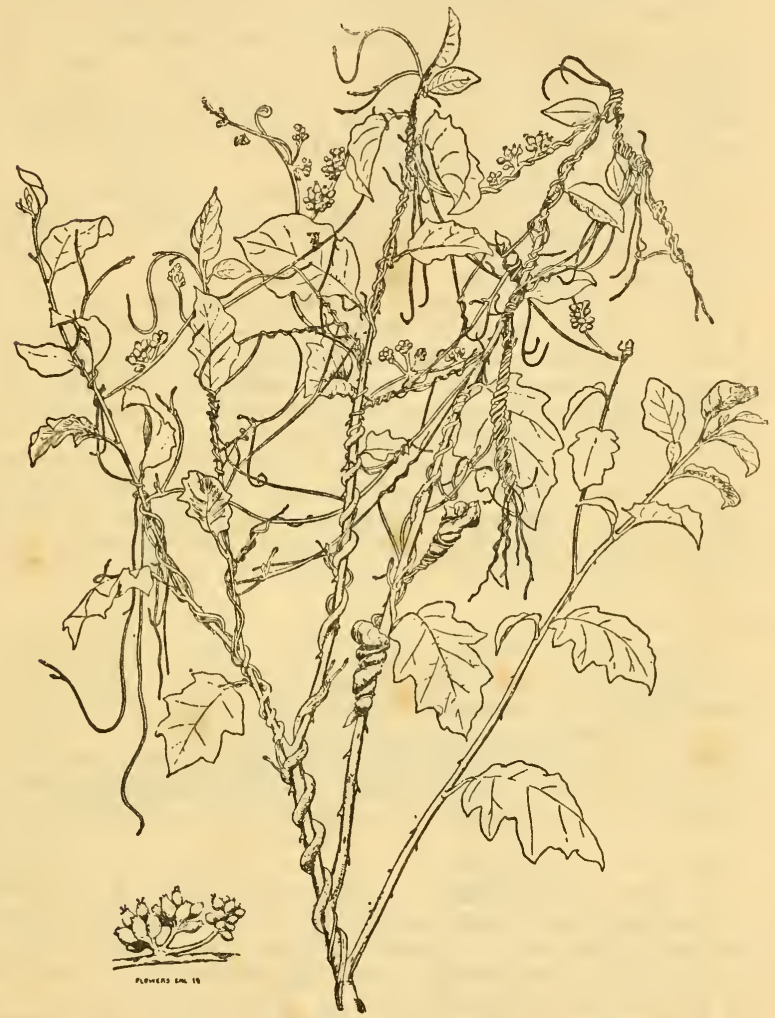

Drawn by]

Fig. 11 Love Vine on Solanum Sp.

[W. Buthn

shorter time. Destruction before seeding is therefore very desirable.

For the control of similar parasites on arable crops in Europe and America most reliance is placed on securing clean seed, but 
the use of spray fluids is also described by various authors. It would seem that treatment of this kind might be more widely adopted in the West Indies.

The substance most recommended is copper sulphate in 2.5 per cent. solution, and 0.5 per cent. sulphuric acid is also mentioned. Cooper's Cattle Dip, I $\frac{1}{2}$ oz. to I gallon of water has been used with success in Trinidad on hibiscus. Trials might be made with strong lime-sulphur sprays. No treatment can be expected to destroy the parasite without also destroying leaves and green shoots, but strengths can be found at which the older twigs will not be seriously affected.

Love-vine is itself subject to parasitism by more than one species of fungus which occasionally destroy it, but this kind of control, being dependent on special conditions, is not likely to be much extended by artillial means.

The crop plant on which love-vine gives most trouble is perhaps the lime, which is liable to become heavily infested. Cacao and cassava are not uncommonly attacked, and the parasite has been reported on sugar-cane. The favourite host of all is the common hibiscus, but there appear to be few shrubs or trees which are not subject to infestation.

Love-vine is a plant which forces itself on the attention, and as it frequents the borders of highways its presence is noted even by the unobservant. Consequently it becomes, like black blight, an object of more public concern than its relative importance as a pest can be considered to justify.

\section{Cassytha.}

A parasite so closely resembling love-vine in habit that it is not usually distinguished from it, though belonging to a different natural order, is Cassytha filiformis L. (Lauraceæ), which is well distributed but not nearly so common as Cuscuta. It may be distinguished in the vegetative condition by its more wiry, very finely striated stems, and its duller colouring of green or greenish yellow. It is more restricted to waste places and bush land.

\section{Bird Vine: Mistletoe.}

A very considerable number of species of mistletoe (Loranthaceæ) are distributed through the West Indies on native and introduced trees. Though they are by no means confined, in most cases, to individual or even related hosts, there is evidence of considerable selectivity in their distribution.

Unlike the love-vine, the mistletoes are fully supplied with green leaves, but their seeds germinate, not on the ground, but on the branches of trees, and their root system becomes embedded in the wood of the host and draws from it the supply of water and mineral salts which ordinary plants obtain from the soil. In addition to this drain on the sap the heavy masses of leaves occupy space and light to the exclusion of part of the 


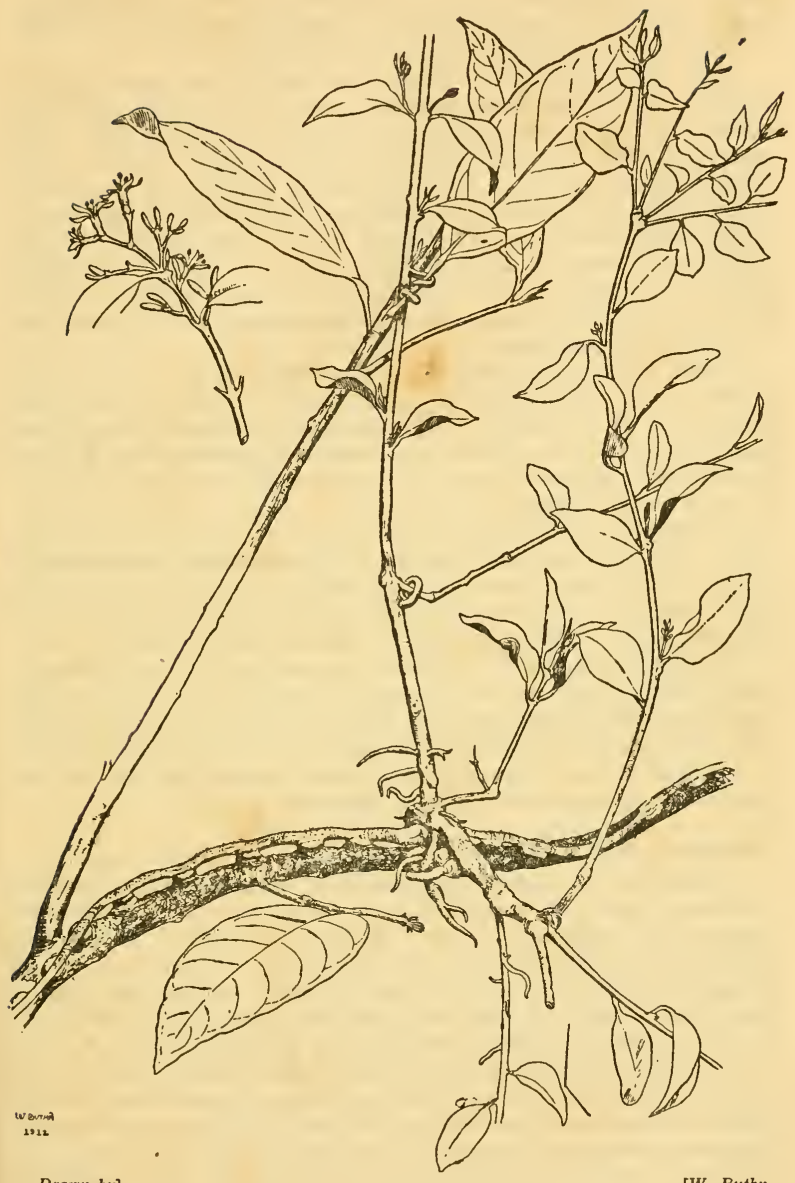

Drawn by]

Fig. 12

BIRD VINE (Struthanthus dichotrianthus) ON CACAO. 
foliage of the infested tree. The combined effect is to produce a sickly ill-nourished condition in the host and frequently the death of the terminal parts of infested branches.

By analogy with the European species it is assumed that the distribution of the local mistletoes mainly depends on birds, which feed upon the berries and leave the sticky undigested seeds adhering to the bark of trees subsequently visited. The primary root produced in germination penetrates the cortex as far as the wood, where it spreads out into an ultimately woody organ of attachment. The wood of the host is not actually penetrated, but the base of the organ becomes more deeply buried every year by the addition of the annual rings of wood to the branch, with which the parasite keeps pace by step-like or finger-like extensions.

When its first appearance is neglected, bird-vine may become a serious pest of cacao and of limes, to mention the two most important of its hosts. The species Dendropemon caribaus Krug. et Urb. is very abundant in semi-neglected lime fields in Dominica. Another species is reported to be common on avocado in the Virgin Islands.

Of the numerous species occurring in Trinidad, by far the worst pest of economic plants is Struthanthus dichotrianthus Eichl, which attacks cacao, mango, orange and many other trees. It is peculiar in the possession of aerial roots which run along the branches of the host and rapidly extend the infestation.

The only remedy for mistletoe is cutting out and pruning, carried out in the course of systematic inspections. The cleaningup of infested trees throughout a district is desirable, and legislative action to secure this has been taken in Trinidad and St. Lucia.

An insect, not identified, has been reported to destroy the berries of the Dominica species above mentioned.

\section{Alectra: Cane Killer.}

In $\mathrm{I} 892 \mathrm{C}$. A. Barber described the occurrence of a Scrophulariaceous parasite reported to be destructive on sugar-cane ratoons in Dominica. The species was Alectra brasiliensis, Benth., which is recorded as also occurring in Guadeloupe, St. Vincent and Trinidad. The plant is erect, unbranched, one to three feet high, with opposite, toothed green leaves, about an inch long, arranged closely on the stem. The flowers occur in the axils of the leaves, are yellow and inconspicuous, and may be recognised by the curved stigma which appears like a broad green band across the throat of the corolla. Immense numbers of minute rod-shaped seeds are produced in the capsules.

The parasitism is partial only, consisting of the attachment of the roots (which are orange coloured) to those of sugar-cane or other plants. It is only effective on old ratoons, and apparently does not occur where tillage is adequate. Nothing has been heard of its existence as a pest in recent years. 


\section{CHAPTER V}

\section{DISEASES DUE TO NEMATODES (EELWORMS)}

NEMATODES are worms of relatively simple structure, typically slender and cylindrical in shape, as indicated in the popular names eelworm and threadworm, although in certain stages some species may become swollen into gourd-like or other forms. Nematodes are hatched from eggs, usually outside the body of the female, have a larval stage in which the sex organs are not developed and a sexually mature stage in which there is usually more or less difference in size or form between the male and the female. It must be noted, in view of the unfortunate American usage of the word worm for caterpillar, which has gained considerable currency in the West Indies, that nematodes are not stages in the development of insects or of anything else : they are and remain worms.

As is the case with the fungi, the order contains a large number of species which live in soil or water or on decaying vegetable or animal remains, and others which are parasitic to various degrees. While the parasitic fungi mostly attack plants and are comparatively rare on animals, the greater number of nematode parasites are found in animals, and a much smaller number are known as the cause of injury or disease in plants.

In animals of all descriptions particular nematodes inhabit the blood, the muscles, the stomach and intestines, the lungs, the heart and other organs, and among them are such notorious organisms as Ascaris, Strongylus, Trichina, Ankylostoma and Filaria.

Nematode diseases of plants have lacked adequate attention owing to their position in a no-man's-land between the entomologist and the mycologist, but recognition of their variety and importance is growing. One species which has become well known is Heterodera radicicola, which infests and damages the roots of more than 500 known host plants. It is more usual, however, for a given species to be restricted to a few hosts or to one only. Where several are attacked a certain amount of biologic specialisation has in some cases been observed, some difficulty being apparent in the accommodation of a strain bred on one plant to a host of another species.

In recent years the investigations of $\mathrm{N}$. A. Cobb have brought to light the fact that predaceous nematodes exist, some of which feed on other nematode species injurious to agriculture. This 
information suggests possibilities in regard to the existence or establishment of control on lines familiar in the case of insect pests.

The nematodes parasitic in plants are typically minute, one millimetre $\left(\frac{1}{25}\right.$ inch) in length or less, and unless massed in large numbers are invisible to the naked eye. The head is provided with a pore-like mouth through which, in many species, can be protruded a needle-like organ, the oral spear, with which punctures may be made in the plant tissues to liberate the juices or allow of the passage of the worm. The degree of development of the spear is to some extent an index of the mode of life of the species. Behind the mouth parts is a tubular œsophagus with a bulbous expansion, and salivary glands which, like the spear, may be well developed or rudimentary. It is probable that the latter provide in some species an excretion toxic to the tissues attacked, as in some sucking insects. There is next a straight gut terminating in an anal orifice near the tail end of the worm. The method of feeding, in conformity with the structure described, is by the ingestion of fluids only.

In most of the nematode diseases of plants which have been made known the worms have been endoparasites, existing for the greater part of their active life within the tissues of the infested plant. Other species are known to live in the soil and puncture the epidermis of young roots without entering: the effect of which, from the nature of the case, is difficult to estimate. Recently two species, referred to below, have been described which are fully parasitic, but are ectoparasites, ascending the outside of stems and lodging in buds, under leaf-sheaths, or in similar situations, puncturing the tissues and feeding from without.

The plant-feeding nematodes have a transparent skin, the external layer of which is a highly impenetrable cuticle. The eggs are similarly enclosed. Considering their fragile appearance, both worms and eggs are surprisingly resistant to solutions of chemical poisons. They are somewhat more susceptible to gases, and the best results obtained in the treatment of infested soils by chemical agents are probably those obtained with carbon bisulphide or ammonia. The usefulness of lime in this connection is disputed, but in any case only heavy applications can be expected to have any notable effect.

The resistance of the worms to dryness varies very considerably with the species. It is not uncommon for a period of dormancy in a dried-out condition to form part of the normal life history, and this has been shown to be capable in some species of extending to six months and more with little mortality or loss of vigour. The larvæ of the wheat nematode, which assume a resting condition in altered grains of wheat, have been recorded as resuming their activity after being dried for 27 years. Where a condition of dryness does not come in to cause cessation of 


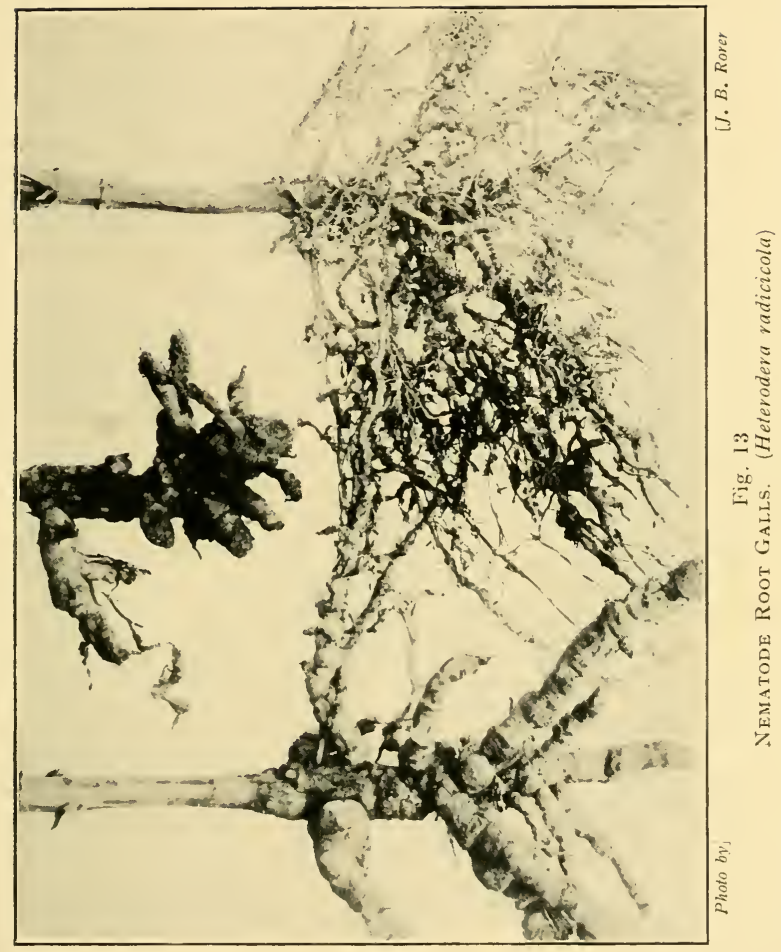



activity the indications are that the worms cannot exist more than a few months without food.

For active life nematodes in general are dependent on the presence of moisture or a high degree of humidity. The rice nematode has been found able to move over a water-free surface in a saturated atmosphere, and to travel on the surface of the
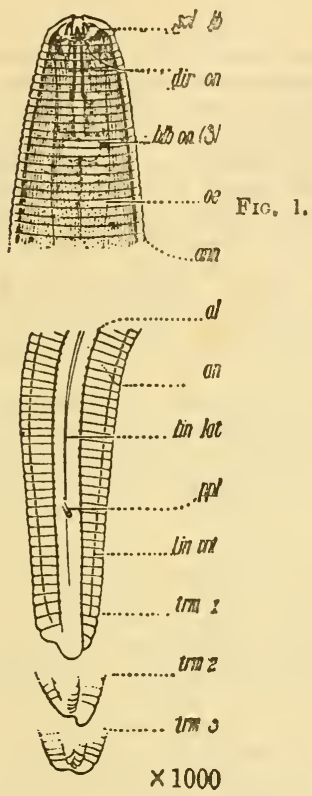

After N. A. Cobb
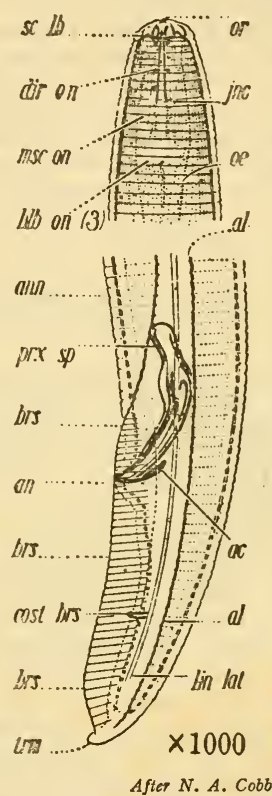

Fig. 15 Tylenchus musicola.

Fig. 14 Tylenchus Musicola. MALE

Female

living plant at humidities below 90 but not below 75 per cent. of saturation. The same species can survive about a month of total immersion in water, but according to Cobb many soilinhabiting and plant-infesting nematodes succumb after a submergence of a few days.

The quality of resistance to nematode attack is shown in certain cases by species or strains of plants related to those infested. Thus Liberian coffee is reported to be definitely resistant to nematode troubles experienced in Java and the French 
Antilles, and the iron cow pea is a variety adopted for its immunity from the attacks of Heterodera radicicola, which are ruinous to other varieties.

The life histories of plant-infesting nematodes and the nature of the diseases they produce may best be illustrated by the following summarized description of typical examples.

\section{Heterodera radicicola, Greef.}

This is the best known of the nematode enemies of plants, owing to its cosmopolitan distribution and its great range of hosts. It is abundant in both temperate and tropical countries, but in those with a severe winter it is mainly or entirely a greenhouse pest. It infests very many common vegetable crops, various trees, and a large variety of weeds and plants growing wild. As regards crops more specially tropical it acts as a serious check to the cultivation of the Chinese banana in Egypt, has been credited with great destructiveness to coffee (concerning which see remarks under diseases of that crop) and has been recorded from Hawaii and Java on young and soft roots of sugarcane. In the British Antilles its status is mainly that of a garden pest.

The effect of Heterodera attack on roots is the production of galls, which differ in size and shape according to the nature of the infested plant. On the lower stem and collar of trees the infested bark becomes swollen and irregular, often presenting a rough and scaly appearance on the outside for a foot or two above the soil.

The eggs are laid in the galls or swellings, and hatch in situ, or in the soil if they are liberated by the death and decay of the galls. From the soil the tiny larvæ, which possess an oral spear, force their way into tender roots and proceed to develop. The body at first swells out to the shape of a bolster, from which state the male worms later return to the ordinary slender eelworm form, which they develop inside the old skin as in a cocoon. The female continues to broaden out until it reaches the form of a gourd, broad and round at the posterior end and tapering off towards the head; its length is about one millimetre and its breadth more than half of this. The time occupied from entering the root to reaching maturity is about 6 weeks. As the development of the ovaries proceeds the female is reduced to a lifeless bag fully occupied by the 300-500 eggs. The males meanwhile perish after copulation.

The principal effect of infestation on the plant appears to be due to root interference arising from malformation and from the premature death of infected roots. The plant attacked is liable to become stunted and sickly, or even to die outright. The secondary effects may be equally or more important, since access to other parasites, especially fungi, is afforded directly by the galls and indirectly by the debility induced. 
Satisfactory control of Heterodera is obtainable where the soil can be heat-sterilised, as in small plots and seed beds. Control by chemical agents has not been found to be feasible on any adequate scale. The system for which the best results have been claimed is that of trap crops, in which highly susceptible plants are thickly sown in infested ground to attract the larvæ and pulled or ploughed out before these can reach maturity. Starving out the worms by a complete fallow or the planting of an immune crop is another well-recommended measure. Carbon bisulphide has its advocates in dealing with permanent crops but it is difficult to conceive of more than palliative effects resulting from this treatment of an organism so well protected during much of its life history by the tissues of the host. The worm has been shown to have little power of resistance to desiccation and heat, which perhaps accounts for its absence as a serious pest of arable land in these islands.

Tylenchus devastatrix, Kuhn.

The eelworms of the genus Tylenchus, which includes many serious plant pests, retain the normal worm-like form in both sexes throughout the life cycle.

$T$. devastatrix affords an example of a species which infests tissues above ground and affects from within the development of the organs of the plant. It causes dwarfing, crumpling and other deformation of leaves and abortion of ears in rye and oats, ring disease of the bulbs and yellow leaf-spots on hyacinths, a seedling disease of onions resulting in abnormal forms, bud proliferation and reduction in leaf size in clover, misshapen spots on potato tubers, and the drying up of flowers in the teasel.

The worms penetrate seedlings or young plants from the soil and ascend to various locations in the stem by way of the parenchyma. Here they breed, and are returned in the course of time to the soil when the plants die down.

\section{Tylenchus tritici.}

The wheat eelworm similarly enters into the seedlings, ascends the stem (where its presence gives rise to stunting and the curling of leaves), and eventually bores into the ovaries, which develop into gall-like bodies resembling somewhat the normal grains among which they occur. The eggs are laid in this situation, and each gall when ripe contains some 500-600 larvæ, which after hatching enter upon a resting stage. It was from this condition that the frequently quoted example of revival after 27 years of desiccation occurred. The worms resume activity when the gall, in company with the grain, is resown, and make their way through the soil to the seedlings of the new generation.

\section{Tylenchus angustus, Butler.}

The rice eelworm is one of the examples referred to above of ectoparasitic nematodes. It is the cause of the destructive 
" ufra " disease of rice in India, and appears to be confined to that crop.

The worms exist in a free-swimming condition in the water which covers the fields, and ascend the outside of the plants when the humidity of the air permits. They infest mainly the leaf-buds at the tops of the shoots, the upper nodes of the stem beneath the leaf sheaths, and the developing ears. In no case do the worms enter the tissues, but puncture the epidermis and absorb the juices so obtained. There is no evidence of toxic action. Severe infestations lead to the ruin of the crops.

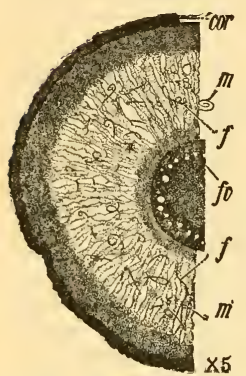

After N. A. Cobb

Fig. 16 COCONUT RoOT With Nematodes

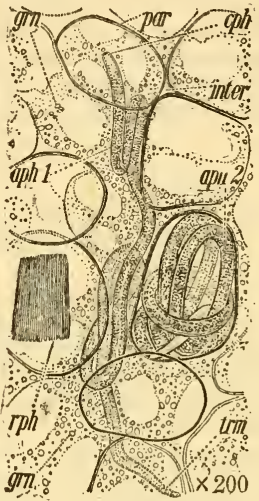

After N. A. Cobb

Fig. 17 Coconut PARENCHYMA WITH NEMATODES

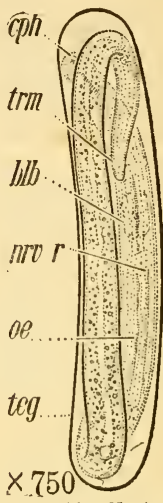

After N. A. Cobb Fig. 18 EgG OF APHELENCHUS COCOPHILUS

Reproduction proceeds vigorously on the growing plant and eggs and larvæ in all stages are found mingled with the adults in the leaf-buds and around the young ear. With the drying out of the ripened plant the worms coil up in the uppermost nodes and within the glumes of the ear, and become dormant. In this condition they are returned to the soil, and await conditions suitable for the infection of the succeeding crop.

Tylenchus ribes, Taylor.

This species infests the buds of black currant bushes in England, ascending the stems on the outside during wet weather in the same way as the rice eelworm. Reproduction takes place within the bud and the worms collect there in visible cottony masses containing many hundreds. The colonies dry out in this situation, and the worms revive and migrate when moist conditions are restored. Seventy per cent. of the worms have been 
found to survive 6 months' desiccation, returning to normal activity after I-2 hours' immersion in water.

Aphelenchus cocophilus, Cobb.

An extended account of the disease caused by the coco-nut eel-worm is given in the section on diseases of that crop. The worms occupy and breed in the ground tissue of a continuous zone in the stem of the palm, and of the stalks and bases of the leaves. They also spread outwards from the base of the stem in the cortex of the roots. The life history has not yet been worked out, but present indications are that the worms may ascend the outside of the stem and enter the leaf base from below; i.e., on its outer side, and near its attachment to the stem.

Tylenchus similis, Cobb, and T. musicola, Cobb.

These species cause diseases of banana in the West Indies which are elsewhere described. They enter the roots and rootstock, causing slight swellings and cracks in the roots, and blackening the tissues of the pockets they occupy in the infested organs. $T$. similis also attacks sugar-cane roots, causing and occupying blackened dead patches and cavities in them, but producing!no swelling. 


\section{CHAPTER VI}

\section{THE RELATION OF INSECTS TO PLANT DISEASES}

THE injurious relationships of insects to plants may be roughly divided as follows :

I. Direct injuries of the nature of wounds (traumatisms).

2. Systemic or organic disturbances originated by sucking insects (stigmonoses).

3. The exposure of internal tissues to infection.

4. Transference of infection.

\section{Insects as the Cause of InjuRIES ANd Diseases.}

The principal of the relationships specified above is that which in practice is the concern of the economic entomologist, and consists in the production of injuries mainly direct and of the nature of wounds. Thus the plant or any of its parts may be destroyed by biting or boring insects or its juices be drawn upon and its tissues perhaps poisoned by sucking species.

Whatever the nature of the injury it must have a reaction on the condition of the plant, and as regards this there is in many cases no essential difference between the results produced by insects and by fungoid parasites. The reduction of leaves, flowers, or fruit, the girdling of a stem, the destruction of roots, have much the same results when caused by one or the other. From this point of view insects as well as mites and nematodes are on the same footing as fungi and bacteria in the causation of plant diseases. The main difference is that with insects the injury and the manner of its production are usually direct and obvious.

\section{STIGMONOSES.}

There are exceptions, however, especially where sucking insects are concerned. The attacks of plant-feeding Rhynchota -hemipterous bugs, aphides, scale insects, leaf hoppers and the like-to which may be added thrips and red spider, often result in more or less general symptoms not obviously related to the direct injury inflicted. To this type of affection the term stigmonose has been applied. No better example could be quoted than the froghopper blight of sugar-cane, or the effects of thrips on cacao and sweet potato. The starved and chlorotic condition induced in certain Solanaceous and other plants by lace-wing bug infestations is another familiar example. 
In some such affections there is reason to believe that besides the drain on the juices of the plant there is a poisoning effect from a toxin injected by the insect into the tissues, the immediate action of which is to overcome the resistance of the protoplasm lining the cell wall and thus allow abstraction of its liquid contents.

\section{INSECT INJURIES AS OPENINGS FOR INFECTION.}

The protective function of surfaces of cuticle or cork and the dependence of many fungus parasites on wounds to secure an entrance have been described. Most commonly such injuries originate from the attacks of insects. Not only do fungi gain access by the grosser wounds, but it has been repeatedly shown that the infection of leaves or fruits may depend on injuries of this nature not appreciable to the naked eye, and the presence or absence of an unconsidered insect may in this way determine the prevalence of a fungoid or bacterial disease.

\section{INSECTS AS CARRIERS OF INFECTION.}

In addition to their function in opening up ways for infection evidence is accumulating that in plant as in animal diseases insects frequently transfer the actual means of infection from plant to plant. The covering of the insect body is usually very suitable for the carriage of fungus spores or bacteria, and next to wind insects are probably the most effective agents in distributing these, and are capable of extending the range of a disease over the long distances sometimes covered in insect migration. It is not necessary that the insects themselves should be of injurious kinds; they may visit the affected plant to feed from its flowers or be attracted by and perhaps bred from the tissues soured or decayed as a result of disease.

The fungi causing the internal disease of cotton bolls are transferred from the fruits or seeds of numerous wild and cultivated plants to the bolls, and from one boll to another, by plant-feeding bugs and by no other known means. The form in which the fungus concerned is carried has not been detected, but there is good reason to believe that the infected material is introduced into the boll or other fruit at the time of feeding.

In the mosaic diseases infection commonly occurs through the agency of aphides, and in one such disease, spinach blight, the virus is handed on to succeeding generations of the insects, as shown by the power of these to produce infection. The virus of curly-top of beets is transferred by a Jassid bug, and it has been recently demonstrated that a period of incubation of about 24 hours in the body of the insect is necessary to the process. The difference between these diseases and the stigmonoses should be noted: in the latter the affection is caused by the insect itself. 


\section{Susceptibility and Resistance to Insect Infestations.}

It has been frequently remarked that there is a reverse relation as well as the direct one between the development of infestations of certain insects and the state of health of the plant infested. Plants growing under wholly favourable conditions may exhibit a resistance-or in unfavourable conditions a susceptibility - which determines the extent to which the insect concerned can establish itself upon them. Such a relation exists in several of the stigmonoses. A. F. Woods, who originated the term, remarks that aphides are specially fond of plants which have made a poor starved growth, and increase rapidly upon them. The cacao thrips, with a whole country-side of cacao apparently open for it to feed upon, infests certain patches year after year, only occasionally and temporarily extending to the surrounding fields. Usually it can be shown that the infested areas are on poorer or less well-drained soil, are insufficiently sheltered, or perhaps have been depressed by some more temporary disability.

It is the general experience with the froghopper blight of sugarcane in Trinidad that it is in fields in poor tilth, in ratoons on red clay soils, which quickly lose the effects of cultivation, and in local patches subject to some similar defect, that the insect finds the most suitable conditions for rapid multiplication.

Infestations of the bug Helopeltis which causes the mosquito blight of tea are reported to depend similarly on cultural conditions, being especially liable to follow upon water-logging of the soil. Bugs of this species in captivity are said to have proved unable to maintain themselves on twigs supplied from resistant bushes, but to recover and thrive on material from plants in a susceptible condition. Scale insects frequently show greatly increased powers of infestation on plants in an unthrifty condition or growing in situations in some respect unfavourable. Thus young lime trees grown with a shelter crop, the system under which they thrive best, have remained practically free from scale when plants of similar age in the open have had to be frequently sprayed to keep them alive. 


\section{CHAPTER VII}

\section{NON-PARASITIC DISEASES}

THE term non-parasitic is now coming into use for the class of diseases often called "physiological." Plant pathology has developed almost entirely on a basis of parasitology, and the newer expression is perhaps the most appropriate for what in practice has been not so much a natural group as a limbo where all affections not shown to have parasites as their inciting cause were detained. It is not possible to have a strictly definitive name for such an assembly, and there is in fact no strict dividing line between parasitic and non-parasitic diseases.

A cacao tree growing in a light soil and subjected to undue exposure suffers repeated losses of its leafy twigs from dieback, and eventually, if the adverse conditions continue, dwindles and dies with all the evidences of inanition. The immediate inciting cause of the dieback would appear to be the want of balance between loss of water from the broad thin leaves and its absorption by the roots. If now, as frequently happens, the failing twigs and branches are attacked by Diplodia, the essential causation is not changed, since the fungus cannot attack healthy twigs, but its presence may increase the severity of the original disease. In a similar way, the production of disease even by obligate parasites may depend on some effect of the physical environment upon the host.

It is convenient to include with parasitic diseases those border-line cases in which a parasite typically appears, though logically, having reference to their actual inciting causes, such affections as root-disease of sugar-cane and dieback of limes and cacao should probably be classed as non-parasitic.

This policy leaves in the group to be considered at least one apparently definite class-affections directly produced by imperfect adjustment between the plant and its physical environment, or, in other words, by unfavourable climatic and soil conditions. These affections show gradations from simple injuries which would hardly be called diseases to systemic disturbances affecting the whole plant. It must be confessed that of the more complex of these types we have very little comprehension, and cases frequently occur in which diseases believed to be of this nature are shown to be of parasitic origin. There is also the difficulty already mentioned in connection 
with the virus diseases, that a similar set of symptoms, as for example in the conditions known as gummosis and chlorosis, may arise from different causes, some of which may be parasites and others physical factors.

The systematic discussion of atmospheric and soil conditions, and the effects their variations produce on plants, is more appropriate to a treatise on plant ecology than to a handbook of plant diseases. A few of the more definite examples occurring locally will be mentioned as illustrations, and for fuller information as to these the reader is referred to Part II. The sections on cotton and citrus diseases, particularly, may be consulted in this connection.

The red leaf blight of cotton and chlorosis of sugar-cane illustrate the kind of effect that may follow from soil defects. Growing plants of Sea Island cotton may at any stage begin to show a rusty discoloration of the foliage, and the leaves so affected fail prematurely. The symptoms may be slight or severe and in the latter case the development of the plant is permanently checked. The condition is at the present time very prevalent in St. Vincent, where it has been shown by S. C. Harland to be a result of potash deficiency. A yellow leaf blight somewhat similar in its nature sometimes occurs, which renders the plants very susceptible to the attacks of certain fungus leaf-spots.

Chlorosis of sugar-cane occurs in Antigua, Barbados, and other islands with limestone soils, and persists on a particular spot year after year. According to H. A. Tempany, this is due in the first instance to the interaction of salt subsoil water with limestone, producing sodium carbonate, and from recent research in Porto Rico, the effect would appear to be produced by a further reaction which prevents the plant from obtaining iron, an element necessary for the development of chlorophyll.

The leaf-curl of Sea Island cotton which occasionally appears on a large scale in these islands is in some way intimately connected with dull rainy weather and is especially liable to occur in shaded and sheltered situations. The internodes grow out to abnormal length, the leaves are strongly crimped at their margins, and the flower buds are shed while very small. The condition may come on at any stage, and passes off entirely with a change of weather.

The loggerhead disease of the same plant occurs sporadically in St. Kitts and Nevis, and in July, I9I4, appeared on a large scale. The plant assumes the form of a low dense bush with crowded foliage. The leaves are mottled with dark and light green areas, and the veins often develop imperfectly, causing internal puckering of the leaf blade. The flower buds mostly fail as in curly-leaf, while those surviving develop with a crumpled corolla. There is no evidence of infectiousness, and distribution may either be scattered or nearly general throughout a field. 
The diseased condition may supervene upon healthy growth, or vice versa, or the plant may be uniformly affected throughout its vegetative phase. The disease is not so clearly dependent on weather conditions as curly-leaf, but the only severe recorded epidemics of the two affections occurred together in St. Kitts, in I9I4. Previous to that time loggerhead was only known to occur in plants raised out of the ordinary season, and since I9I4 its presence has not been reported. Both affections are independent of the source of seed.

To some extent in St. Kitts, Nevis, and much more distinctly, according to specimens and accounts received, in St. Croix, the leaf-curl disease exhibits also the character of the tomosis described by $\mathrm{O}$. F. Cook as occurring on cotton seedlings and young plants in the United States, namely, the fraying of the edges of the leaves and their perforation with small irregular holes.

The blossom-end rot of tomatoes is an example of a wellmarked specific disease which develops in close relation with soil and water factors, is not infectious, and has in its inception no recognisable connection with any parasite. It is marked by the appearance of a water-soaked spot, which soon turns black, near the blossom end of the fruit when the latter is about one-half or two-thirds grown; the spot increases rapidly in size and finally spreads deep into the tissue of the fruit; the affected tissue becoming black, hard, and leathery, and the fruit much flattened. The affection is not uncommon in the West Indies.

The disease may be induced or increased in vigorously growing plants by irregular watering or excessive transpiration, by raising the soil temperature, and by the use of organic and certain chemical manures. In the writer's experience it has been completely arrested by lightly shading the plants, protecting the soil with trash, and regular moderate watering. C. Brooks, from a very thorough study of the disease, arrived at the conclusion that it is probably due to the development of harmful humic and ammonium compounds and an accompanying decrease in the supply of nitrates.

A good deal of importance is attached in the study of some other non-parasitic diseases, particularly certain obscure affections of Citrus species, to the relation of the plants to the nitrates and ammonium compounds in the soil. The subject is a complex one, involving the activities and interactions under given conditions of the soil bacteria, and the results obtained, though highly suggestive, are hardly definite or general enough for concise statement. It is a matter of frequent experience, however, of which local examples could be given, that in particular circumstances the application of rich nitrogenous manures has been followed by serious damage to citrus trees, and this might be accounted for, in relation to the soil flora, on the lines of the theory regarding blossom-end rot quoted above. 
A marked example of the action of the physical environment on the life and vigour of a perennial plant is afforded by the life history of lime trees in t'ae drier islands, described in another section. When they survive the initial critical period of two or three years the trees become established and flourish for about ten years, after which their vigour declines and they gradually die back, the process being accelerated by, but not dependent on, the scale insect and fungus infestations to which their lessened resistance renders them liable. No agricultural measures have availed to arrest this decline, which by comparison of localities is judged to be the effect of irregularity of conditions, especially of the reduction of atmospheric humidity in the dry season.

Another notable case relates to orange trees in Dominica, which on their own roots, but not when grafted on sour orange stocks, are invariably limited to a relatively short period of healthy maturity by the oncoming of gummosis of the collar.

Conditions simulating the effects of disease may be produced by genetic changes, perhaps to be explained as loss mutations, taking place even in what are believed to be pure lines. Ex"mples of this are the "man cotton" and "crinkled-dwarf" rogues in Sea Island cotton described by Harland. In the latter case the plant is severely dwarfed, bears yellowish-green, crinkled and ragged leaves much smaller than the normal, and is rendered nearly sterile by shedding. The "man cotton" differs from normal in the smallness of the vegetative parts, with complete male and nearly complete female sterility. Typically it is a tall lanky plant with very short branches. Both types of rogues, when crossed with normal Sea Island, give a normal first generation. The crinkled dwarf type is known to exhibit simple Mendelian segregation in subsequent generations.

An example of what may perhaps be called genetic incompatibility, producing similar results, is afforded by crosses between Sea Island and some local perennial cottons. Part or the whole of the first generation consists of plants with mottled leaves, partly suppressed internodes, and premature cork formation on stems and petioles. The writer's attention has on several occasions been directed to this condition as a new disease. 


\section{CHAPTER VIII}

\section{ENTOMOGENOUS FUNGI}

THE occurrence of fungus parasites attacking insects has long been known in certain cases, but in recent years this knowledge has been considerably increased, and, as regards tropical forms, is capable of very much greater extension. The rich insect fauna and moist conditions of Trinidad, for example, yield in suitable situations and on various types of hosts a large variety of forms, most of which appear to be as yet undescribed and are certainly unstudied. The scale insects (Coccidæ) of that island, though numerous in species, are relatively unknown as pests, a position mainly due, it would appear, to their inability to attain to large numbers without suffering from an epidemic of fungus disease.

The remaining islands are more or less subject to annual or occasional outbreaks of scale, and the control of these by fungi has been the subject of considerable attention, mainly as a result of what might fairly be called the white-fly fungus boom in Florida a few years ago.

Our knowledge is yet far from exhaustive, even in the limited field of scale-insect parasitism, either as to the fungi concerned or their relative distribution and efficiency, but certain general principles have by now emerged.

While these are not different from what might have been intelligently anticipated, they are valuable as being the results of experience and observation. As such they may be worth stating in view of the impossible hopes which still linger here and there with regard to the artificial distribution of these fungi.

Speaking first of all quite broadly, it may be said that the efficiency of the fungi is proportional to the humidity of the air amongst the plants on which their hosts occur. Their relative abundance in the islands of the Windward and Leeward groups follows pretty closely the amount of rainfall usual to each island, though the distribution of rain is so local that the wetter islands each have areas in which the fungi are of little use, and the driest island has sheltered moist situations in which they are effective. Still speaking broadly, it may be said that in Dominica, in normal years, the control is as efficient as natural agencies can well produce. Conditions are generally such that fungus parasites keep in check established colonies of scale and follow so closely on new infestations that the effects of the insects are negligible. In most parts of St. Lucia, and in the most humid districts of 
Grenada and probably of St. Vincent and Montserrat, the control approaches to that in Dominica. In the drier districts of these islands the fungi, while present, are not so effective, or are more restricted to a seasonal activity. With reasonable accuracy it might be said that excepting the shield-scale fungus and the Aspergillus on sugar-cane mealy-bugs, the limits of possible cacao cultivation are the limits of the effectiveness of scaledestroying fungi.

Consideration must, however, be given to the fact that the matter is not quite so simple as has been assumed for the purposes of general statement above. The rapidity of effective reproduction by the insects has to be taken into account as well as the powers of attack of the fungus parasite, and in this the condition of the plant is usually, perhaps always, the determining factor.

Even in the favoured districts of Dominica and St. Lucia, plants transferred from the nursery to the field may become badly infested until they get established, and require, or would be the better for spraying. In connection with older trees, the influence of other factors stands out where fungus control is less complete, as in cases observed in Grenada, where particular mango trees were heavily infested, though the shield-scale fungus was present in some abundance, while others near by were quite clean.

Resuming the consideration of the effects of humidity on the fungi in question, their distribution in Barbados is instructive. The rainfall is low, and the island in general is open and windswept. With the two exceptions noted, the fungi in question are absent save in deep gullies, and in closely sheltered spots among the hills where the rainfall is greatest. A similar, though perhaps less extreme, situation seems to prevail in Antigua, St. Kitts, and Nevis-islands of relatively low rainfall.

Considering next the fungi mentioned above as exceptions whose distribution is not so strictly limited, the case of one of them, Aspergillus flavus, the sugar-cane mealy-bug parasite, is readily accounted for. It is not less dependent on moisture, but finds it accompanying its hosts in the enclosure formed by the base of the leaf-sheath around the nodes of the cane, a situation in which water collects and lingers.

The shield-scale fungus is more remarkable. Even in Barbados it persists through the driest season with little shelter, and becomes very active with somewhat small encouragement in the wetter months. The only relevant difference known to the writer between its spores and those of the other scale fungi is that they are enclosed in a drop of mucilage. Whether this or some constitutional factor accounts for its hardiness would be difficult to determine.

Having considered the influence of weather conditions on the natural occurrence of scale-destroying fungi, there remains to be 


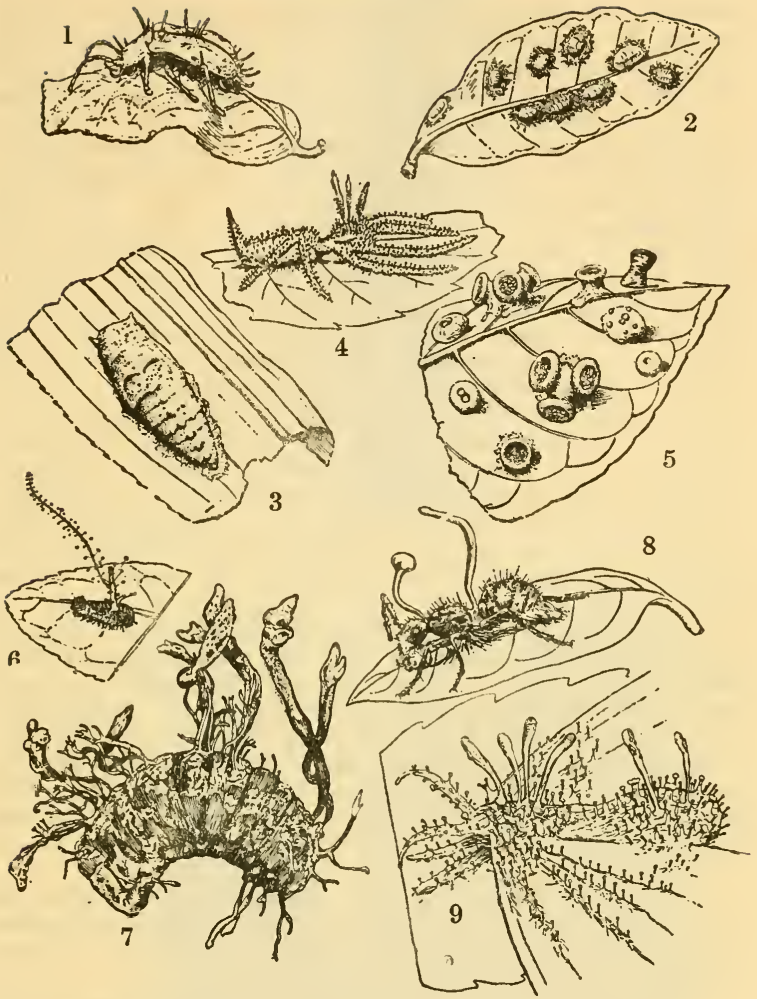

Fig. 19

ENTOMOgenous FungI

1 Hirsutella entomophila on a beetle (Colaspis sp.).

2 Cephalosporium LecaniI on Coccus sp.

3 Metarrhizium Anisopliae on a Homopteron, probably a Jassid.

4 Gibellula arachnophila on a spider.

5 Aschersonia turbinata on a scale insect.

6 Gibellula sp.

7 CORDYCEPS sp. on larva of Rhinoceros Beetle (Strategus).

8 CORDYCEPS Lloydir on an ant (Campanotus sp.).

9 Isaria SPHingum on a moth. 
discussed the question as to how far their efficiency can be increased by artificial distribution. As a consequence of the success, since shown to be due to very special circumstances, of the introduction of Australian lady-bird beetles into California to prey on the cottony cushion scale, a very large amount of attention has been given to the question of natural enemies of injurious insects. The results have been usually disappointing, but the rules of the game are now pretty clear. The rapid increase of a pest which may take place when it is newly introduced into a country where natural enemies adapted to destroy it are few or absent may be checked in some cases by bringing in such enemies from countries where they exist. To use a relevant illustration: should some kind of introduced white fly become troublesome in the West Indies, it would be worth while to introduce the fungi which are parasitic on certain species in Florida, in the hope of their exercising a check on the insect in these islands. Were the introduction successful, the control might be more efficient or less so than it is in Florida, according to the extent to which the conditions favour the fungi. It would not be expected to be complete. Once given a start, however, the fungus parasites might establish themselves and constitute permanent factors modifying the activity of the insect.

When such a factor is already well-established in the country, and it is desired to increase its effect, the element of artificiality becomes much greater. The fungus (or other parasite) already has its place, its settled lines of action, so to speak. By cultivating it, by distributing it, it may be increased for the time, but when such means are no longer used it will settle back to much its old position, which is determined by natural conditions, and changes only in response to their fluctuations. This has been and is the situation with regard to most work on the fungus control of insects.

The method has an insidious appeal, in that it seems to promise to the planter a self-acting remedy, but experience shows that, as might have been expected, results are not to be obtained without an adequate amount of trouble.

The use of fungi does afford an alternative to the employment of poisonous sprays, but save that in the one case a living organism is used, one method is as artificial as the other, and it depends entirely on the particular circumstances of the case which is more efficient or less troublesome. That is a question for the entomologist and for the planter. In Florida, in connection with white fly control, each method has its advocates. In Trinidad, periodic dusting with fungus spores has been tried against froghopper on sugar-cane, spraying with insecticides in this case being out of the question.

In one respect the use of fungi has a disadvantage as compared with the use of poisons. The latter may be applied with advan- 


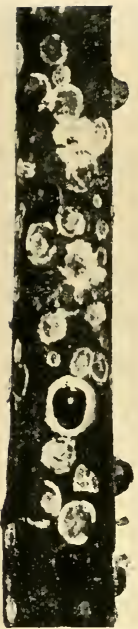

Fig. 20 Cephalosporium Lecanil on Saissetia nigra

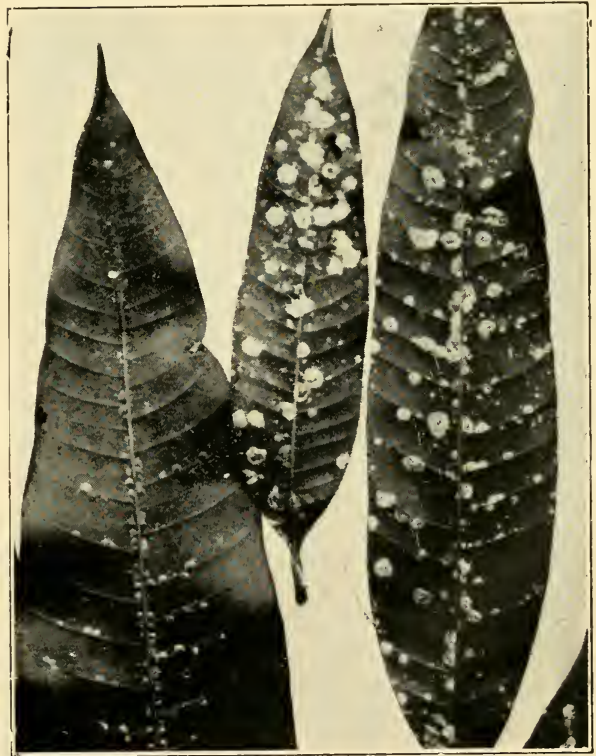

Fig. 21 Cephalosporium Lecanil on Coccus Mangiferae 


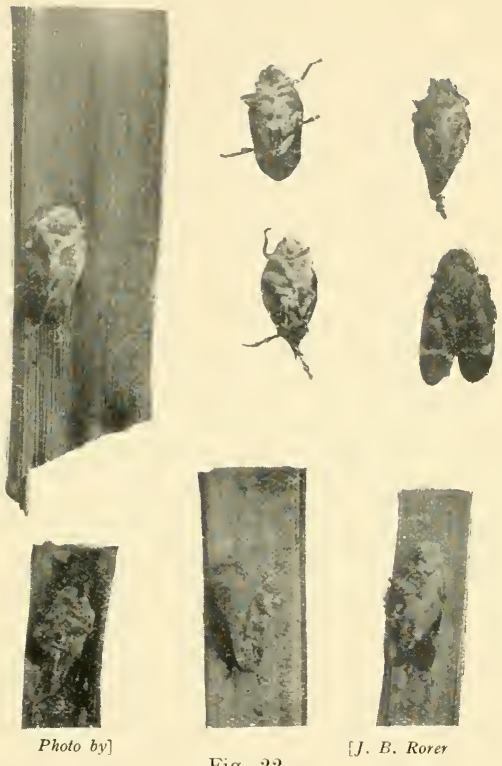

Fig. 20

[J. B. Rorer

FroghopPERS (TOMASPIS SACCHARINA) Killed bY Metarrhizium 

tage at the beginning of an attack, the former do not become very effective until their hosts are plentiful. Like all fatal parasites, they tend to cut their own throats. The more thoroughly they kill off their hosts, the less material they have to live upon. When the chances of infection have been thus reduced, the surviving insects, or colonists from another area, start a fresh wave of insect infestation, which in time is again overtaken by the rising numbers of the parasite.

This succession is perhaps most easily seen in the West Indies in the action of the shield-scale fungus working on more or less isolated trees. In lime plantations, it takes place in sections of the cultivations rather than on individual trees.

Several observers agree that, in the case of white fly control in Florida, the parasites under favourable conditions, and without artificial aid, become effective about every third year.

It was noted above that in certain localities conditions are so favourable to the spread of scale fungi that the matter may be left to itself. What can be done in the districts not so favoured? Unless there is at some period of the year a season when the fungi, if they are present, can be observed to become active, it is not worth while to trouble about them. If they are not present at all, it is probable, since they are so well distributed through the islands, that the conditions are not favourable. Where they have a period of valuable activity in the wet season, followed by comparative scarcity in the dry, something may be done. It will be found that, while they disappear from view in exposed situations, they continue a visible existence in damp and sheltered places. The spores of most species do not appear to be very resistant, and it is probable that it is from such places that the spread begins when conditions become favourable. By distributing the material thus available, or by taking material from the earliest plants to become infested, it is possible, and has often been definitely claimed, that the progress of the fungus may be considerably hastened; especially is this the case with isolated trees.

In Trinidad, a series of steam-heated cabinets has been used for turning out the spores of the froghopper fungus Metarrhizium anisoplixe on a large scale, and these have been dusted on the cane fields. The amount of fungus control in treated as compared with untreated fields has not been demonstrably increased and the practice is in abeyance or abandoned as being too uncertain or indefinite in its results.

Various methods are available in making use of natural material. Branches from the fungus-infested tree may be tied among the leaves of the tree to be infected. Leaves bearing the fungus may be dipped in water and rubbed on the leaves bearing the scales, or pinned in contact with them. The material may be stirred up in water to wash off the spores, or ground up and mixed with water in the case of leaves. 
This mixture may be sprinkled on to the trees with a brush, or the twigs bent down and dipped into it, or it may be applied with a syringe or other type of sprayer after being strained through a wire sieve. Cloth strainers keep back the spores. Brass or copper sprayers may be used if they are clean and the material is not allowed to stand long in the tank.

Comparative trials of these methods have not been made in the case of the West Indian species. Morrill and Back favour the spore-spraying method for distributing the Aschersonias concerned with white-fly control in Florida.

The condition of the material used would appear to have more influence on successful introduction than the method of its application. It should be used as fresh as possible, and, in the active spore-producing stage, recognizable on examination with a pocket lens. In the case of the shield-scale fungus, a powdery glistening appearance denotes the presence of the spores. In the red-headed and white-headed fungi, the loose tufts of ripe spores can be easily made out.

When a branch or twig is tied into a tree, the immersion of the cut end in water contained in a narrow-necked bottle is an obvious benefit. The occurrence of the fungi on insects attacking potted plants suggests that these might in some cases be used with advantage.

The caution must be repeated that all these measures depend entirely for their success on the conditions being right for the development of the fungus. In dry weather they are useless. Moreover, experiments have repeatedly shown that, once a fungus has been given a general start, attempts to increase its efficiency by further spore-spraying have little visible effect.

Caution should also be observed in making use of infested material lest scale insects not already present on the plants be introduced. Leaves of grape-fruit examined by the writer, on which the scales were well infested with three species of fungi, nevertheless had numbers of the young of the mussel scale crawling over them more than a week after they were picked and dried.

In the writer's judgment much more hope of effective interference lies in the direction of increasing humidity by the provision of windbreaks and other forms of shelter. With cacao, and more easily with cotton, this may be carried too far, since diseases of pods and bolls will also be encouraged, but with citrus trees, which are the most liable of common crops to suffer from scale infestation, shelter can scarcely be overdone save in districts so wet that it would not be needed. With orchard crops shelter takes two forms: a temporary crop in which the young trees are nursed, and permanent windbreaks and hedges enclosing or dividing up the fields.

Young coconut trees in dry situations may be sheltered with great advantage in the reduction of scale attacks. 
The common parasites attacking Coccidæ in these islands are the following:
Spharostilbe coccophila .. the red-headed fungus.
Ophionectria coccicola
.. the white-headed fungus.
Cephalosporium lecanii ... the shield-scale fungus.
A schersonia spp.
Myriangium Durici _. the black fungus.
Septobasidium spp.

The first four attack individual insects; Myriangium and
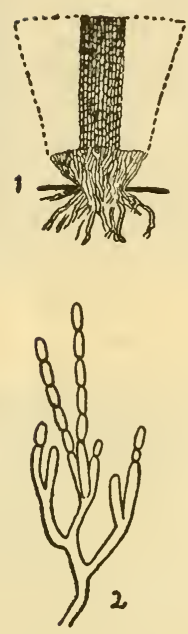

Drawn by]

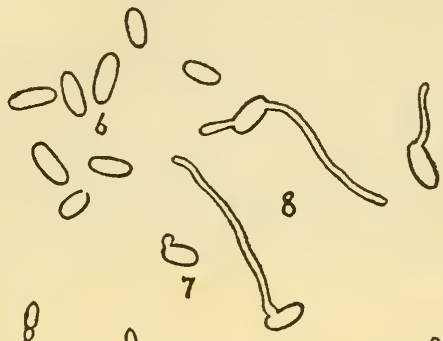

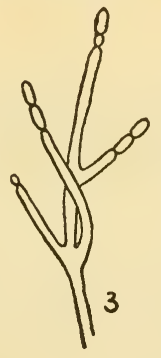

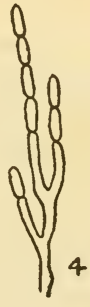

Fig. 23 Metarrhizium anisoplioe Sorok

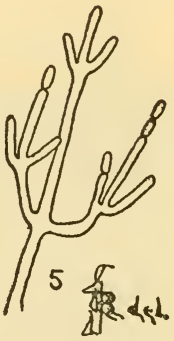

[J, B. Rorer

Septobasidium extend over whole colonies, spreading over the surface of leaves or enveloping leaves or branches.

An undescribed Empusa species appears to be fairly common on Coccus viridis, the common green scale, developing within the body so that its victims merely look dry and brown. Aspergillus flavus is very common on Pseudococcus calceolarice, the sugarcane mealy bug; Verticillium heterocladum has been found on citrus white fly in a Barbados gully.

Aphides are frequently found covered with a Hormodendron sp. which has been experimentally found to be able to kill Coccus viridis.

Thrips on cacao in St. Vincent are subject to epidemics of 
Sporotrichum globuliferum, and a temporary high death-rate has been produced by spraying the spores of this easily cultivated fungus on thrips-infested trees in Grenada.

Of the plant-feeding bugs, Dysdercus spp. the cotton stainers and Nezara viridula, the green bug, have been seen to be subject to epidemics of Sporotrichum globuliferum and Isaria Pattersonii, respectively.

The froghopper in Trinidad is attacked every year by Metarrhizium anisoplice and an Empusa sp., which destroy large numbers of adults when conditions are favourable.

An epidemic outbreak of disease caused by Botrytis rileyi, on caterpillars (Thermesia gemmatalis ?) infesting a field of cowpeas in St. Kitts, was so sudden in its effects that the stiffened bodies clinging to the leaves produced the appearance of a sprinkling of snow.

The sugar-cane moth borer Diatrœa is subject in the larval stage to the attacks of Isaria Barberi.

Gibellula arachnophila is fairly common on leaf-inhabiting spiders.

Besides these established examples there are many individual records of species of which the distribution is unknown. There can be no doubt that fungus parasites play a considerable part in controlling the numbers and distribution of insects, a control which in many cases is the less conspicuous because of its efficiency. Its importance in regard to scale insects is strikingly demonstrated by the infestations which develop on citrus trees after spraying with Bordeaux mixture, which suppresses the fungi without affecting the insects. 


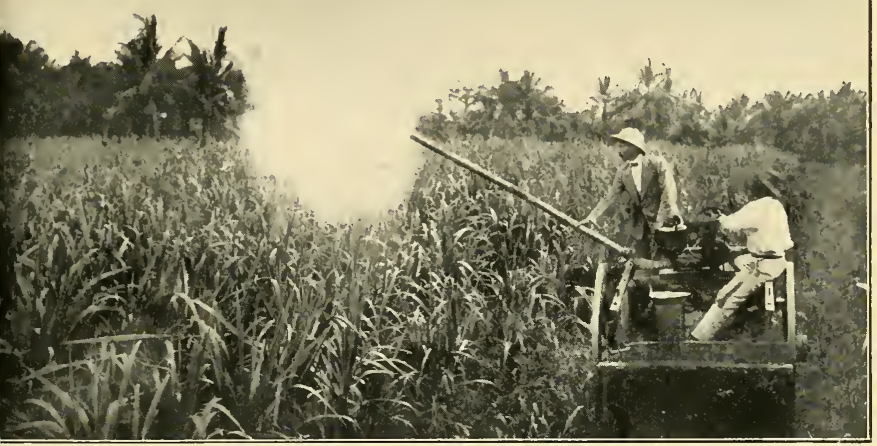

Photo by]

Fig. 24

$[J$. B. Rorer

Dusting with Spores of Froghopper Fungus (Trinidad)

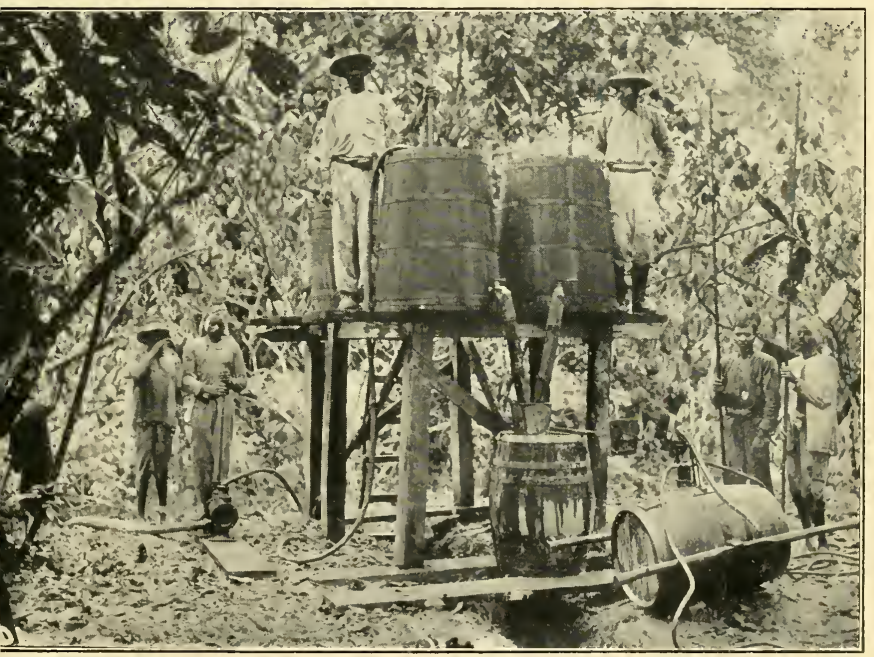

Fig. 25

EOUIPMENT FOR MIXING BORDEAUX BY GRAVITY 



\section{Section II-Prevention and Control}

\section{CHAPTER IX}

\section{GENERAL CONSIDERATIONS}

\section{Arable Crops and Parasitic Diseases.}

A field is to be planted with a certain crop, which is subject to specific diseases. The grower requires to know what can be done to prevent their appearance, and, should they appear, how the resulting damage may be kept to the minimum. For every crop and for every disease of it the answers to these questions must vary, but the general principles of prevention and control are nevertheless capable of useful discussion.

\section{Sources of Infection.}

For a parasitic disease to develop in a crop a primary infection is necessary, and the sources from which infection may arise will first be considered.

I. The parasite may be in the soil, continuing its existence in the soil itself, or on the dead or living remains of the previous crop. To remedy this condition the process of starving out the parasite by denying to it its appropriate host is commonly adopted. This may take the form of resting the field for a period, but usually the result is more efficiently and more economically attained by planting a different crop. In the practice of crop rotation from the point of view of eliminating diseases the principles to be kept in mind are (a) that the successive cropplants should not be susceptible to attack by the same parasites, and $(b)$ that a crop needing deep or frequent cultivation will produce the quickest results. Even where no alternative crop is available much may be done in the desired direction by early removal of the remains of the previous crop and thorough cultivation before replanting. Many attempts have been made to find some direct means of soil sterilization by chemical or physical agencies. It may be stated with confidence that no method involving the use of chemicals or heat is known which - is at the same time cheap enough and effective enough to be applied to areas larger than those of seed or nursery beds or the sites of a few infested plants or trees.

The practice of flooding fields where it is practicable may be very useful. 
2. The parasite may be introduced with the planting material.

In crops which are grown from seed a parasitic fungus or bacterium may be introduced with the seed, either adhering externally or, if it is from an infested plant, as an internal infection. The simplest means of avoiding this is to plant, when possible, seed from a perfectly healthy source; where this cannot be guaranteed, some form of seed sterilization, the methods of which are discussed on a later page, may be adopted. With some crops the trouble this involves is exceedingly well repaid. The same considerations apply with even greater force in the case of crops planted from cuttings. It is often desirable to supply these from nurseries, which may be established in favourable situations, perhaps at a safe distance from the main crop, and can be given special attention to keep them healthy.

3. Infection may come from standing crops or allied plants.

It is commonly the case in the tropics that an older crop may be still standing when fields of the same plant are being established. In this event the conditions are favourable to the passage of spores from old to new, blown by wind or washed by rain, carried by birds and insects, by labourers and by implements passing from one field to another. For this, if the coexistence of crops of different ages is a necessity, as is the case with sugar-cane, there is little remedy. Where the necessity does not exist a voluntary or compulsory adjustment of the time of planting may be of the greatest value, as is demonstrated in those islands where a close season for cotton has been adopted, involving the destruction by burning or burying of all old plants by a certain date some time before planting is allowed. There is much that could be done of a related nature by the control of plants, wild or escaped, growing by the sides of roads and traces and on waste land. Frequently these plants serve to carry over the pests and diseases of allied crop-plants. With some initial trouble and a little care from time to time such situations may be covered with a growth of some harmless and self-maintaining plant, which may moreover serve a useful purpose as fodder, mulch or firewood.

An instance of the kind of action described is afforded by the very effective control of the insect principally involved in the transmission of internal boll disease of cotton, which has been achieved in St. Vincent by eradicating two useless Malvaceous trees on which the insect bred between cotton seasons.

4. Infection may be introduced with manure.

With most fungi, some of the smuts being exceptions, well rotted pen manure may be considered safe. This cannot be said for vegetable mulches when these are derived from plants which are identical with or related to that composing the crop. Sugarcane trash, for example, may carry many of the diseases to which that plant is liable, and the material from infested fields should not be applied until it has been well rotted down in a 
pen. In a few cases such material should be promptly burnt, but as the loss of organic matter is to be avoided in arable agriculture under tropical conditions burning should only be resorted to when specifically advised.

\section{Means of avoiding damage.}

As the incidence of many diseases is unpreventable by the means so far discussed, and in many more is usually unprevented, consideration passes to the means which may be adopted for control.

\section{Resistance.}

Of these the most effective and the least troublesome, because it is automatic, is that which lies in the resistance of the plant to infection or to serious infestation. This, it has been pointed out in a previous chapter, may be due to some hereditary quality or character, or it may depend on the condition of the plant as determined by its environment. Some degree of this acquired resistance can be had in all crops and under all conditions by giving the best care possible under the circumstances, but its extent is limited by the possibilities of soil, situation, and climate, which may not be favourable to the best development of the plant. This kind of resistance is effective against most types of disease caused by saprophytes with weak powers of parasitism, such as root disease of sugar-cane and the Diplodia diebacks, and also against the numerous class of special parasites which principally develop on senescent leaves but advance the time of their attack on weakened plants. The West Indian leaf-mildew of cotton is a good example of this, as are several of the true rusts and many leaf-spot parasites. A vigorous plant moreover, even when not resistant, may keep pace with the development of the disease and produce a crop in spite of it.

It happens in some cases, though they are naturally difficult to recognise, that a dangerous degree of susceptibility in otherwise well-cultivated plants may arise from the shortage of some particular substance in the soil. There are several well-marked instances on record where this condition has arisen through a shortage of lime. In others it has been shown that resistance could be increased by the application in the particular case of potash or of phosphates.

It must be fully recognised that there are many diseases against which the type of resistance just discussed is not effective, in which in fact the parasite may flourish all the better for the abundance or succulence of its food supply, or in which, as in the Rosellinia diseases, the conditions which favour the most perfect development of the host are those which also best suit the parasite.

Inherent (hereditary) resistance, on the other hand, may be effective against infection or infestation with the most virulent 
of parasites, but as a rule, where it is not due simply to inherent vigour, it is narrowly restricted in range. Sugar-cane resistant to red rot, or bananas resistant to Panama disease, for example, are not necessarily protected against any other sugar-cane or banana disease. Nor is resistance of this type necessarily constant under varying environmental conditions, so that varieties perfectly resistant in one locality have sometimes proved susceptible in another, and resistance which operates for the ordinary prevalence of a disease may fail against the mass attack of an epidemic. The utilisation of resistant varieties is also subject to the disability that their produce may be unsatisfactory in some commercial quality, as in the bananas resistant to Panama disease, or may cover only one section of the demand for a graded article such as cotton.

It will be seen that dependence on acquired resistance, or resort to inherently resistant varieties, is subject to many limitations. The possibilities of these methods should, however, be always kept in mind, and growers may usefully call attention to apparently resistant plants when they occur; the critical testing of this quality is a technical matter best handled by the pathologist.

\section{Disease Evasion.}

There are various ways in which disease may, under appropriate circumstances, be evaded. Land may be used which is virgin to the crop, or remote from the same or related crops. Of more general application is the timing of a crop to avoid the seasonal prevalence of diseases; thus cotton, which is highly susceptible to damage from boll diseases in wet weather, may be planted so as to bring the fruiting period within the edge of the dry season. With short-term crops such as Indian corn and many garden vegetables, the first plantings often escape pests and diseases to which later ones are liable.

\section{Elimination Methods.}

The simplest kind of treatment for the control of a disease which has gained access to a cultivation consists in the removal of diseased plants or their affected parts : whole plants may be pulled up or cut down and burnt or buried, diseased leaves and fruit may be collected from the plants or from the ground, diseased twigs or branches pruned away, affected bark or cankers cut from stems; while root diseases may be restricted by the isolation of infected trees. Measures such as these are frequently the only ones it is possible or profitable to adopt, and they are commonly desirable as supplementary measures where spraying or other treatment is applied. The effectiveness of elimination in the control of disease varies widely. In the case of coconut bud-rot thorough campaigns against diseased trees have been reported very successful, and results may be similarly good in 
most slowly developed affections, but when spores are produced quickly and in vast numbers, as they are in so many diseases, the effects are not as a rule satisfactory unless the plants are also sprayed.

\section{Spraying.}

The object of most spraying with fungicides is not, as seems to be commonly thought, the cure of disease, but the prevention of further infection. Fungoid and bacterial parasites, with the exception of the powdery mildews and a few others of similar habit, enter more or less deeply into the tissues and cannot be reached by a spray which does not at the same time destroy the affected part itself. The action of the copper sprays, of which Bordeaux mixture is the type, is to prevent the successful germination of spores lying on the surface; this they do most effectively at the time of germination, so that protection is best afforded by an enduring film in which the toxic ingredient, the copper, which is at the same time the substance injurious to the plant itself, is rendered soluble by slow degrees. For the destruction of developed mycelium where it can be reached, as in the mildews, the sulphur sprays are found more effective.

From the nature of the process spraying is most applicable to affections of leaves, flowers, and fruit, especially when the disease is of a seasonal and more or less epidemic nature.

\section{Permanent Crops.}

Considerations different in some respects from those applying to arable crops arise in reference to permanent crops, in which the same trees occupy the same ground for many years. The protection given by rotation of crops is not available, and the death of individual plants is much more serious, since they may take years to replace. The adoption of more careful and expensive treatment may be commercially sound, for not only the immediate crop, but the future history of the trees has to be considered.

In the West Indies there are all stages of tree cultivation from the simple afforestation of land with limes, coconuts, or cacao-further attention being confined to cutlassing the undergrowth and removal of the fruit-to careful orchard methods in which the cultivation of the soil, the use and sequence of the different types of manure, and the pruning of the trees receive their due consideration. In the former system, as in forestry proper, individual treatment for disease is seldom regarded as practicable; dead branches may be removed at intervals, dead trees are replaced by "supplies," and that is about all, except where the persistent march of a root disease may compel attention. In the more intensive system reached on some cacao estates the recommendation of sanitary measures and of the use of sprays is not considered unreasonable. No doubt as 
time goes on and beneficial results are demonstrated this disposition will increasingly prevail.

For leaf, flower and fruit diseases of trees, the most general remedies are (I) wide spacing, to secure access of air and sun; (2) efficient drainage, to reduce humidity in rainy periods, and (3) spraying. Where the first measure conflicts, as it may, with the requirements of good vegetative development, a compromise has to be made. In the case of debility diseases due to the effects of exposure close planting may have distinct advantages.

Any trees which harbour pests and diseases liable to be transmitted to the crop should be as far as possible eliminated from the neighbourhood.

Pruning for twig and branch diseases, and trenching for root diseases are dealt with in later sections.

There are two pieces of general counsel, of which the soundness is beyond dispute, which may be offered in the present connection to planters of permanent crops. The first is that thought should be given to the possible incidence of disease in laying out fields, so that, by wide and regular spacing, the provision of a regular drainage system, and the separation of blocks by passable roads, accessibility and some degree of isolation may be secured.

The other is that arrangements should be made for steadily replacing, section by section, trees which have passed their prime. In the modern commercial orchard of temperate countries only trees in full vigour are tolerated, and the considerations are the same, if their recognition is at present less, in the West Indies. One great advantage is the resistance offered by such trees to pests and diseases and their greater recuperative powers when injured. 


\section{CHAPTER $\mathrm{X}$}

\section{FUNGICIDES AND THEIR APPLICATION.}

APART from experiment stations the spraying of plants, whether for insecticidal or fungicidal purposes, has come little into practice in the West Indies, and less for the latter than the former purpose. This can be attributed to the usually unintensive methods of raising crops, to the lack of adaptation of available methods to the needs experienced, to the general unsuitability for spraying operations of the type of labour employed, to the difficulties of maintaining the apparatus, especially rubber parts, in order, and not least to a reluctance to face the trouble and supervision involved. Even the simple operation of dusting cotton for caterpillar attacks is often badly organised and carried out, and the most general use of a fungicide, that of Bordeaux mixture for treating cane cuttings, is made in a routine fashion which is frequently inefficient. Improvement in these matters depends on agricultural education, and on the ability of agricultural officers to demonstrate the advantages to be secured.

The use of fungicides may be (I) protective against infection, as in the spraying of leaves and fruits, the dipping of sugar-cane cuttings, and the coating of exposed wood; (2) remedial, as when a fungus growing on the leaves of a plant is directly attacked; (3) disinfectant, when fungi, bacteria, or their spores existins on seeds or other planting material, on a growing plant, or in the soil are destroyed to prevent infection.

By far the most important function, in the extent of its application, is the protective one, and the most common misapprehension regarding fungicides is that spraying designed for this purpose is of value as a remedial treatment, which very frequently is not the case.

Bordeaux mixture is the standard protective fungicide, but it has little remedial value. For the destruction of a fungus on living organs, which naturally can as a rule only be attempted when the mycelium is superficial, the sulphur fungicides are in general most effective. For disinfection various poisons are available for different purposes, such as mercuric chloride, formalin and copper sulphate.

It is necessary to bear in mind that the pint of the United States and Barbados is I6.6 fluid ounces as compared with the 20 ounces of Imperial measure, so that to get comparable results in using American formulæ with British measures five-sixths 
of the indicated number of gallons should be used. The formulæ in this book are given in Imperial measures.

\section{The Copper Compounds.}

The fungicidal action of the copper compounds is principally of value in preventing the successful germination of spores, and for this purpose they have to be adapted for use on the tender surfaces of leaves and growing fruits. In order to have available over as long a period as possible an amount of soluble copper. salt sufficient to kill the fungus without damaging the almost equally susceptible tissues of the plant, they are applied in compounds which only slowly set free the actual fungicide. Bordeaux mixture, which consists of copper salts formed by the interaction of copper sulphate and lime, is for general purposes the most convenient and effective.

\section{Bordeaux Mixture.}

The popular way of indicating the strength of Bordeaux mixture is by formula, thus $6-4-50$ is recognised to mean the mixture obtained by the use of $6 \mathrm{lb}$. of copper sulphate, $4 \mathrm{lb}$. of stone lime, and 50 gallons of water.

For purposes of scientific discussion the strength is best expressed as the percentage of copper sulphate used in preparation, and the Imperial gallon of water having a weight of Iolb.*, the use of Ilb. of copper sulphate to each ro gallons of water makes a I per cent. mixture, which is about the standard strength required for spraying and dipping. A 2 per cent. mixture is sometimes used, and 0.5 per cent. may be found to be strong enough for a particular purpose or may have to be adopted to avoid injury. These strengths are obtained by doubling or halving the proportion of copper sulphate and lime in the I per cent. mixture, taking therefore $2 \mathrm{lb}$. or $\frac{1}{2} \mathrm{lb}$. of copper sulphate for each Io gallons of water.

The amount of lime used, provided that it is of good quality, admits of considerable latitude. According to S. U. Pickering, the requirement to decompose the whole of the copper sulphate is one-fifth of its weight of pure lime. In ordinary practice a considerable excess of lime is used, commonly a weight equal to that of the copper sulphate, and the mixture is in consequence strongly alkaline. This gives a wide margin to cover defects in the lime, and has advantages, but it should be noticed that in an emergency, or where lime is scarce and dear, half this quantity of good lime can be used without changing the nature of the resulting mixture. Attempts are sometimes made to use airslaked lime, but this is quite unsafe and produces a worthless mixture. Where stone lime is unprocurable soda should be used instead. (See Burgundy mixture).

* The American gallon of water weighs $8.345 \mathrm{lb}$. 


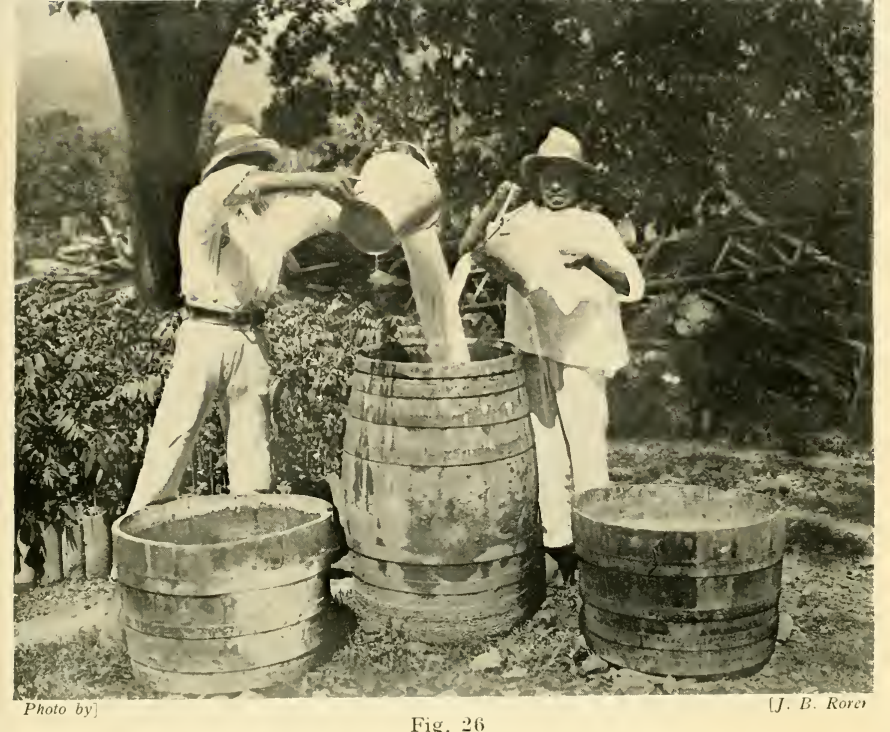

Mixing Bordeaux by HaNd

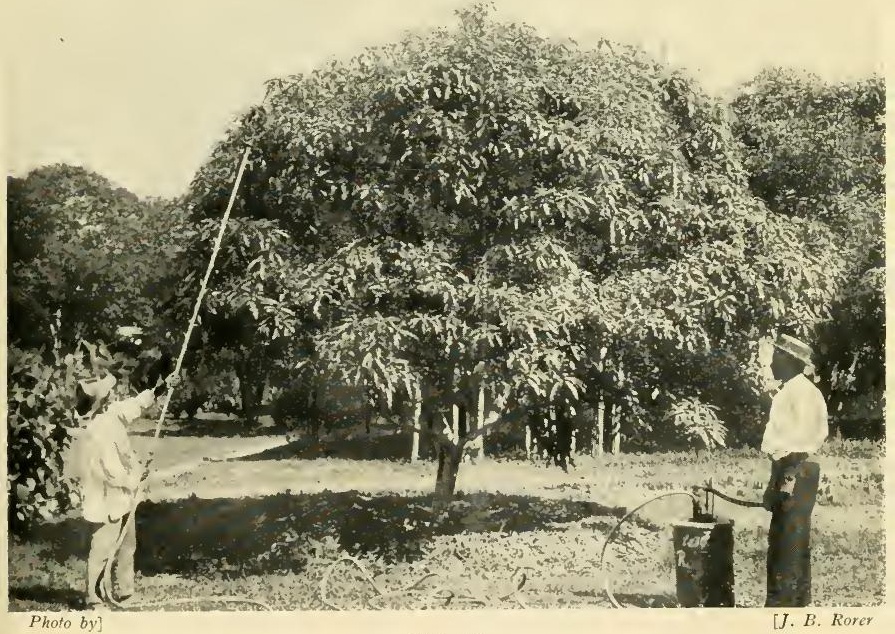

Fig. 27

Sprafing Mango with SPRanotor Pump Mounted on 20-Gallon Oil Drua 



\section{Physical properties.}

The physical properties of Bordeaux mixture are all-important, since on the nature of the precipitate depends the adhesion of the spray. In the freshly made mixture this should be flocculent or gelatinous in appearance, light blue in colour, settling very slowly when allowed to stand. In a few hours the sediment becomes more crystalline, settles quickly after shaking, and has lost its power of adhesion when dried. This is the reason for the customary warning to use only the freshly made mixture. The flocculence of the precipitate can however be preserved to some extent by adding skimmed or whole milk at the rate of $\frac{1}{4}$ pint $(5 \mathrm{oz}$.) to the gallon, which also greatly increases adhesion.

The nature of the precipitate originally formed depends to a large extent on the method of preparation. The mixing of strong solutions of copper sulphate and lime gives a very heavy sediment, and should be avoided. The ordinary way is to dissolve the copper in one half of the water, mix the milk of lime with the other half, and then run the two together. This gives a satisfactory result, is normally the most convenient, and is least likely to go wrong in unskilled hands. It is quite possible to get good results, and under some circumstances with more convenience, by mixing one constituent with about fivesixths of the water and adding the other with the rest. The best result of all, according to $\mathrm{O}$. Butler, is obtained from the addition of weak copper solution to strong milk of lime. Should strong milk of lime be added to weak copper or strong copper to weak lime, it is essential that the liquid should be thoroughly agitated during mixing.

Solutions of copper sulphate must not be brought into contact with metal vessels. For milk of lime this does not matter. The prepared mixture can be contained in galvanised receptacles provided it does not stand more than a few hours. When only one wooden tub is available it may be used to contain the copper sulphate and most of the water, the lime being added from a bucket with vigorous agitation, or if the method of strong copper to weak lime is adopted (which is less desirable) it is only necessary to have a bucket made of wood, in which to dissolve the copper, pouring the solution into the middle of the large receptacle containing the lime and water and stirring vigorously.

The most satisfactory addition to Bordeaux mixture for increasing its adhesion, valuable where sprayed foliage is exposed to tropical rain, is resin soap. This is prepared by boiling $2 \mathrm{lb}$. of resin with I lb. of washing soda in I gallon of water until the mixture is clear, and adding this quantity to 25-30 gallons of Bordeaux as found necessary for the purpose in hand. This also improves the wetting and covering power of the mixture on such leaves as resist in these respects the ordinary type of wash. It is possible that a weak Bordeaux with this addition may be found to be as effective as a strong one without it. 
For insecticidal purposes lead arsenate paste I-2 ounces to the gallon (or powder $\frac{1}{2}$-I ounce), or Paris green I ounce to 7 gallons (added to the milk of lime before mixing), as stomach poisons, or Black-leaf 40 (nicotine sulphate) I ounce to $4^{-6}$ gallons or I teaspoonful to the gallon, as a contact poison, are frequently added to Bordeaux mixture.

G. E. Sanders and A. Kelsall have worked out a method of combining white arsenic, which is relatively cheap, with Bordeaux mixture. One pound of superfine white arsenic (which should pass through a screen of 250 meshes to the inch), mixed with one pound of dry hydrated lime, is first added to each Io gallons of the water used in preparing the usual ro per cent. stock solution of copper sulphate. The latter, thoroughly stirred before dilution, is then used in the ordinary way.

\section{Preparation.}

The standard method for making the usual alkaline Bordeaux mixture will now be described. The proportions are indicated in the following table:-

\begin{tabular}{c|c|c|c|c}
\hline Class & Per cent. & $\begin{array}{c}\text { Bluestone } \\
\text { lb. }\end{array}$ & $\begin{array}{c}\text { Stone lime } \\
\text { lb. }\end{array}$ & $\begin{array}{c}\text { Water } \\
\text { gallons. }\end{array}$ \\
\hline Strong & 2 & Io & $5-$ Io & 50 \\
Ordinary & $\mathrm{I}$ & 5 & 5 & 50 \\
Mild & 0.8 & 4 & 4 & 50 \\
Weak & 0.5 & $2 \frac{1}{2}$ & $2 \frac{1}{2}$ & 50 \\
Paste & & $\mathrm{I}$ & 2 & $\mathrm{I} \frac{1}{2}-2$ \\
\hline
\end{tabular}

It is usual to have two tubs each holding 25 gallons and one barrel holding 50 gallons. The copper sulphate is dissolved in 25 gallons of water in one tub. When left standing it dissolves best if it is suspended near the surface tied up in a piece of sacking. The lime is slaked in a bucket by adding water a little at a time and at intervals of 5-Io minutes until it heats, swells up, and crumbles, after which water can be added freely. Time and trouble can be saved with some limes by using hot water. The resulting milk of lime is turned into the second tub and made up to 25 gallons. The contents of the tubs are now run together at the same rate into the barrel, or baled out bucket for bucket. The mixture is then ready for use, and the more quickly it is used the better. If required, the preservatives, adhesives or insecticides previously described can now be added. In filling sprayers the mixture should always be passed through a strainer of fine copper or brass gauze.

When Bordeaux mixture is needed from time to time, it is convenient to prepare stock solutions of each material. These are usually of Io per cent. strength, I lb. of copper sulphate to each gallon of water in the one case, and I lb. of lime to the 


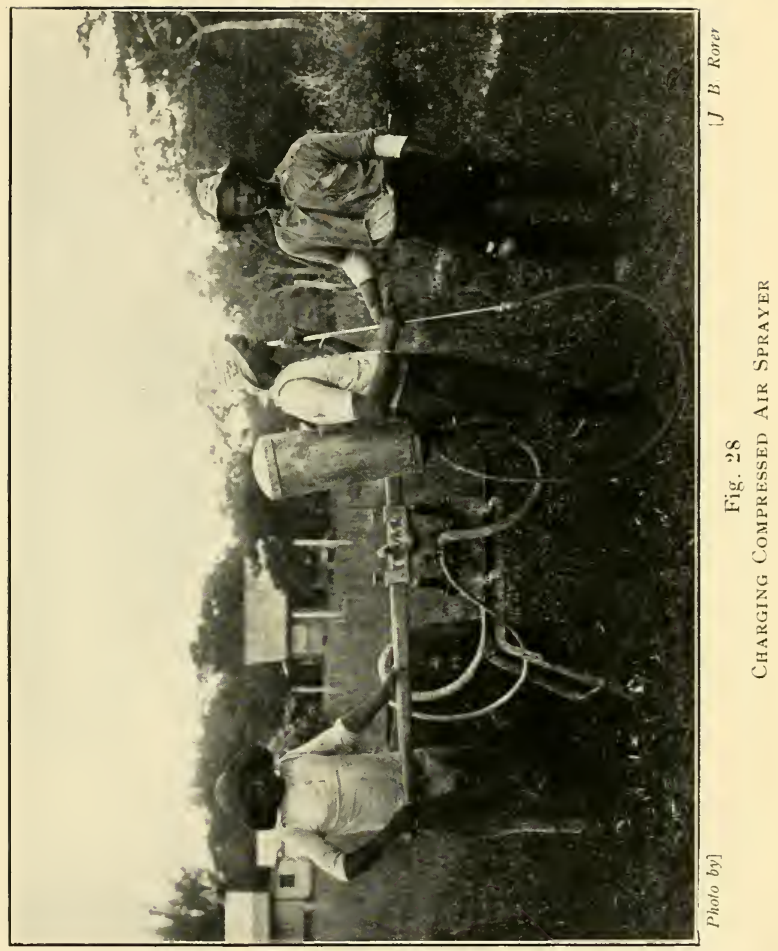



gallon, previously slaked as directed with part of the water, in the other. To make I per cent. mixture an equal quantity of each is separately diluted by the addition of four times as much water, and the two lots then mixed as before, so that to make 50 gallons of mixture, 5 gallons of copper stock solution is mixed with 20 gallons of water, and 5 gallons of lime stock solution with the like amount. The stock solutions may, if desired, be made up at double the strength given above. They keep well if covered, but if evaporation has taken place should be made up with water to the previous level.

Where water at the required level is available, it is an advantage to have the stock solutions and dilution barrels on a raised platform, so that the solutions can be run by gravity into the mixing barrel, and if this is also raised the mixture can be again run into the sprayers.

\section{Testing.}

When the indicated amount of good lime has been used the mixture cannot contain unaltered copper sulphate, but to guard against mistakes, and when the quality of the lime is uncertain, it is advisable to test the mixture. There are three ways of doing this :-

(I) A fresh solution of potassium ferrocyanide is prepared by dissolving a crystal of this substance in a few spoonfuls of water. A piece of white blotting paper is moistened with the Bordeaux, or a little is poured into a white plate, and a drop or two of the testing solution added. A brown discoloration indicates that more milk of lime is required.

(2) A piece of blue litmus paper is dipped into the mixture. If it turns red, add more milk of lime.

(3) A bright iron nail (avoid steel) is allowed to stand for some minutes in a little of the mixture. If a black deposit or a coating of metallic copper is formed on the nail, add more milk of lime.

\section{Bordeaux Paste.}

The thick creamy compound known as Bordeaux paste is used for application to bark or exposed wood, or for any similar purpose in which a temporary paint protective against fungus infection is required. It is prepared by dissolving $\mathrm{I} l \mathrm{lb}$. of copper sulphate in I gallon of water (or using I gallon of ro per cent. stock solution) and separately slaking $2 \mathrm{lb}$. of lime in $\frac{1}{2}$ gallon of water. When the latter is cooled the two are stirred together. The addition of milk ( $I$ pint or more to the gallon) or sugar (4 ounces to the gallon) greatly improves its keeping qualities.

\section{Preparation.}

\section{Burgundy Mixture.}

A mixture which closely resembles Bordeaux and is regarded as interchangeable with it in use is prepared in a similar way 
but with ordinary washing soda (crystallized sodium carbonate) substituted for the lime, using I t times the quantity. The formulæ for various strengths are given in the following table :-

\begin{tabular}{cr|c|c|c|c}
\hline Class & Per cent. & $\begin{array}{c}\text { Bluestone } \\
\text { lb. }\end{array}$ & $\begin{array}{c}\text { Soda } \\
\text { lb. }\end{array}$ & $\begin{array}{c}\text { Water } \\
\text { gallons. }\end{array}$ \\
\hline Strong & $\ldots$ & 2 & 8 & Io & 40 \\
Ordinary... & $\mathrm{I}$ & 4 & 5 & 40 \\
Mild & $\ldots .$. & 0.8 & 4 & 5 & 50 \\
Weak & $\ldots$ & 0.5 & 2 & $2 \frac{1}{2}$ & 40 \\
Very weak & 0.4 & 2 & $2 \frac{1}{2}$ & 50 \\
Paste & $\ldots$ & & 2 & $2 \frac{1}{2}$ & 2 \\
\hline
\end{tabular}

The 0.8 strength has been found by S. C. Harland to be the maximum that can be applied to Sea Island cotton without severe injury, and, according to E. J. Butler, the 0.4 mixture is popular in some parts of France and Germany for spraying vines. The addition of milk, $\frac{1}{4}$ pint $(5 \mathrm{oz}$.) to the gallon preserves and increases the adhesion of the precipitate, or resin soap can be added to increase adhesion as with Bordeaux.

Burgundy mixture can be prepared by the ordinary Bordeaux method of mixing equal amounts of the total water, one containing the copper and the other the soda. It may also be conveniently prepared by dissolving the copper in seven-eighths of the water, and using the remaining one-eighth (as many pints as there are to be gallons of mixture) to dissolve the soda. The latter solution may be made in a bucket or a kerosene tin, the copper solution being then stirred vigorously and the soda solution steadily poured into it. The colder the solutions, the better the precipitate. The mixture should be used fresh unless a preservative has been added. Burgundy paste is prepared in a similar way to Bordeaux paste, and should if possible have milk added.

Stock solution of copper can be used as for making Bordeaux, but it is better to keep the soda in solid form.

\section{Testing.}

There is less need to test Burgundy than Bordeaux, provided the soda is of good quality and the weighing accurate. The soda should be crystalline, without much white powder.

The test is best made with litmus paper, adding more soda if blue litmus is turned red, and more copper solution if the turning of red litmus blue shows that the mixture is more than mildly alkaline. The results of the ferrocyanide test and the iron test do not afford an index to the safety of Burgundy mixture.

\section{Advantages.}

Where spraying is done on a large scale and lime can be 
obtained, there is no particular advantage in substituting Burgundy for Bordeaux mixture, and the latter will usually be the cheaper. But where good lime is not available the use of soda is necessary, and when only a small quantity of mixture is required at a time it is much more convenient. Weighed quantities to make I gallon ( $\mathrm{I} \frac{1}{2} \mathrm{oz}$. copper sulphate and $2 \mathrm{oz}$. soda) can be kept in separate small bottles and made up as required with very little trouble.

Burgundy mixture is less likely than Bordeaux to contain particles which will clog the nozzles of sprayers.

\section{Copper Sulphate Wash.}

At a strength of 3 lb. to 40 gallons of water copper sulphate is sometimes used as a bark wash or disinfectant. It cannot be applied to leaves or to tender tissues of any description.

\section{Cuprammonium Washes.}

The Cuprammonium washes, made by dissolving copper or one of its compounds in ammonia water have no advantages, and some disadvantages, as compared with Bordeaux mixture for the purpose for which the latter is ordinarily used, i.e., prevention of the germination of spores. They have, however, retained an application to cases (I) where the visibility of the deposit left by Bordeaux spraying is objected to as unsightly ; (2) where direct effect on a developed fungus is required. The results of a comparison are summed up by O. Butler to the effect that the cuprammonium washes are more effective than Bordeaux mixture when large amounts of soluble copper are required to give protection, less effective when small amounts suffice. These fungicides have the practical disadvantage in hot climates that strong ammonia is difficult to keep and dangerous to handle. It should be diluted with 5 times its volume of water as soon as it is obtained.

The original eau celeste (cuprammonium sulphate) is made by adding ammonia to a solution of copper sulphate. Modified eau celeste (cuprammonium hydrate) may be made by adding ammonia to Burgundy mixture until the precipitate is dissolved. The method of preparing cuprammonium hydrate usually recommended is by dissolving commercial copper carbonate in ammonia according to the formula :-

$$
\begin{array}{lllll}
\text { Copper carbonate } & \ldots & \ldots & 5 \text { ounces. } \\
\text { Strong ammonia } & \ldots & \ldots & 3 \text { pints. } \\
\text { Water } & \ldots & \ldots & \ldots & 40 \text { gallons. }
\end{array}
$$

The ammonia is diluted with I gallon of water, and the copper carbonate, previously made into a paste with a little water, is 
slowly mixed in, stirring all the time. The remaining water is then added. The solution does not keep well, and should be used fresh.

According to O. Butler the amount of ammonia indicated is insufficient, and should be increased to I $\frac{1}{2}$ pints to each ounce of copper carbonate, a stable stock solution being prepared according to the formula :-

$\begin{array}{lcccc}\text { Copper carbonate } & \ldots & \ldots & \text { I ounce. } \\ \text { Strong ammonia } & \ldots & \ldots & \text { I } \frac{1}{2} \text { pints. } \\ \text { Water } & \ldots & \ldots & \ldots & \text { I pint. }\end{array}$

adding water at the rate of 3 gallons to each pint of stock solution when required for use.

Probably the method which will be found to be in many respects the most convenient is that of dissolving the precipitate of Burgundy mixture by adding sufficient ammonia. According to O. Butler the product compares very favourably in efficiency and cheapness with the ammoniacal solution of copper carbonate made according to the ordinary formula.

\section{Sulphur Fungicides.}

\section{Sulphur.}

Finely divided sulphur is a valuable fungicide for use when action on exposed mycelium is required, as in the case of the powdery mildews (Erysiphaceæ). It is applied direct in the form of dust, or is deposited from liquid sprays.

The dry material has two commercial forms, powdered sulphur or sulphur flour, obtained by grinding, and sublimated sulphur or " flowers of sulphur" deposited from sulphur vapour. The most satisfactory and economical is that which is most finely divided, and both forms vary considerably in this respect. Examination under a lens or sifting through fine gauze enables comparisons of quality to be made.

The fungicidal action of sulphur depends on fumes of uncertain composition which are given off under the influence of the sun's heat. Its effects are therefore obtained to the fullest extent in warm dry weather. Rain and high winds should as far as possible be avoided, and where this cannot be done, lime-sulphur solution should be used. The applications are most effective in the early stages of development of the fungus. The mixture of an equal quantity of powdered lime with the sulphur, often recommended, was found by $\mathrm{F}$. M. Blodget to neutralize to a very considerable extent its fungicidal action.

\section{Lime-Sulphur Solution.}

Lime-sulphur solution may be used to replace sulphur where an adhesive spray is preferred to a powder. It has a special 
use as a substitute for Bordeaux mixture where the effect of the latter in protecting scale-insects is a disadvantage (often the case with citrus trees), and in concentrated form it has a powerful and sometimes very valuable effect in keeping the bark of trees clear of moss and other surface growths.

Stock solution is prepared according to the following formula : Best stone lime (about 95 per cent.) $50 \mathrm{lb}$. Flowers or flour of sulphur .. roo $\mathrm{lb}$.

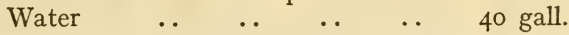

An iron vessel must be used for the boiling, and must be of sufficient size to contain the large amount of froth formed in the early stages. About half the water is first made hot, the lime added, then the sulphur, with vigorous stirring until both are well mixed, and then the rest of the water. The fire should not be allowed to get fierce, and splashes on hands or clothing must be avoided. Either about 3 gallons of extra water should be added at the beginning, or the water lost in boiling should be replaced from time to time, preferably by hot water, so that the level when boiling is complete is near 42 gallons hot or 40 cold, as shown by a measuring stick or mark previously prepared. The volume at boiling point may be taken as 1.05 of the volume cold. Actual boiling should continue for 45 minutes; long boiling reduces the amount of sulphur in solution. A steam jet may be used for boiling, in which case no extra water is required. The sediment should be strained out before storage, using 30-50 mesh brass or tinned iron (not copper) gauze.

If the available boiler is small, half the water may be kept back until boiling is complete, but the resulting solution is not quite so good. If preferred the lime and sulphur may be placed in the boiler and well mixed with half the water before heating, and the remaining half added a little later.

The stock solution will keep well if not exposed to air. It may be stored, after being well mixed to secure even distribution of the sludge, in full stone jars or bottles kept closed down, or in barrels if covered with a layer of mineral oil (kerosene or preferably lubricating oil).

For use as a spray the solution thus prepared, after straining, needs dilution at the rate of about 20 gallons of water to I gallon for resistant foliage, 30-40 to I for more tender leaves. To avoid the danger of scorching foliage, the strength may be controlled by means of a hydrometer, the diluted spray being used at strengths of approximately $\mathrm{I}_{2}^{\frac{1}{2}}{ }^{\circ}$ Baumé for resistant and $\mathrm{I}^{\circ}$ or $0.7^{\circ}$ Baumé for more tender foliage. The correct strength for the work in hand must be determined by experiment.

The new Baumé scale is used in the following dilution table, but hydrometers graduated on the old scale may be used without affecting the results to a significant extent. 


\begin{tabular}{|c|c|c|c|c|}
\hline \multicolumn{2}{|c|}{ Stock Solution } & \multicolumn{3}{|c|}{ Gallons of Water to Each Gallon of Stock. } \\
\hline $\begin{array}{l}\text { Spec. } \\
\text { gravity }\end{array}$ & $\mathrm{B}^{\circ}$ & $\begin{array}{l}\text { Sp. Gr. I. or I } \\
\text { Baumé I. } 5^{\circ}\end{array}$ & $\begin{array}{l}\text { Sp. Gr. I. } 007 \\
\text { Baumé r. } 0^{\circ}\end{array}$ & $\begin{array}{l}\text { Sp. Gr. I. } 005 \\
\text { Baumé } 0.7^{\circ}\end{array}$ \\
\hline $\mathrm{I} .2 \mathrm{IO}$ & 25 & I8 & 29 & $4 I$ \\
\hline $\mathrm{I} .2 \mathrm{I} 5$ & 26 & I9 & 30 & 42 \\
\hline $\mathrm{I} .225$ & 27 & 20 & $3 I$ & 44 \\
\hline $\mathrm{I} .236$ & 28 & $2 \mathrm{I}$ & 33 & 46 \\
\hline 1.246 & 29 & 22 & 34 & 48 \\
\hline I.257 & 30 & 23 & 36 & $5 \mathrm{I}$ \\
\hline I. 268 & $3 I$ & 24 & 37 & 53 \\
\hline I. 279 & 32 & 25 & 39 & 55 \\
\hline I. 290 & 33 & 26 & $4 I$ & 57 \\
\hline I.30I & 34 & 27 & 42 & 59 \\
\hline I. 313 & 35 & 28 & 44 & 62 \\
\hline
\end{tabular}

For use as a bark wash the stock solution is diluted at the rate of I gallon to 7 -Io gallons of water. Arsenate of lead may be added to lime-sulphur sprays, I-2 OZ. of paste or $\frac{1}{2}-\mathbf{I} \mathrm{OZ}$. of powder to the gallon, and increases the fungicidal value as well as acting as a poison for biting insects. Paris green cannot be used with lime-sulphur.

Lime-sulphur solution has a strong caustic action, and contact with skin or clothes should be avoided. Copper vessels should on no account be used in its preparation or application. This includes copper spraying machines, which suffer rapid deterioration. Tinned or galvanised receptacles may be employed. The spraying outfit should be well washed out after use.

\section{Self-Boiled Lime-Sulphur.}

This is a rather weak fungicide which is safer than Bordeaux or boiled lime-sulphur on tender leaves or flowers. In its preparation the slaking of the lime is used to supply the necessary heat. About Io lb. of best stone lime is placed in a barrel; an amount of water nearly sufficient to cover the lime is added, and, as slaking begins, $8 \mathrm{lb}$. of sulphur, carefully freed from lumps, is well stirred in; the barrel is then covered to keep in the heat and the mixture allowed to stand with occasional stirring for not more than IO-I5 minutes. When the action is judged to be complete more water is added and well stirred, and the quantity of wash brought up to 40 gallons. The mixture should have the coarser particles of lime strained out, but the finer sediment should be well worked through the strainer. As the sediment settles quickly good agitation is needed in the sprayer. The mixture can be used as a basis for an iron sulphide spray (see below).

Since different limes vary greatly in their heat of slaking exact instructions cannot be given for the time of cooking. 


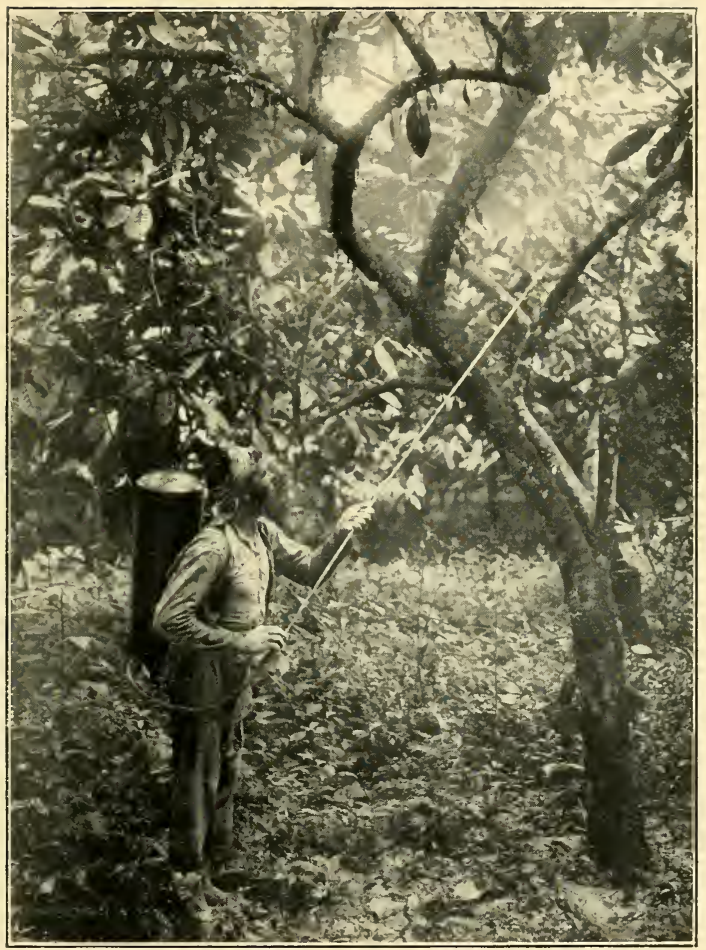

Photo by]

Fig. 29

$[J$. B. Rorer

Compressed Air Sprayer in Action 

Some lime is so sluggish that it is necessary to use hot water to start the process and difficult to raise enough heat to complete it, while with hot limes care has to be taken to stop the cooking by adding cold water to prevent the sulphur going into solution.

\section{Liver of Sulphur.}

Liver of Sulphur has been used in gardening practice for spraying against mildews and in cases where the deposits left on fruit or foliage by other fungicides have to be avoided. The name in its stricter sense is applied to potassium sulphide, but the commercial substance is a mixture of several compounds. Its fungicidal value depends on its content of sulphides, which varies greatly in different samples. Exposed to air its colour turns from liver brown to greenish yellow, and eventually to grey, and its value is lost. It should be stored in well-sealed tins or bottles, which must be kept full. It is applied at a strength of I oz. to 2-3 gallons of water, but owing to the uncertainty of its composition, and its tendency to burn when used at really fungicidal strengths, its use is not to be recommended.

\section{Ammonium Sulphide.}

This compound has recently been brought forward as a much more efficient and less injurious fungicide for use against mildews than liver of sulphur. Its preparation can only be undertaken in a chemical laboratory, so that the purchase of commercial stock solution is necessary. Except for ripening fruit or ornamental plants it has no advantage over lime-sulphur.

\section{Iron Sulphide.}

This is recommended as a good fungicide non-injurious to fruit. A self-boiled lime-sulphur mixture (see above) is prepared with Io $\mathrm{lb}$. of lime and Io $\mathrm{lb}$. of sulphur to 34 gallons of water, and $3 \mathrm{lb}$. of iron sulphate (copperas) dissolved in 6 gallons of water is added. This gives a black spray.

\section{Potassium Permanganate.}

A solution of this substance in water is effective against surface mycelium and some spores. It is convenient for use in small quantities on garden plants. J. J. Taubenhaus found that sweet peas could be sprayed with solutions up to 3 per cent. without injury, and that 0.5 per cent. strength was effective against anthracnose. To prepare a I per cent. solution dissolve I ounce in 5 pints of water ; 2 ounces of soap may be added if found advantageous to increase the wetting properties. Potassium permanganate may be added to Bordeaux mixture with a view to increasing the effect against exposed mycelium.

Spraying.

Successful and economical spraying depends on the application of the fluid in such a manner that after drying a thin and even deposit is left on the leaves or other parts of the plant. This can only be secured by a fine mist-like discharge carefully 
distributed, and this in turn depends on the form of nozzle and the amount of pressure applied.

Spraying machines range from power outfits with petrol engines, through various forms of hand-operated tank or barrel pumps, to knapsack types and hand-syringes. In the choice of a type the nature of the ground to be worked over and the spacing and height of the plants are first considerations. There are few local crops to which power or traction sprayers can be adapted. The most practical is usually some kind of wheeled tank with a hand-pump attached, and, according to the power of the pump, one or two 50-feet lengths of hose. Additional wheeled tanks of convenient form may be used to keep the sprayers supplied with fluid.

Knapsack sprayers of the ordinary type require in the tropics more than ordinary endurance on the part of the carrier to maintain a satisfactory pressure. The compressed-air type, consisting of tanks charged by a separate pump, is the best for use in situations out of the reach of wheeled tanks, and may be used by climbers for spraying coconut trees. The Abol type of syringe is very useful for small spraying jobs in gardens.

The mist-like discharge required for good spraying will not carry far, consequently the nozzles have to be raised to nearly the height of trees to be sprayed by means of bamboo rods, which can be used up to about ro feet in length.

The aim in spraying should be thoroughly to cover the plant, while keeping the drip from the leaves to a minimum. The quality of the work can only be judged after the spray is dry. and expertness is only to be acquired by practice.

Spray injury.

Damage to foliage from Bordeaux mixture is notoriously erratic. It is agreed that the scorching effect which may develop from properly prepared mixture depends a good deal on the weather, being often increased by dull humid conditions. The susceptibility is greater when the leaves are young and when they are approaching senescence, and may be much increased by insect injuries which in themselves are little noticeable. Different varieties of the same plant species ofter show great differences in susceptibility. There is little information on the subject with regard to tropical plants and conditions. Un cotton the effect of too strong an application is the shedding of the incipient flower buds

Lime sulphur injury is less dependent on external conditions, and may be met by reducing strength or in extreme cases by the use of the self-boiled wash.

Both copper and sulphur sprays often show a distinct tonic effect on vegetation apart from their fungicidal action.

Dusting.

The application of fungicides in the form of dust has been 
practically confined to sulphur, to mixtures of sulphur and lime, and of sulphur with Io per cent. of dry arsenate of lead. Recently dry Bordeaux powders have been placed on the market and are coming into favour, but it is difficult to foresee a future for them in places liable to tropical showers. There are various types of dusting machine to be obtained, the best of which, short of power or traction outfits, are certain types with handoperated fans. For garden purposes sulphur may be sifted out from a cotton bag.

\section{Disinfectants.}

The principal use of disinfectants in plant pathology is for the treatment of seeds ; they also have an application to certain other forms of planting material, to the stems and branches of trees, to wounds and, to a very limited extent, to the soil.

Disinfection of Seed.

In a number of diseases the disinfection of seed affords the best opportunity of eliminating a parasitic organism or of reducing its prevalence in the resulting crop. It is of particular value with new introductions, and in planting short-term crops after rotation or a close season.

As a general rule disinfection only extends to spores or other material adhering externally, but in the case of certain smuts it is possible to destroy internal mycelium by means of heat.

There is no universally applicable method of seed disinfection. There are such marked differences in the susceptibility to poisons of seeds on the one hand and parasites on the other that a treatment which is successful in one case may entirely fail in another. There are spores, for example, which can germinate in strong Bordeaux mixture and others which can withstand immersion for a considerable time in I per cent. copper sulphate solution. Difficulties are experienced in securing the wetting of certain kinds of seeds, as for example cotton seed, which is difficult to free from the air entangled in the fuzz.

\section{Corrosive Sublimate.}

Mercuric chloride, or corrosive sublimate, has a wide range of effectiveness. It is used in solution in water, most usually at a strength of one part in a thousand ( $\mathrm{I} \mathrm{oz}$. to $6 \frac{1}{4}$ gallons). It has been used on a considerable scale for soaking cotton seed, but the method is subject to the disability mentioned above unless the seed has been delinted with sulphuric acid or wetted with alcohol, measures only applicable on a small scale. The effects of mercuric chloride are liable to be neutralized by the presence of organic substances of an albuminous nature, and it is inadvisable to use the same lot of solution more than once. It is desirable to wash seeds after treatment.

The solution is often recommended for use as a disinfectant on newly exposed wood of trees, preparatory to a more permanent coating of a preservative paint. 
Mercuric chloride must always be treated with the caution due to an exceedingly powerful poison. Metal vessels should not be used to contain the solution.

\section{Formalin.}

Formalin is the name given to a solution of formaldehyde gas in water, containing, when at full strength, 40 per cent. of the gas. It gives off a vapour which irritates the eyes and throat. Both the solution and the gas are very powerful disinfectants, and are only limited in application by the susceptibility of some seeds and other treated material to injury. They afford the most generally satisfactory means of disinfection.

In the disinfection of seeds formalin is used at strengths of 2 to 0.25 per cent. of the commercial liquid, according to the time of exposure. For prolonged treatment, as of potatoes for scab, or grain for smut, strengths of 0.4 to 0.25 per cent. are used, the thoroughly wetted material being covered up for about two hours. In using the 2 per cent. solution seed is soaked for I5 to 45 minutes according to susceptibility. In some cases better results are obtained by long exposure to weak solutions, in others the reverse. A I per cent. solution of formalin contains I oz. of formalin in 5 pints, and from this the other strengths can easily be calculated.

Certain kinds of seeds cannot be safely treated with liquids, and others are very difficult to wet thoroughly. These difficulties can be overcome by the use of formaldehyde vapour, which is in general less injurious and more effective than the liquid treatment. An apparatus has recently been described which is suitable for use where there is regular need for disinfection of a large variety of seeds. It consists of an arrangement for passing steam, mixed with atomized formalin, into a galvanized iron can with perforated shelves. I0-20 ounces of formalin per $\mathrm{I}, \mathrm{ooo}$ cubic feet, allowed to act for 2 hours, is about the average quantity required.

The method of generating the gas commonly used is that of pouring formalin over potassium permanganate crystals at the rate of I imperial pint to 9 ounces. The crystals should be placed at the bottom of a large bucket (for quantities up to 3 pints) and this placed on a tray of some kind, as the mixture foams vigorously. The fumigatorium should be ready for immediate closing when the formalin has been added, or an arrangement should be made for the release of the liquid after closing.

The above method is also applicable to the fumigation of fruit previous to storage, and has been used with success for pineapples.

For the disinfection of the soil of seed beds, formalin of 0.5 per cent. strength, at the rate of about three quarters of a gallon to the square foot of prepared bed, is distributed with a wateringpot as fast as the soil will take it up. The beds are then covered with bags or tarpaulins for a day or so to keep in the fumes, and are aired for a week before sowing. 
Formalin has lately been found to have some application as a spray. E. Levin reports highly successful control of bacterial soft rot of lettuce obtained by spraying diseased plants with 0.4 formalin ( $\mathrm{I} \mathrm{oz}$. to I $2 \frac{1}{2}$ pints), while the addition of formalin to Bordeaux mixture was at one time claimed to have given promising results in the control of citrus canker in the Philippines.

\section{Sulphuric Acid.}

Treatment of seeds with concentrated sulphuric acid is a means of disinfection particularly valuable in some instances, as with cotton seed, and with most kinds, so far from being injurious, hastens and increases germination if carried out for the right length of time. The seed to be treated is well stirred in a glass or stone jar with a quantity of undiluted acid sufficient to cover it and to give freedom of movement. The commercial grade of acid is suitable. After I 5 to 45 minutes' soaking (according to the resistance of the seed to injury) the contents of the jar are poured through a strainer of wire gauze and the seed then washed in a liberal amount, preferably a stream, of water. It may be sown at once or dried. This method is recommended to be used for cotton seed whenever possible, as it clears away all the lint and fuzz.

\section{Copper Sulphate.}

One or two per cent. solutions of copper sulphate ( $\mathrm{I}-2 \mathrm{lb}$. to 5 gallons) are used for the disinfection of seeds, especially of grain for smuts. Preferably the grain is immersed in a barrel of the solution, the floating matter skimmed off, and then the seed quickly dried and sown. Another method is to sprinkle a heap of seed with the solution, turning and mixing until all is wetted, then drying. If the seed is treated with weak milk of lime after the copper solution there is less resulting injury.

\section{Bleaching Powder.}

The so-called chloride of lime or bleaching powder has recently been recommended as very effective for disinfecting some kinds of seeds. The method of preparation advised by J. K. Wilson is as follows :- "Io grams of commercial chloride of lime (titrating 28 per cent. chlorine) is mixed with I $40 \mathrm{cc}$. of water, ( $5 \mathrm{oz}$. to $3 \frac{1}{2}$ pints). The mixture is then allowed to settle for five or ten minutes and the supernatant liquid decanted off or filtered. The solution or filtrate, which contains about 2 per cent. chlorine, is used as the disinfectant. The volume of the solution employed should be about five times or more the volume of the seed." The permissible period of exposure must be learnt by experiment for each kind of seed. Washing is not necessary.

Bleaching powder has recently been mentioned as a disinfectant for soil.

$$
\text { Eau de Javelle. }
$$

Recent experiments by Duggar and Davis indicate that commercial Javelle water (chlorinated potash), diluted I in Io and used for soaking seeds for 3 hours or upwards, may prove an exceedingly effective means of seed sterilisation. 


\section{CHAPTER XI}

\section{WOOD-ROTS : THE TREATMENT OF TREES}

\section{Structure.}

For the purpose of this section a tree or shrub (excepting coconut and other palms) may be regarded as a more or less inert framework of wood, composing the root, stem, and branch systems, over which is stretched in a thin layer the active living substance of the tree. The woody tissue, once it is matured, contains relatively few living elements, and is capable of no further growth. The wood functions as mechanical support and for the passage of the soil solution from the roots which absorb it to the leaves which discharge its surplus water. In some species only the outer layers of the stem (sapwood) are concerned in conduction, the remainder, the heartwood, being quite lifeless, in other species all the wood continues to function to some extent.

Outside the wood lies what is popularly known as the bark, which consists of (I) the inner living layers, the bast, and (2) the outer dead layers of cork, the bark proper. An important function of the bast is the transference of the food materials elaborated in the leaves, including the supply of the necessary nourishment to the roots. The bark is protective in its functions, as will be noted later. Between the wood and the bast is an extremely thin layer of delicate actively dividing tissue : the cambium layer. From this the growth in thickness of all the permanent parts of the tree proceeds. From its inner face continuous new layers of wood are deposited on the old, and from its outer face new layers are added to the bast.

Increase in length of any woody organ takes place only by additions to its outer end, and these are made at intervals by the outgrowth of buds into new leafy shoots.

\section{Wood-rots.}

It will be readily understood, from what has been previously said of resistance, that the wood, with its relatively few living elements in the sapwood and none in the heartwood, will be susceptible to the attacks of fungi. There is in fact a very large number of fungi which specialise in wood destruction, many of them saprophytes, infesting dead wood with effects universally familiar, others with various grades of ability to attack the wood of living trees.

When a tree is intact the wood is completely enclosed, first by the outer bark, which is impervious to water, and even to air except through the special breathing organs (lenticels), and is 
difficult tor fungus hyphæ to penetrate; secondly by the bast, largely made up of active living tissue, and thus resistant to any but specially adapted parasites. In very many cases, therefore, the fungi attacking the wood of living trees are perforce wound

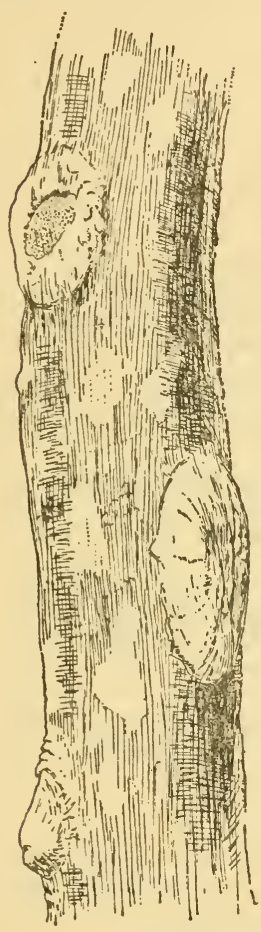

Drawn by W. Buthn

Fig. 30 HEALING OF PRUNING WOUNDS (MANDARIN ORANGE)

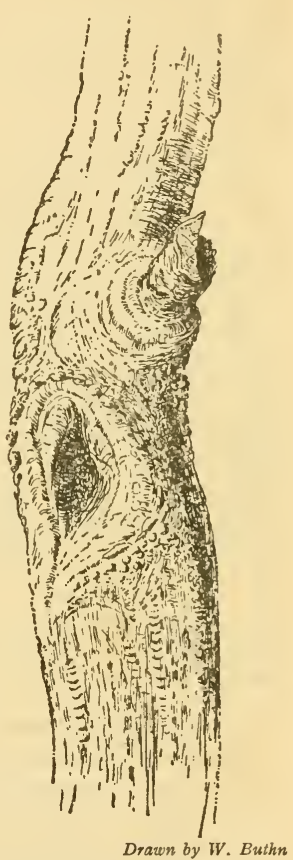

Fig. 31 EFFECTS OF BAD Pruning (CACAo)

parasites, able to make an entry only when the outer envelopes are broken.

The Healing of Wounds.

When the outer wood is exposed, by the cutting or breaking of a branch or by the removal of a patch of bark, it has in itself 
no power to regenerate its covering, only the cambium can produce new material to cover it. The process can be followed on trees from which branches have been cleanly removed. From beneath the cut edges of the bark around the margin of the wound a lateral outgrowth of callus from the cambium creeps in to cover gradually the exposed wood. If the surface is smooth enough and the wood lasts long enough without rotting, this ingrowing callus meets and unites in a more or less central point or line, and restores the continuity of the cambium, so that new wood and new bark are formed over the wound. If on the other hand the exposed wood rots away, leaving a cavity, the foundation for this process is lacking, the callus curls round on itself at the margin of the wound, and an open passage is left to the interior of the tree.

When a branch is cut through or broken some distance from its base, there is a tendency, especially if the branch is situated low on the stem where it is in the shade of the leaves, for the stub so left to be thrown out of the circulation, so to speak, and die back to its base on the parent branch or stem. So long as the dead stub remains, the callus which forms around its base cannot cover its site. If it is left to rot away it usually leaves a cavity which is also difficult to heal.

If a vertical stem is cut through, the upward growth is usually taken on by a shoot or shoots arising below the cut, and a process of healing similar to that just described for a lateral wound begins.

If the new shoots arise close to the cut, so that no dead stump blocks the progress of the callus, the wound will cover, subject to the same condition as before, that the wood resists decay for a sufficient time. For thick stems the required time may be many years. Frequently in such a case the covering remains incomplete, the wood rots and the new stem or stems sooner or later break down owing to the incompleteness of their structure on the inner side.

\section{The Treatment of Wounds.}

On the facts thus outlined are based the principles of tree surgery, which are simple enough, but are commonly neglected. They may be stated as follows:-

I. When a branch is removed it should be cut close to the base and the resulting wound shaped into as close conformity with the form of the parent branch or stem as is possible without making the wound unduly large. The edges of a saw cut should be rounded off, especially the projecting lip usually left on the lower side.

2. The live bark should extend, cleanly cut and not bruised or torn, close up to the edge of the wound. If there is dead bark, it should be cut back until eliminated, and the wood shaped accordingly, 
3. If experience of the kind of tree, the vigour of its growth, and the size of the wound indicate the necessity, the wood should be treated with an antiseptic or a protective covering to preserve it until the wound has time to heal over.

4. If a cavity has formed from an old wound the rotten wood should be dug out, an antiseptic applied, and the cavity filled with cement to the level at which the callus is expected to extend over it.

It will be found that some species of trees heal wounds very much more readily than others, that young trees heal more quickly than old ones of the same species, and of course that some woods are very much more durable than others when exposed.

Wounds near the soil level are the worst to deal with, as the soil moisture greatly increases liability to infestation and rotting of the wood. Treatment of wounds about the collar and the crown roots should be accompanied by removal of the soil about them, and also of sheltering weeds or low branches. In humid localities where moss accumulates the bark should be scoured by spraying or swabbing with lime-sulphur or some other detergent.

The treatment of canker, gummosis, and bark rots generally, consists of cutting back to sound bark, the scraping of the wood, and the application of a preservative to the latter. The practice of gouging out the underlying discoloured wood has to the writer's mind little to commend it. Though fungus hyphæ may be present, the drying out of the wood, its impregnation with an antiseptic or the exclusion of air by a protecting coating, whichever is mosí appropriate to the particular case, is likely to be quite as effective.

Antiseptics.

The antiseptic most in favour at present is o.I per cent. corrosive sublimate solution (see page 99). Its effects are evanescent and are liable to be interfered with by substances present about the wound. Applied to the surface of wounds just previous to the application of a protective paint or filling it may be expected to have a certain amount of usefulness in destroying spores or mycelium already present. There have been grades of carbolineum specially prepared so as not to be injurious to bark, and if a reliable brand could be obtained this material should in many cases be the most satisfactory to use. Bordeaux and Burgundy pastes are to some extent in use as temporary antiseptics.

The covering of a wound with a good waterproof coating is in itself sufficient to alter the conditions to the disadvantage of some kinds of wood-infesting fungi.

Protective paints.

Numerous substances are or have been in use for covering 
exposed wood until the healing process has time to complete itself. What is desired is a durable coating which does not readily crack, which has no ill effects on bark or callus, and preferably is to some extent antiseptic. Coal tar sometimes proves definitely objectionable on the second count ; the differences of experience in this matter probably arise from differences in composition of the material used. Resin-petroleum, prepared by dissolving 3 parts of resin in one part of warm crude petroleum, has been recommended. The simplest treatment, which in many cases has proved quite satisfactory, is the application at intervals of coats of white lead paint.

The writer has experimented with a paint which gives better results where protection is decidedly needed, as on soft and spongy woods, than any other which has been tried. It is prepared by heating over a slow fire until smooth $20 \mathrm{oz}$. of boiled linseed oil and $\mathrm{r} 2 \mathrm{oz}$. of Barbados manjak, a hard bright asphalt. Probably a preparation of manjak and crude petroleum would also be satisfactory.

On young and vigorous trees with durable wood, provided wounds are shaped to cover easily, and provided the conditions of shade and moisture are not extreme, there is commonly no need of any artificial protection, though in some localities consideration has further to be given to the habit of some species of ants in occupying exposed wood, especially Cremastogaster sp., the acrobat ant, which seems to attack the cambium and seriously delays the restoration of the bark. 


\section{CHAPTER XII}

\section{THE CONTROL OF DAMPING-OFF}

DAMPING-OFF is the term applied to the failure of seedlings due to their infection while in a tender state by certain soil-inhabiting fungi. The reason for the name is the association of the trouble with conditions of more or less excessive moisture, which favours the development of the parasite at the same time that it increases or prolongs the tenderness of the plants. Though not necessarily confined to seedlings crowded in boxes or seed beds, it is amongst such that the affection usually appears and, by progressive infection, is able to cause extensive losses.

The longer the soil of the seed-bed has been in use, and the more decaying animal or vegetable material it contains, the more likely it is to harbour fungi capable of causing damping-off. Heavy water-retaining soils are more favourable to the affection than those which are light and porous, and provision for rapid drainage is one of the most important precautions against it. Shade and shelter, by maintaining humidity, increase the tendency to it ; in these respects, as in the supplying of water, the conditions which may favour the seedlings favour the disease, and a mean has to be struck between slow growth and loss.

The trouble occasioned by damping-off in these islands is not so great as might be expected by an agriculturist accustomed to temperate countries, where warm, humid weather, such as is associated with ideas of the tropics, is greatly feared in this connection.

In the first place nearly all the staple food plants-sugarcane, bananas, tannias, dasheens, sweet potatoes, yams, cassava --are raised from cuttings of one sort or another, while cotton, corn and pulses, which are raised from seed, are planted, a few seeds together, in their permanent positions in the open ground. Of agricultural as distinct from garden crops, tobacco, onions, and limes, which are raised in seed-beds, have been the plants to suffer most in the West Indies from the affection under notice.

Merely reducing the density with which the seed is sown is often sufficient to avoid or reduce the damase by permitting increased ventilation, preventing the drawing up of the seedlings, and making the spread of infection more difficult. Further measures to this end are the use of sandy soil, of subsoil, or of a surface dressing of sand or fine gravel, and the choice of an open rather exposed situation for the seed-beds. The use of woodashes or lime is not to be recommended.

The one means so far discovered which can be relied upon to give satisfactory results under any reasonable conditions is the 
disinfection of the soil. For this there are two kinds of treatment available : by heat and by chemicals. Primitive methods sometimes used are the roasting of the surface soil by covering the bed with trash and brushwood, which is fired; or, alternatively, the heating of the soil in some kind of pan. The more modern way is to use live steam for the purpose. A large shallow box of sheet iron (about ro inches deep) with one or more perforated pipes in its base, is inverted over the bed and the edges pressed into the soil. The pipes connect with the boiler of a portable engine, and steam at $80-$ roo $\mathrm{lb}$. pressure is forced into the soil. About 30 minutes is the average exposure given.

Alternatively a stationary boiler may be used and the soil brought to it in a covered box which has perforated pipes arranged for the passage of the steam.

The formalin drench method is carried out with a one in 50 solution of commercial formalin, applied to the prepared bed slowly enough to sink in, and at the rate of two quarts to the square foot. The soil should be covered to retain the fumes for a day or two, and then left open several days before planting.

The steaming method is the better of the two, but both are too expensive to use with any but a valuable and delicate crop.

A cheaper method, using sulphuric acid, is described in papers by C. Hartley and R. G. Pierce. The experiments of these authors relate to the seedlings of coniferous trees, and its suitability for any other type of plant should be determined by preliminary trials. For the requirements of nurserymen the treatment consists in the application, in standard soils, of threesixteenths of a fluid ounce of commercial sulphuric acid to each square foot of seed-bed, applied in solution in water immediately after the seed is sown and covered. This has proved more reliable than the more expensive methods mentioned above.

The amount of water used to carry the disinfectant does not appear to be a matter of importance, provided that the necessary amount of the acid is applied to each unit of area. The quantity used by the authors varies from I pint per square foot when the soil is wet to 2 pints when the soil is dry. There is a possibility, especially in light soils, of a concentration of the acid by evaporation to a strength injurious to the root tips, which in practice has been found to be completely avoidable by watering the beds frequently during the period of germination. When the roottips have penetrated to a depth of half an inch this is no longer necessary.

There are differences in the amount of acid required for successful results in different soils. In sandy soil which was probably somewhat alkaline, a heavier application, one-fourth to three-eighths of an ounce, was indicated. In a fine sandy soil which was probably already acid, chemical injury to seedlings was more difficult to avoid and reduction of the acid to one-eighth of an ounce was advisable. On heavier soils the use of five-eighths 
of an ounce produced no injury and reduced losses by dampingoff to less than I per cent.

On a soil with a high carbonate content, evidenced by a vigorous effervescence when the acid was applied, the method was found to be ineffective. On this soil the use of copper sulphate, one-fourth of an ounce per square foot, gave good results. This substance was applied in the same way as the acid, and the same precaution to avoid chemical injury was found necessary.

An interesting indication was given by the experiments of the effectiveness of cane sugar, $2 \frac{1}{2} \mathrm{oz}$. to the square foot, in the control of damping-off. The authors point out that, if some unrefined sugar-bearing substance were available, it is possible that for certain soils the application of sugar would become an economically satisfactory treatment. Experiments on this subject might well be carried out in the West Indies.

There are secondary advantages to be expected from sulphuric acid disinfection which may be of considerable importance in some cases. Under appropriate circumstances a larger germination percentage is secured, the number of parasites in the soil is reduced and the well-known effect of disinfection on fertility results in increased growth. Another valuable effect has proved to be the reduction of weeds owing to the greater susceptibility of their seeds. Similar advantages are secured from steam treatment.

Some hints are given as to the method of handling the acid. It should always be dissolved by pouring it into the water, reversing the process may cause a serious accident. The solution should be made up in wooden or earthen containers and applied with watering cans which have been coated inside with paraffin wax. Boots may be protected by being heavily greased. Wooden containers should be washed out, immediately after use, with water containing washing soda.

In respect of sterilisation methods generally note should be taken of the evidence which has recently come in from several directions that the condition of sterilised soils favours their more rapid and complete infestation with the parasites concerned when reinfection takes place.

With herbaceous seedlings it is usually quite vain to apply fungicides to the affected plants, but in the case of lime seedlings, which are very subject, among other seedling troubles, to damping-off in the seed drills during wet and cloudy weather, it has commonly been found practicable to save a large proportion of the plants by a dusting process. A mixture of equal parts of finely powdered sulphur and lime is used for this purpose, and success depends on the promptness of its application when the first signs of trouble appear. 


\section{CHAPTER XIII}

\section{PREVENTION OF FRUIT ROTS}

THE rots affecting fruit stored or in transit are mostly caused by saprophytic or weakly parasitic fungi. As fruit approaches ripeness the natural resistance associated with tissue in a state of activity is reduced, and the mechanical protection of rind or cuticle has to be mainly depended upon to prevent the invasion of the tissues.

The fungi most concerned in decay of fruits ordinarily shipped in the West Indies are the Penicilliums (blue moulds) Diplodias, and, on pineapples, Thielaviopsis. It has been repeatedly demonstrated that the occurrence of blue moulds on citrus fruits-the best known type of fruit rot-depends entirely on the presence of injuries, in which either the surface of the rind is broken by scratches, cracks or punctures, or the cells of the rind are burst by injuries of the nature of bruises, which may not be visible even on careful inspection. If neither form of injury is present the fungus is unable to make an entry. Certain types of injury are not preventable, insect punctures and thorn pricks for example, but experience in countries where this matter has been closely followed up in the interests of important industries has shown that a very large part of the damage occurs in the handling, and hence elaborate care is taken at every step of the process which transfers the fruit from the tree to the distant consumer. Such precautions as the wearing of gloves by pickers, the use of padded collecting boxes, and the avoidance of falls of even a few inches are at the opposite pole from local methods, but they are adopted for strictly business reasons, and if ever a successful fruit industry is to be established in these islands it must first be realized that greater care is needed in the handling of fruit for shipment than is necessary for handling eggs.

In many fruits weak spots of another type are provided by the cut end of the stalk, as in pineapples, or the socket from which the stalk is pulled, while, if the end of the stalk is expanded by a persistent calyx, to leave it attached provides cover under which moisture collects and spores may germinate. In the first type there may be advantage in leaving the stalk long or sealing the freshly cut end, in the second dryness is the main protection, and in some cases a touch of shellac varnish has been advocated.

The best general protection is dryness, begun by packing surface-dry fruit and continued by thorough ventilation. Even injured fruit may carry if it is kept free from humidity. Packages 
and storage should be such as to allow the moisture given off to get away quickly, and in this respect the warehouse should be as carefully considered as the ship. Conditions on the latter have often been blamed for mischief which has got well started ashore.

The practice of curing or quailing, where comparative tests have been made, has been usually found to be the reverse of beneficial. Washing citrus fruit has been shown greatly to increase the percentage of loss. With some types of infection, the exclusion by inspection of fruit showing injury or incipient decay is of very great importance. Delicate fruit should not be packed more than one layer deep. All packing should be tight, but squeezing must be avoided.

In particular cases fruit may be fumigated with formaldehyde (see page Ioo) or disinfected with copper sulphate (one in 5,00o to one in 50,000 ), formalin (one in 10,000 ), or potassium permanganate (one in 10,000 ).

Packing sheds should be light and well ventilated. If they can be kept clean it does not appear that periodic disinfection or fumigation is necessary, but rejected fruit should never be allowed to remain long in the building or its vicinity. 


\section{CHAPTER XIV}

\section{PLANT DISEASE LEGISLATION}

THE subject of plant disease legislation, in the present connection, has reference to the enaction and administration of law's for the protection of plant industries against diseases and pests. It divides naturally into consideration of protection against external sources of infection and of the limitation of affections already more or less established.

\section{Plant Importation.}

In island communities such as these of the West Indies, the question of protection against outside infections resolves itsel1 into that of the admission and inspection of plant material at the one or more ports of entry. Such material may be seeds or cuttings for planting, rooted plants with or without soil, fruit, forage, grain or seed for feeding or manufacturing purposes, cordwood, litter accompanying animals, and packing or wrapping of various kinds. When these things, in their nature and origin, constitute a possible source of infection, it may with confidence be stated that the only method approaching safety is that of total exclusion, and even this is qualified by the impossibility in practice of strictly enforcing it. Any system of inspection, however rigorous, is very fallible. Many examples might be quoted in illustration of this statement. The mosaic disease of sugar-cane is highly infectious and is carried by cuttings, yet after careful and long-continued search no visible organism has been found to be associated with it. It can be introduced in material which might be examined with the utmost care and passed as healthy. Citrus canker so closely resembles the comparatively inoffensive and widespread scab disease that it was passed over as such until its characters became known as a result of a disastrous outbreak following its introduction into Florida.

The dangers of admittins unknown and therefore unrecognised diseases, of the introduction of infection on resistant plants which do not show the presence of disease, and the impossibility of determining beforehand what effects a disease or pest may have under new conditions, should by this time, in view of the many instances which have become notorious, be well enougn understood. The local besetting sin in this matter is the tendency to regard the making of an ordinance as the end rather than the beginning of action. 
There are few communities which would consent, or which could afford to consent, to exclusion in any wide sense, but, as regards any plant industry of considerable importance, the only safe way is to reduce importations which have any visible connection with the diseases of the plant concerned to the narrowest possible limits. As regards the exclusion of known diseases, and for general purposes, the effectiveness of regulation depends on (I) the thoroughness with which the pests and diseases of the country of origin are kept surveyed, (2) the promptness with which information is communicated to those responsible, and (3) the efficiency of the inspection carried out. These are matters which in turn depend on the organisation of agricultural departments and of co-operation between them, and the extent to which they receive attention should govern the freedom of exchange permitted.

The regulations relating to the exclusion of plant diseases in force at the present time in the islands of the Windward and Leeward Groups comprise :-

(I) Submission of all material imported for planting to inspection by the local agricultural department, with provision for $(a)$ its disinfection, if thought necessary ; $(b)$ its growth " in quarantine," i.e., in a specified place subject to inspection; (c) its rejection.

(2) Exclusion of material related to the existence of specified diseases in certain countries. At the present time these include, in the islands where the industries affected exist, coffee rust, citrus canker, lime anthracnose, cacao witch-broom, Panama disease of bananas, bud-rot and red ring disease of coconuts, and mosaic disease of sugar-cane.

\section{Internal Regulation.}

The ordinances concerning the control of plant diseases already present apply mainly in the direction of compelling notification and the adoption of measures for prevention or treatment. Their object is the protection of growers in general against injury which may be done to their crops through the existence of infected plants upon which a parasitic disease is uncontrolled. Obviously compulsion can only be justified if the danger is substantial and if some reasonably practicable means of control can be prescribed.

It may be taken as a general principle that such orders can only be successfully enforced so far as they have the support of public opinion. Where general apprehension exists as to the effects of some particular disease the difficulty is comparatively small, the bud-rot disease of coconuts being a case in point, but where this kind of action is taken without the education of the planter as to its necessity it is certain to be looked upon by many as vexatious interference, and to cause an undesirable reaction against the body responsible for its application. For 
this reason the power of compulsion should be exercised with great restraint, should be based on thorough investigation of the subject, and be accompanied by a campaign of education. On the other hand there are certain spectacular troubles, such as black blight and love-vine, with regard to which the demand for governmental action may be stronger than the evidence of damage necessary for its justification.

If the more menacing diseases are made notifiable and classed as such, there remain the non-notifiable infectious diseases, which, if they exist on one man's property unchecked, may cause injury to his neighbour. Probably the best suggestion that has been made for dealing with cases of this kind is that power shouid be given, when a direct request has proved of no avail, to apply to a magistrate for an order directing the person responsible for the property on which the diseas? exists to take steps to remedy the matter. Before granting the order the magistrate would have the opportunity of learning from evidence given before him the nature of the grievance and the measures reasonably applicable for its removal.

The legislation of the kind here discussed now existing in the Lesser Antilles comprises ( $\mathrm{I}$ ) provision in the cotton-growing islands for a close season for that crop, and (except in Barbados) for the eradication of trees which support cotton stainers, the carriers of internal boll disease; (2) provision in St. Lucia, Grenada, and Trinidad for the proclamation of specified diseases, with powers of inspection, for the declaration of quarantine, and for compulsory treatment or eradication. In Trinidad the proclaimed diseases are bud-rot, little-leaf, and red ring disease of coconuts, mosaic disease of sugar-cane, anthracnose of limes, love-vine and bird vine. In St. Lucia they comprise bud-rot, love-vine, and bird vine. 


\section{PART II}

\section{INTRODUCTION}

\section{AGRICULTURAL CONDITIONS IN THE LESSER ANTILLES}

THE chain of islands which with little irregularity of distribution stretches from the Virgin Islands to Trinidad (Lat. $18^{\circ}$ to $10^{\circ} \mathrm{N}$.) affords much greater variation in the conditions governing agriculture than is generally realized. It is true that the difference in temperature, which is perhaps the first consideration to occur to the mind, is not sufficient to have an appreciable influence on the choice of crops, but temperature, in its higher ranges, is among the least effective of environmental factors. First in this respect comes the amount and seasonal distribution of the rainfall, and closely related to this in its influence on crops is the physical nature-lightness and permeability, or heaviness and retentiveness - of the soil. In both these factors there is a very wide range from island to island, and in regard to the rainfall the difference from district to district even in the same island may be extreme, and commonly is distinctly marked in its influence-the degrees of contrast depending on the height and distribution of the hills, and on situation in relation to the north-east trade wind.

The diversity of the conditions produced by the various combinations of soil and climate in the West Indies has come much more into evidence since economic changes rendered it widely necessary to substitute other cultivations for that of the once universal sugar-cane. That plant, with its produce dependent only on vegetative growth, is adaptable to a wide range of conditions which its successors, cacao, limes and cotton, with their crops dependent on flowers and fruit, are quite unable to face.

The more intimate that one's knowledge of local conditions becomes, the more one is impressed with the extent to which an agricultural " natural selection," often at cross purposes with the planter and his advisers, has determined and is proceeding to determine what crops shall be grown in each restricted locality. The principal part of the art of agriculture consists in artificially modifying the environment so as to induce plants to grow in situations and to an extent foreign to them in a state of nature, 
but the limits within which this may be done and especially those within which it may be done profitably are, in respect of many tropical crops, rather strictly drawn. This is the more pronounced because neither management nor labour are as yet capable of going beyond somewhat crude agricultural practices. The relevance of these reflections to the consideration of certain types of plant diseases will appear in the following pages.

To make clearer to outside readers the conditions and crops of the various islands the following summary is given. The islands are arranged in geographical order from north to south.

\section{St. Kitts-Nevis.}

The cultivated land in St. Kitts covers a broad belt of usually gentle slopes stretching from the sides of the central range (highest elevation 3,700 feet) to the coast, and is mostly occupied by estates of the old sugar-plantation size. Sugar-cane is universally grown, with cotton as a catch crop. The steeper slopes for some distance above this belt are occupied in places by gardens in which the usual West Indian provisions-sweet potatoes, yams, bananas, corn, cassava, groundnuts, etc.-are raised. For the greater part of the necessary supplies of this nature St. Kitts depends on the adjacent island of Nevis. The upper slopes of the mountains are covered with rain-forest or tree-fern.

The soil is light and deep, and particularly easy to work. The average rainfall on the cultivated areas is some 40-50 inches, according to position.

The only serious affection of sugar-cane is root disease, which occasionally causes local reductions of crop. The light soil is quickly affected by drought, and lends itself to depletion of fertility when not systematically manured. The prevalence of either condition allows the development of root disease.

The same quality of the soil particularly favours cottungrowing by greatly reducing liability to shedding, and the average yield is high. The plants grow to a large size and the consequent humidity in wet years induces some losses from boll diseases.

The cultivated land in Nevis is arranged around its central mountain $(3,500$ feet) in much the same way as that of St. Kitts around its central range. Many of the old sugar estates have been divided into peasant holdings. Provisions are raised in quantity for local consumption and export to St. Kitts. The staple crops are sugar-cane and cotton. There is a rather large coconut estate near Charlestown, and vanilla is grown in some quantity near the edge of the upland forest at Maddens. The average rainfall at Charlestown is about 50 inches; its seasonal distribution is erratic.

The soil is rather heavy, and cotton is consequently more subject to losses from shedding than in St. Kitts. Sugar-cane 
does well, but in the smaller holdings receives, as is usual in peasant agriculture, irregular attention and manuring. Root disease is in consequence rather prevalent.

\section{Antigua}

Antigua is an island of the open type, lacking forest, with a low or moderate rainfall averaging 45 inches on returns from the whole island, and subject to occasional severe droughts. Agriculturally the island divides into three districts, the northeastern limestone area, with a rather light and stony soil and the lowest rainfall, the southern section of low volcanic hills, with more rain, and the central plain, the soil of which is typically a heavy clay, containing salt in places, generally low-lying, from its nature and situation difficult to drain, and having a tendency to lose tilth quickly in ratooned fields. The lowness of the rainfall is partly offset by the retentiveness of the soil, and there are many hollows in which water lodges for the greater part of the year.

The principal crop is sugar-cane, the cultivation of which was enabled to persist through the years of depression by the early adoption of the central factory system. Scarcely any rotation is practised, the usual course being to grow plant canes and one, two, and in some cases three crops of ratoons, followed by a catch crop of potatoes or corn and by replanting the same year. Crops of corn or of onions are grown with the young canes. The yield of an average estate is about 20 tons of plant cane to the acre and 9 or Io of ratoons, but local yields up to 40 tons of plant cane can occur under very favourable circumstances.

These results are only obtainable by the selection of the better parts of the land, and it is characteristic of Antigua that large stretches of scrub and pasture exist which have been more or less permanently thrown out of cultivation. Could the more intensive methods characteristic of Barbados agriculture be applied, it is probable that a much closer approach could be made to the universal state of cultivation of that island.

Most estates are short of manure, so that not all plant canes receive a share. Chemical manures are used on the ratoon crops. It is the practice to range the trash on alternate banks and cultivate those which intervene. The trash from fields due for replanting is available for the pens. Labour is fairly plentiful, but its efficiency is low owing to prevalent ill-health. Planting is frequently badly delayed by the inability of the factories to deal with the crop in time for the most favourable season to be utilized.

Under the general circumstances described there is no reason for surprise at the tendency for development of root disease, the effects of which are more pronounced in Antigua than in any other island, though the cause goes to some extent disguised as soil grub infestation.

Cotton is usually a separate cultivation, located in the more 
suitable districts, and partly in the hands of peasants. The production has never reached large proportions. There is one working lime estate, situated on the eastern slopes near English Harbour. Coconut palms occur in small patches round the coast. Pineapples are produced with some success on the slopes of ridges in the volcanic area, and where there is good natural shelter the humidity is sufficient for orange trees to exist and for scale insects to be fairly well controlled by the common species of entomogenous fungi.

\section{MONTSERRAT}

Montserrat is one of the smaller islands, about ranking with Nevis. It has a central district of rather bold mountains (highest elevation 3,000 feet), steep and rocky near their summits, falling off in cultivable and often gentle slopes to coastal flats or to the sea. Its streams are few and inconsiderable in size but have cut considerable ravines (guts) in places.

The higher slopes are in forest, secondary bush, or vegetable gardens where these are feasible. Three small cane estates survive, making muscovado sugar, of which a small quantity is exported. Montserrat is the island that has benefitted most of all from the introduction of Sea Island cotton, the growing of which is now the staple industry, engaging both the estates and numerous small holders. Near Plymouth there is about I,000 acres of land in scattered lime cultivation, under climatic conditions marginal for this crop, which shorten the duration of bearing fields and make their re-establishment difficult. There is another 50 acres of limes at Roaches, in a gut from the sea to the hills. About 5o-6o acres of hill land is planted with bay trees, and the area is extending. A peculiarity of Montserrat is its peasant industry in the gathering of papain. There is no papaw cultivation, but in certain districts the plants spring up abundantly when the bush is cut. The milk is collected daily from fruiting trees by women and children, and the coagulum dried in ovens. The annual value of this material is about $£ 2,000$, but the industry has been receiving less attention with cotton at its recent high prices. With this stimulus the latter crop is planted even on rocky slopes where little cultivation beyond the cutting of the bush is possible, and does very well under these conditions.

Not much of the cotton land is as yet manured, even on estates. Occasionally a field is put in a green manure crop, grazed, or given pen manure. The seed is exported to Barbados, and excepting the produce of one group of estates only a small proportion of the meal, for use as stock food, is returned to the island.

Windbreaks, temporary or permanent, are desirable for many cotton fields, but as a rule their provision is neglected.

The provision crop consists mainly of sweet potatoes. Yams, 
dasheens, tannias and cassava are but little grown. There are plantains in the hills, reported to be diminishing; probably, as in Dominica, owing to weevil infestation. Bananas are fairly plentiful in the hill districts, and a coarse species used green is a common article of food. Mangoes, avocados and breadfruit, in their seasons, are staple foods ot the peasantry. The principal leguminous food-crop is the pigeon pea, and the production of black-eye peas is increasing.

The average rainfall is mostly from 40 to 60 inches, according to locality. One estate gets up to 90 inches. In or near the hills the conditions for vegetative growth are very distinctly better, apart from differences of rainfall, owing to increased humidity. This effect is marked enough to exclude cotton from certain districts.

The soils of Montserrat are exceedingly various, ranging from tough hard clays, almost unworkable, through numerous varieties of heavy and light loams to light fine volcanic soils resembling those of St. Kitts and St. Vincent. Trass soils also occur. There is, however, a predominance on the wider slopes and levels of soils light enough to be well suited to cotton in a season of normal rainfal.

\section{DOMINICA}

Dominica is an exceedingly mountainous island (highest elevation 4,750 feet), much broken by ravines and steep-sided valleys. The older cultivated lands are close to the coast or in the inouths of the valleys. The rest of the country is in forest save for an area of scrub known as the Grand Savannah, and a series of clearings situated along the Imperial Road which represent an attempt made some 20 years ago to open up the interior for cultivation. The rainfall ranges from an annual fall of 200-300 inches in the wetter parts of the interior to 80 and 120 inches on the Leeward and Windward coasts respectively. The soil is irregular, rich in plares but often distinctly poor over considerable areas. Most of the estates are complete $y$ orcupied in lime cultivation. There are fairly extensive areas of cacao in some districts, from which the yield is rather small. An attempt is being made to increase the production of coconuts.

The established lime cultivations do well when cared for and have been remarkably free from any active disease or disability. Semi-parasitic fungi hasten the dying-back of trees failing through age and disrepair or from poor nutrition. Mistletoe becomes troublesome when neglected. The newer forest clearings are subject, as is usual in such conditions everywhere in the tropics, to root diseases derived from decaying stumps and logs. Similar trouble exists in the cacao cultivations in connection with damaged or failing shade trees.

During I 922 it was found that the anthracnose of limes had 
become established near the Windward coast, since which discovery the disease has already extended widely and constitutes a grave danger to the future of the principal industry of the island.

Many districts are too wet for the successful growing of cacao; the crop proved a complete failure in the interior with this apparently as the underlying reason. The principal provision crops are dasheens, yams, plantains and bananas, breadfruit and various species of peas and beans. They are produced almost entirely by small holders. Temperate vegetables do well at elevations of $\mathrm{I}, 000-2,000$ feet. Coffee was largely grown up to about 1850 . The reasons for the failure of the industry are discussed in the introduction to the chapter on the diseases of that plant.

\section{ST. Lucia.}

St. Lucia is a decidedly mountainous island, approaching and in some districts equalling Dominica in this respect, but with its contours more systematically arranged. There is a central range some $x, 500$ feet in height, with peaks near its southern end rising above 3,000 feet. From this range ridges run out to the coast in all directions, with numerous narrow, well-sheltered valleys between. Practically the whole island is of igneous material. The average rainfall at Castries is 90 inches, with a range of about 60 to I 20 in other districts where records are taken.

The area of land suitable for arable tillage is for the most part confined to the lower slopes near the coast and to the lower reaches of the valleys. There are several considerable discontinuous areas of this kind under sugar-cane, covering about 3,000 acres, with four factories of the modern type in operation, and sugar is the highest of the colony's exports in value. The diseases of sugar-cane have had little attention.

Some 6,000 acres, well scattered through the island, are under cacao, including numerous estates and a large number of small holdings. Pod-rot and canker, due to Phytophthora, are fairly common, but reach to serious proportions only under conditions of exceptional humidity. Dieback is very prevalent among the more neglected of the peasants' plots. Rosellinia root disease is continually troublesome in some situations, and unless control measures are carefully applied slowly bu surely kills out a group of trees around each centre of infection.

During the last decade the lime industry has attracted considerable attention. An area of some 3,000 acres is planted in the crop, and is still expanding under conditions which appear to be very suitable. So far the trees have suffered little from specific disease. Some foot-rot has been reported on ill-drained land. Scale insects are well controlled on established trees by entomogenous fungi.

In the dryer south-western district some trials of cotton 
have been made, but shortage of labour and the incidence of disease discouraged further development.

\section{ST. VINCENT.}

St. Vincent, like Dominica, is mountainous and broken, but its physical features are on a somewhat smaller scale (highest elevation 4,000 feet) and communication is easier near the coast. A great part of the interior is occupied by forest. The rainfall is heavy, averaging about Ioo inches at Kingstown, and more in some districts, but this is largely offset by the lightness of the soil, a combination which produces conditions of a rather hybrid character, so that the island cannot be classed with those in which the conditions are specifically favourable to limes and cacao, or placed without reserve in those which are distinctly confined to an open arable type of agriculture. Such conditions are well suited to crops of a vegetative nature and to short-term flowering crops which can endure or evade damage from rain. In the former class arrowroot yields the principal product of the island, with cassava as another starch plant supplementing it to some extent. The cultivation of sugar-cane is local in character, and difficulties of transport seem to preclude the centralisation necessary for the application of modern methods of manufacture. Of the crops dependent on flowers cotton is grown to a very large extent. The yields have been usually small, partly as a result of disease induced by the heavy rainfall and partly as a result of insect-borne diseases, but the high value of the product and the returns of occasional fortunate years have enabled the cultivation to continue, and in recent years the control of the cotton stainer has considerably lengthened the crop period, and increased the yield. Black-eye peas and corn as catch crops, and pigeon peas and groundnuts as rotation crops are of considerable importance. There are a few small areas of cacao, but no citrus cultivations. There are small but well-established coconut groves on alluvial lands, and some new plantations are being tried elsewhere; in one case on some $I, 000$ acres of the old sugar land of the Carib country, devastated in 1902 by the volcanic eruption.

BARBADOS.

Barbados lies outside the chain of islands of volcanic origin ; its surface rock is coral limestone except in the north-east corner, where the underlying estuarine and oceanic beds of sandstone, clay, and chalk are exposed. Practically the whole island is cultivated, and the fields are mostly level or on gentle slopes, the land rising by abrupt steps in successive long and rather wide terraces up to the central maximum of I,Ioo feet. There are no streams on the limestone; the fields are drained centripetally into sump wells situated in the hollows. The soil is heavy and retentive, and requires frequent thorough cultivation to maintain a good tilth. The average annual rainfall is about 60 inches. 
Considerable fluctuations occur from year to year, and a distinct difference is maintained between the higher and lower levels.

Sugar-cane has remained the universal crop in default of any other, and the industry was able to survive the period of depression largely by virtue of the North American market for syrup.

Ratooning for one or two years is the rule in the uplands; on the drier coastal districts only plant canes are grown. Heavy manuring is everywhere practised, including the use of large amounts of imported sheep-manure and chemical fertilisers. The common rotation crop is sweet potatoes. In the drier districts cotton had for a few years and may have again an important place in this connection. Yams, tannias and eddoes, and cassava are also grown. Corn is grown as a catch crop; sorghums are raised for fodder and to some extent for grain. Bananas, peas and beans, breadfruit and other local foodstuffs are produced in a scattered way.

As elsewhere in the islands the only serious affection of sugar-cane is root disease, induced in this case by low rainfall and extreme exposure.* The system of agriculture made necessary by these conditions, as also the epidemic of disease which in the 'nineties drove the Bourbon cane out of cultivation, are discussed in the chapter on sugar-cane diseases.

Cotton is even more than usual an uncertain crop in Barbados, owing primarily to the heaviness of the soil. During the flowering and bolling periods a short spell of wet weather is sufficient to cause heavy shedding, and it is common to see fields in which good bearing is confined to borders or patches which happen to be better drained or lighter than the rest. Under these conditions the land needs much more careful preparation for this crop than it usually gets or than is necessary in lighter soil. Success over a term of years has only been obtained in the driest districts and this is qualified by short crops both in wet years and in periods of continued drought. It has been the custom to depend for an important part of the yield on the secondary growth brought out by showers between December and July. The bolls so produced are usually small, but there is much less liability to shedding. The advent of leaf-blister mite has to a considerable extent qualified the success of this system, though the recent adoption of a close season may go some way towards restoring it.

The usual parasitic diseases of cotton occur, but are not commonly the source of any very considerable losses. The absence of the cotton stainer causes the internal boll disease to be rare.

Owing to the dry climate and the open wind-swept nature of the country fungus and bacterial diseases of plants in general are not numerous or usually important. The exceptions are mainly affections of the type of root disease of sugar-cane which depend on the weakening of resistance in their host rather than on humidity.

- Mosaic disease has now become generally distributed. 
GRENADA.

Among the hilly, typically wooded islands Grenada represents a decline in ruggedness of contour as compared with St. Vincent, as the latter does in comparison with Dominica.

Grenada has a central area of forest-clad hills, of which the highest is $2,75^{\circ}$ feet, but a great part of the island combines easy slopes for cultivation with good natural shelter from low ridges and has good or fair means of communication. Much of the soil is very suitable to orchard crops, being of good depth and heavy, enough to be retentive. The average rainfall at St. George's is about 75 inches, but totals of $100-150$ inches are not uncommon in some situations.

Grenada was fortunate in being early to find in cacao a satisfactory substitute for sugar-cane, and has since remained almost completely a country of that one product. To the extent of the limited demand, the growing of nutmegs provides an allied industry, and in recent years the planting of coconuts on open lands has been considerably stimulated.

One or two sugar estates remain, and fair quantities of corn and the usual food-crops are raised by small holders.

As a general rule the conditions are very suitable for the growing of cacao without much loss from pod-rots or root diseases induced by excessive humidity, or, on the other hand, from dieback induced by poor conditions or drought.

This balance of conditions is of course liable to be disturbed by periods of more than usual wetness or dryness which lead to the temporary increase of affections of the one type or the other.

Estates situated on the wetter hill slopes of the interior are liable to have trouble, which in some cases is serious, with root disease caused by Rosellinia Pepo. This species is rare near the coast, but another member of the genus occurs which while slower and less definite in its action appears to be capable of causing root disease under drier conditions.

The cacao estates in Grenada are relatively small and a more intensive cultivation is practised than is the rule elsewhere. Considerable use is made of pen manure, and it is the custom to bury dead leaves, weeds, etc., about the roots of the trees. The yield per acre is distinctly greater than in Trinidad. Very many fields are grown without shade.

\section{TRINIDAD AND ToBago.}

The island of Trinidad, which has an area of $I, 862$ square miles, lies about I 6 miles to the eastward of Venezuela, between $10^{\circ} 3^{\prime}$ and $10^{\circ} 50^{\prime} \mathrm{N}$. latitude. The main body of the island has a form approaching to a rectangle about 55 miles long and 35 broad, with large projections from the N.W. and S.W. angles towards the South American coast. Enclosed by these is the shallow Gulf of Paria, the entrance to which from the south has 
a width of about II miles and the largest channel from the north a width of only 8 miles.

The island is traversed by three ranges of hills running approximately east and west. Only the elevations of the Northern Range, which lies immediately behind the north coast, have the character of mountains and rise to a maximum height of 3,000 feet. This range is an obvious continuation of a similar range in Venezuela, and is connected with it by the promontories and rocky islands which form the northern boundary of the Gulf of Paria. The Southern Range of low and broadly scattered hills occupies a somewhat similar position relative to the south coast, while the Central Range, made up of hills mostly well below I, 000 feet, runs about midway across the island. Between the ranges lie the Northern Plain, an unbroken alluvial flat drained by the River Caroni, and the Southern Plain, which is dissected into shallow troughs and ridges.

From the physical and biological points of view Trinidad must be regarded rather as a detached part of South America than as a member of the Antillean Chain, and its structure clearly indicates a history in which it has formed part of the continent and has been traversed by an outlet of what is now the Orinoco River.

The average annual rainfall is about 64 inches. The dry season extends from January to the middle of May with an average precipitation of about 3 inches per month. From June to November there is an average fall of about 8 inches per month. As regards distribution within the island there is a distinct reduction from east to west; the line separating the area with 50-75 inches from that with 75-I00 inches almost bisects the main body of the island from north to south.

There are a few small areas in the north-east with recorded averages over Ioo inches, while the north-western peninsula and its islands fall below 50 inches.

A great part of the island being covered with forest or with almost equivalent cacao cultivations, the climate is distinctly humid and very favourable to the development of a rich vegetation, much more so than the recorded rainfall would suggest.

The most important agricultural industry of the island is the growing of cacao, of which the production amounts at present in an average year to about 27,000 tons. The crop next in importance is sugar-cane, from which an annual output of roughly 50,000 tons of sugar is obtained. The area under coconuts has been rapidly extended in recent years, and the present production is in the neighbourhood of 25 million nuts per annum. In the minor industries rice is grown for local consumption to the extent of about 2,500 tons and there is a considerable production for local use of Indian corn, peas and beans, cassava, yams, sweet potatoes, dasheens, tannias, eddoes, bananas, mangoes and oranges. The supply of these foods is more than adequate in 
their seasons, but is rendered irregular by the difficulties of storage. Efforts to establish the rubber industry in the island were prejudiced at the critical period by the selection of Castilloa as the tree to be grown, and there is only one considerable plantation of Hevea. Several plantations of limes were made a few years ago, but although the trees grow well the production of fruit is seriously reduced by the prevalence of anthracnose.

The most favourable cacao areas are among the hills of the Central and Southern ranges and the valleys and lower slopes of the Northern Range. Immortelle shade is everywhere used, the species known as " anauco " mainly in the hills and the "bocare" on the plains. There is very little approach to intensive cultivation and the production per acre is consequently low. The reasons assigned for this condition are the inadequacy of the labour supply and lack of capital. The size of holdings ranges all the way from two or three acres to several hundred. Most estates have been built up by the combination of small holdings or by extension on the "contract" system, in which the contractor takes over a new area of small extent, clears and plants it with cacao and temporary crops and hands it over as the trees come into bearing.

The areas occupied by sugar-cane lie immediately behind the western coast : the northern district situated in the basin of the Caroni River, the central about Couva, and the southern in the undulating country south of San Fernando. About half the cane is grown on estates grouped about local factories, of which there are about half a dozen of notable size, and the other half by a class of small cultivators known as cane tarmers who own or rent land and sell their produce by weight to the factories.

The cane is mainly planted in the second half of the wet season (August to November) and the reaping season is from early February to June. Ratooning is a general practice, but, as elsewhere, the number of ratoon crops is undergoing continuous reduction. It rarely now goes beyond three and is in many cases reduced to two and sometimes one.

Coconuts have long been grown on the lands bordering the sea wherever the physical conditions permitted, but considerable areas have recently been established inland, often on old cane lands and to some extent on the site of forest. On the depleted soils of the former type growth is somewhat slow, but fertility may be expected to increase as shade and cultivation take effect.

The island of Tobago, which has an area of Ir4 square miles, lies 26 miles N.E. of Trinidad. It has a dorsal ridge 18 miles in length and rising to $I, 800$ feet, and, except for a district in the south-east, is much broken by hills and ridges. The agriculture of the island closely resembles that of Trinidad, except that the sugar industry, on which it at one time depended, has practically died out. The estates are occupied by cacao and coconuts, and there is a large body of peasant proprietors who grow food and raise stock for their own support and for export to Trinidad. 


\section{Section I-General Diseases}

\section{CHAPTER XV}

\section{ROOT DISEASES}

\section{Rosellinia Diseases}

In the West Indies as in other parts of the tropics where forest land has been opened up to agriculture, destructive diseases make their appearance as the result of infections arising from native fungi which occur on buried roots, on logs, and on other debris remaining from the forest. A number of different fungi are responsible in various parts of the world for diseases arising in this way but the characters of the affections produced are essentially the same.

In the West Indies the fungi concerned are mainly species of Rosellinia. Other forms occur but are comparatively rare. In cultivations of an open nature where sun and wind have access to the soil, and especially in those of arable crops, there is a rapid dissipation of the decaying material necessary for the development of the fungus and the diseases as a rule soon disappear. They can persist, however, in cultivations such as that of cacao in which the conditions, especially where shade trees are abundant, approach to those of the forest in respect of shade and humidity. They also occur in windbreaks and hedges of certain susceptible trees and shrubs in wet or sheltered districts. The causative fungi infect shaded soil rich in decaying vegetable matter and spread slowly through it, destroying every plant with which they come in contact.

The existence of such diseases is traditional in the West Indies, and those under discussion have in all probability been met with from the time of the first settlement. A description of disease of this type occurring on coffee in the French Antilles was published in Paris as early as I842. The first account seen having reference to the British West Indies is that by C. A. Barber, in I893, of root disease of cacao in Dominica, which contains a list of twelve hosts observed. The disease has been from time to time described by agricultural officers since the formation of the Imperial Department of Agriculture. F. W. South (I909-I3) was the first to recognise the genus of the causative fungi. Five species have been met with by the present writer, of which three have been found associated with root 


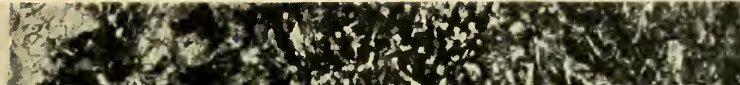

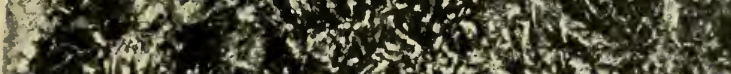
(7)

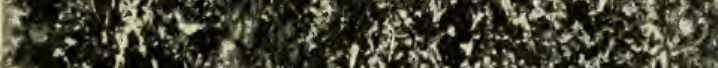
7.

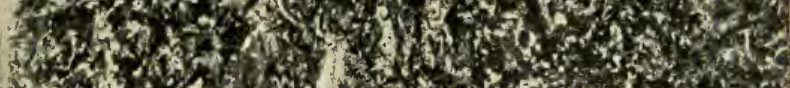

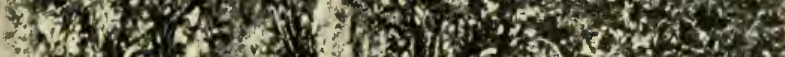

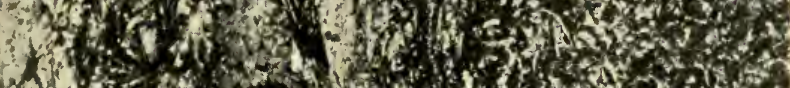
$x$ mo

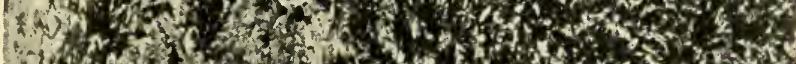
16.6. 20.

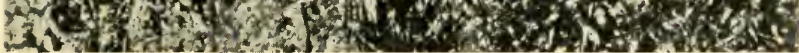

Fig. 32

Rosellinia Pepo: Conidial Fructifications $\times 4 \frac{1}{2}$

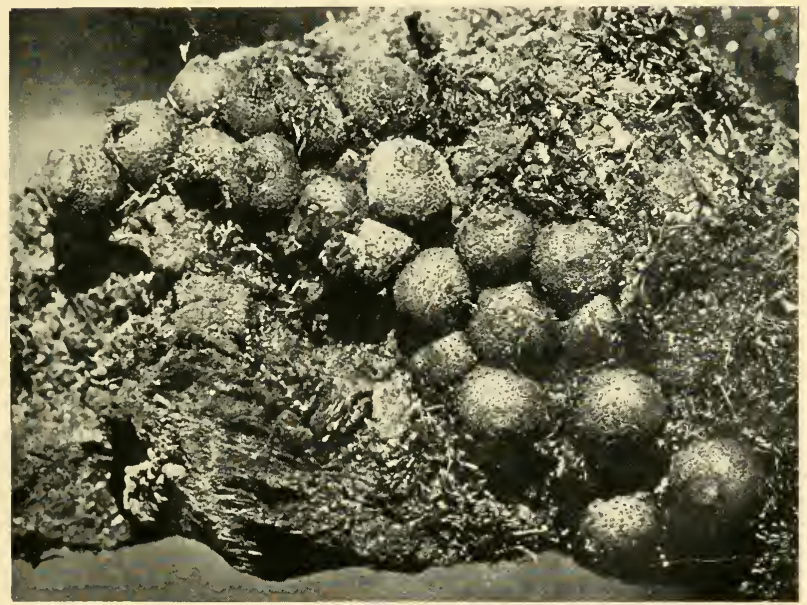

Fig. 33

Rosellinia Pepo: Perithecia : $3 \frac{1}{2}$ 

diseases. They will probably prove to be general in their occurrence in the islands with forest areas.

\section{A. Rosellinia Pepo. Pat.}

This species was originally described by Patouillard in I9o8 from material on the bark of Hymenaa Courbaril collected by Duss in Guadeloupe. In the British Antilles the perithecia have been collected in Dominica, St. Lucia, Grenada, and Trinidad. From the published accounts of root diseases in Jamaica, Porto Rico, and Martinique, it seems probable that the species also occurs in those islands.

Its most general importance is due to its attacks on cacao, but it is capable of producing destructive effects on any of the ordinary crop plants, herbaceous or woody, which are planted on land recently cleared from forest. Under such circumstances, limes in Dominica have suffered severely from this species as well as from $R$. bunodes. Where cacao trees have been killed by the fungus, and other plants have been put in for temporary shade, dasheen, banana, pigeon pea, horse bean (Canavalia) and cassava have all been seen attacked. Sugar-cane seems to possess considerable resistance, and coconut seems almost or entirely immune.

The conidial fructifications (the Graphium stage) are developed in great abundance on all kinds of dead vegetable material lying about on the infested spot, and occur from an early stage on the exposed roots and the base of the stem.

They appear some time before the development of perithecia and are borne on the black surface mycelium which develops wherever the fungus reaches the open under damp conditions. Each has the form of a black bristle-like stalk 2 to $3 \mathrm{~mm}$. long, built up of perpendicular hyphæ which branch out freely at the top into a tuft, which is white or whitish to the naked eye from the conidia which cover it. The conidia are borne laterally towards the terminations of these branches; the cells which bear them have a somewhat zig zag or corkscrew appearance from their tendency to bend away from the point of attachment of a conidium. The conidia are rounded or oval, one-celled, about 5 microns in length.

The perithecia are borne, usually at the base of the stem, amongst and in succession to the conidial fructifications, on the somewhat carbonaceous layer which is formed on and in bark which has become thoroughly infested.

The perithecia are formed much less freely than in the case of $R$. bunodes, and, in spite of long-continued search, material containing ripe asci has only once been obtained in the British islands; this was found by the writer on a dead lime tree in Dominica, in a situation with an annual rainfall of some 250 inches. Examination of this material at Kew resulted in the identification of the fungus as Patouillard's species.

The perithecia are normally slightly verrucose but are some- 
times found smooth. Apparently this is due to weathering, though possibly (cf. $R$. bunodes) there is some variation in the amount of roughness developed.

The most striking characteristic of this species is the production of fans or stars of white mycelium in the region of the cambium (between bark and wood) of the roots. The presence of these distinguishes it at once from $R$. bunodes. A somewhat similar appearance may be produced by $R$. paraguayensis, but, in the examples of the latter fungus seen, the growth has been very much less vigorous.

On the roots the mycelium forms an irregular coating over the surface. In its early stages it is smoky grey in colour, but soon becomes black. It is gathered at first into rather loose branching strands with spreading hyphæ between them. Later the whole is combined into a mass which is more or less woolly on the surface, and tending to be carbonaceous below. It forms dense layers and pockets in the outer bark, and is connected with whitish strands more or less vertical to the surface which everywhere penetrate the cortex. On reaching the surface of the wood these repeatedly branch and spread in all directions over it, so that, when "bark" and wood are separated, a conspicuous white pattern of branching lines, stars and fans is seen on the "bark." From this layer strands penetrate the wood in radial lines along the medullary rays, and send out hyphæ which invade and fill the large vascular elements. In this species the mycelium in the wood, owing to its lack of colour, is not apparent to the naked eye unless a cut surface is exposed for a day or two, when the hyphæ grow out and turn black. In long-infested wood, thin plates, seen as black lines in a section, mark off certain areas, and are believed to belong to this fungus. Such plates, however, are very common in dead wood, and so have little diagnostic value.

The external mycelium is most fully developed and conspicuous when the fungus reaches the base of the stem and appears above the surface of the soil. It is then seen in broad spreading fans, or an advancing sheet, which from the beginning or at an early stage encircles the stem (Fig. 34). The margin while the fungus is actively advancing is light grey in colour for a width of about half an inch, behind which the colour shades off to brown or black with a greenish tint. On smooth bark the sheet is even and glossy, rather like wet fur.

The height to which the fungus reaches is determined by the moisture conditions. When the stem is well exposed, it reaches no further than the few inches for which the moisture of the soil can affect it ; if the stem is enclosed by weeds or low branches, or sheltered by a log, it commonly goes up for a foot or more. The limit of the external mycelium is also the limit of the ultimate infestation of bark and wood. If a diseased tree is uprooted, or is cut below the limit of infestation, and thrown aside where 


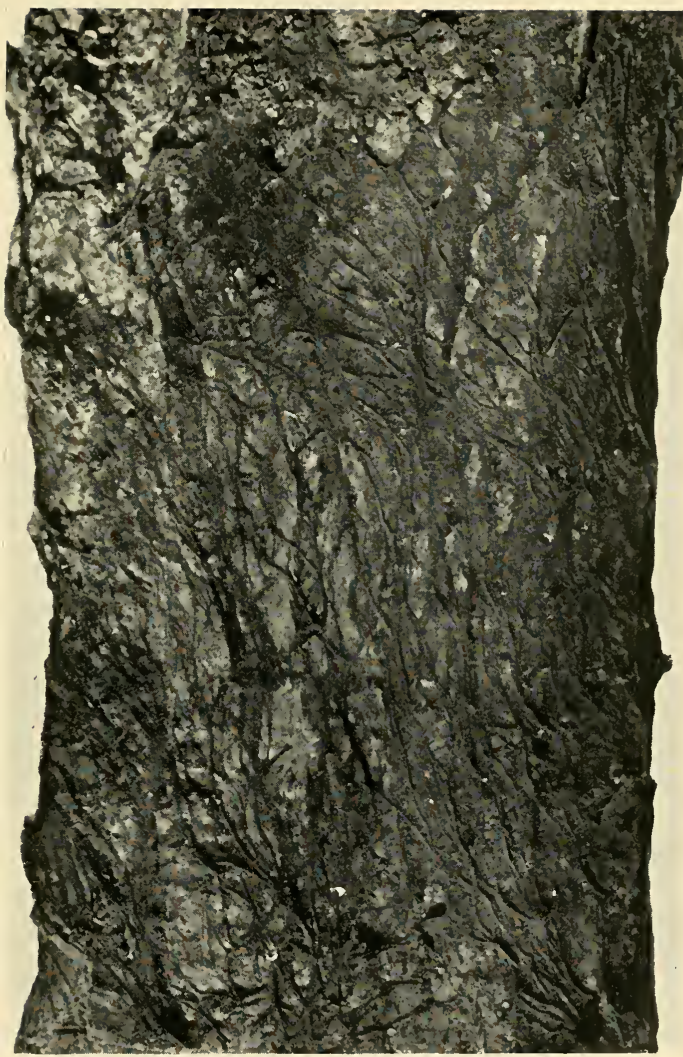

Fig. 34

Rosellinia Pepo: Smoky Mycelium on Surface of Bark $\times 1 \frac{1}{2}$ 


weeds grow up and shelter it, the fungus extends to the whole of the stem and branches thus kept moist.

In the rootstocks of herbaceous plants, as in thick, soft bark, the firm round strands of mycelium, buff-coloured without, white within, penetrate the parenchyma in all directions.

\section{B. Rosellinia bunodes, $\mathrm{B}$. et $\mathrm{Br}$.}

This fungus is recorded as the cause of root disease of coffee, pepper, and associated plants in Southern India, of hibiscus in Ceylon, of coffee and associated plants in Porto Rico. In the Lesser Antilles, South found it on Castilloa and camphor from Grenada, and on limes in Dominica. The present writer has seen it on hibiscus in Grenada, on limes, hibiscus, acalypha and several unidentified native shrubs in Dominica. In St. Vincent a disease of arrowroot is caused by a Rosellinia with the general characteristics of this species, and very probably identical with it, in connection with which examples have been seen of attack on banana, plantain, cassava, tannia, yam, corn, pigeon pea, Sea Island cotton, coffee, and avocado. Sugar-cane and Guinea grass are among the few economic plants which appear to show marked resistance.

There is no doubt that this list could be extended indefinitely. The writer has not met with $R$. bunodes on cacao, but South records an instance of its occurrence on young cacao plants growing near diseased arrowroot.

$R$. bunodes was originally described from Ceylon by Berkeley and Broome. It is at the present time responsible, where proper precautions have not been taken, for steady and serious losses of lime trees on recently cleared estates in Dominica. Since the species previously discussed is about equaily abundant there on the same host, the records made previous to I9I5 regarding black root disease of limes cannot usually be referred to one species as distinct from the other.

Under the conditions prevalent in the uplands of Dominica and Grenada the perithecia are formed very readily and in great abundance on the surface of exposed roots, around the base of the stem of infested trees, and on infested woody material lying about in damp situations.

They are easily distinguished by the coarse, more or less pyramidal warts with which they are densely covered. In one instance only a nearly smooth variety has been seen. The spores are exuded from the perithecium in a narrow thread without much cohesion, and lie in a clump on its summit. The writer has no evidence to offer as to the method or possibilities of their dispersal, but they would be easily carried away by heavy rain.

The conidial fructifications are of the same type as those of

- According to an opinion recently given by Petch on material from Porto Rico the W. Indian species may be found to agree more closely with $R$. goliath Speg. described from Brazil. The two species are in any case very close and not certainly distinct. 
R. Pepo described above, and no character has been detected by which they may be distinguished in the two species.

In respect of the general course of its development and in its main characters $R$. bunodes closely resembles $R$. Pepo. There are, however, certain definite specific differences in the appearance of the mycelium which enable the two to be readily separated in the absence of perithecia.

At the point of infection on a root a dead patch extending to the cambium is formed in the cortex. From this, the fungus spreads over the bark and through the cortex, the infestation of the wood following later. The mycelium on the surface consists mostly of closely applied, firm-textured, branching black strands which thicken into irregular knots along their course. On examples of Castilloa roots examined such knots (the sclerotia of some writers?) had formed over and infiltrated the large transverse lenticels, and on hibiscus similar bodies in the form of dome-shaped papillæ have been seen.

At a later stage the space between the strands may fill in so that a dense layer is formed, which on its lower surface grows between and encloses the outer layers of the bark, and on its upper surface bears in relief a closely ramified system of rhizomorphic strands. From the lower surface abundant cylindrical strands, with a black periphery and a white core, penetrate the cortex in a direction more or less vertical to the plane of the cambium. On reaching the wood they run for a short distance over its surface, and distribute themselves into it by vertical branches which penetrate by way of the medullary rays. From these the adjacent large tracheids are invaded and filled with bundles of parallel hyphæ, hyaline at first, black later.

The result of this distribution is that the strands are seen in the wood of a transversely cut root as black dots and radial lines; in a median longitudinal section as vertical and horizontal lines; in the bark as black threads of irregular length and course.

As in the case of $R$. Pepo, the surface mycelium ascends the stem for some distance above ground as an encircling sheet. In this species the whole sheet when quite fresh may be creamywhite in colour, but eventually turns black. The "bark" beneath commonly remains healthy for some time after it has become covered, but it is eventually penetrated and killed. By the further development of the mycelium a sort of crust is formed on which the conidial fructifications and perithecia successively arise.

The characters by means of which $R$. bunodes may be readily separated from $R$. Pepo at any stage may be gathered from a comparison of Figs. 35 and 38 , and by noting that in contrast with the condition shown in Figs. 39 and 40, the mycelium of $R$. Pepo does not show in the wood until very late, and then only in long zigzag lines formed by cutting through a continuous black film or plate. There is only one caution to be observed: where 
R. Pepo has formed a crust on the bark and is fruiting, some blackening may extend to the mycelium under the bark at that point. The examination of a root will remove any uncertainty. In herbaceous plants the distinction between the yellowish white strands of Pepo and the black ones of bunodes is usually quite clear.

The disease on arrowroot is a special case, brought into prominence by the estate cultivation of that plant in St. Vincent, of the general effects of Rosellinia spp. on herbaceous plants with succulent rootstocks. It is further described under the diseases of that crop.

Rosellinia (paragnayensis, Starb. ?)

A species which agrees fairly well with the description of $R$. paraguayensis occurs on cacao trees in Grenada and St. Vincent. The perithecia have also been found by the writer on the wood of an Erythrina on a cacao estate near Soufriere, St. Lucia.

During a visit to Grenada in I9I 5 several groups of trees were met with which were dying out, although growing in apparently good soil and in favourable situations. The appearances were such as to suggest root disease as the cause. The district in each case was in the drier lowlands where the disease due to Rosellinia Pepo seldom if ever occurs, and some of the characteristic features of that disease were absent. The trees were slowly dying back from the top, and putting out new suckers from below, which in turn failed until the tree was completely dead. In various stages of this process examined, the collar and upper roots bore no sign of disease, but on the lower roots a mycelium was found which formed a white radiating pattern between bark and wood closely resembling that of Rosellinia Pepo but much more scantily developed. These differences might have been put down to the effects of drier conditions had not the finding on dead cacao trees in two of these localities of the perithecia of a distinct species of Rosellinia, associated with a similar scanty white mycelium, brought the existence of a separate, though closely allied, disease into question.

In one instance of a diseased group, the only one on an otherwise healthy estate, the trouble seemed to have had its origin some six years previously in the felling of two examples of the tree known in Grenada as tendre acailloux (Pithecolobium Berterianum, Benth.), in the others no such source was apparent. In another instance bananas planted as cover where trees had died in this way never reached the bearing stage, and examples were seen of banana plants in various stages of a root disease which may have been due to Rosellinia, but which could not definitely be recognised as such.

Some confirmation of the view that this species of Rosellinia attacks cacao was obtained on an estate near Georgetown, St. 
Vincent, where it was found fruiting abundantly on dead cacao trees occurring in patches suggestive of the effects of Rosellinia disease. The degree of parasitism of which this species is capable requires to be established by further investigation, but on the Grenada evidence the conclusion that under certain circumstances it can produce a root disease of cacao seems justified.

As seen so far, the disease is much slower in its action than that due to $R$. Pepo, and the failure of the trees much more lingering. It is capable, however, of existing under conditions of relative dryness such as appear to exclude the more familiar form.

The fruiting habits of the fungus are the same as those of the species already described, and the conidial fructifications have the same form. The perithecia form a dense layer on the surface of the wood, looking like fine shot dusted thickly upon it.

\section{Occurrence of Rosellinia Diseases in New Clearings.}

Serious outbreaks of the diseases due to $R$. Pepo and $R$. bunodes are liable to occur in clearings recently made from the forest. Room for these exists at the present time, in the smaller islands, only in mountain districts. The high rainfall and reduced sunshine of such situations produce conditions particularly favourable to the fungus, but expcrience in cacao plantations indicates that similar troubles would be met with in new clearings made at lower levels.

The fungi concerned have not been found in a purely natural habitat, i.e., in undisturbed forest, although sought for to some extent. From the manner of their appearance in recent clearings there can, however, be little doubt of their existence there as a part of the natural flora.

It is the usual custom in these islands, when clearings are made, to burn as much as possible of the smaller material, but to leave the logs on the ground to rot, and to make no attempt to remove the stumps. Many of the latter send up suckers which have to be cut away from time to time. Under these circumstances it takes very many years before the logs and stumps finally disappear, and during the course of their decay they make the soil around them dangerously rich in crumbling woody matter and humus.

On land so prepared, as soon as the felling and burning are finished, nursery plants are set out in the spaces between the stumps and logs. To get anything like regularity of stand many have to be placed close up to these obstacles. The writer has not seen new plantations of cacao, but has had ample opportunity in Dominica for examining all stages of lime cultivations thus begun.

Fungi are, of course, very abundant on the dead logs and branches, but the Rosellininas are far from conmon on these or, in general, on the decaying stumps. But each newly infested 


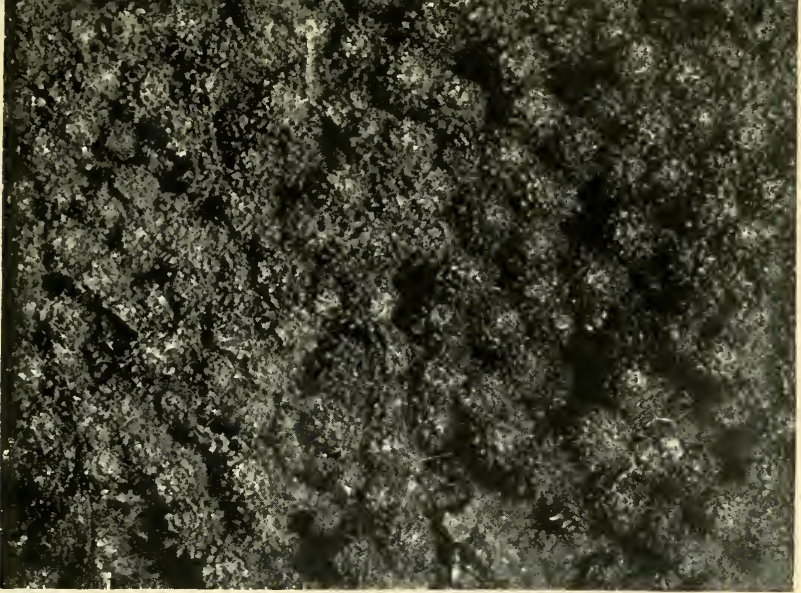

Fig 37 Rosellinia Bunodes: Perithecia : $\times 4$
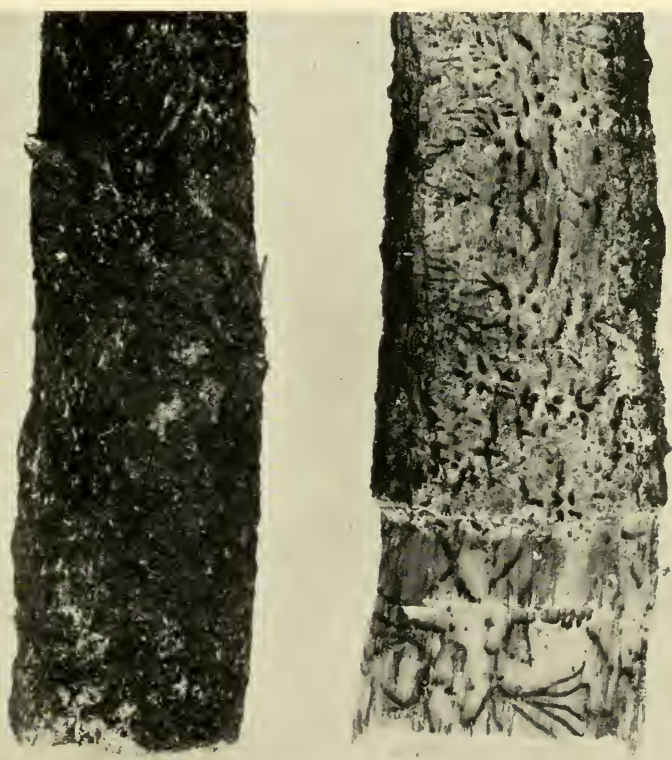

clearing affords unmistakable examples of the association between the diseased trees and forest stumps and sometimes these are very striking, as when the infection of a group of five or six trees can be traced to the spreading roots of a single large stump. In many cases the connection has been traced in detail and newly diseased roots found in contact with infested roots of the forest trees.

Relatively few trees are lost in the first three or four years after planting. This is in part due to the time taken $(a)$ by the fungus to develop on and about the stumps; $(b)$ by the roots of the planted trees to grow out into the infested area, and $(c)$ by the fungus to kill a tree after infection. But observation shows that when the period of heavy losses ensues, most of the trees are infected from one another, so that the characteristic distribution of the disease is in scattered patches, the number of which is very small compared with that of the stumps and logs in the clearing.

There is every reason to believe, and experience in other countries agrees, that the number of species of forest trees of which the stumps are readily infested by the fungus is quite limited, and that the presence of the stumps of these especially susceptible trees in clearings has a good deal to do with the appearance of the disease. It is a well-known fact that there is such a special susceptibility in the case of certain cultivated and semi-cultivated trees. Accurate information as to the identity of the forest trees most concerned is difficult to obtain. In Dominica the largest number of cases occur in connection with Chataigniers (Sloanea spp.), while Mahoe cochon (Sterculia caribca), Mahoe piment (Daphnopsis tinifolia) and bois cabrit or goatwood (Algiphila martinicensis) are also recorded as susceptible.

The disease does not develop in clearings made on poor and shallow soils, or on land which remains in a swampy unaerated condition.

\section{Occurrence in Established Plantations.}

In lime plantations no examples have been met with of the persistence or recurrence of Rosellinia disease after the disappearance of the remains of the forest growth from the soil. In cacao plantations, and probably the same applies to those of coffee, the disease is liable to occur in fields of any age. The liability is greater in degree according to the rainfall and humidity of the situation and is also affected by the kind and condition of the accessory trees in the cultivation.

There is usually no evidence of the disease having persisted from the time of the original clearing, which in many cacao estates is a remote one. Its occurrence seems spontaneous and is mostly unexpected. In a few cases it has seemed to start on the cacao trees themselves, but much more usually it has its 
origin in trees grown for shade or as windbreaks, or shrubs grown as marginal hedges. The most susceptible of the trees commonly grown in or about cacao are avocado, breadfruit, and pois-doux (Inga spp.) Mango and the immortelles are sometimes but less frequently concerned. A year or two after these trees have been cut down, after a large root has been cut in digging a drain, or when they have died from natural causes, the fungus is commonly found to be established on their roots in the same way that it occurs on the stumps in new clearings, and the adjacent cacao trees begin to pick it up. In valley cultivations the disease most frequently appears in situations along the lower courses of ravines or on flats where flood water overflows, a distribution which suggests that the infective material is often water-carried, probably from the upland forest. On hill estates the distribution is usually more irregular.

The cases sometimes met wilis of cacao trees becoming diseased in the absence of stumps can be accounted for by infection of the surface type. The instances noted have been in the wettest districts, where production of organic matter is at a maximum, and where cloudy days, the depth of shade produced by luxuriant growth, and the frequent saturation of the soil with water, all reduce the rate of its destruction. Where rainfall and shade are not excessive the addition of organic matter to the soil does not keep pace with its decay, and the soil met with on the ordinary cacao estate is usually not particularly rich in humus, nor is there much in the way of leaf-mould on its surface.

The spread of the disease along closely planted hedges and windbreaks, of which some striking instances have occurred in St. Lucia, is characterized and probably mainly effected by infestation of the surface soil. The leaves and twigs which accumulate along the base of the windbreak, and decaying, enrich the soil with humus, and the shelter afforded by the trees and by the vegetation which grows up under their protection, provide conditions especially suitable for the fungus. It creeps along the line like a smouldering fire, killing off the trees and their seedlings, and most of the shrubby and herbaceous vegetation, as it comes to them. Windbreaks of pois-doux and galba (Calophyllum Calaba) and hedges of Hibiscus and Aralia are very susceptible to the disease.

\section{The Course of the Disease.}

The course of the disease is much the same in old or new plantations. Typically it starts from one or from several scattered centres and extends slowly but persistently in a widening circle. Its present or past existence in a field may always be suspected where irregular groups of trees are missing or are notably of lesser age.

The fungus spreads at two levels. It works its way along the roots and passes from one root to another in the network that 
extends below the surface of the soil, and can do this at any depth provided there is aeration. It can also infest and extend through the surface soil, independent of roots, where this is rich in decaying matter, and through accumulations of leaves and other decaying material on the surface, provided that in either case the situation is sufficiently shaded and watered to remain continuously moist.

It does not appear that direct spore infections take place. In all cases studied the mycelium has first been developed on dead material before attacking living organs.

Infection by contact or from the soil takes place on the surface of the bark without the necessity for a previous injury. When it has obtained a foothold on a root the fungus has three lines of advance : (a) over the surface of the bark, $(b)$ in the bark and on the surface of the wood, and $(c)$ in the wood itself. These appear usually to follow each other in the order named. If, as is commonly the case, the infection starts on an outlying root the fungus spreads along it infecting other roots attached to it or in contact with it until the crown is reached. Here the mycelium can cross over on to adjacent main roots, which are infested in turn. In nearly all cases there is sufficient moisture and cover about the base of the stem to enable the mycelium to attack the bark of the collar, and commonly to extend for some distance up the stem. It is at this stage that the fungus becomes visible on undisturbed trees. A smooth coating of mycelium, which in the case of $R$. Pepo is black with a light grey margin about half an inch wide, and in $R$. bunodes is at first white, then black, is seen extending up the bark above soil level.

In those trees of which a considerable proportion of the root system has become affected before this stage is reached, a gradual yellowing and thinning of the foliage will have been visible. Where on the other hand the fungus has reached the collar without much destruction of roots, as in the case of infection of short surface roots or possibly the collar itself from the soil, the envelopment of the stem may be seen taking place while the tree is apparently in full health and vigour. The death of the tree soon follows upon the complete infestation of the collar, and in the latter type it takes place with startling suddenness. In a few hours an apparently vigorous tree will stand naked save for the fruit in various stages of development, and a few young leaves on the tips of the shoots. Some weak shoots may afterwards be put out, but they come to nothing. The only previous indication of disease which is commonly present in such cases is the production of an unusually large crop of flowers and fruit.

The dependence of the fungus on continuous moisture usually limits its development to the roots and to the base of the stem, but living branches and the undersides of recumbent stems are attacked if they come in contact with infested soil, while if dead trees become thickly enclosed with weeds or are felled and left to lie they become infested as far as they are kept moist. 
Wherever a tree has died, unless strict measures have been taken to control the fungus, the adjacent trees almost inevitably contract the disease sooner or later. Such cases may develop years after the original tree has been removed and the cause of tts death forgotten, so that they have the appearance of being sporadic. Examination of the position and age of supplies, and the keeping of records of surveyed aréas enable them to be linked up with considerable certainty to previous losses. How far such belated cases are evidence of the slow progress of the fungus along the roots, or how far they are due to delayed infection has not been ascertained, but the general evidence points to the conclusion that the process of investment of mature trees is a distinctly slow one. In a case definitely recorded a fully infested dead lime tree was removed in October, IgI4, and the fungus ( $R$. bunodes) was just coming up round the collar of the next tree in the row, a very large and vigorous specimen, in August, I9I6. The variety of circumstances must produce wide differences, but it is judged that the two years taken in this case is not an unusual period, and is in some cases considerably exceeded.

Typically an infested clearing in which the disease is of several years' standing shows a few large open patches, each representing perhaps a score of trees, with usually two or three around its margin dead or dying, and several more on which the fungus may be found. Sometimes two or three such patches have coalesced. Scattered about are fresh centres in various stages: a single tree, a gap of two or three trees in a row, with another going, or a group of two or three trees in different stages about a large stump. Of the supplies put in, some are several years old and still thriving, others are dead within a few months of being planted. On one cacao estate in a wet mountain district the loss of about I5o trees appeared to be clearly traceable to two original centres of infection.

\section{Counter Measures: I. Prevention}

\section{(a). In New Clearings.}

It would be a counsel of perfection to recommend the removal of stumps or even of logs from new clearings in their earliest stages. In most West Indian plantations such a policy is not economically possible. But, in arranging and planting new clearings for orchard crops, the probability that root disease will occur should be kept in mind, and certain precautions can be taken which will considerably reduce the trouble to be faced when disease appears.

First among these is provision for the construction, immediate or when occasion and funds permit, of a complete and close system of trench drains. To this end the arrangement of the trees should be planned so that each block shall be isolated from 


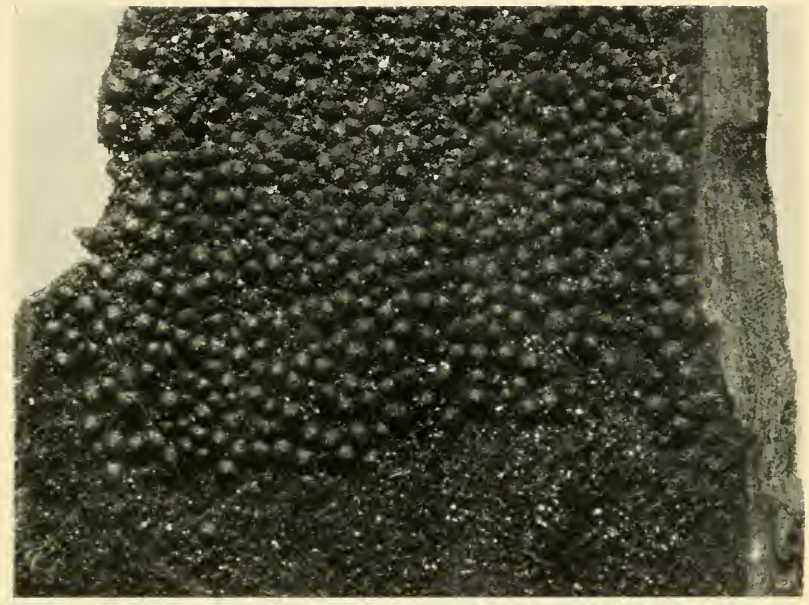

Fig, 41

Rosellinia (Paraguayensis Starb ?) Perithecia $\quad 3$ 

the rest by main drains, and, where possible, each row, or two rows if the planting is close, separated from the next by a trench. There will be many patches encumbered with logs and stumps over which for some years the system will extend only in the plan, but it is necessary to take long views, and too many cases have been seen where, when the need for a trench has urgently arisen, the line has been brought up against trees irregularly planted and now too valuable to be destroyed. Drains are being considered here, of course, not in view of their primary function of removing water, but as isolation trenches preventing the spread of root disease from tree to tree. At the same time, thorough drainage may be considered to have direct value from the point of view of Rosellinia disease, for although, as has been pointed out, the fungus does not thrive in water-logged soil, neither do the trees, and, when that condition has been passed, the drier the soil can become the quicker is the decay of organic matter and the less favourable the conditions afforded to the fungus.

It has been not uncommon in both lime and cacao fields, when a large stump has appeared to be a centre of disease, for a trench to be dug around it, cutting off the widely extending roots. The best plan would probably be to dig a trench some two feet wide well away from the stump, remove all sections of roots, and fill it in again.

In planting the trees, positions in close proximity to stumps should as far as possible be avoided, and a good deal may be done in the way of rearranging the smaller logs so that they do not form too close a shelter about the stem of the prospective tree. Beyond these measures little, for the time being, can be done.

When the first few years have passed and the logs are more or less rotted, it has been shown to be quite feasible to hasten very materially the time of their disappearance by cutting or breaking them up so that they can be easily handled. Merely to dispose of them better by dragging them away from the stems of the trees is a considerable gain, and in some cases it has been found possible to stack much of the material, and even to make good use of it for fuel. The great convenience, quite apart from root disease, of having the ground clear should be an additional inducement to the planter to make every possible effort to this end.

A point to be always kept in mind is that wood which can dry out from time to time, e.g., logs, stumps, or parts of them which are raised above the soil and not shut in by weeds or overhanging branches, is in little danger of harbouring the fungus.

The same consideration applies to the soil. In damp, sheltered clearings, such as are favoured by the fungus, all that is possible should be done to encourage the free circulation of air beneath the trees. Low hanging branches which maintain 
a closely sheltered circle around the base of the tree induce conditions which invite surface infection, and should most certainly be cut away. Grass and weeds should be kept short all the time, not merely in the crop season.

It is highly desirable in infested clearings, and especially in the neighbourhood of infested spots, to go further and clear away the soil and weeds about the base of the stems, completely baring the collars, and liberally exposing the main roots so far as this may be done without forming a saucer in which water will stand. The treatment of the collar and the recesses between the roots with lime-sulphur solution to keep the bark free from moss gives an added protection of considerable value.

All these measures are summarized in the word ventilation, and cannot be too strongly emphasized. The fungus cannot tolerate dry conditions and it is for the planter to take every advantage he can of this weakness.

\section{(b) In Cacao Plantations.}

There are probably few managers of cacao plantations who would nowadays plant breadfruit or avocado trees through their fields. Where these trees are already established, the planter who has learnt respect for root disease has two courses open to him. The one is to take the utmost care of such trees, to prune out dead branches, to avoid injuries to the roots, and generally to try to preserve them in health as long as possible ; the other is to take them out as occasion offers, removing the stumps, and following out and removing every root that can be got at. Striking cases have been seen where the cutting down of avocado, breadfruit, or pois-doux has led to the appearance of the disease in places from which it was thought to be far removed. These trees are the chief victims, but there is none that can be considered to be really safe. It should be the settled policy of cacao planters in wet districts to leave no woody material to rot in the soil if it can possibly be avoided. Where there is deep shade and high humidity, any vegetable matter used as mulch may be a source of danger, though one that may have to be risked in view of manurial requirements. The more careful and prompt the attention that is given to any appearance of the disease on the plantation the less will the risks of this nature be.

With regard to windbreaks: where experience has shown that there is danger of disease arising, it is advisable to keep them as free as possible from undergrowth, and to scrape away any accumulations of leaves or other material from hollows or other sheltered places. This can be burned or used in the pens.

\section{II.-TREATMENT.}

The prospect of saving trees with deep-seated or well-established infections is too remote to pay for the labour and skill required. But experience has shown that in fields in which the 

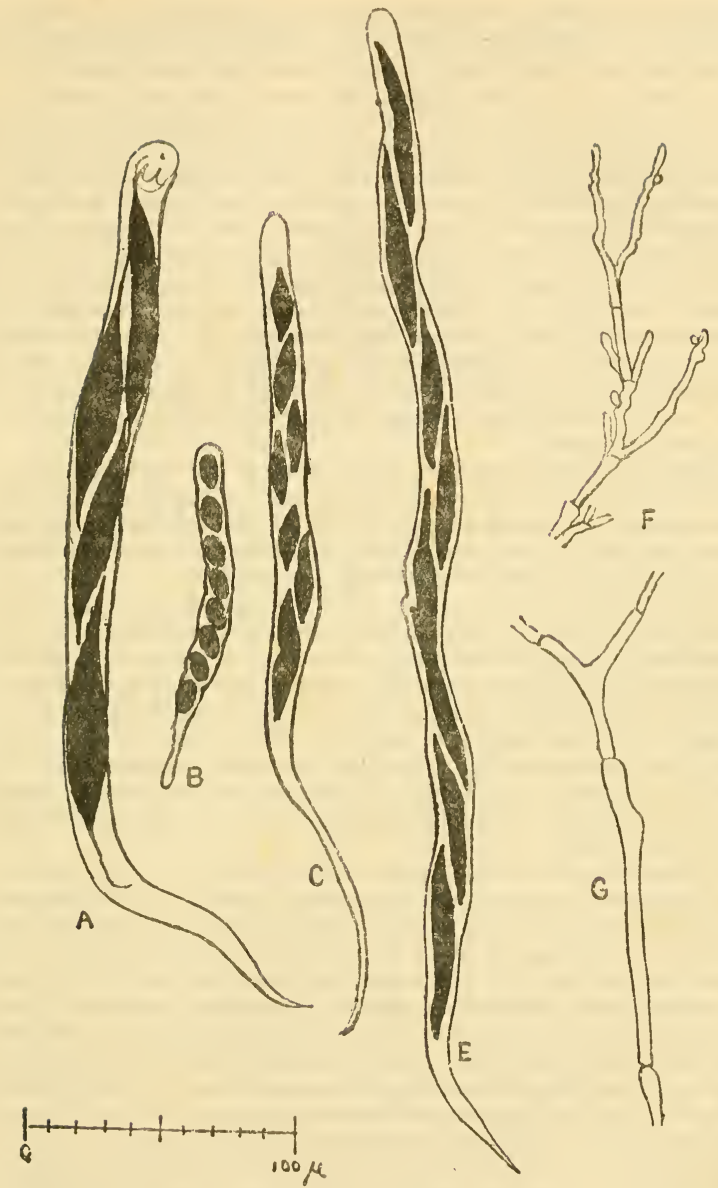

Fig. 42 Rosellinia Spp.

(A) Ascus of R. bunodes. (B) Ascus of R. subiculata. (C) Ascus of R. paraguayensis (?) (E) Ascus of R. Pepo.

(F) Terminal Hyphae from Conidial Fructification of Pepo. (G) External Hypha characteristic of Roselinia SpP. 
fungus is established in the soil and surface infection is taking place, an examination of the trees, involving no more than an initial clearing and periodic inspection of the crown and collar, will directly save many lightly infected trees, and, indirectly, by preventing the formation of new centres of distribution, save very many more. All that is needed is to have the lower branches pruned sufficiently for access to the trunk, a couple of labourers to go on ahead and clear away weeds and earth for a foot or so around the junction of roots and stem, preferably using their hands or a blunt instrument to avoid wounding the bark, and then to make a few minutes' investigation of each tree so prepared. In addition to saving trees, such a system enables the hopeless cases to be detected long before they otherwise would be, and makes it possible to deal promptly with them. It is justifiable to insist that in every clearing in which the disease has become established such an inspection ought to be made at least twice a year.

The principles of the actual treatment are two in number and very simple: (a) complete excision of diseased tissues; (b) exposure as complete as possible of the affected part and its surroundings to freely circulating air, with the object of making the conditions too dry for the fungus to exist.

The cases which repay treatment are those arising from surface infection, in which on inspection the local nature of the infestation appears to be clearly defined. Severed roots should as far as possible be removed; cut surfaces should be cleanly trimmed and treated with wound dressing; excavations made to get at the seat of injury should be left open. It should be hardly necessary to say that the material removed must be carefully disposed of. In many cases a few cuts with a sharp knife will save a tree from an infection which would have meant its certain death.

Where the disease has been detected advancing along one or more large roots but has not reached the collar, and it is desired to give the tree a chance of recovery, after the diseased roots have been cut away as much soil as possible should be dug out about the junction of the main roots and as far back as they can be conveniently followed, leaving the tree more or less on stilts. This prevents the crossing over of the fungus at or near the collar, and may very considerably delay the loss of the tree; but if the fungus, as is probable, exists on the outer roots, it will in time get round in that region and come up each of the main roots in turn as far as the point to which it has been bared. It is not a measure to be recommended. It is better to have the tree out and be rid of the fungus, but the temptation to get an additional crop or two from some specially fine tree is sometimes hardly to be resisted.

The directions here given as to treatment apply equally to limes and cacao, but as has been previously indicated, with the 
latter crop, so far as the writer's experience goes, the cases are more usually of the deep-seated kind, which does not permit of successful treatment.

\section{III.-CONTROL.}

\section{Removal of Diseased Trees.}

When an infested tree is found it is well that its destruction should be prompt, but it is an advantage to choose a dry day for the operation. If the disease is so far advanced that the fungus is producing conidia, either on the stem or on dead leaves and twigs lying about, then before it is disturbed the sporebearing surfaces should be flamed with a torch or by burning trash of some description around them. This disposes for the time being of the means of aerial dispersal of the fungus, and lessens what is otherwise a real danger of the carriage of infection on the persons and implements of the labourers.

The diseased tree should be cut down, the stump dug out, and the roots followed up and removed as completely as possible. One planter gets out the fragments with a builder's sieve, and has had unusual success with his supply plants. It is convenient for the labourers to have baskets handy into which the small roots can be thrown as they are dug out, otherwise they are in danger of being scattered.

The diseased material should be destroyed by fire, preferably on the spot. It has been formerly stated that the whole tree should be cut up and burned, but experience has shown that the necessity for this, which has often been a real difficulty to planters trying to follow instructions, may be avoided. It is easy to note how far the fungus has reached, and if the stem is cut above this point, and the top is disposed of in such a way that it can dry out, it will not develop Rosellinia. This has been verified on trees thrown into the edge of the forest, provided they did not rest upon the ground, and on others perched on large stumps and on rocks. It is better to dispose of even the stump in some such way than simply to leave it lying about as is too frequently done, but all material actually infested certainly ought to be burned. No material, root or stem, infested or uninfested, should be left lying on the ground. In one instance the stem of a cacao tree, some 5 feet long, which had been charred and thrown aside in the grass, was found sheeted from end to end with conidial fructifications, and stems and branches of dead lime trees have been frequently seen, where they have rested for some distance on or close to the ground, in a similar condition. Had they been wedged among the branches of a tree they would have been quite harmless.

Under some conditions it may be necessary to choose a convenient situation and carry to it material to be burned, but such transportation has obvious dangers in the way of scattering bits of diseased material. It should certainly be preceded by the 
scorching of any spore-bearing surfaces. A kerosene blow-lamp is a useful appliance in connection with this scorching, and in starting fires.

\section{Treatment of the Soil.}

Attempts have naturally been made to arrest the progress of the disease in the soil, or to sterilize situations from which diseased trees have been removed, by the application of disinfectants.

There is not much scope for the use of disinfectants in the control of this disease. It is safe to say that at the present time there is no substance available which is cheap enough to be used in sufficient quantity to sterilize any considerable area of ground. When dealing with a fungus which penetrates to every part of even the thickest roots, it cannot be expected that chemical agents will kill it out, or, being necessarily of a transient nature, stop its progress, unless all woody material is removed. When this has been done, exposure of the soil to sun and air is probably just as effective as any disinfectant could be. Where it is required to deal with infested soil or accumulations of vegetable matter under shade, as, for example, in the case of the trees with surface infections specified above, it is better to scrape away the surface soil with a hoe than merely to extinguish the fungus with a disinfectant, leaving material liable to reinfection. Such a scraping of the soil, combined with removal of low branches and of any other hindrances to the tree circulation of air, has in the cases under the writer's observation been sufficient. An application of lime or sulphur would give an additional margin of safety.

The addition of lime to the soil when clearing up a spot from which infested trees have been removed is commonly practised, and is believed to contribute to success in establishing supplies. It seems probable that the results obtained are not so mucn due to the sterilizing effect of the lime as to its action in hastening the disappearance of organic matter. There is a further probability that by neutralizing soil acidity lime produces conditions less suitable to the survival of the fungus.

If the view here taken of the function of lime is the correct one, the main effect may be obtained by the use of slaked lime, which is the only form that can be conveniently obtained in some islands. Quicklime, because of its additional sterilizing effect, is to be preferred when equally available.

Where sulphur has to be imported, its price will not enable it to compete with lime, but there would appear to be possibilities in some places of obtaining it cheaply from local sources. Sulphur has a more definite fungicidal action than lime, and one which may be expected to develop slowly and have considerable persistence.

The effect of sulphur on the soil reaction is to increase acidity, 
and from this point of view it is desirable to follow its use with an application of lime.

\section{Isolation of Contacts.}

The diseased tree having been removed, it is necessary to take steps to prevent the spread of the disease among the trees around. In a regular field, with ordinary distances of planting, the roots of the trees form a continuous system of contacts, interrupted only by the deep drains. By the time a tree is so far diseased as to be noticeable, the probabilities are great that the roots of one or more of the neighbouring trees have also become infected. It is required to cut the connection between the infested roots and those of the surrounding healthy trees, and to break the continuity of the possibly infested surface soil. To be reasonably sure of doing this, it is necessary to carry an isolation trench outside the trees in contact with the one diseased. Thus, in an undrained field, if $\mathrm{D}$ in the first diagram (I.) represents a diseased tree, $\mathrm{C}$ the possible contacts, and $\mathrm{H}$ the healthy trees, the isolation trench should take the course indicated by the unbroken line, and will include nine trees.

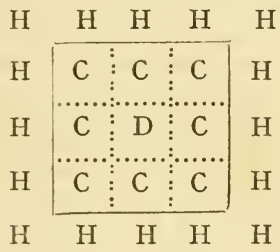

I.

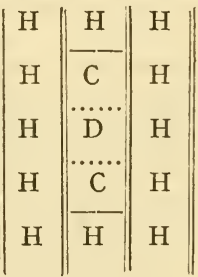

II.

Neither the roots of the trees nor the course of the disease follow regular lines, and it is quite improbable that all the eight contacts are infected, but there is no practical means of knowing which remain free. In order to save those which are still uninfected, it is advisable to cut up the enclosed area chess-board fashion as indicated by the dotted lines. If these secondary trenches are omitted it is likely that the contacts will all go off sooner or later in the manner already described.

In situations where there is a risk of soil infections the trees still further out ( $\mathrm{H} \mathrm{H}$ in the diagrams), should have some special attention, especially if $\mathrm{D}$ is an advanced case when discovered.

In situations liable to root disease there is much to be said for the general adoption of the system represented in the second diagram (II.), where a permanent drain (denoted by a double line) exists between every row and the next. All that is required for isolation is the cutting of cross trenches between $\mathrm{C}$ and $\mathrm{H}$, to 
separate contacts from healthy trees, and secondary cross trenches between $\mathrm{D}$ and $\mathrm{C}$, to save the contacts if they do not prove to have become infected. The length of isolation trench required is reduced to one-sixth. Where close planting is adopted or the whale-back beds which this system produces are objected to, the trenches may be made to include two rows instead of one, the protection obtained being then less complete. Like the preventive measures already indicated, this system should be applied first of all in the situations where the losses are greatest, and extended as opportunity permits.

It is not necessary, from the point of view of root disease, that the trenches should conduct water: indeed, where loss of surface soil by wash is feared more than the alternate danger of water-logging, it may be advisable deliberately to check their function in this respect. They may then be periodically cleaned out, and the deposit returned to the soil. It gives a clearer point of view if the system is regarded as one of permanent isolation trenches with a secondary function as drains, rather than as one of drains in the first instance.

Returning to consideration of the treatment of infested spots, there are two commonly existing situations which need to be dealt with. These are (I) the case where a large patch of trees has already been eaten out of a field, and the disease is spreading outward around its circumference, and (2) the case where one or more trees have been attacked around a large forest stump, infested or likely to become so, which together with its heavy roots prevents the cutting of trenches over an area which may include quite a large number of trees. In both cases the procedure has to be modified to suit each individual set of circumstances but still follows the simple principles set out above. Where roughly parallel main drains or water courses exist on each side of the area, they should be joined across above and below to establish an outward limit, even though it may be a wide one, to the spread of the infection. Then working inward from this, successive trees or rows of trees which appear healthy may be separated off wherever it is possible to dig a trench, and the disease thus confined to the narrowest limits.

In the situations sometimes met with, especially in cacao plantations, where the trees are growing amongst a confusion of fallen rocks, the possible measures are limited to early removal of so much of an infested tree as can be got at, and the liming of the soil about adjacent trees, with a view to preventing spore infections of the material which accumulates in the enclosed pockets of soil.

It has been commonly recommended that a trench be carried in a circle around diseased trees and their contacts. This method has practical disadvantages. The extent of the existing infection can never be ascertained by inspection, and a wide circle, while enclosing many healthy trees, may prove too narrow 
to include some line of infection that has run off in advance of the general spread. A circle leads nowhere, whereas a system of squares may be added to at any point and be carried in any direction, and is capable of any subdivision. It has moreover the great advantage of linking up with an existing or prospective drainage system.

As regards the form of the trench itself, there is but one essential so far as root disease is concerned: that it should be deep enough to cut through all the roots passing across its situation. When digging near an infested tree, the earth removed should be thrown inward as a precaution against the scattering of possibly diseased material among the healthy trees. This refers more particularly to secondary trenches; the outer trench should be put far enough away to avoid, in general, the chance of finding such material. The earth should be distributed, not banked at the edge of the trench, unless put there in exceptional circumstances with the express purpose of avoiding wash. Under no circumstances, however, should the collar of the tree be earthed up. Roots passing into the healthy area should be followed up and removed, so far as this can be done without much injury to other roots. It is better for cut ends of roots to be protected with a coat of tar.

\section{Survival of Supply Plants.}

On the thoroughness with which the clearing up is done depends the chance of survival of an early supply plant. It has been found in St. Lucia, where the results of several years of experience of the treatment of this disease on cacao are now available, that, where the work has been carried out under the personal supervision of the planter, supplies put in a month afterwards have remained healthy. The longer the delay the greater the chance of survival. It must be remembered that a supply may do well for a few months while its roots occupy the site from which the stump was removed, and then become infected from some outlying fragment of the old tree as its roots spread wider. Such cases have been definitely traced.

\section{The Possibilities of Control.}

Rosellinia disease in orchard cultivations is by its nature capable of the most serious consequences. It is cumulative in its effects : each tree that contracts it infects as a rule not merely one but several more, and each tree killed takes at least five or six years to replace. In new clearings, encumbered with stumps and logs, and in cacao fields with large shade trees, the disease is difficult to deal with.

It may be confidently claimed, however, that the application of the principles of prevention and control set out in the preceding pages will reduce the annual losses to a minimum that is not likely to be serious, and one may further expect a gradual diminution year by year of even the sporadic cases. 
Control does not depend on any special apparatus or material, but on operations of a familiar type, demanding little special skill. Everything depends on the vigilance and thoroughness with which they are carried out. Careless or half-hearted work is of little use against this disease, which is apt to pursue its course with a disconcerting appearance of deliberation and inevitability.

\section{SCLEROTIUM Rots.}

The genus Sclerotium is an artificial group in which are placed fungi with no observed process of reproduction by spores, but in which the mycelium forms solid resistant bodies, often resembling seeds in appearance, made up of closely compacted hyphæ.

Sclerotium Rolfsii Sacc. is a widely distributed soil fungus, which under conditions of rather high temperature and marked humidity vigorously attacks the softer tissues of plant parts which come in contact with the ground.

It most frequently comes to notice as the cause of crown-rot and consequent wilting in herbaceous plants. As regards these it appears to come near to being omnivorous, but in these islands is perhaps commonest on leguminous herbs. The susceptibility of different hosts is largely determined by the extent to which they shelter the soil and thus increase local humidity, and probably also by their relative succulence.

The mycelium usually first attacks the stem near soil level, invades and rapidly kills the cortex, and then spreads over the roots. The first sign of its presence noticed is usually the wilting of the leaves which ensues upon the ringing of the stem. Branches, leaves and fruits which touch the soil are subject to independent infestation and rotting. A very copious white mycelium, with a distinctly radial habit of growth, extends upon the infected parts and is often freely developed in the immediately surrounding soil. It shows a distinct tendency to form strands, and when old develops a buff or brownish tint.

In a short time the exposed mycelium becomes dotted with tiny white tufts, which develop into smooth spherical sclerotia white at first, then buff-coloured or brown. Their size when mature is somewhat variable, but usually comes within a diameter range of $\mathrm{I}-2 \mathrm{~mm}$.

It is assumed with great probability that the sclerotia can hold over the fungus for a long time, producing a new growth of mycelium when the conditions are favourable. The readiness with which the disease appears in wet weather even in districts with a severe dry season shows that the fungus is furnished with effective means of perennation.

No very widespread damage has been reported from the disease, but temporarily and locally it can be very destructive. The root disease of ground-nut in these islands described by 


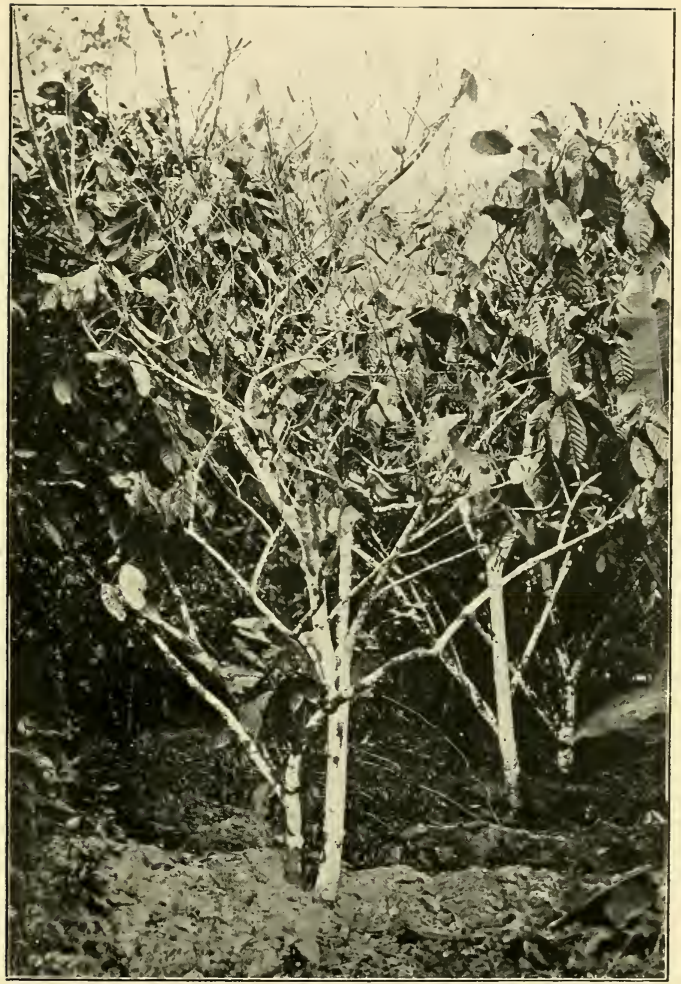

Photo by?

Fig. 43

[F. W. Urich

Root Disease of Cacao (R. Pepo) 

F. W. South was evidently due, in part at least, to this fungus. In addition to its wide range on herbaceous hosts the fungus has occurred in the West Indies on seedling citrus plants, both in the seed-bed and the nursery. In the United States it has been recorded from sweet potato. On sugar-cane it gives rise to a disease of a special type, red-rot of the leaf-sheath, described with the diseases of that crop.

\section{Control.}

The only apparent hope of dealing with the disease is through measures designed to prevent its appearance by reducing humidity, which include close surface draining, wide spacing, and the provision of support for climbing plants. Access of sun and air are very effective checks to the fungus. Affected plants should be promptly pulled up, and in this case should certainly be burnt. The application of lime to the soil has been recommended.

\section{Fomes Root Rot.}

The large bracket fungus Fomes (Polyporus) lucidus (Leys) Fr. has come to notice from time to time as a suspected parasite working on the roots and collar of various trees.

F. W. South regarded it as taking part in the destruction of lime trees in Montserrat and Antigua, but it is impossible to say what is its real position amongst the other factors contributing to the death of the trees. (See Diplodia Dieback.)

A case in which, owing to the absence of complications, the connection of this fungus with root disease was more clearly indicated received some attention from the writer in St. Kitts in I9I4. At the Basseterre Botanic Gardens a row of large Saman trees (Pithecolobium Saman) was thinned out by cutting down alternate trees. About a year afterwards three of the remaining trees died with a fungus rot of the roots, and an adjacent hedge of bread-and-cheese ( $P$. unguis-cati) was similarly killed. The Saman trees have continued to die one by one. White mycelium is plentifully developed, in some places in thick masses, under the bark of the collar and roots, and large sporophores of Fomes lucidus regularly grow out from this when the tree is dying or dead. The bracket-like fructifications attain in well-grown examples to a diameter of 30 centimetres. They are usually supported on short thick reddish-black polished stalks, single or fused; the upper surface is irregularly wrinkled and has the appearance of being coated with brownish-red lacquer; while the underside when fresh is whitish or buff in colour.

The fungus has a similar status in other countries. T. Petch has found it in association with root diseases of coconut, mango, and flamboyante in Ceylon; P. J. van Breemen suspects it to be the cause of a white rot of Casalpinia coriaria and Acacia tortuosa in Curaçoa, and P. A. van der Bijl attributes to it the death of Acacia spp. in South Africa. It will be seen that there is some cumulative evidence of its parasitism on leguminous trees. 


\section{CHAPTER XVI \\ STEM AND LEAF DISEASES}

\section{Pink Disease.}

THIs is a disease in which twigs and small branches appear as if they had been dusted over with pink powder, and sustain damage which commonly leads to their defoliation and death. In the later stages the pink colour fades to grey, and the thin coating cracks irregularly. In some cases the fungus assumes the form of white or pink pustules arranged more or less in lines parallel with the branches.

West Indian records show that pink disease occurs in Porto Rico, Dominica, St. Lucia and Trinidad on cacao, and has been also seen on lime, grapefruit, pigeon pea, oleander and Amherstia. The fungus to which it is due has been found to be identical with that of the pink disease of the Eastern Tropics, which has a very wide range of hosts and gives serious trouble in rubber plantations.

That the disease has not assumed anything like the same importance in the West Indies would appear to be due to difference in climate. The fungus is dependent on a very considerable amount of humidity for vigorous growth. In even the wettest of these islands there are few places opened up to cultivation which are not penetrated more or less by wind and sun all the year round; it is notable that the disease on the lime in Dominica is still known to exist only in one specially wet and sheltered district, although it was recorded from the same place nearly twenty years ago. On cacao in Dominica and St. Lucia the disease has been known the same length of time and remains a rarity. In Trinidad, according to J. B. Rorer, it has been found on cacao only at rare intervals in the northern and eastern districts and has not proved a serious trouble.

\section{Causation.}

The causative fungus Corticium salmonicolor $\mathrm{B}$. et $\mathrm{Br}$. (C. javanicum $\mathrm{Zimm}$.) was referred to for several years in West Indian publications as C lilacino-fuscum B. et C., owing to a mistaken identification by Massee of material from Dominica. The infection probably comes in the first place from some forest plant. The spores germinate on healthy bark and develop a superficial mycelium of cobweb-like texture. The fungus later 


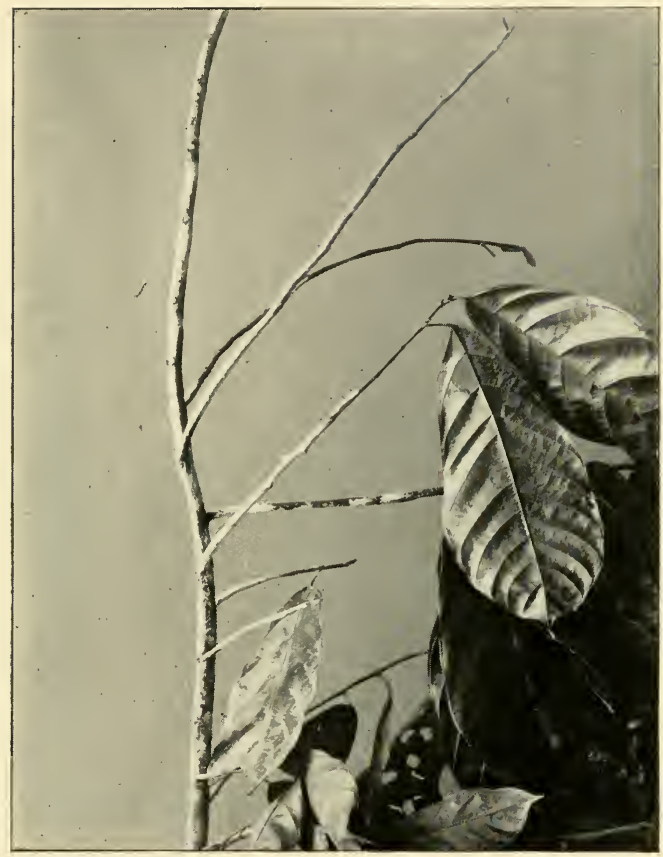

Photo by]

Fig. 44

[J. B. Rorer

Pink Disease of Cacao 

penetrates and kills the bark and frequently enters the wood, in which case a sudden wilting of the leaves may be observed. In the case of lime trees the affected branches are visible from an elevation scattered amongst the healthy foliage. The pink layer is the fruiting part of the fungus, and produces the spores upon its surface. One or more pink fungi which are harmless occur on the bark of trees, and are liable to be mistaken for this species.

A second stage of the fungus, originally described as Necator decretus, Massee, occurs together with or in succession to the Corticium stage, often on wood killed by the fungus. This consists of orange-red pustules about $3 \mathrm{~mm}$. in diameter, made up of irregularly shaped thin-walled spores. This stage has not so far been recognised in West Indian examples.

\section{Treatment.}

The simplest and most effective way to treat the disease is to cut off the branch on which it occurs at its junction with the next older branch or with the stem, taking care to cut well below the affected part. The branch removed should be burned or buried, with as little handling or transportation as possible, and the bark for some distance below its point of origin disinfected. General spraying with Bordeaux mixture or lime-sulphur mixture has given satisfactory results on citrus trees in the Philippines, the latter being preferable owing to its lesser effect in protecting scale insects. No such measure has yet been needed in West Indian cultivations.

\section{THREAD BLIGHT.}

Thread Blight is the name commonly given to affections of shrubs and trees in which white to dark brown compact strands of fungus mycelium run along the twigs, and send out branches to the leaves, on the blades of which they ramify, or spread out into a thin web, generally white in colour.

\section{Distribution.}

Diseases of this nature occur widely over the world, especially in humid situations in the tropics. In the Lesser Antilles thread blights have been found on various forest trees, and on cultivated plants have been most noticed on cacao, coffee and nutmeg. There are in various parts of the tropics several Basidiomycetes which have scandent whitish mycelium of the general type under discussion.

\section{Corticium Stevensii, Burt (Hypochnus ochroleucus, Noack).}

The common thread blight which occurs in humid situations in these islands on cacao, nutmeg, and numerous other plants has been identified by E. A. Burt as due to the fungus above named, which was first described from Brazil, and later as the cause of a 
thread blight of apple, pear and quince in the southern United States. The fructification, which is rarely found, consists of a reticulum or felty membrane, coloured dirty pinkish buff, covering the whole underside of a leaf and easily separable from it.

The basidia are scattered along the hyphæ on short lateral branches; they are simple, measuring II $\times 7-8$ microns, with four short sterigmata ; the spores are hyaline, flattened or slightly concave on one side, measuring 8-II $\times 3$-4 microns.

\section{Nature of the Attack.}

The strands of the fungus pursue a wavy but generally longitudinal course on the thicker twigs. They may reach a width of about a millimetre. The upper surface is somewhat rounded, while the lower is closely adpressed to the bark, to which it adheres rather firmly; the colour is white or cream in young, deep brown in mature examples. The strands are made up of apparently solid hyphæ, which are closely adherent in the brown integument, and in the body of the strand are loose, hyaline, remotely branched, straight, of regular thickness, and mostly following a parallel course. Adhesion to the bark seems to be secured by short rhizoid-like hyphæ. There appears to be no actual penetration of any twig upon which a cork layer has formed.

A branch is given off from the strand at the base of each leaf-stalk reached, and runs up the latter to the blade, where it breaks up into successively finer branches with irregular flat expansions and finally frays out into its ultimate threads. The tissue of the leaf is penetrated by connected mycelium of a different type, thin-walled and with numerous clamp connections. The leaves become spotted where penetration occurs, and finally dry up and remain hanging by the fungus strands. The smaller twigs also die. Where two leaves touch the fungus crosses from one to the other, often making a little knot or tuft of mycelium which firmly joins the two.

At intervals in the course of the strands along the twigs, and sometimes on the leaf-stalk, prominent hemispherical sclerotia are formed. They are creamy white in colour, rather smooth, and reach 3-4 mm. diameter. They are made up of hyphæ similar to those composing the strands.

\section{Control.}

The dependence of the fungus, for its development to an extent sufficient to be seriously harmful, on what may be regarded as excessive humidity, suggests pruning and the reduction of shade as the basis of control. The gathering of infected leaves and removal of infected twigs may be expected to have some influence in checking the disease and preventing its spread, but in the case of trees upon which the infestation is at all general it is ineffectual for its eradication. Spraying with Bordeaux 


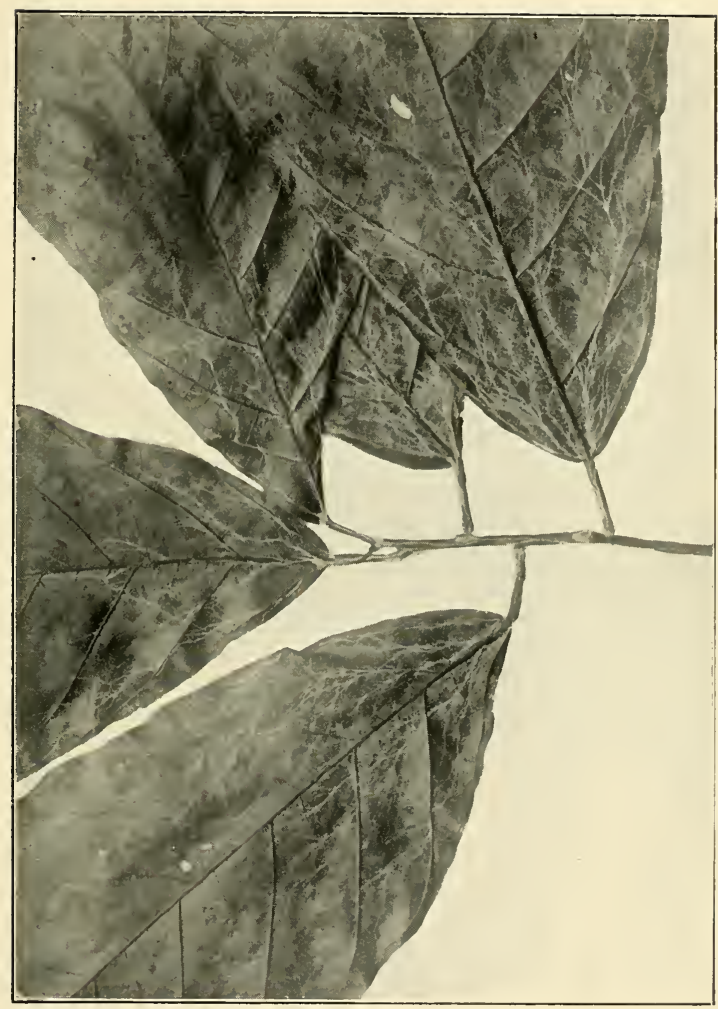

$\vdots$
है
कं
वं

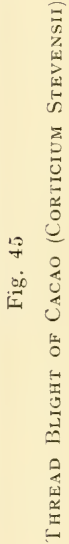

పై 

mixture affords the best means of control, but the expense of periodic application has to be faced as a permanent charge unless the humidity of the situation can be reduced.

\section{Corticium (Pellicularia) koleroga (Cke.) v. Höhn.}

This species occurs on coffee in Porto Rico, Jamaica, Trinidad, Surinam, Venezuela and Colombia, and has been identified with a fungus originally described from Mysore, India. As described by $\mathrm{E}$. A. Burt, the vegetative mycelium forms long, slender mycelial strands of rather uniform diameter, whitish or pallid at first, finally fuscous, running along the branches, and the midrib and veins of the leaves, infesting the leaves and ramifying between the cells of the leaf parenchyma, finally emerging at many points on the underside of the leaf to form minute fructifications which give a mottled appearance to the leaf; fructifications soon laterally confluent into a thin arachnoid, perforate membrane covering the under surface of the leaf between midrib and principal veins, drying pale smoke-grey. Spores hyaline, even, flattened or slightly concave on one side, IO-I $3 \times 3 \frac{1}{2}-5$ microus.

This species is distinguishable from the preceding by the absence of sclerotia and the thinner, lighter coloured, more firmly attached fructifications, which would seem, moreover, to be much more freely produced.

On coffee in Porto Rico, according to G. L. Fawcett, this thread blight is common on all plantations except those at higher altitudes, and is conspicuous from the appearance of the blackened leaves held suspended by its threads. It reduces the foliage and often causes the death of twigs. The berries are also attacked, but the loss from this cause is not important.

The fungus has also been observed in Porto Rico to occur under favourable circumstances on sour orange, Hibiscus, Croton, and two wild vines of the genera Luffa and Cucumis. It has recently been recognised to be rather common in Trinidad on coffee and "croton" (Codiæum).

\section{Control.}

The information from Porto Rico is that gathering and burning the diseased leaves gives poor results. Lime-sulphur sprays have proved ineffective. Bordeaux mixture prepared with an excess of lime is effective if followed by inspection and where necessary re-spraying.

\section{HORSEHAIR BLIGHT.}

This is the name given to fungus strands, closely resembling black horsehair, forming a loose tangle, with occasional attachments, among the leaves and twigs of cacao, nutmeg, and other trees grown under humid conditions.

It appears from recent investigations by $T$. Petch that the 
word blight is inappropriate, as the fungus does not enter living tissue, but derives its nutriment from the materials on which it occurs only after they are dead.

Horsehair blight occurs on cacao in the West Indies in Dominica, St. Lucia, Grenada and Trinidad. Similar forms occur in India and Ceylon on various jungle plants and on tea and nutmeg, and there are also records from Java, Australia, Africa, and South America.

Fructifications are occasionally produced from the threads while they are still on the tree, but more commonly from the leaves to which they are attached after these have fallen to the ground. They reveal that the horsehair-like material is a special type of mycelium pertaining to a group of species of the genus Marasmius.

The West Indian specimens at Kew, according to Petch, represent the species $M$. sarmentosus, Berk. The ideas as to its parasitism have apparently arisen from confusion with the effects of thread blight.

\section{Algal Disease, Red Rust.}

An algal organism, best known as the cause of the troublesome affection of tea twigs in India and Java named Red Rust, is widely distributed and common in the tropics, including apparently all the West Indian islands, occurring especially on the leaves of numerous trees. The twigs of cacao are occasionally attacked, and dieback due to this cause is not uncommon in Trinidad, is recorded from Jamaica and St. Lucia, and probably occurs to some extent in the other cacao-growing islands. This form of the disease occurs also on mango both in India and the West Indies.

\section{Causation.}

Cephaleuros mycoidea, Karst. (C. virescens, Kunze, Mycoidea parasitica, Cunn), the causative organism, is one of a group of mostly epiphytic algæ, and affords an instance of partial parasitism, which outside this genus is exceedingly rare in the algæ. The organism is very common on leaves, especially those with a smooth surface and somewhat leathery texture.

In this type of situation it forms, generally on the upper surface, orange or rusty red, roundish or less often irregular, slightly raised patches up to a centimetre in diameter. As a rule the presence of the alga on leaves causes little or no damage. In the case of tea, cacao, and mango alike it is in its occurrence on the twigs that destructive powers may be developed.

The first outward sign of the disease on cacao shoots is the occurrence during the dry season, on the twigs of the previous season's growth, of dark purplish or black spots ranging up to I-2 centimetres in diameter. With the coming of the rains these take on a rusty-red colour, due to the development of a 


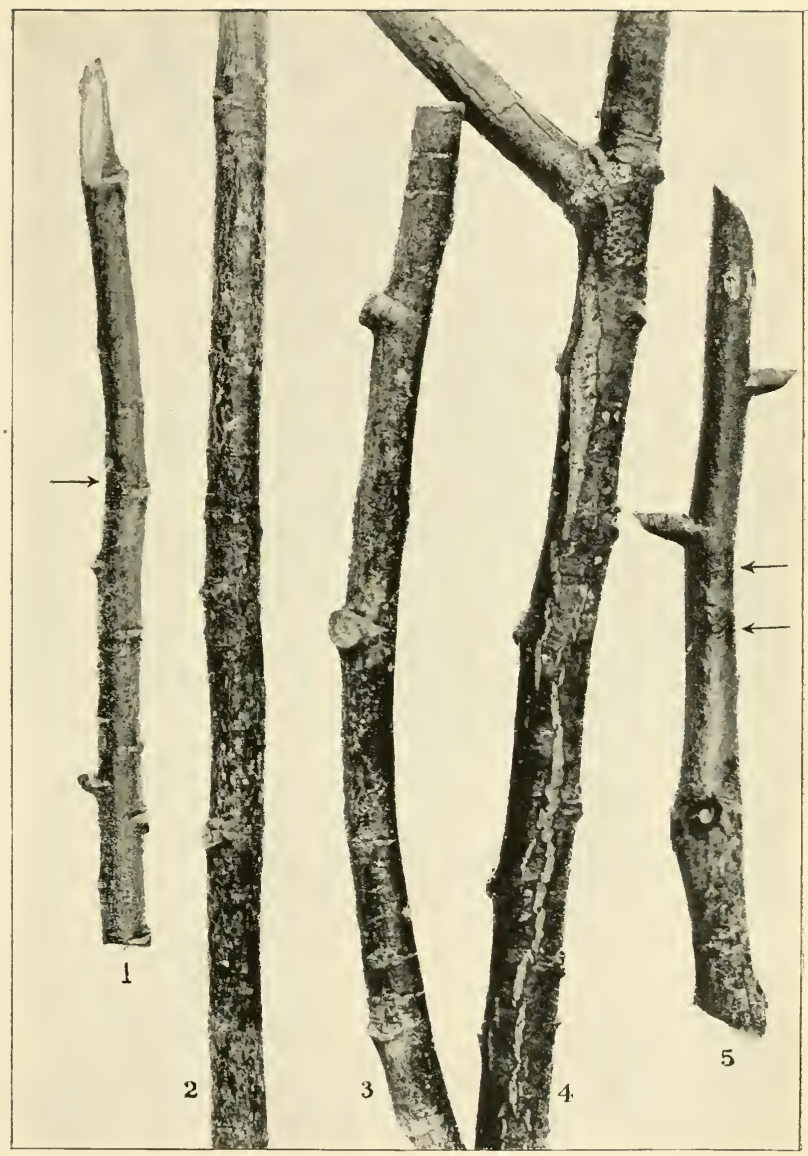

Photo by]

Fig, 46

[J. B. Rorer

Algal Disease of Cacao: Active Stage 

dense pile of fine hairs bearing tiny globular heads, the sporangia of the alga. The latter when ripe discharge upon being wetted numerous biciliate zoospores, which after a short active period come to rest and are capable of germination. The ripe sporangia are capable of being broken off and transported by wind before this discharge occurs.

A second type of sporangium, essentially similar, is formed in the body of the thallus as it occurs on the surface of leaves.

The alga is itself liable to be invaded by fungus hyphæ, the combination producing for a time a type of structure resembling that of a lichen.

\section{Nature of the Attack.}

On various leaves the alga exists in all conditions between the common case of mere attachment to the cuticle and complete penetration leading to the development of thalli (cellular expansions) on both sides of the leaf. The epidermal cells beneath an algal patch are usually but not invariably discoloured and dead. The only importance attributed to the occurrence of the organism on leaves lies in the provision of material which can infect the stems.

Infection of the twigs appears to take place from germination of the zoospores in the surface cracks which develop in connection with the formation of the first layers of bark. The alga pushes in among the cortical tissues, successive layers of which are sloughed away. The irritation caused by the presence of the parasite sometimes results in hypertrophy (abnormal swelling) of the twigs. In severe cases the separate patches first occurring on the twig may coalesce and completely envelop it for some distance.

If growth is not sufficiently vigorous to throw off the infection by new and deeper bark formation the result is the failure of the leaves and the death of the twig, and even if this does not occur the lesions in the bark are liable on weakly trees to afford access to the dieback fungus, Diplodia.

\section{Influence of External Conditions.}

The accounts of the diseases caused by this organism agree as to the dependence of serious injury on lack of vigour in the host. On tea the disease occurs suddenly and constantly whenever bushes become unhealthy from any cause whatever. On cacao most harm has been observed where the trees are in poor condition as a result of exposure or insufficient drainage, or in young plantations where favourable conditions have not yet become established.

The reasons for this are believed to lie in the inability of weakly twigs, as indicated above, to get rid of the parasite, and in the greater susceptibility to infection of twigs in which bark 
formation is weak and slow. It has been also observed that, at the other extreme, very quick-growing shoots produced on tea after severe pruning develop cracks in the bark which are liable to infection.

\section{Control.}

Spraying with Bordeaux mixture carried out early in the dry season has proved more or less effective against the disease, and is the most satisfactory method of control yet found. The means of permanent remedy, adopted with great success in the case of tea, must be sought in close attention to drainage, cultivation, and manuring. 


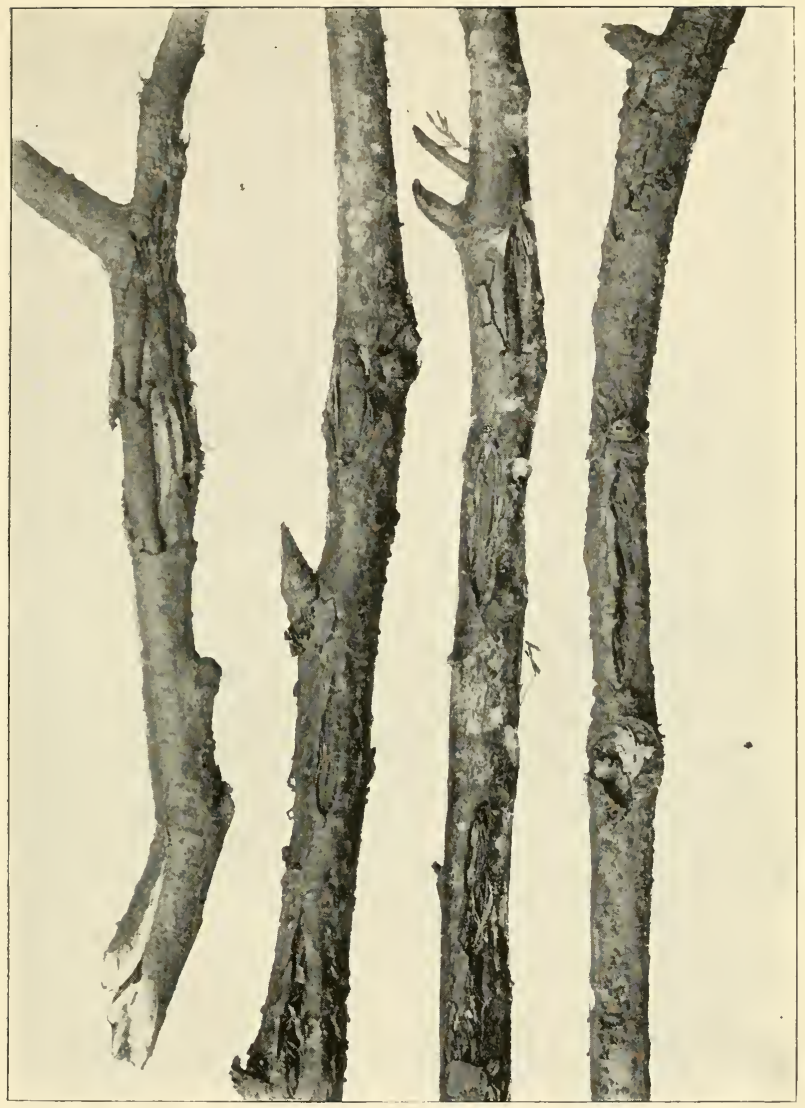

Photo by]

Fig. 47

[J. B. Rorer

Algal Disease of Cacao: Later Stage 



\section{Section II-Diseases of Permanent Crops}

\section{CHAPTER XVII}

\section{DISEASES OF CACAO}

According to Humboldt the home of the cacao tree is the forest of the basins of the Orinoco and the Amazon. The evergreen habit, the large thin leaves, the ability to endure shade and the intolerance shown towards wind are in accord with a moist forest habitat though it would be quite unsafe to conclude on this evidence that such a situation is necessary or even most advantageous for the commercial production of cacao from the tree.

When the factors which most directly affect cacao under cultivation are distinguished it is seen that no single combination of them can be regarded as necessary for its well-being, for within limits a deficiency in one may be compensated for by the surplus of another.

There can be no doubt that a rainfall regularly distributed throughout the year best suits the vegetative habit of the tree and leads to full and rapid development. But where frequent rain is associated with cloudy weather without a dry and sunny season the crop will usually be far less than in situations less favourable to vegetative growth. On the other hand a cloudy sky may be a great advantage when the rainfall is scanty. Any prolonged dry period, unless the soil is particularly deep and retentive, or very well protected, is highly unfavourable.

Cacao is naturally a deep-rooted plant, and, in situations where soil and subsoil permit this habit to be developed to the full, it enables the tree to pass with little harm through a dry season which would defoliate it in less favourable conditions. Deep draining is thus clearly indicated, in order that full penetration may not be hindered by subsoil waterlogged in the wet season. Equally clear is the disadvantage of planting over impenetrable subsoil where marked periods of dry weather are liable to occur. In the absence of such periods cacao is grown in Surinam, according to C. J. van Hall, in soil $x_{\frac{1}{2}}$ to 2 feet deep. In the coast lands of Venezuela the dry season is tided over by irrigation.

While the main roots will penetrate great depths to get in touch with subsoil water, the feeding roots are largely developed in the soil proper. Under some circumstances a dense layer of 
fibrous roots, known in Grenada as bichét, is formed close to the surface. The use of vegetable mulches is objected to by some planters on the ground that it encourages this formation of feeding roots where they are liable to be killed in dry weather. The effect of such a loss is probably not so serious as it is thought to be : some plants, notably the vine, habitually produce feeding roots of short duration.

These effects of rainfall, of depth of soil, and of dry seasons all depend on the conservation of moisture, and to some extent this is capable of being artificially regulated by the traditional method of growing trees for shade. The question of shade or no shade is often debated as though it were capable of a single and universal answer, whereas it depends entirely on local, and sometimes very narrowly local, conditions.

The control of the various pathological conditions arising from lack of vegetative vigour on the one hand and from infections favoured by too great humidity on the other, is largely dependent upon the adjustment of shade conditions, so that it is relevant to consider the subject somewhat closely.

A correct estimation of the factors involved and their effects requires systematic physiological studies which so far as the writer knows have never been made. In default of such studies the indications obtained from empirical observation and from analogy must be accepted.

That shade in some circumstances exercises a most beneficial and even essential influence is certain. The most essential fact, which is quite clear, is that the value of shade depends on its effect in remedying otherwise defective conditions and thus extending the range of situations within which cacao can be successfully grown. Where the natural conditions are in all respects good the introduction of shade is a definite disadvantage ; it is generally admitted that where shade can be dispensed with the trees bear more heavily. With soils of equal quality the estates which have least need of shade are those situated in sheltered humid situations, with no strongly marked dry season - conditions found in the neighbourhood of hills and forestwhile the need becomes more and more imperative with the increase of exposure and of inequality in the distribution of rainfall. Contributory differences in the same direction are seen in the transition from deep to shallow soils and from strong retentive soils to those which are light and very permeable.

The most convincing case of dependence on shade known to the writer is that of plantations on soils of the last-named character in St. Vincent. In spite of deep roots and of a high rainfall, the trees are poorly nourished, and the response they make to pen manure suggests that lack of organic matter, due to the nonretentive nature of the soil, is largely the cause of this. The provision of effective shade very distinctly increases the vigour of the trees. 
While the writer believes that the retention of humidity is an important contributory effect, he is disposed to agree with van Hall in the view that it is the protection of the soil, and not of the tree, that is the most important function of shade trees. The most pressing anxiety of the cacao planter-be his fields with or without shade-is to fill up with quick-growing leafy plants any gaps which may occur in the canopy. The rapid loss of humus which under tropical conditions takes place in exposed soil is well known. This is avoided over a large part of the year by the provision of shade, and a longer period of activity is permitted to the biological processes in the soil which lead to the nutrition of the plant. It is noteworthy that where no shade trees are grown, as on many estates in Grenada, their absence is compensated for by close planting and the use of large quantities of pen manure.

There is another well-recognised requirement of cacao, that of shelter from wind. Its effects are related to those of shade, and shade trees to some extent perform its function. It cannot be dispensed with, and if it is not provided by natural conditions must be artificially supplied. Its influence, without much question, comes from the preservation of a humid atmosphere about the trees.

\section{DIEBACK.}

The term dieback in connection with cacao has been generally used in connection with the effects ascribed to the fungus Diplodia theobrome, which there is little room for doubt often kills back the twigs and not infrequently large branches of trees when these are for some reason not in a vigorous condition. Since in practice it is impossible to draw a line between the cases of failure directly brought about by adverse conditions of growth, in which this fungus almost invariably appears sooner or later, and those cases in which the fungus plays a more active part, the term may be usefully extended to cover the general type of failure it implies.

The cacao tree is by its nature suited to humid conditions, to a considerable depth of soil, and a fairly abundant supply of humus. To secure these conditions a cacao field is usually so managed as to approximate to forest conditions in respect of atmospheric humidity, shading of the ground, and supply of organic material. This is usually accomplished by interplanting with shade trees or, where trees are dispensed with, by taking advantage of natural shelter, by close planting, and by the liberal use of mulch and pen manure. A fairly high and regular rainfall is required to maintain the necessary humidity, and where the rainfall is on the margin of adequacy the means of conservation referred to require to be the more perfect. On light, welldrained soil, again, more protection is required than on soils which are heavy and retentive. 
When the conditions fall short of any of the requirements outlined the effect is to induce in the tree a more or less severe manifestation of the condition referred to above as dieback.

The lightest form is shown only in diminished size and hardening of the leaves. Next comes the condition in which the outstanding twigs lose their leaves and dry off, new foliage being produced later from short shoots which develop further back. Trees in this state are familiar objects and present a more or less dense head of foliage with numerous twigs projecting above it. In yet more severe cases the dying back extends to the larger branches and may gradually involve them all. At every stage in this retrogression any temporary improvement in the conditions stops the process and new shoots are sent out behind the margin of injury, but with the recurrence of unfavourable con ditions the process may continue until the tree is wholly dead.

Some cases of root disease have occurred, in trees unfavourably circumstanced, in which Diplodia has been the only fungus detected.

Such failing trees, and trees in which the condition is as yet only incipient, are particularly liable to severe attacks of the cacao thrips, which contribute materially to their decline. There are good grounds for believing that it is only on trees lacking in vigour that infestations of thrips persist and do more than passing harm.

The part played by the fungus is impossible to define as it varies with every circumstance. It is safe to say that dieback would take place under appropriate conditions if the fungus were entirely absent, for this only means that the range of conditions to which the tree can successfully adapt itself is limited ; but with the fungus universally present as it is there is no doubt that it often takes a definite part in the process. This is especially seen when its mycelium coming down a smaller branch which is dead or dying enters and infests the wood of the larger branch to which it joins, cutting off the water supply and causing the death of that part of the branch above the junction. It may be said in general that the effect of the fungus when it has obtained a footing on the dead twigs is to extend the range of the injury, and give it a progressive nature in weakly resisting twigs or branches which might otherwise have remained for the time being alive. Where the conditions which induce the attack remain unameliorated the result in the end is much the same, but where they are temporary in their nature or exceptional the action of the fungus may greatly increase the resulting loss of branches.

\section{Associated Fungus.}

Diplodia Theobroma (Pat.): Fructifications consisting of black, carbonaceous, more or less rounded pycnidia immersed in the cortex; single or combined in groups or sometimes in a stroma ; pilose when grown 


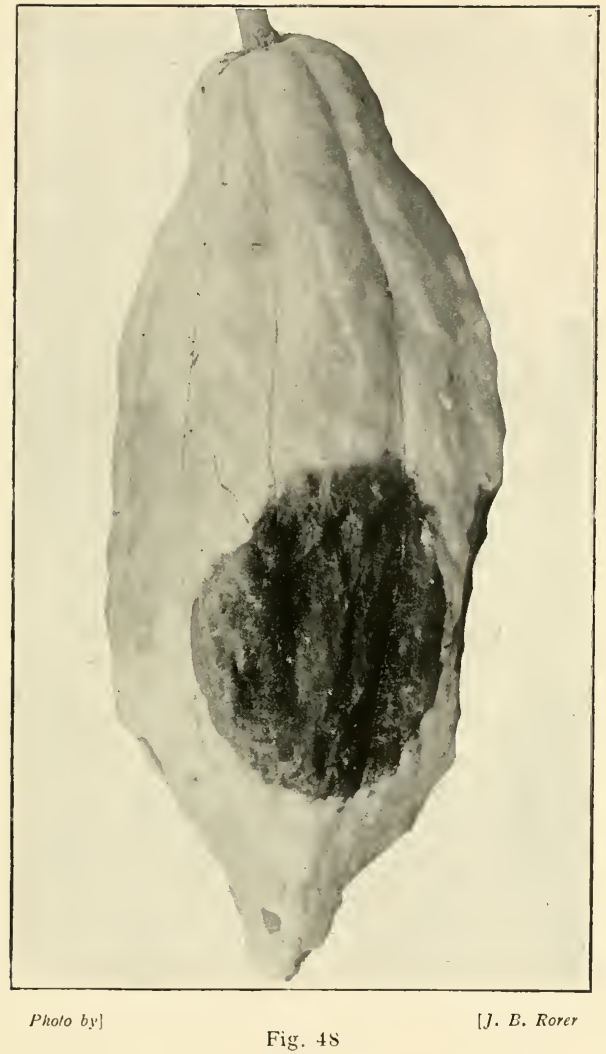

Diplodia Rot of Cacao Pod 

in moist air; 0.2-04. mm. in diameter. Spores on short simple sporophores accompanied by paraphyses; ovate or ellipsoid; when young, one-celled, hyaline, with granular contents, and often extruded in this condition; when ripe, uniseptate, slaty- or brownish-black, often longitudinally striate, usually $25-30 \times$ I 2-I 5 microns.

Mycelium septate, abundantly developed in the wood, hyaline when young, becoming successively grey, slaty-and brownish-black. Commonly gives to infested wood a slaty-grey tint.

The spores germinate in water whether in the one-celled or two-celled condition.

Synonyms: $\quad$ Botryodiplodia Theobrome Pat. 1892.

Macrophoma vestita Prill. et Del. 1894.

Diplodia cacaoicola P. Henn. 1895.

Lasiodiplodia nigra App. et Laub. 1906.

Botryodiplodia elastica Petch 1906.

Chaetodiplodia grisea Petch 1906.

Lasiodiplodia Theobromx Griff. et Maub. 1909.

Diplodia rapax Massee 1910.

The fungus is very widely distributed and common on a wide range of vegetable material. It is regarded as the cause of one type of cacao pod-rot and occurs as a semi-parasite in ripe sugar-cane. The same or closely similar species cause rots of citrus fruits and cotton bolls in these islands. A species not certainly distinct is associated with the dieback of lime trees.

The cacao species affects various other trees in a manner similar to that described above in reference to cacao, and in this way has come into prominence on Hevea in Ceylon and Malaya. It appears to be generally distributed throughout the tropical world, having been recorded from North, South, and Central America, the West Indies, Tropical Africa, Ceylon, Malaya, and the East Indies. It has been described under very many names, and it is still in some degree a matter of choice as to which shall be accepted. The genus Diplodia covers a large and ill-differentiated group of fungi which form sunken pycnidia containing two-celled dark spores, and has been subdivide 1 by splitting off new genera under the names Lasiodiplodia, Botryodiplodia, etc., based on the grouping of the pycnidia and the nature of their surface. The species under notice varies in these characters and has been placed in one genus or another according to the state of the actual specimens examined. The first description assignable to it seems to be that of Patouillard, who called the fungus Botryodiplodia Theobromo. Later P. Hennings described it again under the names of Diplodia cacaoicola, by which in consequence of the writings of Howard it became generally known in the West Indies. Bancroft in IgI claimed to have found the perithecial fructification and described it under the name Thyridaria tarda, which according to rule should rep ace any name given to the pycnidial form. The connection, which was not fully demonstrated, lacks confirmation and the name has not been generally adopted. The fungus is perhaps most zommonly referred to at the present time as Lasiodiplodia Theobroma. but it is evident that this genus is not based on constant characters 
and the combination Diplodia Theobroma would seem to be the soundest to use until a better subdivision of the genus is worked out.

\section{Control.}

The symptoms of dieback often appear in a group of trees or along the borders of a field, and occasionally in individual trees. It will be obvious from the foregoing account that for purposes of control it is first of all necessary to form some idea as to which of the many causes capable of bringing about this condition is responsible in the particular case. Where a group of trees is affected, especially if the trees around its margin are progressively involved, search should be made for the usually well-marked evidence of Rosellinia root disease. If this is not found the adequacy of the drainage and aeration on heavy soils should be next questioned. On light soils the conditions as to exposure both lateral and vertical should be considered in relation with the amount of rainfall received and the retention of sufficient moisture in the soil during periods of dry weather. If deficiencies in these latter respects are suggested by the circumstances they may be met by closing in the edges of the cultivation with quick-growing screens, for which purpose Aralia Guilfoylei has proved very suitable, by providing overhead shade, which may be most rapidly effected by putting in large cuttings of Gliricidia maculata (madura) and by the addition of pen manure or heavy vegetable mulch to the soil. A great deal of dieback, especially in peasant holdings, is directly due to neglect of reasonable measures of cultivation and manuring. The same is true of some neglected estates, while another cause is to be found in injudicious removal of shade. Cacao trees are sometimes planted where the soil is too shallow to maintain them, and the subsoil too dense for root penetration, in which case the trees reach in a few years the limits of their development and begin to fail.

In an affection such as this, which may be due to any of the numerous causes which react unfavourably on a tree which is tolerant only of a distinctly limited range of conditions, it is sometimes very difficult to find the cause of an unthrifty condition. The measures suggested above are all along the lines of good agricultural practice, and will not be wasted if they are applied in turn until the directly appropriate measure is discovered.

\section{Diplodia PoD-ROT.}

The rot of pods brought about by the fungus Diplodia Theobroma has commonly been known in the literature referring to the West Indies as the brown pod-rot, an unfortunate choice of name, since the Phytophthora pod-rot in its early stage colours most pods attacked by it a clear brown, and the anthrac- 


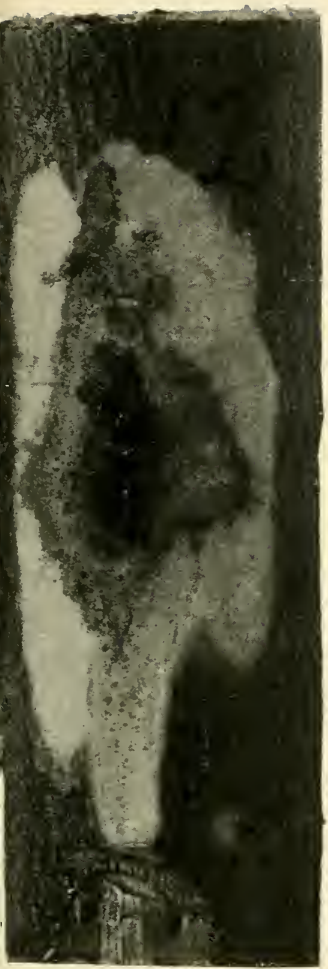

Photo by] J. B. Rorer

Fig. 49

CACAO CANKER

PRODUCED BY I NOCLLATION

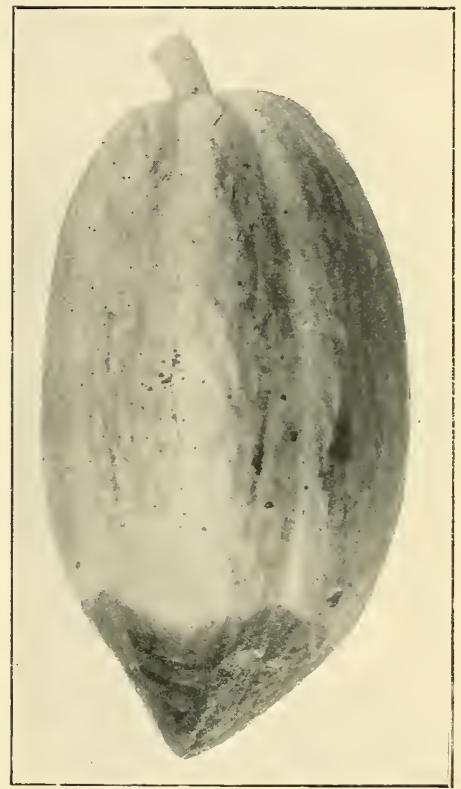

Photo by

[J. B. Rorer

Fig. 50

CACAO POD-ROT: TIP INFECTION 

nose fungus produces a similar effect. There can be little doubt from the present aspect of affairs that a great deal of damage which has been attributed to Diplodia was really due to Phytophthora, which is not always conspicuous on the pods it destroys and is quickly succeeded by saprophytes.

On the other hand Howard and succeeding investigators have found Diplodia capable of destroying pods to which it has gained access by way of injuries and it very commonly attacks pods which are over-ripe or have been left some time after being picked. It is usually abundant on heaps of cacao shells. This rôle agrees with that which it takes in connection with sugar-cane and citrus fruits.

\section{History and Distribution.}

A. Howard, writing in Igor-2, regarded the pod-rot met with in Grenada, Dominica, and St. Lucia as due to the fungus under notice, and described it accordingly. $\mathrm{He}$ failed to recognise the Phytophthora rot, believing it to be more or less confined to Trinidad. He secured artificial infections which quickly rotted the pods, but only through wounds. Van Hall and Drost, who conducted infection experiments in Surinam, found the fungus incapable of infecting sound, healthy pods, but able to cause the decay of picked pods or pods which by some means or other have been wounded or have already been attacked by other fungi. With this statement Petch entirely agrees as regards Ceylon experience, and in Trinidad Rorer has appeared to attach little importance to the disease. It is recorded each year from Grenada, St. Lucia and Dominica, but in view of the difficulties of diagnosis it is uncertain how much reliance can be placed on the differentiation between this and other pod-rots.

\section{Causative Fungus.}

This is described in connection with cacao dieback.

\section{Symptomis.}

The absence of the fructifications of the fungi described under Phytophthora pod-rot and anthracnose, and the presence from an early stage of the very different ones of Diplodia afford the best evidence of this affection. Small pustules, densely distributed, appear below the brown epidermis of the pod and raise small projections which cause the surface to be very distinctly rough. From each pustule as it ripens is emitted a string of spores which are white, grey or black according to the stage of development they have reached. The white unripened spores are one-celled, the black ripe spores are divided by a single septum. Both forms are capable of immediate germination. In damp air they hold together when emitted and form a tendril, when dry they form little powdery heaps. The whole pod is 
penetrated by an abundant dark slaty- or brownish-grey mycelium, which envelops and quickly destroys the beans.

\section{Control.}

The main points in the prevention of loss from this affection are indicated by the conditions of attack, i.e., avoidance of wounds (most of which are made by the pickers) and prompt collection of ripe or injured pods. The fungus is so abundant and the materials for its development so varied that attempts to avoid infection, once a favourable opening exists, seem to a mycologist rather hopeless. Against this has to be set, however, the fact that experienced agricultural officers in close touch with local conditions attribute visibly good results to sanitary disposal of husks and deplore any looseness in this matter. A further means of reducing the amount of infective material lies in the regular removal of dead and sickly branches from the trees.

\section{Phytophthora Pod-Rot ANd CANKer.}

It is regarded as established that the common types of pod-rot and stem canker are due to the attacks of the same fungus, and that there is in many cases a connection between them; they may therefore be most conveniently discussed together.

\section{Distribution.}

Apparently these diseases occur in all cacao-growing countries, though there are very considerable differences in their incidence. In the Western Tropics and in Ceylon both canker and pod-rot are prevalent, but pod-rot is the more prominent trouble, while in Java canker is a very serious disease and pod-rot relatively uncommon. These differences have not been explained, but may possibly be accounted for by the varying resistance of different types of tree and by the close dependence of the fungus on humidity. The loss of ripe pods during the rainy season in Trinidad is estimated by J. B. Rorer at 30 to 60 per cent. There are also heavy losses of young pods, as is shown by the increase obtained from spraying, and, further, the injuries to the trees themselves are a matter of serious consideration.

\section{History.}

The existence in Ceylon of a disease of the nature of canker was recorded in I833. At a much earlier date, in 1727 , the plantations in Trinidad were crippled by an epidemic of blight on the pods, which more likely than not was due to the affection under notice. The industry did not recover until the Criollo then grown was replaced by the more hardy Forastero 30 years later. In recent times J. B. Harrison called attention to pod-rot 


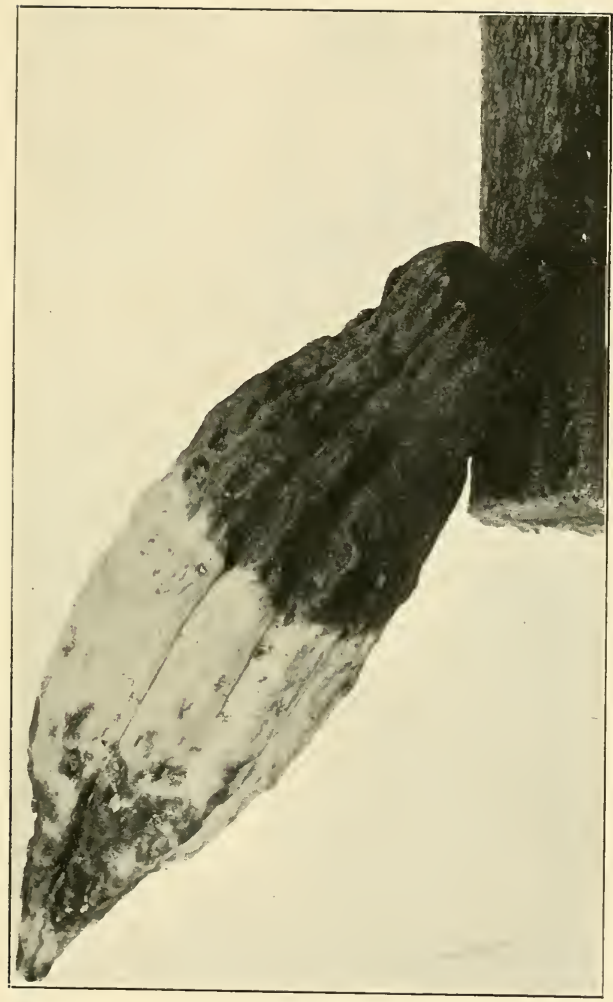

Fig. 51

Cacao Pod-rot produced by Inoculating Stem 

DISEASES OF CACAO
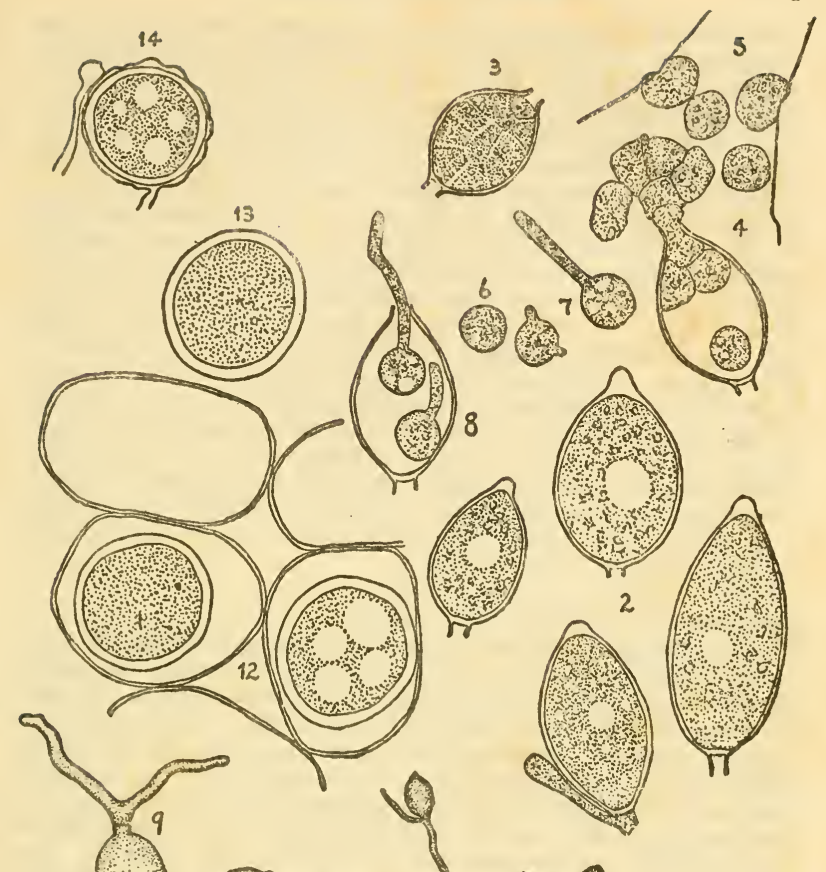

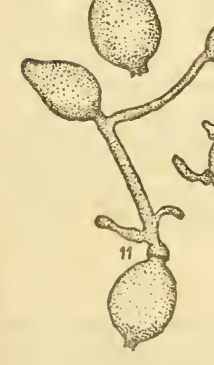

Dravn by] 
in Grenada in 1895, and in 1897 there was a serious outbreak of canker on Criollo in Ceylon. The examination by G. Massee of material sent to Kew led, as in the case of the West Indian sugar-cane epidemic, to a wrong diagnosis, and the researches of J. B. Carruthers, who was engaged through the action of the Ceylon Planters' Association, were inconclusive as to the causative organism. In I899 the fungus associated with pod-rot in Trinidad was identified by Massee as Phytophthora omnivora De B., and shown by J. H. Hart to be capable of producing the affection. The cause of canker remained much longer in doubt. It was attributed by a succession of mycologists to various fungi, mostly to the Nectrias, or their conidial stages, which quickly appear on diseased material. In rgro J. B. Rorer in Trinidad proved by inoculation experiments that the Phytophthora from the pods could give rise to typical canker, a discovery which was confirmed, and extended to the similar disease on Hevea, by $T$. Petch in Ceylon. Rorer also called attention to the susceptibility of the soft tissues of the stem shoots to attack by the same fungus, giving rise to an affection named by him chupon-wilt. The identity of the parasite was later decided as Phytophthora Faberi Maubl.

\section{Symptoms. (I) Phytophthora pod-rot.}

The fungus is responsible for the loss of pods at all ages, without the necessity for any preliminary injury. The cacao tree normally sets a good many more fruits than it proceeds to develop, and in this way the loss of young pods by disease is usually masked. On large pods the course of the disease is plain to see. Usually starting at either the tip or the stem end as a discoloured spot, a browning of the surface (or blackening in the case of dark red pods), with a clear line of demarcation, spreads along the pod until it is all covered. The rot involves the whole of the fleshy tissues of the husk and extends to the pulp and the contained seeds. Only in pods approaching ripeness in which the seeds are no longer in close contact with the shell can they remain for a time unattacked. -

The fungus appears on the surface of the pod as a whitish down which later may develop into a white mould-like covering on which masses of the sporangia accumulate. The pod quickly shrivels and blackens, and at this stage is usually conspicuously infested with secondary fungi.

(2) Canker.

As canker arises from the infestation of a patch of the living tissues of the stem, it is difficult to detect in its earlier stages owing to its effects being hidden by the outer bark. The occurrence of a succession of diseased pods may give rise to the first suspicion of its presence. Sometimes it can be detected by the presence of a dark patch on the bark, and at a later stage there 
is commonly a discharge, from cracks or borer holes in the diseased bark, of a reddish fluid which dries to a rusty deposit.

When the outer bark is shaved off the diseased tissue can be detected by the difference of its colour from that of the healthy tissue surrounding it, which further is commonly marked off by a dark brown line. The colour of the affected tissue may be brownish or claret-coloured. With the latter indication, which is the one commonly referred to, the deep pink colour normally present in some trees is liable to be confused.

The adjacent outer layers of the wood are usually more or less discoloured, and narrow dark lines may extend for a considerable distance from the point of origin.

The injury to the tree is consequent upon the killing of the patches of bark, and its severity is determined by the size and position of these. The main stem or a branch may be girdled and killed outright above the situation of the lesion; the interference with the functions of the bark may cause either local defoliation and death of twigs or a general sickly appearance ; or the effects may remain localized in the bark and natural recovery occur.

\section{(3) Chupon Wilt.}

The affection on the suckers is thus described by Rorer : " the chupon is generally first attacked in the soft tissue near the tip. A small water-soaked area can be seen on the stem which gradually becomes sunken and darker in colour and spreads up and down the stem, frequently girdling the shoot and causing the upper part to wilt. The same disease has been observed on young shoots on the upper branches of the tree. The point of attack is generally in the axil of a leaf, though the leaf blade or petiole may be the first part affected, the disease afterwards running down into the stem."

\section{The Fungus.}

The causative fungus is Phytophthora Faberi, Maublanc (Igog).

According to the original description the conidiophores are I 50-200 microns in length, non-septate, hyaline and terminated by an apical conidium, more rarely branching and bearing two conidia; conidia (sporangia) of various forms, generally lemon-shaped, with a thin smooth membrane, a little thickened at the apex, 30-80 × 25-42 microns; oospores rounded, smooth, with a thick membrane, 45 microns in diameter. Rorer gives the most usual dimensions of the conidia as $30-50 \times 25^{-27}$ microns, the number of zoospores as I5-30, the diameter of chlamydospores as 30-50 microns, oospores $33-40$ microns. There is no swelling of the sporophores below the conidia.

$\mathrm{J}$. Rosenbaum concluded after study of the bodies classed as oospores (from which antheridia are always absent) that they are properly to be regarded as multinucleate vegetative bodies with the function of chlamydospores. He found their greatest frequency of diameter to be 40 microns.

The fructifications of the fungus as seen on the pods consist of a whitish down appearing behind the margin of the brown 
discoloration of the surface, made up of slender stalks bearing the minute oval conidia. These when produced in mass form a white deposit. Fresh conidia continue to form on the stalks if the air is humid, and a felted white covering may be formed over the whole or part of the pod. The thick-walled resistant spores are formed in this layer and in the underlying tissues.

\section{Infection.}

The most abundant, but least resistant, means of dispersal is afforded by the conidia, which may be washed by water or blown by wind on to other pods. If they come to lie in a film or drop of water they function as sporangia, producing ro to 30 zoospores, which swim about by means of the two cilia with which they are provided. The zoospore settles down and produces a germ tube which penetrates the epidermis either directly or by way of a stoma. The whole process occupies only an hour or two. If the surface is merely damp with no free water present the conidium produces one or more germ-tubes without an intermediate zoospore stage.

The thick-walled spores are set free by the decay of the pod and are capable of remaining dormant in the soil or elsewhere until conditions are favourable for their germination. This takes place by the production of a short germ-tube bearing a conidium at its top from which infection may ensue as described above.

By these means pods on a healthy tree may become infected. How far or under what circumstances direct infections of the bark, producing canker, may occur does not seem to be known. It is, however, well-established that diseased pods commonly infect the stem on which they are borne, giving rise to canker, and, vice versa, that pods borne on cankered trees may become infected from the stem.

According to Rorer's experiments, "when the tissue of the pod at the stem end becomes well invaded by the fungus, the mycelium runs back into the cushion either through the bark or the central woody cylinder of the stem of the pod, or through both. If it has gained entrance to the tree through the thin bark layer of the pod stem it generally spreads out in all directions so that the whole cushion and surrounding area of bark becomes cankered; but, on the other hand, if the mycelium grows into the tree through the woody part of the pod stem the cushion may not become cankered. The mycelium will extend in narrow lines for some distance up or down the stem in the cambium layer but sooner or later will grow outward into the bark and then spread out rapidly, forming larger cankered areas."

The canker spots are quickly invaded by secondary fungi which occupy the tissues and complete their decay.

\section{Influence of External Conditions}

The parasite under discussion belongs to a group of fungi 
particularly dependent on humid conditions, consequently the diseases due to it are more prevalent in the rainy season and on trees with a heavy canopy, whether of their own foliage or that of shade trees. The conditions favouring the fungus are, up to a certain point, the conditions which favour vigorous growth of the trees, and a balance has to be struck between the losses and gains which may ensue from pruning and the reduction of shade and shelter. To one operation the antithesis does not apply: the provision of abundant deep drainage is beneficial in both directions.

\section{Inherent Resistance.}

The Criollo types are very susceptible to canker, and it is due to this fact and to their generally less hardy nature that they have mostly been replaced by the much more resistant Forastero and Calabacillo. Alligator cacao (Theobroma pentagona) grown in the Dominica Botanic Gardens proved to be so highly susceptible to canker as to discourage any attempt to use it commercially.

The suggestion that the susceptibility of Criollo is accounted for by the influence of the deeper shade under which it is grown would appear to be disposed of by the fact that in the manurial plots in Dominica Forastero and Calabacillo thrive, whereas under the same conditions the Criollo first planted was attacked by canker when 8-I2 years old, and has been almost entirely killed out. The same conclusion may be drawn from the observation that in grafted plants canker on a susceptible scion is sharply arrested when it reaches a resistant stock.

\section{Control.}

Beyond the general effects of the measures already indicated the control of pod-rot and of canker infections following pod-rot depends upon systematic spraying with Bordeaux mixture. Rorer has conducted large-scale experiments with this treatment for several years and has shown that in Trinidad the protection given to the young pods by spraying soon after a crop has set greatly increases the number of pods which come to maturity, while this and a subsequent application 4-6 weeks later during the development of the pods greatly reduces the amount of "black cacao" from diseased pods present in the crop. The results have been distinctly profitable from a commercial point of view, without taking into account the protection of the trees from canker. No hard and fast rules can be laid down as to times of spraying, they depend on the times of heavy setting and, as to the commercial return, on the extent to which losses occur. By combining nicotine sulphate with the Bordeaux mixture the spraying is made effective against thrips. The amount of 4-4-5o Bordeaux to be used per tree is estimated at I gallon and the number of trees sprayed per man per day at Ioo. The 
cost per Ioo trees, with materials at pre-war prices, was about \$IO per application. An addition of nearly 7,000 pods per $\mathrm{I}, \mathrm{ooo}$ trees, or $635 \mathrm{lb}$. dry cacao, has been obtained from sprayed as compared with unsprayed trees.

Van Hall has issued striking figures as to the success attained in the direct treatment of canker on a large and badly infested plantation of Criollo in Java. The practice of deep excision and treatment with carbolineum and tar having failed to arrest the losses, a change was made to a policy comprising (a) reduction of the heavy canopy by thorough pruning; $(b)$ treatment of the cankers by merely shaving off the outer bark to allow the infested tissues to dry out, the use of tar being avoided as preventing this consummation; and $(c)$ the more careful control of boring beetles, the tunnels of which afford openings for infection. By these means the number of trees attacked was reduced from 4,400 in the first to 318 in the third year, and the annual loss of trees from 5.4 to 0.7 per cent.

Rorer has pointed out that the collection and destruction of diseased pods, on which a good deal of stress has been laid as a sanitary measure, cannot be held to have much effect on the prevalence of this disease, and has been given up as unremunerative by planters who have tried it. There is an early and enormous production of spores from the affected pods while they are on the tree which is quite sufficient to maintain an epidemic, and the only feasible means of prevention during its continuance is the protection of the healthy pods by spraying. On fallen pods and husks the parasite seems unable to maintain itself against the competition of numerous fungi more efficient as saprophytes. In this respect it differs from Diplodia. It should be noted however in this connection that marked infestations of ten exist on the trees in the neighbourhood of the sites to which the pods are brought to be broken.

\section{The Surinam Witch-Broom Disease.}

The principal feature of this disease is the hypertrophy of young shoots, which assume a monstrous form and shortly die. To this feature are also added (I) the production of hardened (indurated) and malformed pods, which either fail to come to maturity or have a part of their contents spoiled, and (2) starblooms, which are crowded blossoms developed on hypertrophied cushions and usually resulting only in a few misshapen pods.

\section{History and Distribution.}

The disease was first reported in the Saramacca district of Surinam, about I895. It spread by degrees through the colony and caused an enormous amount of damage. The average annual export of cacao for the 5 years $1893-7$ was $3 \frac{1}{2}$ million kilos, that for the five years I908-I2 was reduced to I $\frac{1}{2}$ million, 


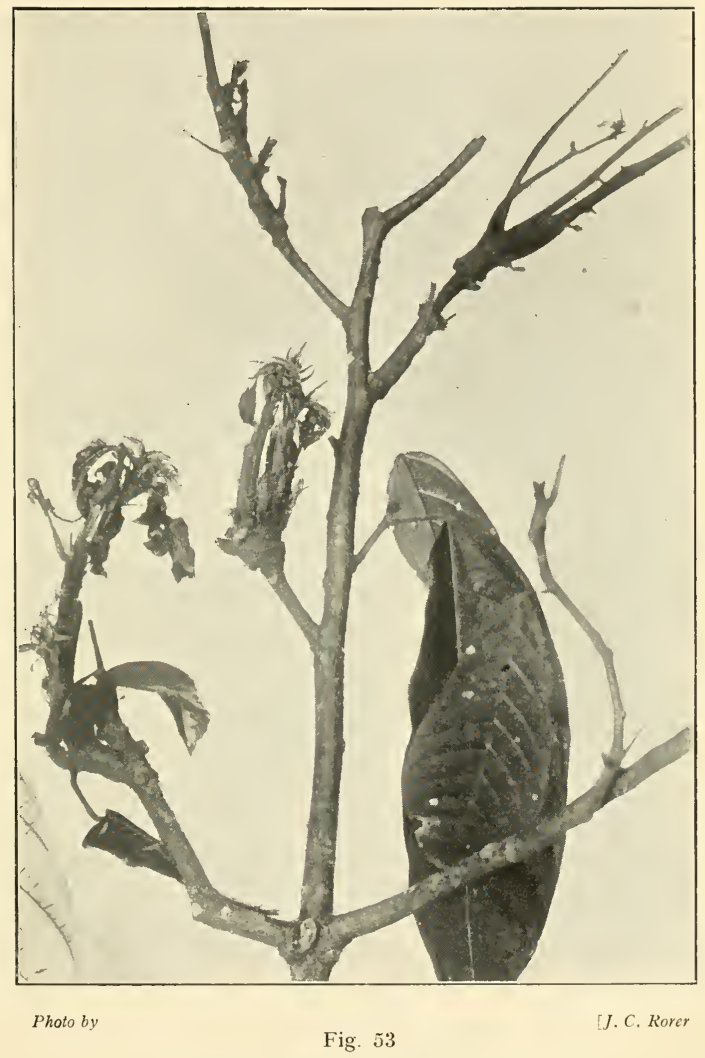

Surinam Witch Broom Disease 

The disease now occurs throughout Surinam, and has extended to the adjacent parts of British Guiana. It has not been recorded outside of the South American continent. A wild

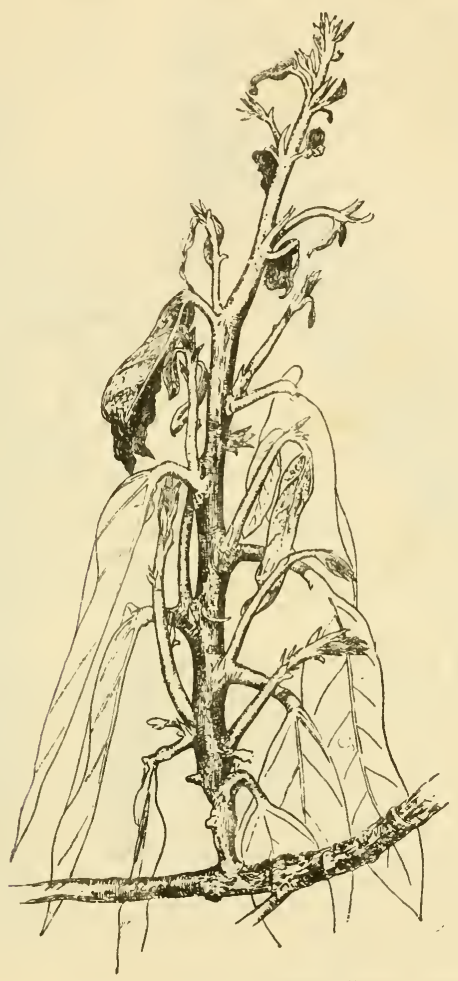

Fig. 54

A Typical Witch Broom

Theobroma ( $T$. speciosum) which occurs in the forests of southern Surinam is very liable to the disease and is thought to have communicated it to the cacao.

Ritzema Bos (I898, I899), Massee (I90I) and Howard (I9OI) examined preserved material. The first-named found traces 
of what he regarded as a fungus of the type associated with some forms of witches-brooms in Europe and described it as Exoascus Theobroma. Massee did not find this fungus present, and Howard observed only Fusarium spores. Went was the first mycologist to see fresh material. He found a mycelium in the tissues which did not fruit in cultures or reproduce the disease from inoculations. Van Hall and Drost (1907) made an elaborate study of the disease and concluded that it was due to Colletotrichum luxificum, which appears abundantly on the affected shoots and indurated pods; inoculations failed.

Rorer (I9I3) pointed out that C. luxificum is common in Trinidad although the disease is absent, and, further, that the mycelium in the affected shoots has clamp-connections which are characteristic of the Basidiomycetes. Inoculations with the mycelium were unsuccessful.

G. Stahel (I9I5) confirmed Rorer's findings, and examining the old witch-brooms for fructifications, found those of a Marasmius commonly present. The spores from this fungus allowed to fall on buds enclosed in test-tubes gave rise to the disease in (a) I4 out of $46,(b) 7$ out of $9,(c) 9$ out of Io cases, and infections were produced on a plantation previously free from the disease. Mycelium in pure cultures from the Marasmius spores agrees with that found in the shoots. The indurated pods contain an exactly similar mycelium and also bear the Marasmius fructifications, and both these and the diseased cushions have been readily produced by infection with Marasmius spores.

\section{Nature of the Disease.}

Van Hall and Drost's description of the appearance of a hypertrophied twig (witch-broom or krulloot) is as follows (Fredholm's translation): "It is generally two to six times as thick as a healthy twig, its surface is rough and somewhat furrowed, its base turgid, at times exhibiting longitudinal corrugations. The leaves do not become fully developed, but remain soft and flimsy like recently unfolded leaves on sound twigs; often they are of a darker colour. Among other characteristics should be mentioned the bending over of axillary buds, even before the witches-brooms are fully developed, the strong tendency to produce side-shoots, the retention of the supporting leaves, the growth of the shoots in a vertical direction and their short duration."

The shoot never becomes woody; it grows quickly, and in three to six weeks it dries up from the base. Both axillary and terminal buds and flowering shoots are liable to the affection. The bud infection does not in all cases involve the growing point, in which event the top of the shoot may develop normally.

The indurated pods, which always occur in association with witch-brooms, are of three types: (I) in which the principal symptom is the hypertrophy of the stalk-these arise from 


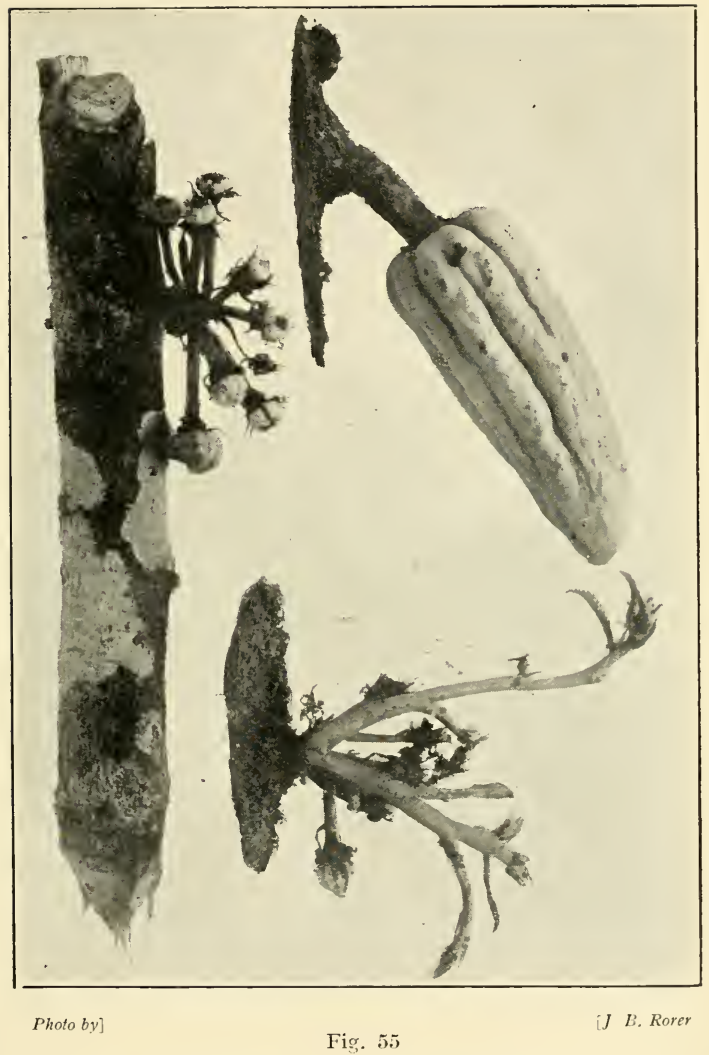

Surinay Witch Broom Disease 

infected cushions; (2) in which there is hypertrophy of the pod itself, producing humps or other malformations; such pods never ripen, but drop as a rule before they are half-grown; these arise from the infection of young pods ; (3) in which black blotches appear on pods beginning to mature, which have been previously unaffected; the damage consequent on these spots varies according to humidity ; there is a tendency for the affected beans to degenerate into a mucilaginous mass, in which the remainder may begin to germinate; the apparently sound beans obtained from such blackened pods are light and not fully ripe.

\section{Effects of the Disease.}

It does not appear that the direct effects of the development of witch-brooms are particularly severe. Each, of course, involves the loss of a shoot, and in the extreme cases in which the tree is infested with the growths this results in partial defoliation. When cut back, however, the trees exhibit considerable vigour in the production of new growth. The dead witchbrooms are liable to become infested with Diplodia, which then gains access to the branches. Canker-like diseased areas frequently form where they have been attached. From one cause or another many trees do succumb, and supplies are generally quickly attacked and prevented from developing.

The cause of diminished production is mainly to be sought in the infection of the flower cushions and the fruits.

\section{Causative Fungus.}

The fungus has been described by Stahel as a new species under the name Marasmius perniciosus, as follows:-

Mycelium intercellular on the living plant; entering the cells and forming abundant clamp-connections only in dead tissue ; when externally developed turns lemon-yellow in a few days and later may show dark crimson patches.

Fructifications on their first appearance spherical, somewhat pointed. Cap successively bell-shaped, flat parasol-shaped, and frequently, when old, concave above ; av. diam. 5-15 mm., max. $25 \mathrm{~mm}$., thin, somewhat fleshy. Primary gills 8-20 in number (aver. 15), corresponding with furrows on the upper surface, $\mathrm{I}-\mathrm{I} 5 \mathrm{~mm}$. wide and about $0.2 \mathrm{~mm}$. thick. Upper surface of cap tinted crimson, usually only faintly, with a dark-red central spot surrounded by rays of the same colour.

Stalk white to lemon-yellow according to age, hollow, 5-1o $\mathrm{mm}$. in length; base swollen, mealy or scaly, light lemon-yellow changing to dark brown or brownish red ; arising from a hyphal mass, not from rhizomorphic strands.

Spores 4-5 $\times 10-11$ mic., pure white in mass; germinate in rain water after 30-40 minutes; killed by one hour's desiccation (if spread out in a thin layer).

Occurs in damp weather on hypertrophied shoots and indurated pods of cacao in Surinam. 
The fructifications, small white toadstools closely resembling those of Marasmius Sacchari, appear in rainy weather on the blackened witch-brooms while still on the tree and also after they have fallen, on the indurated pods, especially small ones which have dried up on the tree, and on infected cushions. They have only been found on dead twigs of normal form when these came from the incompletely affected buds before mentioned. They have not been recorded from any other plant, living or dead. Dried-up fructifications return to their natural form when moistened and resume spore-formation.

\section{Mode of Infection.}

The witch-brooms are produced from buds infected by the spores of the fungus, which, being produced in large numbers from fructifications on the trees, can readily fall or be carried by air-currents into situations favourable for development. The pods are infected directly by way of the stomata, or indirectly from infected cushions.

The spores readily lose their vitality on drying, and it is found that unshaded cacao is very much less susceptible to the disease.

There is no knowledge of any varietal resistance, and both Theobroma bicolor and $T$. speciosum are susceptible to infection. Control.

The recommendations for control based on the discovery of Marasmius as the cause of the disease comprise the following .(I) Admission of more sun and air by pruning and by reducing shade trees. (2) Repeated and frequent clearing of the trees of witch-brooms and other diseased material, including infested cushions, all of which must be effectively disposed of by burning or burying so that the fungus cannot fruit. (3) Spraying with Bordeaux mixture once or twice annually as the season of growth approaches has been recommended, but is not found to be necessary for satisfactory control.

The method of cleaning up the trees by drastic cutting back of the branches before spraying is more quickly effective, but this advantage does not balance the loss of more than a year's crop which it involves.

\section{MONILIA POD-Rot.}

The Monilia Pod-Rot or Watery Disease has in recent years become prevalent to a serious extent in some districts of Ecuador. A general account of it was given by J. B. Rorer in I9I8; no technical description has yet appeared. The disease is doubtless indigenous to Ecuador, where it is found on two wild Theobroma species, and has not been recognised elsewhere. It is especially present in localities with a large rainfall and under such conditions may destroy almost the entire crop. In drier districts much less damage is caused. 


\section{Symptoms.}

The first positive symptoms are manifested on pods about 8 - $10 \mathrm{~cm}$. in length, and may take the form of a small protuberance or a certain amount of discoloration. When the pods which show these external signs are cut open it is observed that dark brown veins are present in various parts of the interior. In more developed pods the external signs of the disease may be slight, there may be one or more dark spots on the surface, or they may be more or less completely invested with a whitish growth of the fungus.

In the first case the pods show abnormality in form or appear somewhat discoloured, presenting areas of a bluish or yellowish colour as if premature maturity were being attained. In the second form the diseased pods display on their surface dark grey spots of different sizes from 0.5 to 3 or $4 \mathrm{~cm}$. in diameter. In the third form the pods from an early stage are partly or completely covered with a dense and shaggy growth of the fungus I-2 $\mathrm{mm}$. thick, white on the margin and slightly yellow or ashen in the centre and bearing an abundance of conidia.

When fully diseased pods are cut open it is observed that the interior of the husk, the central tissues, the pulp, and the seeds have become enveloped in watery matter and in some cases a quantity of water can be drawn off from the pod. The contents of the pod are found surrounded by a dark brown coating, which carpets also the interior partitions of the husk. The husk itself, when cut, exhibits black or dark brown strands or spots in its tissues and sometimes small watery cavities or areas surrounded by a definite dark-brown boundary. In addition there may be areas which present a striped or mottled appearance.

Observations on diseased pods have indicated that infection can only occur in their younger stages.

The causative fungus is a species of Monilia probably undescribed. Monilia fructigena is well known as the cause of the wide-spread brown rot of plums and other rosaceous fruits in temperate countries.

\section{Spheronema Black Spot and Bark Rot.}

Two affections previously undescribed, caused by a fungus of the genus Sphæronema, have been found by J. B. Rorer to be generally distributed in Ecuador. Like Phytophthora, the fungus produces a disease of the pods-black spot-and a bark rot which is so closely associated with wounds from the too ready cutlass of the labourer that Rorer has given it the name Enfermedad del Machete.

\section{Black Spot.}

This affection first declares itself on pods which are almost ripe. One or more dark spots appear on the surface, and gradu- 
ally increase in size up to diameters of $2-4 \mathrm{~cm}$. In the centre of the spot the mycelium occurs in the form of a very white, almost shining network, and sooner or later there appear a large number of slender vertical black stalks about a millimetre in height, each terminating in a minute white pearl-like head of spores.

When a pod so attacked is cut open an appearance of dry-rot is seen, and such pods are always lighter than normal. Occas ionally the seeds germinate inside the pod. The appearance of the spots within the tissues is very dark, and not striped or marbled as in the case of Monilia attack. The damage is much less than is caused by the disease mentioned, not all of the seeds are affected, and owing to the late appearance of the spots it is possible to save the pods by timely reaping.

\section{Bark Rot.}

Examples of the bark infection are stated to exist on almost all the cacao trees in Ecuador. The results are much less serious on the Nacional variety than on the Venezuela, of which thousands of trees are said to have been destroyed. The fungus is unable to attack unwounded bark, unless it be that of a tender twig or shoot, but occurs in practically every cutlass wound made.

The external surface of the bark around the cut becomes discoloured, and if the weather is damp a dark wine-coloured liquid may be observed to drip from the wound. Exposure of the interior tissues shows a yellowish or reddish discoloration which frequently extends some distance above and below the wound and occasionally around the branch. A dark line separates the healthy tissues from those attacked.

\section{The Fungus.}

The fungus which has been proved by numerous inoculations from pure cultures to be the cause of these affections is a species of Sphæronema probably as yet undescribed. The black stalks mentioned above are the slender elongated necks of buried pycnidia, producing pycnospores; the white mycelium on the spots forms conidia in simple chains, and chlamydospores are produced on the hyphæ.

\section{ANTHRACNOSE}

At least one definite anthracnose of cacao pods occurs in the West Indies, existing quite apart from other types of pod diseases. Little importance has been attached to it, and it has not been made the subject of any detailed investigation.

\section{Symptoms.}

With the following description by F. W. South, later observations, made by the writer in St. Vincent, agree. "Infection usually shows itself in the form of small spots on the surfaces 


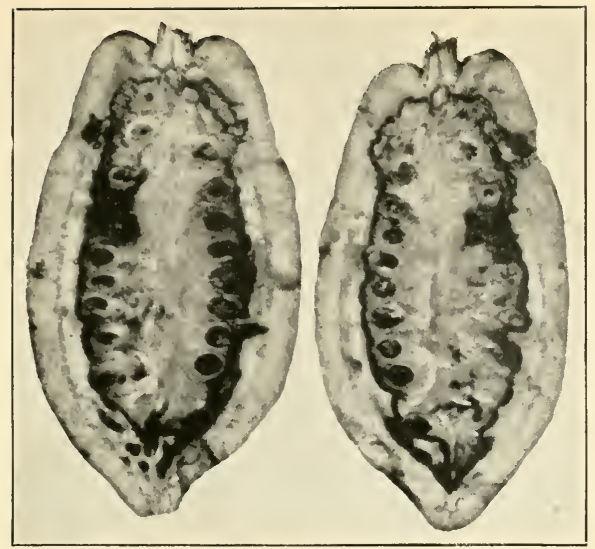

Photo by]

[J. B. Rorer

Fig. 5ti Monilia Disease of Cacao (Ecuador)

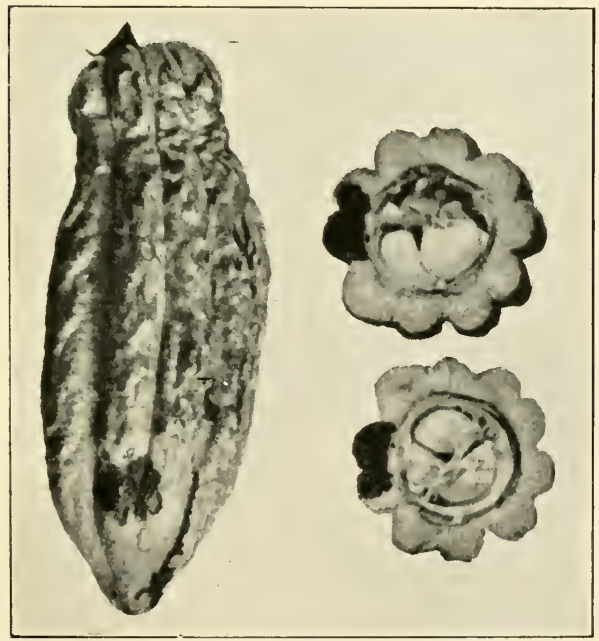

Pholo by]

(J. B. Rorer

Fig. 57 Sphaeronema Black Spot (Ecuador) 

of the fruits, which may be of any age. These spots are at first moderately light-brown in colour, but later become darker and are sunken below the general surface level of the pod; they are usually limited in extent and irregular in outline, while the tissues in the centre of the spots become hard and dry. The tissues of the rind below the spots are brown and diseased, and the causative fungus penetrates as far as the beans. When the spots are commencing to dry, small yellow pustules, not as much as I mm. in diameter, break through the epidermis. These are closely crowded and become pink as they develop, so that the centres of the spots are covered with an almost continuous pink coating consisting of millions of small, colourless, unicellular, hyaline spores belonging to a species of Colletotrichum. In some cases the spots fuse with one another and produce large discoloured areas, while in extreme cases the whole pod may become discoloured and completely destroyed ; this is especially the case with young pods."

The disease is much less prevalent than Phytophthora rot, but can occur under conditions of dryness in which the former disease is absent.

\section{Identity of the Fungus.}

A disease which closely resembles the West Indian anthracnose in its characters has been recorded by Busse from cacao in the Cameroons, and is attributed to Colletotrichum incarnatum Zimm. (C. Theobroma App. et Strunk), originally described from coffee in Java. The same fungus occurs on cacao pods in Ceylon.

In the West Indies C. Theobromicolum Delacroix, C. luxificum, Van Hall et Drost, and C. Cradwickii Bancroft have been described from cacao pods. Whether these are really separate from each other and from the Old World species, and how far any or all of them give rise to disease cannot at present be stated.

\section{"Male" Cacao}

In each of the cacao-growing islands it is a familiar experience that an occasional tree occurs which persistently produces enormous and quite abnormal numbers of flowers thickly distributed over its stem and branches, without setting more than a very occasional and often imperfectly developed pod. Trees of large size and high vigour have been seen in which this condition was reported to have prevailed throughout their history, and this persistence appears, so far as the information collected by the writer goes, to be characteristic. Beyond casual attention no investigation of the condition seems to have been made, its rarity having allowed it to be passed over for matters of more direct importance. Appearances are against the idea of communicability and hence of parasitic origin, since surrounding trees, in cases observed, have shown no sign of alteration after years of close contact. 


\section{WOODY EXCRESCENCES}

Instances are sometimes observed in which large woody nodules or rounded excrescences are produced on stems and branches. In some instances at least, the habit persists throughout the life of the tree, the trunk and branches of which have in consequence a very distorted aspect.

The cause of the condition is so far unknown, but as in the case of "male" trees it has been kept under observation for years without any sign of communication to adjacent trees having appeared.

\section{Root Diseases}

The principal root diseases of cacao are caused by species of Rosellinia, and are described under the heading of general diseases. Occasional instances of root disease are attributed to Diplodia (see Dieback). At least one other form of root disease has been seen in Trinidad, but not yet investigated.

Algal Disease

Thread Blight

HORSEHAIR BLIGHT

Pink Disease

(See under General Diseases). 


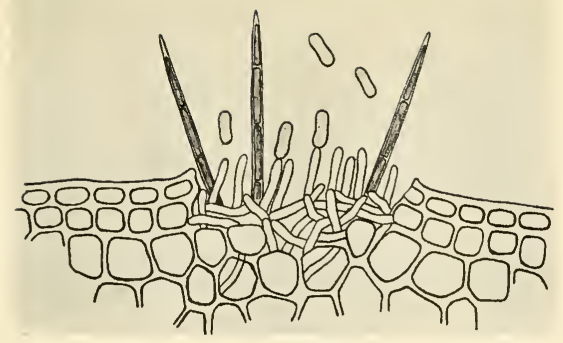

Fig. 5s Colletotrichum Cradwickil

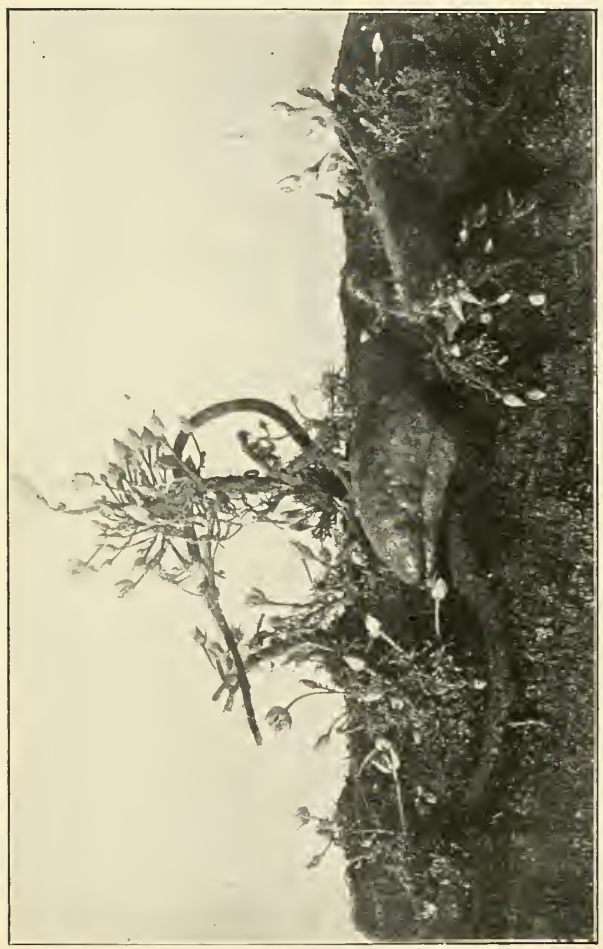

Photo by]

[J. B. Rorer

Fig. 59 Flower Proliferation (Male Cacao) Trinidad 



\section{CHAPTER XVIII}

\section{DISEASES OF COCONUT}

\section{The Red Ring Disease}

THE disease for which the above name is now used was first brought to notice by J. H. Hart, in I905, as occurring in the district of Cedros on the west coast of Trinidad, where it had apparently been in existence for many years. The disease was investigated in Trinidad by F. A. Stockdale, in I906, and distinguished, under the name of root disease, from the specific bud-rot which it resembles in its later stages. It was attributed by him to a fungus of the genus Botryodiplodia. J. B. Rorer about IgIo made an extensive mycological investigation of material from diseased trees, and reached the conclusion that the affection was not due to any fungus parasite but that it was a physiological trouble resulting from unfavourable conditions in the soil.

The present writer first met with the disease in Grenada in I9I8, and finding a nematode to be constantly present in the affected tissues put forward the theory that it was due to the parasitism of this worm. This was supported by later observations in widely scattered localities in Trinidad, Tobago and Grenada, and has been confirmed by numerous experiments in which the introduction of small pieces of nematode-infested tissue among the leaves of healthy trees has invariably led to their rapid infestation with the worm and the reproduction of the characteristic symptoms of the disease.

The disease is widely prevalent in Trinidad and Tobago, and has occurred in the last few years in various districts of Grenada. Several cases are now known to have been met with in St. Vincent about the year IgI2 and a recent occurrence is reported. In I920, W. R. Dunlop found the disease to be very prevalent in the inland plantations of British Honduras, causing losses which appear to be on as wide a scale as those in Trinidad. F. Stell has found typical cases in British Guiana, and J. R. Johnston reports its presence to a serious extent in Panama. There can be little doubt, from various accounts seen of the losses of young trees attributed to bud-rot, that the definitive description of red ring disease will lead to its detection in several other localities in tropical America. The writer has seen typical specimens from Panama and Venezuela. 
The disease has not been found in other palms with the exception of a case in an unidentified species of Cocos.

\section{External Symptoms.}

The failure of the tree is marked by a progressive yellowing and browning of the leaves in order of age, commencing at the tip of each leaf reached in the process. Commonly the lowest living leaves are the first affected, but occasionally one or several of these may remain green while the discoloration, commencing above them, successively involves the younger leaves. In the early stages the process is indistinguishable by external appearances from the natural dying off of the old leaves, especially where this is accelerated by drought, water-logging, or poor conditions of growth in general. The difference becomes apparent however from the steady march of the discoloration, which soon begins to involve leaves in full vigour, and continues to those in which the leaflets are not even fully expanded. A tree at this stage is exceedingly conspicuous from its rich colouring of brown, orange, and yellow, involving all but the central tuft of young leaves. This condition may be reached in three or four weeks from the time of appearance of the first symptoms.

The shedding of green nuts in all stages of immaturity may take place concurrently with or slightly in advance of the discoloration of the leaves and is thus in some cases the first external sign of trouble, though it must be remembered that shedding of small nuts often occurs from healthy trees.

Secondary infestation of the failing leaves with Diplodia sp. results in the development of patches of brown or black rot, wet but firm, in situations on the leaf-stalks, especially towards the base. This appears to be the chief reason for the tendency of the leaves to break across and hang down. Such infestations are common in healthy trees on leaves approaching senility, but have much more scope when the leaves are failing in rapid succession from disease.

In the final stage of the disease there ensues a bacterial soft rot of the tender tissues forming the apex of the stem, as also of the similar tissues at the base of the young inflorescences. There is no connection between this and infectious bud-rot disease : death of the coconut palm from widely differing causes is regularly followed by bacterial putrefaction of the enclosed soft tissues of the bud.

\section{Internal Symptoms.}

The following description applies to trees during the process of failure of the leaves before the secondary rotting of the bud begins. A cross section towards the base of the stem shows a well-marked zone, usually $I-I \frac{1}{2}$ inches wide and beginning $I-2$ inches from the periphery, in which the ground tissue is dull red 

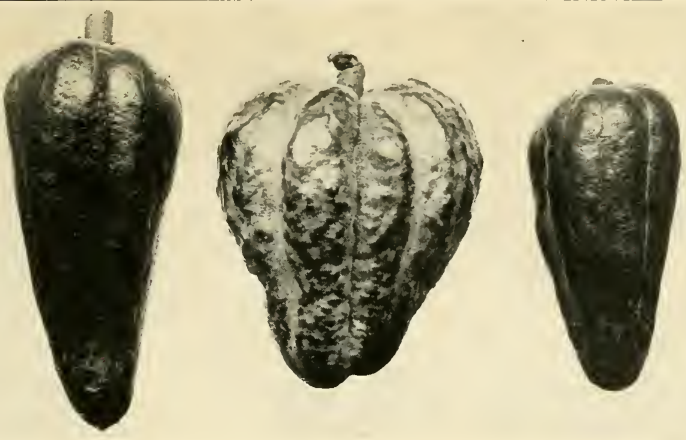

Photo by

Fig. 60 Pods from Male Cacao Tree

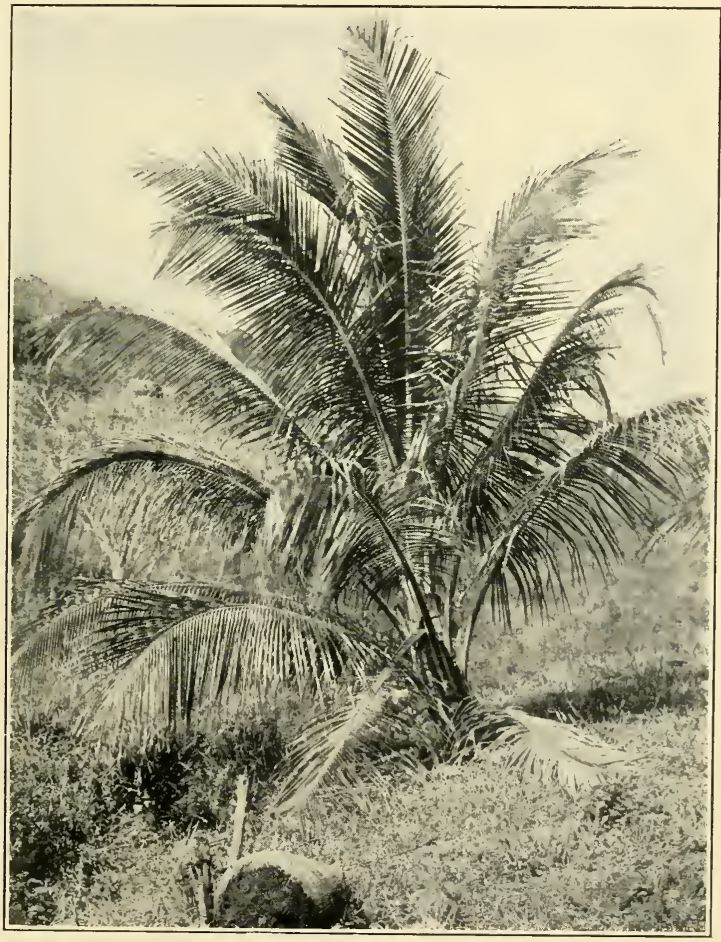

Fig. 61 Red Ring Disease: Fully Infested Tree 

or red mingled with mustard yellow. A vertical section shows the zone completely surrounding the base of the stem, extending upwards as a solid band of reddened tissue to about half its height, then breaking up into longitudinal streaks and finally into scattered dots about I mm. in diameter. In the latter form it extends to the soft meristem underlying the bud, in which region the dots appear generally dispersed below the flattened apex of the stem. In very exceptional cases the discoloration in the stem as a whole is central.

When the leaves of a tree in this stage are split open in the median line a similar red-spotted or red and yellow streaked discoloration is revealed in the leaf-stalk, extending in the fully developed leaves from near the base to a distance of from 6 inches to $2 \frac{1}{2}$ feet outwards. In the older leaves it becomes masked by the development of brown rot or by the natural browning of the tissues. In the leaves of the central column which still remain green, the internal discoloration of the petiole appears with great intensity, and often extends to the undeveloped leaves which they enclose.

In the oldest leaves the infestation extends to the base, but has no apparent connection with the red zone in the stem. As the successive leaves are examined in order of age the discoloration recedes upwards, but has been frequently seen to retain at first a narrow connection with the base on the dorsal side. In the soft white central leaves the petiole for a distance of from several inches to a foot from the base is usually normal in appearance, and then often contains an enclosed central infestation marked by vivid red and yellow spots and sometimes extending for two or three feet within the rachis.

In the roots the visible effect of the disease is confined to the cortex, which consists of radial lamellæ loosely packed into the region between the horny hypoderm and the central woody strand. This tissue is pure white and soft when healthy, but when infested it becomes dry and flaky, and is discoloured, first light yellow or pink, then dark yellow or reddish brown. The infestation may extend for any distance from an inch or two to Io or 12 feet from the point of attachment ; it is continuous, and decreases in intensity in the outward direction. Infested trees vary very widely in the extent to which the roots are affected. A tree which is fully infested in stem and leaves may show only the very beginnings of infestation in the roots.

\section{Causation.}

While fungi and bacteria are rare and casual in their occurrence in the infested tissues until an advanced stage is reached and decay begins, there is a perfectly constant association of the worm with the lesions existing in the stem, leaves and roots; an association which begins with the first trace of discoloration and persists until the infested tissue is dead and decayed. The 
scattered red dots in otherwise sound living tissue, which mark the upper extension of the red zone in the stem and the beginning of infestation in the leaf-stalk, are initial nests containing usually a few adult worms together with larvæ and eggs. The red zone in the stem is in its every part simply a vast infestation with myriads of active worms.

In sections of the tender white meristem of the upper extremities of the stem and of the embryonic leaves the worms may be seen in large numbers threaded along between the cells like fungus hyphæ or lying coiled up in the larger intercellular spaces. In this kind of tissue they appear to be able to travel in any direction and are by no means confined to the discoloured spots which mark their breeding places.

In the roots the worms are present in numbers which have been estimated by N. A. Cobb to exceed 20,000 to the linear foot. These are adult and larval stages, eggs having been rarely found in the roots. On the other hand abundant reproduction takes place in the red zone of the stem, being apparently most active in its upper sections.

The infestation is in all cases confined to the ground tissue, the vascular bundles remaining to all appearance unaffected in any way. Neither the species concerned in this disease, nor any remotely comparable infestation, has been found in careful examination made of trees failing or dead from other causes.

Infection experiments, carried out by the writer in Grenada (with the help of J. C. Moore) and later in Trinidad have given uniformly consistent results, while the equal number of controls have been unaffected. Introduction of a fragment of infested tissue (I) into the stem, by way of an auger hole immediately closed by a tarred plug, (2) into a wound made by cutting out a small cube from the petiole of an upper leaf, (3) into one or several leaf axils, without artificial wounds, produces typical infestation which becomes externally evident usually in about 60 to 70 days. The characteristic red zone in the stem is developed in infections by each method even in trees Io or I2 years old, and is dense at the base and lighter above as in natural cases. In leaf axil infections purposely examined at an early stage infestation of a small number of leaf bases, without evidence of extension into the stem, has been found, and very occasionally such cases have been met with by chance in the field. The next phase of infestation is the appearance of the red ring at the base of the stem.

It is rare for trees to show signs of infection at less than four to five years of age. The writer has met with one plant judged to be not more than three years old which was changing colour and was found to be infested in the leaves only. In the great majority of cases the trees develop the disease during the bearing of the first few crops of nuts. The most critical period may be said to extend from the fourth to the seventh year, but cases 


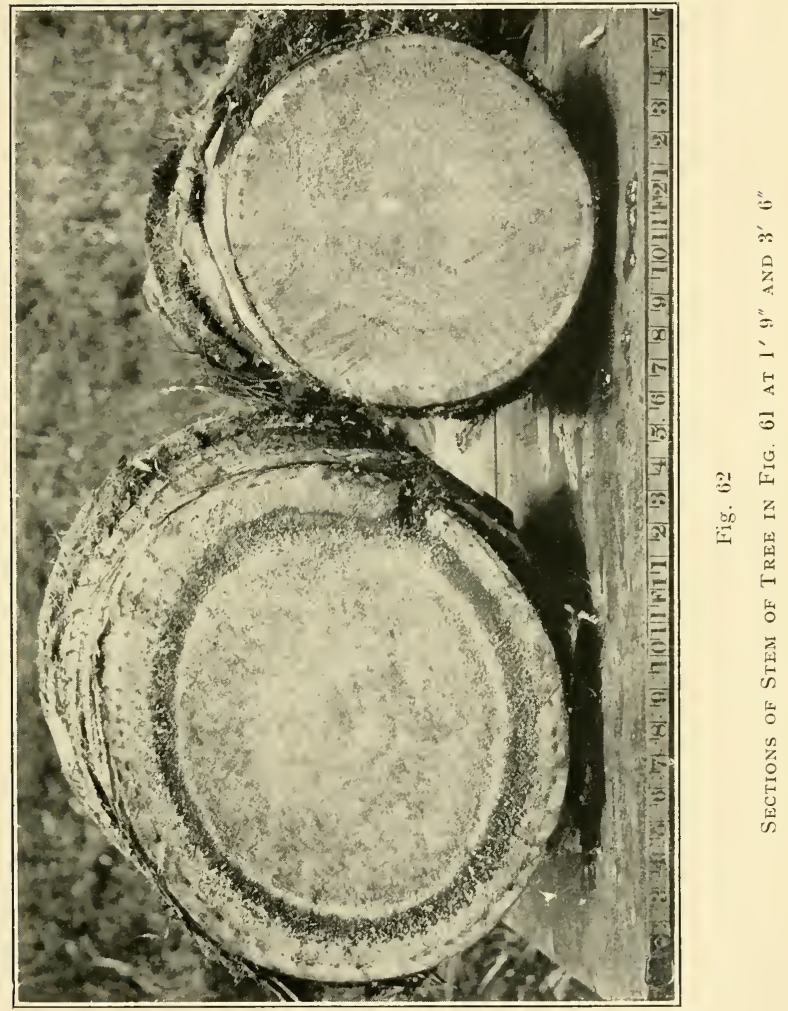







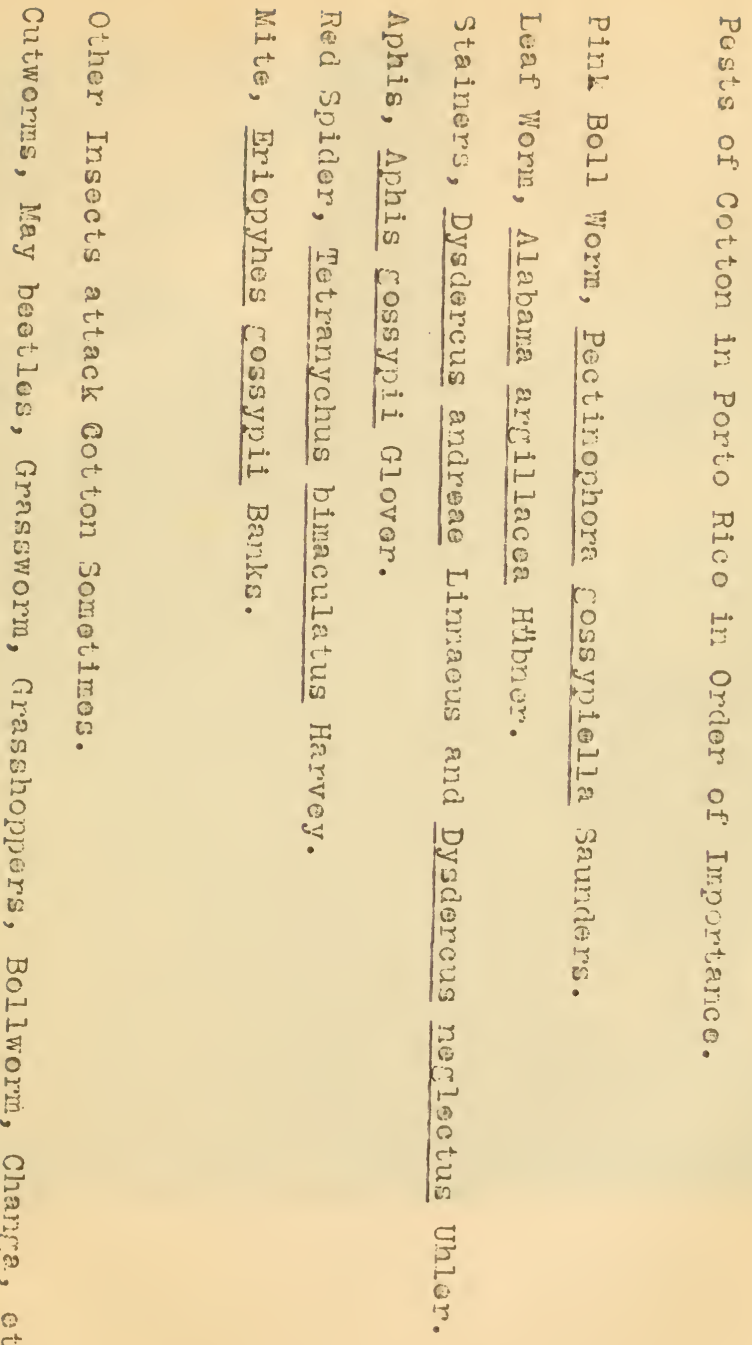





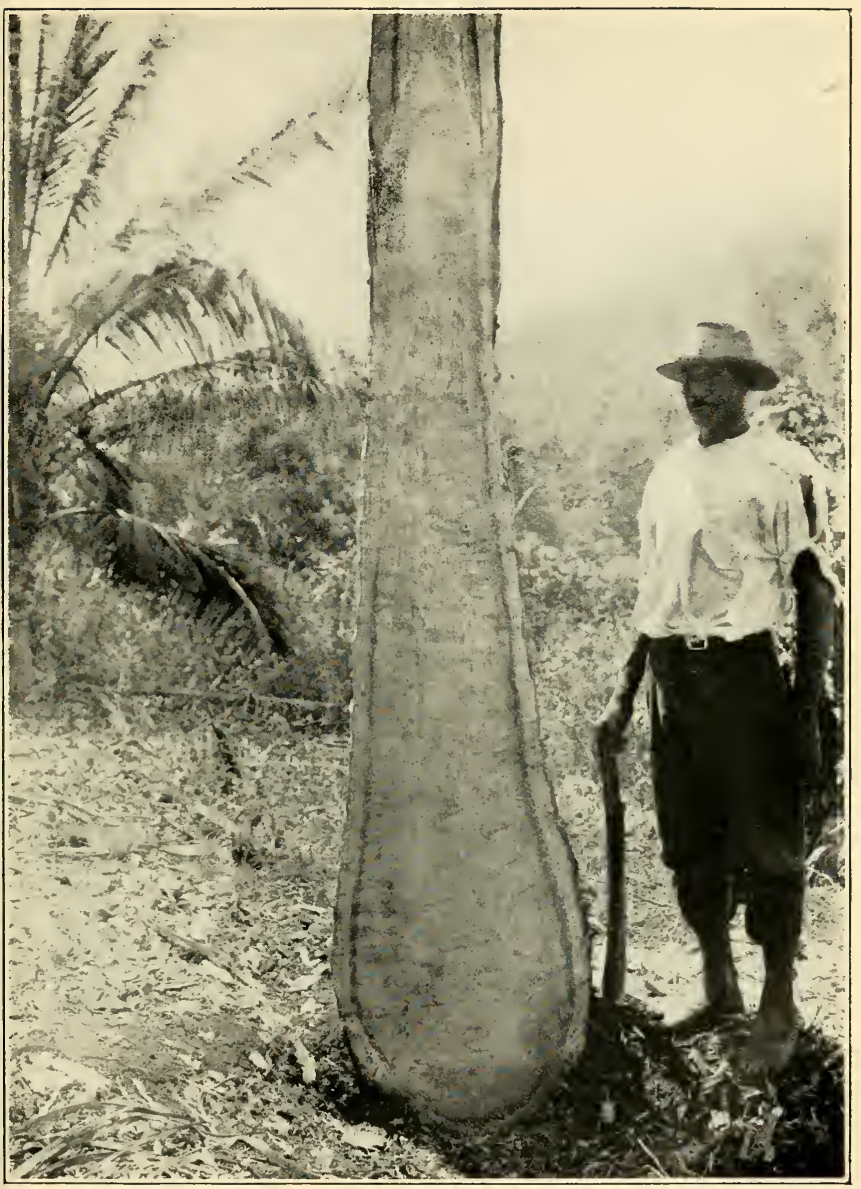

Fig. 63

Red Ring Disease: Median Section of Infested Tree 



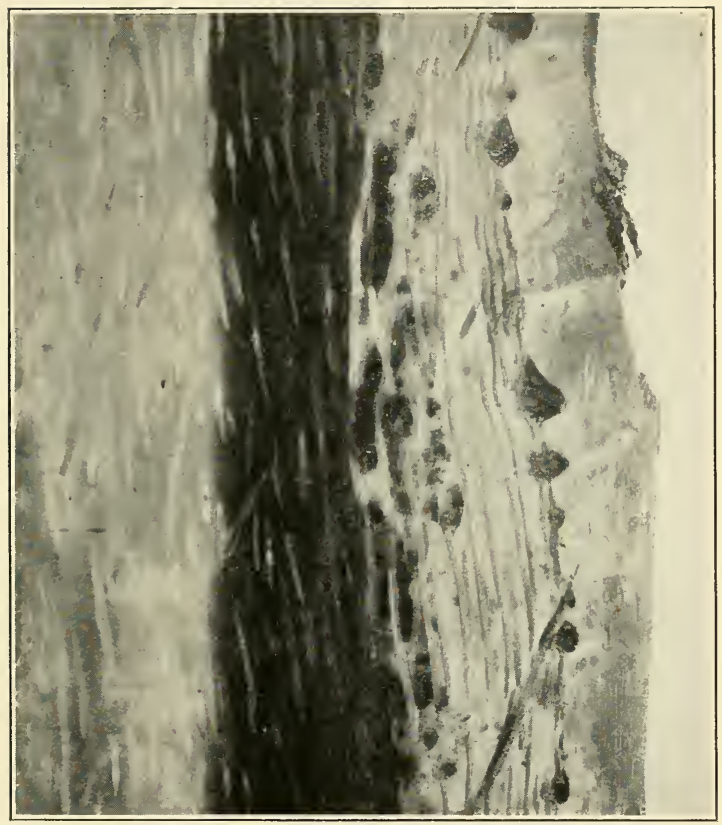

Fig. 64

Red Ring Disease. Longitudinat, Section of Segment OF STEM 



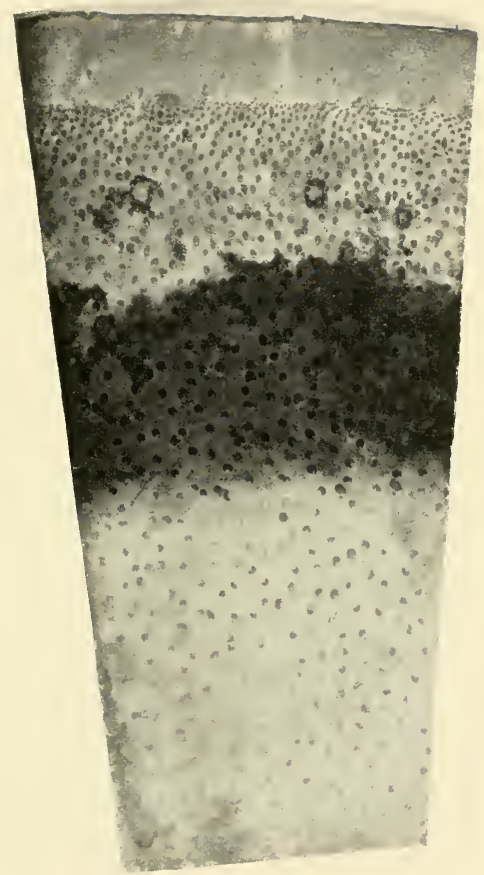

Fig. 65

Red Ring Disease: Transverse Section of Segment of Stem 



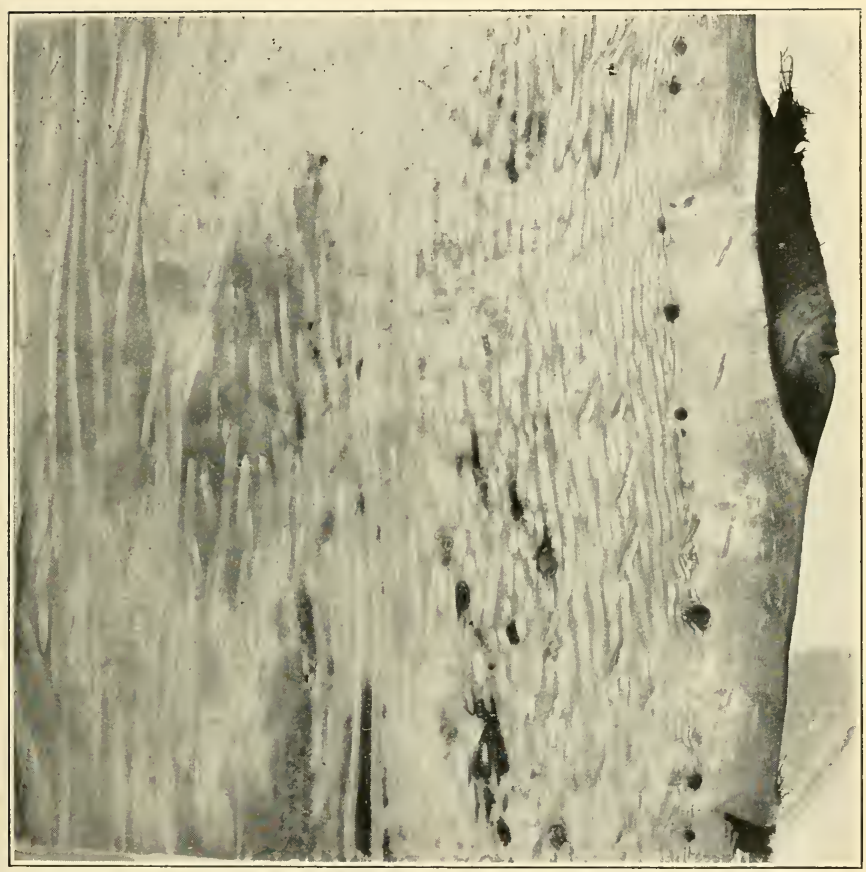

Fig. 66

Red Ring Disease: Section near Upward Termination of Ring 



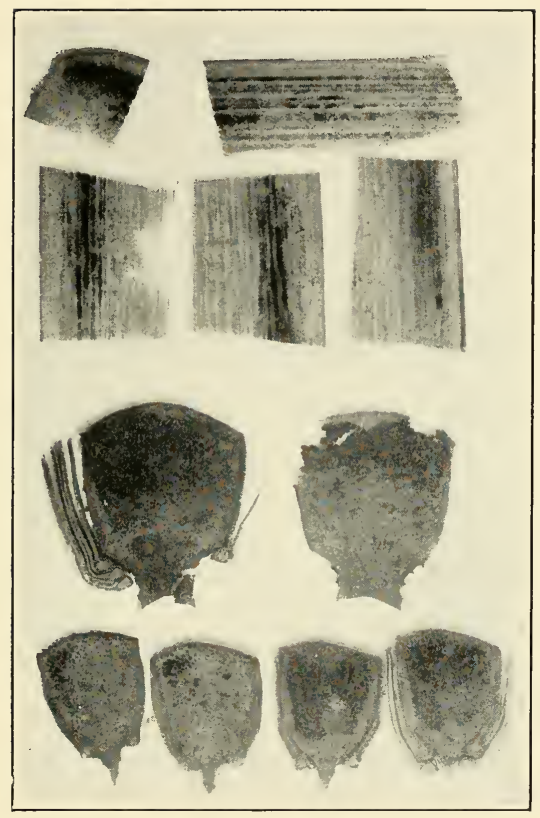

Fig. 67

Red Ring Disease: Infestation of a Young Leaf 

occurring up to ten years are not particularly rare and odd cases have been verified in trees over twenty years old.

Examples of the disease have been seen by the writer in all grades of soil, from beach sand and rich vegetable mould to exceedingly stiff clay. No influence on liability to the disease has been detected as proceeding from these variations or from any unfavourable conditions of growth.

A very large number of cases have occurred in certain plantations on virgin soil cleared from forest, and infestations as severe are found on land which from a remote period has been cultivated in sugar-cane. On the other hand, one large estate in Trinidad converted from sugar-cane to coconuts ten to fifteen years ago has so far not had a single case.

\section{Mode of Infection.}

Information as to the beginning of the disease is as yet scanty and uncertain. The rapidity of infestation shown in the infection experiments renders untenable the hypothesis first put forward that infection takes place at an early age without its effects becoming outwardly visible until the tree matures. Subject to the results of further investigation, it may be said that infection probably takes place at the base of the leaves. The dorsal connection which is very regularly visible between the infestation in a leaf base and the external natural fold which is formed near its junction with the stem suggests that the cracks which occur in this situation may provide an opening for infection.

It is considered probable that the worms ascend from the soil by way of the surface of the stems and gain entrance at the base of the leaves. This is known to occur in nematode diseases of rice and black currant. (See Chapter V.)

The location of the red zone in the stem cannot yet be explained. Its position is the same in trees artificially infected by way of the leaves or through holes bored in the stem.

\section{The Parasite.}

From material supplied by the writer the worm has been described by N. A. Cobb as a previously unknown species, and named Aphelenchus cocophilus. The length of the adults, male and female, is I mm. ( $\frac{1}{25}$ inch). The eggs, which are cylindrical and slightly curved, are deposited in the living tissue. Nothing is known as to the existence of the worm outside of the tree

\section{Control.}

Until the process of infection becomes more certainly known, advice given regarding control measures must be largely conjectural. The manner in which the disease spreads in lines and groups from the scattered cases which first arise is conclusive 
evidence of infection from tree to tree. When a tree dies the soil in its neighbourhood must become heavily infested, and it is reasonable to assume from analogy with the known habits of similar parasites that it remains so for a considerable period.

It cannot be otherwise than desirable to prevent as far as possible the worms in infested trees from reaching the soil, and for this reason trees recognised to be affected should be dealt with as promptly as possible, before the infestation of the roots, which cannot well be dealt with, has become general. It is necessary not merely to cut the tree across at the base, but to dig round it, cut the roots, and turn it out-which is not a very difficult operation in most soils. When the leaves have dried an attempt should be made to roast the stem sufficiently to kill the worms. Planters may have ideas of their own as to the best way of doing this. A slow fire would be most likely to penetrate to the required depth, and it is suggested that the stem be sawn or chopped into convenient lengths, piled in the excavation with the chopped up leaves and added fuel, and banked by scraping up the loose soil and any chips that have been scattered, so as to give something approaching to the structure of a charcoal pit. It is recognised that the problem of disposing of such large masses of material in a satisfactory way is a difficult one, and fire in some form would seem to be its only solution. The worms have been found to be alive in large numbers several months later in a stem which had been merely scorched.

It is conceivabie and sufficiently probable to be the basis of precaution until the facts are known, that the worms maybe harboured in the crevices of the husk of fallen nuts and be transferred with these when they are used for pianting. It would, therefore, be safer to plant nuts which come from areas with no record of infestation, or otherwise to use them only when taken direct from the trees and not picked up from the ground.

It is not believed that any method of soil disinfection with chemicals is practicable. Experiments are in progress to test the protection of trees by banding and by placing a slowly diffusible repellent substance in the top. The common practice of putting lime or salt among the leaves may possibly be of some use in this direction, though nematodes in general are highly resistant to chemical poisons. It is considered possible, on the theory that the worms travel on the outside of the stem, that a band of crude oil may hinder their ascent by producing a quickly drying surface.

Observations of the spread of the disease suggest that drainage trenches act as obstacles to its extension and it is advised that the sites of early cases should be dealt with by the method described in Chapter XV for the isolation of contacts where Rosellinia disease occurs. 


\section{Bud Rot in General}

A great deal of confusion exists among agriculturists regarding coconut bud-rot, and pathologists cannot yet claim to be fully informed on the subject. The ravages in Cuba and Central America of the epidemic disease known by this name became widely known, and a tendency arose and still exists to regard all cases in which similar symptoms appear as affected by the same disease. F. A. Stockdale in I9o6 pointed out that a proportion of the bud-rot occurring in Trinidad was purely secondary in its nature, being a consequence of the failure of the palms brought about by the so-called root disease, now known to be for the most part a specific disease due to infestation with a nematode worm His contention, though denied at the time, has been fully confirmed by later investıgators. Nematode infestation has been recently found to be responsible for a large amount of so-called bud-rot occurring in British Honduras, and may be expected with confidence to account for a good deal more elsewhere. The writer has found that typical bud-rot of this kind, indistinguishabie in appearance from the infectious forms, follows rapidly on the death of healthy trees from poisoning or the severance of the stem. The fact is that a characteristic stinking rot, dominated by bacterial putrefaction, forms the natural process of decay of the large amount of tender tissues deeply enclosed by the successive sheathing bases of the leaves. A similar process can take place within the closely wrapped shoots of other monocotyledons, as for example in the top-rot of sugarcane. Evidence of infectiousness is necessary to establish the existence in any given situation of a specific bud-rot disease.

It is now becoming apparent that the true infectious bud-rot existing in the West Indies is of more than one kind. Until recently the opinion was generally held that the disease occurring in the Western Tropics is bacterial in its nature, while that of the East is fungoid. E. J. Butler and his co-workers have shown that the bud-rot of Palmyra palms in India is caused by Phytophthora palmivora and that this fungus can attack coconut. and S. F. Ashby in Jamaica has found the same fungus causing a bud-rot of coconut palms in Jamaica. A. Reinking in the Philippines has produced a bud-rot which he regards as identical with the form occurring naturally in those islands by artificial infection with a Phytophthora obtained from cacao pods and believed by him to be $P$. Faberi, which is the common pod-rot fungus of the West Indies.

After the removal of these fungoid forms it is believed that there may remain a large residue of bud-rot of bacterial origin, and it has yet to be shown that the epidemic bud-rot of the West Indies, in which bacteria alone have been detected, is not in fact of that nature. A description of this form, as at present regarded, is therefore retained. The question of causation does not much affect the description of the course of the disease, and 
in any case the effects of bacterial invasion are prominent in the affected tissues from an early stage.

\section{BACTERIAL Bud-Rot.}

The early history of bud-rot disease in the Western Tropics is obscure owing to the absence of adequate descriptions and the difficulties of diagnosis. There is a record of epidemic destruction of coconut trees on Grand Cayman as early as I834; in Cuba the disease has been making progress for more than thirty years, and there are large areas once covered with flourishing plantations on which hardly a tree now remains. Heavy losses occurred in Jamaica from I89I to IgIo, and at about the same period in Trinidad, and though checked by compulsory destruction of trees the disease still persists in both islands. In the Lesser Antilles small groups of trees have died from time to time with symptoms taken to be evidence of this disease.

Many incomplete attempts at explanation of the disease were made from time to time. In some cases observers were led by the presence of insects attracted by the decaying parts to attribute to one or another of them its causation, but several of the earlier observers reached the conclusion that bacteria play the principal part. As a sequel to a visit by E. F. Smith to Cuba in I904, J. R. Johnston began the study of the disease in Cuba in I907, and after visiting Jamaica, Trinidad and British Guiana, wrote a comprehensive account of his investigations.

J. B. Rorer in Trinidad, and S. F. Ashby in Jamaica, have also published descriptions of the disease confirming the general features of Johnston's account.

\section{Nature of the Attack.}

The disease does not affect the central bud alone but may commence anywhere in the crown, either at the base of the leaves or inflorescences or on the tissues between them. It never extends far on to the leaf stalk nor does it affect the woody part of the stem; only in exceptional cases does it travel more than a foot or two in the softer central portion of the stem below the crown.

If the infection starts in or near the central bud it rots the tissues at the base of the upright column of unexpanded leaves so that this falls over and comes away, commonly leaving the expanded leaves still green and healthy and their bunches of nuts intact. With the only vegetative bud gone there is, of course, no chance of recovery. The leaves in time dry up and fall, leaving a bare pole.

When infection begins among the expanded leaves the first sign is commonly the falling of unripe nuts, due to the infection of the base of the fruiting branch. The dropping of young nuts is not in itself evidence of bud-rot. It occurs quite commonly 


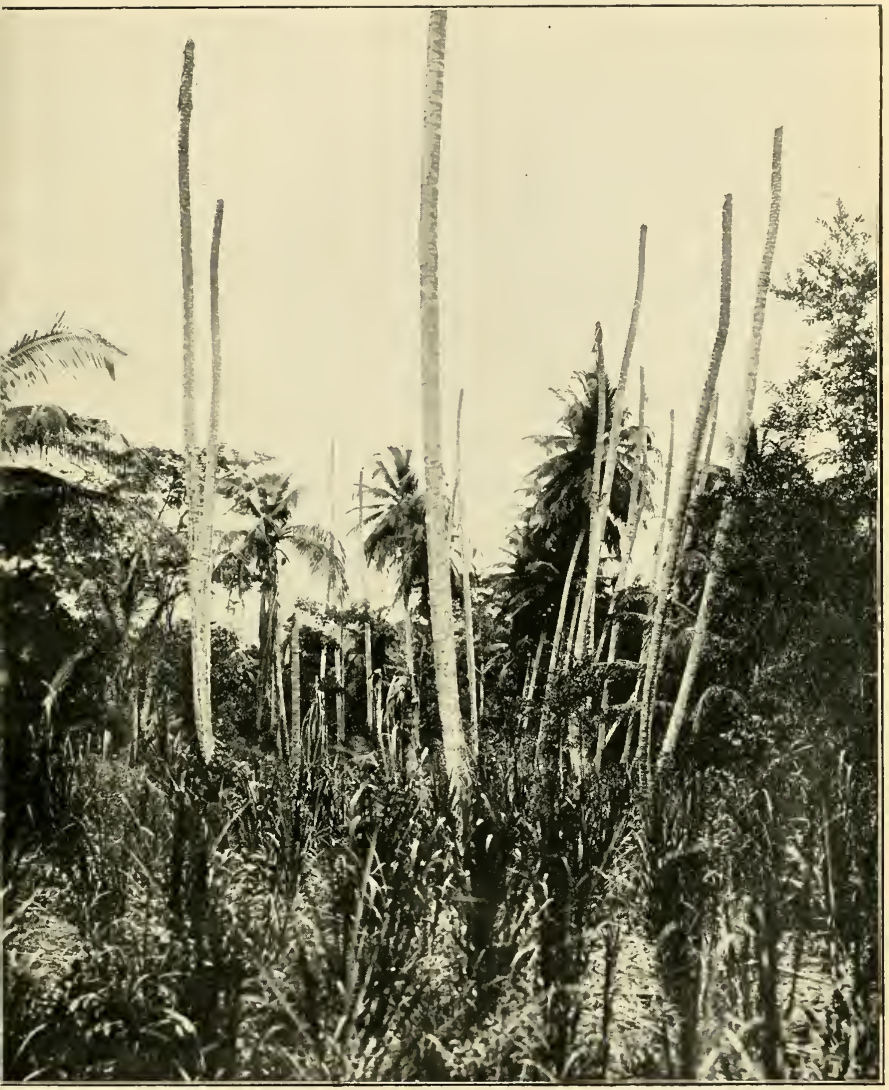

Photo by?

Fig. (is

$[F$, W. Urich

EFFect of a Bud-rot EPIDEMic, Trinidad 

when trees are suffering from drought, water-logging, or any cause which affects the ability of the tree to nourish the full number of fruits set. Injury to the base of the spikes such as may be caused by insects or by careless picking will also cause young nuts to drop.

Another early sign of the disease is the discoloration of the flower spikes, which turn chocolate brown and eventually blacken and wither. Investigation at this time reveals a darkcoloured wet rot about the base of the affected parts. The rot works its way through or under the moist strainer, affecting the leaves or inflorescences as it reaches their points of attachment. Water-soaked areas appear on the leaf stalks, and as the rot progresses the leaves involved turn yellow and hang down. On the relatively hard tissues of the leaf base the rot does not penetrate far below the surface and if the spots become exposed to the air they dry up. The softer tissues adjacent to the bud are much more easily penetrated and when the infection reaches the central column they become entirely involved in a soft rot which gives off a particularly offensive odour.

\section{Causation.}

Apart from the type recently separated in Jamaica, investigators of bud-rot in the Western Tropics have so far agreed in reporting the association of bacteria with the disease from its earliest stages. It has not been possible, however, to correlate the findings of the different workers in respect to the species of bacterium regarded as its probable cause. J. R. Johnston reached the conclusion that a species indistinguishable from Bacillus coli was causative, but unfortunately his inoculation experiments were confined to young plants under glass in Washington, in which, moreover, infections were only obtained through holes made with an auger. Reinking in the Philippines isolated what appears to be the same organism, and with this and with $B$. coli from animals found that infections of seedling palms could be obtained through wounds made in the growing point, but only in case of severe injury or excessive dampness. He no longer regards bacteria as the cause of the epidemic disease in those islands. Rorer in Trinidad mentions having obtained with an unidentified but different bacterium typical infections through wounds and also by pouring material from a culture among the leaves of an unwounded tree.

\section{Control.}

The experience of Jamaica and Trinidad demonstrates that when supported by powers of legal compulsion and carried out under effective supervision, a vigorous policy of cutting down and burning the tops of all infected trees, with periodical inspections for the detection of fresh cases, can quickly reduce the incidence of the disease from serious to insignificant proportions. 
In the case of trees which are attacked in the region of the central bud there is no hope of remedy, but some success has been attained in the treatment of cases where the infection is situated in the outer parts of the crown. One kind of treatment commonly adopted consists in setting fire, if necessary with the aid of kerosene, to the dry material present in the crown. This may give the tree a severe check but is sometimes successful in destroying the infection owing to the shallow penetration of the rot on the harder parts of the tree.

A method sometimes adopted, which is claimed, with what justification is not known, to prevent infection and to cure incipient cases is the tying of a bag containing a pound or two of coarse salt or of copper sulphate, or both, in such a position that rain water will gradually dissolve the chemical and carry it down among the leaf bases.

Spraying with Bordeaux mixture, to which arsenate of lead is added to give it insecticidal properties, has been experimentally tried in Trinidad with apparently good results. The budrot of palmyra palms in India has been successfully treated on a large scale by spraying with resin-soap Bordeaux, applied by climbers furnished with auto-sprayers, after removing infested leaf-sheaths.

In the destruction of diseased trees by fire they should be cut down, the dry material used to start the fire, and the crown dismembered and thrown on piece by piece, care being taken to see that everything is at least scorched through. Excepting its uppermost section there is no need to burn the trunk.

\section{Bud-Rot Caused by Phytophthora Palmivora.}

\section{Incidence.}

S. F. Ashby has described a specific bud-rot which occurs in the eastern and north-eastern coastal lands of Jamaica, where there are large unbroken areas of coconuts subject to a rainfall of 90-I20 inches. It is to a marked degree most prevalent on flat lands with fine silt soils difficult to drain. Periods of heavy rain are followed one to three months later by a heavy increase in losses from the disease, which in one instance of a field of 4,000 trees occurred at the rate of roo a month. Trees from 2-3 up to 20 years old are liable to attack. On one estate the fungus was found associated with the dropping of full-grown immature nuts, and at one nursery seedlings were seen with dead hearts and rotted apices probably due to infection from the husks.

\section{Symptoms.}

The existence of the disease is indicated by the discoloration and withering of the heart leaf or one or more of the youngest leaves. The heart leaf rots at the base and can usually be pulled out, which serves as a rough means of distinguishing this affection 


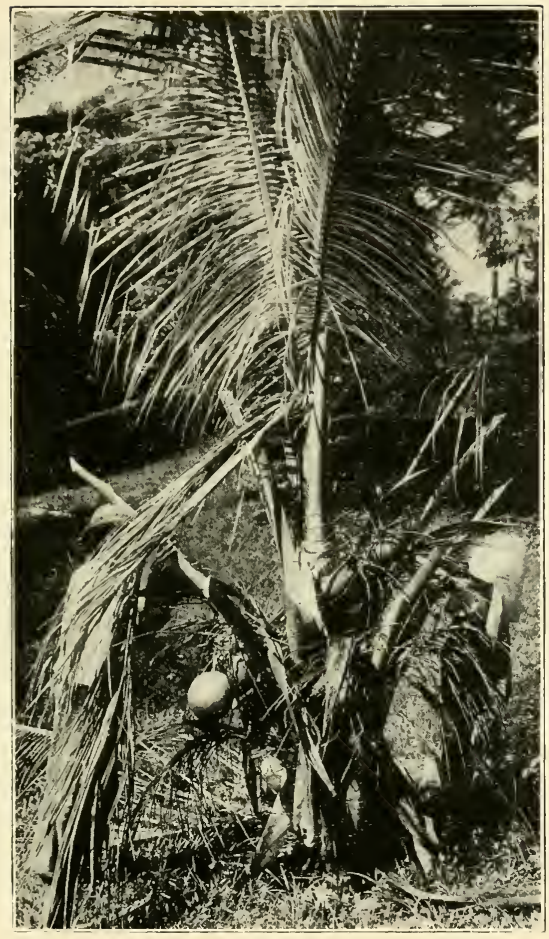

Photo by]

Fig. 69

[J. B. Rorer

Coconut Bud Rot, Outer Leaves removed to show Collapse of Heart Leaves. 



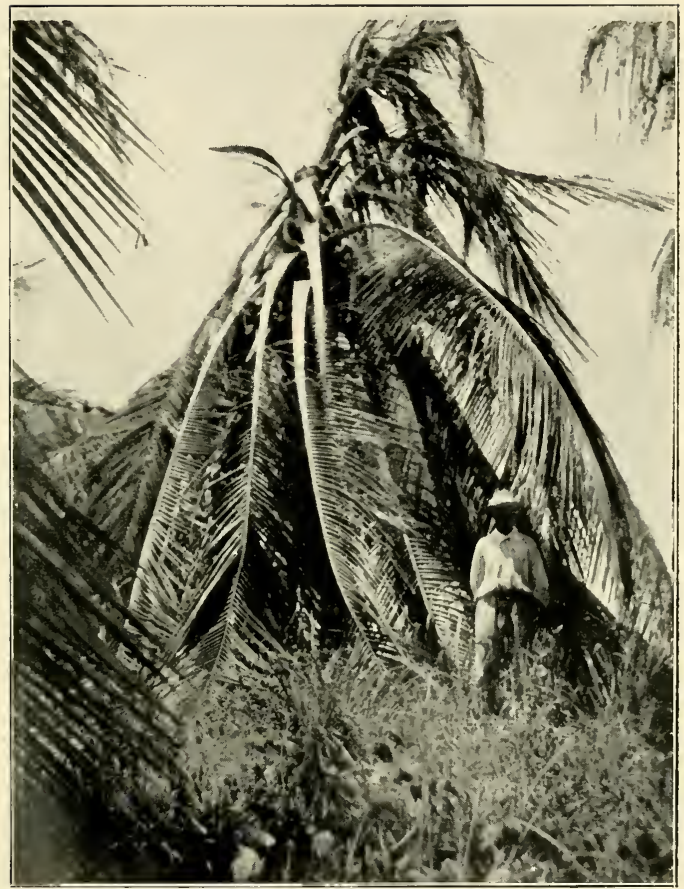

Photo by]

Fig. 70

[E. Miller

Bud Rot PRECEDED By DRoOping of Leaves (Tobago) 

from withering of the leaf-blade caused by Thielaviopsis. The young leaves next in order are successively attacked and the central column falls out leaving the ring of outer green leaves. At the seat of the disease brown sunken spots up to 3 inches in diameter are found existing on the leaf bases and penetrating them successively until the apex of the stem is reached. At the stage of the withering of the heart leaf the heart itself is usually already soft-rotted.

\section{The Causative Fungus.}

The tissues of the leaf-base spots and of the stem apices when these are not already soft-rotted are penetrated by a stout, sparingly septate, intercellular mycelium sending fingerlike haustoria into the cells. Pale brown chlamydospores in the tissues are not uncommon. The surface of the spots may show a white mildew amounting sometimes to a dense felt, and a similar growth is found in connection with spots which sometimes develop on the unexpanded leaves, and show up later as rows across the leaflets when these expand.

The surface web or stroma may show only sterile mycelium or may be abundantly covered with thick-walled brown chlamydospores; kept in a moist chamber it develops sporangia, which are oval with broad prominent papillæ, and when set free are usually stalked. They are believed to liberate 30 or more zoospores. Oospores have not been seen with certainty.

The fungus corresponds with the description of Phytophthora palmivora (Pythium palmivorum) Butler, the cause of the destructive bud-rot disease of palmyra and coconut palms in India, and its identity has been confirmed by E. J. Butler from living cultures.

\section{Inoculations.}

An infection was secured on an unwounded leaf-base, resulting in a spot two inches across and one inch deep, with typical mycelium at its advanced margin. Developing in bright weather the infestation did not penetrate to the leaf-base next underlying in the ten weeks preceding its removal.

The result of pouring suspensions of the fungus from cultures into the hearts of trees 4-5 years old was the production of rows of spots on the leaves next to emerge, but no further effect followed. Complete artificial infestation of the husks of fullgrown green nuts was secured.

\section{Mode of Infection.}

Infection begins on young leaf-bases and often the fungus penetrates several of these before reaching the bud, passing inwards by a direct course. The rotting of the heart is accompanied by secondary bacterial infestation. No definite in- 
formation has been secured regarding the manner of distribution of the fungus; strong winds may detach and transfer fragments of mycelium, and scavenging insects and birds may carry these or spores from one tree to another; it is not thought that transfer by the pickers is of much account.

\section{Control.}

Attempts have been made to prevent infection by applications of mixtures of slaked lime and copper sulphate, Bordeaux paste and mixture, lime and salt, and rock salt. The results are so far inconclusive though good effects are believed to have been obtained in some instances.

The early eradication of diseased trees, when thoroughly carried out, has been effective with this as with other types of bud-rot.

\section{Leaf-Stalk Rot CAUSed By Phytophthora PARAsitica.} Symptoms.

S. F. Ashby has described a disease of coconut palms occurring in Jamaica in which the earliest symptom is usually a yellowing and withering of the tip of a leaf on the outside of the crown. The affection spreads to adjoining leaves and finally most of the outer leaves break down. Progress is slow and typically the bud is not affected. The bunches of nuts fall owing to the removal of the support given them by the leaves, but have not been seen to be infected.

The stalks of the leaves attacked show dark brown somewhat sunken spots, from one to several inches in diameter, on the upper and under surfaces; the lowest spots are usually situated several inches above the junction with the stem. Long dark patches are also frequently present on the limbs, and gum may exude when the affected areas crack. Internally the spots and patches show either a sodden rot with a narrow red margin or are light to dark brown, depending on their age; frequently they pierce entirely through the limb.

\section{Incidence.}

The disease has been so far met with in Jamaica only on three neighbouring estates in a district of high rainfall. Cases have occurred in trees from ten to fifteen years of age, but in the greatest number on trees of five years beginning to bear.

\section{The Causative Fungus.}

The tissue of young spots is penetrated by the stout sparingly septate intercellular mycelium of a Phytophthora, with few branches entering the cells. In older spots the hyphæ show more frequent septation and grow through the cells. Felts and webs have not been found on the surface of the spots. 
Sporangia develop abundantly on material transferred to a moist chamber, and chlamydospores and oospores occur in cultures. The sporangia are decidedly more globose than in $P$. palmivora, with a narrower papilla and less tendency to break away with a stalk.

The fungus agrees with $P$. parasitica Dastur, described on castor oil and Vinca in India. It also agrees with $P$. terrestria Sherbakoff, on tomato fruits in Florida, which is probably synonymous.

\section{Control.}

Attempts at control by cutting out diseased leaves and by the use of Bordeaux mixture or Bordeaux paste have not been successful. More promising results have been obtained by packing banana or coconut trash round the affected limbs and firing it.

\section{STEM-RoT.}

Stem-rot occurring in local patches on trees of any age is a matter of some concern in Trinidad and Tobago. A similar trouble has been noted in Grenada. In the typical form of the affection the outward sign of its presence is the exudation of a liquid which runs for a little way down the rind and dries to a reddish-brown stain. Removal of the rind reveals a patch of sodden tissue with an early tendency to yellow or reddish discoloration followed by browning as decay progresses.

The starting point of the rot is frequently a cut arising from the habit of pickers and others of using the stem as a cutlass rack, or from weeding near the base of the tree. The affection also arises in many cases in connection with the natural cracks common in the rind.

In old and hardened trees the rot spreads little and is not of much account, but in the softer wood of younger trees severe injury may occur and eventually result in death. This may be a matter of months or of several years according to the extent and number of the attacks and the susceptibility of the tissues.

The disease is at present under investigation in Trinidad, where it is very common in some districts and rare in others. A small-celled yeast appears to be general in the affected tissues and F. Stell has recently obtained cultures of Thielaviopsis from the spots.

A small amount of gumming is often associated with the typical affection as above described, but other cases occur where a very profuse exudation of gum from cracks all over the affected patch is the most prominent symptom. The internal appearances are similar, but the relationship of the two types is not known.

T. Petch has described under the name stem-bleeding disease 
an affection widespread in Ceylon in which the emergence of a viscid liquid from one or more cracks leads to the formation on the surface of the stem of black streaks and patches, which may be small or may extend for several feet, and are found to be connected with strands or cylinders of rotted interior tissue which in some cases run nearly the whole length of the trunk. In old and hardened trees the external patches are small and the internal decayed part is usually not more than Io centimetres in diameter. The disease was found to be due to infection of the cortical tissue through surface cracks with the fungus Thielaviopsis paradoxa. The decay is slow and no effect on the health and bearing of the tree is usually apparent. Symptoms of this type have not been observed by the present writer.

A condition more nearly resembling the Trunidad affection described above is also mentioned by Petch and regarded as distinct, being attributed to the effects of injury by root disease root asphyxiation, fire, or lightning.

In Jamaica, according to observations made by S. F. Ashby, natural cracks an inch or more long tend to form on the trunks of trees when rain sets in following a dry period. Thielaviopsis has been found, not infrequently, to start a brown rot at these wounds which may penetrate deeply if neglected.

Extensive yellowish or reddish sodden discoloration of the outer tissues of the trumk at or near the base with exudation of rusty fluid and gum also occurs, and may be followed by the death of the trees. The affected tissues are soaked with gum, but no definite parasite has been detected unless it be a small yeast in the intercellular spaces, not always to be found, however. It will be noted that the description closely resembles that of the Trinidad affection.

The treatment adopted in Trinidad consists of the paring away of the discoloured tissues, an operation which, owing to the confluence of numerous patches, often involves the removal of large areas of the rind, and the application of a coating of crude oil or distillate. This, if thoroughly carried out, has the effect of arresting the progress of the rot, and in most cases the tree withstands even severe cutting very well. It is obviously desirable, however, that the treatment should be applied early, and the site occasionally re-examined.

\section{Leaf-Dwindling or Little-Leaf Disease.}

This affection occurs in Grenada and Tobago and is at the present time quite common in Trinidad, where it is particularly conspicuous on the wayside trees seen in the neighbourhood of villages. A similar affection described by S. F. Ashby under the name Hard or Little Leaf-bitten Disease is reported to be widely distributed in coconut cultivations in Jamaica. 


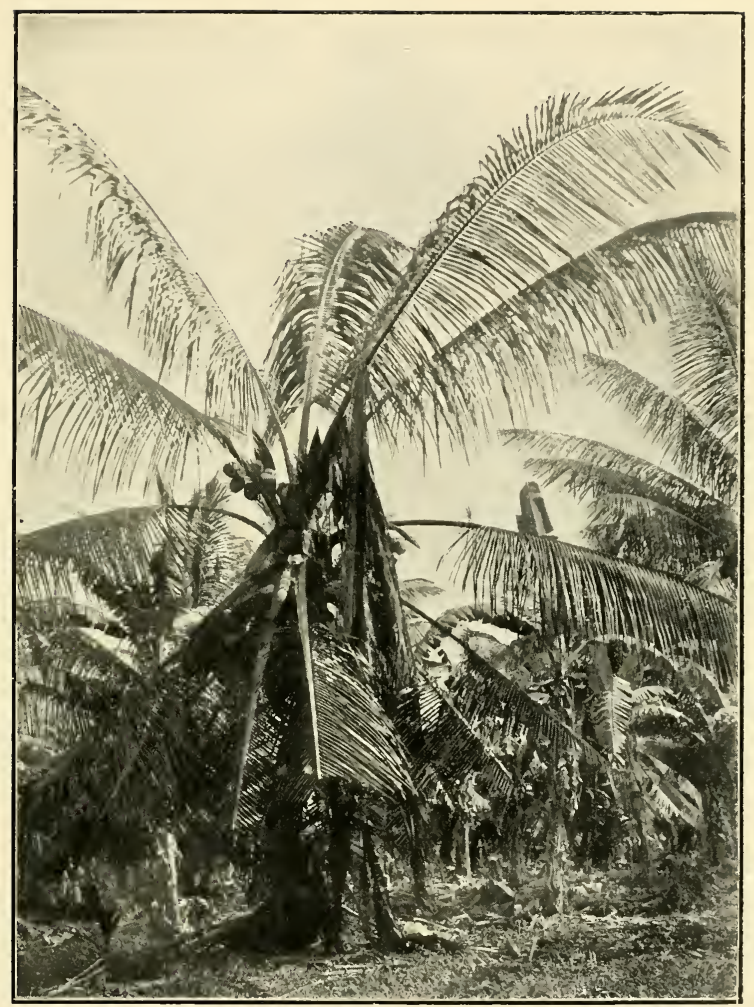

Photo]

Fig. 71

[Dept. Agri., Jamaica

Phytophthora Bud-rot (Jamaica) : Central leaves alone DEAD AND BROKEN 



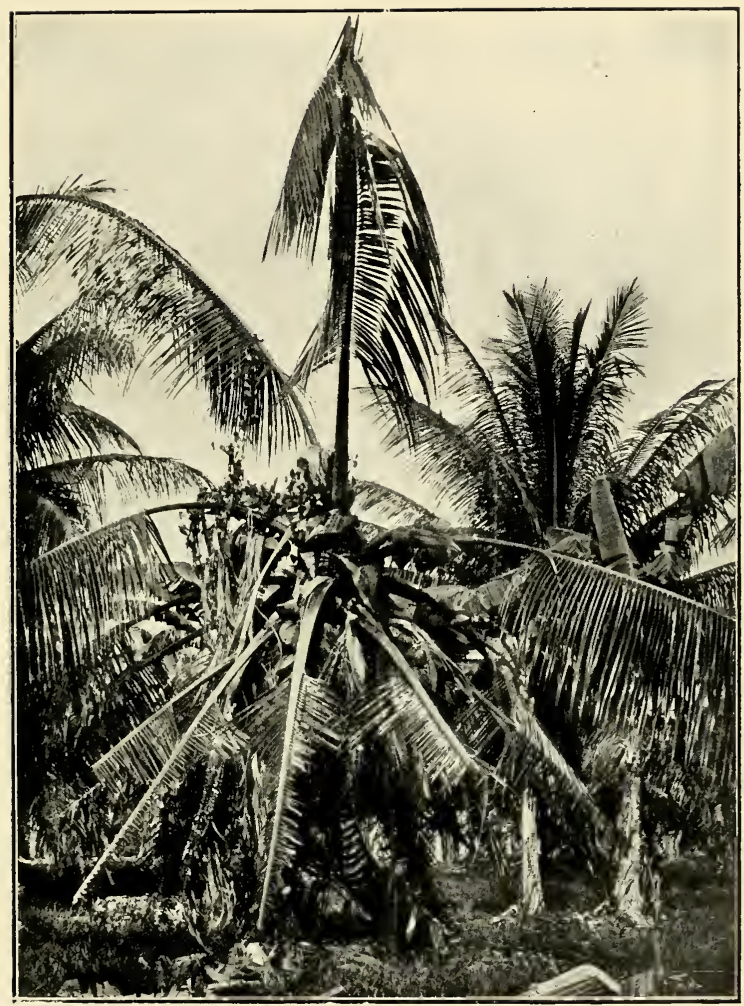

Photo」

Fig. 72

[Dept. of Agri., Jamaica

Phytophthora Bud-rot, Advanced Stage, Central Column Fallen OUT 



\section{Symptoms.}

The most obvious character of the disease as seen in these islands is that after its onset the leaves come out smaller and smaller in size until in the end, if no recovery takes place, they are reduced to a ridiculous little crown of aborted stumps not more than one to two feet long, which may be borne at the end of a stem perhaps 20 or 30 feet in height.

Examination of the central shoot reveals the young leaves with brown necrosed spots and patches on the folded leaflets and on the surface of the leafstalk. As the leaves expand the leafstalks develop a russeted or corky surface, which later becomes hard and woody, more or less raised and misshapen, and exhibits well-marked cracks. The unyielding nature of the leaves so affected causes those which follow to be more and more severely deformed, and in the later stages the leaflets either do not expand or are almost entirely aborted, and the rachis itself is reduced to a pointed stump.

\section{Incidence.}

Trees may be affected at 3 or 4 years old and at any later stage. Natural recovery can take place and the affection be thrown off, to recur again or not as the case may be. Most frequently, it would seem, there is little or no natural interruption to the course of the disease and the tree dies.

\section{Causation.}

Ashby reports that in Jamaica a small yeast occurs in the early spots and on the advancing margin of the hardened areas, and is always obtained, usually alone, in cultures. A similar organism has been found by the writer in Grenada and Trinidad, but inoculation experiments with pure cultures have so far had negative results.

\section{Control.}

The disease has been found by several planters to be easily treated, and if taken in reasonable time few cases fail to recover. The first essential appears to be to relieve the constricted condition of the heart by cutting through the strainers and opening out the leaves, and then it is the practice to pour into the heart milk of lime, Bordeaux mixture, copper sulphate solution, weak Jeyes fluid, or tobacco extract. The last-mentioned substance, obtained from the local tobacco factory and diluted is used with complete success on an estate in Tobago.

\section{Bitten-Leaf Disease.}

S. F. Ashby has described a disease prevalent on the north-east coast of Jamaica which affects the leaves while still folded in 
the bud. It is caused by the attacks of the " pineapple" fungus familiar on sugar-cane, Thielaviopsis paradoxa, v. Hohn. The disease has not so far been recognised in the Lesser Antilles.

Ashby's account of the symptoms is as follows:-

"The younger green unfolded and unfolding leaves appear bitten off at the ends or show successive leaflets lower on the stalks broken or reduced to stumps. Those nearest the heart show spots on successive green leaflets which bend over or break and hang down at these points.

Leaves just pushing up can be detected with black tips; if the end of the heart leaf is cut out with the white leaflets overlapping and pressed on the stalk, characteristic discoloured patches and spots will be seen. Infection usually starts as a yellow discoloration with a brown edge along a narrow line beside the ribs of the leaflets; the infection runs across all the leaflets overlapping at that point. These long, narrow spots widen to wedge-shaped patches with dark brown broad edges and a pale brown centre, with the skin raised into a blister so that it can be torn off to expose the fibres, with the tissue between them more or less decayed away.

"If infection is high up only the tips of the leaflets become black. A heart leaf may show one or more wedge-like patches of disease. Spots are also present on the leaflets, at first minute, round or oval, yellowish with depressed centre, later with pale yellow centre and brown edge; by union these become patches; in bad cases the leaf stalk (rachis) beneath the diseased leaflets is attacked by a dark brown rot so that when pushed out the end of the limb may break off. Spots and patches show black specks consisting of spore masses of the fungus. The frequency of affection beside the ribs of the leaflets is due to a thin line of cells there which regulate the opening and closing of the mature leaflets in dry and moist air, so as to control evaporation of water from the leaf pores which are confined to the under sides of the leaflets.

"The disease, as already pointed out, starts on the heart leaves while still white and tender before they push into the light. Just what conditions favour this infection cannot be stated yet. Check to growth during a period of drought may have started it at some estates while the last two unusually wet years have made it epidemic.

"The diseased patches attract the beetle Metamasius sericeus (weevil borer of sugar-cane) which increases the extent of the damage.

"Cutting out the visibly diseased parts will sometimes remove the infestation, but to be certain of preventing its recurrence it is found necessary to chop back the bud until no more discoloured leaflets are met with. About a pint of a powdered mixture of one part each of salt, lime and copper sulphate is applied to the cut ends. In most cases the trees recover rapidly from the treatment." 


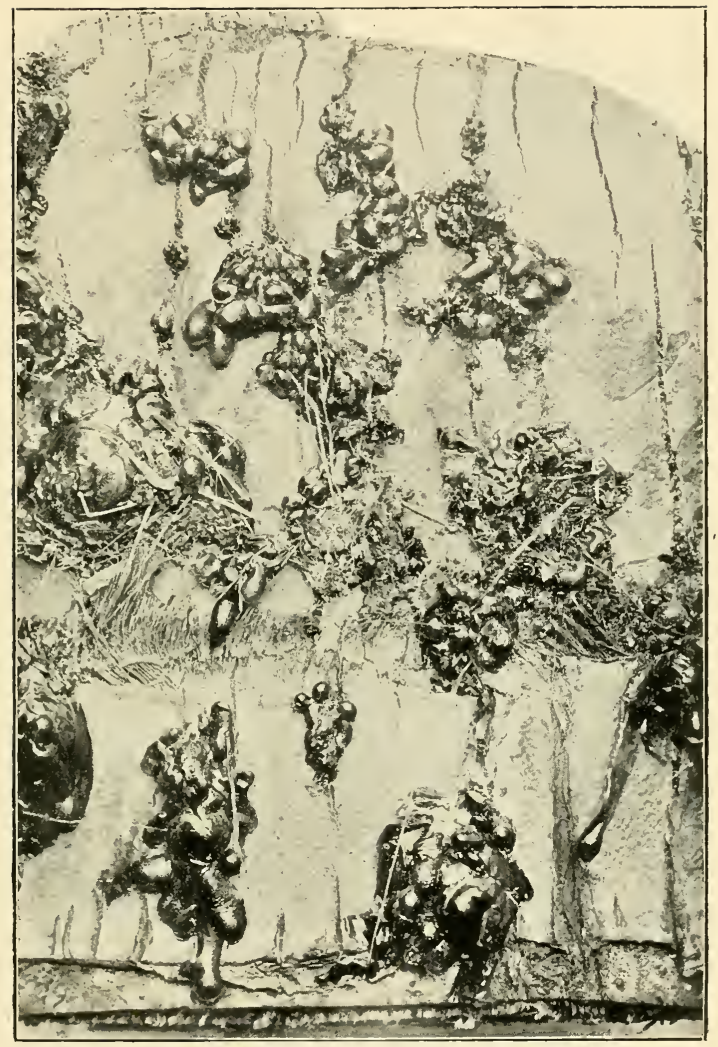

Photo by]

Fig. 73

F. W. Urich

Gumming of Coconut Stem 



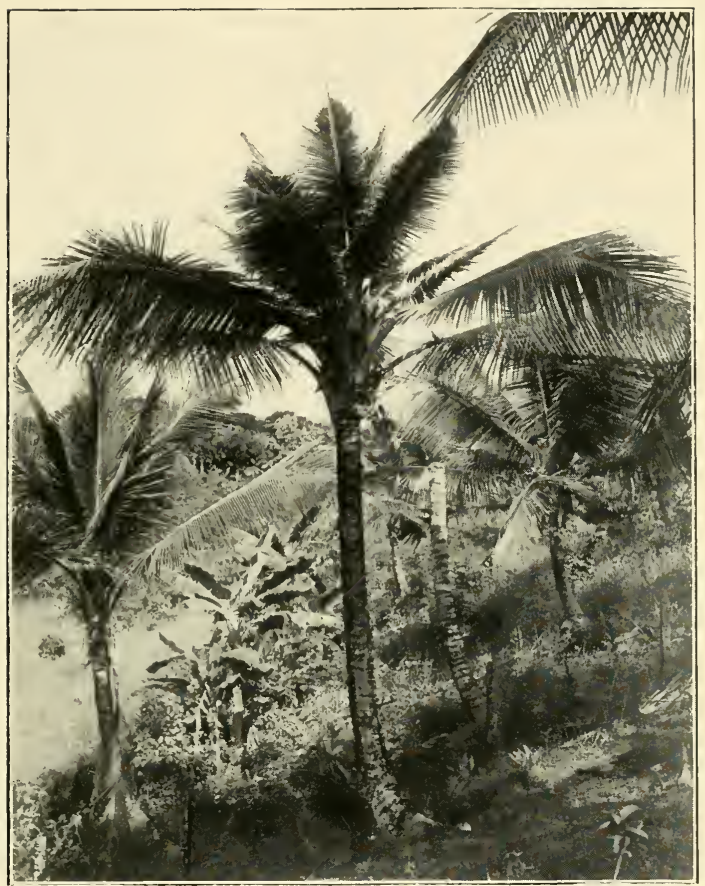

Photo by]

Fig. 74

Little-leaf Disease of Coconut 



\section{DIEBACK.}

In Jamaica the pinnæ of the older leaves die back successively from the tips and the crown of the tree may be reduced slowly or rapidly to a few expanding leaves. The name dieback has been given to this affection and a Diplodia is in most cases found fruiting behind the advance margin of the dead zone. This affection is regarded by Ashby as primarily a root deterioration, possibly of the same kind as those reported recently on cane and other crops in Hawaii and on cane in Porto Rico.

\section{LEAF BLIGHT.}

A condition of the leaves in which they prematurely take on a more or less general yellow colour, while the individual leaflets have yellow, brown, or grey patches scattered over them and dead areas at their tips and along their margins, may be designated by this name. Such a condition arises from unsuitable cultural conditions, of which lack of drainage is perhaps the most common, but packed soil, root competition with other plants, and undue exposure under conditions of low rainfall and absence of available subsoil water will produce it.

Usually the condition is accompanied, and in the immediate sense caused, by infestation with scale insects and weakly parasitic fungi. It is on old and failing leaves, and on younger leaves in a condition of debility that Pestalozzia palmarum Cke. has been commonly observed in the West Indies. This fungus has been reported from Java as being on occasion a serious leafparasite on newly planted trees. Petch has stated that in Ceylon it occurs as a rule on old leaves and does no appreciable harm, and that its appearance on younger leaves is a sign that something is wrong with the conditions and should be met by manuring.

The fungus is found in yellow or brown oval spots which come to have a diameter of a centimetre or more, and dry up in the centre. The conidia are formed in pustules on both sides of the leaf. Each has 5 cells, of which the 3 median ones are brown with thicker walls. The terminal cells are hyaline, the superior one bearing 3 threadlike appendages and the inferior one being prolonged by a portion of the slender conidiophore.

A Diplodia, D.epicocos Cke. is also found occupying dried-out spots on the leaves, and has been recorded from Jamaica, Trinidad and British Guiana. Its pathogenic relations are not established. 


\section{CHAPTER XIX}

\section{DISEASES OF LIME AND OTHER CITRUS TREES}

THERE are distinct differences in the resistance offered by the various citrus species to dry conditions. In the lowland districts of Barbados, for example, the lime, the shaddock, and the rough lemon can exist, though they cannot be said to thrive except under very sheltered conditions. The mandarin will grow and flower but rarely sets fruit. The grapefruit and the orange only exist, and that somewhat precariously, in a few sheltered spots in the wetter uplands.

In Dominica and St. Lucia, on the other hand, the lime is thoroughly at home, and other citrus fruits do proportionately well. The sweet orange, however, is limited in duration unless it is grafted on sour orange stock, by the development of gummosis of the collar at the age of about 25 to 30 years. Two extremes of habit can be recognised in the lime as grown in Dominica. In exposed positions or on poor or water-logged soil, growth is slow and " hard," the leaves are smaller and stiffer, the foliage is scanty and greyish green in colour. On rich and deep soil with good drainage and shelter, growth is vigorous and rapid, the leaves are large and thin, the foliage is heavy and very dark green. There are corresponding differences in the size and juiciness of the fruit. Under the latter circumstances the lime may attain to the dimensions of a considerable tree.

The case of St. Vincent needs a special note. Although the rainfall is more than sufficient and is fairly well distributed, citrus trees are distinctly rare : there is not at the time of writing, for example, a fruiting citrus tree of any kind, other than the lime, in the Botanic Gardens or the Experiment Station. In spite of many attempts at lime-growing there is not a field of bearing limes in the island. Scattered lime trees may be met with and oranges and grapefruit are produced in sheltered situations. The form which the failure takes is that of heavy infestation with scale insects and "black blight," but, as the pests found are common to all the islands, these troubles can only be regarded as due to the general inability of the plants to thrive. This, there can be little doubt, arises primarily from the light and porous nature of the soil, which, except under conditions of very efficient shelter or heavy shade, does not hold a sufficiently stable supply of water or contribute sufficiently to the humidity of the atmosphere during spells of dry weather. The same 
disability is seen in cacao plantations in the island, but the deeper root system of cacao enables the trees to maintain themselves, though not, in general, to flourish. It affords a curious study in crop ecology to find such opposite types as cotton and cacao growing in contiguous fields, while limes, which will grow in many places too dry for cacao, fail to thrive. A contributory reason is no doubt to be found in the more serious and lasting effects produced by the scale insects which infest the lime at periods of low vitality than by the thrips which affect cacao under like circumstances.

The behaviour of the lime tree under cultivation suggests that its natural habitat would be in bush or thicket growth on ground unoccupied by large trees. It profits greatly from the shelter of surrounding vegetation, but is somewhat intolerant of shade. Even in most favourable circumstances, as in the climate of Dominica and St. Lucia, the plants in their first few years benefit enormously from being enclosed in any kind of sheltering growth, and in poorish soils, even in wet districts in those islands, may during the critical period which precedes their becoming " established," die back several times or be killed outright by scale insects unless some such protection is afforded them. Even when the scale insects are kept down by regular spraying growth in the open is nothing like so good. From this has arisen the practice, which is desirable anywhere on previously cultivated land, but especially where the rainfall is somewhat low, of nursing young lime trees in sugar-cane, pigeon pea, or Tephrosia, until they become well established. In fields where this has not been provided for it may be seen how those plants which have the advantage of some bit of natural shelter are the first to take on the shape of trees and how their influence gradually brings on in succession the rest of the field. Manuring is also of great assistance.

Once well established and come to fruiting age the trees generally do fairly well even under rather hard conditions for a number of years. In Dominica unless the soil becomes unduly impoverished or is allowed to get into bad condition they will bear for 20 or 30 years and then be far from worn out. The effect of neglect of the kind mentioned is the death of upper branches, and the extension of the rot caused by the bracket fungi which come to infest them down the stem of the tree, which has not vigour enough to resist. This type of dieback, common in some places in Dominica, can be arrested by appropriate measures as described below, and the tree restored to another period of usefulness.

Such restoration is not possible, or at best is much more temporary, in the dieback which sets in after some ro to I5 years, without obvious neglect as a predisposing cause, in lime fields established under conditions of smaller rainfall and more marked dry seasons, as in Montserrat. The progressive decline 
which ensues, and is associated with Diplodia infestation, marks the limitation of the life of the tree under these circumstances. A similar restriction in the citrus cultivations of some districts in Queensland has been the subject of much investigation, without any other conclusion being reached than that the decline is due to a reduction of the natural duration of the tree. A comparable reduction is recognised in the cacao tree when grown under conditions near the margin of suitability in respect of depth of soil, unequally distributed rainfall, and absence of shade or shelter.

Lime.

\section{Diplodia Dieback}

\section{(The Montserrat Type.)}

As indicated above, the result of experience in planting limes in the Lesser Antilles has been to show that while the tree finds permanently congenial conditions in the islands which are mountainous in character and retain a large amount of forest, in the islands which are more open and more completely cleared its duration is restricted to the period during which it retains its first vigour of growth. A comparison may be made with the more familiar difference in the effective duration of sugarcane stools under similar circumstances.

The climatic conditions by which the difference is determined are reduced rainfall, lower humidity, more exposure to wind, and a more marked difference between the wet and dry seasons. Montserrat being the only island of this type with a considerable lime industry, affords the best illustrations of the effect, but from such opportunities for observation as occur it is evident that the same effect is produced in the other islands where conditions are similar.

The sequence of events in its most regular form is as follows : Young trees, after coming through the critical period elsewhere described, may become established and do well for about ten years, attaining to a good size and bearing normal crops. Then in a uniform field of this nature the most exposed trees begin to show signs of dieback, which sooner or later extends widely and in two or three years may involve the whole field or may leave for a time groups of less affected trees here and there.

To follow out the process of the dieback it is necessary to know the growth form of the tree. This may be described as of the fountain type, i.e., the main shoots, generally several together with no pronounced leader after the first two or three years, grow up long and slender, and sooner or later bend outwards from the top. As they become inclined new vertical shoots arise from the upper side of the curve so formed, and as the outer end of the original branch is bent lower and lower 
by the weight of foliage and fruit the secondary branches in turn lose their upright position and are replaced by further vertical shoots from themselves or from the original branch further back. There is thus a continual tendency to the opening of the centre of the tree and its filling with new vertical branches. Where there is room for full development the mature tree is typically dome-shaped, with its outer branch system supported by a number of more or less equal stems of the first or second order, springing usually from points not far above the crown. As the outer ends of the lower branches become bent into or below the horizontal position the outward growth necessary to keep the foliage in rank with that of the branches above it (it would otherwise be overshadowed) is continued in the same way by shoots arising from points situated on the curve of the branch. This succession of the terminal shoot by a shoot produced further back is in fact the principal characteristic of the growth of the tree.

Its importance from the point of view of duration lies in the fact that, whereas in a vigorous tree the later shoot supplements the leader, in one which is lacking in vigour it tends to replace it. The younger shoot seems to establish a pre-emption on the ascending current of sap, and, when the supply does not suffice for both, the terminal part of the older shoot beyond the junction is stopped in its growth and during some spell of dry weather drops its leaves and dies. By repetition of this process it is not uncommon for the axis of a long basal branch to be made up of successive sections representing ten or more orders of branching and to come at last to bear an insignificant tuft of foliage.

For a time the growth about balances the losses and then begins to fall behind. There is considerable recovery during the wet season, which may be maintained in favourable years or more than lost when severe droughts occur. On the whole the decline, once it has set in, continues, and as the older branches are reached there is a marked acceleration of the rate of loss. The bearing of a heavy crop of fruit, especially in dry weather, is frequently followed by a sudden loss of branches, and this effect may to some extent account for the rapid failure which has often been observed to follow upon heroic attempts to restore the trees by cultivation and heavy manuring.

The dieback is closely accompanied by Diplodia infestation, and when a branch of any considerable size fails, unless it is promptly removed flush with the older branch from which it springs, the sector of wood directly connected with it, and the overlying bark, dry out and are found infested with the fungus, so that long lesions the width of the dead branch above and running out to a point below are produced on the older member and are usually irreparable. Associated with their development there is commonly a considerable flow of gum.

The inability of the fungus to attack wood and bark which 
are in connection with functioning leafy branches is regularly shown by the persistence in a healthy condition of a sector so connected embedded in a branch or stem otherwise dead and infested. Such living sectors may produce considerable growths of callus along their margins, but in the gradually waning tree are not effective in making a permanent repair. The infestation of the smaller branches becomes self-limited at their base.

In Montserrat, and probably elsewhere, a dieback comparable with that of the branches takes place in the root system. The two do not seem to be directly connected, but are presumably related in their origin. Here again Diplodia, and probably other fungi, infest the failing roots, and the same type of replacement by lateral branches and the same persistence side by side of living and dead sectors are seen. The damage to the roots is often complicated by the long groove-like wounds made by the larvæ of weevils of the genera Diaprepes and Exophthalmus. These are quickly healed in actively growing trees, but in trees in failing vigour remain open and afford access to weakly parasitic fungi which infest the wood. A similar slowing-down of the process of repair is seen in the upper parts of the tree where pruning wounds have been made.

A characteristic early symptom of the condition described is the selective loss of shaded branches. This in its origin is a natural process, seen in most trees however healthy, but in the failing trees sensitiveness to shade is so much increased that it leads to persistent reduction of the total amount of foliage.

Behind the whole process there appears to be a decline in vigour such as we.know to be universal in animals which have passed their prime, but do not so readily recognise with regard to plants. The conclusion reached is that, under the conditions described at the outset, the natural duration of the tree is reduced to the period to which the initial vigour extends, and this would seem to be in general somewhere about I5 years. The ensuing failure may be either relatively rapid or long drawn out, according to local circumstances fairly easy to follow.

The history of lime-growing in Montserrat, where to maintain production it has been regularly necessary to establish new fields from time to time, accords well with this interpretation. There is no evidence whatever of the occurrence there of any pest or disease not existing in Dominica or St. Lucia.

\section{Relation of Diplodia to Dieback.}

The fungus accompanying this form of dieback is very regularly a species of Diplodia. It is frequently regarded as $D$. natalensis, but the writer has seen no evidence produced of essential difference from $D$. Theobroma, the ordinary dieback fungus of cacao and many other trees. Infested lime wood is recognisable by its slaty grey colour, and the fungus fruits freely 
in the dead bark. Evidence of its inability to attack tissue in a state of activity is given above, but it is undoubtedly parasitic when growth is checked or vigour is reduced. It would be possible and legitimate to describe the disease as due to this fungus, as has been done by F. S. Earle and J. M. Rogers, in treating of grapefruit dieback in the Isle of Pines, but these authors agree that " no tissue seems to be attacked until it is fully matured or until enfeebled from unfavourable conditions." In the present account the predisposing causes have been regarded as more important, since it is upon the modification of these that control must depend.

\section{Relation of Scale Insects to Dieback.}

Scale insects are so commonly associated with the dieback of lime trees that they are very often credited with a very considerable part or even the whole of its causation. While it is not denied that the presence of the insects intensifies and accelerates the failure of the trees, the writer is in agreement with that section of entomological opinion which in this and similar cases attributes the severity of the infestation to the impairment of the resistance of the tree, or, what comes to the same thing, the special suitability of trees in this condition for the rapid increase of the insects. Numerous cases have been seen in which the dieback has followed its ordinary course in the absence of any significant infestation, and it has always done the same in the face of attempts at prevention by controlling the insects with sprays.

\section{Control.}

The underlying cause of the decline appears to be one of insufficiency and irregularity of water supply, and the duration and completeness of the dry season seems to have more effect than the intensity of the wet. Close shelter to conserve humidity and hinder the soil from drying out has most influence in prolonging the life of the trees. The effect seems mainly to depend on the protection given to the fibrous roots. It is admitted that individual lime trees can and do exist under conditions of low rainfall and considerable exposure, though the writer has no evidence as to the age to which they attain. It is possible that such trees continue to flourish in the open because they have developed a type of growth suitable to their position, but it is none the less certain that, in lime cultivations, the provision of adequate shelter is necessary, first of all to establish a regular stand, and later to delay the incidence of dieback in the fully matured trees. Between these periods it is advantageous but not essential.

The provision of windbreaks in all exposed positions has come to be regarded as a cardinal principle of lime-planting in 
Dominica and St. Lucia, and the importance attached to it could not be more strongly emphasized than by stating the fact that some planters have manured their wind-belts. If the advantages are so definite in these wet islands the need is all the clearer where the rainfall is much lower and less well distributed. In this type of situation it is necessary that the wind-belts should be well-grown and dense to the base, and, to secure the latter condition, it is advisable to grow some suitable plant as secondary cover for the gaps which develop between the stems of the main line of trees. It must be remembered that the direct influence of a wind-belt does not extend very far, but the protection to the first rows of lime trees is passed on by them to the succeeding rows. Conversely, where dieback begins opposite to some gap which lets in the wind, the reduction of the nearest trees gives access to those behind, as a result of which the disease may spread through a field as if it were actively infectious.

The steady use of organic manures may be somewhat confidently expected to increase duration; there is little recorded experience known to the writer to justify a more definite statement. Spasmodic heavy applications of manure have been often tried and seem invariably to make matters worse.

It would be interesting to learn the effect of a system of close draining established with a view to keeping moisture in the soil low during the rainy season, and thus discouraging the -formation of roots at levels at which they are liable to be readily injured by dry weather. Some amount of natural adaptation in this respect is perceptible in the differences of root level in dry and wet districts. It is in this connection that the use of surface mulches in places liable to drought needs careful consideration. They help in such circumstances to retain soil moisture, but some experienced planters hold that this good effect is more than counterbalanced by their tendency to encourage root formation near the surface. The local experiments on which the advocacy of mulching in respect of tree crops is based were carried out under relatively wet conditions and need confirmation for dry ones. If the mulch can be constantly maintained there should be a decided advantage, but this involves large supplies of material. In this, as in all matters relating to the management of limes in dry districts, the maintenance of uniform conditions should be the basis of policy from the time the field is established. Tinkering with the conditions after the trees have begun to fail has always given disappointing results.

The prompt removal of affected branches delays very considerably the course of the dieback, but owing to the slowness of the healing process and the tendency of disconnected wood to dry out and become infested special care is needed to trim the wounds flush with the stem. 


\section{Deficiency Dieback.}

A type of decline quite independent of water shortage, as may be seen by its occurrence on favourably situated estates in Dominica, becomes prominent where the trees are old and cultivation and manuring have been neglected. It is also brought about when growth and heavy bearing are stimulated year after year by transient chemical manures without the condition of the soil being maintained by organic manures of a more lasting nature. The resulting dieback can be very severe. The trees lose their healthy colour and some or many of the upper branches die. That lack of tilth and the exhaustion of the soil, rather than age or parasites, are the cause of the condition, is shown by the large degree of restoration possible by the addition of organic matter to the soil and general good handling.

\section{Wood Rot.}

The dead and failing branches become conspicuously infested with numerous species of fungi, many of them of the bracket type. The bark is usually found to be infested with smaller fungi, of which several species of Nectria and Stilbum are the most common.

The damage done arises almost entirely from the destruction of the woody framework of the tree, and not from any direct attack on the active tissues of the bark and young wood. The destruction is probably largely due to the mycelium of the bracket fungi in question.

These fungi are able to establish themselves on any dead stub left from the failure of a branch or from careless pruning, no matter how healthy the tree may be, but the subsequent progress of the infestation depends on the condition of the adjoining parts. In vigorous trees the decay is arrested when the living branch is reached, and the wood shows considerable powers of resistance. It rots slowly where it is exposed, and unless the wound is trimmed so as to permit the bark to grow over it, there is produced in time an unsightly cavity, but the process is no more than goes on in any tree not carefully trimmed, and, if the wound is not a particularly large one, it does not produce serious results for a long time.

The less vigorous the tree, the less resistant is its wood to decay, and the extreme cases of fungus infestation are to be seen in fields where, after the trees have attained to a good development from the original humus content of the soil, or from the practice of a good system of manuring, the fertility of the soil has then been allowed to run out, and the trees are no longer sufficiently nourished. The policy of substituting sulphate of ammonia, without any backing of humus-building material, for pen manure, mulch, and other organic manures is clearly seen in some cases to have produced this effect. In other cases it has come about from complete neglect of manuring, combined with careless treatment of 
the soil in the way of ignoring drainage, and, in some instances, packing it by the constant pasturing of cattle. As starvation takes effect one or more sections of the tree begin to die back branch by branch, and not only the dead but the failing branches become infested with fungi. The removal of the dead branches does little to arrest the process; the wood of the next larger branch or stem is usually already infected, and offers little resistance to the progress of decay. In the course of time the base of the tree is reached by way of the stem or stems involved, and permanent restoration is no longer possible. Growth is usually continued by suckers put out around the base, which may attain to a considerable size, and give the tree a renewed lease of life. In time rotting of the central part of the crown, due to the downward extension of decay from the original stem, destroys the connection berween the suckers, depriving them of mechanical support, and leaving them with exposed wood on their inner sides in the neighbourhood of soil level. They are rarely able to establish themselves as permanent stems, and sooner or later, from the weight of the crop or the force of the wind, they fall outward, or are broken off. The process of failure thus outlined is a gradual one, commonly extending over some years, and seems in consequence to be usually regarded with indifference until the end result appears. There is, even in the worst cases of this type seen in Dominica, no question of quick destruction of trees such as is produced by an active parasite like Rosellinia.

It has been further noted in cases where lime trees have been grown on poorish land, and without manure, and have in consequence grown slowly from the beginning, that, although they may develop dead branches in the course of time, their wood does not appear to be nearly so susceptible of decay as is the case with trees which have grown more quickly.

\section{Control.}

The remedial and preventive measures which should be adopted are clearly indicated. In fields where dieback is in evidence, or where small and scanty foliage shows that the trees are lacking in vigour, the first essential is to restore the fertility of the soil. If it has become consolidated, or is covered with a firm sod, it should be lightly forked; as much organic material as can be obtained in the shape of pen manure, mulch, cotton-seed meal, lime seeds, and sheep manure should be applied; the weed growth, if rank, may be cutlassed and used as mulch towards the end of the wet season. Leguminous cover crops may be grown if there is light enough for their development.

At the same time the work of clearing the trees of dead and sickly branches should begin. Men who have received instruction in this work should be kept to it as much as possible, and it will 
Jamaica, also similar in character, due to $S$. musarum Ashby. The description of the perithecia of the Dominica species as given by South suggests its identity with $S$. repens.

\section{Symptoms.}

The effects of the disease are usually visible for a longer time in the foliage of the trees than is the case with Rosellinia attack, so that it has the appearance of being slower in its action. This comes from the fact that the root system is in many cases destroyed gradually without the girdling of the collar which in Rosellinia disease very often brings the tree to a sudden end. Sometimes a soft rotted patch is seen extending on the bark of the collar, while much of the root system is still sound, but generally the foliage has become thin and yellow, and the tree is in some cases nearly dead before any damage is visible in that region.

When the roots of a sickly looking tree are laid bare the disease is seen advancing along them in the form of a soft rot of the bark accompanied by a disagreeable smell. On the last 6 inches to a foot of the section adjoining the healthy part of a root the surface of the bark shows a greenish black discoloration, behind which the bark is rotted and easily comes away. Roots that have been attacked for some time are devoid of bark, and the wood is dry and blackened.

Between the layers of the bark, and on the surface of the wood occur flat branching rhizomorphic strands, which may be 6-7 $\mathrm{mm}$. broad in their older parts. In well-developed examples they divide several times, the main branches keeping their ribbon-like form and being mostly blunt and rounded at the tips. They may, however, develop a secondary system of finer semi-flattened branchlets along their margin, producing a sort of fishbone pattern. The advancing tips of the strands are whitish and papery; further back the strands are brownish red and rather fleshy in consistency; still further back the colour becomes dark brown. When old they lose their consistency and are with difficulty recognisable as blackish streaks on the wood or in the bark.

A light brown discoloration extending deeply into the wood accompanies the advancing strands, and has been seen beginning just in front of their white tips as they penetrated healthy tissue. South describes the development near the collar of a flat sheet, red on the surface and white within, of similar material to that composing the rhizomorphs, and situated in the cortex or in the place of the cambium layer.

\section{The Fungus.}

The conidial fructifications of the fungus are of the Stilbella (Stilbum) type, and are produced on the margin of the rhizomorphs, of the mycelial sheet, or from tufts of white mycelium. 


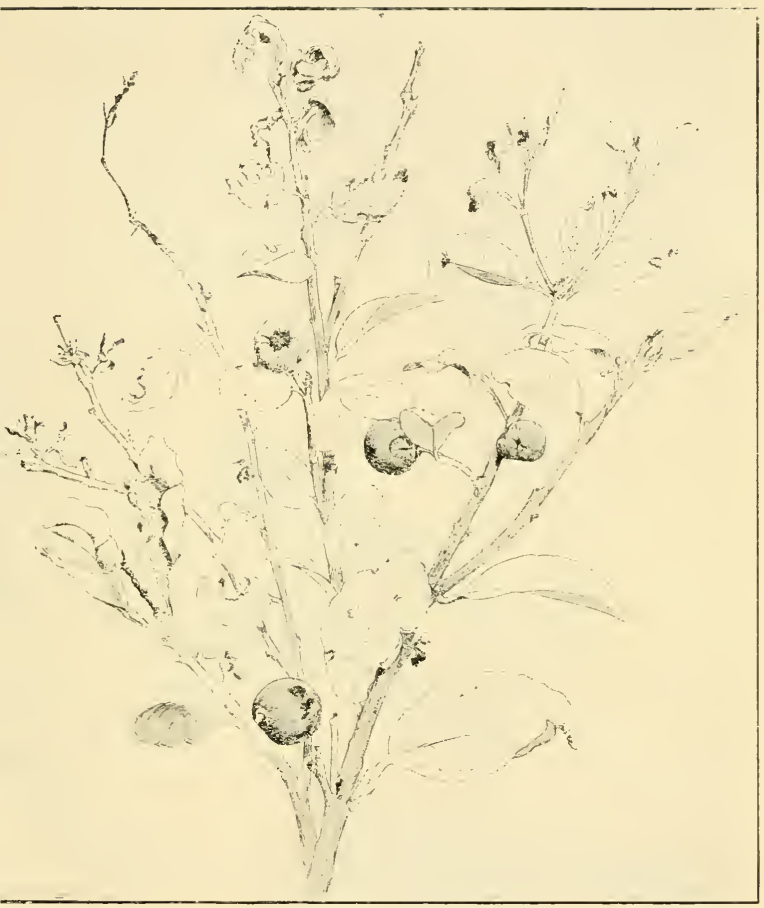

Drawn by

Fig. 76

[W. Buthn

Anthraciose of Lime 

They consist of pink slightly hairy stalks, usually $2-5 \mathrm{~mm}$. in length, but sometimes longer, rather irregular in form, and surmounted by a white tip or by a white opaque cluster of conidia.

The perithecia have been described as follows by South, who found them on one occasion situated in groups on a rhizomorph: "The perithecia are minute, red, flask-shaped bodies, the neck of the flask being often somewhat curved and about as long as the diameter of the lower spherical portion of the organ. Each contains asci and paraphyses. In the ascus eight, bicellular, somewhat reddish-yellow transparent spores are formed, arranged obliquely in a single row. The spores are bluntly pointed at either end, constricted at the septum, somewhat thick-walled, and measure approximately I7-20 $\times 8.5$-10 microns.

"They germinated very readily in about four hours, and in culture media gave rise to rhizomorphs and Stilbum fructifications resembling those found on the lime trees. In cultures a third form of fructification appears, of the Cephalosporium type, the spores formed on the short conidiophores being very similar to those borne in the head at the summit of the stalk or stroma."

\section{Conditions of Occurrence.}

The incidence of the disease suggests its origin from the forest. In new clearings it is probably directly transferred from logs or the roots of stumps: in older cultivations from infested material brought down by floods. This agrees with experience of the Ceylon disease, and is suspected to be the mode of origin of the attack on bananas in Jamaica. Another character in which the Dominica and Ceylon diseases agree is in their occurrence being restricted as a rule to swampy or sour undrained soil.

Once it is established in a lime field the spread of the disease from tree to tree along the roots (it may possibly also occur through the soil) is very definite and results in the death of a group of trees around the original site of the infection. The

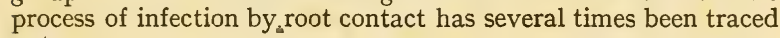
out.

\section{Control.}

The preference of the fungus for undrained situations indicates the point at which the attack upon this disease should be most strongly pressed. A system of isolation trenches like that recommended for Rosellinia disease should be established, and care taken to have the trenches of good depth and linked up with an effective drainage system. The disposition of dead and dying trees should also follow the lines laid down for Rosellinia disease. 


\section{Collar CANKer.}

Lime trees up to four or five years of age, under conditions where growth is slow and uneven, sometimes develop a rough and swollen structure of the basal portion of the stem extending for a few inches or up to a foot above the surface of the soil. The cortex and bark are divided into irregular patches, and the new wood is deposited in lumps and ridges. Open wounds may extend to the wood, and frequently matters are complicated by infestation with the lime bark beetle, Leptostylus pramorsus, which begins on the damaged spots but extends for some distance under the healthy bark. The trees make a persistent struggle against the condition, but not infrequently die from the girdling of the stem. Wounds on the roots such as are described by F. W. South in connection with this affection are caused by the larvæ of Diaprepes or Exophthalmus weevils and have no relation to the disease.

The origin and nature of the disease are not known, and no parasitic organism has so far been found to be at all constantly associated with it. It appears to be connected with somewhat impoverished or insufficiently drained soils, and is in the end overcome by attention to these matters and by the trees which survive outgrowing the trouble.

\section{BRANCH GALLS.}

In one section of Jamaica there is a disease of lime and orange trees, more severe on the first named, which was originally reported in the following terms: "The lime trees are infested with galls, which in some instances appear to do as much harm as the scale insects. The galls are found on old and young trees, but usually they grow first on fairly old limbs. These limbs then send out strong young shoots for a time, but speedily get exhausted and die, large numbers of limbs dying until many fine trees are killed, or so nearly so as to be useless."

\section{Causation.}

The disease was investigated by L. S. Tenney and F. Hedges, who found that a fungus Spharopsis tumefaciens Hedges, could be detected in the galls and that it reproduced the disease when inoculated into healthy trees.

When present in quantity the mycelium imparts a black appearance to the tissues, but frequently only small amounts are present. The fructifications have been found by S. F. Ashby in abundance on branches near the galls. They are in the form of solitary or congregated sub-spherical pycnidia covered at first by the epidermis, and emerging later, producing oblong or ovoid spores, rounded at one or both apices, or sub-acute, sometimes 
curved, continuous or I-septate, I6-32 $\times 6-12$ microns. The mycelium is hyaline at first, darkening later.

The galls are approximately round, attached by a broad base, and vary from the size of a pea to knobs 2 to 3 inches in diameter. They are at first covered by smooth green bark; later by a modified corky bark, which may crumble away leaving the wood bare.

Similar excrescences have been met with on lime trees in Dominica and St. Lucia, and examined by F. W. South and by the present writer. They have been strictly sporadic cases, confined, in each instance seen by the writer, to an individual branch of one tree in a cultivation. The branch is hypertrophied in the sense of producing several abnormally long and thick shoots, and the galls are usually associated with the buds along the course of these. No fungus could be found suggestive of the Jamaica species, nor any which would reproduce the disease from inoculations. Galls occur in a similar way now and again on cacao trees (see p. I76).

It would appear that the Jamaica disease is not present in these islands, and that the galls which do occur are not of an infectious nature.

\section{Anthracnose of Lime.}

\section{(Wither-tip, Blossom Blight, and Fruit Canker.)}

This is a very destructive disease of lime trees, in which the ringing and tip-wither of new shoots, the infection and curling of tender leaves, the blighting of buds and flowers, the loss of newly set fruit, and the production of cankers on fruits which are retained, are due to infestation with the fungus Glocosporium limetticolum Clausen.

\section{History and Distribution.}

The identity of this fungus, and its specialised parasitism on the lime and lemon have only in comparatively recent years emerged from confusion with Colletotrichum glocosporioides Penzig, which is very widely distributed on citrus trees generally, and has been variously regarded as a dangerous parasite and as a harmless saprophyte. The latter fungus (see separate account) is common in these islands, doing little recognizable harm, whereas the affection under notice has been absent so far as is known from the islands lying between Trinidad and Porto Rico until its appearance and rapid extension in Dominica in I922. Recurring heavy losses of the nature indicated in the introductory paragraph occur in British Guiana, where they have been attributed to the direct effects of wet weather, but specimens received in April, I9r9, were found to be heavily infested with a fungus indistinguishable from $G$. limetticolum An epidemic of the 
disease occurred in July and August, I9I8, throughout the colony of Trinidad, where it is now quite general and has put a stop to the development of a lime-growing industry. An attempt is being made to eradicate the disease from the one district in Tobago in which it has appeared. The affection has been longer known as a serious trouble of lime trees in Cuba and Florida, and from accounts seen probably occurs in Jamaica. A severe epidemic results in almost total loss of the current crop, and even a mild prevalence has a marked effect on production.

\section{Symptoms.}

The fungus does not infect mature foliage or twigs, or fruit after it has reached about three-fourths of an inch in diameter. The attack is made on the young shoots while they are still tender, and on the blossoms and young fruit. Infected shoots commonly dry up at the tip for a distance of an inch or more, or are ringed by an infection further back, and leaves which are infected but not killed have dead areas at the tips or edges which cause them to become distorted in their further development. Young plants in nursery beds are similarly affected.

On the inflorescences a proportion of the buds have complete petal infestation, turn brown and fail to open; expanded flowers become infested and fall without setting, and newly set fruit is infested, most frequently by way of the stigma and style, and shed. Infected fruits which are not shed show lesions varying from rounded spots to rough deep cankers occupying nearly half their surface.

The blossom blight and wither-tip may exist together, or either one may be severe without the other being much in evidence, the difference probably depending on the weather prevailing at the time of greatest susceptibility. In the same way considerable differences appear in fields or plantations not far apart.

There can be no doubt, from the variations in the incidence of the disease, that it is greatly influenced by weather conditions, but sufficient evidence has not been collected to enable an analysis of the dependence to be made. No influence from cultural conditions has been detected.

\section{The Fungus.}

The fungus is with difficulty distinguishable from the Glœosporium condition of Coll. glocosporioides, but setæ have never been observed. The distinctions indicated by R. E. Clausen are as follows: the acervuli (pustules) in G. limetticolum are flesh-coloured or salmon pink throughout, while those of the other fungus are frequently dark, and on bleached dead spots on leaves and twigs are black. The conidiophores are hyaline throughout their length, and arise from a rather loose stroma of hyaline hyphæ, while those of $G$. glocosporioides are pale sooty 
at the base and are situated on a compact black stroma. In cultures the latter species forms a black stromatic pellicle, a feature absent from cultures of the parasite. The conidia are more pointed than those of $C$. glocosporioides, with less tendency to be constricted in the middle. The conidia when fresh are markedly less granular, with a less distinct nucleus. The measurements of the two fungi are about the same, the conidia of the parasite being I4-I $8 \times 6-7$ microns, the conidiophores $20-30 \times 5$ microns.

\section{Control.}

A disease of this description could be readily controlled by spraying, were it not that the flushes of new foliage and the blossoming of the lime are liable to be scattered and erratic. There are, however, fairly well-marked times of maximum production, which vary from place to place, but are pretty constant for any particular locality. By spraying at these times it may prove possible to save a paying proportion of the fruit, and it should be noted that it is just as important to save the shoots as the blossom, since it is upon these that the next crop of flowers is formed.

From information regarding field studies of control made on behalf of the U. S. Department of Agriculture, kindly supplied by H. P. Fulton, it is learned that a careful spray schedule applied at the time of blooming and early setting can be used with success, though whether the crop will justify the expense is doubtful. An early cleaning-up spray before the blossom comes is probably desirable. "The first fruit spray should be made as soon as enough petals have dropped to allow for coating a reasonable setting of fruit. This would be when the bloom is perhaps one-half to one-third advanced. Later sprays will depend upon the progress of the bloom and on weather conditions which may favour the disease. In a general way two or three later applications at intervals of one to two weeks are necessary."

Burgundy or Bordeaux mixtures are the most effective as sprays, but have the disadvantage, where scale insects are controlled by fungus parasites, of killing out the latter and so inducing scale infestations. This action is much less marked with lime-sulphur solution, which nevertheless gives satisfactory control of the disease. The best results have been obtained with commercial lime-sulphur diluted at the rate of about one in 30 to one in 40 , care being exercised not to use the greater strength when the temperature is high. For this reason spraying is best done in the cool of the morning or evening. The adoption of a copper spray in the first instance, with the use of lime-sulphur for succeeding sprayings, the combination found desirable for citrus scab in Porto Rico, may be the most satisfactory system to adopt. When no trouble is anticipated from scale insects copper sprays may be used throughout. 


\section{Grey Blight.}

A fungus identified by G. Massee as Thelephora pedicellata, Schwein, now placed in the genus Septobasidium, forms a dense slightly raised layer of felted mycelium, slaty-grey when fresh, changing to brownish grey, on leaves and twigs of lime in St. Lucia, Dominica, and Montserrat. The same or a very similar fungus has been seen in large patches on pigeon pea stems in St. Vincent and Trinidad. S. Langloisii Pat., which may very well be the species above referred to, is recorded by E. A. Burt from Grenada. A brown species occurs in Dominica.

According to T. Petch, the genus Septobasidium, made up of species all of similar encrusting habit, is parasitic on scale insects, and this is so far borne out by local experience that the fungus is found in association with colonies of purple scale on lime, and mass infestations of a white scale (Chionaspis ?) on pigeon pea. In the former case the mycelium has been found growing under the scale and attacking the body of the insect.

An effect which may be accidental but is none the less real is sometimes produced on the enveloped twigs and small branches of lime. There is a free production of gum from raised swellings where the bark is covered by the fungus, and this in a number of cases seen has resulted in the death of the portion of the branch lying beyond the invested part.

No evidence of penetration has been found, and the most probable explanation of the effect is that it is due to suffocation. It has no serious importance.

\section{LEAF SPOTS.}

Brown patches extending from the tip or margin of the leaf, or smaller spots, occur occasionally, and are infested with Colletotrichum glocosporioides. (See Citrus Anthracnose).

Roundish raised spots, foxy red or black, caused by Cephaleuros mycoidea are common in some localities. (See Algal Disease, p. I52).

\section{Citrus Trees in General.}

\section{Citrus Anthracnose.}

A position of some uncertainty exists with regard to the extent of the parasitism of the very generally distributed fungus Colletotrichum gloeosporioides on citrus trees. It has been widely regarded in the United States and some parts of the West Indies as the cause of wither-tip, spotting and streaking of fruit, and spotting of leaves on citrus trees generally. With the separation from it of the active parasite Gloosporium limetticolum (see Anthracnose of Limes) which has been shown to be responsible for the blossom blight, wither-tip, and fruit canker of limes, 


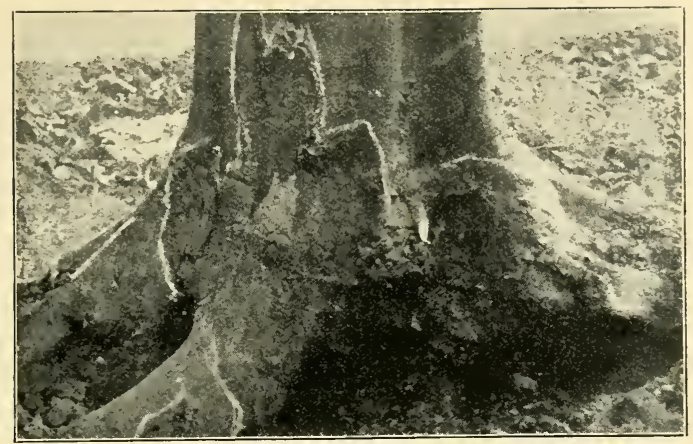

Fig. 79

Foot-Rot on Old Seedling Orange Tree

(a) Margin of Rot indicated by Chalk Line

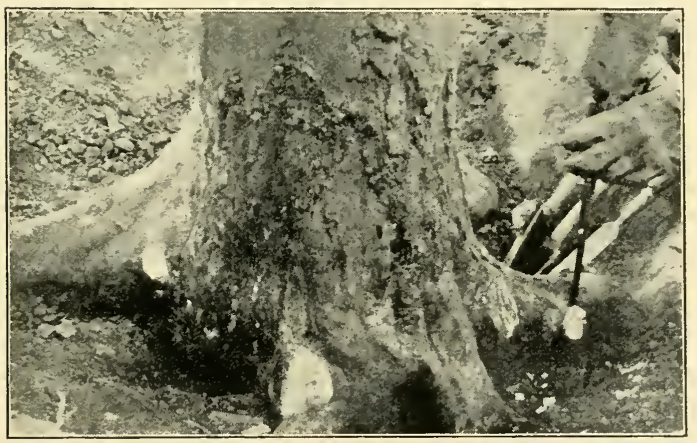

Fig. $79 \mathrm{~A}$

(b) Treatment in Progress

Bull. 262. California Agri. Expt. Sta. 

and is probably the species producing these effects on the lemon, there is a considerable weight of opinion at the present time that the fungus in question is mainly saprophytic, and at most a weak parasite of plants or parts otherwise injured or in poor condition. This is the position taken up in recent accounts from Cuba and Porto Rico, and agrees with experience in the Lesser Antilles, where, owing to the absence of the more active fungus, the affection has never been held to be of much account.

The fungus appears with great regularity on dead and dying twigs or leaves of citrus trees, even when these have been removed from the tree in a healthy condition. It is thus difficult to secure evidence of parasitism, especially as infection experiments on healthy material are reported in many cases to have completely failed.

\section{Symptoms.}

Spots attributed to this fungus occur on leaves in the form of dead brown areas extending often from the tip or margin, in which develop numerous small dark pustules of the fungus, often arranged concentrically. The injury appears usually on senescent leaves or as a consequence of insect injuries.

On the fruits the fungus is found occupying hardened brown spots or large brown to blackish blotches up to an inch or two in diameter on the rind; these are generally somewhat sunken, and are situated in any position. As a rule only a few isolated spots occur in the produce of any particular tree, and usually they can be attributed to some predisposing injury. On trees which are suffering from the general effects of some serious disease, however, a large percentage of fruit may be attacked by anthracnose. Tear-streaking of the rind is attributed to the effect of the germination of spores washed down in quantity from dead twigs.

In the great majority of cases the fungus as it occurs on the twigs appears to be entirely saprophytic; in a few instances which have come under the writer's observation it has assumed the aspect of a parasite on twigs of which the resistance has been lowered by external conditions.

\section{Fungus.}

The fungus in its common Glœosporium condition is difficult to distinguish from G. limetticolum, in comparison with which its characters are discussed (page 208). On dead twigs fringes of dark setæ may be produced around the pustules, which then appear as black dots to the naked eye. Setæ have not been observed in the lime parasite.

\section{Control.}

The position of the fungus as a weak parasite able to attack only injured or debilitated parts indicates the nature of the remedies to be applied where its effects are regarded as serious. 


\section{Gummosis.}

The formation and exudation of gum in citrus trees is a general reaction to injuries which may be caused by. mechanical means, by chemicals, by physiological disturbances, or by infestations with fungi. There are consequently various types of disease of which it is a symptom. Two of these, foot-rot or mal-digoma and Diplodia disease are separately dealt with.

Symptoms closely resembling those of foot-rot, but not confined to the base of the stem, have been regarded as evidence of a distinct disease. On lemon trees in California, according to H. S. Fawcett, gummosis of this type is very common, and has been shown to be due in many cases to the fungus Pythiacystis citrophthora of Sm. and Sm. In another variety of gummosis on lemons in California the fungus found is Botrytis cinerea. The first-named fungus inhabits the soil, infects the bark about soil-level, and spreads indefinitely upwards. It is closely related to Phytophthora. The conditions favouring the disease are the same as in the case of foot-rot, and the same methods of prevention and treatment are successful.

There are other forms of gummosis of stem and branches in which, as in many cases of foot-rot, parasitic causation has not been demonstrated. These affections begin with the degeneration of a patch of the inner bark, resulting in the production of gum or "sour sap" which oozes out if any crack in the bark is available. The bark may die completely over this patch, or the gum layer may be enclosed by new growth and form a characteristic pocket.

The external development varies from dead sunken or bare patches to rough bark broken up into scales owing to the irregularity of its production by the cambium. The latter form of affection closely resembles one aspect of the Florida scaly bark disease, which differs in further attacking the twigs and fruit.

For practical purposes these types of bark affection on citrus trees, including foot-rot, are best regarded as manifestations of some unfavourable relation, which may be temporary or permanent, between the plant and the physical conditions of its environment. Injuries due to temporary conditions may be met by the treatment given for foot-rot. The subject of more general incompatibility is discussed in the introduction of this section on citrus diseases.

\section{Foot-Rot OR MAL-DI-GOMA.}

The type of disease to which these names are applied is characterised by the decay of bark and wood on the crown and collar of the tree, accompanied by the formation of gum and its exudation from the affected parts. Disease of this general type occurs in most if not all the citrus-growing countries of 


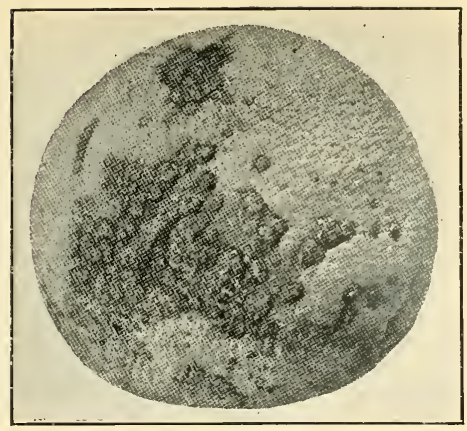

Fig 80

CANKER ON GRAPEFRUTT

Bull, 124, Florida Agri. Expt. Sla.

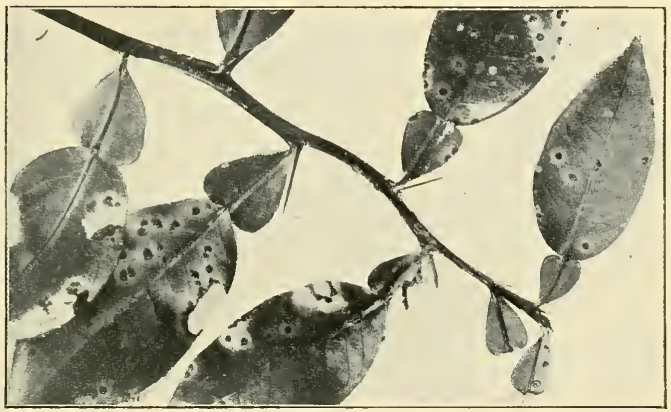

Fig. 81

Canker on Leaves, showing Pale Zone around the Spots Bull. 124, Florida Agri. Expt. Sta.

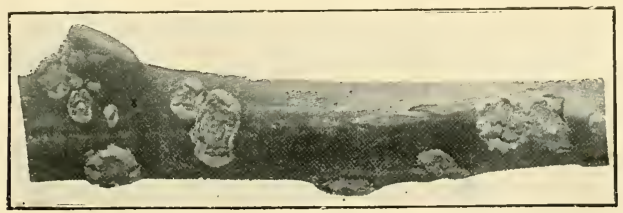

Fig. 8?

CANKER ON YOUNG TWIG 

the world, and has been reported from time to time as the cause of heavy losses.

It is not a prominent disease in the Lesser Antilles, as the principal citrus tree, the lime, shows little susceptibility to it under local conditions. Apparent instances have been met with on this host in St. Lucia, Dominica, and Grenada, but only under special circumstances. The case is very different with seedling orange trees, which, in Dominica at least, invariably develop this trouble as they begin to pass their prime. Similar experience is recorded in the United States and Cuba. In a district of Barbados which has lost most of its orange trees the old surviving trees examined by the writer were affected in this way.

In the heavy clay lands of British Guiana the lime is subject to the disease.

\section{Symptoms.}

Foot-rot proper, as distinguished from other forms of gummosis on citrus trees, is confined to the collar and crown roots. It begins in a patch or patches, often in the hollows formed in the neighbourhood of the crown; there is often an exudation of gum through cracks in the bark, the bark dries up or is rotted by fungi and bacteria, and the wood is eventually left bare and begins to decay. A sour smell usually accompanies the disease. The patch spreads around the base of the stem and for some distance along the main roots and the tree is slowly killed. Usually, as in other bark diseases, a thinning and yellowing of the foliage occurs, and, as the encircling of the stem approaches completion, heavier crops of fruit are set.

\section{Causation.}

Various fungi have been found associated with this type of disease in different parts of the world, but it is generally regarded as of non-parasitic origin. Recently H. S. Fawcett has suggested the complicity of the fungus Pythiacystis citrophthora in at least part of the cases passing as examples of foot-rot in America.

The more recent investigations of $\mathrm{H}$. E. Stevens in Florida have shown that the disease there is caused by Phytophthora parasitica Dast (Ph. terrestria Sherb.) and this fungus has also been found in cases of foot-rot in Cuba, Isle of Pines and the Argentine.

Apart from this question, there is general agreement as to the conditions under which the disease is liable to appear. Heavy or compacted soils, imperfect drainage, too deep or too close planting are recognised as predisposing causes. As noted above, it is also very liable to appear, even under seemingly favourable conditions, on seedling trees of the susceptible species after they reach a certain age. It seems probable 
that some of the so-called epidemics of foot-rot have been due to this stage being reached by the trees of a plantation or of a district.

The mandarin or tangerine varieties, and the sweet orange are most susceptible, the lemon less so, while the sour orange and the rough lemon are decidedly resistant. In these islands the shaddock and grapefruit are regarded as resistant, but according to $\mathrm{H}$. S. Fawcett this is not the case with some strains of the latter.

\section{Prevention and Control.}

The surest method of prevention is the use of sour orange stocks. With seedling trees already established the amelioration of such conditions as are mentioned above should be carried out so far as it is possible. Especially should the collar and crown be kept free from soil. Treatment of existing cases is possible on the following lines : permanently remove sufficient soil to leave the collar and crown roots exposed; scrape and cut away the dead bark until the patch presents a clean surface surrounded by a margin of healthy bark, and paint the whole place over with Bordeaux paste or a good wood preservative such as is used for treating pruning cuts. Remove any low branches which interfere with the free circulation of air around the base of the tree.

\section{SCALY BARK.}

According to H. S. Fawcett, the term scaly bark is used for two distinct affections in California and Florida respectively. The first, psorosis, occurs in California, Florida and Cuba. The same or a closely similar affection occurs on lemon trees in the Dominica Botanic Gardens. A patch of outer bark breaks up into irregular scales, which are pushed up by new growth beneath. The area expands slowly for years, and finally the bark may die quite through and the wood begin to decay. There seems to be little to distinguish the affection from a form of gummosis, and it should be treated by the scraping and painting method described under foot-rot.

The Florida scaly bark, or nail-head rust, is described as a specific disease, mainly of the sweet orange, not known outside that State, and believed to originate from infection with a variety, citricolum, of the fungus Cladosporium herbarum Lk.

On the smooth bark of branches, of the age of 6 to 9 months or more, raised rusty spots one-sixth to one-half inch broad, with well-marked edges, are formed. The bark becomes glazed, and then breaks into flakes and scales. On larger limbs the bark may become rough and shaggy. On the fruit occur brown sunken spots, some of them in the form of rings, one-fifth to one half inch across. The spots are yellowish to reddish brown on 
the green fruit, finally becoming dark. Trees heavily infested have been successfully treated by heading back and spraying with Bordeaux mixture.

\section{Nature and Distribution.}

\section{SCAB.}

Citrus scab is an affection which produces corky raised areas and warts on young growing leaves, fruits and sometimes twigs, resulting commonly also in some deformation. In the tropical and sub-tropical regions of the New World it occurs with great frequency, in some districts quite regularly, on sour orange and rough lemon. From these hosts, in common use as stocks, it appears to have developed strains virulent to grape-fruit, and it is in connection with the important business developed in Florida, Cuba and Porto Rico for the supply of the American market with this fruit that scab has assumed great importance. The lemon industry, so far as it exists in the places mentioned, has also been seriously affected by it. The sweet orange and most of the mandarin group show little susceptibility to the disease The lime is reported to be attacked in the Isle of Pines (Cuba) and in Ceylon. In Porto Rico and in the Lesser Antilles this host has not been noted as susceptible.

The disease occurs on the sour orange in these islands, but owing to the scattered distribution of its appropriate hosts and their small commercial importance has received little attention.

In addition to the localities already mentioned, scab of the type under notice is recorded from Japan, Australia, and South Africa. It fails to develop any virulence in the dry climate of California.

The disease is reported to have made its appearance in Florida in I884, and to have spread rapidly through that and the adjoining States. It is conjectured to have been introduced from Japan.

\section{Appearance and Effects.}

It is advisable to describe the disease in some detail owing to the liability to confusion between scab and canker. As met with by the writer in these islands the affection has usually consisted of small roundish raised corky spots on leaves and green twigs. The following description quoted from J. A. Stevenson refers to the more virulent form occurring in Porto Rico.

"The first signs of infection are circular, minute, translucent areas followed by a rapid production of the corky outgrowths so characteristic of the disease. On the fruit these corky outgrowths, wartlike in appearance, are produced, and vary much in size and shape, often running together or occurring in such numbers as to cover a large percentage of the surface of the infected fruit. At times plateau-like 
areas are produced, of an inch or more in diameter, irregular in shape and marked by the dying of the epiderm and its breaking up into silvery scales. Again it may take the form of ridges, conical elevations, or other shapes. The corky areas are dull brown in colour in some instances, but very commonly are a dull red with brown margins. This latter stage occurs where the disease is especially virulent, the ridge and plateau conditions being more often noted in instances where but little disease is present. This latter is the type found on oranges. Young fruits are frequently much distorted, assuming triangular or other peculiar shapes. Those most distorted fall to the ground soon after attack. It may be noted that a larger percentage of scabbed fruits fall than of normal ones. Infected fruits remaining tend to regain their normal shape by subsequent growth, and as there is no increase in size of the initial infections, the great increase of the surface areas of the fruit gives all appearance of a partial recovery or ' cleaning up' from the disease. This, of course, is not what takes place, but it merely means that there has been no further spread of the scab areas.

"Leaves are frequently distorted, the same corky areas appearing as on the fruit. Where infection is not general, very marked conical projections, often as much as a centimetre in height, appear.

"The disease areas are surface infections only, there being practically no penetration in either leaves or fruit of the inner host tissue. In fact, so effectively are the tissues protected that scabbed fruits are not any more subject to decay than normal ones; less so, if anything. Many such have been kept in the laboratory for long periods of time until they finally become hard and mummified."

\section{Causation.}

There has been some dispute as to the causation of the disease, but those mycologists most closely in touch with it are convinced that it is due to infections, occurring only when external circumstances are favourable, with the fungus Cladosporium citri Massee. The occurrence of the fungus in the scabbed tissue is somewhat obscure and it is said to be masked, in Florida at least, by a saprophytic species resembling the common Cladosporium herbarum. The parasite is regarded as not typical of the genus Cladosporium as ordinarily understood. The only reproductive bodies obtained in pure cultures are thick-walled, dark-coloured packet-like clusters or chains of cells, and these were also found on old withered scabs.

The description of $C$. Citri Mass. is as follows :-Conidiophores tufted, erect, branched, septate, brown, 30-75 $\times 2-4$ microns. conidia fusiform, dusky, continuous, or I-3 septate, $8-9 \times 2.5-4$ microns. 


\section{Influence of External Conditions.}

Infection only takes place on young and tender parts of the plant, and is very largely dependent on the prevalence of moist and cloudy weather in periods when new growth is being rapidly developed. Trees in poor condition are but little subject to attack, presumably owing to the scarcity and slow development of new shoots upon them.

\section{Inherent Resistance.}

According to Stevenson scab was generally prevalent on sour orange and rough lemon stocks in Porto Rico by the year I903, but grapefruit was almost immune until the occurrence of an excessively wet season in I9II-I2. Then the grapefruit was attacked suddenly and in most virulent fashion in one section, and since that date the disease has maintained its new character and invaded most of the other citrus districts in turn. This occurrence gives colour to the suggestion that a new and virulent strain has come into existence in the island.

\section{Prevention.}

Outbreaks of scab are preventable by protective spraying with Bordeaux mixture, but this method has been found to have the serious drawback of also repressing the fungi which keep down scale insects, thus opening the way to serious infestations with the latter. It is found that better general results are obtained from the use of a lime-sulphur spray, which while much less effective against scab is largely free from the objection named.

\section{Black Melanose.}

The affection known as true melanose in Florida, and ascribed to the fungus Phomopsis Citri does not appear to occur in the West Indies. It is described as a superficial marking of the surface of fruits, leaves and stems, consisting of small raised areas with the appearance of wax or of small drops of melted sugar burnt brown. These markings sometimes occur in patches and circles.

The melanose met with in Cuba, Porto Rico, Jamaica and the Lesser Antilles is a leaf affection distinguished as black melanose or greasy spot. It occurs on various citrus species in these islands, including rough lemon, grapefruit and orange The back of the leaf is covered with slightly raised black and brown markings, somewhat resembling, it has been suggested, spots of dark grease under the epidermis. The affection is very persistent, but does no apparent damage. Its nature is unknown. 


\section{Citrus Canker.}

\section{History and Distribution.}

The existence of the serious infectious disease now known as citrus canker became known through its introduction into Florida, though it had been present in some of the Western States of the Union, notably Texas, for some years previously. It appears to have come in from Japan on Citrus trifoliata stocks, upon which the disease is not prominent. The date of first introduction into Florida is authoritatively stated to be November, I9I2, which is a matter of importance to those who have received nursery stock or bud-wood from that State. In the following year the disease began to cause alarm in the grapefruit industry and a special organisation was created to deal with it. The very drastic efforts which have since been made to entirely eradicate the infection have had the effect of thoroughly suppressing the disease, and their ultimate success remains to be tested by time.

The distribution of citrus canker, as known at present, is as follows :- United States (Texas, Louisiana, Missisippi, Alabama, Florida), Japan, China, the Philippines, Java, Singapore, South Africa and Australia.

\section{Symptoms of the Disease.}

The following description of the appearance of citrus canker on leaves, twigs and fruit is quoted from H. S. Stevens :-

"The distinguishing feature of citrus canker as observed in the field is the characteristic spotting produced on the fruit and foliage. As usually seen the infection appears as small light brown spots, from less than one-sixteenth to one-quarter of an inch in diameter. The spots are usually round, and may occur singly, or several may run together, forming an irregular area. This last usually occurs on fruits. The spots project above the surrounding healthy tissue, and are composed of a spongy mass of dead cells, covered by a thin white or greyish membrane. The membrane finally ruptures and turns outward, forming a lacerated or ragged margin around the spot.

"On the leaves, infections first appear as small, watery dots, with raised convex surfaces. These dots are usually of a darker green than the surrounding tissue. Sometimes, however, the surfaces of the spots are broken as soon as they appear. Spots may appear on either surface of the leaf, but they do not at first penetrate through the leaf tissue. They gradually increase in size, change to a light brown in colour, and become visible on both sides of the leaf. In the older spots one or both surfaces may be bulged or raised, and such 
spots are commonly surrounded by a narrow yellowish band or zone. In the more advanced stages, the surface of the spots becomes white or greyish, and finally ruptures, exposing a light brown spongy central mass. Old spots soon become overgrown by saprophytic fungi, and may appear pink or black on account of these fungus growths.

"On the fruits the spots are very similar to those formed on the leaves. They do not penetrate far into the rind. They may be scattered over the surface, or several may occur together forming an irregular mass. Gumming is sometimes associated with the spots formed on the fruits. Canker, apparently, does not cause a rot of the fruits directly, but opens the way for other fungi to enter and cause infected fruits to rot. The spots on young twigs are like those on the leaves and fruit. On the older twigs they are more prominent, and more or less irregular in shape. This is specially true of old spots. They show the same spongy tissue that is found in the spots on the leaves, but assume a cankerous appearance and the surface membrane completely disappears. These spots or cankers are formed in the outer layers of the bark tissue, and do not penetrate to or kill the wood. The spots once formed in the bark are persistent, and are not readily sloughed off. They may remain for a long time and form centres from which infections may readily spread. This was confirmed by observations on infections produced on spotted trees in the greenhouse, and in the grove by artificial infection. Some of these spots have been under observation for over a year, and show no tendency to slough off."

R. A. Jehle in a later account emphasizes the diagnostic value of the translucent, glazed, oily appearance of the zone immediately next to the ruptured portion of the spot. This is lacking from scab, which moreover distorts the leaves and causes warty projections on the fruit, characteristics which are absent from canker. Scaly-bark spots are hard and glazed, those of anthracnose are sunken.

\section{Susceptibility.}

It has not been established that any citrus plant is quite immune from canker, but wide gradations in susceptibility occur. From the Philippines it is reported that the common lime, which is presumably the commercial lime of the West Indies, is highly susceptible, while a variety known as the Tahiti lime seems practically immune.

\section{Effects.}

The direct losses due to the disease result from its effects on the fruit. The rind is more or less covered with the canker 
spots, and, although this condition does not directly affect the edible portion, the fruit is not only rendered so unsightly as to be unsaleable, but is very liable to splitting and to the inroads of secondary fungi, which cause rotting.

The very heavy monetary cost of the disease in Florida has been due to the wholesale destruction of infested groves in the attempt at complete eradication.

\section{Causative Organism.}

The disease is due to the action of a specific bacterium, which has been described under the name of Pseudomonas Citri, Hasse. The organism is yellow, one-flagellate, is variable in shape and size, but as obtained from young cankered tissues is usually a short rod with rounded ends, which measures I.5-2.5 $\times 0.5^{-0.75}$ microns. No host-plants are known outside of the order Rutaceæ.

\section{Mode of Infection.}

Infection occurs through natural openings and through wounds. Drops of dew or rain on affected organs contain the bacteria in large numbers, so that the disease is very readily transferred by physical or animal agency from plant to plant. The disease is, in fact, extremely infectious and has been seen to spread with incredible rapidity.

Fallen leaves are believed to carry over the infection, and inconspicuous lesions containing the parasite can occur on mature wood. H. A. Lee has determined in an extensive series of experiments that the organism quickly disappears from unsterilized soil. Dried on cloth, according to Stevens, it was still alive after five weeks.

\section{Influence of External Conditions.}

The disease is most prevalent and destructive in warm humid weather, and is checked by cool dry periods. It is much more active on thrifty growing trees than on those in poor condition, and on the latter it may exist in a suppressed or dormant condition for long periods. The frequent flushes of growth on limes in Dominica and St. Lucia would, so far as can be foreseen, afford very favourable conditions for the development of the disease should it be introduced.

\section{Control.}

Reports as to the effects of spraying are contradictory. In Florida cutting grapefruit trees down to stumps and coating them with Bordeaux mixture did not prevent the new growth from being infected. In South Africa an outbreak was successfully controlled by pruning and three sprayings with Bordeaux. 
Similar results have been claimed in Texas. Recent work by $\mathrm{H}$. A. Lee goes to show that only alkaline Bordeaux is effective, and that the excess lime, not the copper, is the active agent. Lime-sulphur, at ordinary strengths, is indicated as likely to be effective.

\section{Exclusion.}

Citrus trees imported into the Lesser Antilles in recent times, before the danger from citrus canker was known, have as far as possible been examined, and no trace of the disease has been seen. Thorough surveys of Cuba and Porto Rico have been made with the same result.

In order to exclude the disease ordinances have been issued in the British islands designed to exclude material that may possibly be infected, and it is obviously desirable that these should be carefully enforced.

\section{Diseases, Injuries and Rots of Citrus Fruit.}

Shipping trade in citrus fruits in the Lesser Antilles has been developed on a large scale only in connection with the New York market for green limes. Traffic in oranges and grapefruit is confined to inter-island exchange carried out in an unorganised fashion. Barbados especially, with its dense population and lack of home-grown fruit, affords a market for lowgrade seedling oranges.

It is understood that green limes, selected and packed with reasonable care, usually reach their destination in good condition. Such complaints as are current appear to refer to poor material carelessly packed by casual speculators. No examination of the fruit for defects in condition as it reaches the market appears ever to have been called for, or made by any representative of the growers.

Under these circumstances there is but small interest in these islands in a subject which in countries with a large trade in citrus fruits has received a very large amount of attention. The affections which have been met with are noted below.

It should be borne in mind that in addition to injuries and infestations which take place while the fruit is growing or ripening on the tree, often as part of the manifestation of diseases also affecting other organs, there is a definite class of troubles which are solely due to causes connected with picking and storage, while the damage due to some of the affections of the former class may be greatly extended by the manner of handling the fruit during and after picking.

In this connection reference should be made to Chapter XIII on the subject of handling fruit in general. 


\section{Diplodia Rot.}

The fungus associated with Diplodia dieback of citrus (which see) is the commonest, in fact the only definitely recognised cause of rotting of citrus fruits in the field in these islands, and reports to the same effect have been made from Cuba, Porto Rico and the Isle of Pines. It occurs to some extent on limes, and presumably other citrus fruits, while they are still on the tree, but is most noticeable in the ripe limes lying on the ground.

The fruit becomes thoroughly infested and soured by the fungus, the rind turns brown, gum is often exuded, and under moist conditions pycnidia are developed which cover the surface with a sooty deposit of spores; under circumstances of greater dryness or ventilation the fruit dries up and shrivels. Punctured fruits are especially liable to infection.

Diplodia rot occurs on lemons in Natal, and on oranges and grapefruit in the Greater Antilles and Florida. It is reported as spreading mostly from the stem end or from an injury. The fungus involved is usually named Diplodia natalensis, but no sufficient reason seems to have been given for distinguishing it from $D$. Theobroma.

Scab.

Corky irregularities of the rind, not leading to rot or decay or affecting the contents of the fruit. Refer to general description of the disease.

Russeting.

Silvery or sometimes brownish scurf general on the rind, giving the fruit a dull appearance. The epidermis is broken up into minute scales. Sometimes very common on oranges and limes for a period of a few weeks in a particular situation, then going off. Here as in Florida both rust-mites and a fungus of the genus Coniothecium are found on such fruits, and it is uncertain how far each is responsible, alternatively or in combination, for outbreaks. Dusting with sulphur should be adopted as a remedy where appearance is of value, otherwise there is no harm done.

\section{Oil Spot.}

One of the commonest of blemishes on local citrus fruits is a small superficial green or brown spot, usually more or less circular, which when closely examined is seen to consist of an area in which the ground tissue is slightly sunken, leaving the oil glands standing out as small green or yellowish papillæ. In old examples cork formation has taken place below the spots. The prevalence of this condition caused some alarm on a Dominica orange estate some years ago, as it was thought to facilitate decay. Experiments showed that this belief was unfounded and 
that the defect is one of appearance only. It was found that similar spots could be artificially caused by scratching the rind.

A convincing explanation of this condition, which is troublesome on lemons in California, was supplied by H. S. Fawcett to the effect that it is caused by the action on the tissues of drops of the essential oil of the fruit, when this is liberated by a scratch or a slight bruise. It is found that the spots are only produced when the fruits are moist with rain or dew, and that the restriction of picking to dry fruit largely decreases the number of spots which subsequently develop.

\section{Splitting.}

In Barbados the shaddock is especially liable to this trouble. It is caused by failure of the rind to keep pace in growth with the contents of the fruit. This may be caused by surface injuries due to scale insects or fungi, and apart from these sometimes appears to be brought about by irregularities in conditions. Increased shelter, tillage, mulching, and avoidance of sudden heavy waterings are measures calculated to prevent the occurrence of splitting.

\section{Blue Mould.}

The soft rot of stored fruit due to blue and green moulds of the genus Penicillium is universal and familiar. All experience shows that these fungi are rarely or never able to obtain a footing on sound uninjured fruit, but that any scratch, or a slight and imperceptible bruise may suffice to afford an entry and cause the rotting of the whole fruit. It is this fact which calls for the most meticulous care in handling fruit which is to be stored or shipped-a necessity which it would appear impossible for the heavy-handed West Indian labourer ever to be made to appreciate. Reference on this subject should be made to Chapter XIII.

The course of this type of rot comprises, first, a progressive softening around the point of infection; second, the appearance of white mycelium extending over the surface of the softened spot; and third, the production from this mycelium of conidia in dense masses, forming a blue or green layer, and discharged as dust clouds when disturbed.

\section{Charcoal Rot.}

An affection described by $\mathrm{O}$. T. Wilson as occurring on Florida limes has been several times met with on West Indian oranges bought in Barbados. In the fresh fruit it is recognisable by the presence of surface areas, smooth in comparison with the normal surface and more or less discoloured, the colour varying from a deepened yellow to copper colour, with the margin of the spot mostly brownish. Upon opening a diseased fruit an abnor- 
mal odour can be detected, and a distinctive fungus is always present. It has been cultivated by Wilson, and the disease reproduced in inoculated limes.

When the fruit is surface sterilised and left for developments no soft rot takes place, but it gradually dries up and becomes mummified, the exterior blackening and the contents being converted into carbonaceous material mainly constituted of dense black mycelium, in which condition it remains for months if protected from scavenging insects. Attempts to induce spore formation have uniformly failed.

Anthracnose Spotting.

See under Anthracnose of Limes and Citrus Anthracnose. 


\section{CHAPTER XX}

\section{DISEASES OF COFFEE}

AT the present day coffee is nowhere grown in more than a scattered and casual fashion in the British islands of the Lesser Antilles. From the French islands it is still an important article of export, enjoying a protected market. Coffee-growing was at one time the principal industry of Dominica, and was at the height of its prosperity near the end of the eighteenth century, when some 20,000 acres, mostly at low levels near the coast, were occupied by coffee estates, and the export of beans amounted to 4 to 5 millions of pounds. By 1823 this had declined to 2 millions, and from $I 833$ the reduction was extremely rapid, reaching an average of some $60,000 \mathrm{lb}$. in the years about I 850 and $I_{5}, 000 \mathrm{lb}$. about 1870 . At the present time the export is only about a ton a year.

The almost precipitous decline of coffee production in Dominica has been attributed to the prevalence of "blights," especially a leaf-mining moth. A report made to the President in I875 by $\mathrm{H}$. Prestoe, Government Botanist of Trinidad, definitely denies this, and attributes the failure to the neglect of the most elementary principles of cultivation which followed the disorganisation of estates after the abolition of slavery, together with the effects of the reduction of humidity on the coastal lands brought about by extensive clearing of forest. At the same time sugar production offered a highly attractive alternative industry, which was to a considerable extent adopted.

Apart from these causes one may trace the usual history of planting on virgin soils. In the course of time, slowly with a tree crop such as coffee, the original fertility declines, no means of restoration are adopted, the trees grow old and lose their vigour, while debility diseases and pests of little importance to healthy trees become evident and receive the blame. A period of acute depression ensues and it frequently happens, as in this case, that a change of crop is made.

Alternatively a tradition of sound agriculture based on cultivation and manuring may be gradually established, and if it were commercially desirable to revive the coffee industry on these lines there seems to be no sound reason to believe that the present known diseases of the plant need cause any serious interference. 


\section{Viruela, American leaf Disease.}

A fungus disease of coffee, second only in the attention it has attracted to the Hemileia disease of the Old World, and often known, to distinguish it from that affection, as the American leaf disease, is widely distributed through the American tropics, to which so far it appears to be confined. It is reported from all the coffee-growing countries of Central and South America, and in the Antilles from Jamaica, Porto Rico, and Dominica. The writer has so far seen it only once in Trinidad. It has been found on numerous herbs and shrubs of various natural orders, and some trees, including orange and mango, and even occurs on ferns growing in the neighbourhood of coffee. As is not unusual with fungi attacking introduced plants, it has assumed on coffee an especial virulence.

The presence and dissemination of the disease are closely dependent on humid conditions and in these islands it accordingly occurs most abundantly in the wetter hill districts.

\section{Symptoms.}

The disease consists in the production by the fungus of spots dark at first, ultimately white or light grey, on leaves, young stems, and fruits. On the leaves the spots are numerous and conspicuous. They are approximately round, equally visible on both sides of the leaf, and range from 6 to I2 $\mathrm{mm}$. ( $\left(\frac{1}{4}\right.$ to $\frac{1}{2}$ inch) in diameter. As they become old the central tissue drops out leaving a perforation. On the shoots the spots are more or less elongated and from them the cortex eventually flakes away. The spots on the fruit are similar to those on the leaves; they are rarely more than one or two in number on the same berry. The beans obtained from the affected berries are to some extent discoloured.

The effect of an infestation of the leaves is to cause premature shedding, and entire defoliation may ensue from a heavy attack, so that the ground is carpeted with leaves partly green. This stops the development of any crop that may be on the trees, and may lead, especially if soon repeated, to dieback of shoots and to a condition of debility in the trees.

According to G. L. Fawcett, in Porto Rico the older plantations in districts liable to the disease are well infested, while the younger ones are as a rule free, and the spread of the disease is quite slow, having been estimated in an observed instance to take place at the rate of about 200 yards in a year.

\section{Causative Fungus.}

The nature of the disease was first detected by M. C. Cooke in I880. He described the fungus found on the spots as Stilbum flavidum, a name later changed by Lindau in a taxonomic rearrangement to Stilbella flavida. G. Massee in Igog found peri- 


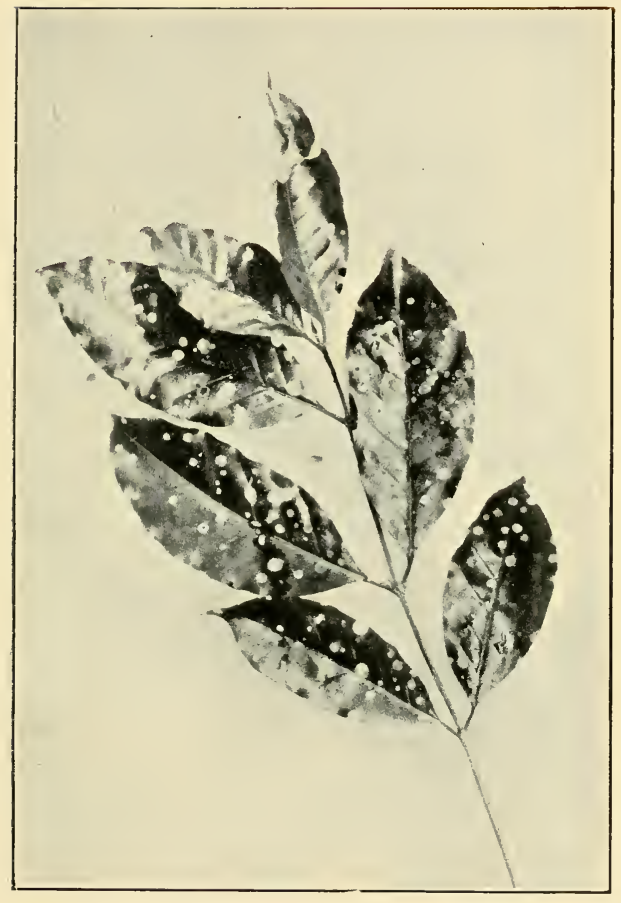

Fig. 83

American Leaf Disease of Coffee Bull. ${ }_{17}$ Porto Rico A.E.S 

thecia on leaves which had been kept for some weeks in a moist chamber, and, claiming to have produced typical spots by. infection with the ascospores, described the fungus as Spharostilbe flavida. Fawcett in Porto Rico failed to secure infections with the spores of a fungus corresponding to Massee's description. More recently A. Maublanc and E. Rangel, working in Brazil, have given a convincing account of experiments in which, by keeping infested leaves in a very moist atmosphere, they obtained an unbroken series of gradations between the form of fructification appearing in the field and a minute agaric (mushroomshaped fungus) with a bristle-like stalk and a membranaceous, radially striated. hemispherical cap. They accordingly changed the name of the parasite to Omphalia flavida. While it is desirable that the observation should be repeated it would seem that this name is at present entitled to stand.

On the spots as they occur on the coffee plant the fungus always has the same peculiar form of fructification, which is to be regarded according to the last-mentioned authors as an abortive one. It is, however, quite effective as a means of reproduction, and may be viewed as an adaptation in some respects superior to the ordinary methods of reproduction by spores. The bodies referred to appear on the spots as slender yellow stalks I.5-2 mm. in height, terminated by a rounded head of the same colour, the whole somewhat resembling a tiny pin. Some writers have described the formation of conidia on the surface of these heads, but no infection has ever been known to be produced by them. What does happen is that the heads themselves, which are very loosely attached and somewhat mucilaginous, drop off and adhere to the leaves or berries on which they fall. When the surface is snfficiently moist a head so lodged sends out numerous hyphæ, which infect the underlying tissue and give rise to a new spot. The heads retain their germinating power for some weeks even after having been dried, and so can be distributed with the fallen leaves.

\section{Control.}

The most obvious way of reducing the prevalence of the disease is by increasing the access of sun and air to the trees, but as in the similar case of cacao pod-rot it may not be possible to carry this measure far without producing equal injury from exposure. Picking off the affected leaves has been found to exercise some control but can only be profitable where labour is cheap. Spraying with Bordeaux mixture is quite effective against the spread of the fungus, provided that the fungicide can be made to adhere for a considerable time to the leaves. In this connection the information elsewhere given regarding adhesives should be consulted. The protection of the upper surface of the leaves is the more important. No adequate account of the use of lime-sulphur sprays has been seen. 
Spraying is likely to have its greatest value when adopted to preserve the freedom of young plantations from the disease. Fawcett quotes an instance where the advent of the disease in a plot of which the annual yield was known resulted in a reduction of output of some 75 per cent.

\section{BRown EyE-SPOT.}

A Cercospora spot disease of leaves and berries is common throughout the Antilles, in Central and South America, and has been reported from various situations in tropical Africa and the East. It is the opposite of the disease last described in being most abundant under conditions of exposure.

\section{Symptomsa}

The spots produced on the leaves are round, 6-1o $\mathrm{mm}$. $\left(\frac{1}{4}-\frac{1}{2}\right.$ inch) in diameter, visible on both sides; at first brown, later becoming almost white in the centre, but retaining a reddishbrown ring with a sharply defined outer margin. The central part docs not break away when dry, which serves as a rough distinction from the previous disease. The leaf spots are produced somewhat scantily and are usually negligible in their results. On the berries black blotches, which may cover as much as half the surface, are produced, and are most fully developed on the upper side where the sun causes earlier ripening. All varieties of coffee are subject to attack.

\section{Causative Fungus.}

The cause of the disease is the fungus Cercospora coffeicola Berk. et Cke., first described from Jamaica. It is visible on the surface of the spots in the form of small greenish-olive tufts made up of the simple conidiophores, on which are formed terminal conidia. These are long and narrow, tapering to one end, several-septate, colourless, with dimensions $75 \times 3$ microns at the thicker end.

Fawcett has obtained in cultures a grey sterile mycelium which produced spots with the typical spores on inoculation.

\section{Losses.}

The affection on the berry causes trouble in the preparation of the produce owing to the adhesion of the flesh to the parchment of the bean. It is also believed to be connected to some extent with the poor development of some of the beans met with in the crop.

\section{Incidence and Control.}

Although the disease is not entirely dependent on poor condition in the trees it is most prevalent where shade is in- 


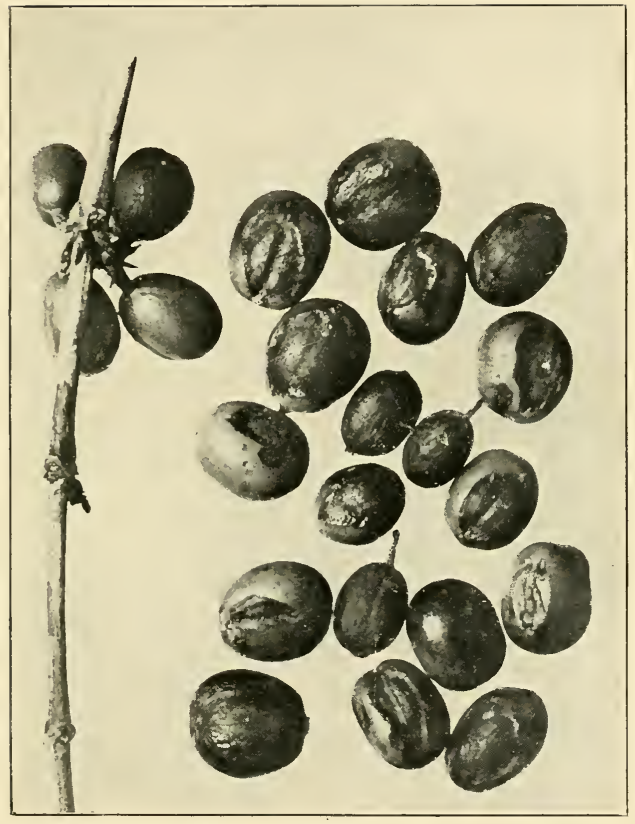

Fig. 84

Brown Eye-spot of CoffeE

From M. T. Cook's Diseases of Tropical Planls, by permission of Macmillan E Co. 

sufficient, where the soil is poor, or where cultivation and manuring are neglected. It is by improvements in these directions that the disease should be combated. The question of spraying is one that does not seem likely to arise, at any rate in the West Indies. The disease has been reported to be more severe in its effects in Africa.

\section{ZoNAL LEAF SPOT.}

A leaf spot disease described from Porto Rico takes the form of large spots characterised by concentric rings, sometimes incomplete and frequently coalescing. On the under side of the mature spots a thin white mould appears, which in places becomes more condensed. This bears Cephalosporium fructifications, and by inoculations from pure culture the fungus has been shown to be parasitic and to be the cause of the spots. The affection is most frequently found on the best grown trees, young and well-shaded leaves being most susceptible. It has been seen on all the varieties in cultivation, but is nowhere abundant.

\section{BARK Disease.}

A disease of stems occurs to some extent in Porto Rico in which local bark-rot occurs in situations ranging from near the crown to some feet up the stem, and is believed to commence from wounds of mechanical or insect origin. The disease develops its effects slowly, finally causing the bark to dry up and fall away, leaving the wood exposed and revealing the callosed margins of the healthy bark beyond. The presence of the affection ia recognisable by the smaller diameter of the stem where the death of the cambium has prevented the deposition of new wood. Under the diseased bark the wood is blackened. G. L. Fawcett, who describes the disease, reports that a fungus of the genus Fusarium is always present in the affected tissues, but that inoculations with pure cultures have failed to produce the disease. It is communicated readily to healthy stems by means of small pieces of diseased material and when thus transferred has shown itself to be rapidly destructive to the living tissues for several inches above and below the point of inoculation.

\section{Nematode Diseases.}

The fibrous roots and the base of the stem of the coffee tree are liable to infestation with the eelworm Heterodera radicicola, a general and cosmopolitan parasite described in another section. On the small roots gall-like swellings are produced and on the stem the infested bark takes on a very rough and somewhat swollen appearance, which may extend for a foot or so above the soil. 
Alarming accounts have been published of the destruction caused by this parasite on the Brazilian plantations, and it is regarded as a serious pest of coffee in Guadeloupe and Martinique. The accounts which have appeared from each of these localities suggest very strongly that the effects described may be largely due to fungus root diseases, with the symptoms of which they are in close accord. This impression is to some extent borne out by Fawcett's remarks concerning the status of the parasite on coffee in Porto Rico. Although Heterodera is often active there in trees suffering from root disease, no good evidence has been found that the trees are injured by it to any extent, and its presence is not a necessary accompaniment of root disease. The effects of the same parasite on coffee in the German African Colonies were reported to be trifling, and easily balanced by the use of suitable manures.

Tylenchus coffece Zimm. is a pest of the local variety of coffee in Java. Liberian coffee is immune, and on the newer kinds the occurrence is sporadic and of small importance. The larvæ enter the tender roots, and occupy the root system of young plants, causing wilting and death. The species is also reported from Martinique and Sumatra.

\section{Sclerotium Disease of Liberian Coffee.}

A preliminary account was given in I9I 8 by G. Stahel of a disease which had assumed importance on Liberian coffee in Surinam in the previous year. An earlier mention of the affection had been made by Kuyper under the name of Coremium disease. Recently (I92I) Stahel has published a full description and has named the parasite Sclerotium coffeicolum.

On mature leaves the fungus produces brown dead spots, with distinctly marked concentric rings. In continuously humid weather these may expand over the entire leaf. The underside of the spots bears white, spiny outgrowths, $2-4 \mathrm{~mm}$. long, which do not bear spores, but are easily broken off and carried by the wind to other coffee trees, on which they serve to originate new infestations.

The ripening fruits are similarly attacked, with the production of concentric-zoned spots, and when dead they are entirely covered with the white spines. On both leaves and berries while still on the tree there may be developed in damp weather brown or orange-brown sclerotia, and these occur in profusion on the fallen berries. In very damp weather a feathery mycelium, on which sclerotia also later appear, is produced on the material lying on the ground.

Where a cluster of fruit is involved as a whole, the fungus may invade the cushion, and thus inhibit further production.

The disease ceases to extend with the onset of dry weather. It is supposed that it is again renewed from the sclerotia, but in 
what manner remains as yet unknown. Spore-formation of any kind has not been observed, but from the presence of clampconnections in the hyphr the fungus is believed to be a Basidiomycete.

Good results have followed the use of Bordeaux mixture. The fallen leaves and berries should be collected in heaps and burned. The disease is at present confined to plantations along the Surinam River, and is especially severe on an estate on the upper river. It has not been detected in the field on Robusta, Uganda, or Surinam coffee, though infections were secured on these by artificial means. Abeokuta and Excelsa are very susceptible.

Stahel has also described another disease of Liberian Coffee in Surinam showing a chronic or an acute phase of wilt. The precise cause is not known, but degenerative changes in the sieve-tubes of the inner bast have suggested to him that the disease is in the nature of a phloem-necrosis like the well-known leaf-roll of the Irish potato.

Rosellinia Root Disease. THREAD BLIGHTS. Algal Disease. 


\section{CHAPTER XXI}

\section{DISEASES OF HEVEA.}

\section{The South American Leaf Disease.}

A FUNGoID leaf-disease which occurs on the wild Hevea species in the forests of Brazil, Peru, British Guiana and Surinam has attacked the plantations of Hevea brasiliensis made in the two countries last mentioned, and has assumed such severity that there seems no likelihood of the rubber industry becoming permanently established. The disease also occurs in Trinidad, where although young plants are severely attacked the mature trees in plantations have so far almost entirely escaped injury. It has not appeared in the rubber cultivations of the Eastern tropics.

The history of the disease is instructive as illustrating the difference between the incidence of disease on plants scattered in a natural way and collected in cultivations, and shows also the advantage that may sometimes be gained by growing a crop plant away from its native country and thus outside the range of its specific parasites.

\section{Nature of the Disease.}

A detailed investigation of the disease has been made in Surinam by G. Stahel, from whose paper the following account is abstracted.

The attack on the leaves begins when they are very young, and, as they develop, yellowish spots with a grey layer of conidia on the under side become apparent. The central part of the larger spots dries up and falls away, leaving a ragged perforation. On full-grown leaves the surface becomes thickly sown with black dots, and on old leaves these have developed into rounded black spots interspersed with several or many ragged holes surrounded by a black ring.

The fungus attacks the petioles and young internodes, but much less frequently than the leaves. On the petioles the check to growth on one side may cause curvature or spiral twisting; on the internodes swollen canker-like patches are produced. The inflorescences and fruits may also be infested.

\section{The Fungus.}

The causative fungus Melanopsammopsis Ulei (Henn.) Stahel, has three forms of fructification: free conidiophores, pycnidia, 
and perithecia. The conidial form of the fungus was named Fusicladium macrosporum by Kuijper, Passalora Hevea by Massee ; it was regarded as pertaining to the genus Scolecotrichum by Griffon and Maublanc, a conclusion with which Stahel agrees. The conidiophores when young are short unicellular brown hyphæ thickened at the base, penetrating the epidermis from subepidermal mycelium; this form appears on the young translucent leaves. On somewhat older leaves the conidiophores are many-celled, elongated, and arise from a pseudo-parenchymatous base. The conidia are formed singly and terminally, measure $20-65 \times 8-12$ microns, normally are divided into a wider basal cell and an elongated terminal cell, and are more or less bent or spirally twisted.

The pycnidial form was first described as Apospharia Ulei, Hennings. The pycnidia occur freely as small black dots on the surface of leaves I-2 months old, mostly on the upper side. They are roughly spherical, with an apical pore and little or no trace of a papilla. The pycnospores are 5-10 microns long, 2 microns wide at the ends, narrowing to I micron in the middle.

The perithecial form was described by Hennings as Dothidella Ulei, but is placed by Stahel in the Sphæriaceæ in a new genus Melanopsammopsis. The perithecia begin to take the place of the pycnidia some two months after the leaves are full grown. They occur in rings of $3-4 \mathrm{~mm}$. or rounded groups of $\mathrm{I}-2 \mathrm{~mm}$. diameter, are smooth, carbonaceous, and closely resemble the pycnidia in form and size. The ascospores are hyaline, twocelled (one larger than the other), constricted at the septum, I 8-22 $\times 6-8$ microns.

A species of Botrytis is common as a parasite of the fungus in all its stages.

\section{Infection.}

The conidia germinate in water in $\mathrm{I}_{2}-2$ hours and cannot withstand more than $15^{-20}$ hours' exposure in a desiccator. Stahel found viable ascospores to be rare, and unable to withstand more than four to six hours of desiccation. According to his observations the pycnospores germinate very weakly and appear to have no part whatever in the spreading of the disease, nor do the ascospores exhibit more than weak powers of infection.

The conidia produce germ-tubes which penetrate the cuticle and give rise to a sub-cuticular hypha, from which branches pass between the cells of the epidermis and produce an intracellular mycelium. Infection takes places only in the very young and tender organs. Leaves are most susceptible in the first four days after the opening of the buds, and lose their susceptibility after seven days' growth. The first sign of infection is a yellowish spot which appears in about five days, and one to two days later the conidial stage appears, followed by pycnidia ten to twelve days after infection. On the fully developed leaves the pycnidial 
fructifications at first predominate, succeeded later by the perithecia.

Contrary to experience with most diseases, infections are most abundant in dry clear weather, and least in rainy weather. This is attributed by Stahel to the more favourable conditions for penetration provided by an all-night coating of dew than by intermittent wetting from rain, owing to the fact that the process requires some ten hours for its completion.

Effects of the Disease.

Severe infestation of the young leaves causes defoliation of the trees, and infestation less severe hinders the growth of the leaves and reduces their efficiency. The production of rubber is in consequence reduced, and should the defoliation, as frequently happens, be repeated, a severe dieback sets in, and the process may eventually result in the death of the top or of the whole tree.

\section{Control.}

No practicable means of control has been found. For spraying to be effective the young leaves would need to be coated at least twice during the first four days, which is more difficult to arrange for since the trees in a plantation come into leaf in a scattered way, and even different parts of the same tree do not come into leaf all at the same time. Moreover, the way the young leaves hang makes them difficult to cover.

Stahel has proposed keeping the trees artificially bare of leaves for three to four weeks to prevent the formation and dissemination of conidia, and has also suggested the use of smoke clouds at night to prevent dew formation, a method practised in vineyards against threatened frosts." 


\section{CHAPTER XXII}

\section{DISEASES OF MINOR FRUIT TREES}

\section{Avocado.}

THIs fruit-tree occurs throughout the islands, grown only in a scattered way. The leaves very commonly bear roundish patches of the alga of "red rust" Cephaleuros mycoidea. Withering of the tips and edges of the leaves, sometimes involving a good deal of leaf surface, occurs in dry situations. The tree is very susceptible to Rosellinia root disease, and where, as in some districts of St. Lucia, it has been planted as shade for cacao it very often forms the originating centre of groups of affected cacao trees. Apart from this disease certain other fungi have been found on the roots and collars of dying trees, under conditions suggesting their complicity in that condition. Diplodia dieback (see Cacao) occurs on the twigs and branches.

\section{Anthracnose.}

Blossom blight, leaf injury, and fruit rot of avocado occur which are due to the attacks of a fungus possibly identical with that which produces similar effects on the mango, both being regarded by some authorities as belonging to the species Colletotrichum glreosporioides found on citrus trees.

According to J. B. Rorer, the disease is very prevalent in Trinidad, so that it is almost impossible to buy a fruit in the market which does not show signs of infection. These are of little importance on the fresh fruit, but result in complete decay during shipment.

Quoting Rorer's account of the attack on the fruit: "The disease appears first as a very small brown spot. If the attack takes place when the fruit is green, the diseased spot ceases to grow and becomes somewhat sunken, and the fruit cracks around the margin; small black pimples may be noticed in the centre of the brown tissue. If the attack is bad, the young fruits fall to the ground prematurely, otherwise the fruit may reach maturity, but the skin is cracked at the various places adjacent to the brown spots. When soft-skinned fruits are attacked, the fungus penetrates into the flesh and forms a cone-shaped mass of diseased tissue, which may extend all the way into the seed, and gradually rots the whole fruit. When attack takes place on ripe fruits, they rot very quickly, as shown in the figure. (Fig. 85.) 
"As in the case of the mango, the fungus also attacks leaves, and causes a certain amount of defoliation."

\section{Date Palm.}

\section{LEAF Disease.}

The date palm is everywhere subject to infestation with a parasitic fungus Graphiola Phonicis, Poit. of unknown affinities.

The fructifications are based on small yellow or brown spots on both sides of the leaflets and on the rachis. They consist of single or grouped black cups of carbonaceous texture, up to I $\mathrm{mm}$. in diameter, from the interior of which project conspicuous buff-coloured cottony tufts, thickly powdered with light yellow pollen-like spores.

Each infection appears very narrowly localized, but their number progresses with the age of the leaf, so that old leaves are very heavily infested.

The writer is not acquainted with the results of any attempt at control. palms.

The same or similar species occur on certain other kinds of

\section{Fomes Stem-Rot.}

The fungus Fomes australis Fr. has occurred on the stems of living date palms in St. Kitts, associated with a process of failure ending in death. The same fungus has been seen on dead palms in Grenada.

\section{Grape-Vine.}

\section{ANTHRACNOSE.}

Anthracnose of the grape-vine caused by the fungus Glocosporium ampelophagım has been met with in Barbados. The disease is well distributed throughout Europe and America. Leaves, berries and shoots are attacked. The spots produced are of the bird's-eye type, consisting of a pale centre with a brown or reddish border. On the shoots they are elongated in the direction of the axis, and sometimes by affecting the cambium give rise to small cankers. The fungus closely resembles other species of Glœosporium; the conidial measurements given are 5-6 6 2.5-3.5 microns.

Repeated spraying with Bordeaux mixture is a fairly satisfactory means of control, but needs to be aided by the pruning out as far as possible of the diseased shoots and the removal of infested leaves and fruit

\section{POWDERY MiLdew.}

The Oidium stage of an Erysiphaceous fungus, in all probability Uncinula necator (Schw.) Burr., a general pest of the 


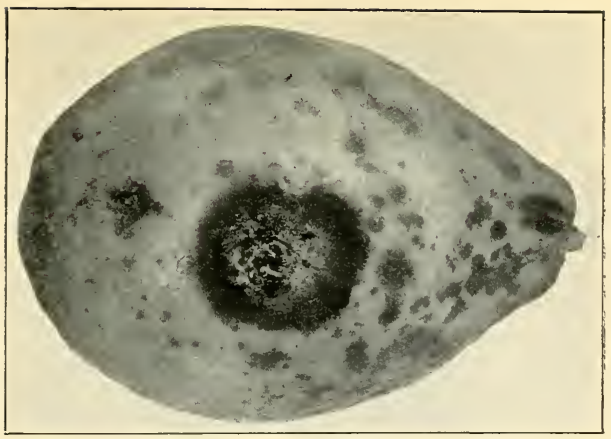

Photo by]

[J. B. Rorer

Fig. 8.5 Anthracnose of Avocado

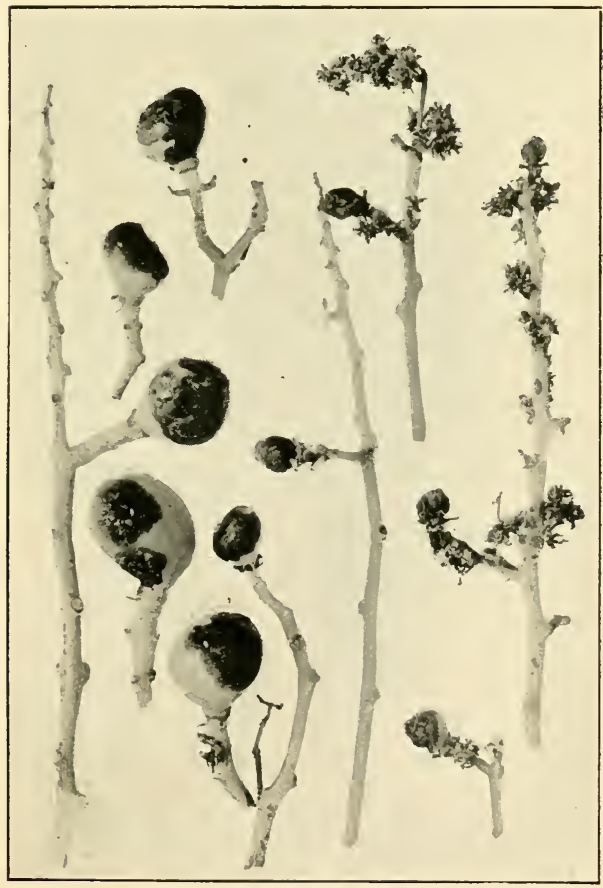

Photo by]

Fig. 86 Anthracnose of MANgo 



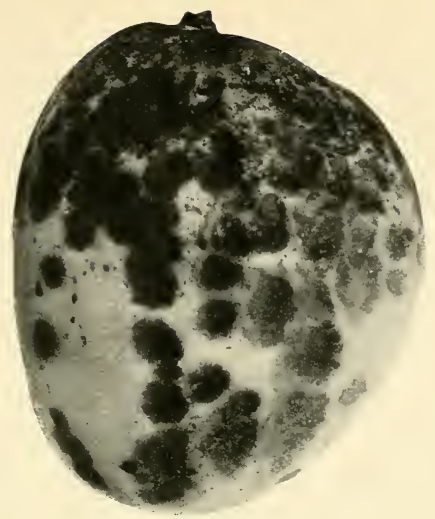

Fig. 87

Anthracnose of Mango Fruit
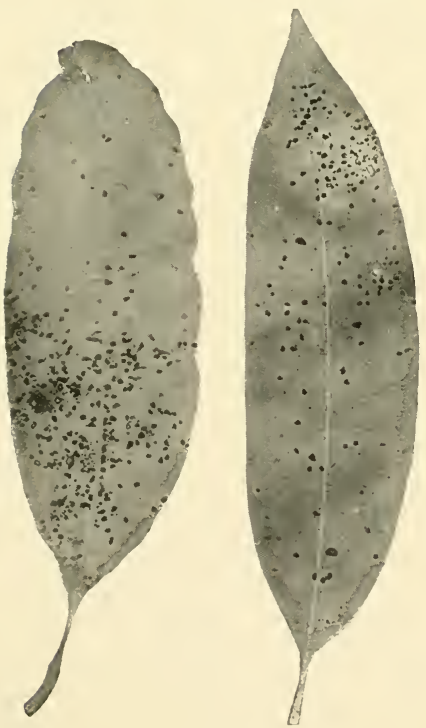

Fig. So

A.xthracNose of MaNgo Leaves 

vine, is common in Barbados and Trinidad. It affects leaves, young shoots, flowers and fruit, appearing in the form of white powdery patches, which may later cover the affected part. The effect of the mycelium on the surface is to cause brown, more or less fern-like markings, and the infestation of young and tender organs stops their development.

The disease is most prevalent in humid weather, and arrangements to give access to sun and air reduce the tendency to its development. The best means of control is dusting with sulphur or with sulphur and lead arsenate mixture, which if carried out under proper conditions (see p. I06) is highly effective.

\section{Rust.}

The older leaves of vines and, in conditions less suitable for growth, the young leaves as well, are liable throughout the West Indies to infestation with a rust fungus, which produces large numbers of small pustules, giving off powdery yellow urediniospores, mostly on the underside of the leaf. The fungus from several West Indian localities has been determined by J. C. Arthur as Phakopsora vitis (Thum.) Syd.

Probably the best means of dealing with it consists in giving increased attention to cultivation, thus tending to confine its attacks to old leaves which have largely passed their period of usefulness. Spraying might also be tried.

\section{Mango.}

Mangoes are grown as scattered trees, for roadside shade, or as windbreaks throughout the islands, much less commonly in Barbados, however, than elsewhere. Trees producing good quality fruit, propagated by grafting, are found only in gardens or mixed orchards. Apart from the anthracnose described below and one or two leaf-spots of no importance the tree is not known to be subject to disease, except where it comes in contact, usually in cacao plantations, with the fungus Rosellinia Pepo, to the attacks of which it is, moreover, not very susceptible.

\section{ANTHRACNOSE.}

A fungus affection comprising a leaf-spot, blossom blight, and fruit spot is fairly general in Florida and throughout the West Indies, and is destructive in some seasons and situations on the flowers and setting fruit.

The spotting of older fruit does not appear to be a very notable character of the disease as it is met with in the smaller islands. The description of this is derived from an account by J. B. Rorer of the various phases of the affection as they occur in Trinidad. 


\section{Symptoms.}

Blossom blight: Small black spots due to fungus infection appear in the open flower panicle, involving the death of groups of flowers either directly or by drying up the flower stalks. The setting fruits are also frequently affected. The loss may be small or may result in the complete stripping of the panicle, according to the conditions prevailing.

Leaf-spot: On the young leaves the fungus causes small dark roundish or angular spots, usually I to $5 \mathrm{~mm}$. in diameter. They do not extend as the leaf grows older, but appear as "shot-holes" in the otherwise healthy tissue. Care must be taken to distinguish these from the injuries to both flower stalks and young leaves due to infestations which may occur at this stage with the larvæ of a Cecidomyid fly. In the latter case there are small swellings of the nature of galls.

Fruit effects: On older fruits black spots of varied form, which may be cracked or sunken, appear and may coalesce to cover large areas. They penetrate deeply, and either cause the rotting of the fruit on the tree or form centres of decay after the fruit is picked. Streaking and russeting, affecting only the skin of the fruit, are attributed to the arrested germination of spores washed down upon the fruit from an affected twig or flower stalk.

\section{Causative Fungus.}

The fungus is usually known as Glcosporium Mangiferce Henn., but it has been held to be identical with Colleiotrichum glceosporioides, best known in its connection with citrus tree diseases. No description of the fungus adequate for its separation from this and some other described members of the genus can be given.

\section{Influence of External Conditions.}

The injury done by the disease is closely dependent on humidity, the prevalence of rain or heavy dews at blossoming time greatly increasing its incidence, and forming the principal factor in determining the difference between a bad and a good mango crop.

\section{Control.}

The disease can be controlled, and a heavier setting of fruit secured even in normal seasons, by spraying with Bordeaux mixture at frequent intervals during the blossoming period. According to Rorer's experiments the fruit from sprayed trees is cleaner and more attractive in appearance, and keeps much better in storage or transit. 


\section{Nutmegs.}

The cultivation of nutmegs on a commercial scale in these islands is almost confined to Grenada, where it exists as a subsidiary industry on cacao plantations suitably situated in the wetter upland districts. The trees often attain to a height of 40 or 50 feet, and sometimes more, so that the conditions prevailing closely resemble those of forest. The diseases which have appeared are well marked, but have been the subject of no close study.

\section{CANKER.}

A somewhat serious disease has been met with from time to time, the symptoms of which, according to the agricultural officers reporting it, are identical with those of cacao canker. R. D. Anstead described it as causing the trees to die back from the head, or, in the case of individual branches affected, from the tips of the twigs. In such cases the bark below is unhealthy and in places bleeding occurs corresponding to that of cacao canker. The sap in these places is of a rich dark red colour and has a foul odour. In the late stages gum may be exuded from the trunk near the base. The disease has been known to cause the death of numbers of large trees.

Nothing definite can be said as to the causation of the disease, but it has been found to be amenable to the same treatment as cacao canker, to which reference should be made.

\section{Perforated Leaves.}

A common affection in Grenada is a leaf-spot, the final stage of which is represented by clean-cut approximately circular holes of I.5 to Io $\mathrm{mm}$. diameter. The brown spot which precedes this condition contains the fructifications of an undetermined species of Phyllosticta, which appears to be the cause of the affection. Hundreds of species of this genus of fungi have been described, from the leaves of almost as many species of plants, often giving rise to affections of this class. How far they are interchangeable has seldom been determined, but they are generally regarded as specific within a narrow range.

In the absence of knowledge concerning the conditions governing the disease on nutmegs no remedial measure can be suggested. Spraying would be impracticable on trees of large size on account of the low value of the product.

\section{RED RusT.}

The alga Cephaleuros mycoidea is very common on nutmeg leaves. It has not been reported as affecting the twigs, in which position it produces its principal ill-effects. (See Chapter XVI.) 
Rosellinia Root Disease.

Nutmeg trees are among the numerous hosts of Rosellinia spp. (See Chapter XV.)

\section{THREAD BLIGHT.}

The nutmeg is very subject to thread blight caused by Corticium Stevensii, described on page I6I. Humidity is the chief predisposing cause of its prevalence and its effects are commonly increased by close planting. The amount of loss is probably always far too low to justify the expense of spraying, which apart from reducing shelter is the only remedy, 


\section{CHAPTER XXIII}

\section{DISEASES OF BANANA}

Banana Wilt, Panama Disease.

\section{History and Distribution.}

A wilt disease of bananas usually referred to as the Panama Disease has during the last twenty years become widely prevalent on the Gros Michel banana in various parts of Central and South America, and by its interference with the great banana industry maintained or controlled by the United Fruit Company has had very serious economic effects. Evidence has been obtained which shows that the fungus giving rise to Panama disease is specifically identical in the countries named and in the West Indies, and the conclusions of reliable investigators are in close agreement as to the nature of the affection and the parasite concerned. Adequate descriptions of the disease have been given by A. W. Drost (Surinam, I9I2), S. F. Ashby (Jamaica, I9I3) and S. C. Prescott (Costa Rica, I9I7). Recently (I9I9) E. W. Brandes has published a comprehensive account of this disease as seen in Porto Rico, Cuba and Central America.

The first record of the disease relates to the recognition of its effects in Panama in I903, and within a few years it devastated plantations over large areas in Panama and Costa Rica. At the present time several areas of 15,000 to 20,000 acres and upwards in Panama are abandoned or badly infested, and similar conditions prevail in Costa Rica.

In Surinam, with the help of the United Fruit Company, a large banana industry was established to replace the cacao industry, which had been heavily reduced by the witch-broom disease. The Panama disease was found in I906 and in I9I3 was so widespread as to ensure the virtual ruin of what had become a thriving business. The Gros Michel was largely replaced by the Congo banana, which proved resistant, but its fruit was found to be unsuitable in certain respects for commercial purposes. In British Honduras plantations more recently established by the United Fruit Company are at the present time suffering severely from the effects of the disease.

Panama disease was recognised in Jamaica in IgII-I2, when several small outbreaks occurred in the Portland district. The strenuous efforts which were made to eradicate it did not succeed, but the latest official expression of opinion is to the effect that 
it can be controlled and prevented from destructive spread by careful measures of quarantine. With Government assistance the infected areas are being planted with the immune "Chinese" banana to be prepared for export as a dried product.

The disease exists to a serious extent on the Manzana variety but not the Chameluco in Cuba and on the Chameluco but not the Manzana in Porto Rico (Brandes) : in each case the most esteemed and most widely grown of the local kinds. An affection believed to be Panama disease prevents the cultivation of the Gros Michel on any large scale in Trinidad, but no adequate description has been published. A reference by Brandes to the existence of the disease in Barbados appears to be due to a misapprehension. A disease which closely resembles and may

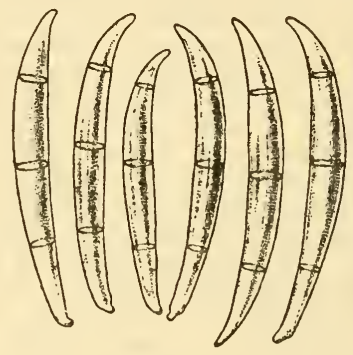

Fig. 89

Macroconidia of Fusarium VASINFECTUM. EXactly LIKe tiose of F. cubense in Size and Shape

From a drawing by $C$. W. Carpenter in Journal of Agricultural Research

be identical with Panama disease seriously affects the Gros Michel in St. Lucia.

In Central America the disease is present in Panama, Costa Rica, Nicaragua, Guatemala, Honduras, and British Honduras. In South America it occurs in Surinam and British Guiana; there is no evidence of its existence in the large banana-growing districts of Colombia, which are irrigated.

In India a disease which appears to correspond in all respects with Panama disease is recorded as exterminating one kind of banana in a district of Bengal, while a disease different in its symptoms, but caused by a species of Fusarium has been described from Pusa. Affections similar in their nature to Panama disease occur in the Hawaiian Islands, Australia and the Dutch East Indies, and in the first named the identity of the fungus with Fusarium cubense has been established. 


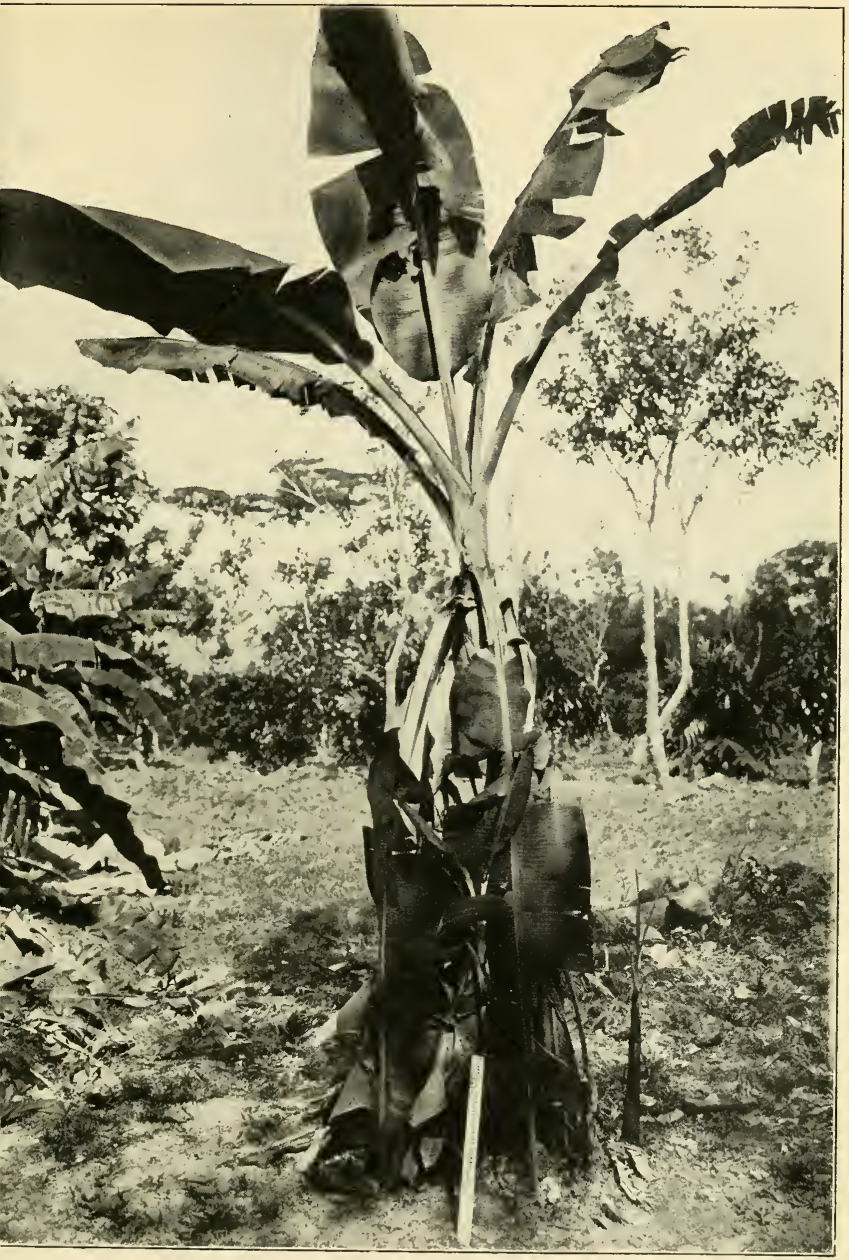

Fig. 90

Bull. 26, Dept. Agri,, Surinam

Panama Disease: EARLy Symptoms 



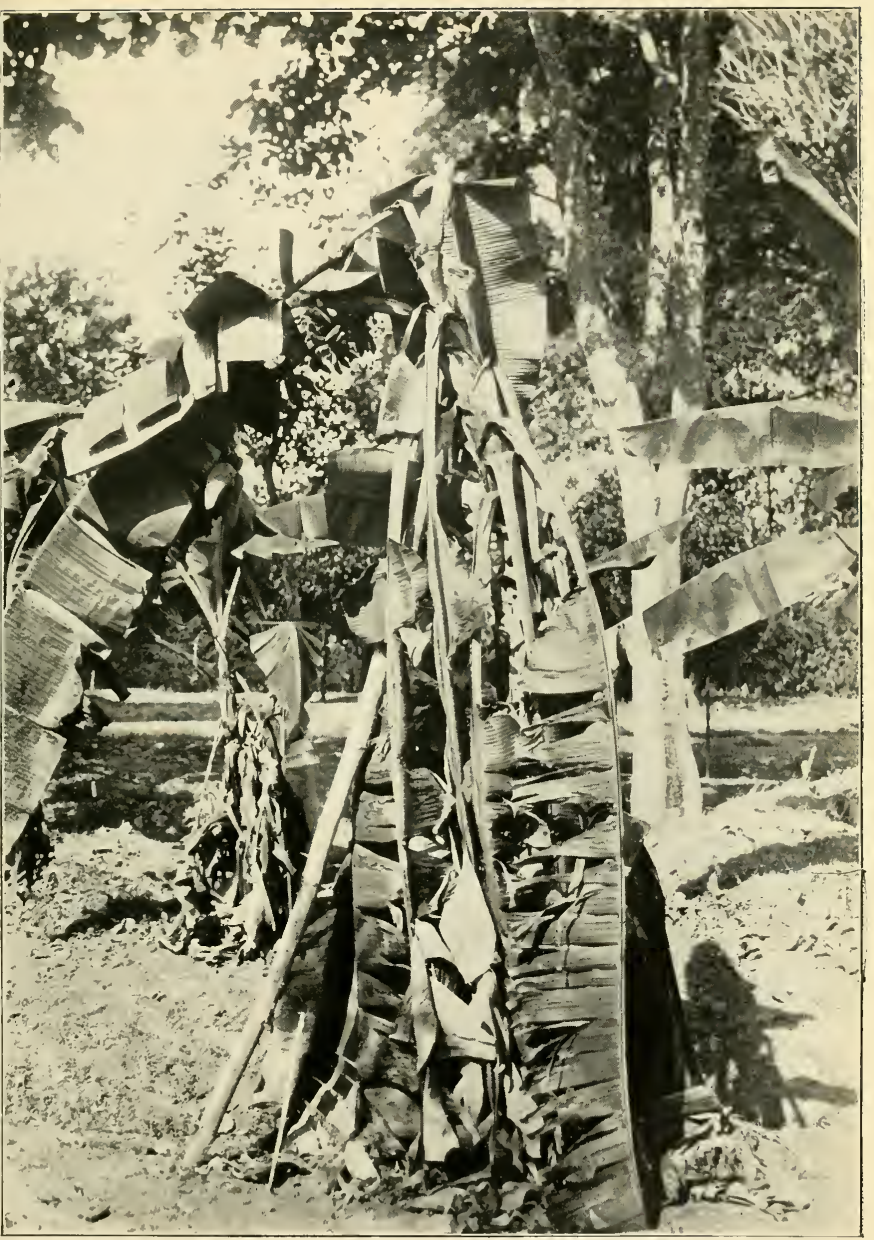

Fig. 91

[Bull. 26, Dept. Agri., Surinam

Panama Disease: Advanced Stage, showing most of the Leaves Broken Down and Splitting of the Stem 
Causative Fungus.

A fungus is associated with the disease from its initial stages, the colourless intracellular mycelium developing primarily on the inner sides of the walls of the vessels in the affected parts. Micro-conidia are formed in this situation and in pure cultures (the Cephalosporium stage); apparently they are carried forward with the ascending sap and give rise to new points of infection within the plant. On the external parts of the plant, especially the failing leaves, and also in pure cultures of the fungus, sickle-shaped, hyaline, mostly 3-celled macro-conidia are developed (the Fusarium stage). Chlamydospores of more or less spherical shape also occur in cultures, borne singly or in pairs terminally on short branches, or singly and in rows (intercalary) on the hyphæ. Irregularly spherical sclerotia about I mm. in diameter, yellow to deep indigo, also occur in old cultures. The spore measurements are: Cephalosporium form, 5-8 $\times 2.5-3$ microns; Fusarium form, mature, 3-septate, 20-40 $\times 3.8-4.5$ microns. Chlamydospores: oval $9 \times 7$; spherical $7-7.5$; paired $13 \times 7$ microns. These are Ashby's particulars of the fungus in Jamaica, and are in close agreement with those more recently given by Brandes of cultures derived from various sources in the West Indies and Central America. The latter author has adopted for the fungus the name Fusarium cubense, on the ground of its presumed identity with the fungus obtained from banana in Cuba by E. F. Smith in Igoo.

Nearly all pure cultures on sterilised media, especially on potato and rice, develop a marked odour (of lilac?) which, as Lathrop has shown, is most probably due to the production of the volatile toxic propylic aldehyde; odourless strains have been isolated also from characteristic cases of the disease. Similar odour-producing and odourless strains of the very closely related Fusarium vasinfectum Atk., the cause of the vascular wilt disease of cotton and okra, have proved to be equally pathogenic to those crops so that in so far as the symptoms indicate a toxic action of the parasite they are apparently not caused mainly by a volatile aldehyde. Like most of the species of Fusarium parasitic in the vascular systems of plants, $F$. cubense develops a characteristic pink or crimson pigment when growing on sterilised rice.

Drost in addition to the two forms above specified describes hemispherical pycnidia with one-celled spores, $8-$ Io $\times 2-3$ microns, and perithecia with 2-celled ascospores. On the basis of the lastnamed form he proposed the name Leptospora $M u s a$, but its connection with the parasite lacks confirmation.

Successful infection experiments are recorded by Drost, Prescott, and Brandes; those of the last named carried out on an elaborate scale, and conclusive in their results. 
Nature of the Attack.

The seat of the disease is the vascular system of the rootstock. It does not appear that the vessels are actually plugged as in many Fusarium diseases, rather it is their walls which are disintegrated. The discoloration of the vascular bundles which ensues is most marked in the rootstock and in the lower part of the pseudo-stem, but frequently may be traced upwards into the leaf-stalks and even into the midribs of the blades. In advanced stages of the disease the fungus is accompanied by bacteria which may cause a more or less general decay of tissue, especially in the rootstock.

\section{Mode of Infection.}

The fungus can enter from the soil either by means of the infection of roots or by way of the cut surfaces produced in the removal of suckers. Attempts to infect parts above ground do not lead to general infection of the plant. In diseased stools the mycelium extends through the connecting vessels to the newly formed suckers, and the severance and distribution of these as planting material is one of the principal factors in the spread of the disease. Mulching with infested trash has also played a perceptible part. The Fusarium spores can be conveyed to a distance by wind, by drainage water, and in earth adhering to implements and to the feet of men and animals, and in this way give rise to new centres of infection in the soil. Various parasitic species of Fusarium are known to be capable of existing for many years in the soil, and in respect of this disease Ashby records a case where re-infection occurred three years after the field had been thoroughly cleared and limed.

\section{Symptoms.}

The external symptoms are in general such as follow the stoppage of conduction in the vessels affected by the fungus, i.e., they are the characters of wilting. Typically the leaves, usually but not invariably in order of age, turn yellow from the margin or develop yellow spots and then dry up in succession. The last leaf often stands erect and green for a time before it falls. Eventually the whole column falls and rots. In young and actively growing suckers the leaves may droop and break down while still green. The symptoms vary in this respect with the season and the age of the plants. A further, but not wholly characteristic symptom is the splitting of the outer leaf-sheaths. The bunch of fruit, where growth proceeds so far, may show signs of arrested development and some or all of the fingers turn black and fail to ripen. On badly infested land the stools are often severely dwarfed, and most of the shoots succumb before they reach the fruiting stage. The external symptoms cannot in every case be depended on to distinguish the Panama disease 


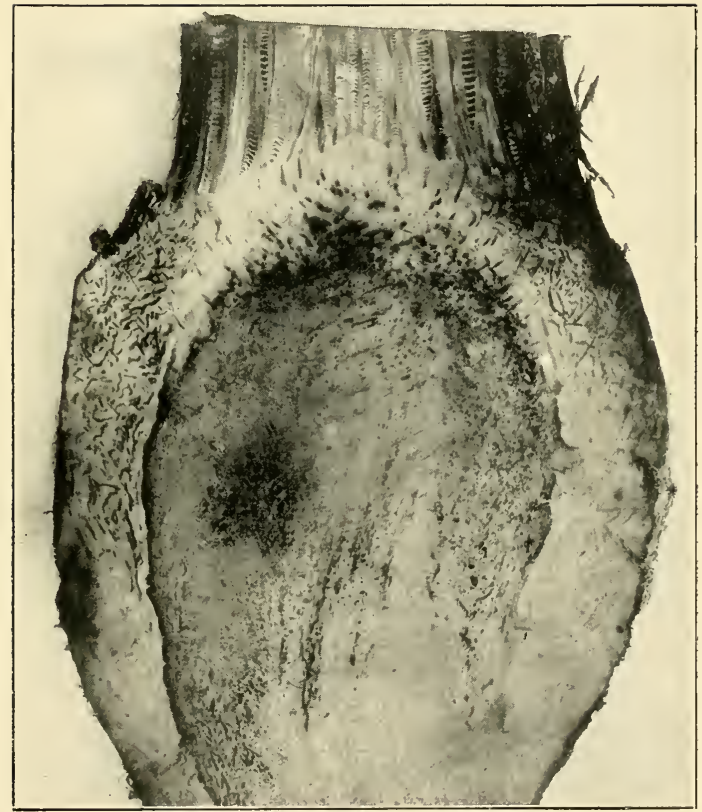

Fig. 92

[Dept. Agri., Jamaica

Panama Disease: Longitudinal Section of a Bulb and Base of THE Stem 



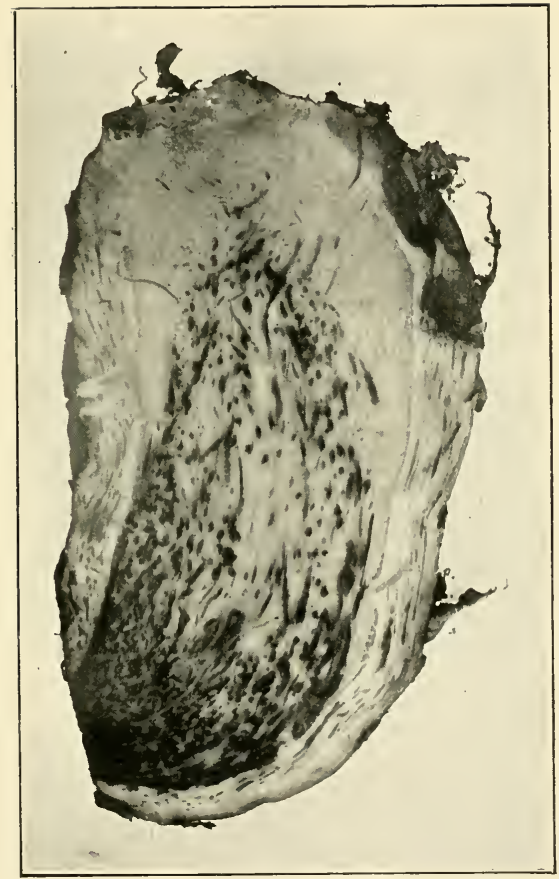

Photo]

Fig. 93

Dept. Agri., Jamaica

Fig. 93

Panama Disease: Young Sucker infested from Parent Plant through the Neck 

from others which operate in a similar manner. They occur in a very similar way, for example, in the nematode disease later described.

The internal symptoms are more specific. A section near the base of the pseudo-stem of a diseased plant shows the cut surface, which in healthy plants is a uniform white, with rows of yellow, orange, red, or red-brown spots marking the position of the diseased vascular bundles. The discoloration thus revealed can be traced into the rootstock, where it is exhibited very plainly, especially towards the centre. It may often be followed further into the central strand of the roots. In advanced cases the rootstock is frequently rotted and may be putrid. The occurrence of a central rot associated with the massed vascular bundles in that region is of value in distinguishing Panama disease from diseases in which the rot extends from the periphery. There may however, even in Panama disease, be no development beyond a diffused yellowing and softening of the upper part of the bulb.

\section{Infuence of External Conditions.}

The disease is destructive on all types of land, though there are indications that physical differences may to some extent influence the existence of the fungus in the soil. Favourable conditions for the plants, as produced by rich soil, good cultivation and manuring, are stated to produce a greater capacity for disease endurance, but there is no evidence of increased resistance being obtained in this way. It would appear from the general evidence that the destructiveness of the disease is mainly governed in extent by the accumulation of the fungus in the planting material and in the soil, so that when the disease once appears in a cultivation it is only a matter of time for it to render the growing of susceptible varieties impossible. The time required depends on the natural factors influencing infection and on the sanitary precautions taken. Wet weather has considerable influence in the rapid dissemination of the disease, and it has been frequently observed that extension is particularly liable to occur in the direction of the flow of drainage water. In arid regions or situations where banana fields are watered by irrigation the disease is unknown.

\section{Inherent Resistance.}

The Gros Michel as stated is highly susceptible. The red or claret banana is somewhat more resistant, but does not maintain itself for more than a few years on infected ground. The "Chinese" (Musa cavendishii) and "Congo" bananas are highly resistant, the former at least, it would appear, to an extent approaching immunity. The plantain (M Paradisaica) is believed to be quite immune. 


\section{Control.}

The most successful form of control against Fusarium diseases has been found to be the adoption of resistant varieties, and it is in the search for a resistant variety with the necessary commercial qualities that most hope for the control of Panama disease appears to lie. The breeding of such a variety by the usual means is made difficult by the partial or entire sterility of the edible species of banana, but in a group with such a wealth of forms it seems obvious that some type of variation must be liable to occur. It should be noted that the seriousness of the disease is mainly in connection with production for export. Varieties adequate for local use, grown in a less systematic way, generally exist undamaged.

An enormous range of materials has been tried for the disinfection of the soil, but in this, as in other soil infections, no commercially applicable method has been found.

Rigid quarantine should be maintained against infected areas, and some other crop substituted on infected land. There is no guarantee that even an extended rotation will free the soil from the fungus. Whether it will lessen its amount sufficiently to allow for paying crops to be again obtained can only be determined by trial.

\section{Marasmius Root Disease and Stem-Rot.}

A root disease of banana, accompanied to some extent by rotting of the leaf-sheaths which combine to form the pseudostem, associated with Marasmius spp., usually, it would appear, with $M$. semiustus Berk. \& Curt. (M. stenophyllus Mont.), seems to occur throughout the Antilles on bananas when grown under conditions which are in some respect unfavourable. It closely resembles in its nature the Marasmius root disease of sugar-cane, and the same species has been recorded from the latter host. The disease was investigated to some extent by F. W. South, to whom the following account is mainly due, in Barbados and St. Lucia, and has been the subject of notes from Jamaica (S. F. Ashby) and from Trinidad.

\section{Symptoms.}

The outer leaves dry up more rapidly than they are replaced by new growth, so that the amount of green top is reduced; in extreme cases to only two or three leaves. The drying of the leaves extends to the outer layers of the pseudo-stem, which turn brown or grey, and adhere closely to the layers beneath, so that they are difficult to strip, or are so rotted that they come away piecemeal. On and between the dead leaf-sheaths are layers or patches of white Marasmius mycelium. The inner living leaf-sheaths when exposed exhibit at various 
points oval patches, up to several inches in diameter, of a dark brown colour, and watersoaked in appearance. The spots usually penetrate two or more leaf-sheaths, becoming smaller as they progress inwards. In extreme cases they reach the centre of the trunk. When the discoloration passes from one leaf-sheath to the next, superficial white mycelium may be developed between them.

The surfaces of the leaf-scales below the soil as well as the bases of the leaf-sheaths are frequently covered with white mycelium, and the leaf-scales are discoloured brown.

Many of the roots are shrivelled and dead for part of their length. The cortex becomes brown and soft and eventually the vascular cylinder darkens and decays. Infested plants are easily uprooted.

On cutting across the trunk the inner leaves are healthy except where the brown patches have penetrated. The vascular bundles are not discoloured in either trunk or rootstock.

The disease spreads from the outside and appears to begin on the outer leaf-sheaths, usually near soil level. In this situation the Marasmius fructifications are freely produced during wet weather. The caps are pale yellowish white to pale reddish tan, the stalks white at the apex, pale reddish below, the spores ellipsoid, smooth, 7-9 $\times 5-6$ microns.

\section{Conditions of Occurrence.}

As to the nature of this disease a good deal of the discussion regarding root disease of sugar-cane will apply. It occurs as the effect of drought, poverty of soil, or defective soil aeration due to lack of drainage or of tilth. It is of small account on good soil adequately watered, but may be severe on gravelly or sandy soil and poor land generally. Drainage, manuring, cultivation, and the use of healthy suckers for planting are the measures of control indicated.

\section{The Moko Disease.}

A disease of banana and plantains in Trinidad was investigated in r909-Io, by J. B. Rorer, and found to be due to a bacterium, not yet described, for which the name Bacillus Musa was suggested. The disease was first found on the "moko," a coarse banana at one time largely used for shading young cacao in Trinidad, but reported to have been almost exterminated by an epidemic somewhere about I8go. The disease attacks other varieties of banana, including the dwarf Chinese or Canary type resistant to Panama disease. The Gros Michel, which is very susceptible to Panama disease, is highly resistant to the moko disease. 


\section{Symptoms.}

The presence of the disease is first shown by a sight drooping and yellowing of the lower leaves, similar to the effect of drought. A little later the petiole of one of the leaves gives way just at the base of the leaf-blade, and all the other leaves quickly fail in the same way. Eventually the terminal leaf bends over and the plant dies and rots to the ground. The longitudinal splitting of the leaf-sheaths characteristic of Panama disease is absent from this affection.

"Transverse sections of the pseudo-stem show that practically all the vessels are discoloured, the colour ranging from pale yellow to dark brown or bluish black, and filled with bacteria. The discoloured bundles run back into the true stem and thence into the young suckers and buds. Sometimes in badly diseased plants the tissues of the leaf-stalks and stems are broken down completely so that fairly large bacterial cavities are formed.

"If transverse sections of leaf or stem are allowed to stand for a short time the cut surfaces soon become covered with bacterial drops which have been forced out from the ends of the bundles. If the sections when freshly cut are put in large covered dishes away from the air, pure cultures of the organism may be obtained directly from these drops. If the disease is not severe, or a plant does not become infected until it has formed a bunch of fruit, it may remain perfectly healthy looking, but many of the young fruits, or ' fingers' do not properly mature; they remain small and eventually become black and rotten. In such cases it is found that there are some discoloured bundles filled with bacteria in the leaves, stem, fruit-stalk, or fruits. When diseased suckers are planted the terminal leaf frequently turns black and dries up, so that the plant dies" (Rorer).

\section{Causation.}

The organism was isolated in pure culture and was found in a series of experiments to reproduce the disease in typical form from inoculations made on the petioles of young leaves. In several cases the whole stool was infested and killed.

The bacterium was distinguished in cultures by the blackening produced on potato cylinders. It is short lived and loses its pathogenic power quickly. Control has been effected by sanitary measures: digging up and destroying diseased plants as soon as they are found and sterilizing by fire the implements used.

\section{Eelworm Black-Rot.}

In Grenada the banana known as the bluggoe, a cooking variety extensively grown as temporary shade for cacao, is 

subject to attacks on a large scale by a disease believed to be due to the infestation of the roots and rootstock with a nematode worm, Tylenchus musicola, recently described as a new species from Grenada material by N. A. Cobb. The bluggoe is probably identical with the moko of Trinidad, but the disease under description is quite distinct from the bacterial disease of the moko described by J. B. Rorer The closely related eelworm, Tylenchus

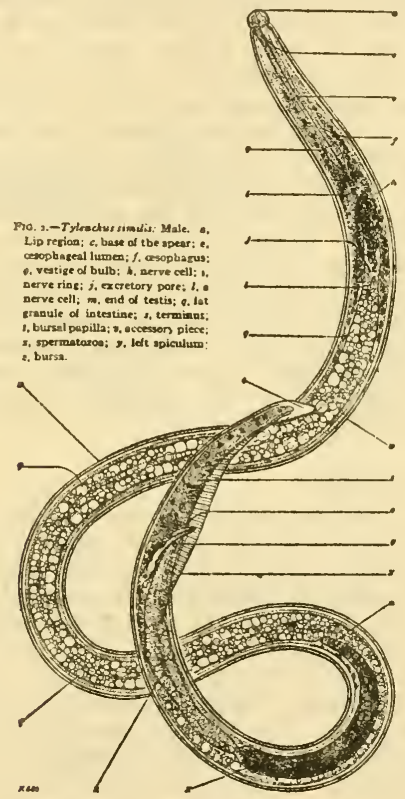

Fig. 95 Tylenchus Similis

After N. A. Cobb

similis Cobb, was described as the cause of a serious outbreak of a disease of bananas in Fiji, in I890-9I, by N. A. Cobb, and has been found by S. F. Ashby in Jamaica in association with a disease similar to the one in Grenada.

\section{Symptoms.}

The disease affects the development of shoots of all ages, but is most evident on those that are approaching or have 
actually reached the fruiting stage. The effect on the plant is that of shortage of water, and the view of an infested field conveys the impression that all the outer leaves have been scorched. The leaves wither in the order of their age, their tissue drying up from the margin towards the midrib. Bearing plants fail properly to mature their fruit, which commonly dries hard and black while only partly grown.

Examination of the base of the plant shows many roots partly or entirely blackened, and extensive black patches, or a general blackening of the external tissues, present on the rootstock. Slices of the diseased rootstock show peripheral blackening penetrating to a depth of about an inch in places, and blackened areas isolated in section but connecting with the exterior at a higher or lower point. The thick roots have short swollen cracks, connecting with extensive discoloured patches spreading upwards and downwards in the tissue of the cortex, reaching in many cases to the central vascular cylinder but not penetrating it. The discoloured tissue is in various stages of disorganisation, but in much of it the cell-walls are not visibly decayed. The nematodes have been found to be regularly present in all the material examined; their eggs occur in the least altered and deepest seated of the discoloured tissues, and the worms themselves may be seen in the cells of undecayed tissue close to the central cylinder of the roots.

\section{Resistance and Control.}

The effects of the disease show up most plainly in dry weather. There is evidence of a considerable measure of recovery during the more favourable conditions of the wet season, presumably because more rapid root development has gained on the progress of the infestation. This points to the usefulness of good cultivation in the control of the disease. The use of suckers from affected clumps as planting material should be carefully avoided, and where land is badly infested the bluggoe should be replaced by some other plant. The Chinese banana and the "silk fig" when seen growing amongst infested bluggoes have been much less severely affected. The former at least seemed to be resistant to a degree which might permit of its successful cultivation in infested soil.

The worms are too small to be seen with the naked eye, their length being only a little more than half a millimetre.

\section{Diseases described from Jamaica.}

Several diseases have been described from Jamaica by S. F. Ashby which have not been met with so far in the Lesser Antilles. This may be due to the fact that bananas are grown only in a scattered way, so that there is less opportunity for disease to become noticeable. It seems desirable to include brief accounts 
of these diseases as it is quite probable that they will be met with sooner or later.

\section{Black Spot of Leaves.}

This leaf disease has been reported from several localities in Jamaica, where it is confined to good soils containing a high proportion of marl. It begins with tiny black spots on the main veins of the leaf-blade, which increase in size and become

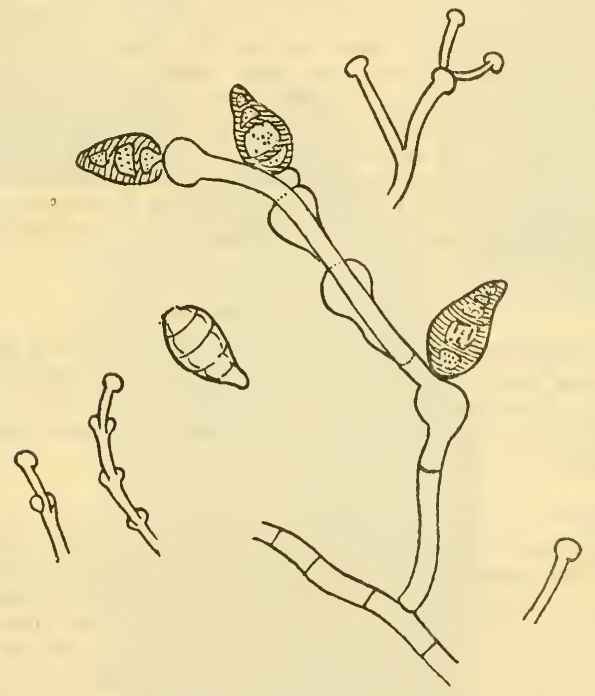

Fig. 96 Cercospora Musarum

Bull. 6, Dept. Agri., Jamaica

lenticular and are then often surrounded by a narrow bright yellow border. As the disease advances dry pale brown areas extend from the largest spots fanwise to the edge of the blade. Later the patches so formed unite and may give rise to a broad zone of dry tissue extending round the outer half of the blade. No fungus has been found in very young spots, but in the later stages hyphæ are found in the tissue round them and the conidiophores of a Cercospora break through the epidermis in large numbers. This fungus regularly accompanies the black spot disease in its occurrence on healthy dark-green leaves and has 
not been found on the sickly leaves resulting from disease of more remote parts of the plant.

\section{Associated Fungus.}

The fungus is described as a new species by Ashby under the name Cercospora musarum. The conidiophores appear mainly on the under side of the leaf. They are septate, simple or once branched, and often elbowed. They terminate in an inflated head bearing one conidium, and may continue to grow producing a succession of such heads. The conidia are smoky olive in colour, pear-shaped, widest above the base, and narrowing thence to a blunt point; the base shows a dark pad or disc marking the point of attachment; they are thick-walled with thick septa, occurring as long forms with 6-9 cells of average dimensions 50-60 $\times 16-17$ microns, and stumpy forms with 4-5 cells, similar in breadth and not exceeding 30-40 microns in length.

Should treatment become necessary the indications are that it would be best effected by spraying with Bordeaux mixture at an early stage.

\section{Bonnygate Disease.}

The Bonnygate disease, named from the place of its discovery, has been found at several scattered points in Jamaica. It is attributed to the infestation of the rootstock with a fungus described as a new species by Ashby under the name Spharostilbe musarum.

\section{Symptoms.}

The leaves show a narrow zone of pale brown dry tissue extending along the margin of the blade, bordered on the inner side by a narrow but sharply defined bright yellow band. This appears on one or several among the older and outer leaves. The younger inner leaves usually bear broader dry and yellow bands. This condition may continue stationary for weeks, the rest of the blade remaining green. Suckers are backward in growth and if they produce a bunch it often fails to reach full size. The lower part of the trunk often turns black for a few inches above the base and the plants may be broken across at the bulb by a moderate breeze.

In the cortical region of the rootstock occur rounded watersoaked areas bounded by a narrow red line. In parts where the affection is more advanced the tissue may be discoloured in dark brown bands which enclose the root-like strands, black without and white within, of the causative fungus.

\section{Causative Fungus.}

As in other Sphærostilbe diseases the fungus produces broad flat branching rhizomorphs, which give rise to the strands 


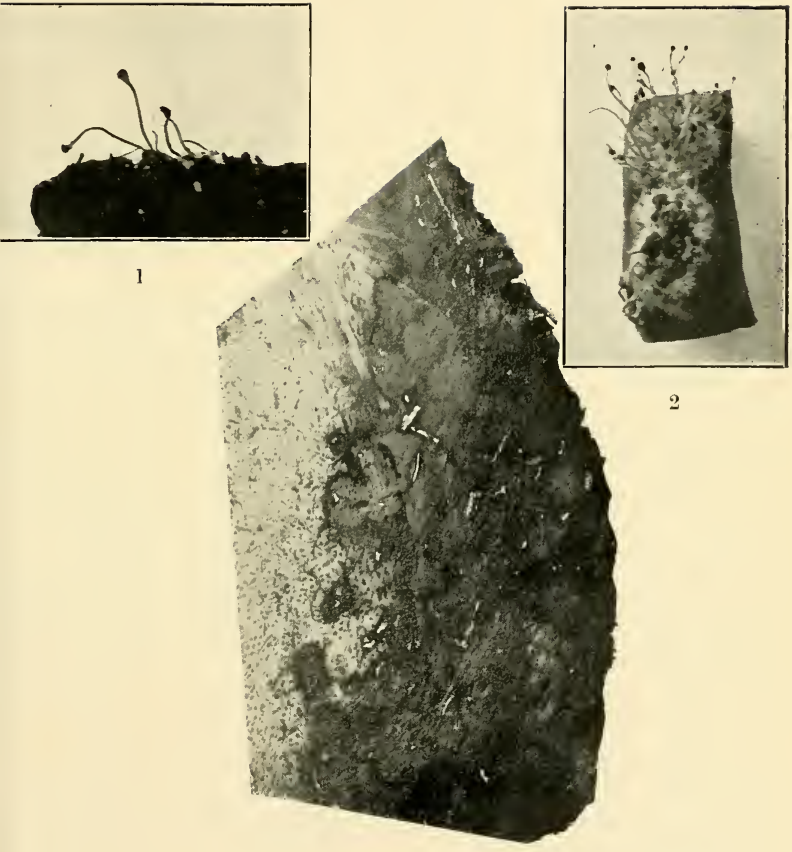

Photol Fig. 97

[Dept. of Agri., Jamaica

BONNYGATE DISEASE OF BANANA

Inset 1. Conidial Fructifications on Head of Bulb Inset 2. Conidial Fructifications in Pure Culture on Sterilized Potato 

described as penetrating the tissue of the rootstock, and these in turn give out hyphæ which grow among the cells.

The fructifications are borne at or just above ground level.

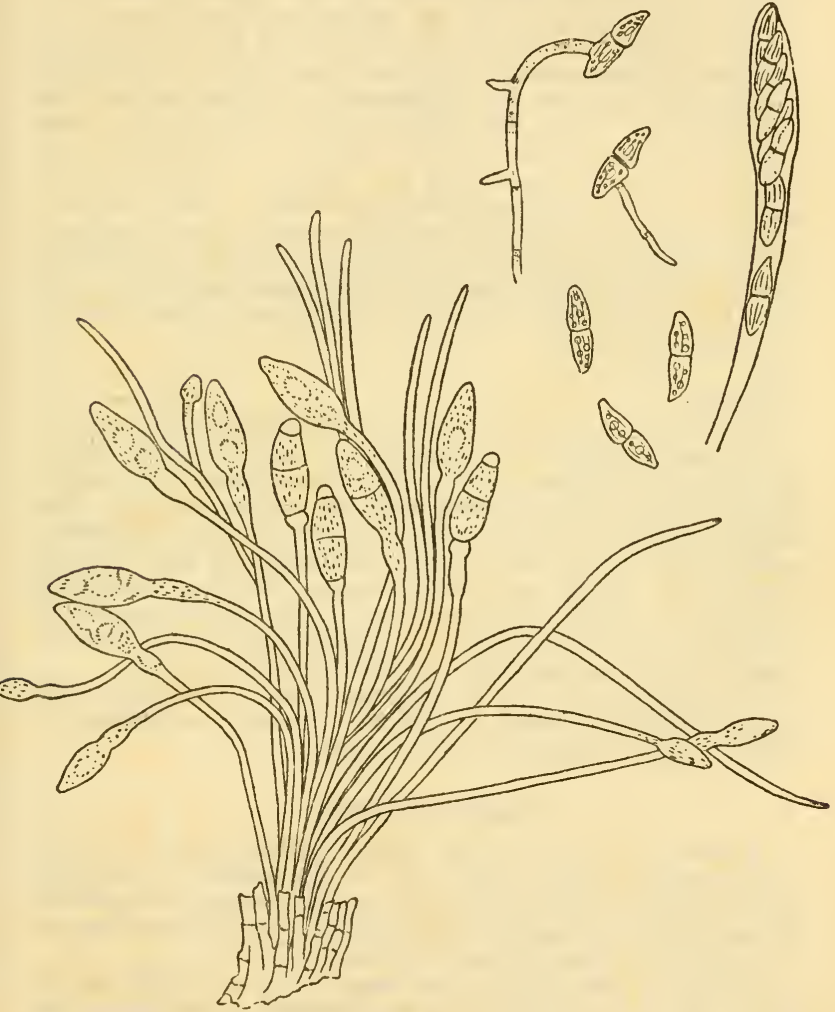

Fig. 98 Sphaerostilbe Musarum, Conidia, Ascus and Ascospores Bull. 6, Dept. Agri., Jamaica

The conidial stage occurs on small yellow or orange cushions up to $2 \mathrm{~mm}$. diameter, bearing one or more slender white stalks furnished with a brown or brownish red spherical head or ending in a point. 
The perithecia are borne either on independent cushions or in succession to the conidiophores; they are yellowish brown, sessile, and crowded closely over the whole surface. The ascospores are brown, two-celled, fusiform, often slightly constricted at the septum and longitudinally striate, with blunt apices.

The conidia are bluntly spindle-shaped and four-celled. The two equal-sized median cells are larger, thicker walled and crowded with oil drops of an orange colour. The terminal cells are hyaline of equal size, inflated, and rounded. The long stalks of the conidia are hyaline, septate, and enlarge rapidly towards their attachment to the conidia. Paraphyses are numerous in the heads, exceeding the stalked conidia in length.

The bark of cacao trees near the base of the stem has been found penetrated by the rhizomorphs of the fungus and covered by its conidial fructifications; the attack was confined to cacao in mixed cultivations with affected bananas on land subject to periodic flooding.

\section{Treatment.}

If the diseased plants are present sporadically Ashby recommends that the stools be dug out, cut up and charred, or cut up and mixed with freshly slaked lime, and returned to the holes, these being then filled in with soil and left for a few months before replanting. The parasite is not present above the blackened region If diseased stools are numerous the cheapest method is to cut off the unaffected parts, then chop the stump down to the ground, cover this with freshly slaked lime, earth up and leave for three months. It is desirable in view of possible spread through the soil to isolate the stools with trenches.

The disease appears to originate most commonly from infested material carried by floods. Thorough cultivation is said to enable the suckers to resist attack.

\section{Blackhead Disease.}

A disease of the rootstock, which produces brown or dark water-soaked patches either near to the surface or working inwards from it, was found to be due to the invasion of the tissues by the fungus Thielaviopsis paradoxa, the cause of stem diseases of sugar-cane, pineapple and coconut.

Conidia or bits of mycelium brought into any slight cut or into a slit in the bulb of a young sucker rapidly invade the tissues with the production of rusty discoloration and formation of spore chains in the cells. The tissues though water-soaked remain firm and united.

As in the case of cane cuttings the disease is most frequently found on planted suckers which are growing with abnormal slowness owing to dry weather, and they may grow away from the attack when rains occur. The cut surfaces of the suckers 
or any wound expose them to infection, and where the disease is prevalent a protective coating of Bordeaux mixture should be applied as soon as possible after the severance is made.

Other forms of blackhead disease are caused by the invasion of the rootstock by Diplodia or by a species of Pythium, in association with a rot of the deeper roots in undrained or imperfectly drained heavy soils, but apparently the most frequent form of all the blackheads is caused by the nematode, Tylenchus similis, Cobb. (See Eelworm Black-rot.)

\section{Heart Leaf Disease.}

An affection occurs in Jamaica in which one or more of the younger leaves are pale or yellow, and the youngest or heart leaf, often almost white in hue, may be pushed up while still folded, and fail to expand before beginning to wilt, turn brown in patches, and rot. The condition of chlorosis may endure for a time, but is frequently followed by a rapid fall of all the leaves at their junction with the trunk, and a speedy brown rot of the latter moving downwards from the top.

The cause of the disease is uncertain. It is considered that the condition of chlorosis may be induced by the depletion in the sandy soil of one or more essential mineral elements through washing with heavy and frequent rains, and that the rapid sappy growth which ensues permits the rotting of the tissues by feeble parasites. 


\section{CHAPTER XXIV}

\section{DISEASES OF CORN AND SORGHUMS}

Corn.

Brown Rust.

THE most widely distributed leaf-rust of maize is caused by the fungus Puccinia Sorghi, which in spite of its name does not attack sorghum. It causes comparatively little discoloration of the leaf, but the brown pustules in which the spores are developed are more or less conspicuous, according to the degree of infestation.

Leaves heavily infested with this fungus were received from Montserrat in February I9I5, accompanied by a report that it was very prevalent on a large field planted some ten weeks previously, and had been common from the time the plants flowered. It has since been reported from St. Vincent, St. Lucia and Antigua.

In the United States this rust is not regarded as having much economic importance. Usually it becomes common too late in the season to do much damage. When favoured by exceptional climatic conditions it may appear earlier and have a considerable influence on the vield. In South Africa serious outbreaks are reported as having occurred in certain districts.

Causative Fungus.

Puccinia Sorghi, Schw. (P. Maydis Bereng.)

(I) Aecial stage (Aecidium oxalidis) on Oxalis spp. Peridia usually on the under side of the leaves, crowded, concentric ; epispore smooth, 24-28 micr.

(2) Uredinial stage, on maize. Sori on both sides of the leaf, numerous, often confluent; spores brown, globose to ovate, $23-30 \times 22-26$ micr., slightly verrucose.

(3) Teliospores black, ovate-oblong or clavate-obtuse, constricted; epispore thick; 28-45 $\times$ I2-I7 micr. ; smooth ; pedicel long ; 5 micr., persistent.

\section{RED RUST.}

The fungus Puccinia purpurea Cke. (see p. 26r), which is very common on sorghums in these islands, is reported to attack maize in Natal. It may be distinguished on that plant by the deep purplish-red discoloration produced on the leaves, like that familiar on sorghum. 


\section{Smut.}

General Characters.

The corn smut, Ustilago Zea (Beck) Ung. (U. zea-Mays, $U$. Maydis) is widely distributed in the West Indies as in North America, without assuming any serious proportions. It is distinguished by the swellings to which it gives rise on the leaves, the ears, or the tassels, which may attain on the ears to an enormous size. The pustules are covered at first with a greyish envelope, which later bursts and reveals the masses of spores. Any young and growing plant is liable to infection The leaves are usually first attacked and the disease may be recognized at an early stage by the whitish swellings there arising.

\section{Mode of Infection.}

When the spores are released a certain amount of direct infection may take place, but the capacity of the spores to germinate apart from the host plant on any moist nutritive material very greatly increases the possibilities of infection. In rich soil, for instance, or in manure heaps, a yeast-like growth takes place, with the result that myriads of conidia are formed, which are easily distributed by the wind, and are able to start the disease on any growing part of the corn plant they happen to reach. A moist atmosphere facilitates infection, so also does the soft growth induced by high fertility. Wide spacing reduces the incidence of the disease. When the original spores do not attain to a situation which favours their growth they remain dormant, and are capable of germinating at any time, should the conditions become favourable, during a period usually to be measured in years.

\section{Prevention and Control.}

It will be seen that the deposition of smutted material in cattle pens or manure heaps, or, since the spores can pass uninjured through the alimentary canal, the feeding of diseased plants to cattle, is a sure way of increasing and distributing the disease.

The idea that the smutted ears, of which cattle are very fond, are unwholesome as food, has not been borne out by experiments which have been made.

Certain sinut diseases, in which infection is confined to the young seedlings, are capable of effective control by seed disinfection, but this is obviously not the case with the disease under consideration. Still, spores may very well be present on the seed, and where land is free from smut, and seed from an outside source is being used, disinfection may be worth while, and may be carried out as described on Pp. III-3.

Where this species of smut already exists, the best means of 
control lies in the cutting out and absolute destruction of diseased plants, or their affected parts, before the spores are ripe.

\section{HeAD Smut.}

Another smut disease which sometimes occurs on maize is due to the fungus Sorosporium reilianum (Kühn) McAlp., which causes the head smut of sorghum. It attacks the cobs and tassels, and is usually confined to them, but may exceptionally occur on the leaves or bracts. It reduces the cob or tassel to a formless sooty mass, and can be distinguished by the absence of the monstrous swellings characteristic of the common corn smut. The spores of the species under discussion are minutely but abundantly warty, those of the latter are prominently though rather bluntly spiny.

Head smut is uncommon in North America, and has not, to the writer's knowledge, been recorded for the West Indies. In Victoria, Australia, it has been reported as occurring to the extent of one per cent in some districts. It occurs in South Africa.

It does not yield to seed treatment, and can only be controlled by the collection and destruction of diseased material.

\section{LEAF SCORCH.}

A disease variously known as leaf-scorch, leaf-blight, and helminthosporiose occurs on maize in N. America, S. Africa, and various localities in Europe and Asia. Two instances of its occurrence are reported from Porto Rico. It does not appear to have been noticed in the Lesser Antilles; possibly the local types are resistant. The affection is capable of causing serious loss of crop.

\section{Nature of the Disease.}

The disease begins on the leaves with the production of pale blotches, which spread and may extend to nearly the length of the blade. Wilting takes place, and the leaf becomes dry and brittle. The conidiophores are then developed and are visible as a dark hairy mould. Infection is said to take place by way of the stomata.

There is definite varietal resistance to the disease, amounting in some cases to almost complete immunity.

\section{The Causative Fungus.}

Numerous species of Helminthosporium cause leaf diseases, and biological races are believed to occur on specific plants. The fungus attacking maize in America has usually been referred to $H$. inconspicuum C. \& Ell., but this is probably a synonym of H. turcicum Pass., described at an earlier date from S. Europe. 


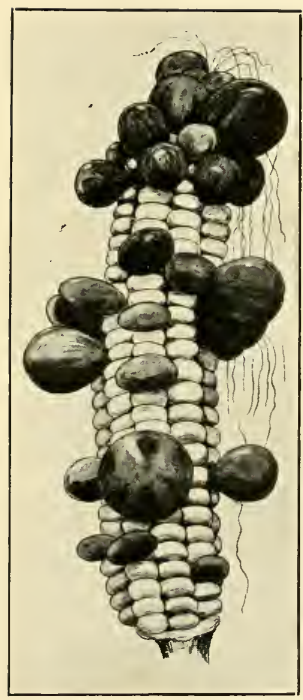

After Nat. Pflanzen

Fig. 99

CORN SMUT 

The conidia are spindle-shaped, pale olive, 5-8 septate, $80-140 \times 20-26$ micr.

\section{Prevention.}

Protection against the disease is to be secured by rotation of crops, avoiding the use of manure made from diseased material, or by the adoption of resistant varieties.

\section{DRY RoT.}

Several fungi are capable of infesting the ears of growing maize, causing the adhesion of the husks and a development of mould on the grain. In North America a very large proportion of this type of injury is due to the fungus Diplodia Zeoe. In some years the disease results in a very serious decrease in yield. Notable losses are also reported from South Africa in connection with the same fungus, and there is strong suspicion that paralysis and death of stock in that country results from feeding on the diseased cobs. The idea that pellagra is similarly caused is now discredited.

So far as the writer is aware, corn in the West Indies is subject to but little loss from the type of disease under discussion.

\section{Appearance of the Disease.}

In the early stages of infection there is little external appearance of disease. The first sign is the premature fading of the bright green of the outer husks to a yellowish colour, while the inner husks may be more or less browned. In the ear the fungus is first visible around the tips of the kernels if these are removed. Later the ear loses much of its weight, becomes mouldy with the development of grey mycelium around the kernels, and these appear dull and dry. The most distinctive sign of the presence of Diplodia is the early development of the minute black pycnidia on the scales which surround the inner ends of the kernels. Pycnidia can also be found on the husks, and in advanced cases on the grains themselves. On old stalks they can be seen as black specks under the rind near the nodes, or breaking through and discharging their spores.

\section{Mode of Infection.}

It has been claimed that the common method of infection is from the soil, the fungus entering by way of the roots, working up the stem, and entering the ears and kernels from within. On the other hand, typical cases can be readily produced by placing spores on the silks or under the outer husk at the base of the ears. Little or no infection takes place from ear to ear in the same season, the period of susceptibility being apparently a short one, confined, so far as external infections occur, to the period when the silks are exposed. 
Causative fungus.

Diplodia Zee (Schw.) Lev. (D. maydis Sacc.) Pycnidia black, spherical to pyriform, obtuse or free; conidia dark brown, cylindrical to elliptical, obtuse, usually slightly curved, oneseptate, $20-33 \times 5-6$ micr. Specific, so far as is known, to corn.

Two or three species of Fusarium have also been described as producing similar dry rots in the United States.

\section{Prevention.}

From the nature of the disease, control must depend on the elimination of infected material which can carry over the disease or infect the soil. Rotation of crops is indicated where soil infestation is suspected.

\section{Root Disease.}

Varying annual losses, sometimes extending to half the crop in certain districts, are attributed to root disease in St. Kitts, Antigua and St. Vincent. The plants show signs of attack when I to 2 feet high, and eventually wilt completely, usually at the time of flowering. If cobs are produced at all they are generally small and misshapen, with little grain.

The disease or diseases are much in need of investigation. F. W. South reports the presence in St. Kitts material of a Fusarium and also of mycelium resembling that of Marasmius Sacchari on the sugar-cane. The only example seen by the writer, said to be typical of the St. Vincent disease, had the leaves cemented around the base of the stem by mycelium of the latter type.

Recently T. F. Manns and J. F. Adams have shown that root disease is widely distributed in the United States and that it may be caused by four species of fungi working singly or in combination-Diplodia Zea, Fusarium moniliforme, Gibberella saubinetii and Cephalosporium Sacchari (the cause of a wilt disease of sugar cane in India and the West Indies). These fungi infect the kernels and are therefore planted in the seed.

\section{Minor Diseases of Maize.}

The rust Uredo pallida Diet. \& Holw, previously known only from Mexico and Central America on the grass Tripsacum lanceolatum was found on maize in Porto Rico in I9I6. It is reported by J. A. Stevenson to attack the older and lower leaves generally at a time when the ears are so nearly mature that little damage can be done. It appears as numerous inconspicuous pale-brown pustules on the under side of the leaves.

The parasitic Ascomycete Phyllachora graminis (Pers.) Fkl., common on various grasses and sedges, giving rise to rather conspicuous black raised spots on the leaves and leaf-sheaths, is 
reported to be common on maize in Porto Rico, hastening the death of old or basal leaves. It has no economic importance.

\section{Sorghums.}

\section{RUST.}

The most conspicuous rust disease in these islands is that caused on the cultivated sorghums by Puccinia purpurea. Cke. It appears to be general on Guinea corn, imphee, Sudan grass, and Johnson grass. It also occurs in the southern United States, in Cuba, Jamaica, Porto Rico and Bermuda.

\section{Appearance of the Disease.}

Elongated purplish-red blotches are produced on the leaves, and in these the sori are developed. In severe infestations the leaves are in this way very much discoloured, and there would seem to be no question that the growth of the plant is considerably affected. The crop is nowhere in these islands of any great importance, and the disease receives no attention.

\section{Causative fungus.}

Puccinia purpurea Cke. (Uredo Sorghi, Fckl. not P. Sorghi Schw.) Urediniospores ovate, $35 \times 25-30$ micr. smooth, brown. Teliospores elongate ovate, brown, long-pedicellate, $40-45 \times 22-25$ micr. Occurs also on maize, which see.

\section{Control.}

Would be best attempted by selection of resistant types.

KERNEL SMUT.

The common sorghum smut, Sphacelotheca Sorghi, occurs from time to time on imphee and Guinea corn in the West Indies. It is of general occurrence about the world, and occasionally is severe in its effects. In these islands, where the crop is more usually grown as fodder than for grain, the disease has not attracted much attention.

The spores of the fungus are usually sown with the seed, germinate in the soil at the same time, and infect the seedlings at an early stage. The mycelium of the fungus keeps pace with the extension of the plant in the form of thin threads which grow up through the softer tissues, especially the pith. No particular damage to the plant is caused and no sign of the disease is visible until the period of flowering, when the fungus develops rapidly in the anthers and ovaries, and there produces masses of black powdery spores which replace the pollen and the seeds. The outward appearance of the panicles is not much altered until the membrane which at first encloses the spore masses bursts, when they appear as if coated with powdery soot. 
The spores are very resistant, and the occurrence of a small quantity of smutted material among the seed corn is capable of producing widespread infection in the following crop. The disease is thus cumulative, and its occurrence even in small proportions should therefore not be considered negligible.

\section{Causative Fungus.}

Sphacelotheca (Ustilago) Sorghi (Lk.) Cl. Spores single, subspherical to spherical, smooth, contents often granular, $5 \cdot 5-8.5$ micr. diameter ; covered at first by a membrane of fungus origin. On various Andropogon (Sorghum) species, including Johnson grass.

\section{Control.}

Treatment is rendered easy by the absence of the fungus from the interior of the seed, and owing to the fact that only very young plants can be infected. Any method which secures the sterilisation of the seed without destroying its germinative power is effective. Steeping the seed in copper sulphate solution, according to the instructions on page IOI is the simplest remedy; the formalin treatment is also applicable.

\section{HEAD SMUT.}

The head smut differs from the preceding disease in that instead of the grains being affected separately, the whole head or, rarely, a section of it is conglomerated into a smutted miss. The same fungus occurs on corn. It has a wide distribution where sorghums are grown, including North America, but is not common in that country. It has not been noticed in these islands. The disease is not amenable to seed treatment, as, although the infestation is systemic and seedlings are commonly infected, this appears to arise from material originating from wind-blown spores in the soil.

The variety known as milo is immune to this as to other smuts, and kaffir and broom corn are resistant to it.

Causative fungus.

Sorosporium reilianum McAlp. (Ustilago reiliana Kühn, Sphacelotheca reiliana Clint) Spores loosely aggregated into groups, minutely roughened, 9-I4 micr. 


\section{CHAPTER XXV \\ DISEASES OF COTTON}

\section{InTERnal Boll Disease}

THE internal boll disease of cotton is a special case, and was the first to be studied, of a type of parasitic disease (stigmatomycosis), in which certain specific fungi are conveyed by plant-feeding bugs, and gain access to the interior of the fruit by means of the punctures which the insect makes in feeding. Similar affections have lately been found to be of very wide distribution in the West Indies and to affect the fruits or seeds of a great variety of plants. (See p. 29.)

In the cotton boll the fungus so introduced develops freely on the immature lint, which may be thus completely rotted or more or less severely discoloured, according to the stage of development reached when infection takes place. The seeds may or may not be infested.

There is in addition, a bacterial form of the disease, in which infection similarly takes place through bug punctures, but in regard to this it has not been demonstrated whether the invading organism is actually conveyed by the bug or only enters from the surface of the boll by way of the passage provided by the puncture. This form of infection has not been noted on plants other than cotton.

\section{History and Distribution.}

The nature of the disease was not discovered until I9I4, but effects undoubtedly attributable to it have been reported from time to time since the revival of cotton-growing in these islands in 1902-3. The greater part of the damage done, especially the recurrent heavy loss in St. Vincent, was attributed to other causes.

Since I9I4, the disease has been verified by the writer as existing in Tortola, St. Kitts, Nevis, Antigua, Montserrat, St. Vincent, Barbados, Grenada and Trinidad. It was independently discovered by S. F. Ashby, in Jamaica, in I9I5, and a reference to fungi found in cotton bolls by $\mathrm{A}$. W. Bartlett shows unmistakably that it occurred in British Guiana in 1907. Its prevalence is closely associated with that of its principal carriers, the cotton stainers (Dysdercus spp.) and the green bug (Nezara viridula), of which the former are by far the more important. 
Their absence from Barbados, and the comparative scarcity of the green bug, make the disease of very little account in that island. The fungoid form of the disease has not so far been reported from other territories.

\section{Symptoms.}

There are no external symptoms on the infected bolls, save in some cases a hardening perceptible to pressure ; the appearance is that of a sound boll even when the contents are completely ruined. The shedding of young bolls is frequently due to infection, but may also be induced by bug punctures alone, and frequently occurs as a reaction of the plant to certain physical conditions. Shedding from bug injury or infection extends to bolls up to three weeks old and $20 \mathrm{~mm}$. in diameter, whereas the limits in natural shedding have been found to be about 8 or 9 days and a diameter of about I4 $\mathrm{mm}$.

In describing the symptoms displayed when green bolls are cut open it is necessary to discriminate between the direct effects of bug punctures (stigmonose) and of added infection (stigmatomycosis). Damage of the former nature is very heavy when the bugs are present in large numbers and has been found in a particular case spoiling 60 per cent. of the locks in a representative sample of bolls. Some or all of the seeds in a lock may be killed outright or the embryo arrested in its development, the immature lint soaking down into a discoloured film. In severe cases the boll, if not more than half-grown, is usually shed. In older bolls a large proportion of the uninfected punctures do not reach the seed, and either have no recognisable effects, or the effect is limited to a superficial patch of discoloration on the lint beneath the puncture. The common pea chink (Edessa medittabunda), which has relatively short mouth-parts, appears to be limited on bolls of any age to the production of the latter type of injury. Very little staining of the lint which reaches the pickers' hands is attributable to direct bug injury. Much of the loss from this cause goes disguised as shedding, and for the rest the contents of heavily damaged locks when dry shrivel into a hard mass which the pickers leave. When only part of the seeds in a lock are attacked the remainder bear good unstained lint.

The result of infection accompanying the punctures is greatly to increase the amount and widen the range of damage. For a lock to be destroyed by direct injury many punctures are required, for the same result from infection one early puncture may suffice, since the fungus can spread from the lint of one seed to that of all the rest. The effects vary with the age of the boll attacked. Among young bolls a great deal of shedding results, similar to that caused by direct injury. In bolls that reach maturity the locks infected young are usually quite ruined. The seeds are reduced to a pasty mass, with a black and yellow covering of rotting lint. Infections made later each produce a patch of 
yellow stained lint, variable in size owing to the decrease of susceptibility and the shorter time available as the boll develops. The staining is not superficial, as in the parallel case of bug injury, but extends to the seed, nor is it confined to the lint of one seed, but is indiscriminate.

To this kind of infection a large part of the staining of seedcotton which has occurred in these islands has been due. Staining indistinguishable in appearance is also caused by the ordinary bacterial boll disease, the organism of which gains access to the lint through the spots caused by external infection of the boll. This disease is largely dependent on wet weather; dry weather staining, which has occurred abundantly towards the end of the season, as well as a variable proportion of that which occurs in wet weather, is the effect of the disease under description.

The statement regarding staining which has been usually repeated by entomologists, that it is due to the excrement voided by Dysdercus and to the crushing of that insect in the gins, has so far as the West Indies are concerned no basis whatever of observation, experiment or probability The staining is present days or weeks before the boll is due to open.

\section{The Parasites.}

A general description of the invading fungi is given in Chapter I, pp. 29-32. Four species, evidently of general distribution through the islands, have been met with in cotton. Species $A$, not yet named, has been predominant in cotton stainer infestations in St. Vincent; Species B (Eremothecium cymbalaria, Borzi) has been found most abundantly in bolls from Nevis and Tortola, again in connection with stainers; Species $C$ has been predominant in stainer infestations in Montserrat; Species D, which is Nematospora Coryli Peglion, or very near that species, occurs in close association with the green bug, a fairly general feeder, which presumably accounts for this fungus having been found over much the widest range of hosts, and especially in leguminous species, which the green bug prefers.

The first three species are hyphal, the fourth, though it produces hyphæ in starved cultures and sometimes in the cotton boll, is normally yeast-like. All four develop freely on the immature lint, and frequently enter and occupy for some distance the lumen of a fibre. Spores are produced in great abundance before the boll opens. Their after-history is unknown, but in cultures they germinate freely. In what form the infection is conveyed to other bolls has not yet been discovered, but bugs taken from infected plants and bagged on previously protected bolls almost invariably cause infection, while with bugs from uninfected plants, though hundreds of punctures may be made, no infection occurs, showing that the insect not merely provides the means of entry but conveys the fungus from plant to plant.

The bacterial form of disease has not been investigated suf- 
ficiently for the species to be recognized, but comparison of cultures has led to the tentative conclusion that Bacterium malvacearum is frequently, but by no means invariably, the organism involved.

\section{Incidence.}

The accompanying curve illustrates the incidence of the disease where cotton stainers become generally abundant about December, as was the case in Montserrat and St. Vincent before controlling measures were taken. Nevis has the same distribution. In St. Kitts, Antigua, and the Virgin Islands the insect is not usually abundant before February, and the damage has consequently been much less in amount. In Montserrat it was possible to avoid the worst effects by early planting, but in St. Vincent the heavy autumn rainfall made late planting a necessity, and the precarious chances of the crop depended on whether the first picking escaped the effects of this weather, since the second picking, produced under more suitable climatic conditions, had come to be regularly and completely destroyed by stainer injury and internal boll disease. (See Fig. Ioo.)

The effects of green bug outbreaks are less severe. Infection as a rule is much less general and the production of stained lint consequently small. (See Fig. Ior.) The outbreaks are usually controlled in the course of a few weeks by egg parasites.

\section{Control.}

Realization of the fact that the constant heavy losses in the second half of the crop in St. Vincent were due to disease borne by the cotton stainer led to more careful study of the habits of that insect on the part of the resident agricultural officers. The previous vagueness as to its connection with staining or other injury had been reflected in the attitude taken towards it as a pest.

It was found that although stainers in the absence of cotton could subsist for a considerable time on other foods they were only capable of breeding to any extent on two trees, the silk cotton (Eriodendron anfractuosum) and the seaside mahoe or John Bull (Thespesia populnea). This observation provided the key to the situation. The trees were eradicated at the cost of much labour but at a relatively small expense. In the following year the appearance of stainers in significant numbers was so far delayed that the picking of clean cotton continued into April, and conditions in other respects being also favourable the crop was double that of the previous year. In the untreated neighbouring island of Bequia the crop was destroyed as usual, but equal success was attained there in the following year by the same method. It is now being tried in the Leeward Islands.

Where Malvaceous weeds, such as Malachra and Sida species 
are abundant, as isireported to be the case in Tobago, the problem of eradication is different and is likely to be more difficult. The

PERcigntTage of DISEASED BOLLS

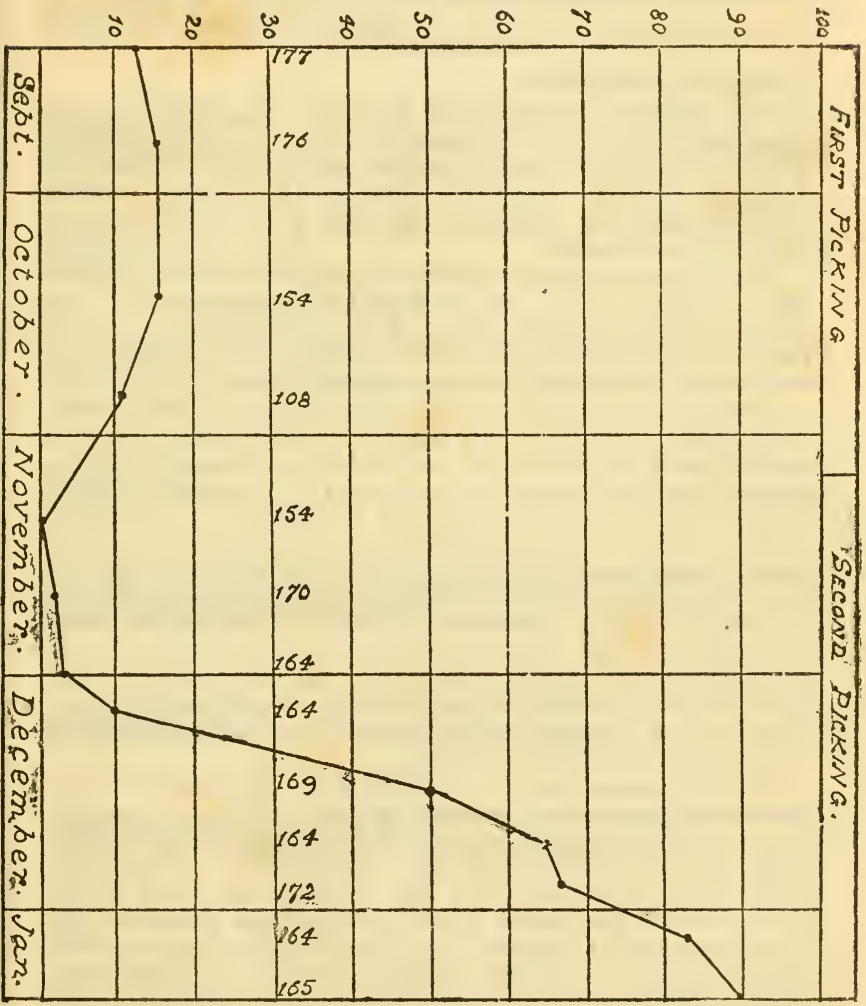

Fig. 100

Incidence of Internal Boll Disease

most promising method to adopt would seem to be the establishment of hardy grasses in the place of roadside weeds, the compulsory cleaning of neglected arable land, and the afforestation of waste ground with shrubs or trees. As cotton stainers readily 
migrate in swarms from one district to another these measures would need to be general over an island.

Natural control of the green bug may be assisted by the transfer of parasitized egg clusters to affected localities.

\section{ANGUlaR Spot.}

\section{History and Distribution.}

The affection produced by Bacterium (Pseudomonas) malvacearum E.F.Sm. on the leaves and bracts of cotton was first described, under the name of angular spot, by G. F. Atkinson in Louisiana in I89I. Some ten years later E. F. Smith isolated and described the causative organism and made successiul infection experiments.

The disease is common in the United States on both Upland and Sea Island cotton. In the West Indies it is general on Sea Island in most districts. Some of the perennial types are still more susceptible, others are highly resistant. Its distribution in other parts of the world is imperfectly recorded.

In the active stage of the disease the spots are not conspicuous. They appear as small water-soaked areas thickly scattered on the undersides of the leaves and on the bracts, irregular in shape, generally angular through being bounded by the smaller veinlets, and not usually more than 3-5 $\mathrm{mm}$. in diameter. A succession of them, more or less in contact, often runs along by the main veins. They quickly penetrate to the upper surface of the leaf, and then undergo no further development. At this stage a slightly yellowish varnish or thin crust of bacteria can often be found on their surface. The tissue involved soon dies and turns brown, and then first becomes very noticeable. As this condition of the spots naturally persists for the remainder of the life of the leaf, a good deal of misapprehension is caused as to the actual time of occurrence and duration of attacks.

Recent observations in St. Vincent in the month of November showed that the disease occurred in fresh condition in periodic bursts which appeared to be connected, at an interval of about a week, with a previous showery day. Studies by R. C. Faulwetter point to the conclusion that the predominant factor in the distribution of the disease is rain splashed from the leaves and blown as spray by the wind. This accords with the known ability of the bacterium to produce infection on healthy leaves provided a film of water is present. The organism is demonstrably present in the film consequent upon heavy dew. Infection appears to take place as a rule by way of the stomata.

Effects.

The disease in itself is not usually considered to be of much importance, though severe attacks, which involve the loss of a good deal of effective leaf-area, cannot be regarded as negligible. 
Expt. Strn.

Botanic Str.

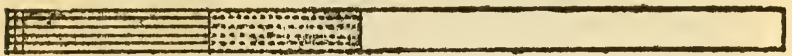

Belarr

Len

Batawia

S

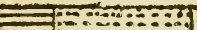

Peter's Hope.

Mr Wynne.

B

Ei:girist

Sion Hill (Stainers)

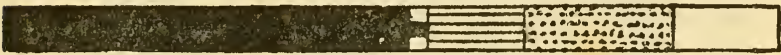

Bequia

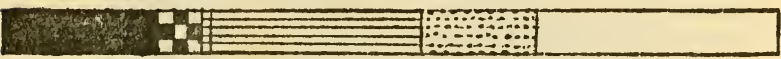

Montserrat

1201

Frfection only, complete. Stained lint.

Infection only, partial. Partly stained lint.

Complete direct injury. Total loss.

Complete direct injury, infected. Total Zoss

Partial direct injuiny. Some clean lint.

Fig. 101 Internal Injuries to Cotton Bolls. St. Vincent, Etc.

1-6: Green _BUG, etc. 7-9: Stainers. 
If the affection on the leaves can be held to be the main source of material for infection producing black-arm and bacterial boll disease, which is a natural conclusion, its presence becomes a matter of serious concern. Frequently, however, there is no obvious evidence of correlation in the prevalence of these affections.

\section{Infuence of External Conditions.}

The affection is so common in the cotton fields of the islands that with little qualification it could be described as universal, but there are wide variations in the degree of its prevalence and in the period at which it becomes abundant. Isolated plots sometimes remain practically free of it throughout the season. In agreement with the theory of its spread noted above, its occurrence is closely associated with rainy weather. When frequent showers fall during the growing period it is usually well distributed through the fields by the time the bolls begin to mature. It has been seen to be abundant on or absent from the leaves of the secondary growth according to the weather in which they are developed.

\section{Inherent Resistance.}

There are undoubtedly degrees of susceptibility and resistance to this affection in various types of the cotton plant, and even what appears to be complete immunity. Attempts carried on over several years to develop resistant strains from the Rivers type, which is the basis of most of the Sea Island strains in cultivation in the West Indies, have not been successful, but in St. Vincent strains evolved from the Superfine type, which is in general less susceptible than the Rivers, are reported to be resistant to a considerable degree.

In hybrids the character of resistance is irregularly distributed and its method of segregation has not yet been worked out.

\section{Control by Spraying.}

F. M. Rolfs has reported that in South Carolina angular spot has been found to be controllable by six sprayings with Bordeaux mixture. Experiments with Burgundy mixture have been made in St. Vincent and reported on by S. C. Harland. Spray fluid containing 2 per cent. of copper sulphate was used in I9I7-I8, but caused very obvious injury to the plants. In the following year a one per cent. mixture was used in the first two applications, and a further reduction was then made to 0.8 per cent. The plants were sprayed 13 times in 5 months. The control of angular spot was almost complete, but there was no significant increase in yield.

The injury caused by spraying chiefly affects the small buds, many of which shrivel and turn black. The amount of this was 


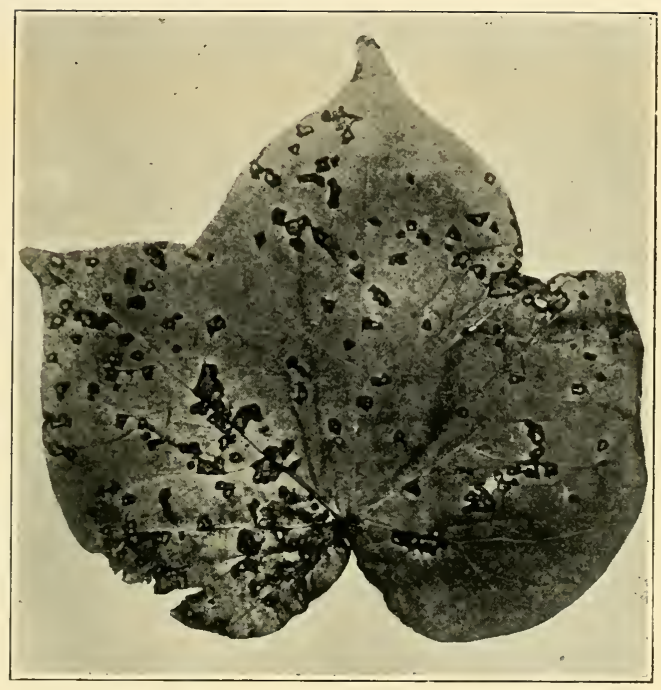

Fig. 102 Angular Leat-spot of Cotton

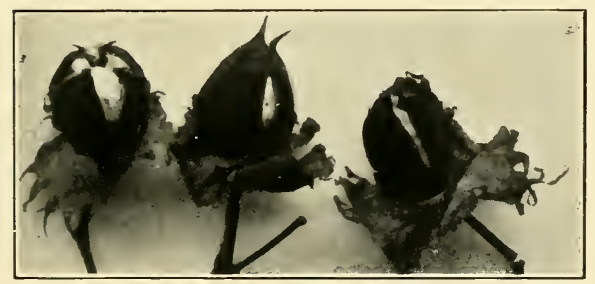

Fig. 103 Bacterial Boll Disease of Cotton

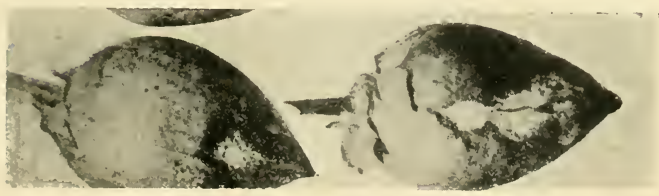

Fig. 104 Anthracicse of Cotton Bolls 



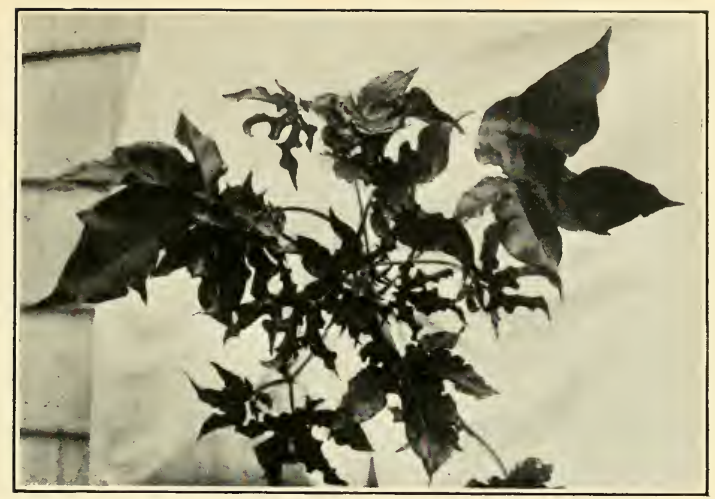

F1g. 105

Curly-leaf Cotton, Top View

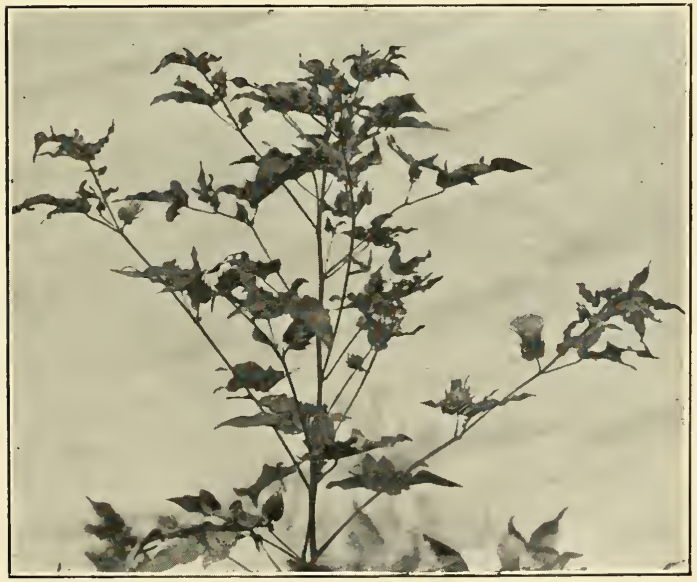

Fig. 106

Curly-leaf Cotton, Side View 

not large with the 0.8 per cent. mixture, and it is compensated for by the lengthening of the flowering period which follows shedding. This point is of importance since spraying may still be found desirable on account of soft rot.

\section{Black ARM.}

Infections with Bacterium malvacearum occur on stems, twigs and petioles of the cotton plant, giving rise to the affection known as black arm. It is characterised by the formation of dead patches in the cortex, which may be small or may extend for several inches, girdling the organ on which they occur. On vigorous plants the effect is small, but on plants which have made poor growth owing to drought or unfertile soil it can be severe, leading to the drying up of the fruiting branches. The weak spots produced by this disease in stems and branches often lead to breakages when the plants are struck by a gust of wind.

\section{Bacterial Boll Disease.}

The disease of cotton bolls arising from infection with Bacterium malvacearum is frequently the cause of very heavy losses in these islands. In the experience of the writer, at least a large part of the damage generally attributed to anthracnose has had its origin in such infections, the spots produced having afforded a foothold to one or other of several fungi, of which that of anthracnose is under some conditions the most frequent.

\section{History and Distribution.}

There is very little literature dealing with this disease. It appears to have been first noticed by E. F. Smith in the United States in I90I, it was referred to as a disease of Sea Island cotton by W. A. Orton in I907, and is discussed at some length, with records of inoculations, by C. W. Edgerton in two papers published in IgI2. As described by that author the position in Louisiana with regard to the disease and its relation to other boll rots closely resembles the local one.

Regarding the disease in the West Indies there is a doubtful reference by $\mathrm{L}$. Lewton Brain in $\mathrm{I} 904$ to a bacterial boll rot attacking the inner tissues and contents of the boll, which seems rather to refer to what was afterwards described by the same writer as black boll and is now called internal boll disease. In I909-IO, F. W. South recognized the disease and published an adequate description of its typical appearance. He records it as apparently prevalent throughout the cotton-growing islands, causing losses estimated to vary from 2 to 20 per cent. This is about its present status, the variation occurring under the influence of external conditions as discussed below.

The disease has been recorded (IgIo) as destructive to Egyptian cotton grown in low-lying wet districts in Nyasaland. 


\section{Nature and Effects.}

The first stage of the disease exhibits a small rounded watersoaked green spot on the surface of the boll. This extends at its margin, while the tissues at the centre dry up and turn brown or black. If the development of the lesion continues the carpel is penetrated and the lint becomes thoroughly infested with bacteria, including species which themselves are unable to attack the boll, very commonly accompanied by one or other of the fungi which readily occupy the original spot. A good deal of lint may in this way be stained bright yellow, as in the internal boll disease, or in severer cases completely blackened and rotted. Infections at the base of the boll often involve the central column, while those near the tip cause premature separation of the points of the carpels and prevent complete separation when it is naturally due. In both base and point infections more than one carpel may be affected, whereas spots on the face of the bolls usually only affect the lock on which they occur.

The development of the lesion may become arrested at any stage, and under some circumstances this occurs before the lint is reached ; the damage due to the disease is thus very variable in amount. The appearance of the developed spots on the green boll similarly varies. If they are infested with the pink anthracnose fungus or the common similarly coloured Fusarium it is identical with that familiar in figures and descriptions of anthracnose injury; if not so infected a somewhat sunken, dry, rough, dark spot or patch, often with a water-soaked green margin, is produced.

In addition to the obvious injuries on developed bolls heavy losses also occur from the shedding of flower buds and young bolls infected at the base.

\section{Causation.}

From the very earliest appearances of the water-soaked spots bacteria are present in the tissue in great numbers, and often form a pale yellow transparent film on the surface of the spot. The organism (Bacterium malvacearum E. F. Sm.) is identical with that which gives rise to angular spot on the leaves.

\section{Mode of Infection.}

The spots are most often located either at the apex of the boll, extending for a short distance down one side, or at the base near to or under the calyx. They occur quite commonly however on other parts of the surface, both between and on the suture lines. Attempts to correlate the spots with bug punctures have revealed no evidence of connection.

The organism is commonly present on the plants in great amount in connection with angular spot of the leaves and bracts. When a plant so infected is thoroughly wetted by rain the bacteria 
cannot fail to be well distributed over its various parts. Since the number of spots arising on the bolls is comparatively few in the circumstances it is a matter of great interest to know what determines the occurrence of an infection

Edgerton reports that infections similar to those of natural occurrence and situated mostly near the apex of the boll are readily produced by dropping a bacterial suspension into the open flower. He obtained 45 per cent. of infections appearing in I2-I4 days in field trials of this method, the controls remaining healthy.

It is possible that many of the natural infections have their origin in the flower, and it is suggested that transfer of the bacteria by insects may play a part in the process. At what stage the basal infections are produced is not clear; they do not appear to be correlated with infestations of angular leaf-spot on the adjacent bracts. Nor is it evident whether the occasional occurrence of spots with a fresh appearance on full-sized bolls is due to late or to delayed infection.

\section{Influence of External Conditions.}

Like other subjects in connection with the disease, this requires a good deal of further study; losses are heavy and general in wet seasons and are usually very small in dry weather. Under certain conditions, however, which are not understood, severe local damage may occur in what may be regarded as a normal or good season. Thus in St. Vincent in November, I9I7, a single field on an estate had a general infestation of the bolls of the first picking, and was giving ro per cent. of stained lint due to this disease, while adjacent fields differing only in being planted a few weeks later were practically free. In early January, I 918 , in dry weather, a field of cotton in Barbados in the stage of full secondary growth was seen heavily infested with bacterial boll disease and black arm There was little or no angular leaf-spot in the foliage present, which was all new.

In such dry weather infestations the bacterium itself is more directly responsible for the damage done than in wet weather, when the occupation of the spots by secondary organisms is the rule.

\section{Resistance and Control.}

It is uncertain at present what relations exist between the prevalence of bacterial boll disease and of angular leaf-spot. From direct or indirect causes certain types of smooth-bolled perennial cottons occurring in these islands are certainly much more susceptible to the boll disease than Sea Island, an awkward fact for those who claim an all-embracing immunity for the so-called native cottons.

Attempts to reduce the amount of the disease, whether by the 
selection of resistant varieties or by spraying, have been made indirectly by adopting these measures for the control of angular leaf-spot. In the St. Vincent spraying experiments a 3 per cent. increase in the percentage of bolls to flowers was obtained in I9I7-I8, which is too small to be regarded as significant. The subject is one which needs further study.

\section{SofT Rot OF BoLls.}

\section{History and Distribution.}

The soft rot of bolls, which is caused by one or more species of Phytophthora, does not appear to have been met with outside the West Indies. It was reported first from Montserrat by W. Robson, in I9I0. From specimens then forwarded the nature of the disease was tentatively determined by F. W. South. In I9I6 the writer was present in St. Vincent towards the end of a period of extremely wet weather, and found the disease to be very destructive so long as this prevailed. In I9I 7 the course of a small outbreak was followed in the same island and cultures of the fungus were obtained, but its specific identity has not yet been determined. The presence of the disease in the other islands is suspected.

Recent observations indicate that boll rot is not always caused by the same species of Phytophthora,. A form isolated from bolls in Montserrat was apparently $P h$. parasitica Dast, while a species isolated from bolls in St. Vincent on which it had developed sporangia luxuriantly proved to be closely related to the Phytophthoras of cacao pod-rot and coconut bud-rot.

\section{Symptoms.}

The first appearance of the disease is shown by a darkening of the colour of the boll, which proceeds from a green darker than the normal to blue-black or black. By the time this is completed the boll and its contents are more or less soft-rotted and completely spoiled. The fungus appears externally on the boll as a white cottony envelope of mycelium, or as a white mealy covering of conidia. No other part of the plant has been seen to be attacked.

\section{Infuence of External Conditions.}

The development of this disease is closely dependent on a high degree of humidity. It makes its first appearance on bolls near the ground, especially amongst crowded bushy plants after heavy rain. Only in very wet, cloudy periods does it attack bolls on the higher branches. At such times it is responsible for a very large part of the heavy losses which occur. Severe outbreaks pass off very quickly with the succession of dry sunny weather, 


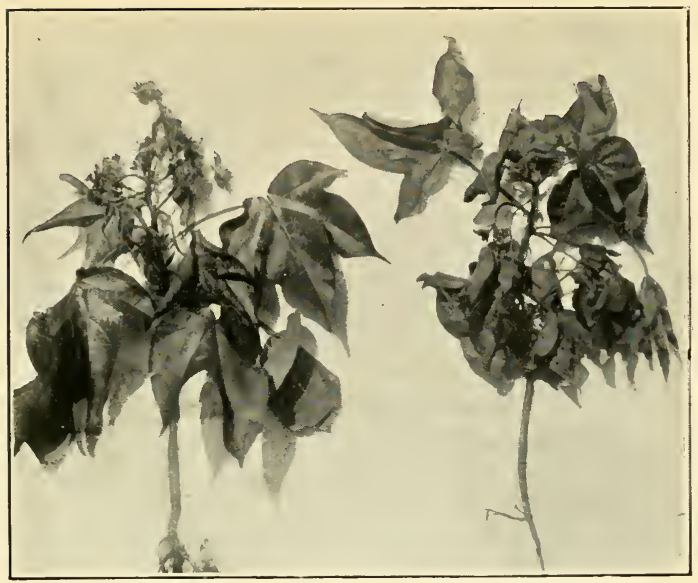

Fig. 107

Loggerhead Cotton, Young Plants

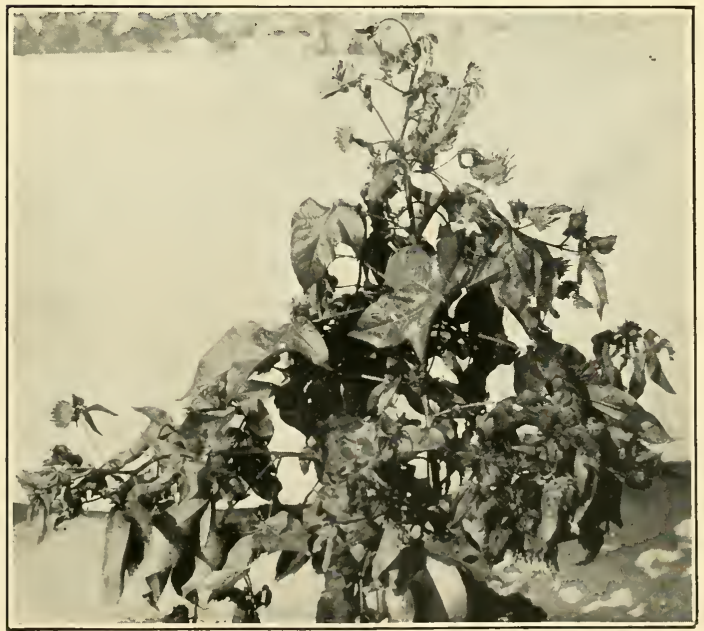

Fig. 108

Loggerhead Cotton, Old Playt 



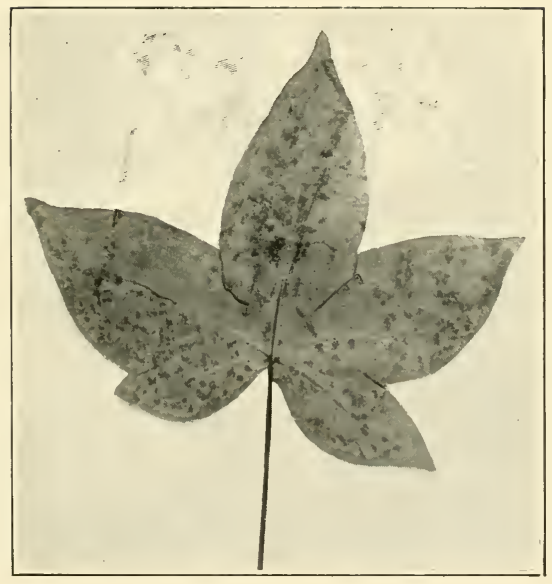

Fig. 109

West India Leaf Mildew of Cotton 

though the indications are that when once the disease has made its appearance it is liable to recur on the lower bolls under circumstances less extreme than are needed to induce the first attacks.

\section{Mode of Infection.}

Nothing is known as to the carrying over of the fungus from year to year, but the assumption is made that, as in other members of the group, resting spores are retained in the soil. The means by which infection is conveyed from boll to boll have not yet been studied, but may be assumed to be the same as in other Phytophthora diseases (p. 2I).

\section{Resistance.}

S. C. Harland reports that the Montserrat strain $\mathrm{H}_{23}$, when introduced in I9I9 into the wetter climate of St. Vincent, proved so highly susceptible that practically all the bolls were destroyed. Another Montserrat strain D.I. was more resistant under the same conditions, approaching nearer in this respect to the ordinary St. Vincent strains, and gave a fair crop. The St. Vincent strains A.B. and A.N., developed from the Superfine type, show considerable resistance to soft-rot as well as to the angular spot disease.

No type has been found sufficiently resistant to avoid loss of the lower bolls in wet weather, the difference being expressed in the survival of the bolls on the upper parts of the plant.

The control of soft-rot by spraying with Bordeaux or Burgundy mixture has not yet been sufficiently tested. No cases occurred in the sprayed plots in St. Vincent in I9I8-I9, while a fair number appeared on the unsprayed plots. It may be possible to show, when an opportunity occurs, that spraying at the outset of a threatened epidemic can arrest the progress of the disease, which at such times is liable to destroy most of the visible crop of bolls.

\section{Diplodia Boll Rot.}

\section{History and Distribution.}

The existence of a species of Diplodia on cotton bolls has been several times recorded in the United States since M. C. Cooke described Diplodia gossypina from Indian material in I879. C. W. Edgerton, in I9I2, seems to have been the first to attribute a definite boll disease to its agency. He reports that considerable loss from this cause occurs throughout the State of Louisiana, averaging perhaps 2 per cent. on the whole crop, but occasionally in small areas reaching Io per cent. The present writer has long been familiar with the envelopment of rotted West Indian Sea Island bolls with masses of black Diplodia spores, but only in 
I9I6 became acquainted with the fungus as the apparent cause of a brown rot of bolls, to which his attention was called by S. C. Harland at the St. Vincent Experiment Station. Some further notes were made at the same place under the drier conditions of I9I7, when the affection was almost confined to one perennial plant. Certain perennial types appear to be specially susceptible. in I9I9 more Sea Islands bolls than usual were seen to be affected. These are so far the only records of Diplodia disease in the Lesser Antilles.

\section{Nature of the Attack.}

The earliest external sign of attack as seen on the St. Vincent bolls is a brown patch of discoloration of somewhat indefinite form which rapidly extends over a great part or the whole of the boll. The surface soon becomes dry and hard, and is roughened by the appearance all over it of slight projections marking the developing pycnidia. The contents are by this time fully infested with the dark slaty-grey mycelium. The pycnidia discharge at first whitish tendrils of hyaline one-celled spores, and later the more mature black two-celled spores are produced in such quantity as to cover the whole boll in a soot-like layer. The boll is completely ruined.

These notes agree with Edgerton's account of the disease in Louisiana.

\section{Mode of Infection.}

According to Edgerton, the fungus gains entrance through an insect puncture or other wound, and infests the contents of the boll before it is able to attack the outer wall. The fungus is found on dead stems and other parts of the cotton plant, but is regarded as saprophytic in these situations.

The most significant function of the fungus in these islands is judged to be that of the infection and complete destruction of bolls already attacked by other diseases.

\section{Control.}

The inability of the fungus to penetrate the uninjured epidermis suggests that measures taken to preserve the bolls from injury offer the best means of protection against this disease. An additional reason, if one were needed; is thus given for efforts to keep down the numbers of bugs infesting the cotton plant.

Prevention of the damage resulting from its function as a secondary parasite likewise depends on the control of other external boll diseases which cause the formation of spots on the boll and thus give it access to the lint and seed, 


\section{AntHracnose.}

The most destructive boll rot occurring in the United States cotton belt is agreed to be the anthracnose produced by Glomerella .. (Colletotrichum) gossypii (Southw.) which on occasion may destroy 50 per cent. or more of the crop in some localities.

\section{Occurrence in the Lesser Antilles.}

A disease which in general appearance closely resembles anthracnose was noticed in the West Indies soon after the revival of the Sea Island industry. Bolls from Barbados submitted to W. A. Orton were found to bear a fungus which agreed with the characters of the American species, except for the smaller size of the conidia. This was described by L. Lewton Brain as O. gossypii, var. Barbadense, and it has been generally accepted that boll rot due to anthracnose existed to an extent sometimes serious in all the cotton-growing islands. It was regarded as particularly destructive in St. Vincent, where practically the whole of the heavy losses occurring in the wet periods to which that island is subject were attributed to anthracnose. Investigations made by the writer in St. Vincent on various occasions since I9I5, and the maintenance of constant observation on boll diseases there by S. C. Harland, have shown that at least a very large part of the loss is due to internal boll disease, Phytophthora rot, and bacterial boll disease. Lesions closely resembling the anthracnose of American writers and infested with a similar pink-spored Colletotrichum or with a pink Fusarium are fairly common, but in all the examples seen by the writer they appear to develop on the spots initiated by Bacterium malvacearum. The status of Colletotrichum gossypii on Sea Island cotton in these islands is therefore at the present time a matter of doubt, and requires to be completely re-investigated. The description which follows refers to the American type of disease.

\section{Symptoms.}

The fungus attacks the boll, according to the account given by C. W. Edgerton, through the pistil from conidia reaching the flowers, by penetrating the uninjured epidermis of young tender bolls, and by way of insect punctures or bacterial spots on older bolls. Beginning with a small spot the lesion extends to a variable extent and may cover half the boll. The affected patch is sunken and brownish, with usually a red border.

The lint and seed are affected to an extent varying from slight damage to complete destruction, depending on the age of the boll and also on the previous or concurrent presence of other organisnis. 


\section{Course of the Disease.}

The seeds are liable to be infected in the boll without necessarily impairing their power of germination, and when they are subsequently planted the fungus develops and produces spots or marginal injury upon the cotyledons. The conidia are also carried on the surface of the seed. A certain amount of dampingoff, and of spotting on young stems are also produced.

The fungus continues its existence in dead spots on the leaves and stems of mature plants, but does not spread to any marked extent in the living tissues apart from the bolls.

Carried over as above described the fungus only assumes prominence when the bolls are formed. The first infections on these produce enormous numbers of conidia, which are released when wetted, and the combined effects of rain and wind, probably supplemented by insect carriage, serve for their distribution, and enable them to give rise in suitable weather to epidemics of the disease.

\section{The Fungus.}

The manner of production of the conidia is that typical of the anthracnoses (p. 22). The conidia are hyaline, one-celled, cylindrical, generally straight but sometimes slightly curved, with rounded ends, and usually slightly narrower towards the middle. They measure about $3.5-7 \times$ I2-25 microns. The measurements of the variety Barbadense are given by Lewton Brain as $4-5 \times$ II-I4 micr.

The ascogenous (Glomerella) stage has beaked perithecia, dark brown to black in colour, subglobose to pyriform, 80-I20 $\times$ I00-I60 microns, usually buried in the host tissue with only the beaks protruding; ascospores nearly elliptical, hyaline, I2-20 $\times$ 5-8 micr.; paraphyses abundant.

\section{Control.}

As pointed out above, the amount of injury effected by anthracnose in these islands, alone and in association with bacterial boll disease, requires to be determined, Should the need for control arise the most promising measures are selection for resistance and the use of clean seed. In view of internal infections the latter can only be secured by picking from uninjured bolls. It is desirable on general grounds that all cotton seed for planting should be externally disinfected.

\section{Curly Leaf, Chibble Leaf.}

Under certain conditions which appear to be closely connected with the prevailing weather Sea Island cotton during its vegetative period may take on an abnormal form of growth to which the names above have been applied. It most frequently 
supervenes after some amount of normal growth has been made, and sooner or later it is thrown off and normal growth resumed. Meanwhile the form of the plant is strikingly changed and bearing is almost entirely inhibited.

The affection was widespread and long-continued in St. Kitts and Nevis in June-July, I9I4. It had been noticed in previous years affecting fields here and there in St. Kitts, and more regularly in particular localities in Nevis. It has also occurred from time to time in Antigua, Montserrat, and St. Vincent. An affection with symptoms the same in kind but developed in somewhat different proportions has been troublesome in St. Croix.

\section{Description.}

The general character of the form of growth in curly leaf disease is shown in Figs. I05-6. It is most noticeable towards the upper extremity of the main shoot, but occurs also on the laterals. The internodes of stems and branches, and usually the leaf stalks as well, grow out to be abnormally long and slender. The productive branches commonly have only two or three nodes, which makes the number of possible flowers small. The leaves from their earliest appearance are strongly crimped all round their margin; they are thin in substance, and pale green, tending more or less to yellow, in colour. In some cases there is a diffusion of still paler colour bordering the larger veins. In what have seemed to be the more extreme cases examined numerous small irregular holes occur torn in the body of the leaf and on its edges. They arise from the inability of small brown spots formed in the very young leaf to expand with the rest of the tissue.

The effect on bearing of the onset of this condition is profound. There is a strong tendency for the flower buds to dry up, turn black, and drop at a very early stage in their development; very many are lost when the bracteoles are but 2 or $3 \mathrm{~mm}$. across, others at various later stages. Some plants are rendered completely barren even of flowers in this way. Of the flower buds which do succeed in developing many fail to open; the outside of the petals becomes slightly discoloured pink and takes on a characteristic rather woolly appearance, and as the corolla becomes mature the margins of the overlapping petals towards the tip of the bud lack their normal firmness and cling together, failing to expand. Complete withering of the petals follows. Flowers examined in the first visible stages of the process have been found to have the anthers already brown and withered. The effect is possibly produced by gradual wilting of the petals from the margin inwards, or it may be that they lack from the first the consistency necessary for the expansion of the corolla.

All experience has shown that so long as the curly-leaf condition is prevalent the yield is exceedingly small. 
Comparison of notes and specimens with those of Longfield Smith in St. Croix shows that in that island the crimping of the leaves is not developed to the same extent, but that the occurrence of small irregular holes, as mentioned above, is so abundant as to make this the most prominent feature of the disease. The symptoms on the flower-buds and the consequent effect on bearing are the same.

\section{Nature of the Affection.}

Careful investigation has revealed no evidence of association with any insect, fungus, or other organism. The manner of occurrence does not suggest a parasitic origin and the affection does not appear to be communicable. It has no connection with seed of any particular origin and can occur in old or newly imported strains. It must therefore be attributed to some functional disturbance connected with external conditions.

\section{Conditions of Occurrence.}

It is the firm opinion of local observers that the appearance of curly-leaf is connected with dull rainy weather, and it is especially liable to occur in shaded and sheltered situations. In St. Croix the disease is always associated with vigorous growth in the first two months after planting and is especially prevalent on the eastern side of the island where the soil is deep. Cotton planted on new land is generally worst affected. The stunting of plants through water-logging has been noticed to cause their escape from the disease, and the outermost rows of affected fields commonly remain normal.

The affection is by no means regular in its occurrence in the same district at the same time. It is usually generally distributed through a field in which it occurs, but in other fields may be absent or only slightly developed.

Accounts agree that normal growth is always resumed when a period of dry sunny weather ensues.

\section{Causation.}

The conclusion indicated is that the curly-leaf disease is definitely connected with rapid growth brought about under certain soil conditions, including depth and easy permeability, when plants in the active vegetative stage receive an abundant supply of water and the checks to growth ordinarily exercised by sun and wind are removed by the prevalence of still cloudy weather, the shading of the situation, or the crowding of the plants themselves.

\section{LOGGERHEAD.}

In the same season (I9I4) that the curly-leaf affection was most abundant in St. Kitts and Nevis, a second form of abnormal 
growth, locally named loggerhead, occurred to about the same extent. This appears to be closely similar in nature, but produces changes in the form of the plant which are in many respects the exact reverse of those seen in curly-leaf.

The most striking feature of the loggerhead form of growth is the shortening, to a greater or lesser degree, of the internodes of both stems and branches. A plant which is affected at an early stage of growth assumes the form of a low dense bush, with the primary leaves, and the shortened reproductive branches with their leaves and flowers, all crowded together on the shortened vegetative axes. If the plant becomes affected only after normal growth has been made, then the tops of the main stem and of the vegetative branches show similar close bunchy masses. The flowering branches have numerous internodes, so that large numbers of flower buds are produced.

The leaves of the loggerhead form are very distinctive. They are normal in thickness; the general colour is a dark green, usually distinctly darker than that of the leaves of normal plants; there is no tendency to the crimping at the edges which is the most conspicuous feature of the other form, but frequently the leaf substance is puckered along the main veins owing to their insufficient elongation; the secondary veins, instead of diverging at the usual wide angle may be tied at a narrow angle to the primary veins for some distance, apparently from the failure of the intervening ground tissue to expand. Such undeveloped spots are almost transparent and of a light yellow colour. In many cases there is not this interference with the form of the leaf, but in all cases there is a definite mottled effect produced by the presence of lighter green or yellowish areas. In all typical cases the mottling is quite different in appearance from the diffused yellowish discoloration along the course of the veins which has been already described as occurring in some cases of curly-leaf. A few examples have been noticed, however, where in plants of the loggerhead form the light areas have followed the course of the veins. In such cases the yellow colour has usually been more definite than in the curly-leaf examples, but occasionally the approach is very close. This was seen in plants in which the suppression of the internodes was hardly noticeable.

As in the case of curly-leaf, large numbers of flower buds turn black and drop in their earliest stages. This symptom cannot, however, be regarded as a specific character of these affections, since the same thing has been observed on cotton plants of normal form when exposed to unfavourable conditions.

The abnormal condition of the flowers described in connection with curly-leaf also occurs in plants of the loggerhead form.

The loggerhead form of growth can be assumed at any stage at which active growth is proceeding, including plants only a few inches high. Most commonly its occurrence is distinctly 
sporadic, much more so than with curly-leaf. A few cases have been seen in which its incidence was fairly general over the whole or part of a field, but more often the majority of the plants have been normal.

Sometimes a single abnormal plant, sometimes two or three, have occurred in a large field.

\section{History and Distribution.}

Attention seems to have been first attracted to the loggerhead affection in IgIO, in which year it appeared to an alarming extent on an estate situated towards the western extremity of the island of St. Kitts. Then, as later, it was not regular or universal in any field. The seed was from the local Experiment Station at La Guerite. It has since been noticed to some extent in the same district every year. In I9I3 it was severe on two estates 2 or 3 miles to the north-west. Again the cotton happened to be from local seed, and in consequence a change was made in I9I4, and seed of a Barbados strain, grown three years in St. Kitts, was used. Early plantings from this seed were so badly affected that a fairly large area was cleared about June and replanted.

In the neighbourhood of Basseterre, sporadic examples have occurred each year since the affection was recognised, and have been usually rogued out. In July, IgI4, the affection appeared to a much greater extent, but still with a scattered distribution, in various fields situated on the La Guerite lands. This cotton was planted, owing to the occurrence of early rains, some two months earlier than is customary.

In Nevis, though curly-leaf has been common on some areas since I9II, the loggerhead affection has only occurred sporadically, and has not been regarded as of serious importance. In IgI4 it was somewhat more common, and in two or three places seriously affected small areas. One of these was a plot at the Experiment Station planted with St. Vincent seed.

Loggerhead has not been recorded from any other island.

\section{Conditions of Occurrence.}

As in the case of curly-leaf there is nothing to indicate a parasitic origin for the loggerhead disease, or its transmission by infection or by seed. The evidence as to the conditions inducing its appearance is less definite than that regarding curly-leaf. A plant recovering from the affection can occur within a few yards of one of the same age just developing it. Whole plots of similar age separated only by a road have shown the same contrast. Frequently two plants, one healthy and one badly deformed, have been seen growing in close contact from the same " hole."

The one definite piece of evidence bearing on the origin 
of loggerhead is that its appearances have mostly been made in fields planted out of the normal season.

There is no evidence of direct relationship between curly-leaf and loggerhead. They may occur in the same field, or be entirely dissociated. But it is suggestive of the similarity of their nature that both reached their fullest development in St. Kitts and Nevis in the same season, that both ceased to be developed when fine sunny weather set in, and that neither has since been noticed to any significant extent.

\section{Rust.}

A species of rust fungus is common on the leaves of perennial cottons throughout all the islands. The variety known as Nevis Purple and some others are specially susceptible to it. Sea Island is usually only attacked on old leaves toward the end of the season, but earlier infestation occurs on unthrifty plants.

The fungus in all cases appears to be Kuehneola Gossypii (Lager.) Arth., first described as Uredo Gossypii by Lagerheim, in IS9I, from specimens collected in Ecuador. It is recorded from British Guiana, the Lesser Antilles, Cuba, Porto Rico, and Florida. The uredospores commonly met with are borne mostly on the underside of the leaves in numerous small round sori, which are generally enclosed by a purple ring and marked on the upper side of the leaf by a purple spot.

\section{Red Leaf Blight.}

Cotton grown in poor or deficient soil is liable to show a special symptom of ill-health which is known as red leaf-blight or as " rust." The latter name is unfortunate as the affection has no relation with the actual rust fungus occurring on cotton. The condition referred to is marked by a discoloration of the leaves, which become conspicuously suffused with red or reddish brown. It is commonly associated with poor growth but may occur on large plants in the middle or later stages of their existence. The affected leaves tend to fall prematurely.

In St. Vincent the affection is very common from an early stage on the undersized plants produced by land inadequately manured, especially on slopes subject to loss by washing. The manurial experiments conducted in that island appear definitely to connect the affection with shortage of potash, a conclusion reached many years ago in connection with the closely comparable affection occurring in the United States,

\section{Yellow LeaF Blight.}

A condition which in its general characters resembles the affection described under this name by G. F. Atkinson, and also known in the United States as " mosaic disease," or in its later 
stages as " black rust," is sometimes met with in these islands, on plants suffering from drought or poor nutrition, usually on shallow or sandy soils.

According to Atkinson, in the normal and usual progress of the disease there first appears a peculiar yellowing of the leaf, which gives it a checkered or mosaic appearance. The yellow colour appears in small areas and bears a definite relation to the venation of the leaf, being bounded by veinlets which subtend areas more or less rectangular in outline. The green colour is found along the larger and intermediate veins.

$\mathrm{Up}_{\mathrm{p}}$ to this stage the affection is non-parasitic, and due to imperfect nutrition. Later the weakened leaves are usually infested with weakly parasitic fungi (Alternaria, Macrosporium, and Cercospora; see below) which give rise to the condition known as black rust, in which leaf-spots are heavily developed.

The treatment found to be successful in preventing the development of yellow leaf blight on light soils in Alabama is the manurial application of potash salts.

\section{MACROSPORIUM LEAF-SPOT.}

In the condition known as yellow leaf blight one of the fungi commonly found on the browned margins and in zoned spots on the failing leaves is a Macrosporium sp. In the United States, G. F. Atkinson described the species thus occurring as M. nigricantium, as follows :

"Hyphæ amphigenous, subfasciculate, or scattered, 50-I40 $\times$ 6-7 micr., nodulose, septate, olive brown. Conidia $18-22 \times 36-50$ micr., strongly constricted about the middle, stoutly rostrate at one side of the apex, smooth, transversely, longitudinally, and obliquely septate, olive brown."

Whether the Antillean form or forms are identical with this has not been determined; in some cases the agreement with the description above is not very close.

\section{Alternaria LEAF-SPOT.}

A species of Alternaria is common in these islands on leaves which are failing or are damaged by disease. Similar records have been made from time to time in the United States and the fungus is generally regarded as probably assignable to Alternaria tenuis Nees., a species described from cotton in Italy.

R. C. Faulwetter has recently made a study of Alternaria leaf-spot as it occurs in S. Carolina, and his conclusions are as follows :

"The lesions are characterised by a pale green, then strawyellow and finally rusty brown colour, brittle papery texture and irregular concentric ridged zonations.

"The identity of the fungus causing the disease cannot be 
determined with certainty. but it is very similar to Alternaria tenuis, Nees.

"Artificial inoculations show the fungus to be a weak parasite and able to infect healthy tissue only under most favourable conditions."

\section{LeAF Mildew.}

Under the name of West Indian leaf mildew a leaf affection of Sea Island cotton has been referred to in all accounts of the diseases met with on Sea Island cotton in the Lesser Antilles since the revival of cotton-growing. Perennial cottons are also attacked. The disease is universally distributed through the islands and occurs in abundance in most fields towards the end of the crop. The fungus was described in I 920 from material collected by the writer as Ovulariopsis Gossypii E. M. Wakefield.

\section{Symptoms.}

The affection is caused by the growth of the fungus, in patches or with a general distribution, on the backs of the leaves. The dark patches produced are covered with a more or less dense white web on which abundant large conidia are produced. On the upper surface of the leaves the infested areas are marked by irregular reddish-purple or purplish-black blotches or by a more general suffusion of the same colours.

\section{The Fungus.}

The mycelium is almost entirely superficial, hyaline, and freely septate. A few hyphæ penetrate by the stomata into the mesophyll. The conidiophores are upright and simple, septate, bearing terminally in succession the hyaline, reticulate conidia, which are oblong or broadly elliptical, with one end rounded or slightly produced, the other flattened at the point of attachment, and measure 50-60 $\times 16-22$ microns. Not more than two, one immature, have been seen attached to the conidiophore at the same time.

\section{Incidence.}

The disease has been usually reported from the various islands as attracting attention only after periods of wet weather. Its occurrence on the foliage borne by the plants towards the end of the crop season is not limited in this way, for it can be general even in very dry weather, but it appears that excessive moisture induces an earlier prevalence, and in such an event it is probably responsible for some indirect loss of crop. That it is not necessarily confined to old or even to mature plants has been shown by its occurrence on the fresh leaves of quite young plants grown in pots, but under normal conditions the plant is resistant up to a 
time when the prevalence of the affection is of no practical importance.

\section{AReolate Mildew.}

The cotton leaf disease known in the U.S.A. as areolate mildew, due to Ramularia areola, has recently been recognised to be common in Trinidad. It gives rise to small angular whitish spots on the undersides of the leaves.

\section{Crinkled Dwarf, Man Cotton, Motrled Hybrids.}

Certain types of cotton plant abnormal in form owing to their genetic constitution are met with in the cotton-growing islands and are liable to be regarded as diseased. In the first two cases to be described they occur as very occasional individuals in a normal Sea Island population, in the third as a result of accidental or deliberate crossing of Sea Island with local perennial cottons.

\section{Crinkled Dwarf.}

This type has been noticed for many years in Barbados, and has been studied from a genetic point of view by S. C. Harland in St. Vincent.

The plant as a whole is not more than 2 feet 6 inches in height and is generally less than 2 feet. There is a general reduction of all the vegetative and reproductive parts. The leaves are small and characteristically crinkled, with torn and ragged edges, and are uneven in colour from the presence of patches of yellowish green. Vegetative branches are seldom produced and flower production is early and profuse. Shedding takes place to such an extent, however, that only an occasional boll matures and many plants are quite sterile.

Crosses with normal Sea Island result in a first generation indistinguishable from the normal parent. The second and subsequent generations reveal segregation of the simple Mendelian type into pure and heterozygous Sea Island and pure dwarf. It would appear that the crinkled dwarf is a mutation resulting from the loss of a single factor.

\section{Man Cotton.}

The definite morphological type known as "man cotton" occurs in Barbados, St. Kitts and St. Vincent, and probably in the other islands. Its genetics have been studied by S. C. Harland.

Man cotton differs from normal Sea Island in the reduction in size of its parts and in a degree of sterility which is complete as regards the absence of viable pollen from the anthers and almost complete in respect of the ovules, even when pollinated from normal plants. Many of the fruiting branches abort after producing one or two nodes. The effect of these factors on habit 
is to produce a plant which is at once recognisable by its wiry upright stem without spreading branches.

The plants grown from the only three seeds which have been found, which must have developed from pollination with normal Sea Island, were themselves normal in appearance. The abnormal type has occurred in small proportions in apparently pure strains of Sea Island which have been selfed for four successive years.

\section{Mottled Hybrids.}

In crossing Sea Island with native perennial cottons a proportion of the progeny not seldom shows a form of growth somewhat similar to that seen in the loggerhead affection already described. It is reported that Ioo per cent. of such plants regularly occur in crosses with the St. Croix native. The writer has met with 50 per cent. on one occasion in Barbados, and 20 per cent. is recorded in Nevis. Some years ago such plants were fairly common in Barbados fields as the result of accidental crossing.

The internodes of the plants in question are very much shortened so that a low and bushy habit is developed. The leaves are always strongly mottled with yellowish green. The stems exhibit a precocious formation of cork which gives even the youngest internodes and the petioles a rough scaly appearance. Bearing is not affected, and the plants may give a very high yield. The abnormal characters usually but not invariably persist throughout the life of the plant. 


\section{CHAPTER XXVI}

\section{DISEASES OF SUGAR-CANE}

THE sugar-cane is by origin a coarse and vigorous grass, which retains in the forms developed by cultivation the general habit of grasses, and is therefore particularly suited to field conditions. The principal diseases to which it is subject are not such as are encouraged by heavy rainfall, and in good soil it is well able, especially while the shoots are young, to withstand exposure to sun and drying winds. It produces a crop which is dependent only on vegetative growth, and not as in the cereal grasses on the successful ripening of grain. For these reasons it is adaptable to a very wide range of conditions of soil and rainfall.

Succeeding on an original diversity of crops, the cultivation of sugar-cane was for a period general throughout the settled parts of the British West Indies ; it grew in light and heavy soils, under copious and scanty rainfall, in humid and in exposed and wind-swept situations.

The disastrous depression of the cane-sugar industry in the second half of the nineteenth century led to replacement of sugar cane by other crops wherever this was seen to be possible, and the nature of the alternatives available meant for the most part that the well-watered and more humid situations were planted in cacao and limes. This applies to Dominica, much of St. Lucia, Grenada, Tobago, and a considerable part of Trinidad. On the other hand, St. Kitts, Antigua, Barbados and certain areas of Trinidad, unsuited to orchard crops, maintained a much impoverished sugar industry; while the remaining islands became almost derelict until the revival of cotton cultivation.

Though the central factory system increased stability and the Great War brought temporary prosperity, this remains, with a few survivals in other localities the distribution of the sugar industry in these islands. An account of the conditions prevailing in each island is given in another section. In general the present position, as the outcome of the history outlined above, is that sugar-cane cultivation is mainly restricted to the drier islands or in the case of Trinidad the drier or more exposed districts, a result of considerable ecological importance.

The outstanding factors favouring the growth of sugar-cane are rainfall, atmospheric humidity, soil aeration, and nitrogen supply The combination of optimum conditions in these respects 288 


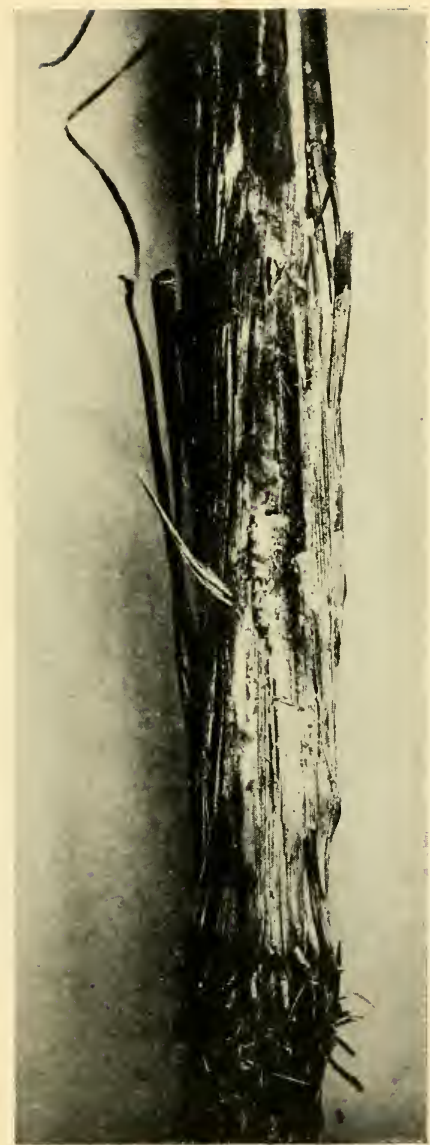

Fig. 110

Marasmius Mycelium on Sugar-Cane 



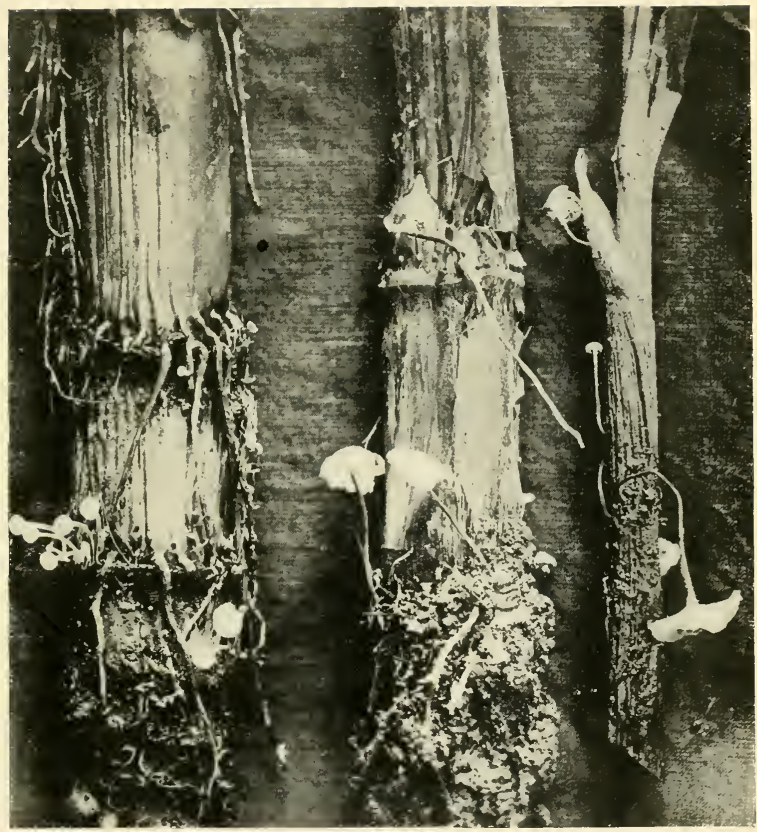

Fig. 111

Fructifications of Marasmius associated with acute Root Disease of Sugar-Cane, Trinidad 



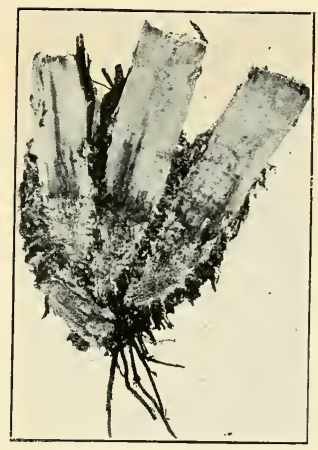

Fig. 112 Acute Type of Root Disease

Infestation of Young Plant Cane with Marasmius

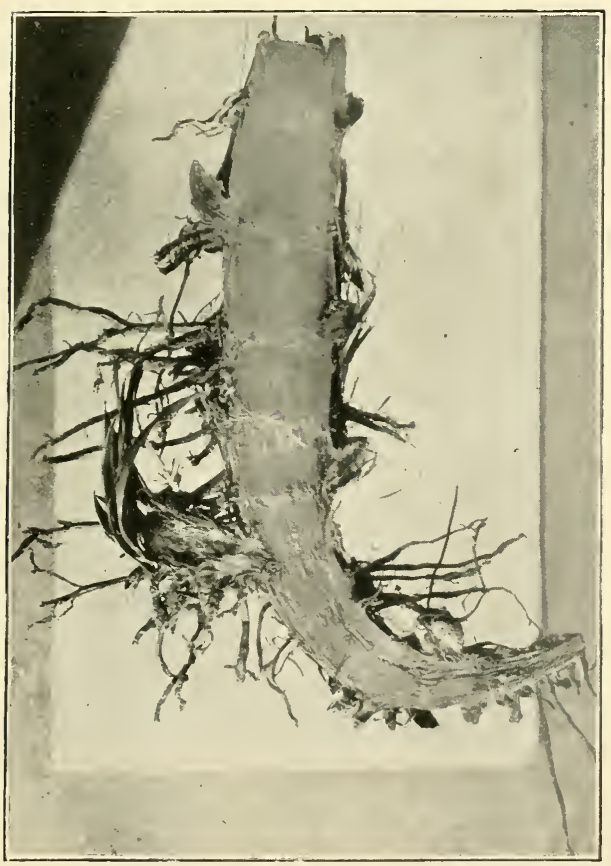

Fig. 113 Acute Type of Root Disease

Buds of Young Plant Cane infested with Marasmius 



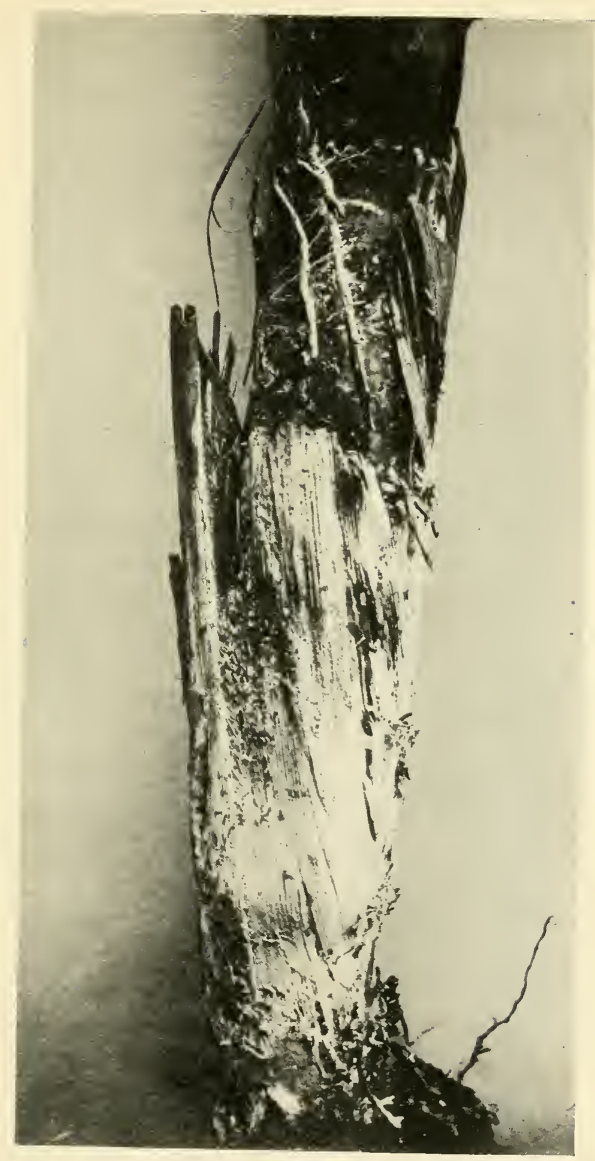

Fig. 114

Fructification of Odontia Sp. on Sugar-Cane 

is rare, and the deficiencies encountered in different situations and circumstances lead to wide diversities in agricultural practice.

The primitive method of growing sugar-cane, still practised where good forest soil is available, is to plant up the cleared land and take off a long succession of ratoon crops, then perhaps letting the land relapse for a time to bush. Sooner or later this method has to be replaced by a more permanent system of agriculture, with more frequent replanting, more careful cultivation, the use of manures, and eventually the interposition of rotation crops or fallow. The extent to which these measures have to be adopted to get an average crop with average ability of management is a measure of the general suitability of the conditions for cane production.

On good soils in Trinidad, where heavy dews and humid air supplement the effects of the actual rainfall, it is still possible in some places to pursue a system of continuous cropping and long ratooning. The opposite extreme is reached in the arid seaboard districts of Barbados, where plant canes only can be grown and these have to be alternated every third or even in some cases every second period with a rotation crop, in addition to the land being thoroughly prepared well ahead of each planting season and each crop heavily manured.

Between these extremes there is a variety of practice, with a general tendency in recent years to the further reduction of ratoons, which is variously interpreted as the result of less efficient cultivation owing to shortage and increased expense of labour, the substitution of chemical for organic manures, and the demand for increased tonnage under the system of central factories.

It is more than usually necessary in the case of sugar-cane that an understanding of agricultural practice should precede the study of its diseases, for the manner in which any defect in the adaptation of agricultural methods to conditions of soil and climate finds expression is in the prevalence of the general condition known as root disease. It is thus permissible from one point of view to regard all the modifications of practice referred to above as measures for the avoidance of this condition.

Excepting injuries of insect origin, root disease is at the present time the only serious affection of sugar-cane in these islands, and the effects of insect injury are often so entangled with those of root disease that they cannot be studied apart.

\section{Root Disease: General Type.}

\section{The Nature of Root Disease.}

In its application to sugar-cane the term root disease in its general sense is an expression for the form which is taken by failure due in the first instance to adverse conditions of soil, climate, or insect infestation. It owes its recognition as a disease 
to the fact of the invariable association with it of the mycelia of certain fungi which frequently become conspicuously developed on the affected stools. The presence of these fungi is not in itself sufficient to prouluce any notable effect on the health of the plant, for with the system of cultivation followed in localities favourable to the cane they occur in some abundance in fields bearing good crops, and it is certain that they are present to some extent, though it may be in an inconspicuous condition, in all cane fields.

It is usually assumed, and the evidence as a whole supports the idea, that while the root fungi normally exist on dead or senescent material they are able to attack and injure the plant when its vigour is for any reason depressed. The amount of this injury cannot be exactly determined, for it must in the nature of the case be exceedingly variable. The adverse conditions which enable such injury to take place produce their own direct effects, and it is in all cases a matter of judgment to what extent the action of the fungus has increased them.

In accordance with these characters root disease may be regarded in either of two ways :

(a) as a condition of ill-health non-parasitic in its origin, increased to a varying extent by secondary infestation with semiparasitic fungi; or

(b) as a fungus disease for the development of which a weakened condition of the plant is necessary as a predisposing cause.

The difference is mainly one of phrases, and one or the other conception may be the more appropriate in a given case.

\section{Distribution.}

The association of the fungus Marasmius Sacchari with a root disease of sugar-cane in Java was described by J. H. Wakker in I895. Root disease in which this fungus among others commonly appears is generally distributed through the West Indian region from Louisiana to British Guiana. It occurs in the Hawaiian Islands and in Queensland and has recently been reported from South Africa.

In the West Indies the fungus was first recognised and its relation to root disease described by $\mathrm{A}$. Howard. The affection has been discussed by every mycologist who has had to do with sugar-cane in these regions, but almost entirely in general terms. There is need for detailed investigation of the several fungi concerned and their relationship to the plant, but from the nature of the case this study to be complete would need to include the whole ecology of the sugar-cane.

\section{The Associated Fungi.}

Marasmius spp. The fungus most usually associated with 
root disease is Marasmius Sacchari Wakker, which is very common in cane fields generally, its mycelium developing freely in the thrown-out parts of cane-stools after cutting, on dead shoots, and on adhering trash; it can be shown to occur in old roots. The extent to which it appears above soil level is largely determined by the amount of moisture locally present. The mycelium is recognisable by the way in which, by developing a gelatinous consistency, it sticks the leaf sheaths together, appearing when they are separated like a layer of dried flour paste. It is further distinguishable from that of the fungus next to be described by the absence of either feathery structure or of a uniform granular layer formed on the external leaf sheaths of the infested stools.

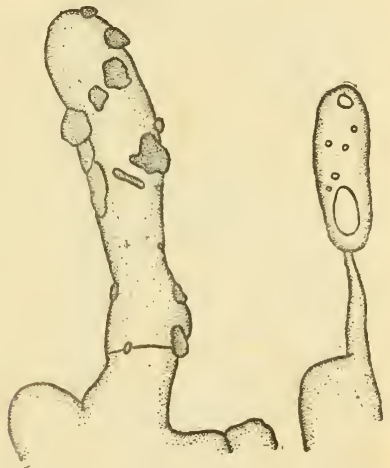

Fig. 11 ร

Odontia sacchari, Cystidium and Basidium with Single Spore From Bull. Porto Rico, Ins. Expt. Sta.

The fructifications of Marasmius are small white papery toadstools, usually less than half an inch across. They may be formed in abundance on infested material, but only under very moist conditions, generally after heavy rain. They quickly dry up and disappear on a sunny day. Their connection with the white mycelium described has been established by cultures, and they develop on infested material, including dead roots, kept in a moist chamber.

There are other species of Marasmius occurring on sugar-cane, seen especially in Trinidad, but to some extent in Barbados Their mode of occurrence appears to be essentially the same as that of $M$. Sacchari. 
Odontia spp. A white mycelium, easily distinguishable from that of Marasmius by its feathery pattern of growth and the production of abundant stellate crystals of calcium oxalate, has long been known as apparently capable of producing effects similar to those of Marasmius. It has been commonly referred to as the stellate crystal fungus, and, as a mycelium of unknown affinities, was given the name Himantia stellifera by J. R. Johnston. More recently E. A. Burt has described the fructifications of Odontia Sacchari and O. Saccharicola from Porto Rico material : two closely related fungi which produce their spores on cane trash in a close-lying, granular, buff-coloured layer hardly distinguishable without the aid of a lens from the surface of the dry trash itself.

The constant association and apparent organic connection of Odontia fructifications with the typical stellate crystal mycelium of Himantia suggests strongly that the two belong to the same fungus, to which the name Odontia would in that case apply. The relationship is highly probable but has not to the writer's knowledge been proved by pure cultures. Both Odontia and Himantia are generally distributed in these islands.

Other fungi:-In Hawaii the stinkhorn fungus Ithyphallus coralloides has been regarded as responsible for some amount of root disease and in British Guiana the mycelium of the related Phallus aurantiacus is commonly met with. Forms of infestation with distinctive mycelia have occurred in Antigua but without identification of the fungus concerned.

C. W. Carpenter has shown recently that root decay, particularly of the Lahaina cane, in the Hawaiian Islands is caused by Pythium butleri Subram, which he considers to be responsible also for wilt disease of the pineapple and a root-rot of rice.

\section{Symptoms.}

The prevalence in growing canes of the ordinary type of root disease results in a backward and stunted condition of the stools. The general effect is that of shortage of water brought about by interference with absorption through reduction of the roots. The leaves of affected shoots have their edges rolled inwards when those of healthy plants are expanded; they eventually turn brown from their edges inward, and in order from below upwards, until the shoot is withered to the top. The trash, where it has not been stripped, is cemented firmly around the lower joints of the canes, and under it matted roots occur up to a foot or more from the ground, sent out in an endeavour to find the necessary water. A clump infested early has a characteristic stunted appearance and several or many of the shoots may be dead and dry. Infested stools are easily turned over and exhibit roots which are mostly either dead or lacking in fibrous branches

It is not usual in this type of the disease for the stem bases to be attacked, and the amount of injury to the roots is often 


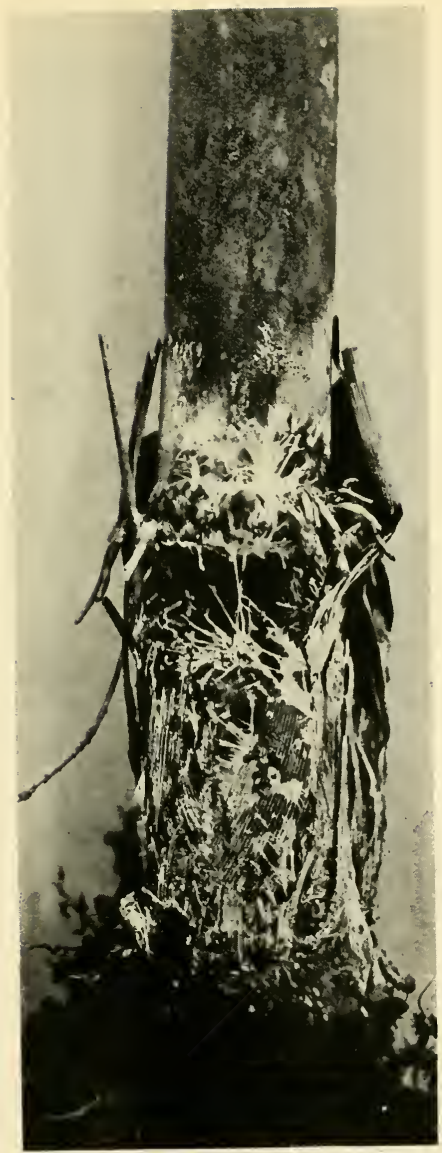

Fig. 116

Himantia Stellifera

Mycelium on Sugar cane 

difficult to estimate. Senescence and death of the older roots is to some extent normal, and changes in aeration brought about by the saturation or packing of the soil frequently cause the gradual replacement of the deeper roots by others nearer the surface, without necessarily producing much effect on growth so long as the weather is favourable. The most that one can usually say in moderate cases is that the number of functioning roots is less than one would expect to find in the situation, or than is found in normal plants at the same stage. It is also possible to trace a certain amount of invasion of the young roots by the hyphæ of the fungus; th ir tips are frequently brown and dead, the cortex

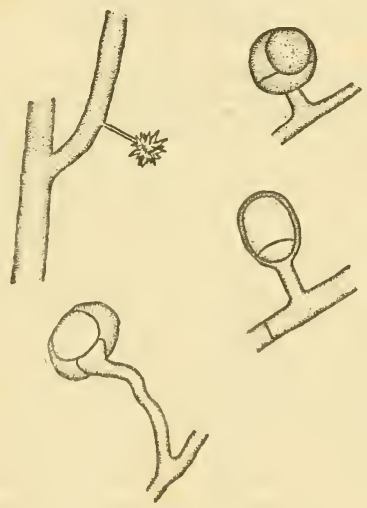

Fig. 117

Hrmantia stelifera, Hypha with Stellate Crystal and Swollen BODIES

From Bull. Porto Rico Ins. Expt. Sta.

is red or brown in spots, and considerable distortion may be present as a result of interference with the growing tips.

In the acute type of root disease later described, the ability of Marasmius to become parasitic on roots, buds, shoots and stem bases is convincingly demonstrated, and it is reasonable to assume that, in the general type now under discussion, this ability is exercised to some extent.

Conditions of Occurrence.

The condition of infestation described is very rarely general and uniform over a whole field. Typically it occurs in its pronounced form in patches related to the 
contour of the ground or the nature of the soil. Where its origin is due to drought the windward edges of the field are often worst affected. The predisposing causes of its prevalence may be summed up under the headings: dry weather, poverty of soil, defective aeration, and insect injuries.

Soil poverty and drought are much the same in their results, and root disease as the effect of the former most frequently becomes evident as rain fails. On the other hand, it is possible by thorough cultivation, by heavy manuring, by reducing ratoons and by rotation of crops, to so increase the resistance of the cane and reduce the quantity of fungus that the effects of a low rainfall are largely offset. It is from this point of view that the intensive agricultural methods characteristic of Barbados must be regarded.

Defective aeration, which confines the roots to the upper layers of the soil, reducing their feeding range and leaving them susceptible to the first influence of dry weather, may be due either to want of tilth in the soil or to the saturation of the soil with water. Both causes operate to induce root disease. The retention of tilth depends, $(a)$ on the physical consistency of the soil, so that some soils are for this reason less suited to ratooning than others, $(b)$ on its content of organic matter, $(c)$ on the frequency and thoroughness of cultivation, and $(d)$ on restriction of the operations of implemental tillage to suitable weather. The wate logging of the soil is usually due to imperfect provision drainage, but in some cases is attributable to the highly retent nature of certain soils, which in wet weather refuse to drain at c. adequate rate even on the margin of the trenches. At the samt time that the drying out of water-logged soil causes an improvement in canes suffering for that reason, dry weather takes effect on those in light or compacted soils and makes their condition worse.

Insect injuries and root disease may be intimately associated, as in the froghopper blight of Trinidad. The fields attacked by froghopper are usually those which by their age or situation are most liable to root disease, and after they are damaged by the insect the fungi get a hold on them which prevents recovery when the insect infestation has passed. In this way an end result of whole fields or tracts appearing completely crippled by root disease is produced in the situations where the froghopper has been prevalent. The infestation of stools with root grubs also produces or increases susceptibility to root disease.

So far the discussion has emphasized the harmfulness of root fungi, but an account of root disease would give a wrong impression which did not indicate the ability of plants growing under good conditions to make excellent growth in spite of heavy infestation of the stools. This is best seen when canes in good soil, infested as a result of drought, resume growth with the return of rains. Stools which appeared dead will send out vigorous 
shoots and abundant new roots and continue to thrive so long as the conditions are favourable. In the same way fields of ratoons which have been infested in a dry year and have given next to no return have produced good crops when the following year provided suitable weather. This is in strict conformity with the nature of the disease as set out above, and no such recovery can be expected where the soil is in a defective condition.

\section{Infection.}

It is not at all uncommon for cuttings and especially for top plants to have root fungus present upon them in a living condition when they are put into the ground. It is in fact the custom of some planters, from motives of economy, to take their plants from their worst fields, which in many cases are running out owing to infestation with this disease. Such material may give quite good results in a favourable season, but the fungus is present from the beginning, ready to take advantage of any unfavourable circumstance that may occur. Infection may also take place from the old stools left in the ground, from imperfectly rotted trash and, where there has been no suitable rotation of crops, from mycelium present in the soil. Ratoons are especially liable to infestation owing to the fungus which has gained a footing on the plant canes attaining to a vigorous development on the material thrown out of action when the first crop is cut, at the same time that the effect on the plant of the progressive deterioration of the unworked soil affords it increasing opportunities for harmfulness. The spores of the fungus afford another means for its dissemination, but of this nothing is directly known.

\section{Varietal Resistance.}

In a given localitv there are stronglv marked differences in the susceptibility of sugar-cane varieties to root disease. It is questionable, however, how far resistance or susceptibility can be regarded as constant varietal characters. It is the writer's opinion that canes which are well or ill-suited to a particular district, especially in regard to soil, show differences in vigour which are reflected in their relative liability to root disease. A cane which has an excellent reputation in one place may have a very poor one in another, and various degrees of such differences give rise to the strong and varied local preferences which exist.

Under present conditions the Bourbon and B 208 appear to be the most widely susceptible of standard kinds; both require soils in good tilth to succeed. To these C. K. Bancroft added D 625 and Green Transparent from British Guiana experience, with D Iog rather susceptible, D I45 and D II8 more resistant, and D 216 and D 159 not affected. White Transparent shows an increase of susceptibility over most other varieties in the dry 
conditions of Barbados and on heavy soils in Antigua. In Antigua Sealy Seedling is highly valued for its resistance on heavy clay soils and D 95 is fairly satisfactory under the same circumstances. The most strongly resistant of all canes grown in the West Indies is the Uba, which is used for planting in poor soils and on thin patches in Trinidad and Antigua. Even this becomes severely infested and can even be killed outright by root disease in combination with froghopper attack.

\section{Control.}

It is clear from the foregoing that it is to the general efficiency of his agricultural practice rather than to direct action against the fungus that the planter must look for the control of root disease. The greatest of all safeguards against it lies in the rotation of crops. Where this is not practicable the more thoroughly the ground is worked in the necessary interval between reaping and planting the better, since exposure leads to the rapid decay of infective material, and tends to the sterilization of the soil. Under such circumstances deep ploughing is advisable at an early time. The practice of leaving the stools in " resting " or thrownout lands is a very bad one from this point of view. With regard to the ratooning of infested fields, although as has been mentioned above it may be possible in a good year to get satisfactory results, such conditions are not so frequent in most of the canegrowing islands as to make the chances worth taking. The advantages of selecting healthy material for planting have been pointed out above. The soaking of the sets in Bordeaux mixture, originally recommended as a precaution against pineapple disease, is of very little value against the mycelium of Marasmius.

Where the disease appears in single stools or patches some local cause such as soil grubs, sucking insects, bad drainage or shallow soil should be first looked for. The effects of exposure may cause the disease to appear on the outside rows of windswept fields.

The digging of isolation trenches sometimes recommended is not regarded as having any practical value. Another recommended measure, the application of lime, must be considered with due regard to the general condition of the soil and the indications found of the causes of the infestation. Quicklime has a directly sterilizing effect, slaked lime hastens the decay of material that would support the fungus in the soil. Exposure of the soil by repeated turnings is probably quite effective enough for practical purposes.

It should be noted that chemical manures applied to diseased stools are wasted unless the formation of new roots has first been stimulated by moisture and cultivation. 


\section{Root Disease: Acute Type.}

Instances have on several distinct occasions come under the observation of the writer in young plant canes in Barbados, and recently in fields of first ratoons in Trinidad, in which plants growing in good well-tilled soil and previously healthy and vigorous have rapidly failed, and have been found to be heavily infested with Marasmius, not only on the roots and leaf-sheaths, but in the tissues of the basal joints of the cane. In such cases the fructifications of the fungus have been produced with unusual readiness and in considerable quantity.

The attacks on plant canes have occurred in somewhat scattered stools during the dry season. On one occasion numbers of stools of $\mathrm{Ba} .6032$ were quite killed out in this way, while plants of B 6450 , in the same field, which were not nearly so forward, were unaffected. The basal joints, and the sprouting buds in all stages were internally reddened and filled with Marasmius mycelium. This type of disease agrees with the effects of Marasmius Sacchari as first described by Wakker in Java, where the ordinary West Indian type, presumably owing to the scarcity of ratoons, does not seem to be familiar. In Barbados $M$. Sacchari was the species met with in the cases described.

The most striking instance seen in Trinidad was in a field of Hill's Seedlings 6 and I2, unusually well-grown first ratoons in deep and fairly heavy loam, sufficiently drained. Very many of the large canes were badly infested or completely rotted for several joints at the base, the parts above remaining sound until dried up by the cutting off of their supply of water. The young leafy shoots were also dying upwards owing to infestation in their base. The stools were exceedingly loose in the soil, and many were turned out by the weight of their own canes. An unidentified species of Marasmius, with bluish black stalks, was fruiting abundantly from the roots, the root " eyes" on the stem, and the young shoots. Other fungi were not conspicuous.

While no proof can be offered, the cases described, and others similar, present the appearance of active parasitism by Marasmius species. The Barbados examples were attributed to the weakening of resistance by drought, and stools not completely killed recovered after rain. The sudden failure of the Trinidad field described could only be attributed to the effect of a second dressing of sulphate of ammonia on a soil already almost depleted of its small supply of lime.

\section{The Epidemic on the Bourbon Cane}

The Bourbon cane was introduced into the West Indies in the I8th century from the island of Otaheite, where it is believed to have originated, and up to the years about I 895 was the variety in general cultivation in all the islands. About 1890 the fields in 
some places began to return large quantities of " rotten cane," and the epidemic of disease of which this was the first sign developed with great suddenness and intensity throughout the islands.

Losses variously estimated at 25 to 50 per cent. are reported from Trinidad, Grenada, St. Vincent, Barbados, Antigua and St. Kitts in the years from I892 to I894. The disease is reported to have appeared in British Guiana in the latter year and subsequently to have made rapid progress in the colony.

The diseased canes showed infestation with a "shot-borer" beetle (Xyleborus perforans) and the affection was at first attributed to this agency. Material was sent for examination to the Royal Gardens, Kew, and from the examination of this and on the strength of cultures and inoculation experiments made at Kew, G. Massee, in I893, reported that the "vexed question" of the nature of the disease had been " conclusively settled," and that it was caused by a fungus named by him Trichospharia Sacchari, which formed perithecia on dead canes and had as active conidial stages a Melanconium form (M. Sacchari, Mass.), and a form producing micro and macro-conidia (the Thielaviopsis ethaceticus of Went). Later he added as probably another form of the same fungus Colletotrichum falcatum Went, to which, from its presence in certain stools examined, he attributed root disease in Barbados. From the general occurrence on the surface of the shrivelling canes of the acervuli and conspicuous sooty conidia of Melanconium Sacchari the affection was commonly known as rind disease.

Later research has produced no support of Massee's pronouncements: Trichosphæria does not seem to have been met with again, and Melanconium, Thielaviopsis, and Colletotrichum are now recognised to be entirely separate fungi, each of which, under certain conditions, produces a distinct affection of sugarcane, while root disease is attributed to Marasmius spp.

A. Howard, working in Barbados, sorted out the confusion, bringing the situation into line with Went's researches in Java, and in I903 brought forward evidence to show that the epidemic was primarily due to the somewhat obscure infestation of the canes with Colletotrichum falcatum, a conclusion which all later experience goes to confirm.

The situation was met by the adoption of resistant varieties, of which White Transparent, Caledonian Queen, and some others were then available, and these have been followed by a successir, $n$ of seedling varieties mainly raised in Barbados and British Guiana. The shot-borer still occurs in damaged cane, Meismconium Sacchari is everywhere abundant on over-ripe or injured stalks, and Thielaviopsis causes losses of cuttings in dry planting seasons. Colletotrichum on the other hand has become rare except when an attempt is made to re-establish the Bourbon, when the symptoms of the original trouble usually reassert 


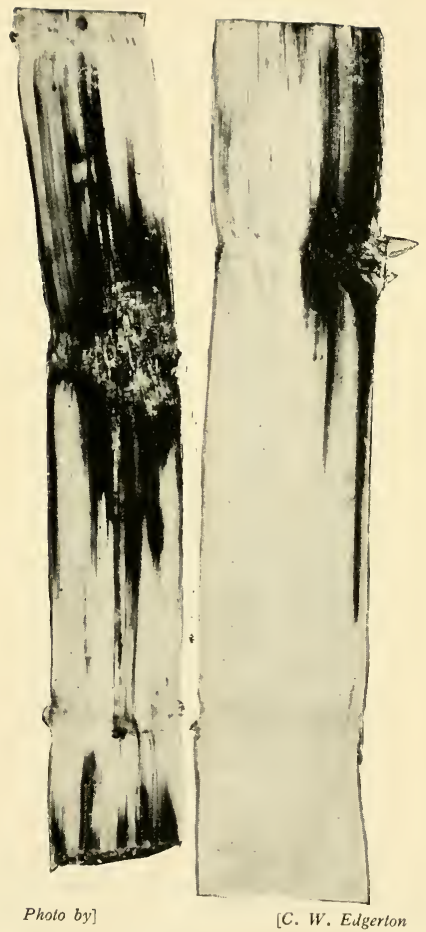

Fig. 118

RED-ROT OF SUGAR-CANE

From M.T. Cook's Diseases of Tropical Plants, by permission of Macmillan \&. Co. 


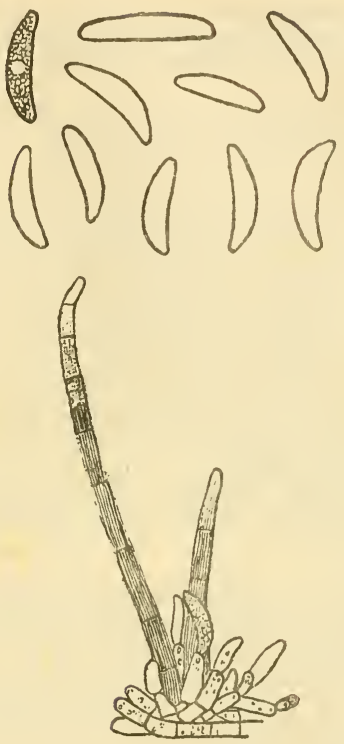

Fig. 119 COLletotrichum FALCATUM From Bull. Dept. Pathology, H.S.P.A.

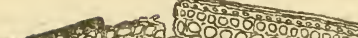

600001000 .

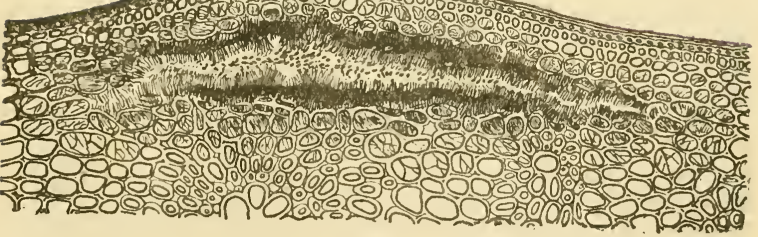

Fig. 121 Melanconium Sacchari: Vertical Section of Stroma From Bull. Dept. Pathology, H.S.P.A. 
themselves with undiminished intensity. In some remote districts in Trinidad, and to a more considerable but rapidly diminishing extent in British Guiana, the cultivation of the Bourbon is still continued.

The statements of some writers that the breakdown of the Bourbon was mainly due to root disease is not supported by the evidence. Accounts agree that the crops grew well until they were about 6 months old, and often for 9 or Io months, and that the attack then became general, while good soil, heavy manuring, and efficient cultivation did nothing to reduce its severity. This type of incidence is entirely different from that of root disease. In the trials of Bourbon made from time to time by planters, and in the plots maintained by experiment stations, the failure is usually demonstrably due to Colletotrichum.

At the same time the Bourbon cane is very susceptible to root disease under adverse conditions, and no doubt the losses occasioned in this way were indiscriminately set down to the account of " rind disease."

The question that remains most interesting is that of the origin of the epidemic. Three explanations worth considering have been offered :-

(I) That a fungus previously occurring as a saprophyte had evolved a strongly parasitic strain.

(2) That the Bourbon cane, from long vegetative reproduction in the same soils, had degenerated and become susceptible to parasites previously unable to attack it.

(3) That a parasite previously absent had been introduced from another region.

A fourth idea held by some of the older school of planters, that the disease resulted from the use of chemical manures, was negatived by its prevalence in districts where these had not been adopted.

The first theory was mainly based on the belief that the disease was due to Melanconium, which fungus was remembered to have been noticed for many years. There is no evidence to show how long the inconspicuous Colletotrichum had been present in the West Indies, but it was described as a parasite with its present characters in Java in I893, and its distribution suggests that it is indigenous to the Eastern Tropics.

The theory most generally adopted was that of the breakdown of the "constitution" of the Bourbon cane. It is in several respects unconvincing. There was no progressive degeneration ; the transition was a sudden one from a condition apparently as good as had prevailed in the previous hundred years to a sudden and almost complete failure. What seems at first sight conclusive is that some other varieties are recorded as having shown little or no more resistance. It is too much to assume that degeneration 
in their case should have coincided with a similar process in the Bourbon, so that all became susceptible at the same time to a fungus previously present, but there is a possibility, on the other side of the argument, that mass exposure to the fungus developed on the Bourbon may have led to their infestation, as is recorded of the Ribbon cane first adopted as a substitute in Martinique.

The third theory, of introduction from without, involves the fewest difficulties and is supported by many analogous cases. The records of the time show that there was an active exchange of varieties between neighbouring and in some cases distant countries. The Queen cane, for example, was brought from New Caledonia to Trinidad in 1874 , and sent from Trinidad to Jamaica, whence it was introduced into St. Kitts in I888 and passed into cultivation in one district. It was brought to Barbados from St. Kitts some years previous to 1893 . This cane is recorded to have proved highly resistant but not immune. That in some such way as this Colletotrichum falcatum was introduced from the East and distributed on the original or other varieties to the various Botanic Stations is by far the most likely theory of a matter that will probably never be conclusively settled.

The objection that the attack was almost simultaneous throughout the Lesser Antilles affects all the explanations alike, and is to some extent lessened by the consideration that the attention drawn to the disease in one island led to its recognition in another. The more remote localities in the larger area of Trinidad were much later in becoming infested, and, as mentioned above, some continue at least relatively free to the present time. The outbreak in British Guiana was also distinctly delayed.

\section{RED-ROT.}

The disease of sugar-cane caused by Colletotrichum falcatum Went was first described by Went in Java in I893, under the Dutch name " het rood snot "- the red smut. The adoption of red-rot as its name in English requires that care be taken not to confuse it with " het rood rot " of Wakker and Went, which is a sclerotium disease.

Red-rot is the most serious disease of sugar-cane in India, and is widely, probably universally, distributed through the tropics. Its epidemic appearance as the cause of " rind disease" in the West Indies about I890 has been described above. Owing to the general adoption of resistant varieties its interest at the present time in these islands is mainly historical, but it can sometimes be found by a careful search among seedling varieties, and still occurs in quantity when the Bourbon cane is re-introduced. 


\section{Symptoms.}

On the Bourbon cane the effects of the disease usually became apparent during the last quarter of the year and increased, often with startling rapidity, until the fields were reaped. The mature leaves began to wither from the tip and edges inwards. Some time later a brown patch appeared on one or more joints, became wrinkled and sunken, and soon showed signs of secondary infestation with Melanconium Sacchari. At reaping time a large proportion of the canes were dry and rotten, and others were badly deteriorated.

The symptom accepted as most typical of the disease is the appearance, when a cane is split open, of a broad, irregular, more or less central stripe of uneven red discoloration, broken here and there by whitish patches. It is necessary to examine stalks not far advanced in the disease to avoid the interference of the more general discoloration produced by Melanconium. The writer has seen an appearance very similar to that above described produced in the lower joints apparently by Marasmius, and certain diagnosis is only to be obtained from the recognition of the fungus.

\section{The Fungus.}

The acervuli of Colletotrichum falcatum-tufts of black bristles with the colourless conidia heaped about their base-are produced in velvety patches on the surface of canes well advanced with the disease, especially about the nodes, and on dead or dying leaves or leaf-sheaths. The fruiting of the fungus in the field is by no means abundant, and usually is decidedly obscure, in striking contrast with the behaviour of Melanconium. If a freshly diseased cane is split open and prevented from drying out too rapidly or becoming mouldy from too much moisture, the fructifications sometimes appear with great freedom on the cut surface.

The conidia are hyaline, unicellular, more or less sickleshaped, with bluntly pointed ends, and measure about $25 \times 4-5$ microns.

\section{Infection.}

In the West Indies infection has been regarded as mainly proceeding from borer holes and other wounds in the stem. The studies of E. J. Butler in India have shown that while this means, and the infection of exposed roots or root " eyes," probably account for the initial entry of the fungus, the infection of standing canes is too small in amount to give rise to heavy infestations. These, it has been shown, occur from the use of infested canes as planting material, in which case the whole stool, and not individual stalks, becomes infested. 

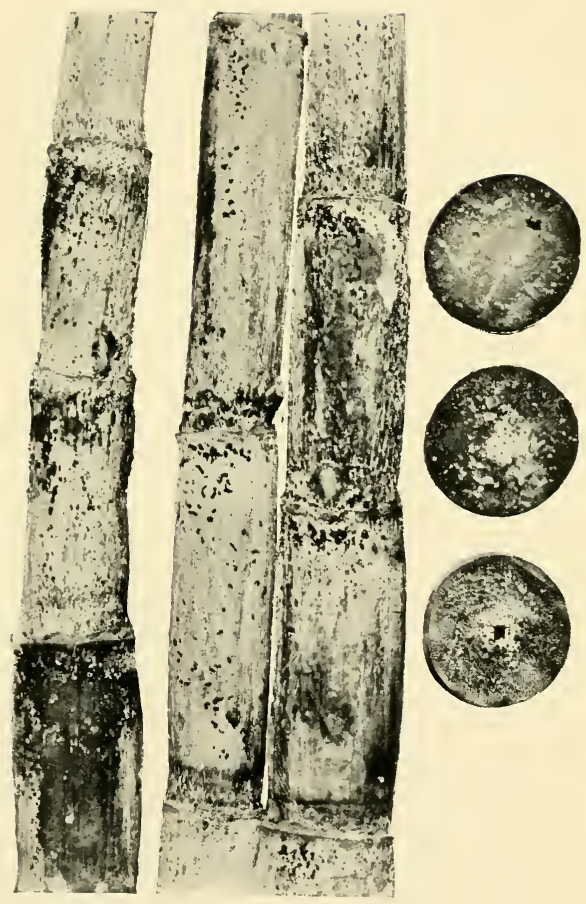

Fig. 1:0

Rind Fungus of Sugar-Cane

From M.T. Cook's Diseases of Tropical Plants, by permission of Macmillan \& Co. 

On resistant varieties the fungus appears to be able to make headway only in injured or otherwise weakened stalks. Insect attacks, defective soil aeration, and premature ripening as a result of dry weather decrease resistance.

\section{Control.}

Butler has worked out a successful system of control based on the information as to infection noted above. Starting with healthy stock, a thorough inspection is made each year of the cuttings prepared for planting. All which show reddening at the ends are discarded. A previous selection of healthy-looking stools as the source of the sets diminishes the trouble and increases the efficiency of the process. By eliminating in this way the results of casual infections it is found that in ordinary circumstances the condition of the stock can be maintained.

\section{The Rind Fungus.}

Although Melanconium Sacchari (Cke.) Mass. was not the originating cause of the epidemic of " rind disease," it certainly provided the feature which led to the use of that name, and it seems appropriate to retain the adjective in speaking of this fungus. As Strumella Sacchari it was described by M. C. Cooke from material received from Queensland in 1890 . As already related its uniform occurrence on diseased canes received at Kew from the West Indies led to its being regarded as the cause of the failure of the Bourbon cane. It is still everywhere abundant in the West Indian cane-fields, occurring on probably every sickly, damaged, or dead cane. It appears on the soundest and healthiest canes with great regularity if these are cut and laid aside either indoors or out. It occurs in a similar way in Louisiana, in Mauritius, Java, and the Hawaiian Islands. In India it appears to be very rarely met with.

\section{Conditions of Occurrence.}

The germ-tubes of the fungus are unable to penetrate the unbroken rind, but gain access through borer holes, torn leaf scars, cracks, or wounds of any other description. In healthy growing canes the invasion seems to be definitely restricted to the tissue affected by the wound. In over-ripe canes, however, it is able to spread, and when they have stood long in the fields an ever increasing proportion of them become infested with this fungus without there being any apparent reason for suspecting preparation by any earlier organism. The view now generally held regarding the degree of parasitism of which this fungus is capable is that it is only able to occupy tissue which has undergone scme degenerative change, due either to a wound, to the action o a previous organism, to senescence, or to 
death. Johnston and Stevenson attribute some importance to the infestation of cuttings.

\section{Description.}

The first external sign of the occurrence of the fungus is a

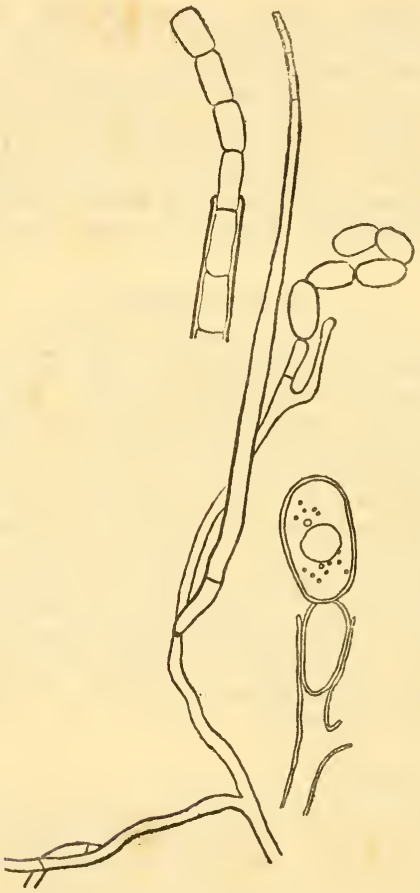

Fig. 122

Thielaviopsis paradoxa, Sporophores of Micro- and Macro-conidia From Wakker \& Went

browning of the surface, which is accompanied by souring and reddening of the interior tissues. Numerous small pustules appear just beneath the rind. The pustules open and from each is extruded a black thread which under some conditions becomes long and curly, in others settles into an irregular heap; it is made 
up of the conidia cemented together by mucilage. The conidia are unicellular, pale brown, cylindrical, straight or curved, I4-I5 $\times 3 \cdot 5-4$ microns.

The infested cane dries up and becomes very light.

\section{Pineapple Disease of Cuttings.}

\section{History and Distribution.}

This disease, caused by Thielaviopsis paradoxa (De Seynes) v. Höhn. was described by Went in Java in I893. He gave it the name Pineapple Disease owing to the smell, resembling that of a ripe pineapple, noticed when a cane containing the fungus in a fresh and vigorous condition is split open. The fungus would seem to occur in all cane-growing countries, and, from its invariable appearance when conditions favour it, would seem to be universally distributed on sugar estates in the West Indies. It is a somewhat curious coincidence, considering the name given to the disease on sugar-cane, that the fungus has since been found to be the cause of several diseases of the pineapple. It occurs also on coconut and banana.

\section{Causaive Fungus.}

The fungus was discovered by De Seynes in 1886 in France, and again by Went in Java in 1893 in connection with the disease under consideration. Went gave it the name Thielaviopsis ethaceticus, under which it has become generally known, but in accordance with the rules of priority the earlier specific name must be adopted. The fungus grows and fruits in the interior tissues of the cane. The abundant mycelium produced in the cells is at first hyaline but turns brown or nearly black as it matures. Two forms of conidia are produced from the hyphæ within the tissues, sometimes one, sometimes the other predominating. The macro-conidia are black, thick-walled, oval, produced in a chain by septation at the tip of a hypha; the micro-conidia are short, hyaline, cylindrical or oval, formed by the sub division of the internal contents of a hypha and pushed out successively from its open end. No other form of fructification is known.

\section{Nature of the Attack.}

When trouble is experienced from this fungus it is in nearly all cases connected with the infection of planted cuttings, which takes place from the cut ends in a manner strongly suggesting infection from the soil. It is, however, to be noted that unplanted cuttings, set aside in moist air or transported to a distance involving close packing for several days, are also very liable to be attacked. The fungus usually involves the centre 
of the cane, extending from one or both ends, so that when a cutting is split open it shows a blackened core, around which the tissues may retain their normal colour or be somewhat reddened. The smell is often an aid in diagnosis, being distinctly more fruity than that of merely sour cane.

Attacks on standing cane are comparatively seldom noticed. Their occurrence is favoured by wet weather. There is the same blackening of the tissues as in cuttings. The fungus is undoubtedly capable of parasitism and may extend to a considerable distance up and down from the original point of entry.

In the case of cuttings there is no difficulty about entrance; in standing canes it occurs most commonly by way of borer holes, but may take place through the leaf scars.

Loss of cuttings from this disease usually occurs when owing to the prevalence of dry weather they remain a long time in the ground before springing. In such an event the fungus has time to destroy the whole cutting and the loss of a planting may be complete. There is no evidence of varying resistance in different cane varieties, though it is a matter of common experience that these differ greatly in their germinating capacity.

\section{Control.}

The standard measure for the protection of cuttings against infection is to dip or soak them in Bordeaux mixture, and improved germination has on occasion been secured by this treatment. On the other hand many disappointments have been experienced when the measure has, nominally at least, been adopted. When the weather is favourable the treatment is not found to be necessary, but since this cannot be depended on it is usually desirable as a precautionary measure. It needs to be pointed out to planters, however, that dipping has no ceremonial value, so that unless, after the cutting has been handled, placed in the ground, and covered in, there remains on its ends a well-distributed film of blue sediment, the benefits of the process will be looked for in vain. Nor must it be expected to give protection if the ends of the cuttings are split or ragged. Dipping the ends in gas tar has been advocated as affording a more adhesive coating, but it is difficult to apply on a large scale and most planters will prefer to take chances, as indeed many do rather than trouble with the comparatively simple Bordeaux treatment.

The method commonly in use in applying Bordeaux mixture is to prepare it in a tank or hogshead and soak the cuttings either loose or in bags. There is no virtue in soaking and the crystallization of the precipitate after standing makes it less adhesive. The points that are of importance are (I) the preparation of a mixture with a finely divided and adhesive precipitate and its use while fresh, (2) the agitation of the mixture so that 

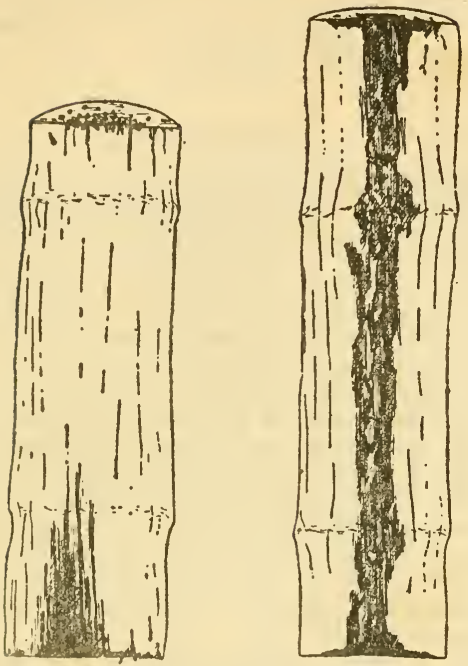

Fig. 123 Thielaviopsis in Sugar-cane Cutting

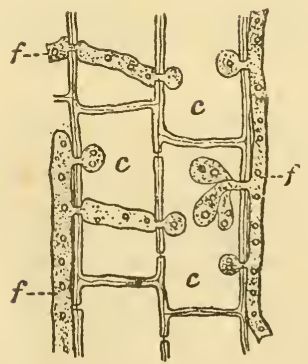

Fig. 124 Thielaviopsis in Cells of Sugar-Cane 
each cutting gets its share of the precipitate, (3) the drying of the cuttings to allow the film to set, and (4) careful subsequent handling so that the film is preserved.

\section{Diplodia Rot.}

The fungus Diplodia Theobrome (Pat.), common throughout the tropics as a weak parasite and as a saprophyte on the branches of various trees, occurs also on sugar-cane. A. Howard described it on this host in Barbados and British Guiana, and E. J. Butler has found it to be not uncommon in India. Although Howard succeeded in infecting healthy canes with the fungus it appears from general experience to resemble Melanconium Sacchari rather than the active parasites in the nature of its occurrence. It bears a close resemblance to Melanconium in general appearance also, and it is not always easy in the field to discriminate between them. Under the microscope the spores of Diplodia are at once distinguishable if mature by their two-celled condition. The small and crowded pycnidia occur just under the rind, mostly about the nodes. The little swellings which mark their position open with a tiny longitudinal slit, from which the spores are extruded. The interior of the affected cane takes on a general red discoloration, and later becomes darkened by the presence of the mature mycelium.

The fungus is mostly found on over-ripe canes or such as have been seriously damaged or killed by borer or other means.

\section{WiLt Disease.}

This disease was first described by E. J. Butler in Igr 3 from India, where it was discovered during the investigation of red-rot. It is found to occur over a large part of India, generally mixed with red-rot, but sometimes doing considerable damage where the latter is not present. As a rule the disease has not proved serious in its effects.

An affection having characters which so far as they can be judged by figures and descriptions are identical with those of the Indian disease has been detected in Barbados and in Nevis. Over a fairly wide area in Barbados in I9I5 it occurred in considerable quantity in some fields. Very little further spread was noticed and the final result on the crop was not important. The most probable explanation of its occurrence to this marked extent was that the canes attacked had been somewhat damaged by the wrenching action of high winds experienced some time before. Infestation of the stools with Marasmius also seemed to function as a predisposing cause. The circumstances under which the fungus is occasionally found suggest that normally it is present in scattered infections of borer holes. 


\section{Causative Fungus.}

The disease is due to a very inconspicuous fungus, Cephalosporium Sacchari, Butl., of which the slender colourless hyphæ penetrate all the tissues of the stem. In the hollow which forms in the centre of diseased canes the fungus collects in a white fluffy mass and there the hyphæ bear on short, mostly simple branches, terminal heads of one-celled conidia, variable in size and shape. The fungus can live as a saprophyte on a variety of materials and probably occurs in the soil.

\section{Symptoms.}

As seen externally the effects of the disease in India are

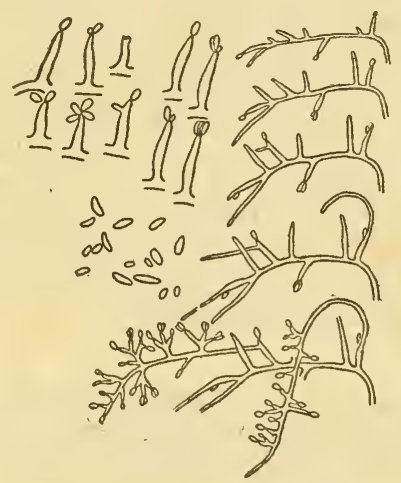

Fig. 125 Cephalosporium Sacchari

From Memoirs, Dept. Agri., India

reported to be very much the same as those of red-rot, namely the drying-up of the leaves, and, finally, of the stems. In the Barbados outbreak it was observed that canes might be attacked rather severely in the lower internodes without the tops being very noticeably affected. As mentioned above, however, the disease in this case seemed to be rather suddenly checked. In Nevis more notable damage was reported.

The discoloration seen on splitting the cane differs from that typical of red-rot, being a more uniform and duller red, tending to muddiness, and without the contrasted white patches seen in red-rot. In the earlier stages the discoloration tends to run in vertical lines. A brown patch on the outside marks where the fungus has killed the underlying tissue. This in the Barbados examples extended from the nodes, and the internal discoloration 
grew less intense from without inwards. These observations presumably indicate the course of the infection.

\section{Infection.}

According to the experiments made in India the fungus cannot penetrate the unbroken rind of the internodes, but can enter by way of wounds, leaf scars, or the root eyes of the nodes. Cuttings were also experimentally infected by dipping them before planting in water containing spores and mycelium of the fungus. It is further reported from India that the infection so far as it has been followed is not virulent; spread within the cane is gradual and communication from one plant to another slow. A large number of borer holes become infected late in the season, but the parasite usually remains confined to a few internodes. Leaves have been artificially infected with the fungus, but it has not been found occurring upon them in the field.

J. S. Dash carried out inoculation experiments in Barbados and found that in healthy canes the fungus was only weakly parasitic and made slow progress beyond the point of infection.

The point of greatest interest in connection with the presence of this disease in the West Indies is that under certain circumstances it can produce effects similar in their nature to those of red-rot in varieties which are regarded as practically immune from the latter disease, and may thus to some extent account for reports of their occasional infestation.

\section{Control.}

No general measures are at present called for in respect of the disease on West Indian canes, which would seem to be more resistant than those of India. Should it become more serious it will be necessary to avoid suspected stools as sources of material for planting and to reject cuttings showing red discoloration.

\section{Top-Rot (Bud-Rot)}

In the year I895 an affection to which the name top-rot was given began to assume epidemic form in Java. It had previously been known only through sporadic cases. At an earlier date a disease with similar characteristics had been described from Australia under the name of gum disease. Cases have occurred from time to time in the West Indies which have had somewhat similar general symptoms and have been described under this name.

The Javan disease consists essentially in the failure of the terminal joints of the cane; the leaves attached to the growing point may remain normal, or degenerate into a pulp, while the interior of the nodes immediately below it becomes involved in a sort of soft rot, producing a glassy appearance of the tissue and 
marked off from the healthy outer tissue by a red line. The young leaves are soft and reddened near their base and withered towards their tips. In some cases the uppermost leaves are distorted and fail to grow out properly. The result of this failure of the top is that while further direct growth is stopped the eyes are stimulated into growth and produce useless side shoots. The decayed portion affords an easy means of access to stemrotting fungi.

Bacteria are found in the degenerating tissues and some gumming usually takes place. It has been fairly satisfactorily established that the Australian disease is due to Bacterium vascularum, and it is separately described on another page. J. H. Wakker found in Java several kinds of bacteria present, and that the condition is associated with abundant rain and high atmospheric humidity. Wakker's view is that some disorganization is first produced by too rapid growth, which then renders the tops susceptible to bacterial infection.

In Porto Rico the condition described as top-rot usually occurs in over-ripe cane, but it is observed that some varieties rot back after maturity much more quickly than others. This type of rot occurs particularly in dry weather.

In the froghopper blight of Trinidad the cessation of growth at the tip of immature shoots, brought about by excessive injuries to the leaves, is followed by reddening of the region about the growing point and watery degeneration and death of the soft upper joints enclosed in the bud. This, and similar injury arising from root disease or borers, has been called top-rot.

Top-rot in general is obviously no more than a term for the soft-rotting of the enclosed termination of the stem, and like the similar bud-rot of the coconut palm includes conditions in which similar symptoms arise from very different causes.

\section{Gumming Disease, CobB's Disease.}

The disease of sugar-cane caused by Bacterium vascularum (Cobb) E. F. S. has been recorded in the West Indies only from Porto Rico (I920), and such accounts of top-rot as have appeared do not suggest that it has so far occurred in the British islands.

The disease was first adequately described by N. A. Cobb in Australia, where it occurs in New South Wales and Queensland. An affection with identical symptoms has been reported from Brazil. It is also recorded from the Fiji Islands, Mauritius, Java, Borneo and New Guinea, and is suspected to occur in the Argentine.

\section{Symptoms.}

The specific symptom of the disease is the appearance in the vascular bundles of a yellow slime and a red stain. When infested stalks are cut across so as to leave a smooth surface, 
a yellowish gummy ooze collects in droplets on the ends of the severed bundles. This material dries to a bright yellow stain. The disease is primarily one of the vascular system, but in advanced stages the parenchyma is attacked, especially just below the terminal bud, and cavities are formed which are filled with the yellow bacterial slime ; this may also ooze from the stomata of the inner surface of the leaf-sheath.

The external signs of the disease are various degrees of dwarfing, striping of the leaves, drying of tops, and decay of the terminal bud (top-rot).

Inoculations which demonstrated the causative connection of $B$. vascularum with the disease have been described by E. F. Smith. Wilbrink has recently investigated bacterial vascular disease as it occurs in Java, where it is characterised by external and internal symptoms similar to those of Cobb's disease, with the important exception that no gum nor slime is produced by it in the canes. The bacterium does not develop gum in pure cultures, but resembles $B$. vascularum in other physiological characters.

\section{Incidence.}

Condition of soil, other than lack of drainage, is said not to influence the prevalence of the disease. Canes rich in sugar, grown on good land, are subject to it. The evidence suggests that infection in any way from stool to stool is not very active, but that the extension of the disease mainly comes from the planting of diseased sets. Both in Brazil and in Australia the disease proved exceedingly destructive on susceptible varieties.

\section{Control.}

The means of control consist in the planting of resistant varieties, some of which are nearly or quite immune, or, where the cultivation of susceptible canes is continued, the careful selection of healthy sets, rotation of crops, and provision for good drainage.

\section{SMut.}

The Smut disease, due to Ustilago Sacchari, Rab., is common in the East on the thin canes of the Indian type. C. K. Bancroft reports its presence in British Guiana, stating that little damage has been attributed to it. It is often quoted as occurring in Trinidad, but the reference usually given, to $O$. W. Barrett's record that " a leaf rust, probably Ustilago sacchari, was very common " is obviously worthless. No other record in the West Indies is known to the writer.

The disease is at once recognisable by the occurrence of a long, curved, whip-like shoot, often several feet in length, at the apex of the cane. This abnormal growth, which probably 
represents a flowering shoot, is at first covered by a silvery white sheath, which soon ruptures, exposing the spores as a dense mass of black dust.

Direct infection by spores appears to take place at the nodes, and sets containing the mycelium give rise to infected plants. The spores germinate in water or moist soil and give rise to sporidia, which develop yeast-like budding cells.

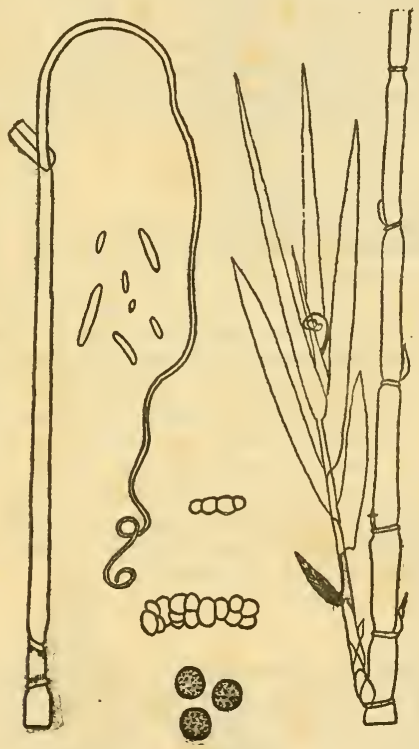

Fig. 126 Ustillago SACChaRI

From Wakker \& Went

SCHIZOPHYLLUM ROT.

The conspicuous fungus Schizophyllum commune, Fries., is everywhere common on dead cane as on various dead branches, bark and other vegetable material. It is sometimes seen on standing cane, especially the dried or half-dried stalks met with in reaping and known as " rotten cane." There is no reason to believe that it ever occurs apart from previous serious injury by borers or by other fungi, except perhaps on cane very much over-ripe and beginning to dry up by reason of age. 


\section{The Iliau Disease.}

The name Iliau, from an expression meaning " hide-bound " is given to a disease endemic in Hawaii and regarded by H. L. Lyon, who investigated it there, as having caused more loss than all other cane diseases combined. The affection is also common in the more northern parts of Louisiana. The effects are liable to be confused with a common symptom of root disease, and the fungus with Melanconium Sacchari, so that very possibly the affection occurs unrecognised in these islands, but the fact that it assumes importance in Hawaii only in periods of continuous cool damp weather would seem to exclude its appearance as a serious trouble in the sugar-cane districts of the West Indies.

\section{Symptoms.}

Iliau is entirely a disease of young shoots, which are attacked from the soil, and mainly affects the leaf-sheaths, which become very tightly cemented to each other and to the surface of the underlying stalk by the growth of a mat of white mycelium in and between them. The adhesion is much more firm than that produced by Marasmius and the rind is entered to some extent. Further useful growth of the shoot after this condition is attained is entirely prevented, though the stem is often found variously bent or doubled by the elongation of the joints while the tip is firmly held. Sometimes the shoot grows through before the barrier is firmly established. Large numbers of young shoots, both in young and older stools, are killed out in this way. Older shoots are not injured. Much more damage is done to plant canes than to ratoons.

\section{Causation.}

The disease has been demonstrated by experiment to be due to a fungus which has an ascigerous stage, Gnomonia Iliau, Lyon, and a Melanconium stage, $M$. Iliau, Lyon. The former is the commoner form in Louisiana, the latter in Hawaii. The perithecia are flask-shaped, immersed in the substance of the leaf-sheath, with long, hard necks which project from the surface. The spores are spindle-shaped, with two cells. The Melanconium closely resembles $M$. Sacchari in general appearance, but the spores are larger $\left(7-10 \times I_{5}-28\right)$, and are usually filled with large globules which are quite distinctive.

\section{Control.}

Immune varieties are not known, but the Demerara seedlings grown in Hawaii are the most resistant. Thorough preparation is recommended as a very efficient measure for reducing damage. 

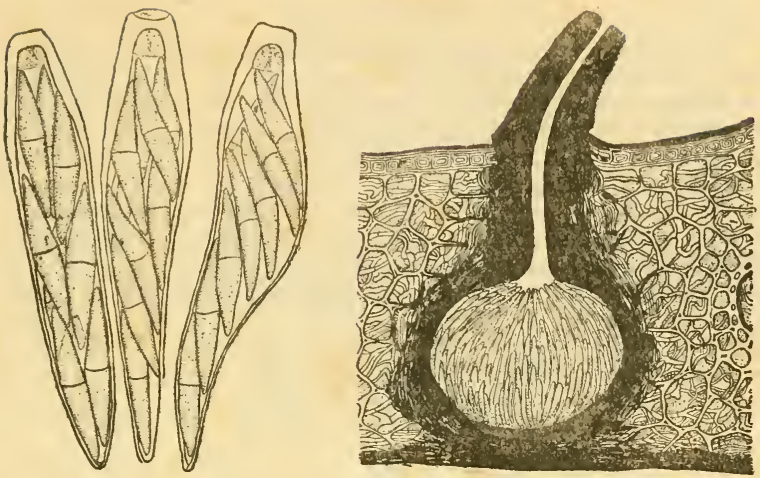

Fig. 127

Gnomonia Iliau, Vertical Section of Perithecium and Asci From Bull. II, Dept. Pathology, H.S.P.A.
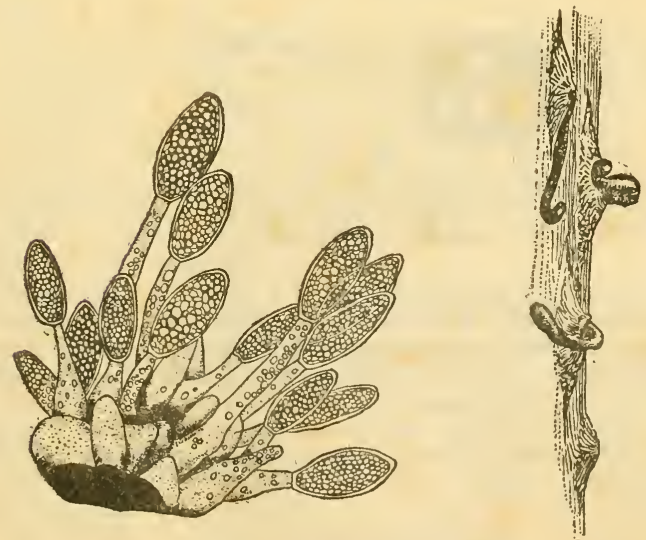

Fig. 128

Melanconium Iliau. Stromata and Conidia From Bull. II, Dept. Pathology, H.S.P.A. 


\section{CyTOSPORA Rot.}

The fungus Cytospora Sacchari Butl., originally described from sugar-cane in India, has been found by J. R. Johnston on certain susceptible Barbados seedlings in Porto Rico, causing an affection of young shoots very similar in its nature and effects to the Hawaiian Iliau disease, but producing also nodal infections on older canes. The fungus occurs in Barbados, but is not known to be injurious. The leaf-sheaths of young shoots are firmly bound together by the mycelium : their exposed portions take on a very dark, dull red colour, and are profusely covered with the pycnidia, the comparatively long pointed necks of which

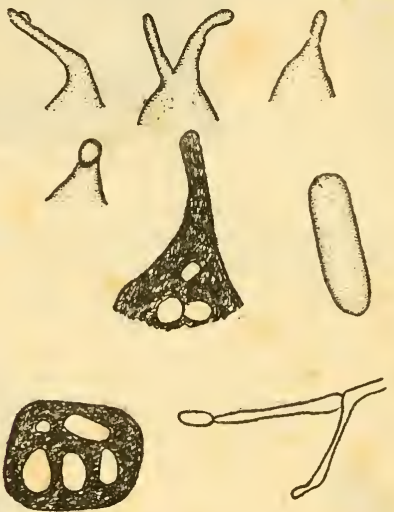

Fig. 129

Cytospora Sacchari: Surface and Sectional Views of Pycnidia; SPORE AND SPOROPHORE

From Memoirs, Dept. Agri., India

project beyond the surface sufficiently to be readily seen, and to give a rough sensation when the finger is passed over them. During wet weather a minute yellowish globule of conidia exudes from the tip of the beak. The spores are cylindrical and slightly curved, obtuse at both ends, $3.5 \times \mathrm{I}-\mathrm{I} .5$ microns.

With the elimination of the susceptible varieties in Porto Rico no further evidence of parasitic activity on the part of this fungus has been seen.

\section{Leaf Sheath Rot}

Under the name of "rood rot" (red-rot) this disease has been known from Java since $r 890$ It is generally distributed 
there, but is more common in the hills, where the moisture is greater. It is not uncommon in some districts in Barbados, is reported as very common in Porto Rico, and has been recorded from St. Lucia, St. Croix, and Trinidad. The fungus is very generally distributed through the islands and no doubt occurs at times on sugar-cane in all of them, but it nowhere attracts much attention.

\section{Causative Fungus.}

The fungus to which the disease is due produces an orange or brick-red discoloration of the leaf-sheaths, often on young shoots. It is distinguished by a copious white radiating mycelium, on which occur as it matures large numbers of white to brown spherical sclerotia like small seeds. The fungus has been shown by cross inoculations to be identical with Sclerotium Rolfsii Sacc. described under the heading General Diseases.

\section{Nature of the Attack.}

There is no doubt as to the parasitism of the fungus. The mycelium spreads over the surface and penetrates the tissues of the leaf-sheath by way of the stomata. On young shoots the leaves and even the stem may be more or less affected. Infection apparently always proceeds in the initial stage from the soil, where it is assumed to be carried over by the resistant sclerotia.

Effects.

The extent of the damage caused by the fungus on sugar-cane is uncertain. Some planters attribute considerable importance to its presence on young shoots, which are dwarfed and reduced in vitality by its attack. On the other hand it is reported from Porto Rico that in one instance careful observation for six months of a field in which it was growing vigorously owing to the wetness of the season revealed no visible difference in the condition of infested and uninfested stools. The fungus develops only under moist conditions.

\section{Red Spot of the Leaf-Sheath.}

This is the most general of the diseases attacking sugar-cane in the West Indies. In many districts it is difficult to find a shoot which does not show more or less evidence of its presence. It occupies a similar position in Java.

The affection appears on the outer leaf-sheaths as a large bright red patch, commonly somewhat oval in shape, but illdefined, with a dark brown spot of dead tissue in its centre. Under this spot, by pulling off the successive leaf-sheaths, one may trace the infection inwards, in the form of red spots which are smaller and smaller until only a red dot appears at the 
limit of penetration. The spots are caused "by the fungus Cercospora vagina Kruger, the progressive stages in the development of which are represented in the series just described. The mycelium of the fungus grows in the tissue of the leaf-sheaths, to which it gains access by way of the stomata, and by passing from one to the next penetrates towards the middle of the shoot. The brown central portion of the oldest spots marks the tissue finally killed by the fungus. Upon it is found a brown external mycelium with short upright branches, which at their tips produce the elongated narrow conidia. These readily and quickly infect other leaf-sheaths to which they may happen to be borne.

The damage done by the fungus is inappreciable. It finds its nourishment in the tissues lying between the vascular bundles, and the latter are little if at all affected until a rather late stage in the development of the spot.

The newer leaf-sheaths become infected so early from the spots on the older ones that stripping would usually be rather useless. The use of top-plants undoubtedly helps to carry over the fungus, since traces of the infection may usually be seen upon them. Unless the fungus can be shown to have more importance than is usually attributed to it its presence does not afford a reason for the discouragement of the use of such plants.

\section{Ring-Spor.}

The leaf disease known as ring-spot was investigated by Breda de Haan about the year I893 in Java. It occurs in India, the Hawaiian Islands and other Eastern localities. In the West Indies it has been definitely recorded from Cuba, San Domingo, Porto Rico, Antigua, Barbados, Trinidad, British Guiana and Surinam, and probably occurs in all the islands.

\section{Causation.}

The disease is caused by a parasitic Ascomycete Leptospharia Sacchari Br. d. H. It has two spore forms. The conidia are curved bodies consisting of a central cell with one or two smaller cells at each end. They are capable of infecting leaves upon which they come. The ascospores are formed later in small perithecia, which appear as black dots in the substance of the leaf near its upper surface; the spores are four-celled, the terminal cells with thinner walls.

\section{Symptoms and Incidence}

The spots are generally most abundant towards the outer end of the older leaves, giving rise when abundant to a general rusty appearance. The spot starts as a purplish fleck on the surface, which as the fungus grows expands outwards and dries up in the middle, so that it comes to consist of a small brown or yellowish patch enclosed by a purple or brownish band, with 


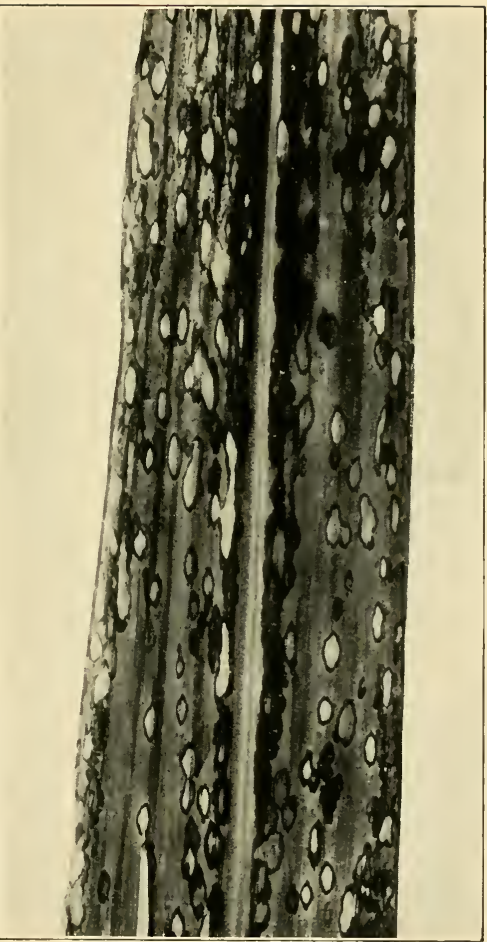

Fig. 131

Ring Spot of Sugar-cane (Leptosphaeria Sacchari) 



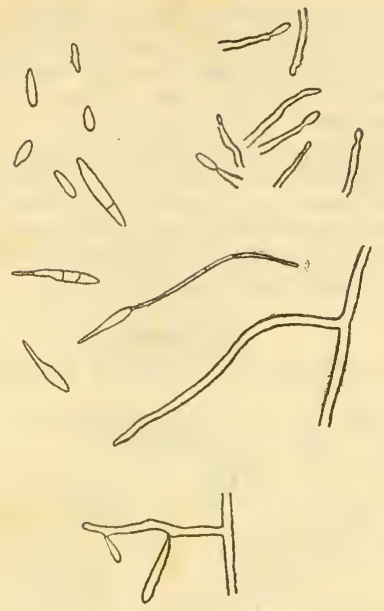

Fig. 130 Cercosyura VAginae From Wakker \& Went
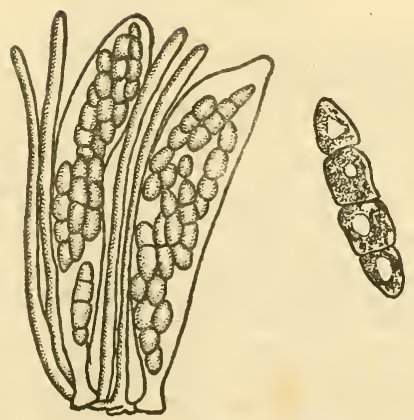

Fir. 132 Lertosphaeria Sacchari. Asci and Spore From Memoirs, Depl. Agri., India 
sometimes a faint yellowish outer margin. The spots are irregular in shape, somewhat elongated in the direction of the length of the leaf, usually less than half an inch in length, but often confluent. When they are abundant they are apt to cause premature death of the whole leaf.

Marked local epidemics sometimes occur in moist weather. When the infestation occurs on mature canes, as it often does, no considerable harm can result, but earlier outbreaks when at all severe must administer a somewhat severe check to growth. Their occurrence is usually so erratic that they cannot be anticipated by any preventive measure.

\section{EYE-SPOT.}

The eye-spot disease of the leaves was originally reported

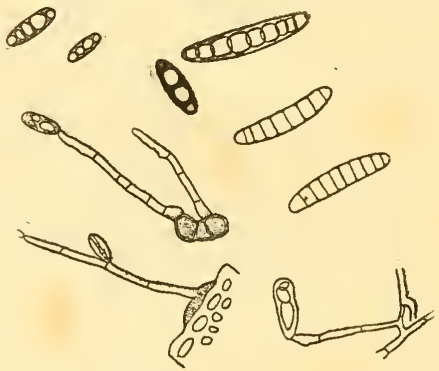

Fig. 133 Helminthosporium Sacchari From Memoirs, Dept. Agri., India

from Java, the fungus being named Cercospora Sacchari $\mathrm{Br}$. d. $\mathrm{H}$. It is now usually admitted to be a Helminthosporium and is probably identical with $H$. Sacchari Butl. found in India. The affection is known to occur in Cuba, Jamaica, Porto Rico, Barbados and Trinidad. In the last-mentioned island C. B. Williams reports that during the last few years it has been found only on D Iog in certain small areas, and only exceptionally appears before the month of December. In I9I9 a severe local epidemic two or three months earlier than this soon passed off. The affection takes the form of elongated spots and streaks, red to dark brown in colour and developing a straw-coloured centre. In severe infestations they are crowded together and the leaves are so generally discoloured that the stools have a blighted appearance. In such cases the spots may be found even on leaves just unfolded, and a distinct check to growth can be detected.

The conidiophores are stout, erect, rather rigid hyphæ, 
produced from small stromatic masses on the surface of the spot. The conidia are cylindrical or long elliptical, with very thick walls, olive green to brown in colour, 3-ro septate.

\section{RED LEAF-SPOT.}

Red leaf-spot, originally described from Java, is recorded
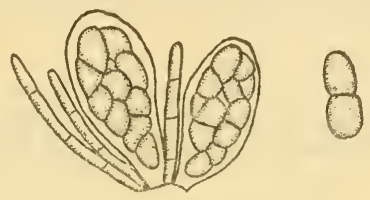

Fig. 134 Eriosphaeria Sacchari, Asci And Spore From Wakker \&. Went

from the West Indies by Went in Aruba Island and L. H. Gough in Trinidad. It is caused by an ascomycete with round black perithecia and two-celled spores, Eriospharia Sacchari Went.

The spots are roundish except when two or more interfere. They begin as red dots with a yellowish border; when mature they are reddish-brown, surrounded by a narrow yellow border that is sometimes scarcely visible. The centre of the spot does

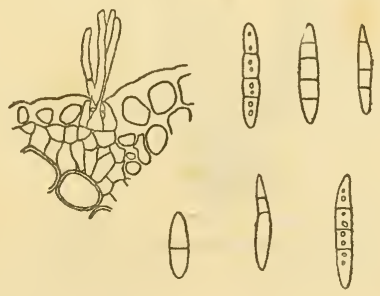

Fig. 135 CERCOSPORA KOPKEI From Wakker \&. Went

not dry out, which serves to distinguish this affection from eyespot or ring-spot; from yellow-spot it differs in the narrowness of the margin.

\section{YelLOW LEAF-SPOT.}

The yellow leaf-spot, which is very generally distributed in Java without being the cause of notable damage, was recognised by Went in Barbados, Trinidad and Demerara. It is caused by Cercospora Kopkei Krug. 
The affection begins on young leaves and develops thickly sown irregular spots, bright yellow on the upper surface of the leaf, covered on the under side in moist weather with a dirtywhite web of hyphæ. Later the spots show red dots or stripes, and in individual instances may become dull red.

On the under surface bundles of short conidiophores project from the stomata and bear elongated hyaline conidia of varying length and with I-6 cells.

\section{BROWN LEAF-SPOT.}

Brown leaf-spot is recorded by Gough in Trinidad and as one of the rarer leaf-spots in Porto Rico by Johnston and Stevenson.

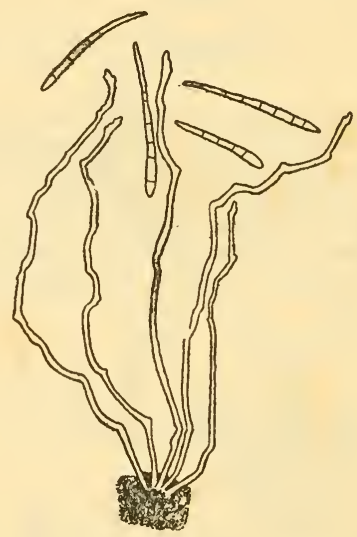

Fig. 136 Cercospora Longipes

From Memoirs, Dept. Agri., India

It is reported to be by far the commonest leaf disease on the thin canes of India, to which it is practically confined. The spots appear on the blade of the immature leaf and continue during maturity. At first they are narrow, oval, about $\frac{1}{8}$ inch in length, and reddish in colour. A brown centre early becomes evident, and a yellow border is formed, so that the spot is tricoloured. When fully developed the spots consist of a broad oval deep-brown ring, with a straw-coloured centre, the whole reaching to half an inch in length.

The causative fungus is Cercospora longipes, Butler. Long brown unbranched conidiophores, abruptly bent, form a velvety 
cushion on the under surface, and bear hyaline conidia with 5-7 cells.

\section{History.}

\section{SEREH.}

The Sereh disease caused in Java in the 'eighties of last century a crisis comparable with the effects of the "rind disease" epidemic in the West Indies. The disease received its name from the resemblance of seriously affected plants to bunches of lemon grass, the Javan name of which is Sereh. There is no reason to believe that the affection occurs in the West Indies, but as alarm concerning it has arisen from time to time, and in view of the possibility of its future occurrence, a brief description based on Went's account of the disease in Java is here supplied.

In the first years following its discovery the Sereh disease progressively extended over the greater part of the cane fields of the country, with serious results. A re-organisation of the industry on a scientific basis took place, and measures were found and adopted which made evasion of the disease possible. These are troublesome and expensive, but no direct remedy has been found to take their place.

\section{Nature of the Attack.}

The outward signs of attack are seen in changes in the habit of the plant, which may occur to very different degrees.

In the worst cases the internodes are largely or entirely suppressed, so that there are few stems of any length to be seen. The leaves are small and expand prematurely, and being crowded together in two ranks they give to the top of the shoot the appearance of a fan. Abnormally large numbers of shoots are produced from each stool. A thick network of roots develops under the leaf-sheaths of those canes which possess a stem.

In cases of less severity stems of normal length are produced, but they develop fan-like tops and many of the buds upon their sprout and form short side-shoots. As in the first type, roots develop along the stem. In the third and least severe type there is hardly any outward alteration beyond the formation of the characteristic short joints at the top of the stems.

An internal symptom which is common to all the types consists in the discoloration of the vascular bundles entering the stem from the leaf-sheaths, which are reddened for a longer or shorter portion of their course and under the microscope are found to contain a gummy substance. According to recent findings by H.M. Quanjer, necrosis of the phloem strands in the vascular bundles is a constant and fundamental character.

Starting with sound canes planted in an infected area the typical course of the disease on plant cane is that the first crop 
may be only slightly attacked, that from the first replanting much more severely, and the second replanting may be so badly affected that a whole field looks like a cultivation of lemon grass, with here and there a cane stalk rising out of the low grass-like clusters. Ratooned fields are almost invariably badly attacked

No parasitic organism has been shown to be connected with the causation of the disease, and it is now usually regarded as coming within the class of virus diseases.

It will be seen from the foregoing description that the actual symptoms of Sereh may be somewhat indefinite, and as a matter of fact the appearances described by Went can all be found exactly reproduced, including the reddening of the vascular bundles in the nodes, in stools affected by froghopper in Trinidad, and are more or less simulated by the results of other affections elsewhere. In no such case, however, has there been developed the progressive degeneration which is the essential character of the disease.

\section{Control.}

The system by means of which the disease is avoided consists in the use of cuttings raised in hill nurseries, which are not subject to the disease. The canes from these are reproduced in the plains for only two or three vegetative generations before they are again replaced with plants from the hills.

Mosaic Disease, Mottling Disease, Yellow Stripe Disease.

\section{History and Distribution.}

About Igr6 the existence of a serious epidemic disease on sugar-cane was noticed in the north-western quarter of Porto Rico. The affection was described by J. A. Stevenson under the name of mottling disease. Later it was found to be identical with the "gele strepenziekte" (yellow stripe disease) of Java, in which island it was described by J. H. Wakker in I896.

The disease was known in Java in 1890 , and circumstances point to its having then been present for many years. It was regarded there as due to recurrent bud variation. Elimination methods, and its operation as a factor in selection have restricted its prevalence. It occurs in Java on all types of soil and, with greater or less severity, on all kinds of sugar-cane except the wild species.

When attention was first attracted to the disease in Porto Rico, it was restricted to a single district, but it had then assumed epidemic form, and its spread was so rapid that in I9I9 more than three-fourths of the cane-growing area was invaded.

E. W. Brandes reports the finding of the disease in Cuba 


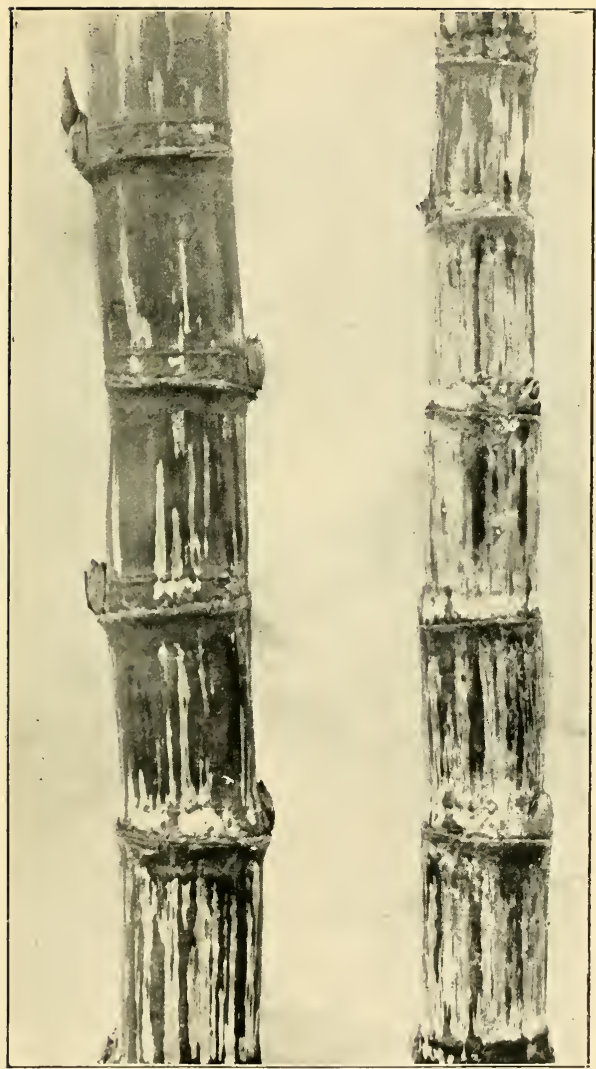

Photo by]

Fig. 137

C. B. Williams

Sugar-cane : Sten Canker 

in IgI9 at three separate points, at one of which it was believed to have been present for nearly twenty years. In 1918 the disease was found at many places in Santo Domingo, and it has been discovered in St. Croix on plants from Porto Rico.

A survey of the cane-growing districts of the United States, made in consequence of the discovery of the disease on planting material received in Porto Rico from Louisiana, has revealed its wide distribution in Louisiana and Florida, and its occurrence in the adjoining States. The river district of Louisiana was in I9I9 already badly infested, the proportion of diseased plants reaching 75 per cent. on some plantations.

At the St. Augustine Experiment Station in Trinidad the existence of a peculiar and abundant marking of the leaves on the plot of D 3956 was noted by C. B. Williams in I9I8 and I9I9. The adjacent plots appeared at this time to be practically free. Early in I920 the condition was recognised to be mosaic disease, and a survey showed that it was then more or less present not only throughout the Station but in the adjoining district for several miles east and west, while many new centres of infection had arisen on estates to which cuttings of selected varieties had been sent.

Early in I920 the disease was found to be widely prevalent in Jamaica in its typical form. It is now common in Barbados. In the Argentine Republic the disease is reported by G. L. Fawcett to have been present for many years. It is common on the Java canes there grown, which exhibit the symptoms to varying degrees, but are not prevented from giving satisfactory yields. Canes of the White Transparent type are uniformly affected and have suffered deterioration, which is not, however, attributed to the effects of mosaic disease. The Barbados and Demerara seedlings are worst affected, except D II35, which is the only one suited to local conditions.

\section{Symptoms.}

The one marked and constant primary symptom of the disease is the peculiar mottling of the leaves.

This is difficult to describe, but is seldom difficult to recognize after being once learned. Its commonest form is a general longitudinal streakiness of the green colour, caused by the paling of many small and ill-defined areas. It is hardly definite enough to be called spotting, and a form of whitish or yellow spotting is the appearance most frequently mistaken for it. It is often best seen by transmitted light, and may be quite conspicuous in the upper leaves as seen against the sky. In different cane varieties and under various conditions the amount of the normal green colour retained differs widely, in extreme cases being present itself as patches on a lighter background. On certain varieties in Trinidad the affected leaves as they grow old con- 
stantly develop reddish dots thickly scattered, but as a rule the variation is only from dark to pale yellowish or whitish green. Most of the doubtful cases can be determined by examining the young unfolding leaves, which always show symptoms if mosaic disease has infected that particular shoot.

In many varieties of cane the shoots when thoroughly infested show distinctive markings on the surface of the cane itself. On the younger joints (internodes) these are usually in the form of streaks or stripes, which may be pale yellow on green, or red on yellow. On older joints the surface may be marked with irregular whitish stripes, the development of which is followed by cracking and often by local shrinkage and drying out. The joints of infested canes tend to be short, and where the symptoms just described are prevalent there is great loss of weight.

In plants from infested cuttings a further symptom appears in the form of white opaque spots and streaks in the light-coloured areas on the leaves. These have no pigment whatever and range from pin-point spots to streaks several inches long. This white tissue remains firm and does not turn red or brown as do the pale spots caused by the feeding of froghoppers.

Fields planted with infected cuttings soon show pronounced dwarfing of growth, and a similar result is seen in ratoons of the more susceptible varieties which have become infected after planting.

\section{Influence of External Conditions.}

The disease occurs under all conditions of soil and climate. Cultivation, manuring, and the use of lime do not notably decrease its prevalence, but rather tend to bring the leaf markings into prominence.

\section{Losses due to the Disease.}

Regarding the losses which have occurred in Porto Rico, F. S. Earle stated in I9r9: "We are safe in concluding in a general way that when infection reaches an average of 60 to 80 per cent., losses of sugar will be from 30 to 40 per cent." A table published in the Hawaiian Islands in I9I2 showed losses due to this disease varying from 0.5 to 34 per cent., according to variety. In Jamaica S. F. Ashby records tonnage reductions, by comparison with healthy canes, of 33 per cent. in D II6 and 27 per cent. in Purple Ribbon.

The losses in advanced cases of the infestation of highly susceptible varieties extend to the complete failure of the crop ; in others to reduced yields in all degrees according to the proportion of stunted stools and rotted stalks. The affected canes have a tendency to be pithy and poor in juice, and on account of changes which follow the splitting of the internodes the behaviour of the juice is liable to cause trouble in the factory. 


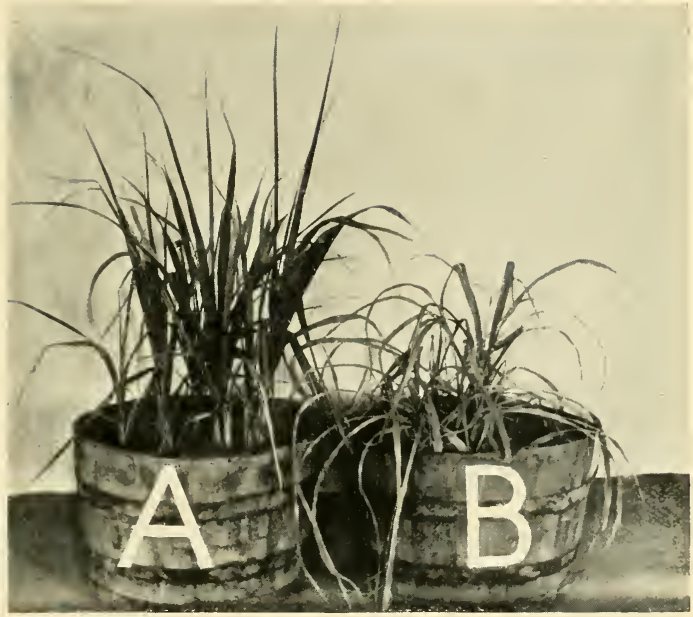

Photo by]

Fig. 138

[H. A. Tempany

ChIorosis of SUgar-Cane 

Causation.

No fungus or bacterium has been found to have any causative connection with the disease. The evidence points to its association with the affections caused by infective viruses, the existence of which is established in the mosaic diseases of tobacco, tomato, cucumber, bean, potato and other plants, and is strongly indicated in diseases such as sereh, potato leaf-roll, and curlytop of beet. (See Chapter III.)

\section{Communicability.}

Cuttings from affected plants invariably reproduce the disease, and it is in this way that it has been distributed about the world. The infection of healthy strains brought within the range of the disease shows clearly that it is in some way transferable. Contact alone does not produce this result, nor is there any evidence that the infective principle resides in the soil.

Healthy cuttings planted in fields or in pots from which badly diseased plants have been recently removed are not infected. The spread of the disease by infection is observed to be very erratic, rapid at one time or place, slow or absent at another. The evidence points to distribution by a carrier, probably an insect. E. W. Brandes, in greenhouse experiments at Washington, has proved transmission of the disease from sorghum to cane and corn by Aphis maidis. Extensive experiments in Porto Rico with all the common insects found on sugar-cane have, so far as reported, had only inconclusive results, as the infections obtained (with cane-fly, leaf-scale, yellow aphis, and mealy-bug) were so few that chance infection is not certainly excluded from their origin. No infections were secured in experiments made by C. B. Williams, in Trinidad, with several insects, including the frog-hopper (Tomaspis). Cane-fly and aphides are exceedingly rare on sugar-cane in Trinidad. In that island there is little or no evidence of infection in dry weather, but rapid extension of the disease becomes apparent a month or two from the beginning of the rainy season.

Artificial infection tested in many ways has only proved successful when juice exprejsed from affected plants, with precautions against oxidation, has been directly inoculated into the tips of growing canes, and with this method positive results have been difficult to obtain.

\section{Resistance and Susceptibility.}

In Porto Rico all the standard varieties, and all the local, Barbados, and Demerara seedlings are attacked. The Bourbon cane is exceedingly susceptible and the Striped (Rayada), White Transparent (Crystalina), and Yellow Caledonia, all of which are grown in quantity in the island, are severely injured. Certain seedlings imported from and much favoured in Java (P.O.J. 
Series) show a high degree of endurance of the disease, suggesting that this character has influenced their selection. They become generally but lightly infested, and make an apparently normal growth.

Perfect immunity exists, it would appear, only among canes of the thin Indian type. The well-known Uba cane, the only one of the type adopted in the West Indies, has been severely tested without developing any symptoms of infection. The references to "Kavangire" by Porto Rican and American writers on the disease really apply, according to more recent information, to Uba, introduced by way of the Argentine to Porto Rico.

According to Brandes, corn, sorghum, rice, millet, crabgrass, foxtail, and Panicum have been found to be subject to infection, but are stated to be attacked with difficulty, contracting the disease when grown in the close neighbourhood of diseased cane. In Trinidad appearances strongly suggestive of mosaic have been seen on corn and on so-called "corn-grass" (Manisurus exaltata).

\section{Control.}

Uninfected regions should be protected by careful quarantine, with special precautions against introduction on highly resistant varieties, which may transmit the disease without showing signs of infection in themselves.

Light infestations may be dealt with by pulling up the affected plants. There is no need to burn or otherwise destroy them beyond taking precautions against the resumption of growth, as wilted plants are no longer infective.

Severe infestation should be dealt with by the thorough clearing of the fields after crop, followed by the use of disease-free material for replanting. If a rotation crop is interposed, the security will be greater against reinfection from growing fragments of the old stools.

\section{Chlorosis, Gall Patches, Moonshine.}

Chlorosis as known in the West Indies is a condition regularly induced in cane planted on certain restricted patches in limestone districts, in which the leaves become exceedingly pale in colour or even milk-white. In addition to these permanent locations, the condition may be manifested more or less over wider areas in wet years. Chlorosis of this type is reported from Cuba, Jamaica and Porto Rico; it occurs to a small extent in Barbados, and is particularly well-marked in Antigua, where the areas subject to it are known as gall patches. H. A. Tempany has shown that the condition is due in Antigua to the presence of soluble material, indicated by analysis to be sodium carbonate (" black alkali"). This is believed to originate from interaction between the calcium carbonate of the soil and sodium chloride brought up in solution 
from saliniferous deposits at deeper levels. The condition is thus not dependent on an excess of lime, as is sometimes supposed, but on the presence of salt in the soil water, a conclusion which agrees with the observation that cane will grow quite normally on soils with a higher lime content than those affected.

No permanent remedy has been found. Experiments in Porto Rico have shown that temporary recovery of colour follows the application of iron salts.

In order to complete the review of diseases attacking the sugar cane, a brief account is added of two diseases which have been recognised in the Pacific Region for a number of years, but, as in the case of Sereh, are not known to occur in the West Indies; these are the so-called Fiji Disease and the Sclerospora disease.

\section{Fiji Disease.}

This disease owes its name to the fact that it was discovered in the Fiji Islands (about I905), where it threatened the stability of the industry ; it was found later in Australia and New Guinea, and more recently in the Philippines.

The unique and characteristic symptom of the disease is the occurrence of elongated swellings or galls on the under sides of the leaves ranging in length from I/I2th to several inches and restricted to the large veins. According to H. L. Lyon, similar galls may be found in the vascular bundles of the stems. A stalk may grow to a considerable length and develop a succession of galled leaves, otherwise normal in appearance; finally and rather suddenly, only short crumpled leaves, often reduced to stumps, unfold from the spindle, growth ceases, and the death of the stalk follows. After the disease has appeared on a single stalk the whole stool becomes involved and finally succumbs. The disease is invariably transmitted in cuttings from affected canes, and the soil may carry the infection for a time with the result that susceptible varieties may make practically no growth when planted in such soil. No immune variety of cane has been found but the New Guinea cane Badila is strongly resistant and is now the most widely planted kind in Fiji. The disease has been brought under practically complete control in Fiji by rigid selection of cuttings only from healthy stools; experience has shown that this selection must be maintained even after disease has been reduced almost to the vanishing point. Plasmodium-like bodies occur regularly in the cells of the galltissue and this observation has led to the belief that Fiji disease might be due to a slime-mould (myxomycete) related to Plasmodiophora brassica Wor., the well-known cause of club-root in plants of the order Cruciferæ. 
Sclerospora Disease.

This disease was described for the first time by Miyake, in Formosa, where it appeared in I909. It is believed, however, to be the same as the leaf-splitting disease known earlier in Australia and Fiji. It was introduced into the Philippines, apparently in cane cuttings from Formosa. The earliest symptoms on the leaf show as a few yellowish stripes parallel with the veins; the stripes increase in number until the greater part of the leaf turns pale and becomes marked by scattered long reddish-brown spots. At the same time a fluffy growth appears on the under surface and the leaf dies and dries up or before dying becomes torn or shredded at the tip. In some varieties of cane the internodes may be much lengthened or thickened and diseased stalks may be 2-3 feet longer than uninfested stalks. The cause of the disease is a downy mildew-Sclerospora Sacchari Miyake, which sporulates abundantly on the under sides of the leaves during the night. The disease is transmitted by infected cuttings and from plant to plant under humid conditions by means of the air-borne conidia. Maize and teosinte (Euchlona Mexicana) become infected readily but endure the disease better than cane. Attempts have been made to control the disease by roguing the young plants which have arisen from infested cuttings before the spores of the fungus are developed on the leaves, and by careful seed-piece selection from uninfected stools. If Sclerospora disease reached the West Indies it would find difficulty in maintaining itself in the islands having a dry climate. 


\section{CHAPTER XXVII}

\section{DISEASES OF ROOT CROPS.}

\section{Cultivated Aroids.}

Although species of Colocasia (dasheens and eddoes) and Xanthosoma (tannias or cocoes) are widely grown as provision crops there is little record of their liability to disease in the southern West Indies. An undescribed affection known as "el mal" occurs in Porto Rico, and S. F. Ashby has given an account, summarised below, of a disease of cocoes in Jamaica.

\section{DRY-ROT OR SALTPETRE.}

This is a frequent disease of the tubers of Xanthosoma in certain parishes of Jamaica, affecting mainly the variety "Commander."

\section{Symptoms.}

Leaf development is backward, and the outer leaves have a tendency to wilt and to become infested with weak parasites, which produce large pale dry spots.

In diseased tubers the vascular strands are discoloured yellow or brown. Splits in the internal tissue are frequent, and when these extend to the surface cavities are formed which become infested with various scavenging insects, mites, and worms. Such cavities may come to occupy half of the tuber or more, leaving the cortex as a relatively sound shell.

\section{Causative Fungus.}

The yellowed vascular bundles are infested with a mycelium of colourless septate hyphæ abundant in the spiral vessels. In the darker strands this mycelium bears long chains of conidia or gemmæ of a yellow or brown hue, generally longer than broad with rounded ends and narrowing in the middle. Neither hyphæ nor gemmæ have been seen outside the vessels. They are well seen in the large vessels of discoloured roots.

The fungus is described as Vasculomyces xanthosoma Ashby. Its action is similar to that of the Fusariums causing wilt diseases, the subsequent rotting being due to the admission of secondary organisms. 
A Jamaica disease resembling this in most particulars was attributed by G. Massee in I887 to a fungus named by him Peronospora trichotoma.

Control.

Certain varieties are immune to the disease and may be safely grown on infested land. Susceptible varieties should only be planted on clean land, and care must be taken not to introduce infection with the planting material or with instruments used in cultivation.

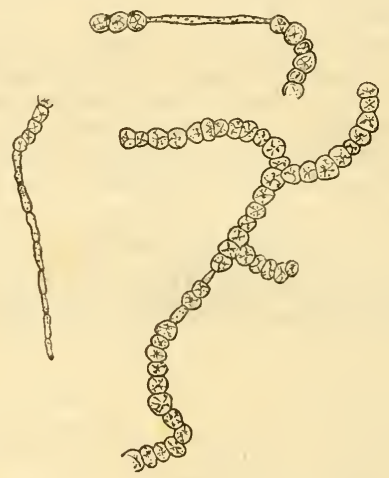

Fig. 139 Vasculomyces Xanthosomae Bull. 6, Dept. Agri., Jamaica

In Jamaica and more recently in Hawaii a disease of Colocasia sp. (taro) has been attributed to a species of Pythium.

Arrowroot.

Burning Disease (Rosellinia).

In I89I specimens of arrowroot rhizomes from St. Vincent affected by a disease knowning as " burning" were examined by H. Marshall Ward. They were reported by him to be badly affected by a subterranean fungus mycelium, and to have produced conidia in the manner of the genus Spicaria when kept in a damp chamber.

No further outside attention seems to have been given to this affection until South, after a visit in I9II, gave an account of it in an unpublished report. He described the disease as occurring in the fields in patches varying in area from a few to several 


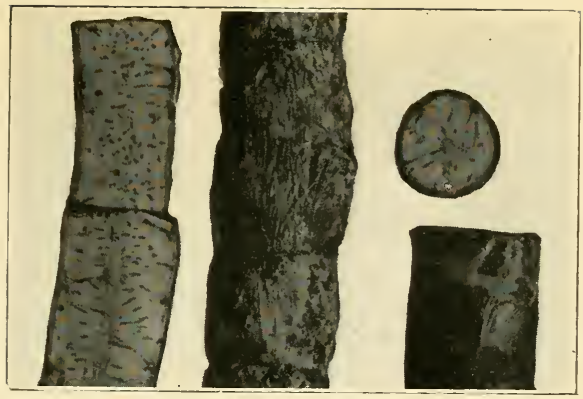

Fig. 1+11

"Burning Disease" of Arrowroot

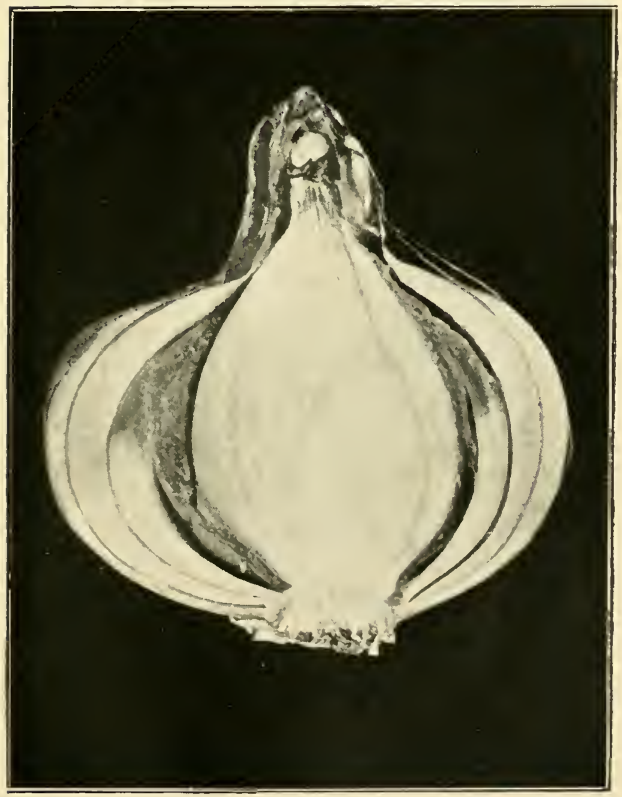

Fig. 141

Bacterial Rot of ONion

Bull. I64, Nere York Agri. Expt. Sta. 

hundred square feet, and constant in position from year to year. The symptoms do not make themselves apparent until the rhizomes are nearly ripe for digging. At this time the affected plants have fewer leaves than the healthy ones growing in their vicinity, and these leaves are often rolled up and somewhat wilted. Extension of the patch is very slow, but the fungus is very persistent, and the disease was reported to have reappeared in the first crop on a field replanted after remaining in bush fallow for twenty-five years.

In I9I5 the present writer visited a field in which the rhizomes had recently been dug and were lying in small heaps on the ground. The material from a diseased patch was conspicuous owing to the black discoloration of the rhizomes. Towards the base of the heaps sufficient moisture had been retained for the fungus to continue growing, and there were woolly tufts and strands of greenish grey mycelium, undoubtedly that of a Rosellinia, and an abundance of the typical conidial fructifications. Allowing for the difference in structure of the two plants, the appearance of the mycelium in the rhizome corresponds exactly to that of $R$. bunodes in lime roots, that is to say, the mycelial strands are identical and their distribution throughout the relatively soft tissue of the arrowroot rhizome is similar to that seen in the bark of the lime. South records the presence of perithecia of $R$. bunodes on other plants in close proximity to a diseased patch.

On the exterior of the arrowroot rhizomes as seen when they are dug there is little or no loose external mycelium. When such does occur, the hyphæ are of the usual "varicose" type. On the surface of both rhizome and scale leaves there is a dense scatter of shiny raised dots and ridges (less than I to about $3 \mathrm{~mm}$. in diameter) consisting of compact aggregations of dark hyphæe in the superficial tissue. From these the slender compact branching strands, black with a white core, radiate through the parenchyma both of the scale leaves and of the rhizome.

In the latter they mostly follow a radial course, and are conspicuous to the naked eye as black dots and lines in a section. At this stage the rhizomes are still full of starch. At an early time on the scale leaves, and later on the rhizomes, the black spots tend to run together until the whole surface is black and shining, and about this time the parenchyma of the rhizome may be found generally infested with hyaline hyphæ and depleted of its starch.

The special characteristics of the disease on arrowroot are: (a) that the disease occurs in patches which are reported to show little or no observable increase from year to year; $(b)$ that in such patches the disease persists for a long and apparently indefinite period of years.

The explanation of these features is probably to be found in the methods pursued in arrowroot cultivation. The fields are 
usually kept in this crop for many years in succession, and, although the crop is an annual one, the ground is never clear of plants. In the first place it is impracticable to remove the smaller fragments and offshoots of the rhizomes from the ground, as shown by the large number of plants which spring up after a change has been made to some other crop, and, secondly, it is the custom when digging the rhizomes to break off pieces and return them to the soil, to provide plants for the succeeding crop. The persistence of the disease, under suitable circumstances of soil moisture, may with great probability be thus accounted for, and it is helped by the custom of leaving the diseased rhizomes to decay on the spot. The fungus attacks the plants of almost any crop which succeeds arrowroot on the diseased patches, but there is no evidence of its persistence on such a crop after the arrowroot has been completely eliminated.

Its origin, as regards the primary patches, probably goes back to the cases appearing when the land was cleared of trees. One can readily conceive of secondary patches occurring, due to careless disposal of diseased material, or to the germination of spores on any accumulation of decaying tops or weeds sufficient to give the fungus a start.

Accurate and systematic observations, involving measurement of the extension of the patches, are wanting, but it does not appear from the evidence available that the fungus makes much progress from plant to plant in the soil, and there are no spreading roots to conduct it as in the case of the tree crops.

\section{Control.}

All the plants in a diseased patch and on its margin should be carefully dug out, dried as far as possible, and burnt with the aid of added fuel. The spot should be left fallow in the succeeding crop, kept clean-weeded, and forked from time to time. Lime should if possible be liberally applied. Any diseased trees on the land should be disposed of as directed in the section on Rosellinia diseases in general.

\section{Cigar Disease.}

In I900 a disease of arrowroot in St. Vincent producing a condition known to planters as " cigar root" was reported on by A. Howard. It has not been further investigated, but the writer has recently learnt that it still occurs and renders necessary the restoration of invaded fields by the use of planting material from uncontaminated sources, and in severe cases causes the fields to be thrown out of cultivation in this crop.

On the estate visited by Howard the affected plants first appeared in a section irrigated by the effluent from the starch factory and later spread widely through the various fields. 
These plants continued in an active state of growth when normal plants had ripened.

The affection produces an attenuated condition of the rhizomes, which develop long internodes and abundant roots. The yield of starch is small and difficult to extract.

Microscopic examination showed that the cells contained few normal starch grains in the older parts, but many corroded grains in all stages of disintegration. Preliminary studies suggested that the active agent in this was a filamentous bacterium which was found to be abundant in the slime deposited by the mill water.

\section{Cassava.}

Cassava is very widely grown in the Lesser Antilles, but seldom on a very large scale. It is grown for starch manufacture in St. Vincent and is used to some extent as a rotation crop on sugar estates in Barbados; a few years ago attempts were made to extend its cultivation in Trinidad.

Apart from injuries due to insects and mites no disease of serious importance has been met with on this plant.

\section{WITHER-TIP.}

A wither-tip and dieback disease apparently due to a Glœosporium occurs occasionally in Barbados, on plants with reduced vigour, and has been seen to follow on defoliation by caterpillars. The fungus is probably Glocosporium manihot Earle, known as the cause of a similar disease in the United States and Porto Rico.

\section{LEAF-SPOTS.}

A bacterial leaf disease occurs in Barbados in which a distinct varnish-like deposit of bacteria appears on the surface of the angular leaf-spots produced.

Two leaf-spot diseases unidentified are reported to be prevalent in Trinidad. A leaf-spot due to Cercospora henningsii,
All. is common in Porto Rico.

Under appropriate circumstances cassava is liable to be killed by Rosellinia root disease.

Onion.

\section{BACterial SOFT-Rot.}

Onions in the West Indies as in North America are liable under certain circumstances to a soft-rot of the bulb scales caused by bacteria of the Bacillus carotovorus type. Very heavy losses were experienced on some estates in Barbados after a wet season in I904, and in the islands where onions are now grown on a large 
scale, as in Antigua and Montserrat, the affection is occasionally troublesome.

\section{Symptoms.}

The disease may become prevalent in the fields about reaping time, or during storage or transit of the harvested crop. Usually the rot starts at the neck of the onion, and it may be confined to the heart, to one or more scales enclosed between others which remain sound, or the outside may be sound with the whole interior decayed, or vice versa. The organism is unable to penetrate the epidermis and only passes from one scale to another by way of the base. The presence of the rot may often be detected by a reduction in resistance to pressure.

\section{Conditions of Occurrence.}

Various kinds of injury can induce the appearance of the rot, but the scale of its occurrence in the field is generally determined by the prevalence of wet weather during ripening and by conditions as to moisture generally. Good drainage and open clean cultivation tend to reduce it. Careful harvesting, curing, and packing, and good ventilation of the place of storage lessen the losses subsequent to reaping. Experience in Montserrat leads to the conclusion that not only are onions grown under wet conditions more liable to decay in the field, but that they suffer much more during storage and shipment than the lots which are grown in drier situations.

\section{Sweet Potato.}

To a reader familiar with the long and formidable list of sweet potato diseases occurring in the United States the absence of recorded diseases of this important vegetable in the West Indies will appear remarkable.

So far as the storage rots are concerned the explanation is to be found in the fact that these are so much more severe under tropical conditions that storage for any considerable period is not practised. A somewhat similar explanation is probably true in part of field diseases; under conditions where they become severe the sweet potato is not grown. The chief area of production is the dry and open cane land of Barbados. A third reason may, perhaps, be found in the existence of sweet potato cultivations in America on the margin of the climatic range of the plant.

\section{WHITE RUST.}

Effects on the leaves ranging from small spots to considerable pocket-like distortions are caused by infestation with the fungus Albugo I pomoece-pandurance (Schw.) Sw. White, somewhat waxlike swellings appear under the epidermis, and this eventually 
bursts to expose the pustules of the fungus, which produce masses of white spores.

Young stems are to some extent attacked, and S. F. Ashby has found in one district of Jamaica the potatoes themselves bearing rounded mammillated galls which may exceed two inches in diameter, and are occupied by a stout non-septate mycelium with spherical haustoria bearing oospores characteristic of Albugo. The galls soon decay and spoil the appearance and keeping qualities of the potatoes.

The wild Ipomcea biloba, a common plant on sandy beaches, is often infested with a fungus assumed to be the same as the one on the sweet potato.

A true rust, Coleosporium Ipomoece Burr, is reported common in Porto Rico, but has not so far been noticed in the Lesser Antilles.

Yam.

\section{WILT.}

One or more wilt diseases of which the nature is as yet obscure occur in Antigua and Barbados and probably in other islands. Under certain conditions, in Barbados usually dry weather, the yam vines become black-spotted on the leaves and in sections of the stem and dry off prematurely in much the same way as they normally do at the end of the season. Several fungi are recorded in other countries, associated with black spotting of yam foliage, but careful and repeated examinations have not revealed any such on the Barbados material. The indications are somewhat more in keeping with a root disease.

\section{TUBER RoT.}

A rot of the growing tubers has several times been reported from Antigua in which browning and blackening of the tissues starts in spots and patches from the outside and leads to the production of large cavities containing pulpy remains of the broken-down tissues, and infested with fungi, bacteria, and scavenging insects. The decay apparently ceases to make progress after the yams are dug and stored, the rotted tissues being then found enclosed by layers of wound cork. Material showing the active condition of the disease has not yet been obtained, and infection experiments with cultures of the fungi found have had negative results.

\section{LEAF BLOTCH.}

A Cercospora leaf-spot is common on the yam in Trinidad, taking the form of large black blotches on the leaves. 


\section{CHAPTER XXVIII}

\section{DISEASES OF LEGUMINOUS PLANTS}

GRound nuts are grown rather extensively as a field crop in St. Vincent, and to a small extent in some other islands. Pigeon peas are also grown as a field crop in St. Vincent. and are grown everywhere in a scattered way, in small holdings, gardens or on the margins of fields. Cow-peas and Rounceval peas (Vigna spp.) are fairly common as a rotation crop on arable land. Velvet, Bengal and Lyon beans (Stizolobium spp.), Sword and Jack beans (Canavalia spp.) Woolly Pyrol (Phaseolus mungo) and the Tephrosias are grown to some extent as cover crops and green dressings. Bonavist (Dolichos lablab) and Lima bean (Phaseolus lunatus) are grown mostly in provision plots and small holdings.

The diseases of peas and beans have had little attention. In addition to those described below there exist numerous leaf-spots and one or more each of rusts, mildews, and wilts which have not been studied.

Of the general diseases the most serious are the infections following bug punctures (especially those of Nezara viridula, which is partial to these plants) and the rot, affecting all parts near the soil, caused by Sclerotium Rolfsii, both of which are elsewhere described.

\section{Cround Nut.}

\section{LEAF RUST.}

The rust fungus Uredo Arachi.its Lagh. (Uromyces Arachidis P. Henn.) occurs on ground-nut hroughout the Antilles from Cuba and Porto Rico to Trinida', and in South America. The pustules are small, yellow-brow? to dark brown, scattered or thickly crowded, occurring on both sides of the leaf but in greatest abundance on the under side, and present to some extent on the stems. The urediniospores are ovoid-round, minutely echinulate, 24-30 microns in diameter, with a yellow epispore.

The rust is more prevalent in wet than in dry seasons, and worse on heavy or wet than on light land. It has attacked imported varieties more severely than the local ones.

The incidence of the affection is somewhat erratic. Under favourable conditions it only occurs in quantity towards the end of the season, and mostly on falling leaves, but in other 
circumstances an infestation can bring about the partial defoliation and premature ripening of the haulms, with the production of a large proportion of shrivelled kerncls. W. Robson has carried out in Montserrat a series of annual tests of the effect of spraying with Bordeaux mixture. The treatment results in the control of the fungus, the leaves on the sprayed plots remaining at the end of the season green and healthy, with only a few scattered pustules, when those on unsprayed plots have on occassion been heavily infested and failing. The effect on the crop is variable. In some years an obvious and considerable increase has resulted, in others very little. This is probably to be explained by the absence of any serious injury from the fungus when the infestation is developed late.

The indications are that the first spraying should be given at 6-8 weeks from planting, and that one or two more applications should be made at intervals of a fortnight.

\section{LEAF-SPOT.}

A leaf-spot disease produced by the attacks of the fungus Cercospora personata Ellis (Septogloeum Arachidis Rac.) appears to be met with in all parts of the world where this crop is grown, being capable of transmission by spores adhering to the seed. In St. Vincent, where ground-nuts are grown extensively as a field crop, it is not in general regarded seriously, but local attacks are sometimes heavy enough to cause appreciable damage. This is more or less the position in other islands where the crop occurs. The disease is more prevalent in wet weather and more severe in its effects on imported varieties. In India it is regarded as one of the major diseases of cultivated crops, and is responsible at times for very great destruction. Its effect is described as not unlike that of potato blight, the plants being almost entirely defoliated.

The older leaves are first attacked, and brown to black nearly circular spots, usually $2-4 \mathrm{~mm}$. in diameter, are produced. Yellowing and shedding of the leaf may follow.

The conidiophores are brown, tufted, short, and irregular in outline. The conidia are light brown, mostly more or less club-shaped, several (usually 3-4) celled, 30-50 $\times$ 5-6 microns.

Trials of spraying with Bordeaux mixture have not been successful either in the West Indies or India. Very satisfactory control has been achieved in India by the introduction of exotic varieties with better powers of endurance, which seems to have reduced the disease to a position similar to that which it occupies on the varieties established in these islands.

\section{Root Disease.}

The "root disease" described by F. W. South is due to the 
fungus Sclerotium Rolfsii, discussed in another section as a general parasite.

Its attacks on ground-nut have caused very considerable losses during periods of wet weather.

\section{Kidney Beans.}

\section{Anthracnose.}

Kidney, Haricot, or bush beans (Phaseolus vulgaris) are grown to some extent as a garden crop in these islands, usually from American seed. The bean anthracnose is of fairly frequent occurrence, being probably in most if not all cases introduced on the seed, and sometimes causes considerable loss of crop. It is much less severe on local forms of Phaseolus.

\section{Symptoms.}

The disease makes its appearance on the young seedlings, and ultimately infects the leaves, stems and pods of the developed plants. The fungus penetrates the pods to the seeds within, causing spots to be developed on the latter which form a starting point for a new cycle of disease. The spots appear on the seeds as sunken black or brown specks in the case of light attack, or as brownish or blackened spots, usually in the form of a ring with a dark or rifted centre, where the attack is severe. On the seed-leaves, circular or kidney-shaped blotches appear, which may enlarge until the whole leaf is involved. Elongated cankers are produced on the stems, and many young plants are lost from the direct or indirect consequences of stem and root infection. Young leaves may be crinkled owing to the effect of the fungus on the margins; older leaves are affected mostly on the veins, and the portion of the leaf-blade beyond theattacked vein turns yellow and dies for want of water. On the pods the lesions start as small reddish pin-point spots, which enlarge into circular or kidney-shaped sunken areas with a raised rim. Yellow or pink spore-masses are produced in the centres of these spots. Severe infestation occurs as a consequence of continued wet weather, and a general yellow appearance, due to the dying of the leaves, is then recognizable in the fields.

\section{The Fungus.}

The causative fungus is Colletotrichum lindemuthianum (Sacc. et Magn.) Br. et Cav. The hyaline spores are at first one-celled, but later are divided by a single septum. They are surrounded by a mucilaginous envelope. In mass they are at first pink, later becoming more or less creamy. They are usually kidneyshaped, $2.7-5.3 \times 10.6-20$ microns.

\section{Control.}

Spraying with Bordeaux mixture usually gives disappointing 
results. There are notable varietal differences in resistance, but the adoption of this means of control is complicated by the existence of strains of the fungus which attack varieties resistant to other strains. Wells' Red Kidney is reported to be very satisfactory in this respect, and it is expected that resistant white types will be made available.

A very considerable degree of freedom from the disease can however be secured by taking precautions against planting infected seed. Pods should be selected which have no spots whatever upon them. It is not sufficient to select unspotted seed, since a slight infection may not be noticeable. An infection so slight as this upon a pod would have little significance, since the fungus would not have penetrated to the seeds within. It is advisable, however, in order to prevent infection from such a source, or from merely adherent spores, to dip the pods for ten minutes in corrosive sublimate solution (I part to rooo of water). The seed so obtained should be used to plant a seed plot on clean ground. Cases arising after this treatment should at the worst be few, and capable of elimination by hand-pulling.

In using imported seed the best that can be done is to reject all those which show signs of injury (which in many samples examined have been very numerous) and to treat the remainder with a disinfectant.

\section{BACTERIAL BLIGHT.}

This disease which is widespread in the United States has been frequently noticed on beans in these islands. It is caused by Bacterium phaseoli E.F. Sm.

The signs of its attack on the seed are, in light cases, yellow spots or blotches, not definitely circular, frequently on the side of the seed which was attached to the pod; in severe cases, yellowing and shrivelling of the whole seed. On the seed-leaves, small amber-coloured spots appear, with which may be associated a light yellow slime. On the foliage leaves the disease produces irregular water-soaked areas, which are usually bordered with distinct yellow or red lines. These areas gradually enlarge until the entire margin, or half the leaflet, may be involved. The watery areas later become brown and dry. On the pods, watery pustules are first formed, which develop into amber-coloured irregular blotches with uneven green centres; clumps of the bacteria ooze out, and dry into yellow crusts on both leaves and pods. The general appearance of a field, when the prevalence of humid weather conditions has led to a severe infestation, is described as suggesting that the plants had been drenched with hot grease. At a later stage the older leaves look dry and burnt, and excessive new growth occurs in the attempt to provide new foliage. Fruiting is seriously interfered with, and the pods cease to fill out. 
This disease is more capable than anthracnose of withstanding hot dry weather.

\section{Control.}

No fully effective means of control is known. The germs are able to resist drying for a long period, and become widely spread, so that probably reinfection does not entirely depend on seed. The measures recommended for anthracnose should, however, also reduce considerably the incidence of blight.

\section{STEM Rot.}

Bean plants raised in Barbados gardens from American seed have several times been seen to develop brown decayed patches on the young stems within the first two or three inches above the soil. The injury extends deeply into the tissues and often either girdles the stem or causes it to break. From the nature of the mycelium found in the lesions the disease is believed to be due to the soil fungus Rhizoctonia, which has been described as the cause of stem rot of beans in the United States, and there is a distinct possibility that the fungus is introduced with the seed. Pods near the ground are said to be attacked by the mycelium, which can enter maturing seeds without destroying them.

Seeds should be carefully picked over before planting, and those which show even slight injury rejected. The disease can be prevented to some extent by wide spacing and the avoidance of a shaded condition of the soil.

\section{Pigeon Pea.}

\section{Root and Stem Diseases.}

The pigeon pea (Cajanus indicus) is subject in the West Indies to diseases, probably two or three in number at least, which cause the death of the whole plant by infestation of roots, collar, or lower stem. These are additional to the known susceptibility of this plant to Rosellinia root disease. The occurrence of these affections seems to be sporadic, though sometimes the losses are fairly heavy. Their nature is at present almost entirely unknown.

In I9I7 old and young trees died off in large numbers but in a scattered way in several districts of Carriacou, in the Grenadines, and a similar occurrence amongst young plants was seen by the writer at a later date in the island of Bequia. In the Carriacou material the disease is distinctly of the nature of a stem and collar canker, and it is evident from the irregular development of ribs of new wood about the lesions that it may be present for a considerable time before killing the plant. The only fungus found to be uniformly present is an Ascomycete with dark hyphæ giving a slaty appearance to the wood, pro- 


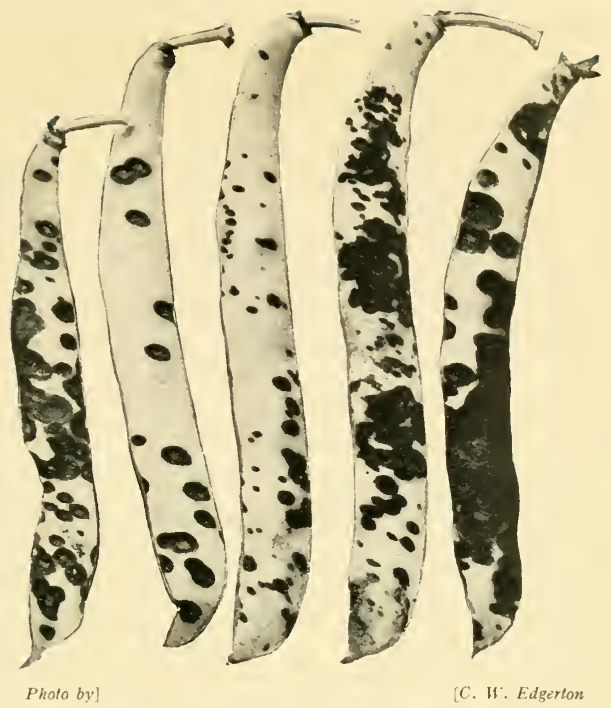

Fig. 14:2 Anthracnose of Bean

From H. T. Cook's Diseases of Tropical Plants, by permission of Macmillan \& Co.

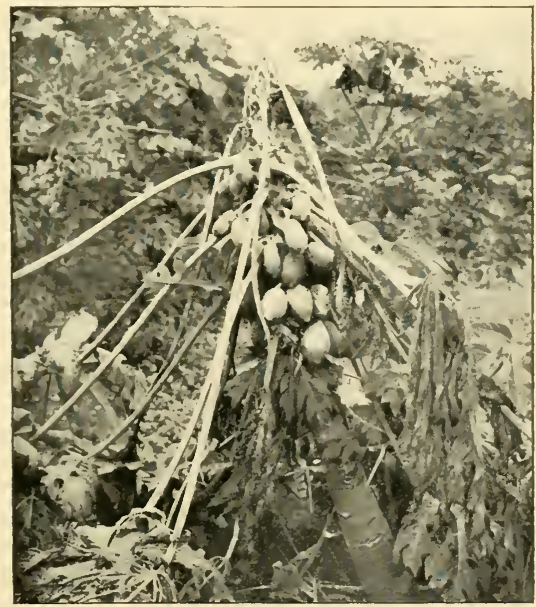

Fig. 143 Stem-Rot of PAPAW 


$$
2
$$


ducing a black stroma throughout the affected bark, with longnecked perithecia in dense clusters more or less united at the base, ejecting both from these and from adjacent pycnidia white tendrils of unicellular spores, the former coffin-shaped, the latter oval or oblong. Infection experiments, made in dry weather, gave negative results. J. A. Stevenson records the existence of an undescribed but serious stem canker in Porto Rico, and a disease closely resembling that described above occurs in Trinidad and Tobago.

A wilt disease, apparently due to infestation of the roots, occurs sporadically in Barbados.

RUST.

The rust fungus Uromyces Dolicholi Arthur, occurs on the leaves of pigeon pea in Trinidad and Porto Rico, and is probably to be found in the intervening islands. It produces small dark brown pustules, with powdery spores, on the lower side of the leaves, and causes discoloration of the foliage. 


\section{CHAPTER XXIX}

\section{DISEASES OF MINOR FRUIT PLANTS}

\section{Pineapple.}

THE pineapple belongs to an order (Bromeliacex) the greater part of which consists of epiphytes and lithophytes (tree and rock inhabiting plants) and the pineapple itself, while belonging to one of the soil-inhabiting genera, is closely related in its constitution and its vegetative structure to those of epiphytic habit. This is reflected in the fact, emphasized by all authorities on the cultivation of the plant, that it is most decidedly intolerant of any interference with free root-respiration, such as is brought about by soils which are close-lying or tenacious of water. Thus in Antigua, where pineapples are more regularly grown than in the other islands of the Lesser Antilles, the industry has practically speaking been confined to the section of the island which possesses soils of volcanic origin with a minimum of clay.

Given good aeration the consistency of the soil is of minor importance; it appears that the plant will grow well in any soil rich in humus, but in light soil it is especially necessary that the supply of plant food be well maintained. The plant will grow for a time in well-rotted leaf mould, and is grown in Florida in sand with the addition of chemical manures. It would seem that some of the difficulties attributed to disease have arisen through a mistaken belief in the ability of the plant to thrive in any light soil, which has resulted in the use of land in a dried out or exhausted condition. It is important to note in this connection that the plant has a very limited root range.

The plant is well protected against drought, but cannot be expected to do more than survive in periods when the comparatively shallow layer penetrated by its roots is dry. This points to the need, in dry districts, of close planting to shade the ground, mulching of the surface with leaves, or the maintenance of an efficient dust mulch.

\section{TANGLE-RooT.}

The condition known as tangle-root is a frequent accompaniment of the root diseases described below, as it also is of some dry soil conditions. In the affected plants the main roots, instead of growing directly out into the soil, wind round and round the rootstock, often quite tightly. The range of the roots 


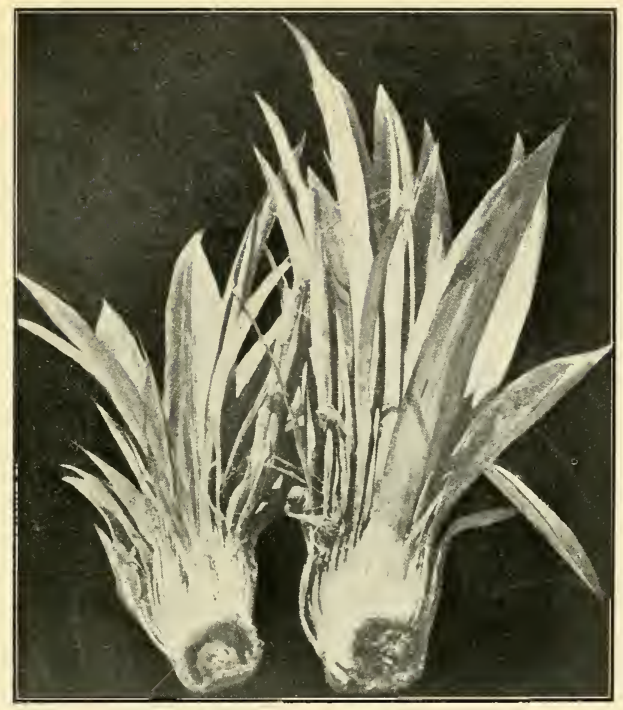

Fig. 144

Base-rot of Pineapple Cuttings

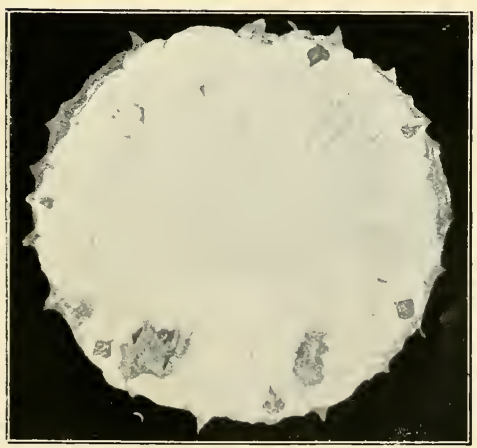

Fig. 145

Cross Section of Pineapple Fruit showing; TWO INFECTIONS OF BLACK-EYE Bull. то, Dept. Pathology, H.S.P.A. 

is thus greatly reduced, and in extreme cases the plant has hardly any hold on the soil.

The condition arises from the persistence of old leaf-bases in a leathery condition at the time when new roots are being produced from the internodes above. The new roots are unable to penetrate the obstacle thus presented, and are deflected so that their growth partly or wholly encircles the stem. Failure of the first formed roots from asphyxiation or other causes, or decay of the base of the rootstock, induce the condition by forcing premature development from higher nodes. In planting out suckers in dry soils it is advisable to remove beforehand the lower leaf-sheaths so as to allow a free course to the roots; in wet situations decay of the old leaves is more rapid and the operation may be dispensed with.

The existence of the tangle-root condition is not necessarily a symptom of disease, but it impairs the efficiency of the rootsystem, reduces the rate and vigour of growth, and may in extreme cases cause the failure of the plant under the strain of fruit production.

\section{Root Disease, Wilt, or Blight.}

A condition of ill-health and failure known under one of these names or an equivalent appears to be familiar in every country in which any considerable cultivation of pineapples is carried on. It has not been established as being due to any particular parasite or any single cause, and it is not probable that this is the case. Rather it is in its general aspect a form of failure like the root disease of sugar-cane, and in its simplest form may be brought about as the direct result of unfavourable conditions, but in addition may develop characters tending more and more towards those of parasitic disease according to the nature of the organisms, usually fungi, which invade the weakened roots or rootstocks. In this way variations in the final form of the condition arise which differ in different situations and cause the confusion of attempts to correlate them. One important question on which evidence is definitely conflicting, probably for the reason just given, is that of transmissibility. The disease as it exists in Hawaii and Queensland has been reported to be seldom or never communicated; in Porto Rico, Jamaica and the Philippines it has been regarded as infectious.

\section{Symptoms.}

In the form of the disease seen by the writer in Montserrat, which is believed to be the one most common in these islands. the plants showing external signs of the disease first occur in patches and the affection appears to spread slowly through the beds attacked, taking several months in the process.

The general appearance is that of a slowly progressive wilting 
and drooping of the leaves, beginning with reddish discoloration and resulting in withering from the tips, loss of colour, and eventually the complete drying-up of the plant, frequently when the fruits are partly grown.

Examination of the plants in various stages of failure showed quite clearly that it was a question of root decay. The worst affected plants had hardly any functioning roots, the least affected were fairly well provided, and the intermediate forms showed corresponding gradation. In all the specimens the actual tissues of the stems, apart from the discoloured root traces, were quite sound, thus differentiating this disease from stem base-rot due to Thielaviopsis.

\section{Associated Fungi.}

In the affection as met with by the writer and as described by previous investigators in the West Indies fungus hyphæ have been found in the roots and root-hairs from an early stage of failure. Their presence is referred to by most writers on the subject but in itself is not of much value as evidence of their pathogenic nature, especially as no particular fungus has been found to be well-marked and constant. Fusarium and other soil-inhabiting types are met with, but in no case has a necessary connection with the disease been demonstrated. On several occasions the mycelium and fructifications of Marasmius Sacchari have been associated with diseased plants in the West Indies, but this is not by any means general.

C. W. Carpenter has demonstrated very recently that wilt in the Hawaiian Islands is due to destruction of the finer roots by a fungus which he considers to be identical with Pythium butleri Subram. the cause of root rots of tobacco and ginger and foot-rot of Carica papaya in India.

\section{Control.}

Until the particular types of affection included under the name of root disease have been investigated and defined there is not much that can usefully be said on the subject of control.

So far as the disease is primarily due to some unfavourable condition or conditions of growth, including physically unsuitable, poorly prepared, insufficiently drained and cultivated soil (all leading to a restriction of aeration), poverty of soil, lack of water, and poorly prepared planting material, the means to be taken are obvious. There can be no doubt that much of the trouble experienced has originated in this way

The appearance of communication from plant to plant and the way in which the trouble slowly extends over the beds, as described above, afford fairly convincing evidence that parasitism is an important factor in at least one form of the disease. Its existence in an affection of this nature introduces the usual 


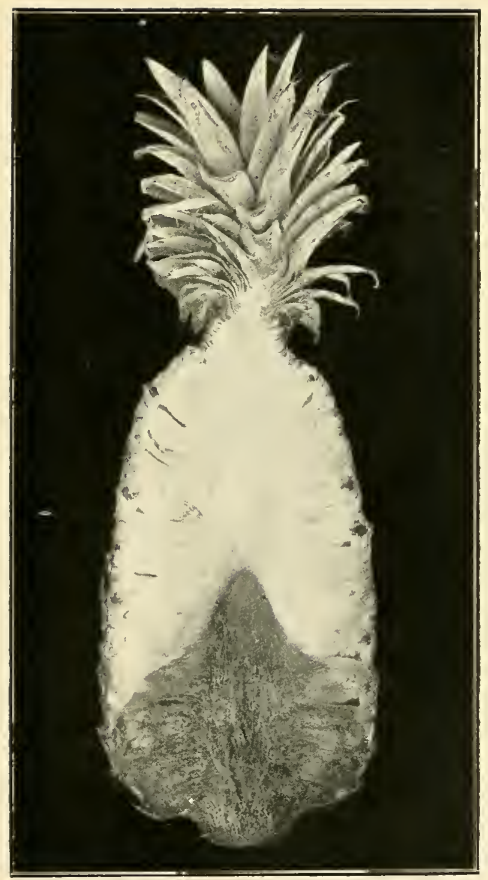

Fig. 146

Thielayiopsis Soft Rot of Pineapple Bull. 1о, Dept. Pathology, H.S.P.A. 

difficulties in dealing with soil parasites. Attempts at control involve the very early eradication of affected plants and their immediate neighbours, some effort towards sterilization of the infested soil, the avoidance for a long time (at least a year and possibly several) of the use of infected land for replanting, and careful precautions against infecting new land with any sort of material from the old.

\section{Resistant Varieties}

The most hopeful measure lies in the search for and adoption of suitable resistant varieties. In Montserrat the Red Spanish variety was reported first to be immune, and later to show a high degree of resistance to the disease as compared with the Queen types, which include the Ripley.

\section{BASE RoT.}

A disease which has been previously described from the Hawaiian Islands and is apparently indicated in a Porto Rico reference, was observed in I9I4 in a series of plots at the Experiment Station in St. Kitts.

\section{Symptoms.}

The plots in question were established with cuttings of the Ripley pine, which were disinfected with Bordeaux mixture before planting. About the time the first fruits were beginning to ripen a sickly yellow appearance of the plants became very noticeable and was made the subject of investigation. It was found that the more seriously affected plants were easily lifted by hand and the number of living roots was very small. The underground parts of the stem were rotted to a degree broadly corresponding to the condition of the top, the worst cases retaining only a few roots attached immediately below the bases of the lowest leaves. No evidence of attack on the remaining roots and rootlets was found, the loss of roots appearing to proceed from the rotting of the stem to which they were attached.

The blackened tissues of the stem proved to be filled with dark hyphæ, penetrating the tissues in every direction, lying in coils in the cells, and producing an abundance of black spores in simple chains. A large plant with healthy green leaves and a well-developed root system was found when cleaned to have a brown spot about the middle of one side of the underground stem, and when kept for four days in a closed chamber a rot of the nature observed in the field had extended from this point throughout the stem accompanied by the advance of the same fungus.

The fungus was identified in the plant and in cultures as Thielaviopsis paradoxa, v. Höhn., the cause of pineapple disease 
of sugar-cane cuttings, and was transferred to sugar-cane, upon which the usual effects were produced.

L. D. Larsen, in Hawaii, inoculated pineapple cuttings with the spores of this fungus through punctures and by means of a sprayed suspension, obtaining complete infection by both methods and the development of the disease in typical form, the controls remaining healthy.

\section{Losses.}

In Hawaii, where the existence of an organised pineapple industry allows of observations being made on the subject, the loss of plants in the field due to this disease has been found in different instances to be 23,27 and 65 per cent. The loss of cuttings during transport has on occasion reached similar figures.

\section{Control.}

The causative fungus is widely distributed in these islands and in the soil of sugar-cane fields appears to be universally present. It occurs in connection with a pineapple leaf-spot and is the common cause of decay in the ripe fruit after cutting. The fungus can be generally assumed to be present where pineapples are grown, and since large numbers of plants can be raised under these conditions and escape the disease, it is obvious that infection depends on some local factor. What the predisposing causes may be has not been ascertained further than that dry weather after planting seems to favour infection of the sets. This agrees with experience in the parallel case of sugar-cane cuttings, which, according to the writer's experience, are destroyed by Thielaviopsis only when lack of rain delays their development. The experiments in Hawaii showed that the removal of as few leaves as possible from the sets, and the drying out of the cut ends before planting are effective methods of preventing infection. The use of Bordeaux mixture gave negative results.

\section{White LEAF-Spot.}

A leaf-spot which is fairly common in the West Indies has been investigated by L. D. Larsen in Hawaii. It occurs on wellgrown plants and its effect on their development is not usually appreciable. It has been shown to be due to the infection of insect and spine punctures, or other injuries, by the fungus Thielaviopsis. Infection and development depend on the prevalence of moist and cloudy weather or on the shading of the plants.

\section{Description,}

Larsen's description is as follows :

"The spots vary considerably, as regards size, shape and 
colour. Many are large and white, and are noticeable from a long distance, while others are small and inconspicuous. In typical mature spots there is a straw-coloured central area surrounded by a dark margin. Very often there is a dark centre within the straw-coloured area, or dark blotches, due to the formation of the black macrospores within the tissue, may be scattered over it in an irregular manner. Sometimes long white arms extend beyond the dark border, and, again, the entire spot may be white or straw-coloured throughout. The internal tissue is soft and decayed at first, but this soon dries out, leaving the injured area dry and sunken. The white or straw-coloured area is not due simply to drying of the affected tissue, as is often the case with similar diseases, but comes on while the tissue is still quite firm, and long before it has begun to dry out. In early stages the spots may be olive brown in colour and fairly regular in outline, or they may be white or irregular from the start. The size of the spots increases very rapidly, so that in two or three days what was a small brown. spot will have become from two to six inches in length. Even twelve inches is not an unusual length."

\section{LEAF-BASE Rot.}

In Jamaica, S. F. Ashby reports the occurrence of a rot of the leaf-bases, occurring especially in young plants, which is caused by infestation with Phytophthora parasitica. A secondary malodorous bacterial soft-rot is usually also present. The Ripley variety is most susceptible.

\section{Fruitlet Spot, Black Eye, Black Spot.}

\section{Nature and Distribution.}

For the past twenty years a disease of ripening pineapples has frequently come to notice in the West Indies, in which the fruit appears externally quite normal, but when cut open reveals dark brown or blackish spots situated in the flesh beneath a few or many of the "eyes." The inappropriate names " black heart" and " core rot," sometimes used for this affection, have probably been transferred to it through confusion with the ripe rots due to Diplodia and Thielaviopsis.

In Antigua the disease is sometimes very common, at others rare or absent. It occurs in St. Kitts, Montserrat, Dominica and St. Vincent, and has been found in pines purchased in Martinique. Similar affections have been described from Jamaica, Queensland and Hawaii ; in the last two countries, associated with species of fungi different from that met with in the West Indies.

The disease was investigated by A. Howard in I9or, so far as this was possible from transmitted specimens, and, in the absence 
of opportunities for prolonged study on the spot, Howard's observations have been confirmed but not materially supplemented by the successive mycologists of the Imperial Department of Agriculture.

\section{Description of the Disease.}

The spots are very erratic in their occurrence and may be found in few or many of the fruits in a given consignment; large and well-grown specimens appear to have no advantage in this respect. The discoloration may be narrow and linear, extending inwards for half an inch or more from the base of an " eye," perhaps with one or more small bulbous expansions which become cavities, or it may be in the form of a conspicuous spot, of varying length and width but usually rather sharply defined. It does not appear that any notable extension of the lesion occurs during storage of the fruit, nor, apart from the spots themselves and the disfigurement they cause, that the edibility of the fruit is affected.

A species of Penicillium is uniformly found to occupy the spots, fruiting in small cracks and in the cavities of the ovary. The beginning of the spots, and the entry of the fungus into the tissues, is associated, commonly at least, with perforations in the tough wall of the old floral chamber (the eye), near the insertion of the style. Species of Penicillium are generally present on the withered floral organs, and it is regarded as probable that the fungus depends for access to the pulp on punctures made by insects or mites inhabiting the enclosed floral chamber. Mealybugs and mites are usually to be found in this situation. To establish this theory of the disease it will probably be necessary to study the general biology of the flower and fruit up to the time the affection begins to develop, and until this has been done no remedial measures can be suggested.

\section{Economic Aspect.}

The existence of this trouble has a serious reaction on attempts to establish a pineapple industry. It is impossible to know when selling, shipping, or buying pineapples whether they will or will not show a disfigurement which greatly reduces their value for table purposes.

\section{Thielaviopsis SoFt-Rot.}

Pineapples which are bruised in gathering or in transit or which sustain an injury while still on the plant are liable to be attacked by the fungus Thielaviopsis paradoxa, which spreads rapidly through the fruit and sets up a soft and watery rot. When the infested tissues are exposed they are quickly blackened by the abundant development of spores which then takes place. This is the commonest type of decay in the harvested fruit, whether 
green or ripe, and is responsible for the largest part of the losses which take place in storing and shipping pines. Its incidence in the field, where it occurs on ripe fruits, is inconsiderable as a rule. While infection usually takes place through wounds, experiments have demonstrated that in a moist atmosphere the germinating spores can penetrate the surface of uninjured fruit.

\section{Diplodia CoRe-Rot.}

In the traffic between these islands, pineapples which have been some days in transit are frequently found to be infected through the cut end of the stalk by a species of Diplodia. The fungus passes up the vascular core of the fruit, from which it spreads to the adjoining pulp. It produces a water-soaked appearance of the tissues recently invaded, and these are later darkened by the development of brown coloration in the mature mycelium infesting them. The fructifications of the fungus appear as dots under the rind of the fruit near the stalk, later breaking through as pustules and discharging immature white or mature black spores which in the latter condition are two-celled.

Diplodia wound infections of ripe or ripening fruits are very common in the West Indies (see p. 25), and the one or more species causing them are quite generally distributed.

\section{Prevention of Fruit Rots.}

The measures to be adopted for the prevention of these troubles are largely matters of handling and packing arising principally in connection with export ; though it must be remembered that the intrusive fungi develop so rapidly in a tropical climate that fruit intended for local consumption is liable to be quickly spoiled.

In dealing with the fruit it should be taken for granted-it is indeed usually a fact-that spores are present and only await suitable conditions for their development. These conditions are supplied by the presence of moisture and a certain degree of heat. Unless the fruit is artificially cooled the latter may be taken as in all cases sufficient, and it is on the control of the former that success will depend. The requisite moisture may be supplied by the juices of the fruit on cut or bruised surfaces, or by the water given off by the fruit accumulating either on the packing material or in surrounding air enclosed or allowed to remain still.

It follows that the pineapples must throughout be handled with the greatest care to avoid bruising or scratching. They must not be broken off from the stem, but cut with a stalk 3 or 4 inches long, which itself must not be stripped. It would probably 
be of advantage to cut off an inch of the stalk when the fruit is brought in from the field and then sear the freshly cut end or dip it in melted adhesive wax. The fruit should belaid out for twenty-four hours to cool and dry before packing. It is obvious that the method of packing should be such as to prevent contact between, or movement of, the fruit, while permitting free circulation of air, and that storage and stowage should be in well-ventilated places.

J. E. Higgins, in Hawaii, and Vera $\mathrm{H}$. Charles, in Washington, have experimented with the use of formaldehyde gas for fumigating pineapples previous to storage, the object being to kill the spores adhering to the outside of the fruit. Both report very considerable improvement in the keeping qualities of fruit so treated.

\section{Papaw.}

The papaw is generally distributed and common throughout the islands, grown usually in a scattered way as a fruit tree. In Montserrat a peasant industry exists in the collection of coagulated milk from the unripe fruits of plants which occur in considerable numbers on uncultivated land. Attempts which have been seen to establish papaws in field cultivation suggest that insect and fungus troubles would become severe under these conditions, and plots of superior imported varieties have in several cases failed owing to their greater susceptibility to disease. Only casual attention has as yet been given to the affections which occur.

\section{BLACK LEAF-SPOT.}

The leaves of the papaw are liable to heavy infestation with the fungus named below, which produces thickly sown and conspicuous spots, rounded except where they impinge on a vein, ranging in size from mere specks to about $3 \mathrm{~mm}$. diameter; on the upper surface they are dark brown, with a whitish centre in the larger examples, below they are a uniform velvety black.

The fungus as usually met with is confined to a conidial form, Asperisporium Carice (Speg.) Maub., the uncertain taxonomic position of which is shown by the variety of genera (Cercospora, Fusicladium, Scolecothricum, Epiclinium, Pucciniopsis) in which it has been placed.

The short vertical cylindrical-clavate conidiophores are crowded side by side in a dense and even layer on the under surface of the spot. Each has several minute papillæ on its rounded summit, and bears single terminal conidia in succession. The conidia are thick-walled, rough, irregular in outline, often more or less pear-shaped, and I, 2 or occasionally 3 -celled. A. 


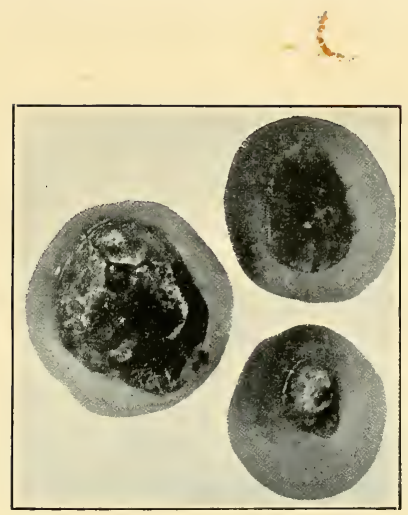

Fig. 147

Blossom End Rot of Tomato

Bull. I 4 , Florida Agri. Expt. Sta.

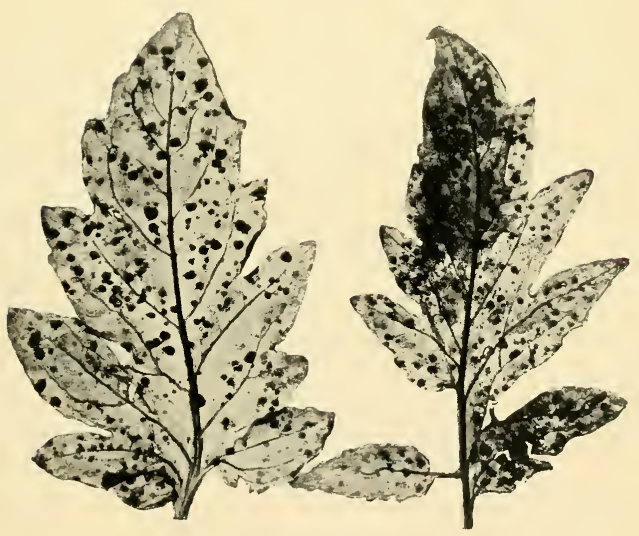

Fig. 148

SePtoria LeAF-SPOT OF TOMATO

From M. T. Cook's Diseases of Tropical Plants, by permission of Macmillan \& Co. 

Maublanc has recorded a perithecial form associated with the spots, to which he has given the name Spharella Carica.

The disease is reported from Brazil, Paraguay, Florida. Bermuda and Porto Rico. It has recently been found in Trinidad, and the only previous record from the Lesser Antilles known to the writer is based on specimens forwarded by W. Robson from Montserrat, with the information that the disease was only met with in a locality which for some reason has proved distinctly unsuitable for the cultivation of this plant.

\section{Stem AND FruIt Rot.}

Localised stem rots of the papaw similar in their appearance and perhaps identical have been seen in Montserrat, St. Vincent, Barbados and Trinidad. A similar trouble has been mentioned in Porto Rico. The causative organism has not with certainty been isolated in any of these cases. Imported varieties are highly susceptible, and considerable losses have occurred at times on the local kinds. Plants growing under very favourable conditions are liable to attack.

A water-soaked area first appears on the stem, apparently in any situation, the tissues turn brown, and a depressed and shrunken patch, which may be several inches long, is produced. This soon becomes infested with bacteria and with fly and beetle larvæ, and usually leads to the failure of the leaves and the breaking of the stem. Lesions which in their earlier stages are similar in appearance may also occur on the fruit.

A species of Glœosporium or Colletotrichum has been found in early and close association with the disease on stem and fruit in material from Barbados and Montserrat. A Colletotrichum is exceedingly common on failing leaves.

Cultures of a Fusarium were obtained in St. Vincent, but gave doubtful results in infection experiments. A similar infection in India has been produced by inoculation with Pythium butleri.

No actual experience of control has been obtained, but, as natural recovery sometimes occurs, it seems likely that the cutting out of the patches in the stem before they are far advanced, and the treatment of the wound with an antiseptic such as weak Jeyes fluid, might be effective.

\section{Tomato.}

\section{Blossom-End Rot.}

Blossom-end rot is a disease of tomatoes which seems to occur in most if not all of the countries in which the fruit is grown. In the West Indies the writer has seen it in Barbados, St. Vincent, and Antigua, on plants grown in black loam, light volcanic soil, and heavy clay respectively. 


\section{Description.}

The affection is not a typical fruit rot. Though as much as half the fruit may be collapsed and blackened the rest remains sound unless affected by the secondary organisms which may enter by way of the original injury. It appears first as a patch of dark green water-soaked tissue at or near the blossom end of the fruit, usually when this is one-half to two-thirds grown. The patch darkens, becomes more distinct in appearance and definite in outline and may remain small or spread until the distal half of the fruit is covered. The affected part in a few days becomes black and leathery, and usually more or less flattened or sunken.

\section{Causation.}

The disease has been the subject of much investigation, and has been attributed by different authors to numerous fungus or bacterial parasites. Several of these are liable to occur in the later stages of the affection, and may extend its scope, converting it into a real rot, but it is now coming to be generally accepted that in its origin the affection is non-parasitic. Its association with certain physical conditions, especially with variations in water supply, has frequently been pointed out, and C. Brooks published in I9I4 the results of a wide range of studies made to determine the influence of physical and chemical factors on its prevalence.

The disease is most severe on vigorous plants in a very active state of growth, and a sudden check to the water supply of plants in this condition is one of the most usual ways in which the disease is induced, while Brooks has further shown that continued excessive watering produces the same effect. Most nitrogenous manures, and especially stable manure, increase its incidence, and liberal applications may cause the losses to become very heavy. Aeration of the soil decreases the tendency to the disease, and lime has some effect in modifying the influence of heavy watering. The evidence available gives no clear indication of the actual nature of the disease, or even of the mode of operation of the factors which induce it, but recognition of these factors provides, so far as they are under control, the means of reducing its incidence.

\section{Control.}

Where the plants are artificially watered care must be taken to make the supply regular but not excessive. With either natural or artificial watering the drainage and aeration of the soil should be as good as it can be made. The prevention of excessive transpiration by shelter and light shade, the effect of which may to some extent be obtained by close planting, have good results. The soil may also be protected by trash of some description.

In an instance coming within the writer's experience heavy 
losses were stopped by restricting watering to one application in the early morning, trashing the soil, and shading the plants lightly with muslin.

There is distinct varietal difference in susceptibility to blossom-end rot. Brooks reports trials in which the percentage of loss was zero with Bonny Best, low with Stone and Golden Queen, medium with Earliana and Ponderosa, and heavy with Matchless.

\section{LEAF-MOULD.}

The leaf-mould disease of tomato foliage has been seen by the writer on plants in St. Vincent, Barbados and Trinidad, grown from American seed. It is reported by J. A. Stevenson to be destructive to the first-crop (December-February) plantings in Porto Rico, but absent from the second (April-June) crop. In Trinidad its prevalence appears to be one of the main factors in the failure of this crop during the wet season.

\section{Description.}

The disease is caused by the fungus Cladosporium fulvum Cke. The conidiophores emerge on the underside of the leaves, forming dense velvety patches of indefinite extent, white or grey at first, later smoky brown. On the upper surface the leaves show. yellow patches which turn brown as the tissues die. The fungus also appears in streaks along the stem, and may form scattered patches on the fruit. The conidia are elliptical, somewhat elongated, very variable in size, mostly one- but sometimes two- or threeseptate,

The disease spreads rapidly under moist and shaded conditions, and where these continue it can largely defoliate the plants. It is inhibited by dry air and sun.

\section{Control.}

No varietal resistance to the disease appears to have been recorded. Spraying with Bordeaux mixture has been recommended as effective in the early stages of infection, but Stevenson reports that repeated applications started before the fungus appeared had no good effect in the experiments observed by him.

Choice of season for planting and avoidance of humid situations are the measures indicated where this affection has proved troublesome.

\section{SePtoria LeAF-Spot.}

Leaf-spot is recognised as the most serious disease of tomatoes occurring in the United States, where it has earned distinction as the " tomato blight." It was first reported from the Argentine, is widely distributed in Europe, and occurs in Australia and 
South Africa. It is destructive in Porto Rico, and, though it does not seem to have been recorded from the Lesser Antilles, may with some confidence be expected to occur.

\section{Description.}

A recent and full investigation of leaf-spot has been made by G. H. Coons and E. Levin. The disease is mainly one of the leaves, beginning with small water-soaked spots on the underside, which later penetrate the leaf and dry into definite more or less circular spots, firm in texture, dark or greyish-white, with a black or brown margin. Typically the spots are small, not exceeding one-eighth of an inch in diameter, but they may by coalescence approach to half an inch. In each spot the pycnidia of the causative fungus occur to the number of 3 to ro, appearing to the naked eye as black dots, usually situated on the upper surface of the leaf.

The lower leaves are first attacked, and as the spots become numerous they turn yellow, wither, and fall. In severe infestations the disease extends to successively younger leaves until only terminal tufts are left. The attacks of the fungus on stems and fruits are of minor importance. The quantity and quality of fruit produced are affected in proportion to the injury to the leaves, and total failure of crop may ensue. The disease readily attacks seedlings and young plants, and is often carried by them into the field.

\section{Causative Fungus.}

The disease has been demonstrated by infection experiments to be caused by the fungus Septoria lycopersici Speg. The mycelium is of two types, a hyaline thin-walled vegetative form, and a dark closely septate thick-walled type associated with reproduction. The former is intercellular with knob-like haustoria. The spores from the pycnidia are filiform and hyaline, $60-120 \times 2-4$ microns, with 2-8 septa. The thickness of a spore is not uniform throughout and the shape of the ends varies from pointed to globose. The spores are exuded under the influence of moisture in mucilaginous masses which disintegrate in water.

\section{Conditions of Occurrence.}

The spores are washed and splashed about by rain and are readily transported during the handling of the crop under wet conditions. In dry weather the disease does not spread, and the spores do not appear to be able to tolerate drying for more than a few days. Infection is stomatal, and takes place for the most part and with greater effect on the lower surfaces of the leaves. The source of the infectious material initiating an outbreak appears to be mainly the remains of previous crops. It is not known that infection can be introduced with the seed. 
The mycelium does not grow well at high temperatures, and it is quite likely that this character prevents the disease from assuming importance in these islands.

\section{Control.}

The use of clean seed in clean soil is the best means of prevention. Training the plants on stakes reduces infection and enables spraying, when it becomes necessary, to have more effect. Under favourable conditions the periodic use of Bordeaux mixture has given good results, but these are in general uncertain, and $J$. A. Stevenson reports that no benefits resulted from repeated applications in trials made in Porto Rico.

\section{BACTERIAL WILT.}

During a visit of the writer to St. Vincent in I9I7, some attention was given to a wilt disease which was found to be occurring extensively at the Experiment Station, Kingstown, in beds of hybrid tomato plants (Ponderosa $\times$ Native) and in a row of the variety Earliana from American seed.

The symptoms of the affected plants, the appearance of the associated bacterium under the microscope and on agar cultures, and its virulence when inoculated into healthy plants, leave no reason to doubt the identity of the disease with the wilt due to Bacterium (Bacillus) solanacearum, E. F. Sm.

This disease is very prevalent in the southern United States, and makes the growing of tomatoes impossible over large tracts of country. A closely similar, probably identical, affection has been reported in many countries of the Old World. Several other members of the natural order Solanacer, especially eggplant, potato, and Datura spp. are liable to serious diseases produced by the same organism. The whole series has been grouped together under the name of Brown Rot of Solanaceæ, and very fully treated in Volume III of E. F. Smith's "Bacteria in relation to Plant Diseases."

So far as the records of the Imperial Department show, the disease has only been previously reported in the Lesser Antilles on one occasion, on tomatoes from Union, St. Lucia, in January, I904.

\section{Symptoms}

The outstanding character of the affection on tomatoes, as seen in St. Vincent, is the wilting, usually sudden, of the whole plant, which has just the appearance which would be produced by severing the base of the stem from the roots. No preliminary browning of leaves or stems was observed. When the bacterium was artificially introduced into a single stem, wilting above the point of inoculation took place in from two or three days to a week, while downward infection proceeded only slowly. 
Since wilting of the same type is produced by Fusarium disease, and would ensue from any other cause which cut off the supply of water through the stem, it is necessary for the purpose of a field diagnosis to have some further evidence of the presence of this particular disease. Confirmation fairly satisfactory for this purpose may be obtained by cutting across the stem at intervals with a clean sharp knife. When the region of infestation is reached the woody ring in the stem is found to be discoloured brown, and in a short time dirty white or brownish beads of bacterial ooze collect on the ends of the cut vessels. In the region of serious infestation this discharge is copious enough to be quite apparent to the naked eye. The pith may or may not be discoloured; the principal seat of the disease is in the vascular tissues, from which circumstance, when the infestation of any section of the stem is complete, the wilting of all parts of the plant beyond that section follows.

\section{Susceptibility.}

There seems to be no evidence of varietal resistance in tomatoes given in connection with the published studies of this disease. Solanum mammosum is reported from Porto Rico to be resistant, and the suggestion has been made to use it as a stock for grafting tomato and egg-plant. At the St. Vincent Station natural infection occurred to a considerable extent in American varieties of the Ponderosa type (which includes Earliana). The type with small round fruits, common in these islands and reputed to be native, proved fully susceptible to inoculations. A bed of $\mathrm{F}_{2}$ hybrids between Ponderosa and Native was with few exceptions destroyed when in full bearing. It is very much open to doubt whether the survivors were really resistant to the disease, in view of the known lessening of susceptibility to infection in matured plants. From whatever circumstances arising, some of the plants did resist artificial infection at this stage, and cuttings were taken from the survivors for further trial. A batch of hybrid seedlings, inoculated through needle pricks when a few inches high, succumbed in five days, showing at the point of introduction of the bacterium an infestation which was greatest in the protoxylem and the immediately adjacent cortical parenchyma. Attempts to infect tomato fruits with Bact. solanacearum resulted in slight local injuries which developed no further. This is in agreement with the results of previous investigators.

\section{Infection.}

The plants in which natural infections occurred were transplanted seedlings, in some cases very widely spaced, and the distribution of the diseased plants was of a sporadic type. In one rather close-planted row of Earliana several scattered plants died when coming into fruit without infecting their neighbours. 
The failure of attacked plants was completed at one stroke, and the indication given by this feature was confirmed in all the cases examined by the finding of the most severely affected sections at or near the base of the stem, and in one or more of the principal roots.

It seems on the whole most likely that infection had proceeded from the soil, probably, in some cases examined, through wounds made by removing basal shoots. The possibility remains, however, that wounds kept moist by nearness to the soil may have been more susceptible to infection from the pruning knife than those higher up, and it is somewhat easier to conceive of the knife becoming contaminated than the soil in some of the cases noted, where no Solanaceous plants appear to have been grown in recent times.

\section{Control.}

According to E. F. Smith, it seems probable that the organism is strictly a wound parasite. He has shown that it may be transmitted by insects, and is inclined to attach great importance to the action of nematode worms in opening the way for root infections, regarding their presence as prohibitive of tomatogrowing in infected soil. The St. Vincent plants did not show any obvious signs of the presence of nematodes. The further precaution on which most dependence must be placed, according to the author quoted, lies in avoiding even trifling injuries to the roots in transplanting. For this reason, if the seed cannot be germinated in situ, the transfer must be made with great care while the seedlings are still small enough to make the avoidance of injury possible. It is also obvious that infections may be easily made in pruning. A branch may be infested for a part of its circumference while not yet showing signs of wilt, and the cutting of it will smear the knife with large numbers of the causative bacteria. It would be safest to avoid pruning altogether when infected plants are known to be present.

It should be noted in conclusion, that it is reported from North Carolina and from Sumatra that ground luts grown on infested soil have proved susceptible to the attacks of Bacterium solanacearum.

\section{BubBLy Fruit-Rot.}

At the Kingstown Experiment Station, St. Vincent, in I9I7, there came under the writer's observation a bacterial rot of tomatoes of a very swift and decisive nature.

Bacteria which invade injuries, and cause ripe rot of tomato, as of other fleshy fruits, are not at all uncommon, but the one in question was distinguished by its ability to cause very destructive effects in fruit of any age, and of any size from the small "Native" to the large fruits of Earliana. Its outstanding character was the 
formation of very large or very numerous gas bubbles under the transparent skin of the fruit, replacing the pulpy tissues as they were rapidly broken down. Finally, the whole content of the fruit except the seeds was reduced to slime and gas, which escaped sooner or later by the rupture of the pendent skin, leaving the latter empty on the stalk. Needle-point inoculation of half-ripe fruits in the evening gave rise to a hollow an inch in diameter in two or three hours, and by next morning the process was complete. Smearing the skin with the slime produced did not cause infection unless a crack or other wound was present. The natural infections examined appeared to have their origin in bug punctures, made by Nezara and Leptoglossus. The losses due to the disease were significant but not severe.

Growths of the bacterium, apparently pure, were obtained by transfers from one fruit to another, and consisted of long, actively motile rods. Cultures were obtained on nutrient agar but time could not be spared from other work to continue the study further. Inoculations from diseased fruits into succulent stems had no effect.

No other record has been seen of a disease answering to this description. 


\section{CHAPTER XXX}

\section{DISEASES OF PLANTS NOT CLASSIFIED.}

Agave.

\section{Anthracnose.}

Various species of Agave, including sisal, are subject to a leaf disease of wide distribution caused by Colletotrichum Agaves Cav. There are records of its occurrence in the West Indies in Antigua, Trinidad, and British Guiana.

Dark spots are caused on the leaves which may remain local or result in a general sickly appearance and, according to reports, the eventual death of the plant.

The pustules, which produce masses of pink or orange-coloured conidia, are usually arranged in concentric rings.

Removal of infested leaves and spraying with Bordeaux mixture may be expected to control the disease.

Rose.

\section{BLACK SPOT,}

The commonest disease of roses in the West Indies as elsewhere is the black spot of leaves caused by infestation with the fungus Diplocarpon Rosa Wolf (Actinonema Rosa Fr.).

The disease reveals itself usually in mature or old leaves, which show first brownish blotches with fringed edges and set with black dots. Later the blotches turn black and examination with a lens shows upon them a raised pattern of radiating lines. The roundish dots are at first covered by the cuticle, which later bursts irregularly and reveals beds of two-celled conidia. The radiating lines mark the course of sub-cuticular hyphæ, while another set of hyphæ penetrate the tissues of the leaf.

The result of the infestation is that the affected leaves turn yellow and fall. When this is confined to old leaves not much harm is done, but under weather conditions favouring the disease repeated defoliations may occur, which weaken the plants and result in some dieback of the twigs.

The disease may be controlled by timely applications of Bordeaux mixture or lime-sulphur, but, as deposits left by these sprays are objectionable in appearance, a preferable treatment, which is simple and at least as effective, is dusting with a mixture of fine sulphur 9 parts and powdered arsenate of lead, I part. 
The first application should be made on the appearance of the first signs of the disease or at the beginning of seasons in which experience has shown it to be prevalent.

\section{MILDEW.}

Certain varieties of roses, particularly of the rambler class, are subject to severe attacks of powdery mildew on developing shoots and young foliage. Only the Oidium stage has been observed in these islands, consisting of a white surface mycelium, on and about which a powdery deposit of conidia occurs. The fungus is assumed to be the conidial stage of the common rose mildew Spharotheca pannosa Lev.

Dusting with sulphur, or with sulphur 9 parts and arsenate of lead powder I part, forms the most effective means of control.

\section{Other Diseases.}

A disease referred to by J. B. Rorer as canker occurs in Trinidad, and an affection probably identical is somewhat common in Barbados. Small purplish spots appear on the stems and gradually increase in size, sometimes even girdling the branch. The bark becomes shrivelled and sunken and in the later stages is covered with the bright red stalks and red globular heads of a species of Stilbella (Stilbum). Affected branches should be pruned out, or the whole crown is liable to become infested.

Rorer records a leaf-spot due to Cercospora rosicola Pass., which causes rounded spots which are yellowish with a distinct brown or purplish margin, and also reports very severe effects from infestation of the stems with the algal disease, described in Chapter XVI. 


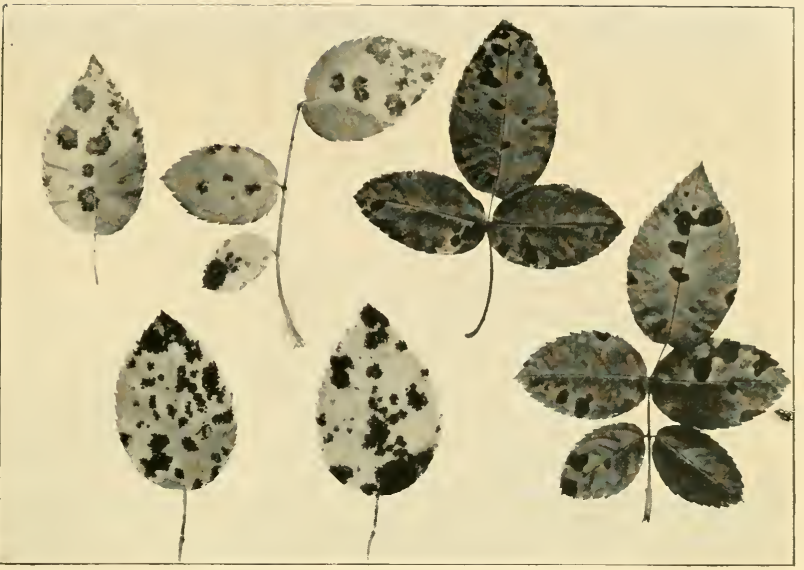

Fig. 149 BLack Spot of Rose

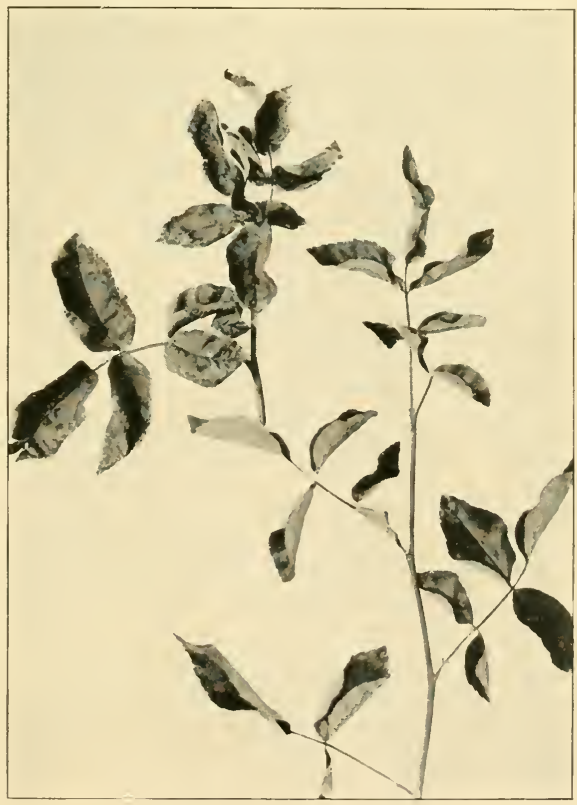

Fig. 150 ROSE Mildew 



\section{PRINCIPAL REFERENCES}

The Author regrets that his transfer to a situation with more limited library facilities has prevented the preparation of a complete list of the sources to which acknowledgment is due. The following list is intended for the direction of readers to some of the principal papers dealing with the subject concerned.

\section{CHAPTER I. NOTABLE GROUPS CONCERNED IN FUNGUS DISEASES.}

Duggar, B. M. Rhizoctonia. Fungous Diseases of Plants, pp. 444-452. Duggar, B. M. Rhizoctonia crocorum (Pers.) D.C. and R. solani Kühn (Corticium vagum, B and C). Ann. Missouri Bot. Gard. II, pp. 403-458. I 915 .

Petch, T. On Lasiodiplodia. Ann. Roy. Bot. Gard. Ceylon, IV. p. $4+5$. I9ro.

Peltier, G. L. Illinois Agr. Exp. Sta. Bull. I89 (I9I6). Rhizoctonia.

Stevens, G. L. The genus Meliola in Porto Rico. Illinois Biol. Monographs II. iv. (I9I6).

CHAPTER II. DISEASES CAUSED BY BACTERIA.

Smith, E. F. Bacteria in relation to Plant Diseases. Vols. I-III.

Bacterial Diseases of Plants. I920. Carnegie Institute, Washington.

CHAPTER III. DISEASES CAUSED BY INFECIIVE VIRUSES. Allard, H. A. Papers on Mosaic Disease. Jrn. of Agric. Res. III, 295 ; V, 25I; VI, 649; X, 615; XIII, 6I9.

CHAPTER V. DISEASES DUE TO NEMATODES.

Butler, E. J. The Rice Worm and its Control. Mem. Dept. Agric. India $\mathrm{X}$, i. (I9I9).

Taylor, A. M. Black Currant Eelworm. Jrn. Agric. Sci. VIII, 246. I9I7.

CHAPTER VI. THE RELAT ION OF INSECTS TO PLANT DISEASES. Pierce, W. D. and Rand, F. V. A Co-ordination of our Knowledge of Insect Transmission in Plant and Animal Diseases. Phy topathology X. p. 190.

CHAPTER VIII. ENTOMOGENOUS FUNGI.

Morrill, A. W. and Back, E. A. Natural Control of White Flies in Florida. U.S. Dept. Agr. Bur. Ent. Bull. IO2. I9I2.

Johnston, J. R. The Entomogenous Fungi of Porto Rico. Bd, of Commrs. of Agr. P. R. Bull. ro.

CHAPTER X. FUNGICIDES AND THEIR APPLICATION. Butler, O. Bordeaux Mixture. Phytopathology IV, I25. I9I4. The Cuprammonium Washes. Phytopathology VII, 235. I9I 7.

Thomas, C. C. Seed Disinfection by Formalin Vapour. Jrn. Agric. Res. XVII, 33. 
CHAPTER XII. THE CONTROL OF DAMPING-OFF.

Hartley, C. and Pierce, R. G. Control of Damping-off of Coniferous Seedlings. U.S. Dept. Agric. Bull. 453. I9I7.

CHAPTER XV. ROOT DISEASES.

Rosellinia Root Diseases.

Petch, T. Root Disease of Tea. Circ. and Agr. Jrn. R. B. G. Ceylon, V. No. II, I9IO.

Nowell, W. Rosellinia Root Diseases in the Lesser Antilles. West Ind. Bull. XVI, 3I. 1916.

\section{Sclerotium Rots.}

Taubenhaus, J. J. Recent Studies on Sclerotium Rolfsii Sacc. Jrn. Agric. Res. XVIII, I27. I9I9.

\section{CHAPTER XVI. STEM AND LEAF DISEASES.}

Pink Disease.

Brooks, F. W. and Sharples, A. Pink Disease. Dept. Agr. Fed. Malay States Bull. 2I. I9I4.

Pink Disease of Plantation Rubber. Annals of Applied Biology II, 58 . Thread Blights.

Burt, E. A. Corticiums causing Pellicularia Disease of the Coffee Plant, Hypochnose of Pomaceous Fruits, and Rhizoctonia Disease. Ann. Missouri Bot. Gard. V, II9. I9I8.

Stevens, F. L. and Hall, J. G. Hypochnose of Pomaceous Fruits. Ann. Mycologici VII, 49. 1909.

Fawcett, G. L. Fungus Diseases of Coffee in Porto Rico. P. R. Agric. Exp. Stn. Bull. I7. I915.

Horsehair Blight.

Petch, T. Horsehair Blight. Ann. Bot. Gard. Ceylon VI, 43.

Algal Disease.

Rorer, J. B. Algal Disease of Cacao. Proc. Agr. Soc. Trinidad XVII, 345. 1917.

Butler, E. J. Red Rust; p. 4I3, Fungi and Disease in Plants. Calcutta, I918.

\section{CHAPTER XVII. DISEASES OF CACAO.}

General.

South, F. W. Fungus Diseases of Cacao. West Indian Bull. XII, 277. 1912.

Canker and Pod-rot.

Rorer, J. B. Bulletin Dept. Agric. Trinidad IX, 79.

Petch, T. Circulars and Agric. Jrni. R. B. G. Ceylon V, No. I3. I9ro.

Van Hall, C. J. J. Meded. Laboratorium von Plantenziekten, Java. No. 30 .

Witch-Broom.

Stahel, G. Dept. v. d. Laudbouw, Suriname. Bulls. 33, 39.

Monilia Pod-rot, Spharonema Diseases.

Rorer, J. B. Enfermedades y Plagas del Cacao en el Ecuador. 1918. Anthracnose.

South loc. cit. Bancroft, C. K. West Ind. Bull. XI, 34. I9II.

Van Hall, C. J. J. Meded. Proefstat Midden-Java Nos. 6, I9I2; I 4 , I9I 4 . 


\section{CHAPTER XVIII. DISEASES OF COCONUT.}

Red Ring Disease.

Nowell, W. West Indian Bull. XVII, 189. 1919; XVIII, 73. 1920.

Cobb, N. A., ibid. XVII, 203. I9I9.

Bacterial Bud-rot.

Johnston, J. R. Bureau of Plant Industry, U.S.A. Bull. 228.

Ashby, S. F. Bull. Dept. Agric. Jamaica II, viii. 299. 1915.

Rorer, J. B. Board of Agriculture, Trinidad. Circ. 4. IgI I.

Phytophthora Bud-rot.

Ashby, S. F. West Indian Bulletin XVIII, 61. 1920.

Stem-bleeding Diseases.

Petch, T. Circ. and Agr. Jrnl. R. B. G. Ceylon IV, xxii. I909.

CHAPTER XIX. DISEASES OF LIMES AND OTHER CITRUS TREES.

Red Root Disease.

South, F. W. West Indian Bull. XII, iv, 490. I9I2.

Collar Canker.

South, F. W. Rpt. Agric. Dept. Dominica. 1912-13.

Fawcett, H. S. Phytopathology X, 397. I920. Galls.

Tenney, L. S., Hedges, F. and Bureau Plant Industry, U.S.A. Bull. 247.

Hedges, Florence. Sphæropsis tumefaciens. Phytopathology I,6 3 . I9II.

Anthracnose of Limes.

Clausen, R. E. Phytopathology II., 2I7. I912.

Grey Blight.

Burt, E. A. Ann. Missouri Botan. Gard. III, 335. I9I6.

Citrus Anthracnose.

Clausen loc. cit.

Scab.

Stevenson, J. A. Dept. Agric. Porto Rico. Bull. I7. 1917. Canker.

Hasse, Clara H. Pseudomonas citri: the cause of Citrus Canker. Jrn. Agric. Research IV, 97. I9I5.

Stevens, H. S. Florida A. E. S. Bulls, I 24, I 28.

Wolf, F. A. Jrn. Agric. Research VI, 69.

Jehle, R. A. Quart. Bull. Pl. Board, Florida I. 1916, 2 ; $1917,24$.

Oil Spot.

Fawcett, H. S. California A. E. S. Bull. 226.

Charcoal Rot.

Wilson, O.T. Notes upon a market disease of limes. Phy topathology VIII. 45. 1918.

CHAPTER XX. DISEASES OF COFFEE.

General.

Fawcett, G. L. Fungus Diseases of Coffee in Porto Rico, Porto Rico Agr. Exp. Stn. Bull. 17. I915. 
Viruela.

Fawcett, loc. cit.

Maublanc, A. and Rangel, E. Bull. de Soc. Mycol. de France XXX, 4I. I9I4.

Sclerotium Disease.

Stahel, G. Dept. Land. Suriname. Bull. 42. I92I.

CHAPTER XXI. DISEASES OF HEVEA.

Stahel, G. De Zuid-amerikaansche Hevea-Bladziekte. Bull. 34, Dept. Land. Suriname. I9I 7 .

CHAPTER XXII. DISEASES OF MINOR FRUIT TREES.

Avocado.

Anthracnose.

Rorer, J. B. The Fungus Diseases of the Avocado. Bull. Dept. of Agric. Trinidad XVIII, p. I32. I9I9.

Anthracnose.

Mango.

Rorer, J. B., ibid., XIV, I64. I9I 5.

\section{CHAPTER XXIII. DISEASES OF BANANA.}

General.

Ashby, S. F. Ball. Jamaica Dept. Agric. II, vi, 95. I9I3.

Panama Disease.

Ashby loc. cit.

Brandes, E. W. Banana Wilt. Phytopathology IX, 339. I919.

Moko Disease.

Rorer, J. B. Phytopathology I, 45. I9II.

Black Spot of Leaves et seq.

Ashby loc. cit.

CHAPTER XXIV. DISEASES OF CORN AND SORGHUM.

Dry Rot.

Van der Bijl, P. A. Dept. of Agric. South Africa, Sci. Bull. 7. 1916. Head Smut.

Potter, A. A. Jrn. Agric. Res. II, 339. I9I4.

McAlpine, D. Jrn. Dep. Agric. Victoria VIII, 5, 290. I9Io.

CHAPTER XXV. DISEASES OF COTTON.

General.

Edgerton, C. W. The Rots of the Cotton Boll. Louisiana Bull. I37. I9I 2.

Internal Boll Disease.

Nowell, W. The Fungi of Internal Boll Disease. West Indian Bulletin XVI, I 52 .

Internal Disease of Cotton Bolls in the West Indies, ibid., XVI, 203 ; XVII, I. 
Angular Spot.

Rolfs, P. H. Angular Leaf-spot of Cotton, S. Carolina Bull. I84, 1915.

Smith, E. F. Bacterial Diseases of Plants, p. 314, 1920.

Bacterial Boll Disease, Diplodia Boll Rot, Anthracnose.

Edgerton, C. W., loc. cit.

Curly Leaf, Loggerhead.

Nowell, W. Two Physiological Affections of Sea Island Cotton, West Indian Bulletin XIV, 304. I9I4.

Yellow Leaf Blight.

Atkinson, G. F. Some Diseases of Cotton. Alabama Bull. 4r. I892. Alternaria Leaf-Spot.

Faulwetter, R. C. The Alternaria Leaf-spot of Cotton. Phytopathology VIII, 98 . 1918.

Leaf Mildew.

Wakefield, E. M. On two species of Ovulariopsis from the West Indies. Kew Bulletin. I920. 235.

Crinkled Dwarf.

Harland, S. C. Genetics of Crinkled Dwarf Rogues. West Indian Bulletin XVI. Nos, I, 1916 and $4,1918$.

Man Cotton.

Harland, S. C. Note on a peculiar Type of Rogue in Sea Island Cotton. Agricultural News. Barbados, XIX, 29. 1920.

Mottled Hybrids.

Nowell, W. West Indian Bull. XIV, p. 3ro. I914.

CHAPTER XXVI. DISEASES OF SUGAR-CANE.

General.

Wakker, J. H. and Went, F. A. F. C. De Ziekten van het Suikerriet op Java, Leyden. I 898.

Howard, A. On some Diseases of the Sugar-Cane in the West Indies. Annals of Botany, Vol. XVII, pp. 373-4II. I903.

Johnston, J. R., et al. Diseases of Sugar-Cane in Tropical and SubTropical America, especially the West Indies. West Indian Bulletin, Vol. XVI, pp. 275-308. I 918 .

Johnston, J. R., and Stevenson, J. A. Sugar-cane Fungi and Diseases of Porto Rico. Journal of the Department of Agriculture of Porto Rico, Vol. I, No. 4. I9I 7.

Butler, E. J. Fungi and Disease in Plants, Chap. XI. Calcutta, I9I8.

Cobb, N. A. Fungus Maladies of the Sugar-Cane. Hawaiian Sugar Planters' Association, Bull. 5. 1906.

Root Disease.

Wakker \& Went, Howard, Johnston, Johnston \& Stevenson loc. cit.

Bud Rot.

Wakker \& Went, Howard, Butler, loc. cit.

Rind Fungus.

Howard, loc. cit.

Johnston, J. R. History and Cause of Rind Disease. Journal Board of Commissioners of Agriculture, Porto Rico, Vol. I, pp. I 7-45. i91 7 . 


\section{Pineapple Disease.}

Wakker \& Went, Cobb, loc. cit.

Howard, A. Field Treatment of Cane Cuttings, West Indian Bulletin, Vol. III, pp. 73-88. 1902 .

Petch, T. Thielaviopsis. Ann. Roy. Bot. Gard. Ceylon IV, 5II. I9Io. Diplodia Rot.

Howard, A. Diplodia cacaoicola, a Parasitic Fungus on Sugar-cane in the West Indies. Annals of Botany, Vol. XV, pp. 683-701. I90I.

Butler loc. cit.

Wilt Disease.

Butler, E. J. \& Khan, A. H. Some new Sugar-Cane Diseases. Memoirs Dept. of Agriculture India, Vol. VI, No. 6. I9I3.

Top Rot.

Wakker \& Went, loc. cit.

Cobb's Disease.

Smith, E. F. Bacteria in relation to Plant Diseases, Vol. III. WashSmut. ington, I9I4.

Butler, loc. cit.

Iliau.

Lyon, H. L. Iliau, an Endemic Cane Disease. Hawaiian Sugar Planters' Association. Bull. XI. I912.

Cytospora Rot.

Johnston, J. R. and Stevenson, J. A., loc. cit.

Leaf-sheath Rot.

Wakker \& Went, Johnston \& Stevenson, loc. cit.

Sereh.

Wakker \& Went, loc. cit.

Lyon, H. L. Three Major Cane Diseases: Mosaic, Sereh and Fiji Disease. Bull. Hawaiian S. P. A. Bot. Series III, pt. I. I92I.

\section{Mosaic Disease.}

Stevenson, J. A. An Epiphytotic of Cane Disease in Porto Rico. Phy topathology, Vol. VII. 4I8. I9I 7.

Brandes, E. W. Mosaic Disease of Sugar-Cane and other Grasses. U.S. Dept. Agric. Bull. 829. I9I9.

Lyon, H. L., loc. cit.

Chlorosis.

Tempany, H. A. The Gall Patches in Antigua Soils. W. I. Bulletin Vol. XVI, pp. 137-1 44. I9I 7.

Fiji Disease.

Lyon, H. L., loc. cit.

CHAPTER XXVII. DISEASES OF ROOT CROPS.

Dry Rot.

Aroids.

Ashby, S. F. Jamaica Dept. Agric. Bull. II, vi, p. I50.

Bacterial Rot.

ONION.

Stewart, F. C. New York (Geneva) Agr. Exp. Stn. Bull. I64. I899. 
CHAPTER XXVIII. DISEASES OF LEGUMINOUS PLANTS. GROUND Nut.

Fungus Diseases of Ground Nut in W.I.

South, F. W. West Ind. Bull. XI, p. 157. I9II.

Leaf Spot.

Butler, E. J. Fungi and Disease in Plants. Calcutta, I9r8.

KIDNEy BeANS.

Anthracnose, Bacterial Blight.

Muncie. Michigan, Sp. Bull. 68. 1914. Tech. Bull. 38. 1917.

Barrus, M. F. Phytopathology I, p. I07. I9I.

CHAPTER XXIX. DISEASES OF MINOR FRUIT PLANTS.

General.

Pineapple.

Henrickson \& Iorns. Porto Rico Agric. Exp. Stn. Bull. 8. Igog.

Larsen, L. D. Hawaiian Sugar Planters' Association Bull. ro. Igro.

Stockdale, F. A. West Ind. Bull. VIII, P. I 58. I908.

Black Leaf-spot.

PAPAW.

Maublanc, A. Bull. Soc. Mycol. de France XXIX, p. 353. I9I3.

Blossom End Rot.

Tomato.

Brooks, C. Phy topathology IV, v, p. 345. 1914.

Septoria Leaf-spot.

Coons, G. H. and Levin, E. Michigan Tech. Bull. 25. 1916. 


\section{GLOSSARY OF WEST INDIAN TERMS}

ANAUCO-the mountain immortelle (E. micropteryx, Poepp). B. 208, ETC.-seedling sugar canes raised by the Barbados Department of Agriculture.

BLACK BLIGHT-investment of leaves, fruits, etc., with a sooty covering of fungus mycelium (see page 44).

BLACK EYE PEA-a form of cow pea.

BLUGGOE-a coarse cooking banana in Grenada (the moko of Trinidad).

BOCARE-the lowland immortelle ( $E$. glauca, Willd).

BOURBON CANE-a variety of sugar-cane, in general cultivation in the W.I. until near the end of the Nineteenth Century ; believed to have been introduced from Otaheite.

CANARY BANANA-see Chinese banana.

CANE-FLY-Stenocranus (Delphax) saccharivorus.

CASSAVA-Manihot utilissima.

Chinese banana-Musa Cavendishii, Lamb; also called Canary or Governor banana.

coco-Jamaican name for Xanthosoma sp.

CORN-confined in the West Indies to maize.

COTTON STAINERS-plant bugs of the genus Dysdercus.

COW-PEA-Vigna catjang.

CRIOLLO CACAO- a superior and more delicate variety of cacao producing white beans, apparently at one time in general cultivation in Trinidad, but now almost extinct in its pure form.

CUSHION-the raised areas on cacao stems developed in connection with repeated localised production of flowers and fruit.

CuTLASS - a large and heavy knife used for chopping, pruning and light digging.

D. Iog, ETC.--seedling sugar-canes raised by the British Guiana Department of Agriculture.

DASHEEN - a cultivated aroid of the genus Colocasia, a common food plant in the wetter islands. 
EDDOE-a cultivated aroid of the genus Colocasia, a common food plant.

EYES-dormant buds, especially in sugar-cane.

FROGHOPPER (SUGAR-CANE)-Tomaspis saccharina, a serious pest in Trinidad.

GALBA-Calophyllum calaba, a guttiferous tree used for windbreaks.

GOVERNOR BANANA-see Chinese banana.

GREEN BUG-Nezara viridula.

GREEN SCALE-Coccus viridis (Lecanium viride).

GROS MICHEL-the common large-fruited commercial banana.

GUINEA CORN-Andropogon Sorghum, a variety with compact heads.

IMMORTELLE-leguminous trees of the genus Erythrina, used generally for shading cacao fields.

IMPHEE-Andropogon Sorghum, a variety with loose panicles.

LEAF BLISTER MITE (COTTON)-Eriophyes gossypii, Banks.

LEMON GRASS-Cymbopogon citratus (DC) Stapf, a scented coarse grass.

MANDARIN-Citrus nobilis, an orange with small dark foliage and red loose-skinned fruit.

MUSCOVADO-sugar made on the old open-pan system.

OKRA-Hibiscus esculentus, the succulent young capsules of which are used as a vegetable.

PAPAW-Carica papaya.

PEN MANURE-manure accumulated for several months on the floor of stock pens, usually with liberal additions of cane trash or other litter.

PIGEON PEA-Cajanus indicus.

PLANTAIN-Musa paradisiaca, Linn., a distinct type of cooking banana tending to be restricted to forest soils.

PLANT-CANE-the first crop of sugar-cane from planted cuttings. POIS Doux-Inga spp. Leguminous trees used as windbreaks. RATOONS-the second and subsequent crops of sugar-cane obtained without replanting.

ROUGH LEMON-Gitrus limonum, Risso, a lemon with large roughskinned fruits.

SEA ISLAND COTTON-long staple cotton of the type developed in certain islands off the coast of S. Carolina.

SHADDOCK-Citrus decumana, var., producing a very large and rather dry fruit.

SILK FIG-Trinidad name for a variety of banana mostly grown as temporary shade on cacao estates; fruit with a thin smooth skin. 
SOUR ORANGE-Citrus vulgaris Risso, a tree with a scattered distribution about estates or villages, useless in itself, but valuable as a stock.

STRAINER - the fibrous canvas-like material developed at maturity from the sheathing base of the coconut leaf.

SudAN GRASS-Andropogon Sorghum sudanensis, Piper.

SUPPLIES-plants or cuttings used to fill up gaps in a planted field.

SYRUP-cane juice concentrated in open pans.

SWEET POTATO-Ipomœa batatas.

TANNIA-cultivated aroids of the genus Xanthosoma.

TRASH - the old dry leaves, especially of sugar-cane and banana. UBA-a thin reed-like sugar-cane of the Indian type, used to some extent in the West Indies for planting on poor land. YAM-Dioscorea spp. 


\section{INDEX}

Ecidium oxalidis

Agerita-

Agaricaceæ -

Agave, diseases of

Albugo

A. Ipomoece-pandurana

Alectra

Alfalfa, collar rot of -

Alga and Fungi, distinguished

Algal Disease

Allard, H. A.

Alligator cacao (Theobroma pentagona) -

Alternaria

leaf-spot

A. tenuis

American Leaf Disease

Ammonium sulphide

Amphispores

Angular spot

Anstead, R. D.

Anthracnose

Agave

Avocado -

Cacao

Cotton

Grape-Vine

Kidney beans

Lime

Mango

Spotting

And see Citrus.

Antigua.

Agave Anthracnose _ _ _ - 36 I

Agricultural conditions - - - IIf

Brown rust of corn - - . . 256

Cotton disease - _ - _ - 279

Entomogenous fungi - . - - 74

Fomes Root rot - - - - - 147

Onion disease - - . - . 336

Pineapple cultivation and diseases 344,349

Root disease of corn - $\quad$ - $\quad 260$

Sugar diseases - - $\quad-293,296,328$

Yam diseases

Aphelenchus cocophilus

Aphides

Aphis maidis

A posphocria Ulei

Aralia bedges

Areolate mildew of cotton

Arrowroot Diseases

Red Root disease

Rosellinia

Arthur, J. C.

Aschersonia -

Ascomy cetes

Ascospores - - - - - 6, 7, 233

Ashby, S. F. 183 et seq., 203, 24 I et seq.,

Aspergillus -

$263,326,337,349$

A. flavus

Asperisporium Carica

Atkinson, G. F.

Authorities referred to Avocado

Diseases of

65. 337

$66,67,79$

- $\quad 327$

233

I35, 160

286

$332-5$

130, I32, 332

332

79

43

$-\quad 43,74$

74,79

- 352

268,283

$363-9$

susceptible to Rosellinia - r35, I39, 235

B 208 sugar cane

Bacillus carotovorus

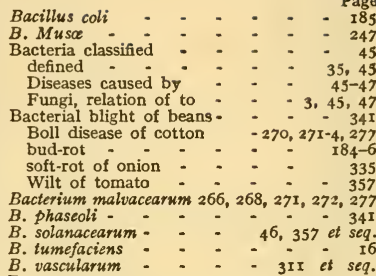

Banana

Diseases - - - - - 24I-55

trash for controlling leaf-stalk rot -189

Bancroft, C. K. - - - - 295, 312

Barbados

Agricultural conditions - . -

Banana disease - - - - $\quad-242,246$

Cassava diseases - - - - $\quad-335$

Cotton diseases $-\quad-273,277,286,287$

Cotton stainers absent - - - 264

Entomogenous fungi - - - - 74

Foot-Rot - - - - - - 213

Onion disease $\quad \cdot \quad \cdot \quad \cdot \quad-336$

Papaw diseases - - - - -353

Powdery Mildew of Grape-vine - 237

Rose diseases - - - - 362

Shaddock Splitting - - - - 223

Sugar cultivation - - - - 289,294

Sugar diseases 296,297 et seq., 308 et seq., 328

Yam Wilt - - - - - 337

Barber, C. A. - - - - 58, 126

Bark disease of coffee - _ _. 229

Bark rots - - - - - - 15, 173

Barrett, O. W. - - - - - - 312

Basidiomycetes - - I8, 38, 44, I49, 231

Basidiospores - - - - - 6, 19

Beans, diseases of - - . - - 340-2

Berkefeld filter - - - - 50

Bequia, cotton boll disease - - - 266

pigeon pea disease - - - 342

Bichet - - - - - - - 156

Bird Vine - - - - - - 56-8, II 4

Bitten-Leaf disease of coconut - I9I

Black-arm disease of cotton - $270,27 \mathrm{I}$

Black Blight - - - $\quad-8,32,37, \mathrm{xI}_{4}$ and see Sooty Mould

"Black cacao" " . -

Black-eye disease of pineapple - - 349

Blackhead disease of banana - - $\quad 254$

Black leaf-spot of papaw - $\quad 352$

Black melanose - - - - - - 217

"Black rust" of cotton - _ _ . 284

Black spot

banana leaves. - - - - $25 \mathrm{I}$

pineapple $\quad-\quad-\quad-\quad-349$

rose - - - - - - $-36 \mathrm{r}$

Bleaching powder - - - - - IOI

Blight, Pineapple - - - - - 345

"Blights" of coffee - - - - - 225

Blodgett, F. M. - - - : 94

Blossom blights - : - : - :
Avocado -

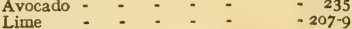

Blossom-end rot of tomatoes - - 7r, 353

Blue Moulds, see Penicilliums.

Bluggoe banana - - - - 248

Bonnygate disease of banana - 252 
Bordeaux mixture 22, 85, 87 et seq., 149, Page I50, 151, 153, 167, 172, 186, 188, 189, I9I, 209, 215, 217, 227, 234, 252, 254, $270,275,296,306,339,340,347,355,36 \mathrm{I}$ Formula

Physical properties

plus formalin

Preparation

Testing

Bordeaux paste.

Bordeaux powder-

Botryodiplodia

B. Theobromo

Botrytis

$B$. cinerea

Bourbon cane

Epidemic -

replaced in West Indies

susceptible to disease

Bracket fungi

Brain, L. Lewton

Branch Galls of Limes

Brandes, E. W.

24 I et seq., 324,326

British Guiana

Agave anthracnose

Bourbon cane epidemic

Cotton rust

Foot-Rot -

Hevea disease -

Leaf blight of coconut -

Red ring of coconut

Red Root disease of limes

Sugar diseases

Witch-Broom disease

Wither-tip

Eritish Houduras

Bud rot of coconut

Panama Disease

Red ring of coconut

Brooks, C.

Brown eye-spot of coffee

Brown leaf-spot of sugar -

Brown rot, Solanaceze

Bubbly fruit-rot of tomato

Bud rot

Coconut - $\quad I 6, I I 3, I 83-8,274,3 I I$ distinguished from red ring - -179 Sugar - - - - _ - Bug punctures - $14,29,264,338,360$ Burgundy mixture 22, 91-3, 209, 270, 275 Burgundy paste 20,92, I05 "Burning "disease of arrowroot - 332-4 Burrill, T. J.

Butler, E. J.

Butler, 0 .

Calabacillo cacao

Cacao

Bonnygate disease -

Canker

conditions favourable to

Corticium Stevensii

Diseases of

drying up of young fruit

Pink disease of

pod-rot

red rust of - - : $\quad-\quad 14,120,159$

Rosellinia diseases of $126,127,132,139-4 I$

shade trees - - . II, I56, I60, I72

Caledonian Queen variety of cane - 298

Cambium

Canary type of banana:- : : $: \begin{array}{r}15 \\ -\end{array}$

Canker Cacao Citrus
9. $120, \quad 162-8$
Canker

Page

Nutmeg - - - - - - - 239

Rose - - - - - - 362

Capnodiæ. See Sooty Mould.

Carbon Bisulphide - - - - - 63

Carpenter, C. W. - - - - - 293, 346

- 342

Cassava, cultivation and diseases - : 335

Cassytha - - - - - - 56

Castillu, Rosellinia on - - - - I30

Cephaleuros mycoidea - 152, 2 I0, 235, 239

C. virescens $\quad$ - _ - - 152

Cephalosporium 24, 42, 79, 205, 229, 243

C. Sacchari - - - 260, 309

Cercospora - - - $\quad 43,228,251,337$

C. coffeicola - - - - - - -228

C. henningsii - - - - - - - 335

C. kopkei - - - - - - - $32 \mathrm{I}$

C. longipes - - - - - - - $\quad-322$

C. musarum - - - - - - $\quad-252$

C. personata - $\quad-\quad$ - $\quad-\quad$ - $\quad$ - 339

C. rosicola - - - - - - - 362

C. Sacchari - - - - - - - 320

C. vagince
Chæotodiplodia

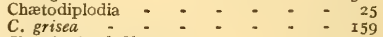

Chamberland filter : - : - : $\quad-\begin{array}{r}159 \\ -\end{array}$

Chamcluco banana - - - - - 242

Charcoal rot of Citrus - - - - 223

Charles, V. H. - - - - - - 352

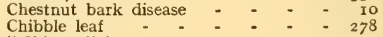

"Chinese" banana - : - $242,245,249$

Chionapsis - . - - - - -2 I0

Chlamydospores - - - 19, 21, 189, 243

Chloride of Lime. See Bleaching Powder.

Chlorinated potash. See Eau de Javelle.

Choanephora infundibulifcra - - 36

Chloropbyll absent in Bacteria - - 45

absent in Alga - - - : : $\quad 35$

$\begin{array}{ccc}\text { reduced by Mosaic disease } & - & 49 \\ \text { Chlorosis of sugar-cane - } & - & 70,328\end{array}$

Chupon wilt of cacao - - - 164, 165

"Cigar" disease of arrowroot - - 334

Citricolum variety of Cladosporium - 214

Citrus

Anthracnose - - - - 210, 211,219

Canker - - - IO, II2, 2I5, 2I8-2I

Diseases - - - - - - I94, 224

Fruit injuries and rots - . $221-4$

Scab - - - 215-7, 222

Cladosporium - - - - - - 43

C. citri - - - - - - 216

C. fulvum - - - - - + - 355

C. herbarum - - - - - $\quad 214$

Climate, effects of - - - $\quad 7,9,12$

Coal tar for protecting trees - - - 106

Cobb, N. A. 59 et seq., I80, I8 r, 249, 3 I I

Cobb's disease of sugar-cane - - - $31 \mathrm{I}$

Coccidæ. See Scale insects.

Coccus Viridis - - - - - - $\quad$ - 79

Coconut

diseases of - - - - $177-93$

dropping of nuts - - - $\quad-\quad 185$

immune from Rosellinia Pepo - $\quad$ - 127

trash for controlling leaf-stalk rot 189

Coffee, diseases of - - - - 225-3I

Coffee, leaf rust - - + - _ - $\quad$ - 17

Coleosporium Ipomoece - - - - $\quad 337$

Collar canker of limes : - : - :
Collar rot - $\quad-\quad 206$

Colletotrichum - - $\quad$ 22, 35, I75, 353

Colletotrichum Agaves - - - $-36 \mathrm{r}$

C. falcatum - - - - - - 298, 30I

C. glcosporioides $\mathrm{I} 4,23,207$ et seq., 235, 238

C. gossypii - - - - - - - 277

C. incarnatum - $\quad-\quad$ - $\quad$ - $\quad$ - 175

C. lindemuthianum - - - - - 340 
Colocasia, diseases of -

"Congo " banana

Conidia, Conidiospores

Coniothecium

Convolvulacem

Cook, O. F.

Cooke, M. C.

Coons, G. H.

Cooper's Cattle Dip .

Copper Sulphate 56, 93, IOI, III, I88, I9I, 270

Coremium disease of coffee -

Corn, diseases of

256-62

Corn smut - - - - - 16, 20, 257

Corrosive sublimates - - - - $\quad$ - 99, I05

Cortex, infections in the - - I4, I6

Corticium genus - - - - - - 40

Corticium javanicum - - - - - I48

C. lilacino-fuscum - - - - - - I48

C. (Pellicularia) koleroga - - - - I5I

C. salmonicolor - - - - - - 148

C. Stevensii - - - - - - $\mathbf{r}_{49}, 240$

C. vagum - - - - - - - 26

Cotton, boll diseases 9, I2, 67, 263 et seq. diseases - - - - - 263-87 leaf blister mite - - - - - 10 perennial - - $\quad-273,283,287$ Rivers type - - - - - -270 superfine type - - - - - 270 shedding of young fruit - : $\quad 14$ soft rot - - - : - I4 stainers. See Dysdercus - - . II4 strains, resistance of - - - - 275 vascular wilt disease - - - $\quad 243$

Cremastogaster spp. - - - - - I06

"Crinkled-dwarf" in cotton $\quad 84,286$

Criollo cacao and canker - . 179

Crop rotation. See Rotation

Crossing - - - - - - 10, 287

Crown gall disease - - . - . 16

Cuprammonium washes (suphate and hydrate)

Curly leaf of cotton - _ - 278-80, 283

Curly top of beet - - . - $5 \mathrm{I}-3$

Cuscuta Americana - - - - $\quad 54$

Cytospora - - - - - - 42, 316

C Sacchari - . - . - $\quad 316$

D 95 sugar-cane - - - - - 296

D 109 " " - - - . 295, 320

D 116 " " " - - - - - 326

D II8, I45, I59, 216, 625, canes - - 295

D Ir35, 3956, canes - - - - - 325

Damping off - - - - 107-9, 278

Dash, J. S. - - : - : - $\begin{array}{r}3 \text { - } \\ \text { Date palm, diseases of }\end{array}$

Debility diseases $\quad 2,5$, I I, I2, 225

Decay

Deficiency dieback of lime : - $20 \mathrm{I}^{3}$

Dematiacem-: - : - : 42, 43

Dendropemon caribaus - - - $\quad-42,43$

Diaprepes - - - - - - r98, 206

Diatrœa

Dieback

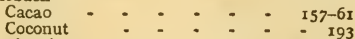

Coconut

Diplocarpon Rosa - - - - 14, 15, 25, 120

Diplodia boll rot - - : - $275-6$ core rot of pineapple - - - - 351

Dieback, Avocado

Dieback, Cacao. See Dieback.

Dieback, Lime - - 196-200, 222

Pod rot - - - - - - 160, 168

Rot, citrus fruit - - : - - 222

Rot, Sugar-cane - - - - 308

D. cacaoicola
Diplodia epicocos Page

D. gossypina - - : - : : 275

D. maydis - - - - - - -

D. Natalensis - - - - 198, 222

D. rasa - - - * - - 159

D. Theobromce - - 157-60, 198, 222, 308

D. Zea - - - - - 259, 260

Diplodias 5, I3, I4, I 5, 25, 44, 69, I I 0,153

Control of

171, 178, 193, 196, 255

Discomycetes caused by fungi - $-:-45-47$

caused by infective viruses $\quad 48-53$

caused by nematodes - - - 59-65

classified - - - - - - - I, 2

leguminous plants - - - 338-43

minor fruit plants - * - 344-60

minor fruit trees - - - 235-40

legislation against - - $\quad$ I12-4

nature of - - - - $\quad \mathbf{x}_{1} 2$

non-parasitic - - - - - 69-72

permanent crops of - - 155,240

prevention and control of - $\quad-81-6$

root crops - - - - - 33I-49

Disinfectants, use of - - 99-IOI, I42

Dominica

Agricultural conditions - - - $\quad$ II9

Cacao pod-rot - - - - $\quad$ - $16 \mathbf{1}$

Citrus diseases - - - - I94 ot seq

Coffee industry - - - - -225

Entomogenous fungi - - - $\quad$ - 73, 74

Horsehair blight - - - - - 152

Lime diseases - - - 198 et seq.

Lime trees, life of $\quad-\quad-\quad-195$

Mistletoe in - - - - - - 58

Orange diseases - - - - $\quad-72$

Pink Disease - - - - - I48

Rosellinia in - - $\quad$ 127, 130, 134

Wither-tip, 1922 - - - - -207

Dothideales - - - - 38,44

Dothidella Olei - - - - - - $\quad 233$

Downy Mildews (Phytophthora) - 14, 2 I

Drainage

for Root Diseases - - - 137-8, 143-5

for Red Ring disease - : - $\quad$ I82

for Red Root disease - - - - 205

for Sugar diseases - - - 296

Drost, A. W. - - - - 161, 170, 241

Dry-rot disease of Xanthosoma - - 33I of Maize - - - - - - 259

Duggar, B. M. - - - - - 27, IOI

Dunlop, W. R. - - - - - $\quad-177$

Dusting with fungicide - $\quad 99,222,237$

Dysdercus spp. - - - - 80, 263 et seq.

Earle, F. S.

Eau Celeste

$-\quad \cdot-0.03$

- - - - - IOI

Edessa medittabunda - - - - 264

Edgerton, C. W. - - - 271 at seq.

Eelworm black-rot - - - - - 249

Eelworms. See Nematodes.

"El mal" disease - - - - - 33I

Empusa - - - - : $\quad 79,80$

Enfermedad del Machete - - - - 173

Engler's classification of fungi - $\quad 43$

Eremothecium cymbalarice - - - 30, 265

Eriospharia Sacchari - - - - 321

Erysiphacea. See Powdery Mildews.

Euascomycetes - - - - - - 37

Eubasidii - - - - - - - 35, 40

Eumycetes - - - - - 35, 43

Eutettix tenella - - - - - 53

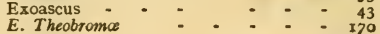




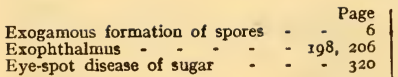

Fanlwetter, R. C. - - - - 268, 284 Fawcett, G. L. - - $\quad$ 15x, 226 et seq. 325 Fawcett, H. S. - - - - 212 ef seq.

Fiji Disease of sugar - - - - 329

Fission Fungi. See Schizomycetes.

Flowers, diseases of - - - - 13

"Flowers of sulphur" - - - - 94

Fomes australis - - - - - -

Fomes Root Rot - - - - - I47

Fomes Stem Rot - - - - - 236

Foot Rot of citrus - - - - - 212

Forastero cacao - - - - - I67

Forest land, effect of clearing II, 137, 205

Formaldehyde vapour - - I00, III, 352

Formalin - - - - 100, I08, 111, 262

Froghopper blight of sugar-cane 68,294 ,

Fruit 296,3 II, 324

diseases of - - - $\quad$ 13, I10, 238

handling of - - I IO, 22I, 223, 35I

Trade requirements - : $-{ }^{2}$ I

Fruitlet spot of pineapple - - $\quad 349$

Fulton, H. P. 209

Fumago

Fungi

and Algæ distinguished

Classified

Diseases caused by

Entomogenous - - - . 73-80

Host's resistance and susceptibility

Imperfecti

Nature of

Reproduction and infection

Their place in Nature
Fungicides, use of, 87 -ror. See also Spraying.

Fungus diseases

Notable groups - - - - I7-44

types of - - - - - - 12-17

Fusarium diseases, control of - $\quad-\quad 246$

F. cubense - - - - - 242, 243

F. moniliforme - - - - - - 260

$F$. vasinfectum - - - - - - $\quad$ - 243

Fusariums $8,17,23,43,44,229,260,331,353$

Fusicladium macrosporum - - 233

Gaillard

Galba susceptible to Rosellinia - $\quad$ I3

Gall patches - - - - - 328

Galls - - - - - - 15, 62-3, 206

Gas tar - - - - - - 306

Gasteromycetes - - - - - - 44

"Gele strepenziekte" - : - : - $\quad-324$

Gibellula

Gibberella saubinetii

Glaosporium limetticolkm -

G. Mangiferae

43,80

G. manihot

G. spp. -

$-\quad-13,22,353$

Glomerella - - - - - $\quad-\quad 22,23,35$

G. gossypii - - - - - - -277

Glossary - - - - - 36I-3

Gnomonia - - - - - $-\quad-22$

G. Iliau - - - : - : - 314

Grand Cayman, Bacterial bud-rot in - 184

Grapefruit,

dieback

Grape-Vine, diseases of

Graphiola Phanicis -

Graphium
Green bug. See Nezara viridula

Green scale - - - - - - 79

Green Transparent sugar-cane - - 295

Grenada

Agricultural conditions - - $\quad$ - 123

Banana disease - - - - $\quad$ - 248

Cacao pod-rot - - - - - 161

Cacao thrips - - - - - - 80

Date palm disease - - - 236

Entomogenous fungi - - - - 74

Foot Rot - - - - - $\quad-213$

Grey blight - - - - - - 210

Horsehair blight - - - - $\quad 152$

Legislation against disease - $\quad$ - II4

Nutmeg cultivation - - - - 239

Red ring of coconut - - - 177, 180

Rosellinia root disease - $\quad 1_{30}, 1_{32}$

Shade trees, absence of - - - I57

Stem rot of coconut - - - - $\quad$ - 89

Grey Blight of Lime - - - - 210

Gros Michel banana - - $\quad$ - 24I, 245, 247

Ground Nuts

diseases - - - - - 338-40, 359

Root disease - . - - $\quad 146,339$

Gum disease of sugar-cane - - - 310

Gumming

Coconut - - - - - $\quad 189$

Lime

Sugar

Gummosis - . - . $\quad 15,72,212-4$

Hard leaf-bitten disease of coconut - 190

Harland, S. C. - 70, 72, 270 et seq., 287

Harrison, J. B. - - - - - 162

Hart, J. H. - - - - - 164, 177

Hartley, C. - - - - - - 108

Haustoria in fungi - - $\quad 8,18,19$

Head smut of sorghum - - $\quad-258,262$

Heart leaf disease of banana - - 256

Hedges, F. - - - - - - 206

Helminthosporiose - - - - - 258

Helminthosporium : - * $\quad$ - 43, 258

H. inconspicum - - - - - 258

H. Sacchari - - - - - - - 320

H. turcicum - - - - - - - 258

Helopeltis bug - - - - - - 68

Helvellineæ - - - - - - 44

Hemiascomycetes - - - - 36, 43

Hemibasidii - - $-38,44$

Hemileia. See Coffee leaf rust. - - 159
Hennings, P. - - - _

Heterodera radicola - -- $\quad-59,62,229$

Heterccism - - - - - - I7

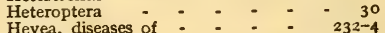

Hevea, diseases of : : : $: \quad{ }^{232-4}$

Hibiscus susceptible to Rosellinia - $\quad$ - 135

Higgins, J. E. - - - - - - 352

Hill's Seedlings - • - - _ - 297

Himantia stellifera - - - - 43, 292

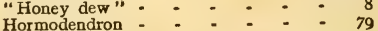

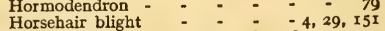

Howard, A. I6I, I8I, 290, 298, 308, 334, 349

Hymenaa Courbaril : : - 127

Hymenomycetes - - - - - - 44

Hypertrophied twigs of cacao - I70, I7I

Hyphæ in Fungi - - - $\quad 4,6,8$

Hyphomycetes. See Moniliales.

Hypochnaceæ - - - - - - 40

Hypochnus ochroleucrs - - : 149

Hypochreales - - - _ . 38,44

Iliau disease of sugar cane - $\quad-\quad 3 I 4$

Imperial Department of Agriculture 126, 350 Insects

enemies of - - - 73-80 
Insects

injuries from

Internal boll disease of cotton Iron sulphide Isaria

I. Barberi

Ithyphallus coralloides

Page
$-\quad 66-8$
$263-8$
$-\quad 97$
$-\quad 43$
$-\quad 80$
$-\quad 292$

Jamaica

Banana diseases 205, 24 I et seq., - 250-5

Bitten-leaf disease - - - - - I9I

Bud-rot of coconut - - - $\quad-183-7$

Coffee eye-spot disease - $\quad-\quad 228$

Dieback of coconut - $\quad$ - $\quad$ - $\quad$ - 193

Hard or Little Leaf-bitten disease - 190

Leaf-blight of coconut - - $\quad$ I93

Leaf-stalk rot - - - - - $\quad$ - I88

Legislation against disease - - $\quad$ r85

Mosaic disease $\quad-\quad-\quad-325$ et seq.

Panama disease - - - -241 et seq.

Pineapple diseases - - $\quad-349$

Red Rust - - - - - - 152

Root crop diseases - - - $33 \mathrm{I}^{-2}$

Sorghum rust - - - - . $26 \mathrm{I}$

Stem-rot of coconut - - - - 190

Wither-tip

Jassid bugs

Jehle, R. A.

Jeyes fluid -

John Bull tree

- 208

53. 67

219

Johnston, J. R. - $\quad 177,184,185,292,316$

Kelsall, A.

Kernel smut of sorghums

Kidney beans, diseases of

Kuehneola Gossypii

Larsen, L. D.

Lasiodiplodia

L. nigra

L. Theobroma

Leaf-base rot of pineapple

Leaf-blight of coconut of Maize

Leaf-blister mite of cotton

Leaf blotch of yams

Leaf-curl of Sea Island cotton

Leaf Diseases of date palm

Leaf-dwindling disease of coconu

Leaf mildew of cotton

Leaf-mould of tomato

Leaf-roll of potato

Leaf-rust

coffee

ground nuts

Leaf-scorch of maize-

Leaf sheaf rot of sugar-cane -

Leaf spots

Cassava

Ground nuts

Lime

Nutmeg

Tomato

Leaf-stalk rot of coconut

Lee, H. A.

Leptostylus promorsus

Lemon, diseases of -

Leptoglossus

Leptospharia Sacchari

Leptospora Musce

Levin, E.

Lime, use of

Lime-sulphur solution $94-7,149,151,209$

348

25

I 59

I 59

349

193

258

- 122

337

12, 148

I $2,148-54$

236

- 190

285

355

17

338

258

- 316

- 355

- 338

- 210

- 239

- 355

- $\quad 88$

- 220

- 206

210-24

- 360

$3 \times 8$

- 243

356

354

22I, $36 \mathrm{x}$
Lime Trees

diseases of - - - - - 194-224

natural habitat - $-\quad-\quad-195$

Limes, Anthracnose of - $\quad$ 13, I19, I25, And see Anthracnose.

Rosellinia disease of - - 9, 130, $x_{40}$

Little-leaf disease of coconut - - $\quad$ I90

Liver of sulphur - - - - - 97

Loggerhead disease of Sea Island cotton

Loranthace

$70,280-3$

Love Vine - - - - - - $54-6$, II

Lyon, H. L. - - - - $\quad$ - 314, 329

Macroconidia

Macrophoma vestita -

Macrosporium Leaf-spot - - - - $\quad$ - 159

M. nigricantium - - - - - - 284

Maize. See Corn.

Mal-di-goma, See Foot-Rot.

"Male" cacao - - - - - - -

"Man cotton" - - - - - 84, 286

Mandarin, diseases of - - 194, $210-24$

Mango

Blossnm blight - - - - - 235

diseases of - - - - - $237-8$

Manjak for protecting trees - - - 106

Manns, T. F. - - - - - 260

Manure, organic or cbemical 200, 201, 289.

296,300

Manuring II, I2, 71, 82, 156, I60, 195, 200,

Manzana banana - _ $245,284,354$

Marasmius - - - I7, 28, 44, 152, 242

Marasmius root disease of banana - 246

M. perniciosus - - - - 29, I7I

M. Sacchari - I72, 260, 290 et seq., 297, 346

$M$. sarmentosus - - - - - - I52

$M$. semiustus - - - - - - - 246

M. stenophyllus - - - - - - 246

Massee, G. - I49, I64, I9I, 226, 298, 332

Maublanc, A. ? : - _ - 227, 233

Mealy-bug - - - - - - 74,79

Melanconiales - - - - - 42, 44

Melanconium Iliau - - - - $\quad$ - 314

M. Sacchari - - $\quad-298,308,314$

Melanopsammopsis Ulei - - - 232

Melanose - - - - - - - 217

Meliola - - - - - 33

Mercuric Chloride - - - - $\quad$ - 99

Metamasius sericeus - - - + - 192

Metarrhizium anisoplice - - - 77,80

Microconidia - - - - - 24, 243

Mildew

fungicide for - - - - - $\quad$ - 97

on leaves - - - - - - $\mathbf{I}_{3}$

Rose - - - - - - 362

See also Downy, Powdery. - - $\quad 54-8$
Mistletoes

Monilia pod rot - : - : - - 172

Moniliaceæ - - - - - - - 42

Moniliales - - - - - 42,44

Monocotyledons - - - - - 16,183

Montserrat

Agricultural conditions - - - 118

Brown rust of corn - - - - 256

Cotton disease - - - 265, 274, 279

Diplodia Dieback of Lime - - I97, 198

Fomes Root Rot
Grey blight of Lime : : : : $\quad-\quad 147$

Ground-nut leaf rust - - - - 339

Lime growing in - - - $\quad-198$

Onion disease - - - - $\quad-336$

Pineapple diseases - $\quad 345,347,349$

Moonshine. Sze Chlorosis.

Moore, J. C. - - - - - - 180

Moro Disease of banana - : - $\quad 247$ 
Page

Mosaic diseases - - - - - 49-5I

$\begin{array}{lllllll}\text { cotton - } & - & - & - & - & - & - \\ \text { infection } & - & - & - & - & - & -\end{array}$

symptoms

sugar-cane

tobacco

transmission

effect of germicides

Mottled hybrids of cotton

Mottling disease of sugar

Mucedinacea

Mucors, the

Mycoidea parasitica - - - - 152

Mycologist

origin of term

province of

Mycelium, the -
Myriangium Duriai - - - - -

Myxomycetes

34,43

Nail-head rust - - - - - - 2 I4

Necator decretus - _ - _ - . 149

Nestriz - - - $38,44,164,2$ OI

$-\quad-229$

Nematodes - - $13,59-65$, I77, I83, 359

N. Coryli - - - - - - - - -265

N. Lycopersici - - - - - - 3 I

Neocosmospora - - - - - - 38

Nevis cotton disease - $\quad-265,279,287$ Sugar diseases - - - - 308 See also St. Kitts.

Purple cotton - . - . . 283

Nezara - - - - - - - - 360

N. Viridula - - 80, 263 et seq., 338

Nutmegs, diseases of - - $\quad 149,239$

Obligate parasites

Odontia, spp.

O. Sacchari -

O. Saccharicola.

Oidium -

Oil Spot on citrus fruits

Okra, vascular wilt disease

Omphalia flavida

Onion, diseases of

Oomycetes -

Oospores

Ophionectria coccicola

Orange, diseases of

Orton, W. A.

Ovulariopsis

O. Gossypii

Palmyra palms, Bud-rot of

Panama disease of bananas

Papaw, diseases of

Parasitic diseases

classified

infection, sources of

prevention and control

Parasites explained classified

phanerogamic

Passalora Hevece

Patouillard

Peach yellows; Peach rosette

Pellagra

Peltier, G. L.

Penicillium -

Perjsporiacea

Perisporiales

Perithecia of - -

Red Root disease - $\quad-\quad 205$

- Peronosporacea

$$
\begin{aligned}
& -\quad 5,9,17 \\
& I 7, \quad 40,292 \\
& =\quad-\quad 292 \\
& =\quad-\quad 292 \\
& 20,42,362 \\
& =\quad-\quad 222 \\
& =\quad-\quad 243 \\
& -\quad-\quad 227 \\
& -\quad 335-6 \\
& -\quad 35,43 \\
& -\quad 21,189 \\
& -\quad 38,79 \\
& \hline 06,210-24 \\
& -\quad 271,277 \\
& -\quad-\quad 20 \\
& -\quad-\quad 285
\end{aligned}
$$

183

$352-3$

- I

$8 \mathrm{r}-86$

- 4,5

- 54-8

- 233

127. 159

- 5I-3

- 259

27

43, II0, 2 I3, 350

32,37

332
36
Pestalozzia palmarum - - Page

Petch, T. 147, I5I et seq., 189, 193, 2 IO

Phakospora vitis - - - . . - 237

Phallus aurantiacus - - - - - $\quad$ - 292

Phaseolus vulgaris - - - - - - 28

Phloem-necrosis - - - - - - 234

Phoma - - - - - - - - 44

Phomopsis - - - - - - - 42

Phomopsis Citri - - - - - - 217

Phycomycetes - - - - - 35,43

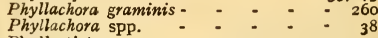

Phyllosticta - * - - - - 239

Physiological disease - - _ - $\quad$ 2, 48, 69

Phytophthora and Gummosis - - $\quad 212$

P. faberi - - - - - - 177, 183

P. omnivora - - - - - $\quad$ - 164

P. palmivora - - - $-183,186-8,189$

$P$. parasitica - - $\quad 188,213,274,349$

$P$. terrestria - - - - - 189, 213

Phytophthora of cotton - - - - 274

Pod-rot - - $\quad 160,173,175,274$

And see Downy Mildews.

Pierce, R. G.

Pigeon pea, diseases of - : - -

Pineapple, diseases of - . - 344-53

"Pineapple" fungus of sugar-cane I92, 305-8

Pink disease - _ - _ - 15, 148

Plantain immune from Panama disease 245

Plasmodiophora brassicce - _ - - 329

Plectasci - - - - • • - 43

Pod-rot. See Cacao.

Poix-doux susceptible to Rosellinia - I35

Polyporaceæ - - - - - - 40

Potash and cotton disease - $\quad 283,284$

Potassium permanganate - $\quad 97$, III

Potassium sulphide. See Liver of Sulphur.

Potato blight

Powdery Mildew of Grape vine - $\quad 236$

Powdery Mildews (Erysiphacea) 20, 37, 94

Prantl's classification of Fungi - - 43

Prescott, S. C. - - - - - - $24 \mathrm{I}$

Prestoe, H. - - - - - - 225

Protoascomycetes - - - 36,43

Protobasidii - - - - 38, 40, 44

Protoplasm, resistance of - $\quad-\quad 8,9,67$

Pruning of cacao trees - - - 168, I72

Pseudococcus calceolariæ. See Mealy Bug.

Psorosis of citrus - - - - - 2I4

Puccinia purpurea - - - 256, $26 \mathrm{I}$ sorghi - - - - - - 256, 26I

Purple ribbon sugar-cane - - 326

Pycnia ; pycnidia; pycniospores I8, 26

Pyrenomycetes - - - - 38,43

Pythiacystis citrophthora - - - 2I2, $2 \mathrm{I}_{3}$

Pythium - - - : - : - -36

Pythiacystis - - - - - - 36

P. butleri - - - - $293,346,353$

$P$. de Baryanum : : : : : : 28

Quanjer, H. M. - : - : - $\quad-\quad-\quad \div 323$
Quicklime

Rainfall, influence of II5, I57, I93, I99, 294

Ramularia areola - - - - 286

Rangel, E. - - - - - - - 227

Ratooning - - - $\quad 289,294$ et seg., 324

Red leaf-blight of cotton - - 283

Red leaf-spot of sugar - - - - 321

Red or claret banana - - - - 245

Red ring disease of coconut - - $177-82$

Red root disease of limes - - 203-5

Red rot - - - I0, 30I, 3I0, 3I6

Red rust - - - - - -

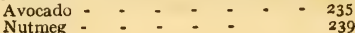


Red spot of sugar leaf-sheaf - - - $3 \mathbf{I} 7$

Reinking, A. $8-10,68,83$

Resistant varieties, disadvantages of - 84

Rhizoctonia - - - - 26, 43, 44, 342

Rhizomorphs - - - $4,217,252$

Rhizopus nigricans

Rhynchota, plant feeding

"Rind disease" of cane -

Ring-spot of sugar-cane -

Robson, W.

Rogers, J. M.

Rolfs, F. M.

"Root " “ " - - - - 270

Root crops, diseases of - 301, 316

Root diseases I5, 25, II7, II9, I23, I26-47

Corn - : : : : 260

Ground Nut - : - : - - 339

Pineapple - - - - - 345

Sugar-cane - - - - 289-97,345

Rorer, J. B. I48, I6I et seq., I77, I84, 235 .

Rose, diseases of - - $\quad \begin{array}{r}237,248,362 \\ 361-2\end{array}$ Rosellinia $5,9,17,43,83,120,126-46,160$ $204,235,240,335,342$

R. bunodes - - $127,128,130-2,137,333$ $R$. paraguayensis - - - $\mathrm{I}_{28}, \mathrm{I}_{32}-3$ R. pepo I 23, 127-30, 131, 136, 238

Rosenbaum, J. - - - - ? - 177

Rotation of Crops 9, I I, 20, 8I, II6, 258,

Rots of fruit 294,296

Russeting of Citrus fruit -

Rust-mites

Rusts (Uredinea)

classified -

cotton

grape-vine

on leaves -

pigeon pea

sorghum -

Rutaceæ

Saccharomycetaceæ. See Yeasts.

\section{St. Kitts-Nevis}

Agricultural conditions in

Fomes lucidus in -

Curly leaf of cotton

Date palm disease

Loggerhead disease

"Man Cotton"

Pineapple diseases -

Root disease of corn

Sugar diseases

St. Lucia

Agricultural conditions

Avocado -

Banana disease

Brown Rust of corn

Cacao pod-rot

Citrus diseases

Entomogenous fungi

Horsehair-blight

Legislation against disease

Pink Disease -

Red rust

St. Vincent

Agricultural conditions -

Angular spot of cotton

Arrowroot diseases

Brown rust of corn

Cacao thrips

Citrus trees, absence of

Cotton diseases, 265 et seg., 274, 279.

Grey blight

Ground nut diseases
St. Vincent

Page

Mistletoe - - - - - 58

Papaw diseases - - - - . 353

Rain, influence of - - - - 12, 266

Red ring of coconut - - - $\quad-177$

Root disease of corn - - - - 260

Rosellinia - - - - - 130, 133

Sea Island cotton diseases - $\quad 70,82$

Shade trees - - - - - - I56

Tomato diseases - $353,355,357$ et seq.

Saltpetre disease : ? - $: 33 \mathrm{I}$

Sanders, G. E. - - - - - 90

Saprophytes

cacao - - - - - I6I, I68

fruit and flowers - - - - $\quad$ I4, 22

leaves - - - - - - - 13

Saprophytism explained - - - $\quad 4,5$

Scab disease of citrus - - - $\quad-215$

Scale insects

$73,79,118,209$

and dieback - - - - - - 199

Scaly bark citrus disease - $212,214,219$

Schizomycetes - - - - 35, 43,45

Schizophyllum - - - - - - 40

rot of sugar-cane - - - - - 313

S. commune - - - - - - - 313

Sclerospora Sacchari - - - - - 330

Sclerotinia - - - - - - 43

Sclerotia in fungi - - - -4, I3I

Sclerotium disease of Liberian coffee $\quad-230$

rots - - - - - - - - 146

S. coffeicolum - - - - - 230

S. rolfsii - - - 16, 146, 317, 338

Scolecotrichum - - - : -

Sea Island Cotton, close season Io, 82, I I4 losses through bacterial boll disease - $27 \mathrm{I}$ non-parasitic diseases - - - - 70 And see Cotton.

Sealy Seedling cane - - - $\quad 296$

Seaside Mahoe - - - - - - 266

Seeds, disinfection of - - 99, 257, 278

infection through - - - 82

Septobasidium - - - - 40,79, 210

S. langloisii - - - - - - 210

Septoglaum Arachidis - - $\quad$ - $\quad 339$

Septoria - - - - - - - 42

leaf-spot of tomatoes - - - $\quad 355$

S. lycopersici - - - - - - 356

Sereh disease of sugar-cane - $5 \mathrm{I}-3,323$

Shaddock, diseases of - - . $210-24$

Shade Trees, question of - - - - I56

Shellac varnish for fruit rot - - - Iro

Shield-scale fungus - - - - 74, 77

"Shot-borer" beetle - - - - 298

Silk cotton - - - - - - - 266

"Silk fig " banana - - - - - 250

Sisal, anthracnose of - - - - 36r

Slime-fungi - - - - - $\quad 34,329$

Smith, Erwin, F. 45, I84, 243, 268, 27 I,

Smith, Longfield - - _ - 312, 357

Smoke-clouds to prevent dew : - 234

Smuts (Ustilaginece) 5, 44. And see Corn.

Smut disease of sugar cane - - - 312

Soft rot of cotton bolls - - . $-274-5$

Soil

aeration - - - - - - 354

grade immaterial with Red Ring - I8I

infection - - - - 259

influence of $70,115,201,203,229,245$,

poverty - - _ - _ _ 280,344

St. Vincent - • - - - - I95

treatment - - - - - $-I_{42}$

virgin - - - - $\quad 11,18 \mathrm{I}, 225$

Sooty Mould - - - - - - 8

Sorghums, diseases of - - 258,262

Sorosporium reilianum - - - 256, 62

South, F. W. 126, I30, 147, I74, 203, 206

$246,260,271,274,332,339$ 


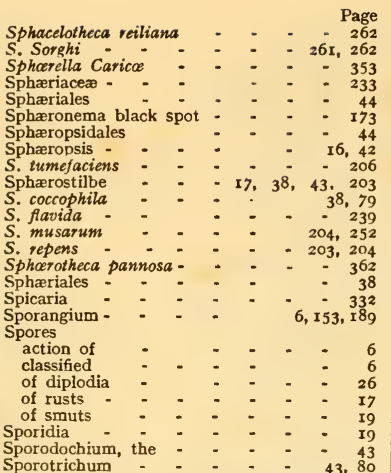

Sporotrichum - _ - _ - 43,80 Spraying - 20, 22, 34, 56, 109-13 Anthracnose control - : - 209 Citrus diseases - - - . - - 220 compared with parasite fungi - - 76 cotton - - - - 270, 274, 275 injury from - - + - $\quad$ - rro, 270 Machines - - - - - - Iro method of - - - - - . IO9 object of - - - - - 85

Tomato diseases - - - - - 357

West Indies, little used - - - 87 And see Bordeaux, Sulphur, etc.

Stahel, G. - - I70, 17I, 23I, 232, 234 Staining of seed cotton, cause of - -265 Stell, F. - - - - - I77, 189

Stem-bleeding disease of coconut - - I89

Stem canker of pigeon pea - - 342

Stem diseases - - $-\quad-I_{4}-\mathrm{I} 6, I_{4} 8-54$

Stem rot

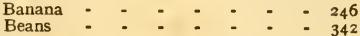

Coconut - - - - . - - $\quad$ - 889

Stevens, F. L. - - - - - - 33

Stevens, H. E. - - - - - 213

Stevenson, J. A. 2 I5, 260, 324, 343, 355, 357

Stigmatomycosis. See Bug Punctures.

Stigmonoses - - - - - 66, 264

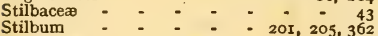

S. flavidum, Stilbella flavida - - - 226

Stinkhorn fungus of sugar - - $\quad 292$

Stockdale, F. A. - - - - I77, 183

Stumps and logs favour root diseases I3I,

Sugar-cane

$133-4,137$

as remedy for damping off . conditions favouring

diseases of

resistant to Rosellinia - - - $\quad-\quad 288-330$

weevil-borer - - - - - - I92

Sulphate of Ammonia - - - 201, 297

Sulphur, use of $20,94-7,142,237,362$

Sulphuric Acid - - roI, I08, I09

Surinam. See Witch Broom.

Susceptibility of plants - . - I0, 68

Sweet potato diseases - . - . 336

$$
\text { af: }
$$

Tangle-root of pineapple .

Telia : Teleuto-sori : Teliospores - 97

Tempany, H. A. - - - 70, 328
Temperature effect Page

Tenney, L. S. - - - : - 1115

Thalli through algal attacks - : 153

Thelephora pedicellata - - - - 210

Thelephorace» - - - - - 40

Thermesia gemmatalis - - - - 80

Thielaviopsis - - 43, I87, I89, 346

soft-rot of pineapple - - -

$T$. ethaceticus - - - - 298, 305

T. paradoxa - I90, 192, 254, 305, 347, 350

Thread blight - - - $-4,149,240$

Threadworm. See Nematodes.

Thrips on cacao -

Thyridaria tarda

Tilletiaceæ -

Tip-wither -

Tobacco extract -

Tobago

agricultural conditions - - , 125

Malvaceous weeds - - - $\quad-267$

Red ring of coconut in - - - 177

Stem-rot of coconut - - $\quad-\quad-189$

"Tomato blight " - - - - 355

Tomato, diseases of - - . - 353-60

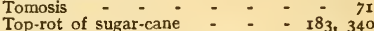

Tortola, boll disease of cotton 263,265

Trees, age and size attained by - 15, 198 structure of - - - - : 102 surgery of - - - - - - IO4

Trenches for isolation. See Drainage.

Trichosphoria Sacchari - - - 298

Trinidad

Agave anthracnose - - - $\quad-36 \mathrm{I}$

Agricultural conditions - - $\quad-\quad$ I23

Avocado anthracnose - - - 235

Banana disease - - . - - 246

Bud rot of coconut in - - $-183 \rightarrow 5$

Cacao pod-rot - . - - - I6r

Cassava diseases - - - - $\quad$ - 335

Corticium koleroga - - - - $15 I$

Cotton mildew - - - - - $\quad 286$

Entomogenous fungi - - - 73,77

Grey blight - - - * - - 210

Horsehair blight - - - - - 152

Leaf-blight of coconut - - - 193

Leaf-dwindling disease - - - 190

Legislation against disease - Ir4, I85

Mango disease - - - - - 237

Marasmius diseases of sugar - $\quad 292$

Mistletoe - - - - - - 58

Panama Disease - - - - - 242

Pink Disease - - - - - $\quad \mathbf{1 4}^{8}$

Powery Mildew of Grape Vine - - 237

Red ring of coconut - - - 147, 180

Red rust - - - - - - 152

Root disease of cacao - - - $\quad$ - 776

Rose canker - - - - - - 362

Stem-rot of coconut - - - - r89

Sugar cultivation - - - - 288, 289

Sugar diseases 294, 297, 31 I, 32r, 325

Wither-tip - - - - - 208

Tropics, their influence on fungi - : 4

$\begin{array}{llllll}\text { Tuber rot of yams } & - & - & - & - & -\end{array} 337$

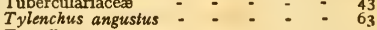

T. coffece - - - - - - - 230

T. devastatrix - - - - - $\quad-63$

T. musicola - - - - - $\quad$ - 65, 249

T. ribes - - - - - - 64

T. similis - - - - - 65, 249

Uba cane - - - - - - 296

Uncinula necator - - - - $\quad-236$

United Fruit Co. - - - - - $24 \mathrm{I}$

Uredinea. See Rusts.

Uredo Arachidis - ? - . $33^{8}$ 


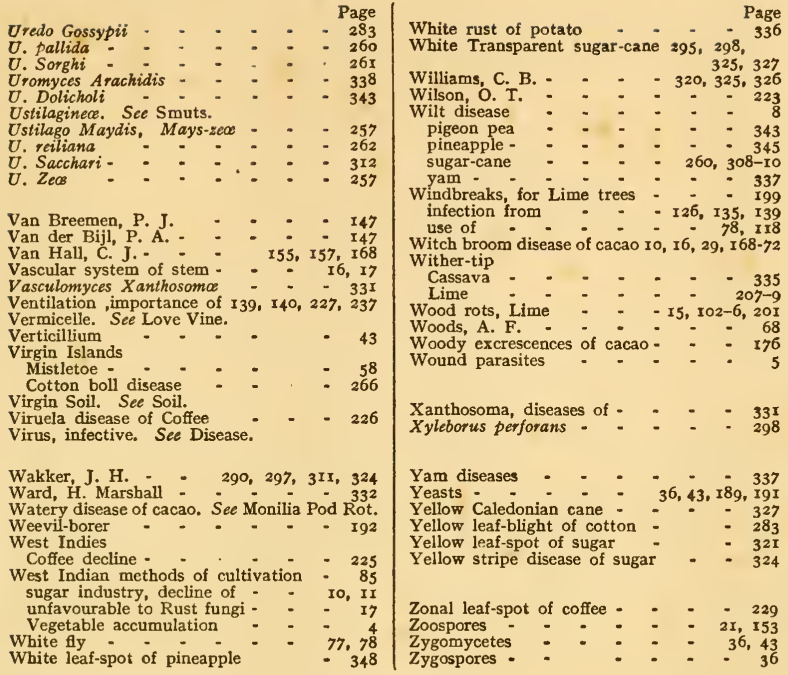










